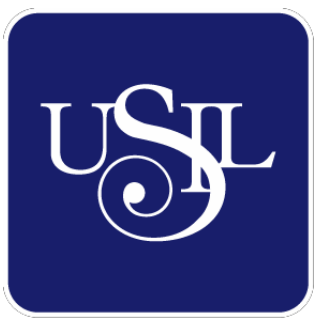

UNIVERSIDAD

SAN IGNACIO

DE LOYOLA

ESCUELA DE POSTGRADO

\title{
PLAN DE NEGOCIO PARA LA PUESTA EN MARCHA DE UN FAST FOOD EN LA CIUDAD DEL CUSCO, 2017
}

Trabajo de Investigación para optar el grado de:

DINA PILAR APAZA CCASA

Maestro en Ciencias Empresariales con Mención en Gestión del Capital Humano

MARITA CCAHUA MESCCO

Maestro en Ciencias Empresariales con Mención en Gestión de Marketing

\section{LIZBETH HUAMÁN ARCE}

Maestro en Ciencias Empresariales con Mención en Gestión de Marketing

\section{RICK ANDERSON PUENTE LÓPEZ}

Maestro en Ciencias Empresariales con Mención en Gestión del

Capital Humano

\author{
Asesor: \\ Horacio Javier Barrios Cruz \\ Lima - Perú
}

2019 


\section{Resumen Ejecutivo}

De acuerdo al titulo del proyecto de investigación; "Plan de negocios para la puesta en marcha de un Fast Food en la ciudad del Cusco, 2017”, se determino el año 2017 como inicio de las investigaciones. El presente proyecto en ese sentido, tiene como objetivo evaluar la viabilidad de la puesta en marcha de un restaurante tipo fast food (comida rápida) de cocina americana, que incorpore como valor agregado, insumos originarios de la región Cusco, es decir generar una fusión de ambos estilos de cocina, también conocido como fusión novoandina.

Con el objetivo de dar a conocer la propuesta de valor que representa este proyecto, se identificó como público potencial a los jóvenes y adultos entre 18 y 45 años de los niveles socioeconómicos A, B y C que gusten de la comida tipo fast food americano y que viven en distritos cercanos o adyacentes a la Av. La Cultura, dentro de la provincia del Cusco, dicha avenida se caracteriza por ser la vía de conexión de varios distritos de la ciudad, además de ser una importante zona comercial. En base al estudio de mercado llevado a cabo se determinó que los consumidores tienen preferencia por productos a base de pollo y hamburguesa, así mismo se logró definir el tiempo de permanencia promedio que va de 16 a 30 minutos y tiempo de espera del servicio deseado de 15 minutos, entre otros factores relevantes sobre las expectativas en relación a los gustos y preferencias sobre el producto y servicio propuesto.

En base a los estudios de investigación de mercado e ingeniería del proyecto en estudio, se pudo determinar una localización óptima para el negocio, el cual estaría ubicado en la Av. La Cultura en el distrito de Wanchaq cerca a zonas altamente comerciales, este local contaría con un 
área de $104 \mathrm{~m} 2$ y seria ambientado con temática moderna que incorpore colores, luces y temas relacionados a la cultura andina.

Por otro lado, la empresa llevará el nombre de Uchucuta S.A.C, para lo cual se desarrolló el plan de marketing del negocio donde se evidenció aplicar como estrategia base la penetración de mercado y desarrollo de nuevos productos, puesto que se está ingresando a un mercado existente con alta demanda. Así mismo, se aplicará estrategias de posicionamiento para ganar participación en el mercado y se definirá los precios bajo una estrategia basada en costos, además de la distribución que será directa al consumidor final y la promoción se llevará a cabo bajo la estrategia de atracción, a través del uso de diversos medios de comunicación, y alianzas estratégicas con instituciones y empresas que promuevan el posicionamiento del negocio.

El proyecto de inversión ha sido evaluado con un horizonte de cinco años considerando que la inversión inicial requerida para la implementación de la idea de negocio asciende a S/ 154,588.19 soles, el cual será financiado con el 71.68\% de capital propio proveniente del aporte de cuatro socios y la diferencia correspondiente a $28.32 \%$ será financiado vía préstamo bancario, que representa un monto de S/ 43,779.24 soles a una TCEA de $36.03 \%$.

El flujo económico del plan de negocios refleja un VANE de S/ 416,643.11 soles con un TIRE de $94 \%$ y VANF de S/ 437,830.76 soles con un TIRF de 108\%, lo cual indica que el proyecto satisface el costo de oportunidad exigido por el inversionista de $26.13 \%$, demostrando una viabilidad económica del negocio. 
Con todo ello, se puede determinar que este negocio será rentable porque al basarse en un concepto conocido a nivel nacional como es la comida fast food e incorporar insumos de la región Cusco, lo que se busca es la identificación del consumidor con el producto. Y conforme al estudio de sensibilidad económico llevado a cabo, se pudo identificar la tolerancia de la propuesta ante cambios drásticos en los ingresos y costos. Por ello, se recomienda la ejecución del proyecto propuesto. 


\section{Índice}

Resumen Ejecutivo

Introducción

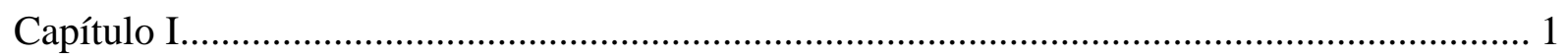

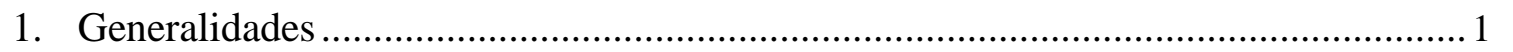

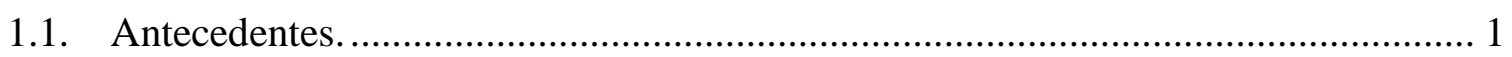

1.2. Determinación de la oportunidad.................................................................... 3

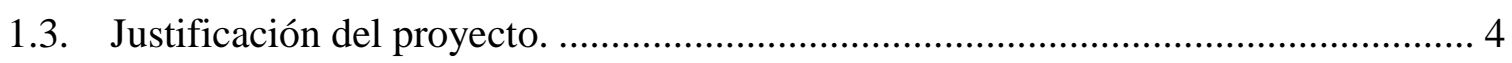

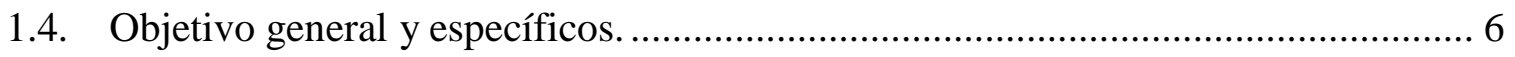

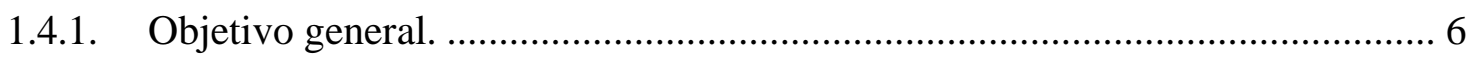

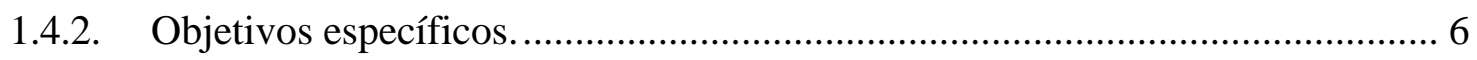

1.5. Alcances y limitaciones de la investigación. ………………………………........ 6

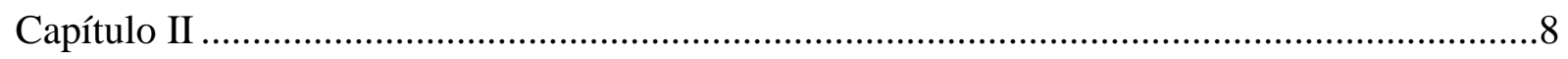

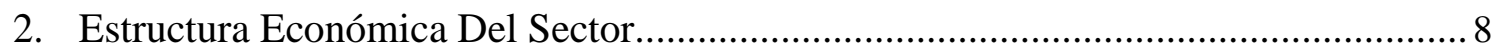

2.1. Descripción del estado actual de la industria ...................................................... 8

2.1.1. Segmentación de la industria.................................................................... 8

2.1.1.1. Segmentación de mercados de consumo en la ciudad del cusco. ................... 8

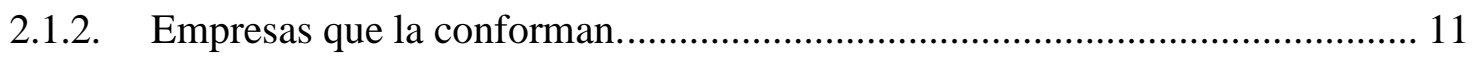

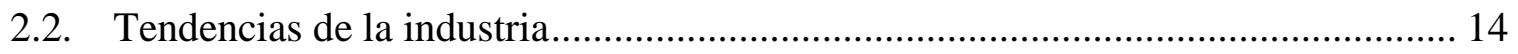

2.3. Análisis estructural del sector industrial.......................................................... 16

2.3.1. Poder de negociación de los compradores....................................................... 18

2.3.2. Poder de negociación con proveedores. ........................................................ 21

2.3.3. Amenaza de entrada de nuevos competidores............................................... 24 
2.3.4. Competencia de los productos sustitutos ................................................ 27

2.3.5. Rivalidad entre empresas competidoras. ................................................ 31

2.3.6. Influencia de las 5 fuerzas de porter en el segmento.................................... 34

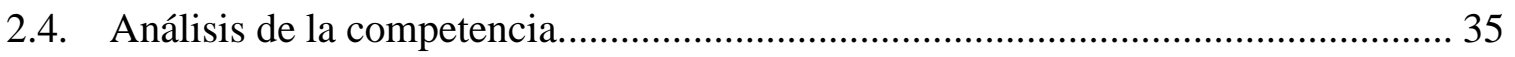

2.4.1. Empresas que ofrecen el mismo producto o servicio. ................................ 35

2.4.2. Participación del mercado de los competidores. ............................................ 38

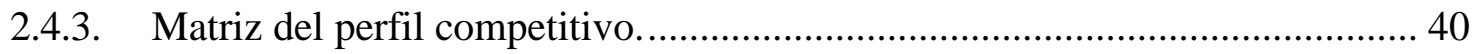

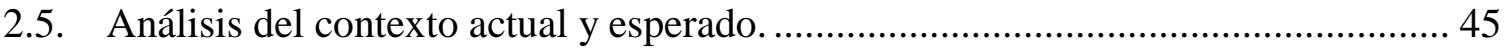

2.5.1. Análisis político-gubernamental........................................................... 45

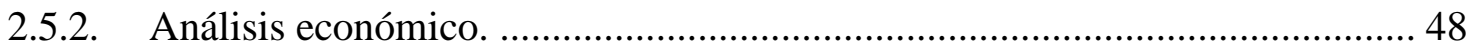

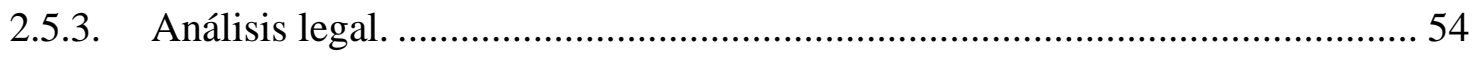

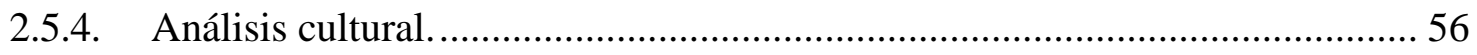

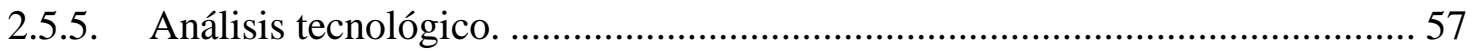

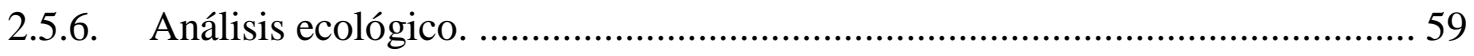

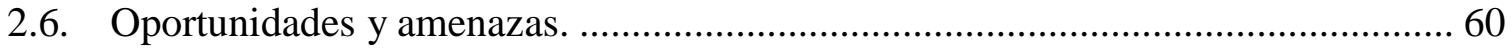

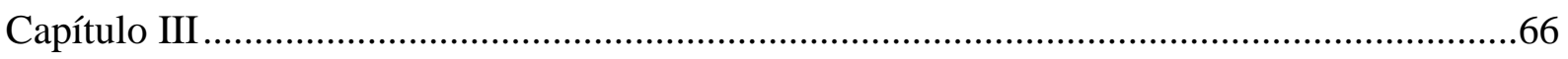

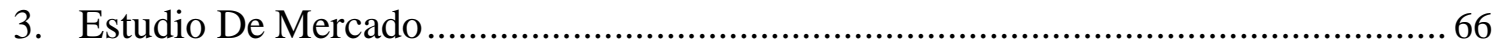

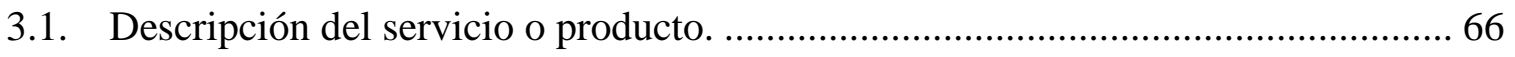

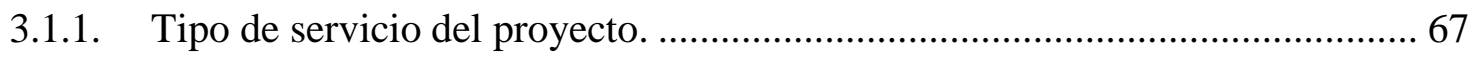

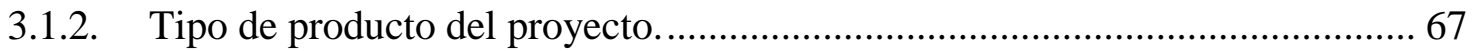

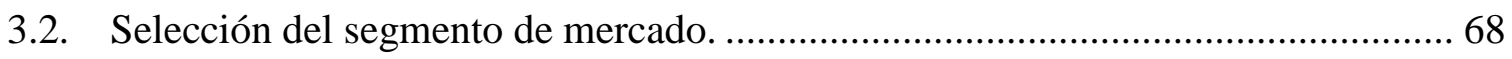

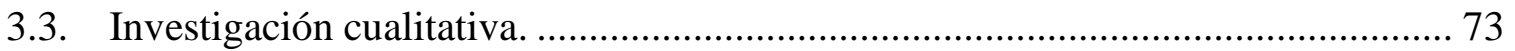

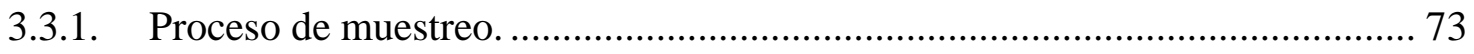




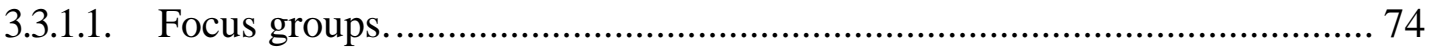

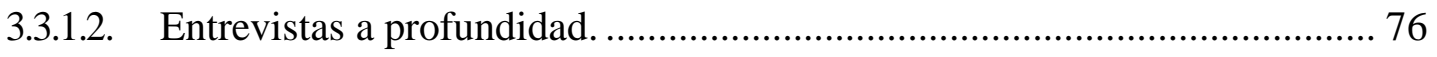

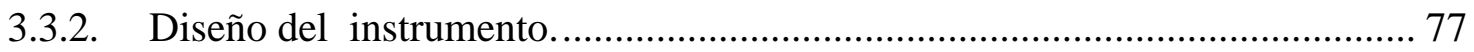

3.3.2.1. Guía de pautas para focus group................................................................. 77

3.3.2.2. Guía de preguntas para entrevista a profundidad. ………............................ 77

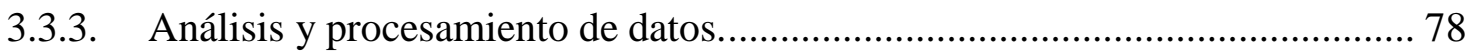

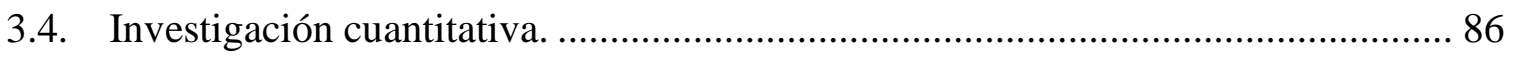

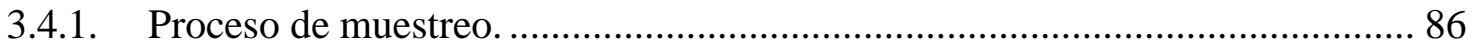

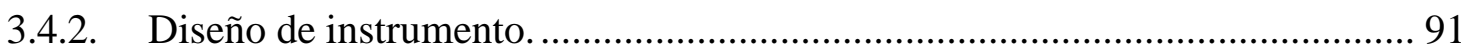

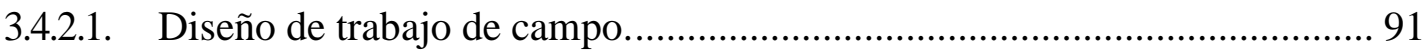

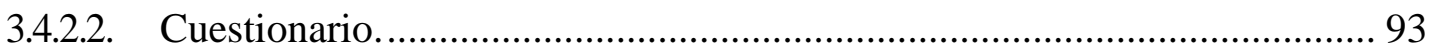

3.4.3. Análisis y procesamiento de datos.............................................................. 95

3.5. Conclusiones y recomendaciones del estudio cualitativo y cuantitativo............... 137

3.6. Perfil del consumidor tipo y sus variantes......................................................... 139

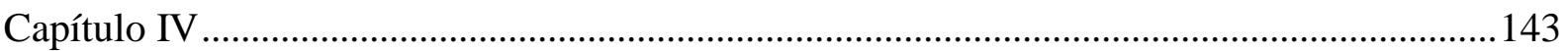

4. Proyección Del Mercado Objetivo ........................................................................... 143

4.1. El ámbito de la proyección. .............................................................................. 143

4.2. Selección del método de proyección........................................................................ 143

4.2.1. Mercado potencial. ...................................................................................... 144

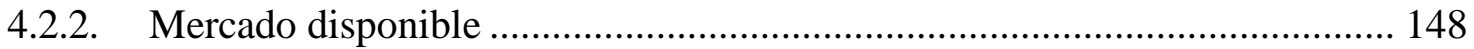

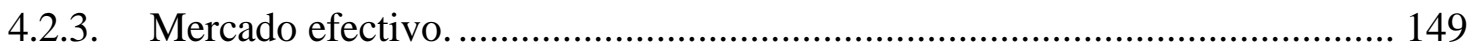

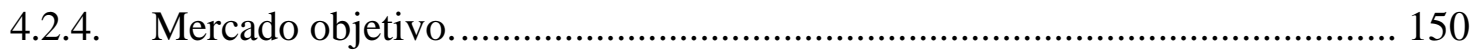

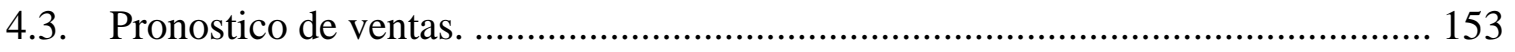


4.4. Aspectos críticos que impactan el pronóstico de ventas................................... 155

4.4.1. Factores externos. ............................................................................ 155

4.4.2. Factores internos........................................................................... 158

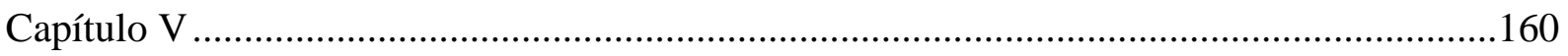

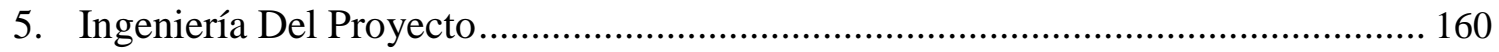

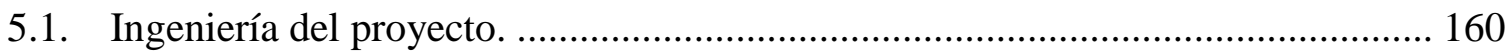

5.1.1. Modelamiento y selección de procesos productivos. .................................. 160

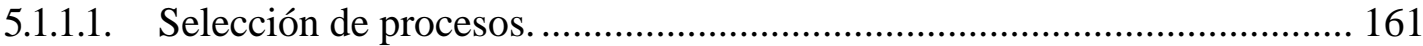

5.1.2. Selección del equipamiento................................................................ 165

5.1.2.1. Elección del tipo de equipo para especificar las propuestas..................... 165

5.1.3. Lay out. 171

5.1.4. Distribución de equipos y maquinaria .................................................. 177

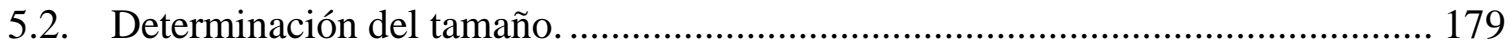

5.2.1. Proyección de crecimiento. .................................................................. 181

5.2.2. Recursos. 182

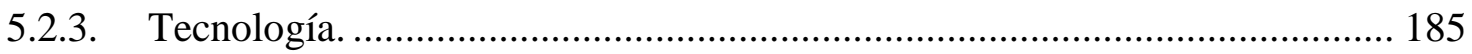

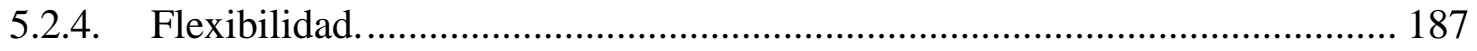

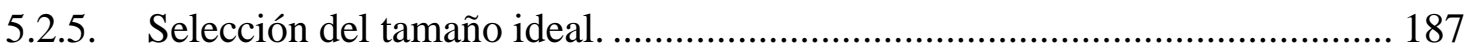

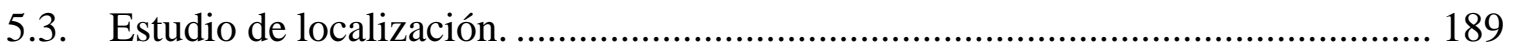

5.3.1. Definición de factores locacionales........................................................ 189

5.3.2. Consideraciones legales................................................................. 192

5.3.2.1. Identificación del marco legal. .......................................................... 192

5.3.2.2. Ordenamiento jurídico de la empresa ................................................ 195 
5.4. Determinación de la localización óptima............................................................. 200

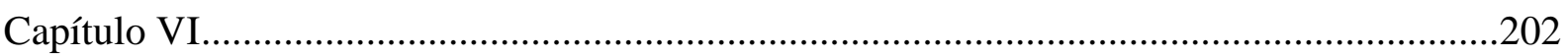

6. Aspectos Organizacionales …………………………....................................... 202

6.1. Caracterización de la cultura organizacional deseada............................................ 202

6.1.1. Visión. 202

6.1.2. Misión. 203

6.1.3. Principios. 205

6.2. Formulación de estrategias de negocio............................................................. 207

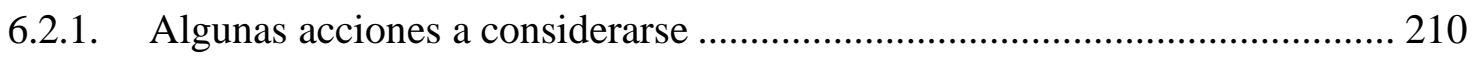

6.3. determinación de las ventajas competitivas crítica................................................. 214

6.4. Diseño de la estructura organizacional deseada.................................................. 217

6.5. Diseño de los Perfiles de Puesto Claves ................................................................ 218

6.6. Remuneraciones, compensaciones e incentivos. .................................................. 237

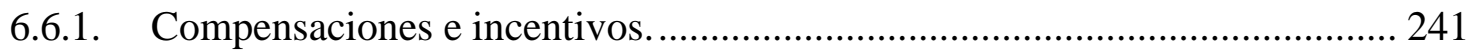

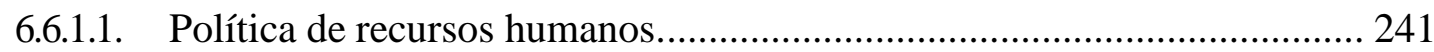

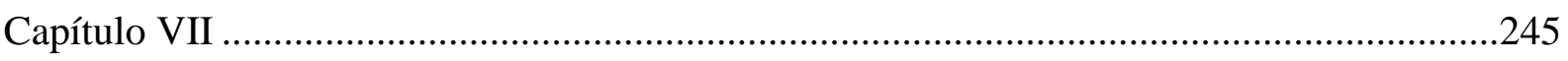

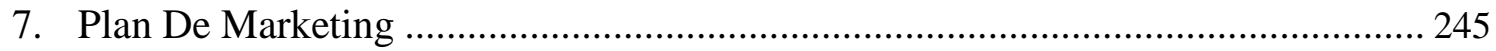

7.1. Estrategia de marketing................................................................................ 245

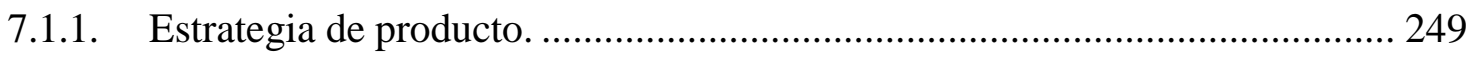

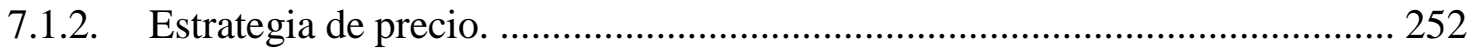

7.1.3. Estrategia de distribución ........................................................................ 254

7.1.4. Estrategia de promoción y publicidad. ........................................................ 256

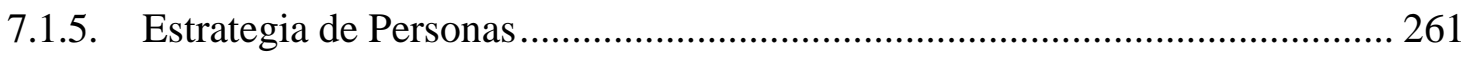




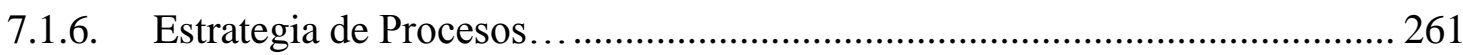

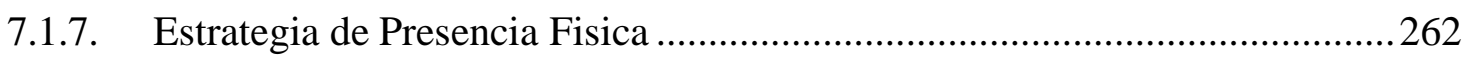

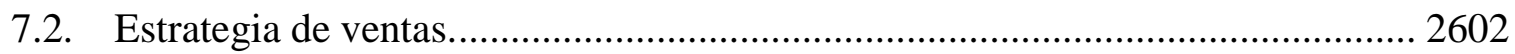

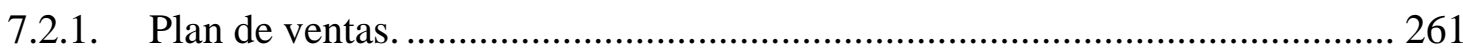

7.2.2. Política de servicios y garantías..................................................................... 267

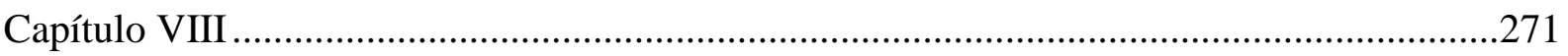

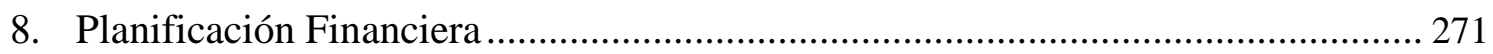

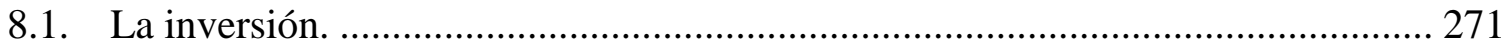

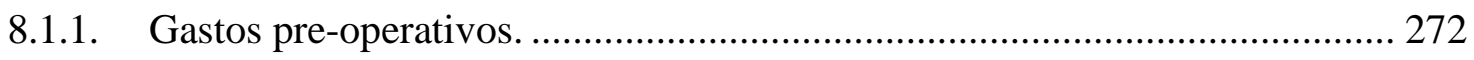

8.1.2. Inversión en capital de trabajo..................................................................... 277

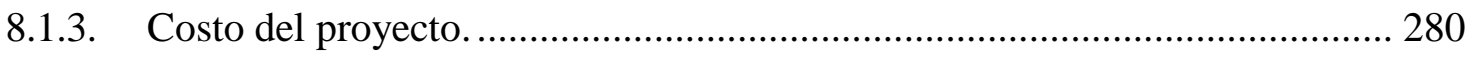

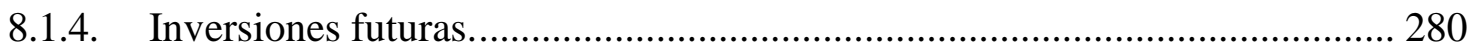

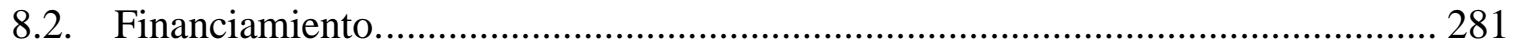

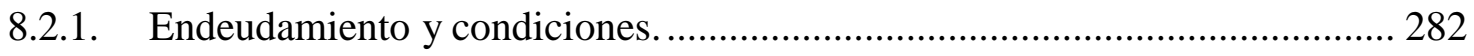

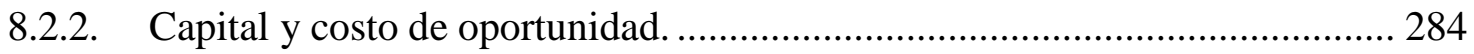

8.2.3. Costo de capital promedio ponderado. .......................................................... 284

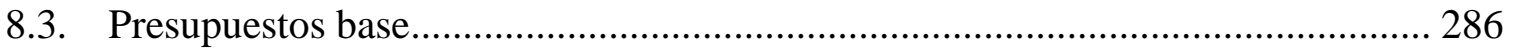

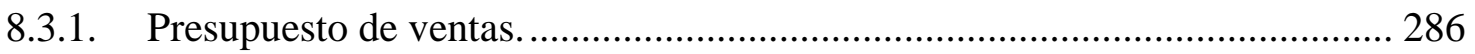

8.3.2. Presupuesto de costos de producción. ........................................................... 287

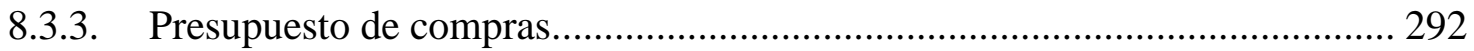

8.3.4. Presupuesto de costo de ventas................................................................... 293

8.3.5. Presupuesto de gastos de administrativos..................................................... 294

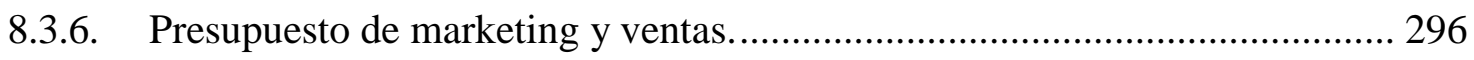


8.3.7. Presupuesto de gastos financieros. ............................................................. 297

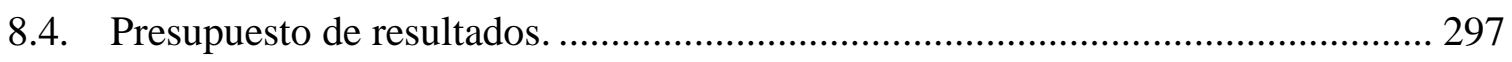

8.4.1. Estado de ganancias y pérdidas proyectado. ................................................. 297

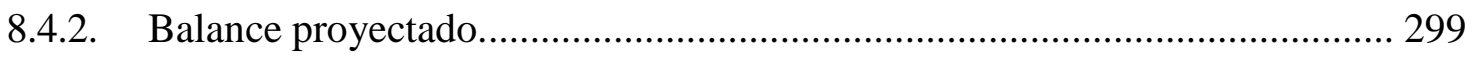

8.4.3. Flujo de caja proyectado.............................................................................. 301

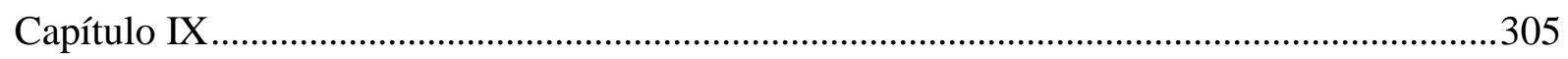

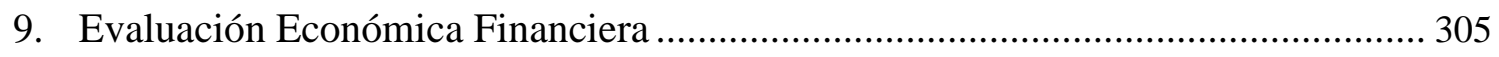

9.1. Evaluación financiera........................................................................................ 305

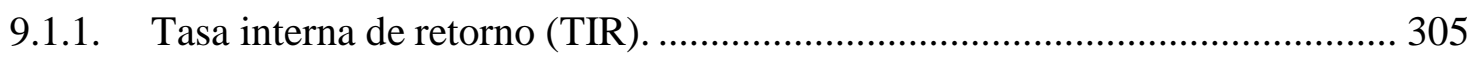

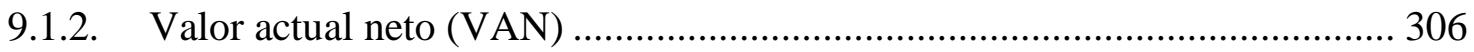

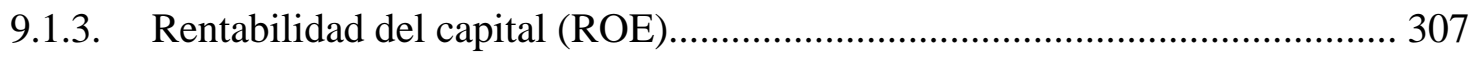

9.1.4. Ratios. 308

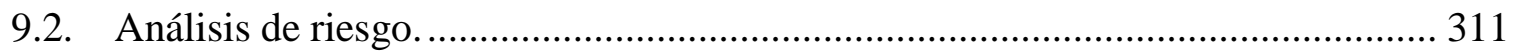

9.2.1. Análisis de punto de equilibrio.................................................................. 311

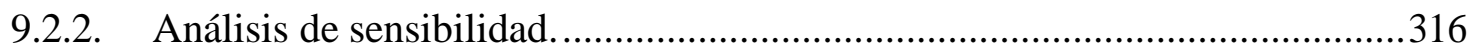

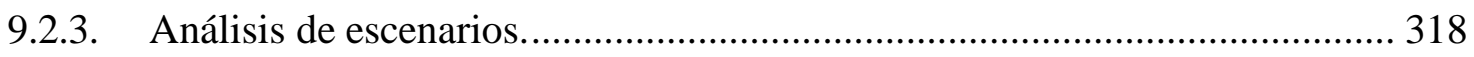

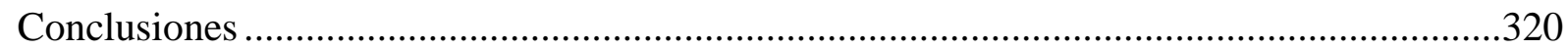

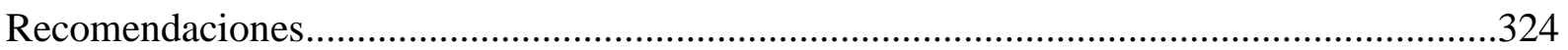

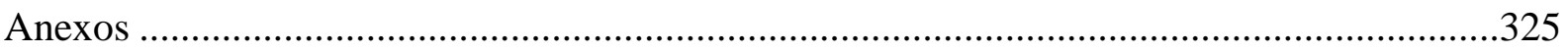

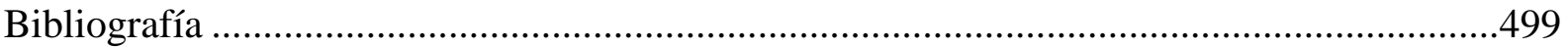




\section{Índice de Tablas}

Tabla 1. Restaurantes de Fast Food del segmento pollo y hamburguesas en Cusco ..................... 12

Tabla 2. Indicadores de evaluación de las Fuerzas de Porter........................................................ 17

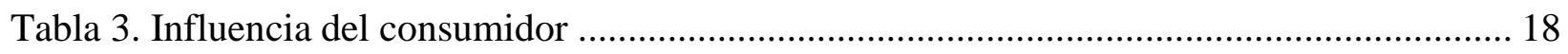

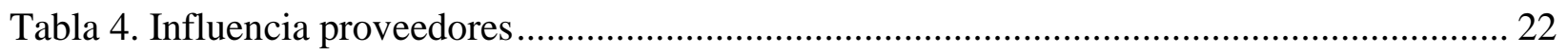

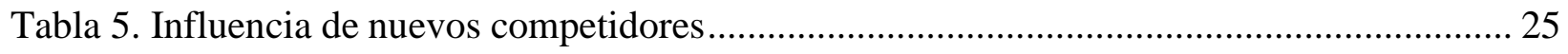

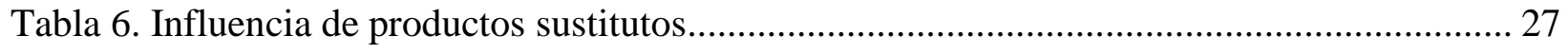

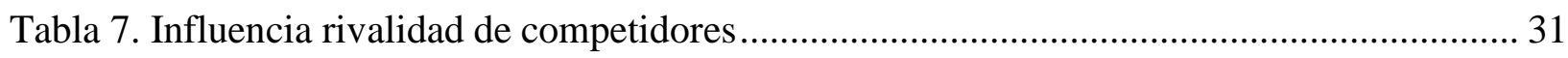

Tabla 8. Influencia de las 5 fuerzas de Porter ............................................................................ 34

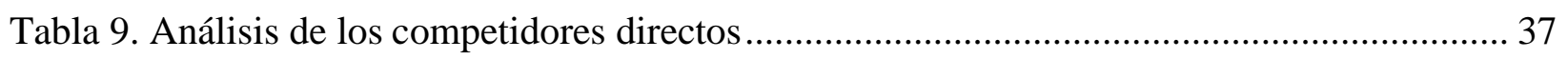

Tabla 10. Participación de mercado competidores directos............................................................ 39

Tabla 11. Valores de calificación para la matriz de perfil competitivo .......................................... 41

Tabla 12. Distribución de pesos de los factores críticos .............................................................. 42

Tabla 13. Evaluación de factores críticos de éxito del perfil competitivo ...................................... 43

Tabla 14. Justificación de calificaciones de la Matriz del perfil competitivo.................................. 44

Tabla 15. Oportunidades y amenazas del proyecto y justificación de ponderación ......................... 61

Tabla 16. Matriz de factores externos - EFE, análisis de oportunidades y amenazas................... 63

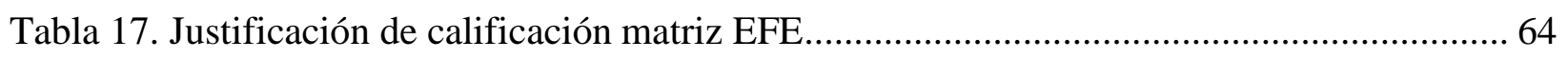

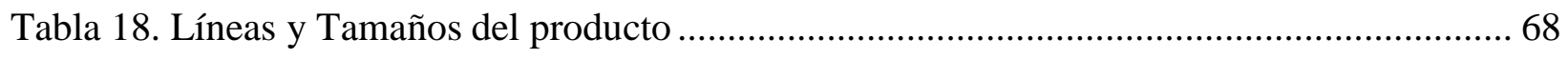

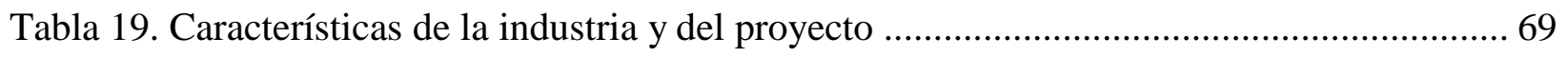

Tabla 20. Caracteristicas socio-demográficas del mercado objetivo ............................................ 70

Tabla 21. Segmentación geográfica: Población proyectada al 2017............................................... 72

Tabla 22. Segmentación demográfica: estimación porcentual de edades por grupo etario ........... 73 
Tabla 23. Ficha técnica de estudio cualitativo de focus group ………………………............... 75

Tabla 24. Ficha técnica de estudio cualitativo Entrevista a profundidad....................................... 76

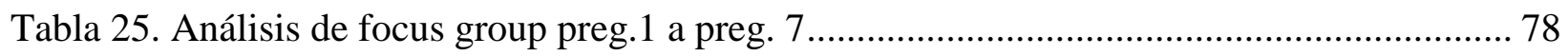

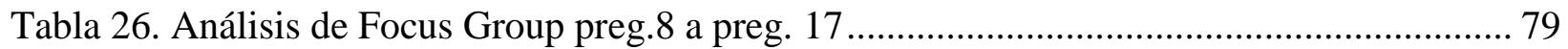

Tabla 27. Análisis de focus group preg. 18 a preg. 23............................................................... 79

Tabla 28. Análisis de focus group - propuesta valor preg.1 a preg. 10 …..................................... 81

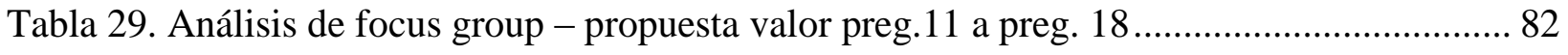

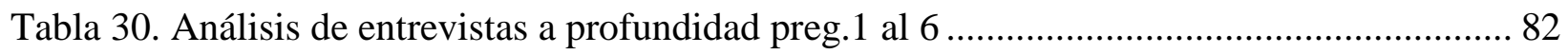

Tabla 31. Análisis de entrevistas a profundidad preg.7 al 14 ....................................................... 84

Tabla 32. Análisis de Entrevistas a profundidad preg. 15 al 21 .................................................. 85

Tabla 33. Determinación del factor K/2, según población por distrito.......................................... 88

Tabla 34. Esquema de aplicación de encuestas bajo el sistema de muestreo sistemático ............. 90

Tabla 35. Presupuesto de personal para la aplicación de encuestas............................................... 92

Tabla 36. Presupuesto de materiales para la aplicación de encuestas............................................ 93

Tabla 37. Presupuesto servicios de terceros para aplicación de encuestas .................................... 93

Tabla 38. Preguntas del cuestionario base de encuesta de preg 1 a preg. 24 ................................ 94

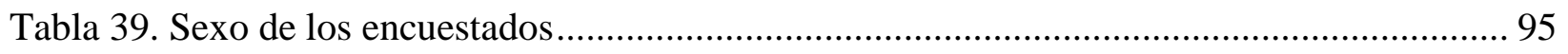

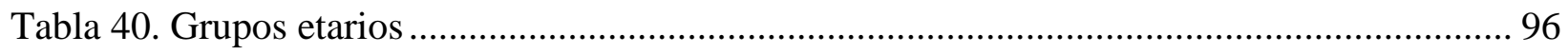

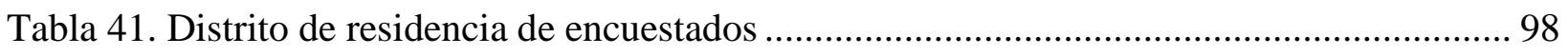

Tabla 42. Nivel de ingresos por NSE de encuestados ................................................................ 99

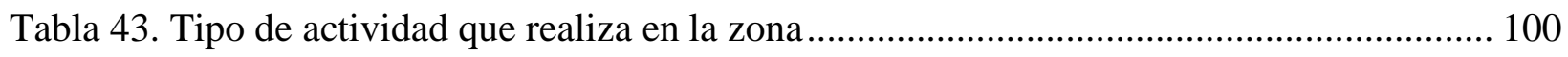

Tabla 44. Ocupación de encuestados .................................................................................... 102

Tabla 45. Asistencia a establecimientos de comida rápida .......................................................... 103 
Tabla 46. Frecuencia de asistencia a fast food según Encuesta ................................................. 104

Tabla 47. Estimación de frecuencia semanal, mensual y anual - promedio ponderado.............. 105

Tabla 48. Horario de asistencia a establecimientos de fast food ............................................... 107

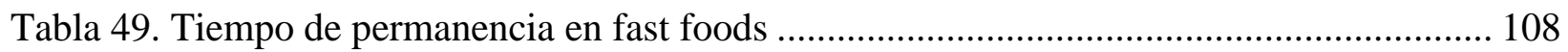

Tabla 50. Personas acompañantes durante visita a establecimientos fast foods......................... 109

Tabla 51. Factores importantes en un fast food ..................................................................... 110

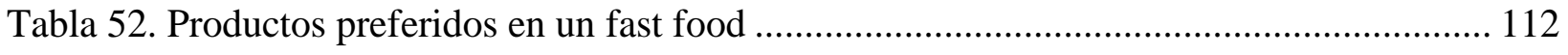

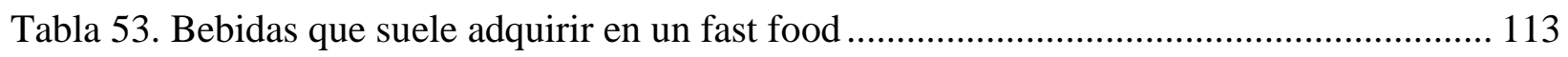

Tabla 54. Ranking asistencia a establecimientos de fast food .................................................... 115

Tabla 55. Participación de mercado de competidores ........................................................... 116

Tabla 56. Factores para elección de Fast food preferido ........................................................... 117

Tabla 57. Insumos andinos preferidos para nuevo fast food novoandino.................................... 119

Tabla 58. Adicionales andinos preferidos para implementar un nuevo fast food novoandino ... 120

Tabla 59. Bebidas andinas preferidas para nuevo fast food novoandino..................................... 122

Tabla 60. Pago promedio por combo personal en nuevo fast food novoandino.......................... 123

Tabla 61. Pago promedio por adicional en nuevo fast food novoandino.................................... 124

Tabla 62. Postres andinos para el nuevo fast food novoandino ……………………………...... 125

Tabla 63. Pago promedio por postre en nuevo fast food novoandino ........................................ 127

Tabla 64. Aceptación de nuevo fast food novoandino ................................................................ 128

Tabla 65. Tiempo de espera por pedido en nuevo fast food novoandino .................................... 129

Tabla 66. Tiempo de permanencia en nuevo fast food novoandino ........................................... 130

Tabla 67. Horario de asistencia a nuevo fast food novoandino .................................................. 132

Tabla 68. Medios de comunicación para promocionar el nuevo fast food novoandino .............. 133 
Tabla 69. Zonas de la Av. La Cultura para nuevo fast food novoandino 135

Tabla 70. Importancia de servicios adicionales en nuevo fast food novoandino. 136

Tabla 71. Nivel de Ingresos según grupo etario 139

Tabla 72. Rango promedio de pago combo personal según grupo etario 140

Tabla 73. Con quien suele asistir según grupo etario 140

Tabla 74. Tiempo de espera de pedido según grupo etario. 141

Tabla 75. Tiempo de permanencia en el local según grupo etario 142

Tabla 76. Efectividad del método de encuesta del mercado. 144

Tabla 77. Proyección población 2019 al 2023 con regresión lineal 145

Tabla 78. Mercado potencial según mercado residente y flotante del 2019 al 2023 147

Tabla 79. Mercado disponible del proyecto del 2019 al 2023 148

Tabla 80. Mercado efectivo del proyecto del 2019 al 2023 149

Tabla 81. Estimación del porcentaje de crecimiento del mercado. 150

Tabla 82. Captación del mercado objetivo 151

Tabla 83. Mercado objetivo del proyecto del 2019 al 2023 152

Tabla 84. Frecuencia de asistencia y cantidad que consume cada vez por combos 154

Tabla 85. Rango de precio promedio 154

Tabla 86. Pronóstico de ventas combos y postres 155

Tabla 87. Equipos de Cocina para el proyecto 166

Tabla 88. Equipos de counter y comedor para el proyecto 169

Tabla 89. Equipos del área administrativa 171

Tabla 90. Determinación del área de comedor del local 172

Tabla 91. Estimación de áreas potenciales 173 


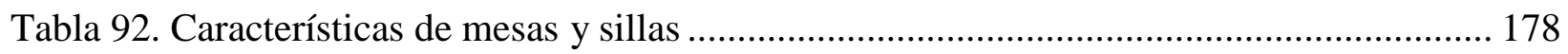

Tabla 93. Cantidad de mesas a implementar en el local ........................................................ 178

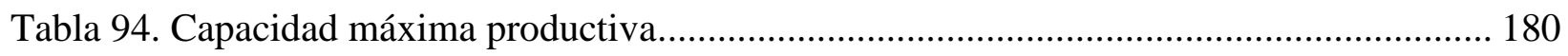

Tabla 95. Producción anual proyectada según número de visitas ............................................. 181

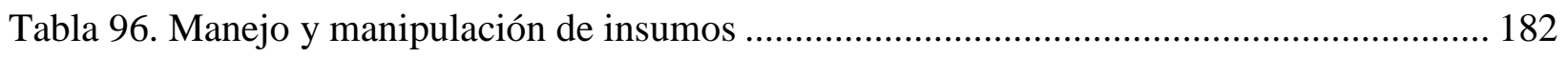

Tabla 97. Mermas y rendimientos de insumos A ……............................................................ 183

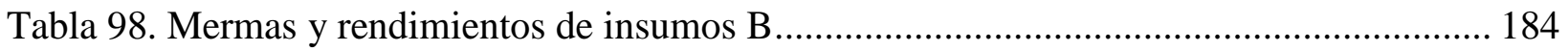

Tabla 99. Cantidad y capacidad de equipos a implementar........................................................ 185

Tabla 100. Programa de producción anual por combos y postres ............................................... 188

Tabla 101. Estudio de localización del proyecto ................................................................... 190

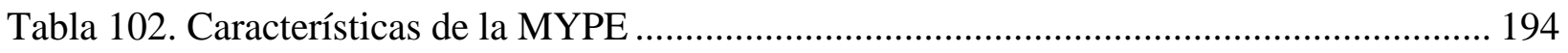

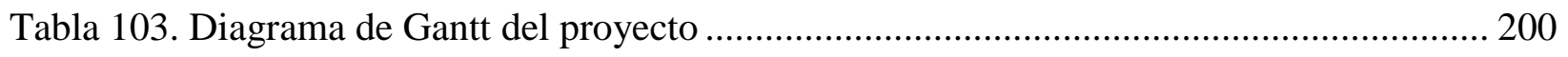

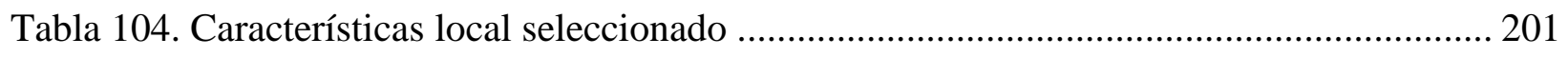

Tabla 105. Componentes de la declaración de misión.................................................................. 204

Tabla 106. Características de los bienes e insumos en producción ............................................. 211

Tabla 107. Características y recursos que se ejecutaran en la etapa de operación........................ 211

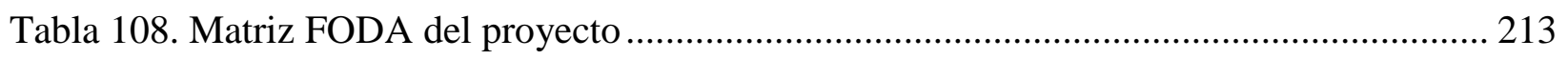

Tabla 109. Justificación de asignación de valor Sí o No, matriz VRIO ...................................... 214

Tabla 110. Recursos o capacidades que generan ventaja competitiva, matriz VRIO.................. 215

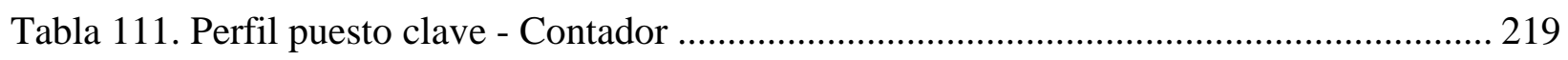

Tabla 112. Perfil puesto clave - Contador, requisitos del cargo ………………………............. 220

Tabla 113. Perfil puesto clave - Contador, funciones ................................................................. 221

Tabla 114. Perfil del Administrador ....................................................................................... 222 
Tabla 115. Perfil puesto clave - Administrador, requisitos del cargo ................................... 223

Tabla 116. Perfil puesto clave - Administrador, funciones ................................................. 224

Tabla 117. Perfil puesto clave - Jefe de Cocina .............................................................. 225

Tabla 118. Perfil puesto clave - Jefe de Cocina, requisitos del cargo...................................... 226

Tabla 119. Perfil puesto clave - Jefe de Cocina, funciones ............................................... 227

Tabla 120. Perfil puesto clave - Asistente de Tienda..................................................... 228

Tabla 121. Perfil puesto clave - Asistente de Tienda, requisitos del cargo ............................. 229

Tabla 122. Perfil puesto clave - Asistente de Tienda, funciones ......................................... 230

Tabla 123. Perfil puesto clave - Jefe de Almacén, distribución y mantenimiento..................... 230

Tabla 124. Perfil puesto clave - Jefe de Almacén, requisitos del cargo .................................. 231

Tabla 125. Perfil puesto clave - Jefe de Almacén, funciones .............................................. 232

Tabla 126. Perfil puesto clave - Asistente de Cocina ....................................................... 232

Tabla 127. Perfil puesto clave - Asistente de Cocina, requisitos del cargo ............................. 232

Tabla 128. Perfil puesto clave - Asistente de Cocina, funciones ............................................ 233

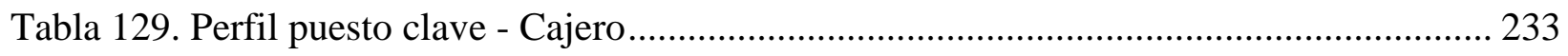

Tabla 130. Perfil puesto clave - Cajero, requisitos del cargo .............................................. 233

Tabla 131. Perfil puesto clave - Cajero, funciones ......................................................... 233

Tabla 132. Perfil puesto clave - Almacenero.................................................................. 234

Tabla 133. Perfil puesto clave - Almacenero, requisitos del cargo ....................................... 234

Tabla 134. Perfil puesto clave - Almacenero, funciones ...................................................... 234

Tabla 135. Perfil puesto clave - Colaboradores ................................................................ 234

Tabla 136. Perfil puesto clave - Colaboradores, requisitos del cargo .................................... 235

Tabla 137. Perfil puesto clave - Colaboradores, funciones .................................................. 235 
Tabla 138. Perfil puesto clave - Personal de Delivery .............................................................. 235

Tabla 139. Perfil puesto clave - Personal de Delivery, requisitos del cargo................................ 235

Tabla 140. Perfil puesto clave - Personal de Delivery, funciones …………………………...... 236

Tabla 141. Perfil puesto clave - Personal de Mantenimiento …………………….................... 236

Tabla 142. Perfil puesto clave - Personal de Mantenimiento, requisitos del cargo ………......... 236

Tabla 143. Perfil puesto clave - Personal de Mantenimiento, funciones ..................................... 236

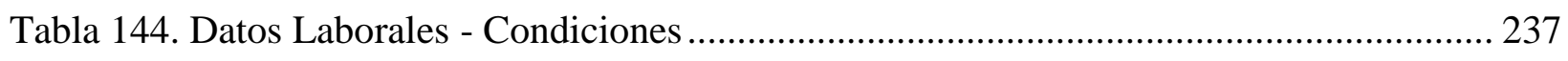

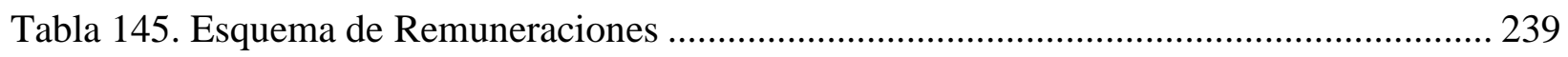

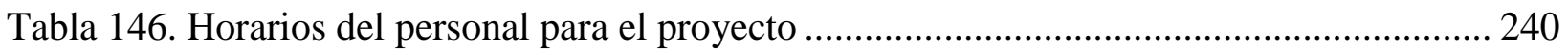

Tabla 147. Matriz de Ansoff, principales estrategias de marketing ........................................... 248

Tabla 148. Mezcla del producto en base a sus dimensiones ..................................................... 250

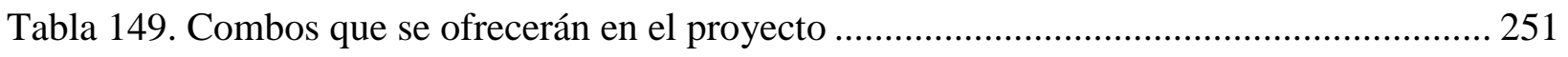

Tabla 150. Precio promedio de combos de competidores directos ............................................. 252

Tabla 151. Criterios para la fijación de precios ....................................................................... 253

Tabla 152. Criterios para definir las estrategias de distribución................................................... 254

Tabla 153. Plan de promoción y publicidad para el periodo de evaluación del proyecto .......... 259

Tabla 154. Estrategias para el manejo de la fuerza de ventas...................................................... 260

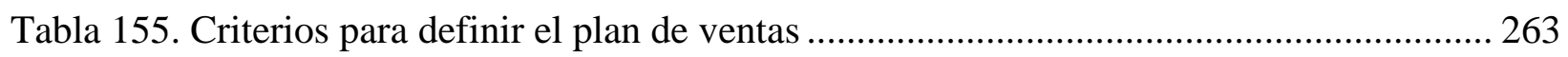

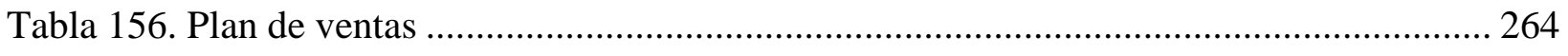

Tabla 157. Presupuesto del plan de marketing año 1 y año 2 ...................................................... 265

Tabla 158. Presupuesto del plan de marketing Año 3 y Año 4.................................................... 266

Tabla 159. Presupuesto del plan de marketing Año 5................................................................. 267

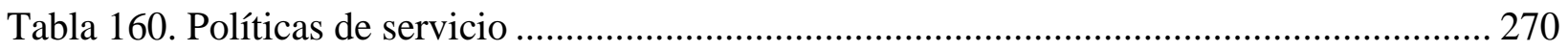




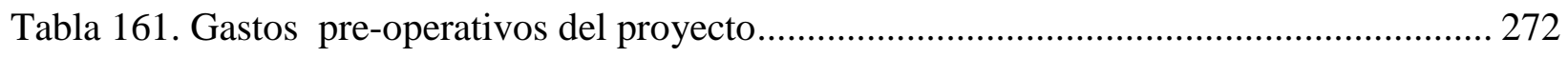

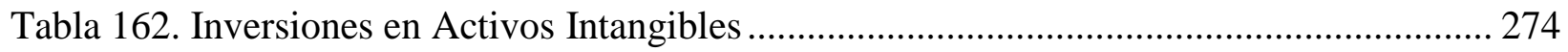

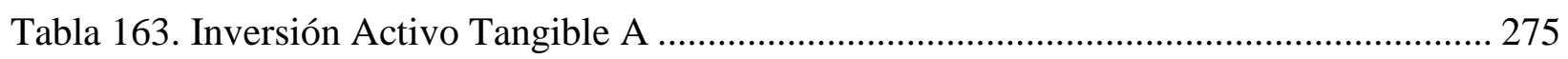

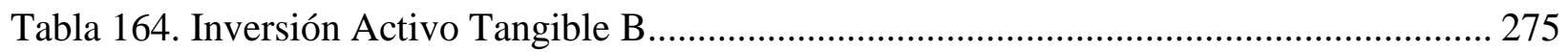

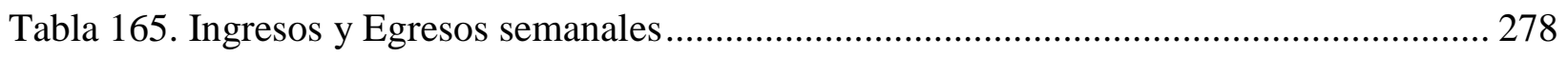

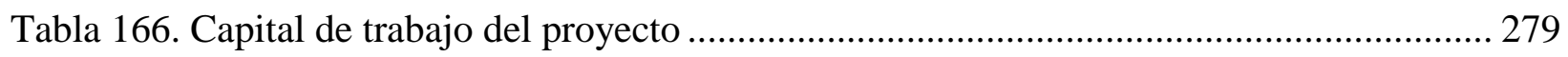

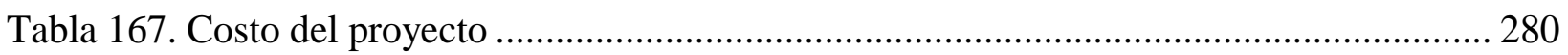

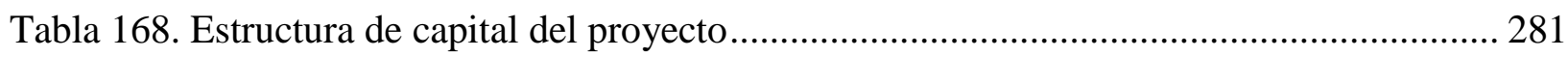

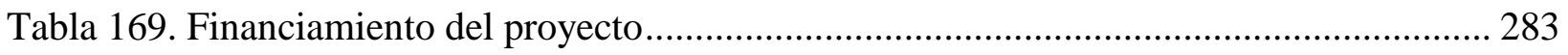

Tabla 170. Determinación del costo de oportunidad del negocio................................................ 284

Tabla 171. Determinación del Costo de Capital promedio ponderado ......................................... 285

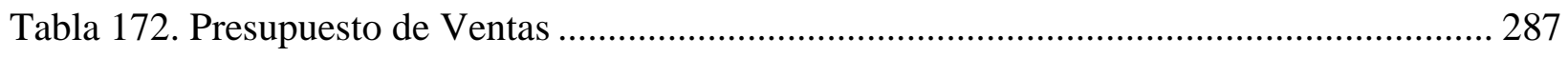

Tabla 173. Productos que se ofrecerán en el Proyecto ………………………………............. 288

Tabla 174. Programa de costo de Materia prima directa del proyecto ......................................... 289

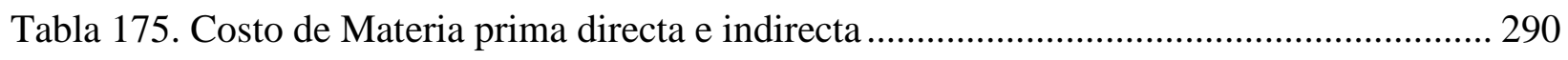

Tabla 176. Costo de mano de obra Directa e Indirecta ............................................................... 291

Tabla 177. Otros Costos indirectos de Fabricación ...................................................................... 291

Tabla 178. Costos de producción del Proyecto ........................................................................... 292

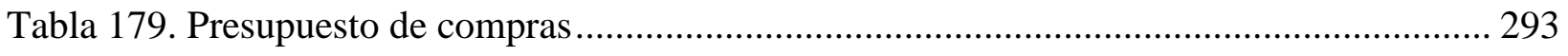

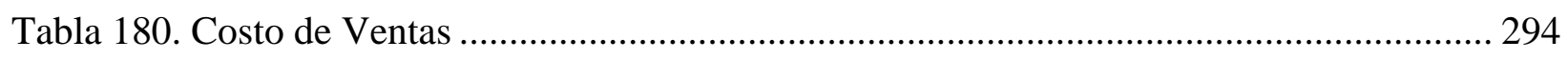

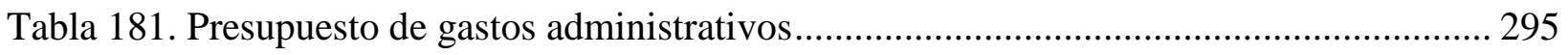

Tabla 182. Presupuesto de Marketing y Ventas............................................................................ 296

Tabla 183. Presupuesto de gastos financieros............................................................................. 297 
Tabla 184. Estado de Resultados proyectado .................................................................... 298

Tabla 185. Balance de situación financiera ........................................................................ 300

Tabla 186. Flujo económico y financiero del proyecto ................................................... 302

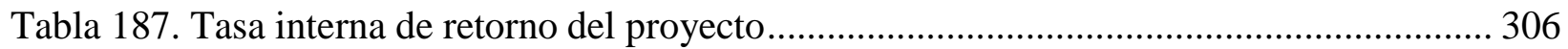

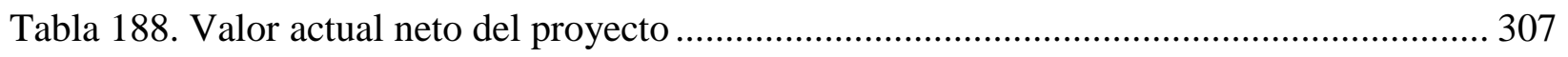

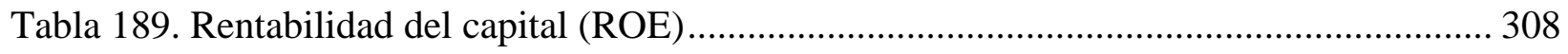

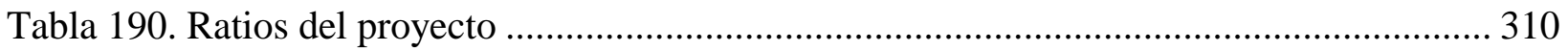

Tabla 191. Punto de equilibrio en Combos ........................................................................ 313

Tabla 192. Punto de Equilibrio en Postres ..................................................................... 315

Tabla 193. Análisis de sensibilidad del proyecto............................................................. 317

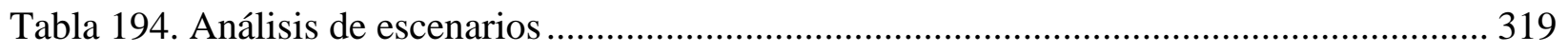




\section{Índice de Figuras}

Figura 1. Segmentación de empresas de servicio en la Ciudad de Cusco .................................... 10

Figura 2.Principales empresas que conforman el sector de comida rápida en Cusco................... 13

Figura 3. Cadenas de Fast Food con más 'fans' en el Perú........................................................ 15

Figura 4.Modelo de las cinco fuerzas competitivas de Porter. ...................................................... 17

Figura 5. Índice de confianza del consumidor latinoamericano tercer trimestre 2017 ................. 47

Figura 6. Cusco: Sintesis de Actividad Economica Febrero 2018 …........................................... 48

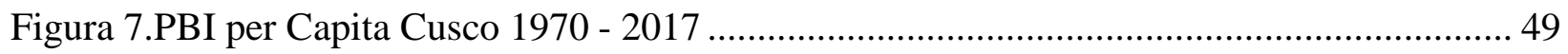

Figura 8. Índice de precios al consumidor de ciudades de sur de Febrero 2017 a Enero 2018 .... 50

Figura 9. Proyección inflación 2015-2019. Sintesis Reporte de Inflación BCRP .......................... 51

Figura 10. Crecimiento del PBI Real proyección del 2016 al 2050............................................ 52

Figura 11. PBI por sectores.Marco Macroeconómico Mundial 2018-2021 ................................. 52

Figura 12. Cambio en el crecimiento del PBI 2017-2018....................................................... 54

Figura 13. Mapa, Ciudad de Cusco-Distritos céntricos y aledaños a la Av. La Cultura................. 71

Figura 14. Segmentación demográfica - población urbana por NSE de la ciudad de Cusco......... 72

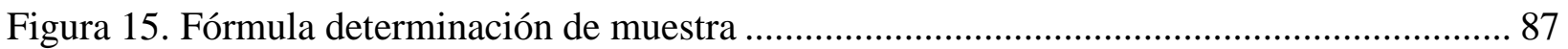

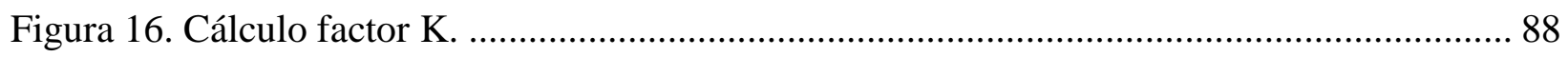

Figura 17. Puntos de aplicación de Encuestas. ……………….................................................... 90

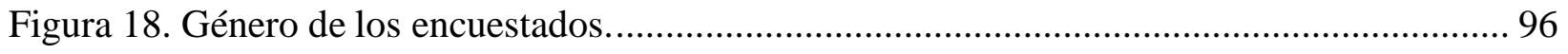

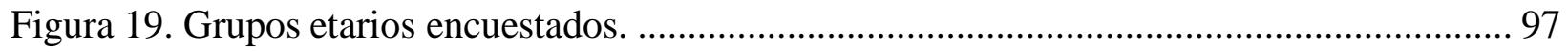

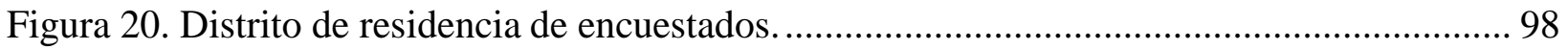

Figura 21. Nivel de ingresos por NSE de encuestados. ............................................................... 99

Figura 22. Tipo de actividad que realiza en la zona................................................................... 101 
Figura 23. Ocupación de los encuestados. 102

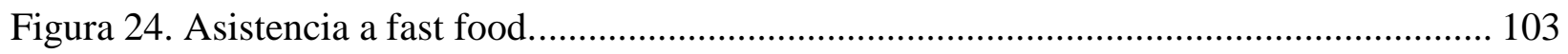

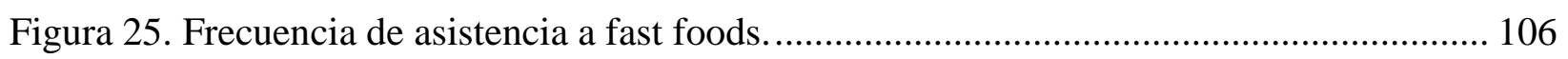

Figura 26. Horario de asistencia establecimientos de fast food................................................ 106

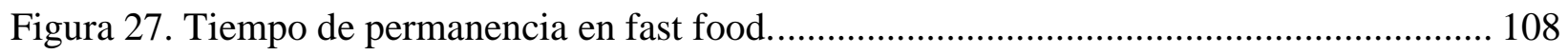

Figura 28. Personas acompañantes durante visita a fast food..................................................... 109

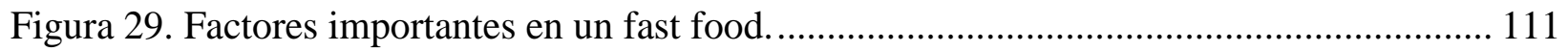

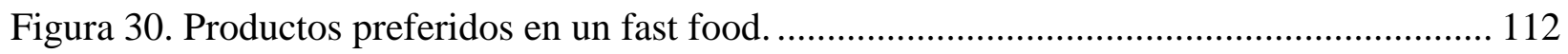

Figura 31. Bebidas que suele adquirir en un Fast Food............................................................ 114

Figura 32. Ranking asistencia a establecimientos de Fast Food................................................. 115

Figura 33. Participación de mercado de competidores. ............................................................ 116

Figura 34. Importancia de factores para fast food preferido.................................................... 118

Figura 35. Insumos preferidos para nuevo fast food novoandino............................................. 119

Figura 36. Adicionales andinos preferidos para implementar nuevo fast food novoandino....... 121

Figura 37. Bebidas andinas preferidas para implementar un nuevo fast food novoandino. ....... 122

Figura 38. Pago promedio por combo personal en nuevo fast food novoandino. ...................... 123

Figura 39. Pago promedio por adicional en nuevo fast food novoandino. .................................. 124

Figura 40. Postres andinos para el nuevo fast food novoandino................................................ 126

Figura 41.Pago promedio por postre andino en el nuevo fast food novoandino. ....................... 127

Figura 42. Aceptación de nuevo fast food novoandino. ........................................................... 128

Figura 43. Tiempo de espera por pedido nuevo fast food novoandino....................................... 129

Figura 44. Tiempo de permanencia en el nuevo fast food novoandino..................................... 130

Figura 45. Horario de asistencia a nuevo fast food novoandino................................................ 131 
Figura 46. Medios de comunicación para promocionar el nuevo fast food novoandino. 134

Figura 47. Zonas de la Av. La Cultura donde se ubicaría el nuevo fast food novoandino. 135

Figura 48. Importancia de servicios adicionales en nuevo Fast Food Novoandino. 137

Figura 49. Cálculo base de participación de mercado. 151

Figura 50. Fórmula, cálculo de ventas. 153

Figura 51. Tasa de ocupación por departamento 2016. 156

Figura 52. Diagrama del proceso del área de atención al cliente. 162

Figura 53. Diagrama del proceso productivo. 163

Figura 54. Diagrama del proceso de elaboración de Hamburguesas. 164

Figura 55. Equipos de cocina para el proyecto. 167

Figura 56. Equipos de comedor y counter 170

Figura 57.Equipos del área administrativo. 171

Figura 58. Lay out local del proyecto con flujos y áreas claves. 175

Figura 59. Plano de señalización de rutas de evacuación y zonas de seguridad...... 176

Figura 60. Distribución de equipos y maquinaria zona de producción y personal. 177

Figura 61. Modalidades de tipos de empresa como persona jurídica 193

Figura 62. Local seleccionado para el proyecto............................................................ 201

Figura 63.Riesgos de las estratégicas competitivas genéricas.......................................... 208

Figura 64.Determinación de la estrategia competitiva de Porter para el proyecto. .................. 209

Figura 65. Asignación de ventajas competitivas a los recursos............................................. 214

Figura 66.Organigrama funcional del proyecto........................................................... 217

Figura 67.Derechos de los trabajos de las pequeñas empresas......................................... 238

Figura 68.Logo del proyecto - Uchucuta S.A.C. ................................................................. 246 
Figura 69.Niveles de productos del proyecto............................................................ 249

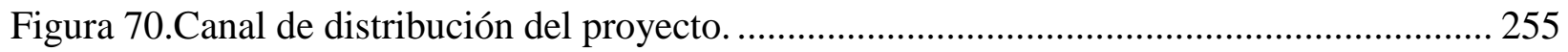

Figura 71. Fórmula para el cálculo del WACC .............................................................. 285 


\section{Índice de Anexos}

Anexo 1. Ficha Técnica de Investigación Cualitativa - Focus Group ......................................... 326

Anexo 2. Ficha Técnica de Investigación Cualitativa - Entrevista a Profundidad....................... 333

Anexo 3.Transcripción Focus Group NSE B, de 30 a 45 años ................................................. 337

Anexo 4. Transcripción Focus Group NSE B, de 20 a 35 años .................................................. 354

Anexo 5.Transcripción Focus Group NSE C, de 18 a 29 años .................................................... 378

Anexo 6.Transcripción Focus Group NSE A, de 30 a 45 años................................................... 394

Anexo 7.Transcripción Entrevista Gerente de Tienda KFC ………………………................... 417

Anexo 8.Transcripción Entrevista Gerente de Rhupa's ............................................................... 432

Anexo 9.Transcripción Entrevista Gerente de Turno McDonald's .......................................... 443

Anexo 10.Transcripción Entrevista Gerente de Native Restaurants ............................................. 450

Anexo 11.Ficha Técnica de Investigación Cuantitativa.................................................................. 456

Anexo 12.Encuesta acerca de un fast food en la ciudad del Cusco .......................................... 470

Anexo 13. Regresión lineal de población ................................................................................. 476

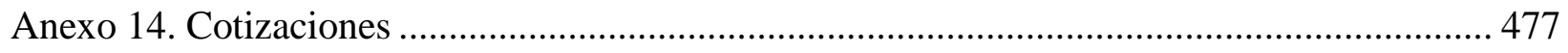

Anexo 15. Trámites, Licencias, remodelación de local y Tasa de Inversión Financiera ............. 483

Anexo 16. Calculo del Cok real de Estados Unidos ................................................................... 486

Anexo 17. Costo unitario de producción, ingresos por ventas..................................................... 488

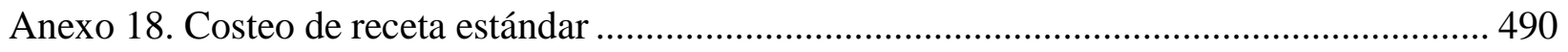

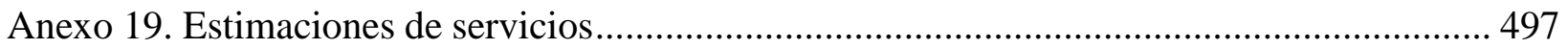




\section{Introducción}

El presente proyecto se ha elaborado con carácter de trabajo profesional para la obtención del grado de Magíster en Ciencias Empresariales. El objetivo principal de este trabajo es evaluar la viabilidad de la puesta en marcha de un restaurante tipo Fast Food en la ciudad del Cusco.

Bajo esta premisa, lo que busca el proyecto es fusionar el estilo de cocina americana fast food o comida rápida con insumos y productos oriundos de la región Cusco. Esta iniciativa nace gracias al crecimiento del consumo de comida rápida estilo americana en el Perú, debido a factores como tiempo, ocio y ansiedad; para su elaboración o preparación se utilizan insumos clásicos de la cocina americana, por ello lo que se busca es que los cusqueños se identifiquen con el producto y conozcan que los insumos que se producen en la región también pueden adaptarse a este tipo de cocina. En consecuencia, se busca fusionar insumos regionales con el estilo de cocina americana dentro del concepto de comida rápida, a través del uso de estándares de tiempo de servicio y producción.

Con el fin de analizar y determinar la rentabilidad del proyecto, se realizará un análisis de la estructura económica del sector, además de un estudio de mercado para definir las preferencias del mercado objetivo y el volumen potencial de ventas. También, se determinará la ingeniera del proyecto y los aspectos organizacionales del mismo. Asimismo, a través del plan de marketing se definirán las estrategias de promoción y ventas. Finalmente, se llevará a cabo la planificación y evaluación económica y financiera del plan de negocio; para todo ello se considero el año 2017 como inicio de las investigaciones de acuerdo al título del proyecto en estudio; "Plan de negocios para la puesta en marcha de un Fast Food en la ciudad del Cusco, 2017”. 


\section{Capítulo I}

\section{Generalidades}

En el presente capítulo se desarrollarán los antecedentes, la determinación de la oportunidad del proyecto y la justificación del proyecto donde se plantearán los motivos por los cuales se decide llevar a cabo la realización del plan de negocio, además se plantean: el objetivo general y los objetivos específicos; así como los alcances y limitaciones que se tendrán en el proceso de investigación.

\subsection{Antecedentes.}

La comida rápida (fast food) es un concepto culinario que busca optimizar los tiempos de preparación y expendio de los alimentos. Arbaiza, Cánepa, Cortez, \& Lévano (2014) señalan que este estilo de alimentación llegó al Perú en 1980 y la tendencia de este tipo de negocios es que se encuentran actualmente en expansión. "En el país, se considera como establecimientos de comida rápida o al paso, a aquellos que expenden sus productos al pie de la calle” (DePeru, n.d.), sin embargo existen en el país diferentes niveles de estos tipos de establecimientos, puesto que dependiendo del tamaño de la empresa o negocio se puede encontrar desde establecimientos tipo carretillas en las esquinas o vías públicas, hasta establecimientos de tamaño mediano y grande con servicios adicionales como mesas, juego para niños, baños, entre otros. Así mismo, existen franquicias internacionales de comida rápida que cuentan con presencia en el país, como son: (a) McDonald's, (b) Burger King, (c) Subway, (d) Pizza Hut, (e) Domino’s Pizza y (f) KFC (Kentucky Fried Chicken).

Se han identificado 557 locales de medianas y grandes empresas de comida rápida en Perú, de estos , 482 pertenecen a las grandes cadenas de comida rápida nacionales e internacionales, 
encabezadas por KFC, seguido de Pizza Hut, Bembos y McDonald's. En Lima y Callao se pueden encontrar 419 locales de fast food y 138 en provincia. (Serperuano, 2013).

Arbaiza, Cánepa, Cortez, \& Lévano (2014) señala que en el interior del país también se ha observado un fuerte crecimiento de este rubro; en especial, en departamentos como Arequipa y La Libertad, donde los locales para la venta de fast food suman 44 y 24 respectivamente.

Como se puede apreciar, el negocio de los fast food o comida rápida cada vez tiene mayor aceptación de la población en todas partes del Perú, y Cusco no es ajeno a tal tendencia. Al respecto se puede observar que, en la ciudad de Cusco existe un crecimiento de establecimientos de servicio de comida rápida con estilo de cocina americana, conformado por grandes y medianas empresas de cadenas nacionales e internacionales, tales como Bembos que inició operaciones en el 2007, McDonald's en 2008, KFC en 2011, Burger King, Popeyes en 2014, y Rhupa's Diner en 2015.

El consumidor cusqueño caracterizado fuertemente por sus costumbres, tradiciones, y su propia gastronomía, no dista de las tendencias y conductas que a nivel nacional y mundial se refuerzan, como la preferencia o aprobación por la comida rápida americana.

La gastronomía cusqueña además está caracterizada por la elaboración de alimentos con insumos autóctonos y ricos en proteínas como la papa, maíz, quinua, etc. Asimismo, por los diferentes tipos de ajíes y variedad de carnes como el cuy, alpaca, chicharrón, cordero, entre 
otros; además, hay que tomar en cuenta que la condimentación es la encargada de poner le especial y particular sabor especial característico a cada plato típico.

Una de las corrientes culinarias que incorpora estas preferencias del consumidor cusqueño actualmente es la cocina novoandina, esta corriente culinaria es un concepto que fusiona el uso de productos andinos con técnicas de preparación internacionales, cuyo principal promotor de esta tendencia en el Perú es el reconocido chef Gastón Acurio. (Jornada Online, 2015)

Todo ello hace pensar en la necesidad para el mercado del Cusco, de generar una propuesta innovadora de comida rápida, que no difiera de la oferta tradicional, por el posicionamiento de sus productos ya ganados.

\subsection{Determinación de la oportunidad.}

La ciudad del Cusco se caracteriza por su importancia cultural e histórica, gracias a los atractivos arqueológicos que posee, así como a las tradiciones, costumbres y gastronomía que aún se practican y que forman parte del patrimonio inmaterial de la humanidad para el mundo. Esta característica contribuye al enorgullecimiento de los cusqueños por sus productos originarios.

Sin embargo, conforme se percibe en el mercado local, el ir a comer a un establecimiento de fast food, es una práctica que se vuelve cada vez más habitual entre los consumidores cusqueños, sobre todo en el público joven. 
Según un estudio del Boston Consulting Group en relación a la generación de los millennials, quienes son jóvenes entre los 18 a 34 años de edad, quienes se encuentran influenciados por diversas culturas y el uso de redes sociales, estos prefieren los servicios de comida rápida cuando deciden salir a comer fuera de casa. (Diario Gestión, 2014)

Por otro lado, esta misma generación conformada por jóvenes y adultos trabajadores no cuenta con el tiempo necesario para dedicarse a la preparación de alimentos en casa, por ello se ven en la necesidad de recurrir a establecimientos que le brinden alimentación conforme a un tiempo y servicio limitado que les permita continuar con sus actividades a tiempo.

Del mismo modo, actualmente en la ciudad del Cusco, no existen establecimientos de fast food que incorpore insumos de la región y que además cuenten con precios accesibles destinados a consumidores de variados niveles socioeconómicos.

Todo ello genera un ambiente propicio para el desarrollo de proyectos que satisfagan estas necesidades e incorporen nuevas tendencias en el rubro de los fast food, adaptados además a la cultura gastronómica de la región.

\subsection{Justificación del proyecto.}

Existe una oportunidad de negocio que incorpora los cambios culturales que se vienen dando en el sector de restaurantes, las repercusiones en los hábitos alimenticios de la población, las 
tendencias en el incremento del consumo de alimentos fuera de casa, el ritmo de vida actual principalmente de la población joven y adulta.

Considera también la participación creciente de la mujer en el aporte del ingreso familiar. El hogar tradicional en el que la madre o la trabajadora del hogar debían cocinar el almuerzo o desayuno para la alimentación familiar es cada vez menos frecuente; las nuevas parejas, ambos por lo general trabajan fuera de casa; el tener empleada en casa además de ser costoso es también considerado de alto riesgo para los hogares. La restricción de contar con tiempo dedicado a la cocina es creciente; los tiempos de viaje hacia el trabajo en el transporte urbano de la ciudad del Cusco se han incrementado, principalmente por el aumento del parque automotor. La incorporación de análisis de las variables señaladas, constituyen aspectos que justifican la formulación del presente plan de negocios.

El negocio del servicio de comida rápida o fast food con estilo de cocina americana, complementado con la incorporación de insumos andinos de la región Cusco, brindan una opción novedosa para el mercado cusqueño aun no aplicado en otros establecimientos de fast food en la región.

La envergadura de este negocio permite poner en práctica los conocimientos obtenidos durante el proceso de estudio de la maestría para formular un plan de negocio que sea útil en un futuro, mediante este plan se pretende analizar los factores técnicos y económicos que permita la puesta en operación del negocio. 


\subsection{Objetivo general y específicos.}

\subsubsection{Objetivo general.}

Evaluar la viabilidad de implementar un negocio de comida rápida (fast food) que incorpore como valor agregado el concepto de comida novoandina en la ciudad del Cusco.

\subsubsection{Objetivos específicos.}

- Determinar el mercado objetivo al cual estará orientado el plan de negocio.

- Diseñar la infraestructura y equipamiento ideal para el plan.

- Definir y analizar a los principales competidores del proyecto.

- Realizar un análisis externo del segmento para conocer el nivel de influencia de factores políticos, económicos, legales, culturales, tecnológicos y ecológicos en el proyecto.

- Determinar la estructura legal, organizacional y funcional necesaria para la implementación de un negocio de comida rápida.

- Diseñar el plan de marketing del proyecto.

- Realizar la evaluación económica y financiera del proyecto.

\subsection{Alcances y limitaciones de la investigación.}

Entre los alcances del estudio se tiene que el proyecto contempla la creación de un restaurante tipo fast food que fusione el estilo de cocina americana con los insumos andinos que se producen en la ciudad del Cusco (novoandino). El ámbito geográfico de influencia directa será la zona urbana metropolitana de la ciudad del Cusco, que comprende los distritos céntricos y aledaños a la Av. La Cultura, una de las avenidas principales e importantes de la Ciudad. El plan de negocio 
considera un horizonte de proyección de cinco años, en base al cual se evaluará la rentabilidad del plan de negocio. Las limitaciones que se presentan en la formulación del plan de negocios están referidas a:

- La consistencia de información que brindan las fuentes primarias durante las investigaciones cualitativas (focus group y entrevistas) y cuantitativas (encuestas), podrían ser sesgados voluntariamente o por desconocimiento en algunos casos. Para ello se desarrollará un perfil básico de las características y cualidades con las que deben contar las personas que participan en dichas investigaciones para garantizar la transparencia en la información.

- La inexistencia de datos en referencia a estudios estadísticos, históricos o de investigación sobre el origen, evolución o tendencias del mercado de Fast Foods en la Región Cusco. Para compensar dicha limitación se recabará información de fuente primaria, a través de una investigación cuantitativa (encuestas) en base a un muestreo probabilístico sistemático que brinde una visión más amplia del mercado, así como la incorporación de preguntas que permitan recabar información que no se pueda encontrar en fuentes secundarias; también se aplicará una investigación cualitativa (focus group y entrevistas) que considere puntos clave como expectativas en cuanto al desarrollo del sector Fast Food y percepciones sobre el mercado objetivo, así como gustos y estilos de vida del mismo. 


\section{Capítulo II}

\section{Estructura Económica Del Sector}

En este capítulo se llevará a cabo la descripción de la industria actual, analizando a las empresas de la competencia que ofrecen el mismo servicio; analizar con qué nivel qué nivel de participación cuentan en el mercado cusqueño para poder obtener semejanzas y diferencias frente al plan de negocio que se quiere desarrollar.

\subsection{Descripción del estado actual de la industria.}

Para el presente proyecto se realizará un análisis del estado actual en el que la industria de los fast food se vienen desarrollando, se va a considerar la segmentación y el análisis de las empresas que la conforman, para ello se utilizará como herramienta el estudio de las Fuerzas de Porter.

\subsubsection{Segmentación de la industria.}

El proyecto a desarrollar pertenece al sector de empresas de servicio, es decir se debe aplicar los criterios de segmentación referentes a los mercados de consumo (Cifuentes, 2010). Asimismo, se determinó los grupos estratégicos dentro de este tipo de empresas en la ciudad del Cusco. Según Guerras \& López (2007), estos grupos están compuestos por aquellas empresas que comparten igual o similar estrategia.

\subsubsection{Segmentación de mercados de consumo en la ciudad del cusco.}

Para determinar los criterios de segmentación adecuados al proyecto, se tomó como referencia la segmentación de mercados de consumo en la categoría de segmentación por criterios 
relacionados con el producto, ello debido a que el proyecto está enfocado en brindar un producto innovador.

En ese sentido, se consideraron todas aquellas variables que conllevan a la determinación final de tipo de producto al que estará orientado el proyecto, como son: el tipo de establecimiento (tipo de empresa y categoría), frecuencia de uso (tipo de servicio), ocasión (tipo de cocina) y ventajas buscadas (tipo de producto); conforme a ello se determinó la siguiente segmentación determinada a criterio del evaluador, acorde a la realidad de la ciudad de Cusco.

- Segmentación por tipo de empresa.

- Segmentación por tipo de categorización.

- Segmentación por tipo de servicio.

- Segmentación por tipo de cocina.

- Segmentación por tipo de producto.

Conforme al esquema anterior se desarrolló la gráfica de la figura 1, para ello se consideró en evaluación a los establecimientos localizados en la zona urbana de la ciudad del Cusco. 


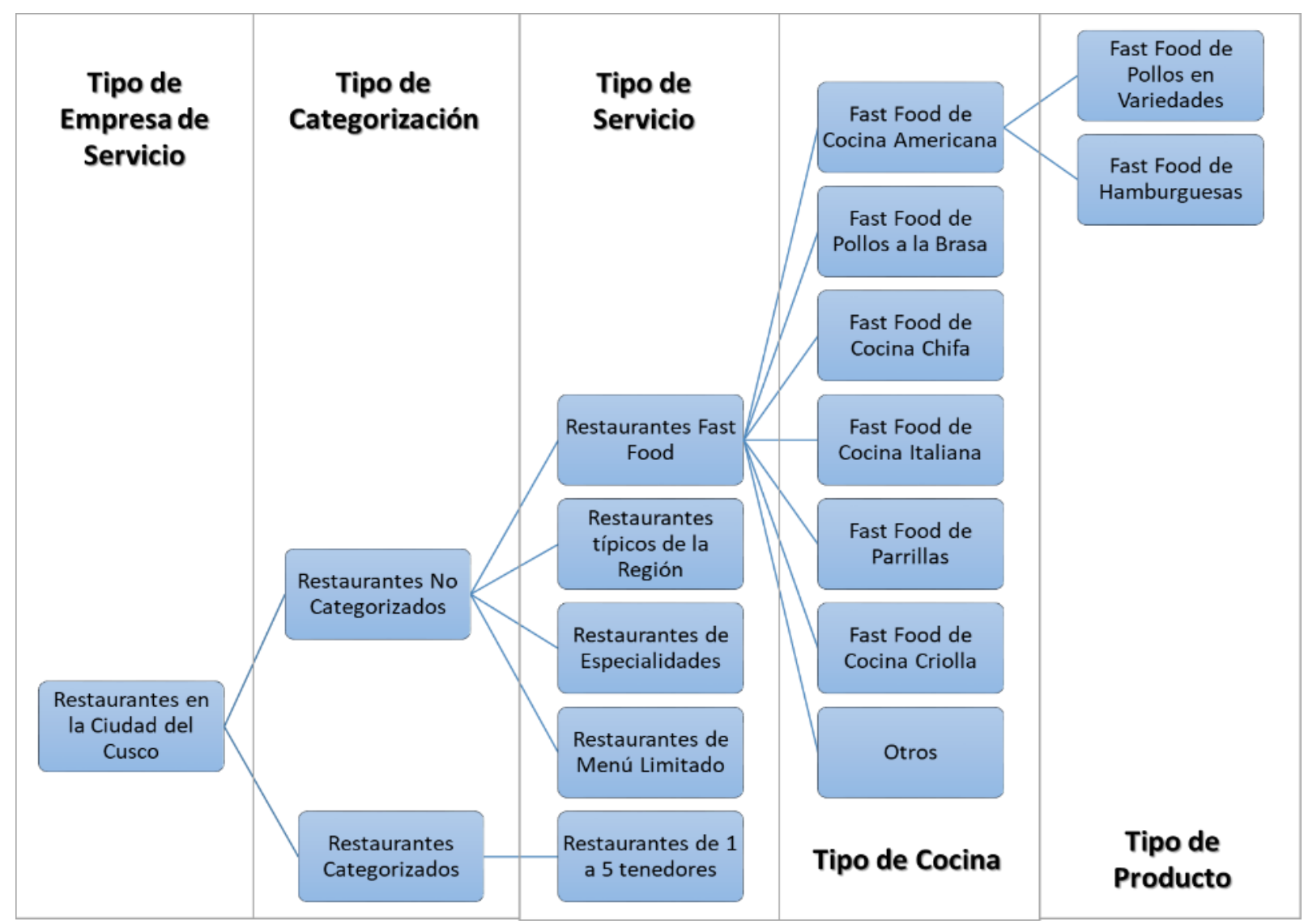

Figura 1. Segmentación de empresas de servicio en la Ciudad de Cusco. Fuente: Elaboración propia

Conforme Figura 1, el proyecto busca incursionar en el segmento de restaurantes no categorizados tipo fast food de cocina americana de pollos en variedades y hamburguesas, esto explicado por el elevado consumo de pollo al interior del país; por ejemplo, “el consumo de pollo a la brasa en provincias fue de 14 pollos por familia en el 2015”. (El Comercio, 2016)

Del mismo modo, el mercado de hamburguesas es altamente atractivo, "incluso empresas como McDonald's están implementando nuevos estilos tipo gourmet los cuales piensan aplicar también en un futuro próximo en la ciudad del Cusco”. (Diario Gestión, 2016) 


\subsubsection{Empresas que la conforman.}

En la ciudad de Cusco, se puede considerar a la marca KFC como uno de los principales líderes del rubro dentro del segmento al que se dirige el plan de negocio, puesto que según el "Instituto Nacional de Estadística e Informática, el 33.2\% del gasto de los peruanos que viven en la región de la sierra está destinado al consumo de alimentos fuera del hogar donde la preferencia está dada por el consumo de pollo broaster” (Gestión.pe, 2014). “KFC pertenece al grupo Delosi S.A, esta empresa ha evidenciado un fuerte crecimiento sobre otras empresas del mismo rubro obteniendo un importante liderazgo principalmente por dicha marca" (Diario Gestión, 2015). A continuación, se presenta la información de las franquicias de fast food más reconocidas que actualmente operan en la ciudad de Cusco, según la Tabla 1 y Figura 2. 
Tabla 1

Restaurantes de Fast Food del segmento pollo y hamburguesas en Cusco

\begin{tabular}{|c|c|c|c|c|c|}
\hline Nombre & $\begin{array}{l}\text { Origen /tipo de } \\
\text { cocina }\end{array}$ & Principales productos & $\begin{array}{c}\text { Ubicaciones y locales } \\
\text { en Cusco }\end{array}$ & $\begin{array}{l}\mathrm{N}^{\circ} \text { de locales a } \\
\text { nivel nacional }\end{array}$ & $\begin{array}{c}\text { Inicio de operaciones } \\
\text { en Cusco }\end{array}$ \\
\hline KFC & Americano & $\begin{array}{l}\text { Pollo broaster soft o crispy con papas } \\
\text { fritas. }\end{array}$ & $\begin{array}{l}\text { 1. Plaza de armas. } \\
\text { 2. Centro comercial Real Plaza. }\end{array}$ & $104^{\mathrm{a}}$ & $2011^{\mathrm{a}}$ \\
\hline McDonald's & Americano & $\begin{array}{l}\text { Hamburguesas de pollo y carne con } \\
\text { diversos complementos y papas fritas. }\end{array}$ & $\begin{array}{l}\text { 1. Plaza de armas. } \\
\text { 2. Centro comercial Real Plaza. }\end{array}$ & $31^{b}$ & $2008^{b}$ \\
\hline Bembos & Peruano/Americano & $\begin{array}{l}\text { Hamburguesas de pollo y carne con } \\
\text { diversos complementos y papas fritas. }\end{array}$ & $\begin{array}{l}\text { 1. Plaza de armas. } \\
\text { 2. Centro comercial Real Plaza. }\end{array}$ & $110^{\mathrm{c}}$ & $2007^{\mathrm{c}}$ \\
\hline $\begin{array}{l}\text { Burger } \\
\text { King }\end{array}$ & Americano & $\begin{array}{l}\text { Hamburguesas de pollo y carne con } \\
\text { diversos complementos y papas fritas. }\end{array}$ & Centro comercial Real Plaza. & $32^{d}$ & $2014^{\mathrm{d}}$ \\
\hline Popeyes & Americano & $\begin{array}{l}\text { Pollo broaster estilo louisiana con } \\
\text { papas fritas. }\end{array}$ & Centro comercial Real Plaza. & $18^{\mathrm{e}}$ & $2014^{\mathrm{e}}$ \\
\hline $\begin{array}{l}\text { Rhupa's } \\
\text { Diner }\end{array}$ & Cusqueño/Americano & $\begin{array}{l}\text { Hamburguesas de carne con diversos } \\
\text { complementos, pollos en variedades y } \\
\text { papas fritas. }\end{array}$ & $\begin{array}{l}\text { Av. La Cultura } \\
\text { Av. Pardo } \\
\text { Av. Tullumayo }\end{array}$ & $4^{\mathrm{f}}$ & $2015^{\mathrm{f}}$ \\
\hline
\end{tabular}

Nota. Fuente: Elaboración propia.

a KFC. $N^{\circ}$ de Locales. Recuperado de http://diariouno.pe/2016/07/17/kfc-se-renueva/; Año de Operación Cusco. Recuperado de

http://www.andina.com.pe/agencia/noticia-kfc-abrira-diez-nuevos-restaurantes-y-cuatro-estaran-cusco-huancayo-cajamarca-y-chimbote-360131.aspx

b McDonald's. N de Locales. Recuperado de http://www.lavanguardia.com/vangdata/20150820/54434771508/el-ranking-de-paises-con-mas-restaurantesmcdonald-s.html; Año de Operación Cusco. Recuperado de http://ebiz.bligoo.com/cadena-de-hamburguesas-mcdonald-s-abre-primer-local-en-elcusco\#.WPUJY_k1_IU

c Bembos. $\mathrm{N}^{\circ}$ de Locales. Recuperado de

http://www.bembos.com.pe/locales?utm_source=search\&utm_medium=cpc\&utm_campaign=BembosBranding $16 \& u t m \_c o n t e n t=B e m b o s \& u t m \_t e r m=S i t e l i n k L o$ cales\&gclid=CPa7xsqGrNMCFUdDhgodE6cMIA; Año de Operación Cusco. Recuperado de http://peruempresa.blogspot.pe/2007/06/bembos-abrir-cincolocales-en-lima-y.html

d Burguer King. $\mathrm{N}^{\circ}$ de Locales. Recuperado de http://elcomercio.pe/economia/negocios/burger-king-abrio-nuevo-local-real-plaza-salaverry-noticia-1741248; .

Año de Operación Cusco. Recuperado de http://cusconoticias.pe/07-06-2014/real-plaza-cusco-fiesta-por-su-inauguracion-oficial

e Popeyes. $N^{\circ}$ de Locales. Recuperado de http://www.popeyes.com.pe/locales; Año de Operación Cusco. Recuperado dehttp://cusconoticias.pe/07-06-

2014/real-plaza-cusco-fiesta-por-su-inauguracion-oficial

f Rupha's Diner. No de Locales. Recuperado de https://es-la.facebook.com/RuphasDiner/; https://www.tripadvisor.com.pe/ShowUserReviews-g294314-

d8548073-r404589795-Rupha_s_Diner-Cusco_Cusco_Region.html 


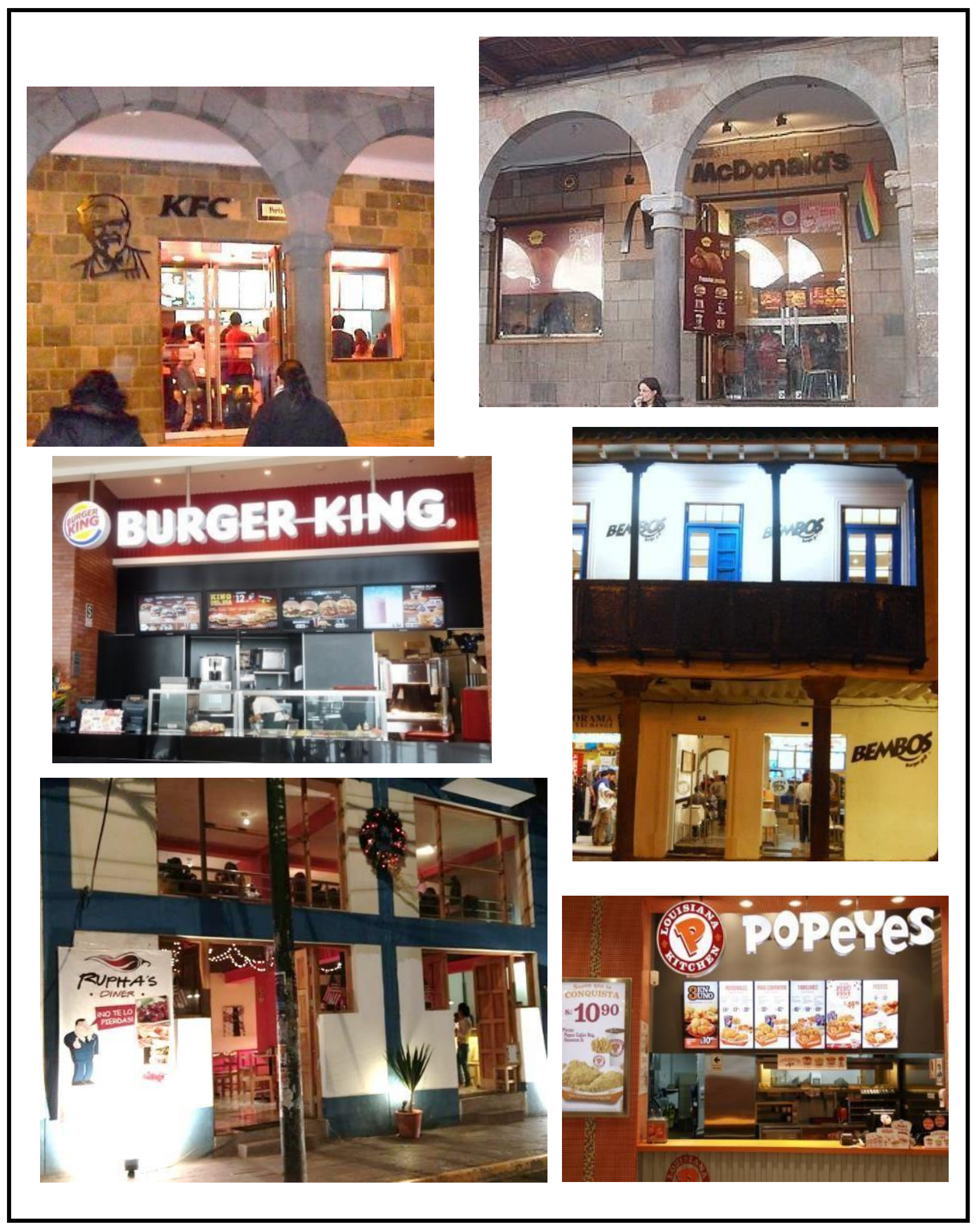

Figura 2.Principales empresas que conforman el sector de comida rápida en la ciudad de Cusco. 


\subsection{Tendencias de la industria.}

El mercado de los establecimientos de comida rápida o fast food en el Perú representa una de las más altas facturaciones en cuanto a expendio de comida se refiere, las grandes cadenas de comida rápida han alcanzado una gran evolución en los últimos años y a su vez generan empleo para muchos jóvenes.

Gracias a la expansión de nuevos centros comerciales y el incremento del poder adquisitivo, la industria de comida rápida viene creciendo a pasos agigantados en el Perú y también en provincias donde se ha evidenciado un crecimiento del $15 \%$ en el mercado de franquicias, cada vez más nuevas marcas están incursionando en nuevas ciudades y explotando nuevos mercados. (Diario Gestión, 2017)

“En una prospectiva para el año 2021, el panorama de consumo de las familias peruanas se modificará gracias a los diversos cambios demográficos de condición, de nivel de adquisición y apreciación.” (Arbaiza, Cánepa, Cortez, \& Lévano, 2014)

Asimismo, diversas investigaciones indican que existen las nuevas tendencias del cuidado de la salud sobre los establecimientos de fast food en el Perú, las cadenas ya están empezando a escuchar a un público más preocupado por su buena alimentación por ejemplo; "franquicias con cartas que incluyen ensaladas, jugos o agua, entre otros productos con bajas calorías o con alto contenido nutricional, como es el caso de McDonald's y su línea "signature"." (Diario Gestión, 2016) 
A continuación, se muestra un gráfico con el top cinco de establecimientos de fast food con más "likes" vía facebook en Perú, según Figura 3.

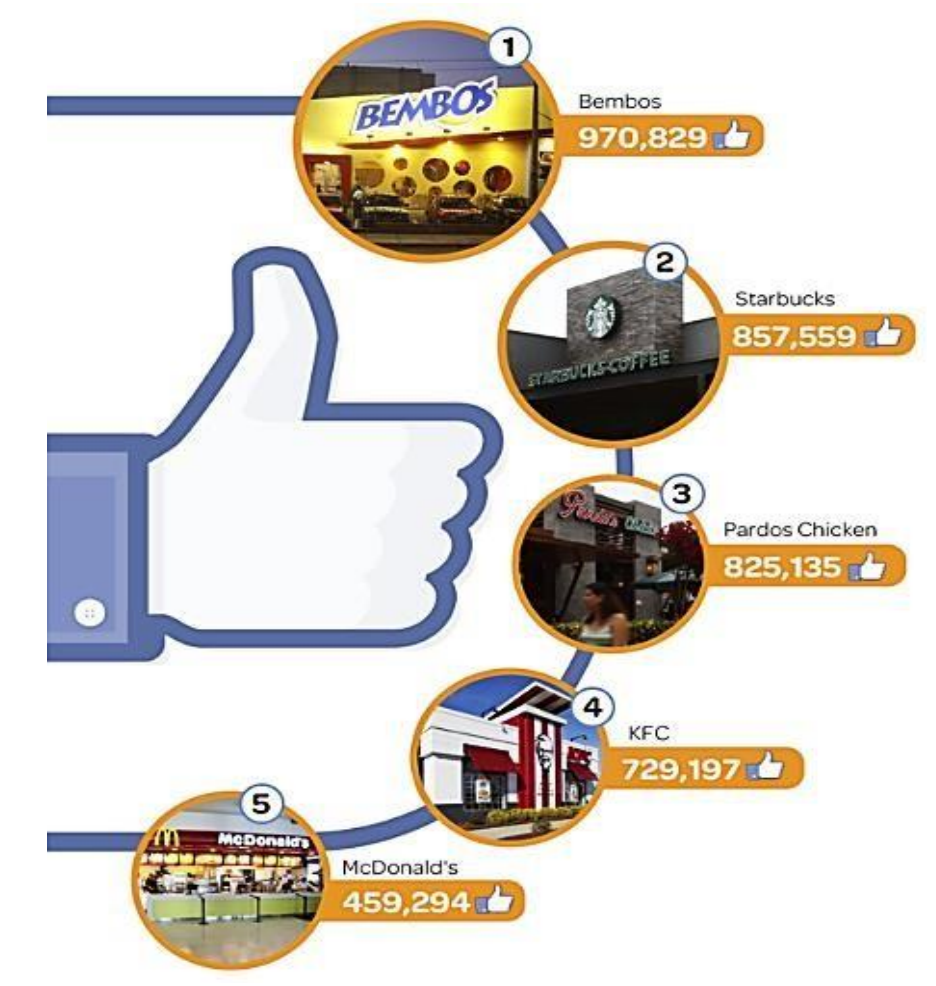

Figura 3. Cadenas de Fast Food con más 'fans' en el Perú. . Recuperado de http://gestion.pe/tendencias/facebook-estas-son-cadenas-fast-food-mas-fans-peru-2137470

Conforme a la Figura 3, se puede estimar que en términos sociales, los fast food han calado en la población no sólo como respuesta a la necesidad del consumo rápido de alimentos, sino también como un lugar de entretenimiento, así mismo se puede determinar que el pollo y las hamburguesas son las preferidas por los peruanos.

Según estudios realizados, se ha concluido que habrá un crecimiento sostenido del sector, incremento en el desarrollo urbano con zonas comerciales, grandes posibilidades de 
incremento del ingreso familiar, parte del cual se invertiría en consumo y entretenimiento, posibilidades de cambios de hábitos de consumo locales como producto de las tendencias mundiales que se orientan al consumo de comida más nutritiva, mejora de know-how especializado que permitirá ofrecer precios cómodos y de calidad. (Arbaiza, Cánepa, Cortez, \& Lévano, 2014)

Las estadísticas apuntan que este sector tiene bastantes opciones para ser aprovechadas, y el mercado cusqueño no es ajeno a sumarse a este potencial, Cusco ha crecido como ningún país o región del mundo.

En la actualidad la principal tendencia de la industria de empresas de servicio en el ámbito del sector de restaurantes es el desarrollo de la comida fusión. Un ejemplo de ello es que en el año 2017, Perú participó en la Cumbre Internacional de Gastronomía Madrid Fusión, donde el Perú destacó por la innovación y el uso de insumos andinos con técnicas de cocción extranjeras, así como chefs españoles que elaboraron platos típicos de su país incorporando insumos andinos. (Portal del Turismo, 2017)

\subsection{Análisis estructural del sector industrial.}

Para llevar a cabo el análisis del segmento restaurantes de comida rápida americana de pollos y hamburguesas y sus variedades, las cuales pertenecen al sector restaurantes dentro de la industria de empresas de servicio, se aplica el modelo de las fuerzas competitivas de Michael Porter, que se muestra en la Figura 4, "este modelo permite realizar un análisis de las 
oportunidades y amenazas de la empresa, asi como brindar una ayuda para determinar la posición del misma frente a sus competidores”. (Donawa Torres \& Morales Martínez, 2018)

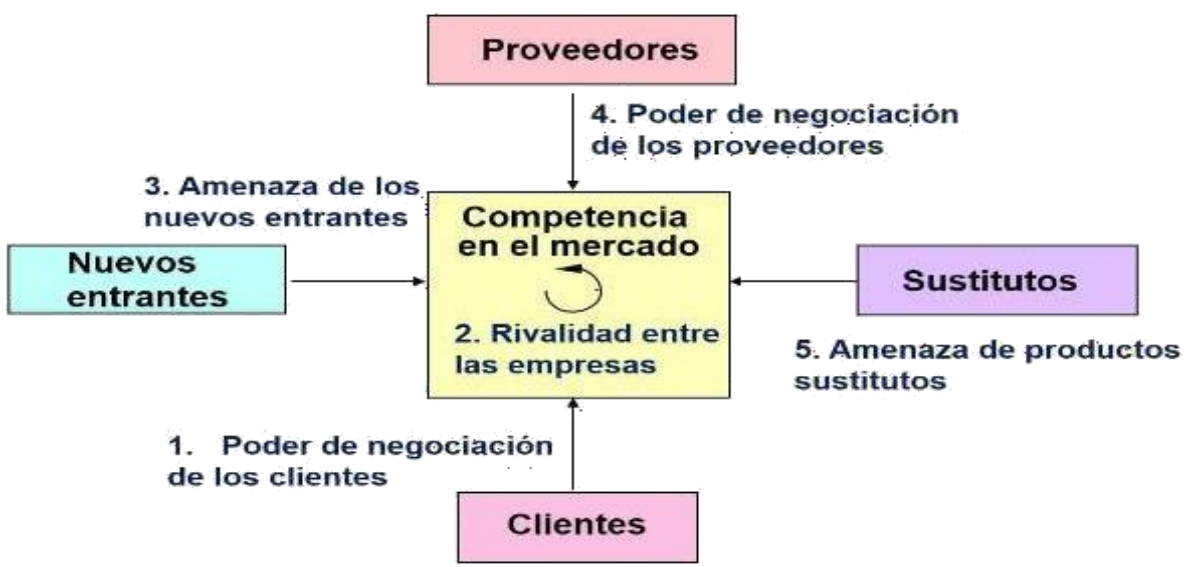

Figura 4.Modelo de las cinco fuerzas competitivas de Porter. Recuperado de http://www.5fuerzasdeporter.com/

Se desarrollará cada una de las fuerzas de Porter para la evaluación del segmento en estudio, para ello primero conforme Tabla 2, se determinó los indicadores de evaluación con los que se medirá la influencia de cada fuerza en el segmento de estudio.

Tabla 2

Indicadores de evaluación de las Fuerzas de Porter Indicadores de evaluación Detalles

Influencia Rango de muy baja (1), baja (2), media (3), alta (4) y muy alta (5)

Factores

Medición de las fuerzas

Tendencia del segmento
Siete factores por cada fuerza de Porter

Promedio ponderado de cada fuerza

Aumentó, se mantiene, disminuye

Nota. Adaptado de Análisis estructural del sector azucarero y el etanol del Valle del Cauca. http://www.scielo.org.co/scielo.php?script=sci_arttext\&pid=S0120-46452010000100008. 


\subsubsection{Poder de negociación de los compradores.}

"Es la capacidad de poder de decisión del consumidor de acuerdo a los intereses propios." (Buenos negocios, 2014)

Conforme la Tabla 3, se elabora un estudio sobre la influencia del consumidor en el segmento; restaurantes fast food americano de pollo en variedades y hamburguesas, para ello se tomaron en cuenta diversos factores que impactan en la decisión de consumo de este tipo de segmento, así como las tendencias de la industria para cada factor.

Tabla 3

Influencia del consumidor en Segmento de Fast Food Americano, pollos y hamburguesas

\begin{tabular}{|c|c|c|c|}
\hline $\mathrm{N}^{\circ}$ & Factores & $\begin{array}{l}\text { Grado de } \\
\text { influencia }\end{array}$ & $\begin{array}{c}\text { Tendencias del } \\
\text { segmento }\end{array}$ \\
\hline 1 & Según la demanda del segmento & 2 & Aumento \\
\hline 2 & Según la percepción de valor del segmento & 5 & Aumento \\
\hline 3 & Según el nivel de diferenciación del segmento & 3 & Aumento \\
\hline 4 & $\begin{array}{l}\text { Según la facilidad del cliente para desarrollar } \\
\text { los producto por su cuenta }\end{array}$ & 3 & Se mantiene \\
\hline 5 & $\begin{array}{l}\text { Según la accesibilidad de la información sobre } \\
\qquad \text { el segmento }\end{array}$ & 4 & Se mantiene \\
\hline 6 & Según el costo de cambiar de segmento & 1 & Aumento \\
\hline 7 & $\begin{array}{l}\text { Según el posicionamiento de las grandes } \\
\text { franquicias del segmento }\end{array}$ & 3 & Se mantiene \\
\hline & Promedio total & 3.00 & \\
\hline
\end{tabular}

Nota. Fuente: Elaboración propia. 
Como primer factor se presenta la demanda del segmento de fast food americanos, la cual cuenta con una "rentabilidad de $10 \%$ a $20 \%$ en el país y que a su vez presentó un crecimiento general de la industria de fast food de USD \$700 millones de dólares americanos en ventas, durante el 2017" (La República, 2017). Esto demuestra la tendencia de este factor puesto que se evidencia un importante crecimiento en el país por lo cual se puede presumir que se encuentra en aumento y por ende, la influencia del consumidor es baja debido a que a mayor cantidad de clientes, menor poder de negociación tendrán sobre el segmento.

El segundo factor es la percepción de valor del segmento, actualmente las cadenas de comida rápida internacionales están realizando grandes inversiones para cambiar la percepción de los consumidores en cuanto a alimentación poco saludable que ha venido generando en los últimos años y están buscando alternativas más saludables para sus consumidores ofreciendo mejores productos que se adapten a las nuevas tendencias de comida rápida nutritiva y saludable. (Diario Gestión, 2016)

Esto conlleva a un incremento de la influencia de los consumidores en cuanto a la percepción de valor que esperan del segmento, haciendo que la tendencia del segmento sea muy alta puesto que aumenta su percepción de valor e incluso los consumidores están dispuestos a pagar hasta 50\% más por el valor agregado de comida saludable. (Diario Gestión, 2017)

El tercer factor también se relaciona con el tema en mención; puesto que, si bien actualmente se vienen implementando poco a poco la nueva tendencia de comida saludable, está todavía se 
encuentra en crecimiento por lo que la influencia en la diferenciación del segmento es media, pero la tendencia del segmento se encuentra en aumento.

Cuarto factor, facilidad del cliente para desarrollar el producto; como se puede inferir, el consumidor de comida rápida es una persona que busca en su mayoría la optimización del tiempo, por ello si bien el producto es fácil de preparar en casa, el factor es el tiempo lo que incentiva a los consumidores para asistir a establecimientos de comida fast food, así la tendencia del segmento se mantiene.

Por otro lado, como quinto factor está la accesibilidad de la información sobre el segmento, las franquicias internacionales han abierto el camino a los consumidores para que conozcan más sobre sus procesos y actividades, que gracias a las redes sociales y el internet, la información está a libre disponibilidad del consumidor, lo que permite a los consumidores tener mayor poder sobre los fast food, este factor gracias a la tecnología hace que la influencia sea alta.

Como sexto factor se cuenta con el costo de cambiar de segmento, para lo cual la influencia del consumidor es muy baja puesto que el segmento de pollos y hamburguesas es de alta demanda, siendo líderes en posicionamiento KFC (47\%) y Bembos (18\%) (Infomarketing, 2016); por lo cual es poco probable que en el mediano plazo el consumidor decida fácilmente cambiar de segmento, sin embargo esto podría cambiar puesto que están apareciendo nuevos conceptos y tendencias en alimentación saludable incluso alimentación sin carne. 
Finalmente, como último factor está el posicionamiento de las grandes franquicias para lo cual la influencia del consumidor es media, que como se mencionó anteriormente el segmento de pollos y hamburguesas son los de mayor demanda y posicionamiento en la industria, por lo que la tendencia del segmento se mantiene.

De acuerdo con el análisis, el promedio ponderado es de 3.00, entonces se puede determinar que el nivel de influencia de los consumidores es medio.

\subsubsection{Poder de negociación con proveedores.}

"Es la capacidad de un proveedor para que pueda o no imponer precios y dominar el mercado o en su defecto depender de los precios que impongan sus compradores." (Buenos Negocios, 2014).

A continuación, conforme la Tabla 4, se analizará el nivel de influencia que tienen los proveedores en el segmento; restaurantes fast food americano de pollo en variedades y hamburguesas. 
Tabla 4

Influencia proveedores segmento Fast Food Americano, pollos y hamburguesas

\begin{tabular}{|c|c|c|c|}
\hline $\mathrm{N}^{\circ}$ & Factores & $\begin{array}{l}\text { Grado de } \\
\text { influencia }\end{array}$ & $\begin{array}{l}\text { Tendencias del } \\
\text { segmento }\end{array}$ \\
\hline 1 & Según la cantidad de proveedores en el segmento & 2 & Aumento \\
\hline 2 & Según el costo de cambiar de proveedores & 3 & Se mantiene \\
\hline 3 & $\begin{array}{l}\text { Según los proveedores clave que hay en el } \\
\text { segmento }\end{array}$ & 5 & Aumento \\
\hline 4 & $\begin{array}{c}\text { Según la calidad del producto que ofrecen los } \\
\text { proveedores }\end{array}$ & 4 & Aumento \\
\hline 5 & $\begin{array}{l}\text { Según la facilidad del proveedor para desarrollar } \\
\text { el producto por su cuenta }\end{array}$ & 1 & Se mantiene \\
\hline 6 & $\begin{array}{l}\text { Según el volumen de compra que favorece las } \\
\text { ventas del proveedor }\end{array}$ & 2 & Aumento \\
\hline 7 & $\begin{array}{l}\text { Según la accesibilidad a la información sobre los } \\
\text { proveedores }\end{array}$ & 3 & Aumento \\
\hline
\end{tabular}

Nota. Fuente: Elaboración propia.

Como primer factor se cuenta con la influencia de los proveedores según la cantidad de proveedores para el segmento.” En Perú la mayoría de los establecimientos de comida rápida realizan la compra de sus productos del extranjeros, principalmente importan las papas pre cocidas de Holanda" (Revistaganamas.com, 2015), en ese sentido los principales proveedores para las cadenas de fast food de pollos y hamburguesas se encuentran en el mercado internacional, por ello la influencia de los mismos es baja, puesto que a mayor cantidad menor poder tienen en el segmento, así mismo la tendencia del incremento de proveedores va en aumento, puesto que la demanda de la comida fast food es alta. 
Como segundo factor se tiene el costo de cambiar de proveedor, debido a que las compras son internacionales y gracias a la cantidad de proveedores en el mercado, la influencia que ejerce el proveedor es media puesto que hay muchos que ofrecen el mismo tipo y calidad del producto, por ello la tendencia del segmento se mantiene.

Por otro lado como tercer factor, se cuenta con los proveedores clave que hay en el segmento, con el fin de diferenciar el producto y debido a las nuevas tendencias de alimentación saludable que contribuya con el planeta, "muchos establecimientos de fast food vienen estableciendo alianzas con pequeños y medianos productores locales puesto que buscan ofrecer productos de alta calidad y especializados a través de la terminología 'gourmet'.”(El Comercio, 2016); ello conlleva a que la influencia de estos proveedores sea muy alta, y la tendencia del segmento es que la cantidad de proveedores clave para el segmento se encuentre en aumento.

Del mismo modo como cuarto factor se tiene la calidad del producto, como se mencionó anteriormente la nueva tendencia gourmet de los establecimientos de comida rápida origina que la calidad de los insumos sean de gran valor, por ello la influencia de los proveedores por su calidad es alta para el segmento y la tendencia del segmento también está en aumento.

Como quinto factor; capacidad del proveedor de desarrollar el producto por su cuenta, esta influencia es muy baja por el volumen de ventas que representan los establecimientos de fast food, no les sería del todo ventajoso además que saldrían de su core bussiness, por ello la tendencia se mantiene, esto mismo influye en el sexto factor, puesto que el crecimiento de la rentabilidad de los fast food generan incremento en las ventas de sus proveedores, por ello la 
influencia que ejercen los proveedores es baja pues dependen del volumen de compra del segmento, y a mayores establecimientos de fast food mayores ventas tendrán por lo que la tendencia del segmento está en aumento.

Del mismo modo, como último factor; la accesibilidad a la información sobre los proveedores. Gracias a las nuevas tecnologías y al internet la información está disponible, por ello la influencia es media y la tendencia del segmento va en aumento.

En base al análisis realizado se pudo concluir con un promedio de 2.86 que la influencia de los proveedores en el segmento es media-baja.

\subsubsection{Amenaza de entrada de nuevos competidores.}

Según Grant (2014), la amenaza de entrada más que la entrada real puede resultar suficiente para asegurar que las empresas establecidas rebajen sus precios hasta el nivel competitivo. (p.111)

A continuación, según la Tabla 5, se evaluará al segmento; restaurantes fast food americano de pollo en variedades y hamburguesas, en cuanto a la influencia que podría tener el ingreso de nuevos competidores. 
Tabla 5

Influencia de nuevos competidores en el segmento de fast food americano de pollos y hamburguesas

\begin{tabular}{|c|c|c|c|}
\hline $\mathrm{N}^{\circ}$ & Factores & $\begin{array}{l}\text { Grado de } \\
\text { influencia }\end{array}$ & $\begin{array}{c}\text { Tendencias del } \\
\text { segmento }\end{array}$ \\
\hline 1 & $\begin{array}{l}\text { Según volumen de ventas de competidores } \\
\text { actuales }\end{array}$ & 2 & Aumento \\
\hline 2 & Según el nivel de diferenciación del producto & 3 & Aumento \\
\hline 3 & $\begin{array}{l}\text { Según el posicionamiento de marcas de } \\
\text { competidores actuales }\end{array}$ & 1 & Se mantiene \\
\hline 4 & Según el costo de cambiar de competidores & 4 & Se mantiene \\
\hline 5 & $\begin{array}{l}\text { Según la inversión inicial para ingresar al } \\
\text { segmento }\end{array}$ & 3 & Disminuye \\
\hline 6 & Según rentabilidad del segmento & 5 & Aumento \\
\hline 7 & $\begin{array}{l}\text { Según la reacción esperada de los competidores } \\
\text { actuales }\end{array}$ & 2 & Aumento \\
\hline & Promedio total & 2.86 & \\
\hline
\end{tabular}

Como primer factor se tiene el volumen de ventas de los competidores actuales, como se sabe "las ventas de fast food en el Perú crecieron para el presente años en USD\$700 millones de dólares y más aún la rentabilidad del segmento fue de 10\% a 20\%.” (Larepública.pe, 2017); esto permite concluir que la influencia de nuevos competidores es baja puesto que las grandes franquicias generan grandes volúmenes de ventas y abarcan gran parte de la demanda del mercado y esto sigue en aumento gracias a las nuevas reinvenciones que están iniciando estas franquicias para permanecer en el mercado a través de líneas gourmet y alimentos saludables. 
"Esto también influye en el segundo factor puesto que estas nuevas reinvenciones hacen que las grandes franquicias generen mayores barreras de entrada como por ejemplo KFC quienes el año 2016 decidieron reinventar el sabor de sus productos" (Diario Gestión, 2016), por lo cual la influencia de nuevos competidores con ideas innovadoras sea media, y por ende la tendencia del segmento en cuanto al tema de diferenciación se encuentre en aumento. Estas reinvenciones de las franquicias de pollo y hamburguesas generan también que su posicionamiento se mantenga en el tiempo, lo que genera que la influencia de nuevos competidores sea muy baja como se muestra en la Tabla 5 como tercer factor.

Como cuarto factor; el costo de cambiar de competidores en el segmento es bajo, todos ofrecen precios similares por ello la influencia de nuevos competidores con nuevas ideas y precios más accesibles es alta y esta tendencia se mantiene, y por el tipo de comida el precio promedio es similar entre competidores.

Como quinto factor; inversión inicial para este segmento, para lo cual la influencia de nuevos competidores es media, puesto que las barreras de entrada no son muy altas; "la inversión es moderada y se puede comenzar desde un local hasta crear una cadena incluso adquirir una franquicia” (El plural, 2017) y cada vez es más fácil de ingresar a este segmento por lo que la tendencia del segmento disminuye.

Como sexto factor; la rentabilidad del segmento, como se mencionó inicialmente se encuentra en crecimiento, por lo que la influencia de nuevos competidores es muy alta lo que hace que el 
segmento sea atractivo para el ingreso de nuevos conceptos e innovaciones haciendo que la tendencia en crecimiento de la rentabilidad del segmento se encuentre en aumento.

Finalmente, como último factor se consideró la reacción esperada de los competidores actuales, al ser un segmento altamente competitivo por su nivel de demanda, se espera que la reacción que tomen ante el ingreso de nuevos competidores sea fuerte en el sentido que pueden bajar sus precios o mejorar sus promociones gracias a las economías de escala que manejan, por ello la tendencia del segmento en cuanto a la reacción de los competidores iría en aumento, generando que la influencia de nuevos competidores sea baja.

En base al análisis llevado a cabo, con un promedio de 2.86 la influencia de nuevos competidores en el segmento es media-baja.

\subsubsection{Competencia de los productos sustitutos.}

Según Grant (2014), significa que "los clientes pueden optar por estas en respuesta a un incremento del precio del producto (...) la demanda es elástica respecto al precio (...), depende de la relación precio/prestación”. (p. 110)

A continuación, conforme la Tabla 6, se analizará el nivel de influencia de los productos sustitutos.

Tabla 6

Influencia de los productos sustitutos en el segmento fast food americano de pollos y hamburguesas 


\begin{tabular}{|c|c|c|c|}
\hline $\mathrm{N}^{\circ}$ & Factores & $\begin{array}{l}\text { Grado de } \\
\text { influencia }\end{array}$ & $\begin{array}{l}\text { Tendencias del } \\
\text { segmento }\end{array}$ \\
\hline 1 & Según el precio relativo de sus productos & 5 & Se mantiene \\
\hline 2 & $\begin{array}{l}\text { Según la importancia de la relación } \\
\text { calidad/precio de los consumidores }\end{array}$ & 1 & Aumento \\
\hline 3 & Según la accesibilidad de los sustitutos & 4 & Aumento \\
\hline 4 & $\begin{array}{l}\text { Según el costo de cambiar por productos } \\
\text { sustitutos }\end{array}$ & 3 & Disminuye \\
\hline 5 & $\begin{array}{c}\text { Según la preferencia del cliente por los } \\
\text { productos sustitutos }\end{array}$ & 2 & Se mantiene \\
\hline 6 & Según el tipo de servicio que ofrece el segmento & 2 & Se mantiene \\
\hline 7 & $\begin{array}{l}\text { Según el tiempo de servicio que ofrece el } \\
\text { segmento }\end{array}$ & 2 & Se mantiene \\
\hline & Promedio total & 2.71 & \\
\hline
\end{tabular}

Nota. Fuente: Elaboración propia.

Como primer factor se cuenta con el precio relativo de los productos sustitutos, existen tres tipos de productos sustitutos para el segmento.

Las picanterías turísticas con servicio en mesa o buffet que ofrecen carne de vaca y pollo en diferentes presentaciones cuyos precios son altos, por otro lado están las picanterías de barrio que ofrecen también platillos regionales con pollo y carne de vaca a precios moderados y por último las comidas al paso o carretillas que ofrecen platos de pollo, carnes de vaca y hamburguesas a bajo costo. (Peru, 2016) 
Por todo ello esta variabilidad de precios y opciones generan que la influencia de los productos sustitutos en el segmento de pollos y hamburguesas sea muy alta y la tendencia es que esta dinámica de precios se mantenga.

Como segundo factor esta la importancia de la relación calidad/precio del consumidor, actualmente el consumidor peruano se está volviendo cada vez más exigente, los productos básicos están pasando de moda y las nuevas tendencias gastronómicas en cuanto al cuidado de la salud y lo natural están teniendo mayor realce. (Diario Gestión, 2015)

Por ello la relación en mención en crucial para la decisión de compra de los consumidores del segmento de pollos y hamburguesas, por ello la influencia de los productos sustitutos es muy baja puesto que las franquicias internacionales de comida manejan estándares sanitarios y de insumos altos implementan el uso de técnicas de manipulación de alimentos y normativas internacionales, es así que la tendencia de la importancia de la relación calidad/precio está en aumento.

Por otro lado como tercer factor está a accesibilidad de los productos sustitutos, "las comidas al paso son de fácil acceso y de gran consumo por la población cusqueña y se pueden encontrar en cualquier esquina” (Llallarco, 2017). Así mismo existen en la ciudad de Cusco las “picanterías las cuales actualmente son reconocidas como patrimonio cultural de la nación y existen asociaciones cuyo objetivo es asegurar su existencias ante las nuevas tendencias y cambios sociales, lo que genera una importante demanda por su reconocimiento nacional e internacional" (Contreras, 2016). Por todo ello, la influencia de los productos sustitutos según su 
accesibilidad es alta y la tendencia es que sean cada vez más accesibles por lo que la tendencia estaría en aumento.

Cuarto factor; el costo de cambiar por productos sustitutos, la influencia es media porque las “nuevas generaciones cuentan con preferencia por la comida rápida como son los de la generación millennials" (Diario Gestión, 2014), además que en el caso de las picanterías, el costo de este tipo de producto es el tiempo puesto que este tipo de producto conlleva el servicio en mesa.

Quinto factor; preferencia del cliente por los productos sustitutos, la influencia de este tipo de productos es baja para el segmento de comida rápida de pollos y hamburguesas, debido al tipo y calidad del producto que ofrecen, puesto que no va acorde con el concepto de comida rápida que espera el consumidor para satisfacer su necesidad del momento lo que permite inferir que la tendencia se mantendrá en el tiempo.

Sexto y séptimo factor; tipo y tiempo de servicio, como ya se mencionó, los productos sustitutos no satisfacen la necesidad de tiempo, calidad y tipo de producto que esperan los consumidores del segmento, por lo que la influencia que ejercen es baja, lo cual se prevé según la tendencia es que se mantendrá en el tiempo.

Finalmente con un promedio de 2.71 de los resultados determinó que la influencia de los productos sustitutos en el segmento media-baja. 


\subsubsection{Rivalidad entre empresas competidoras.}

"Esta fuerza suele ser la más poderosa de las cinco fuerzas, consiste en generar ventaja competitiva sobre las estrategias de las empresas rivales “(Grant, 2014). A continuación, según la Tabla 7, se analizará la influencia de la rivalidad de los competidores.

\section{Tabla 7}

Influencia rivalidad de competidores en segmento Fast Food Americano, pollos y hamburguesas

\begin{tabular}{|c|c|c|c|}
\hline $\mathrm{N}^{\circ}$ & Factores & $\begin{array}{l}\text { Grado de } \\
\text { Influencia }\end{array}$ & Tendencias del segmento \\
\hline 1 & $\begin{array}{l}\text { Según la concentración de competidores en el } \\
\text { segmento }\end{array}$ & 4 & Aumento \\
\hline 2 & $\begin{array}{l}\text { Según la diversidad de competidores en el } \\
\text { segmento }\end{array}$ & 3 & Aumento \\
\hline 3 & $\begin{array}{l}\text { Según la diferenciación del producto de los } \\
\text { competidores en el segmento }\end{array}$ & 4 & Aumento \\
\hline 4 & Según la dificultad para salirse del mercado & 4 & Se mantiene \\
\hline 5 & $\begin{array}{l}\text { Según el costo de cambiar de competidores en } \\
\text { el segmento }\end{array}$ & 5 & Disminuye \\
\hline 6 & Según la rentabilidad del segmento & 3 & Aumento \\
\hline 7 & $\begin{array}{l}\text { Según el posicionamiento de principales } \\
\text { competidores en el segmento }\end{array}$ & 3 & Se mantiene \\
\hline & Promedio total & 3.71 & \\
\hline
\end{tabular}

Nota. Fuente: Elaboración propia.

Como primer factor; concentración de competidores en el segmento, la influencia de la rivalidad de competidores es alta puesto que el segmento cuenta con gran cantidad de locales en provincias, “existen 25 locales restaurantes de KFC, Bembos 18 locales, McDonald's 10 locales, Burguer King 7 locales y Popeyes 5 locales” (Código, 2017), lo cual presenta una tendencia a 
seguir aumentando debido al ingreso de nuevas franquicias internacionales en las provincias del país.

Segundo factor; la diversidad de competidores en el segmento, como se mencionó anteriormente, el ingreso de nuevas franquicias evidencian la tendencia a seguir incrementándose la oferta del segmento para los competidores, sin embargo la influencia de la rivalidad de los competidores es media; en Cusco aún es poco la variedad de opciones de establecimientos tipo fast food de pollos y hamburguesas; a comparación de Lima donde existen incluso los food trucks, un nuevo concepto de comida al paso y de calidad.

Por otro lado, como tercer factor está la diferenciación del producto, como se ha mencionado, las nuevas franquicias están empezando a incursionar en el ámbito de la comida saludable incluso "McDonald's piensa implementar la línea 'signature' en la ciudad del Cusco" (Gestión.pe, 2016), esto genera que la influencia de la rivalidad de los competidores sea alta en el segmento y la tendencia es que siga creciendo.

Como cuarto factor; dificultad de salirse del mercado, la influencia de la rivalidad de competidores es alta, lo que dificulta la salida del segmento al ser altamente rentable y competitivo, y la tendencia es que esto se mantenga en el tiempo.

Como quinto factor; el costo de cambiar de competidores dentro del segmento, para ello la influencia de la rivalidad de los productos sustitutos es muy alta y es que todos ofrecen precios similares por lo que se eleva la competitividad, la tendencia a disminuir gracias a la aparición de 
nuevas tendencias en alimentación que incrementaran el precio del producto y la competitividad será más por el lado de la diferenciación.

Como sexto factor; la rentabilidad del segmento, se puede evidenciar la alta rivalidad entre las corporaciones DELOSI S.A. y NG restaurant del grupo Intercorp, ambas dueñas de la franquicia de marcas reconocidas a nivel internacional; "DELOSI S.A actualmente con su marca KFC ha logrado obtener el liderazgo gracias a las preferencias del consumidor peruano por el pollo y la comida condimentada" (Diario Gestión, 2015), la influencia de la rivalidad de los competidores en el segmento es alta y la tendencia es a seguir aumentando por el ingreso de nuevos competidores al mercado.

Finalmente, como último factor está el posicionamiento de los principales competidores, como se mencionó anteriormente en el análisis de influencia de los consumidores, KFC y Bembos ambos líderes en posicionamiento del consumidor, por ello la influencia de la rivalidad de los competidores es moderada, estas grandes franquicias tienen economías de escala importantes y especialistas en temas de marketing que les permiten tener herramientas para ejercer presión en el segmento, lo cual se prevé se mantendrá en el tiempo.

Del análisis anterior, el promedio obtenido es de 3.71, la influencia de rivalidad de competidores en el segmento es media-alta. 


\subsubsection{Influencia de las 5 fuerzas de porter en el segmento.}

Conforme se detalla en Tabla 8, se determinó el grado de influencia de cada fuerza para obtener el nivel de influencia del segmento.

Tabla 8

Influencia de las 5 fuerzas de Porter en el segmento de fast food americano de pollos y hamburguesas

\begin{tabular}{|c|c|c|}
\hline $\mathrm{N}^{\circ}$ & Factores & $\begin{array}{l}\text { Grado de } \\
\text { influencia }\end{array}$ \\
\hline 1 & Poder de negociación de los consumidores & 3.00 \\
\hline 2 & Poder de negociación de los proveedores & 2.86 \\
\hline 3 & Amenaza de nuevos competidores & 2.86 \\
\hline 4 & Amenaza de productos sustitutos & 2.71 \\
\hline \multirow[t]{2}{*}{5} & Rivalidad entre competidores existentes & 3.71 \\
\hline & Promedio total & 3.03 \\
\hline
\end{tabular}

Nota. Fuente: Elaboración propia.

El segmento de restaurantes fast food americano de pollo en variedades y hamburguesa es muy atractivo y según al análisis de la influencia de las fuerzas de Porter es media, el promedio obtenido es de 3.03, conforme la Tabla 8, puesto que aún existen nichos dentro del mercado por explotar y el consumidor es cada vez más exigente. El experto Martin Jiménez, Gerente de Rhupa’s Diner - Cusco, señala que "El Cusco cuenta con un gran potencial para el sector fast food”, que indica prevé que en el futuro habrán más centros comerciales, mayor población, mayores puestos de trabajo y por ende la necesidad del consumo de comida rápida. 


\subsection{Análisis de la competencia.}

Según Fred R., (2013) el análisis competitivo es un enfoque que muchas empresas lo utilizan con el objetivo de crear estrategias que ayuden a sobresalir en comparación con las otras empresas que pertenecen a la misma industria.

Se puede dividir la competencia en directa e indirecta:

- Competencia directa: "son empresas que pertenecen al mismo sector y que ofrecen productos parecidos o similares" (Impulso Regio, 2015), en cuanto al plan de negocio; se ha considerado a los establecimientos de tamaños medianos y grandes empresas de los restaurantes fast food americano que venden pollo o hamburguesa en la ciudad del Cusco.

- Competencia indirecta: "son empresas que pertenecen al mismo sector, cuyo producto es diferente pero satisface las mismas necesidades" (Impulso Regio, 2015). Para el presente proyecto la competencia indirecta está conformada por los establecimientos fast food que venden otros productos diferentes al pollo o hamburguesa bajo el mismo concepto de comida rápida. Como son los chifas, pollo a la brasa, parrillas entre otros.

\subsubsection{Empresas que ofrecen el mismo producto o servicio.}

Uno de los aspectos más importantes para toda empresa es enfrentarse a la competencia que está en todos lados, sobre todo a la directa, la cual gracias a la tecnología y" la globalización ha ido en crecimiento, y las exigencias son cada vez más fuertes y cambiantes 
por parte de los consumidores. Comprar productos de mayor calidad a precio competitivo, que se ajuste a su percepción de valor.” (Balandra, 2016)

Sin embargo, muchas empresas pasan por alto el análisis de sus competidores a la hora de entrar al mercado. Lo ideal es contar con un sistema de información continua, para identificarlos y encontrar la manera de hacer las cosas mejor que ellos.

De acuerdo a la información recopilada en campo, el plan de negocio, cuenta con competidores directos e indirectos, con productos muy similares; especialmente en el sector de la zona céntrica de la ciudad y en el centro comercial Real Plaza.

En base a las entrevistas llevadas a cabo para el presente proyecto, los expertos coinciden que los líderes en el mercado de fast food en la ciudad del Cusco están conformados por las marcas: (a) KFC, (b) Popeyes, (c) Bembos y (d) Burguer King. Por otro lado en el desarrollo de los focus group los entrevistados resaltaron su preferencia por el consumo de pollo y especial aprobación hacia el pollo del KFC.

Por ello se considerará a estas marcas como los competidores directos. Sin embargo se incluirá además a una mediana empresa cusqueña llamada Rhupa’s Diner que actualmente está creciendo en la ciudad y cuyo Gerente, Martin Jiménez, refiere que ya cuentan con tres locales en Cusco y uno en el departamento de Piura en la ciudad de Máncora, además de tener pendiente una proyección para ingresar a nuevas localidades; lo que permite validar su nivel de participación en el mercado local gracias a su crecimiento. 
Conforme la Tabla 9, se realizará un análisis de los competidores.

Tabla 9

Análisis de los competidores directos

\begin{tabular}{|c|c|c|c|c|c|}
\hline Ítem & KFC & Popeyes & Bembos & Burguer King & $\begin{array}{l}\text { Rupha's } \\
\text { Diner }\end{array}$ \\
\hline Ubicación & Buena & Buena & Buena & Buena & Regular \\
\hline Horario & $10 \mathrm{am}-11 \mathrm{pm}$ & $11 \mathrm{am}-11 \mathrm{pm}$ & $11 \mathrm{am}-11 \mathrm{pm}$ & $10 \mathrm{am}-11 \mathrm{pm}$ & $6 \mathrm{pm}-12 \mathrm{am}$ \\
\hline Precio & Moderado & Moderado & Moderado & Moderado & Medio-bajo \\
\hline Posicionamiento & Alto & Medio & Alto & Alto & Bajo \\
\hline $\begin{array}{l}\text { Uso de Buenas } \\
\text { Prácticas de } \\
\text { Manufactura y HACCP }\end{array}$ & Bueno & Bueno & Bueno & Bueno & Regular \\
\hline Tamaño de la empresa & Grande & Grande & Grande & Grande & Mediano \\
\hline Calidad de atención & Buena & Buena & Buena & Buena & Buena \\
\hline $\begin{array}{l}\text { Publicidad y } \\
\text { promoción }\end{array}$ & Poca & Poca & Poca & Poca & Regular \\
\hline Infraestructura & Buena & Buena & Buena & Buena & Buena \\
\hline $\begin{array}{l}\text { Diversificación de } \\
\text { productos }\end{array}$ & Poco & Poco & Alto & Poco & Alto \\
\hline $\begin{array}{l}\text { Calidad de los } \\
\text { productos }\end{array}$ & Buena & Buena & Buena & Buena & Buena \\
\hline $\begin{array}{l}\text { Tiempo de espera } \\
\text { estándar }\end{array}$ & $5^{\prime}$ a $15^{\prime}$ & $5^{\prime}$ a $15^{\prime}$ & 5 ' a $15^{\prime}$ & 5 ' a 15 , & 5 ' a 15 \\
\hline
\end{tabular}

Nota. Por observación directa, se visitó establecimientos en horas pico y en horas de baja afluencia. Fuente: Elaboración propia.

Como se observa en el análisis de competidores en la Tabla 9, las franquicias debido a su alto posicionamiento han disminuido su inversión en publicidad, es muy poca la promoción que realizan en la ciudad del Cusco, esto se valida con el comentario de los expertos, quienes afirman 
que debido al alto nivel de recordación de la marca no se lleva a cabo inversión por promoción, más que la emisión de volantes y publicación de ofertas estandarizado a nivel nacional.

Por otro lado, la diversificación de los productos que ofrecen las franquicias es poco, debido a conceptos ya estandarizados y no pueden realizar modificaciones al producto, en contra parte Bembos y Rupha's Diner al ser empresas peruanas, tienen que adaptarse al paladar del consumidor nacional y local, por lo que se arriesgan a realizar modificación a sus productos conforme a los cambios en los gustos o tendencias gastronómicas.

Así mismo se observa que Rupha's Diner al ser una empresa pequeña e independiente aún no cuenta con áreas de calidad que le permitan llevar control del manejo de los alimentos e inocuidad constante, como lo tienen las franquicias que al ser grandes corporaciones necesitan mantener un estándar en sus prácticas y para ello cuentan con áreas de supervisión de calidad que controlan la manipulación e higiene de los alimentos bajo estándares internacionales.

\subsubsection{Participación del mercado de los competidores.}

Según Headways (2016), la participación de mercado es el porcentaje de las ventas de una empresa frente a un producto en relación a las ventas totales de la competencia, es decir, a las ventas de otras empresas que comparten el mismo mercado y la misma categoría.

A continuación, se muestra una tabla con los competidores directos del proyecto y su respectiva participación en el mercado según Tabla 10, información obtenida del estudio cuantitativo llevado a cabo para el proyecto. 
Tabla 10

Participación de mercado competidores directos

\begin{tabular}{lc}
\hline Competidor & $\begin{array}{c}\text { Porcentaje de } \\
\text { participación }\end{array}$ \\
\hline KFC & $30.9 \%$ \\
Popeyes & $16.7 \%$ \\
Bembos & $16.6 \%$ \\
Burguer King & $19.5 \%$ \\
Rupha's Diner & $15.5 \%$ \\
Otros & $0.64 \%$ \\
\hline Total & $100 \%$ \\
\hline Nota. Ver Figura 26. Fuente: Elaboración propia.
\end{tabular}

Como se aprecia en la tabla 10, KFC es la empresa líder en el mercado cusqueño con una participación de $30.9 \%$, esto contrasta con la preferencia de la población peruana por el pollo, además del posicionamiento de la marca gracias a los años que lleva en el mercado.

Seguidamente se presenta Burguer King con 19,5\% de participación, esto porque ofrece variedades de hamburguesas a base de pollo y carne al estilo americano, y cuyo único local en Cusco se encuentra en el centro comercial Real Plaza el cual al ser también el único centro comercial más grande en la ciudad, la misma que cuenta con una alta afluencia de personas, en contraste se encuentra la empresa Bembos que cuenta con $16.6 \%$ de participación y que en los últimos años ha evidenciado una baja rentabilidad debido a que ha ido perdiendo poder de negociación con sus proveedores y ha llevado un mal manejo de sus costos debido a un afán expansionista mal manejado (Chiarella, 2016), lo cual afecta su estrategia de venta y por ende va perdiendo su participación en el mercado. 
Antecediendo a Bembos se encuentra la empresa Popeyes con 16.7\% de participación, quienes ofrecen un producto a base de pollo similar al KFC pero con otro estilo de condimentación y llevan recién tres años en el mercado cusqueño. Por último se encuentra la empresa Rupha’s Diner que va abriendo paso en el mercado local con un $15.5 \%$ de participación y gracias a sus productos elaborados a base de hamburguesas de carne de vaca al estilo americano y la opción de servicio en mesa con venta de bebidas alcohólicas.

\subsubsection{Matriz del perfil competitivo.}

La matriz del perfil competitivo es aquella herramienta que identifica a los competidores principales de una organización, así también sus fuerzas y debilidades, en relación con una muestra de la posición estratégica de la empresa. Las ponderaciones y puntuaciones de una MPC o una EFE (Matriz de evaluación de factores externos) tienen el mismo significado. Sin embargo, los factores de una MPC incluyen cuestiones internas y externas; las puntuaciones dan referencia a las fuerzas y a las debilidades. (Fred R., 2013)

Para conocer el perfil competitivo del plan de negocio, se están considerando los principales factores críticos de éxito en la industria, según los resultados de la investigación cualitativa realizada (entrevistas a expertos).

Según Hernández (2017), los factores críticos de éxitos son características o condiciones de una empresa, variables importantes que determinarán la eficiencia y eficacia de una organización. 
Según los focus group desarrollados y las entrevistas a expertos para el presente plan de negocio, los consumidores participantes coincidieron en los siguientes valores críticos para la selección de compra en un fast food:

- Atención

- Inocuidad

- Tiempo de espera

- Calidad de productos

- Ubicación

- Precio

- Variedad de productos

- Ambientación

Luego de determinar los factores críticos, se realizará una evaluación en la cual se utilizará una escala de calificación entre 1 y 4 para determinar el nivel de fortaleza y oportunidad con el que cuenta cada competidor en función de los valores críticos seleccionados, donde 4= mayor fuerza, $3=$ menor fuerza, $2=$ menor debilidad y $1=$ mayor debilidad, conforme Tabla 11 .

Tabla 11

Valores de calificación para la matriz de perfil competitivo

\begin{tabular}{cc}
\hline 1= Mayor debilidad & $3=$ Menor fuerza \\
\hline 2= Menor debilidad & $4=$ Mayor fuerza
\end{tabular}

Fuente: Elaboración propia.

Nota.

Se asume que los nueve valores críticos seleccionados para el proyecto corresponden al $100 \%$ de los factores preponderantes para la determinación de las fortalezas y oportunidades de los 
competidores, en ese sentido se asignaran pesos a cada valor tomando en cuenta el nivel de relevancia necesario para el óptimo desarrollo de un establecimiento bajo el concepto de comida rápida. La distribución del peso para cada factor se considerará en base al siguiente análisis expresado en la Tabla 12, en base a ello se procederá a realizar la matriz del perfil competitivo del proyecto como se detalla en la Tabla 13, además de la justificación de calificaciones asignadas conforme la Tabla 14. Cabe resaltar que las calificaciones se validaron a través de la asistencia de cuatro evaluadores a dichos establecimientos para analizar las características en estudio.

Tabla 12

Distribución de pesos de los factores críticos de éxito para la evaluación de los competidores

\begin{tabular}{|c|c|c|}
\hline Factores & $\begin{array}{l}\text { Peso } \\
100 \%\end{array}$ & Criterios de asignación \\
\hline Atención & 0.14 & $\begin{array}{l}\text { Uno de los más altos por que la rapidez y el trato amable en la atención es crítico. } \\
\text { (Preg.7, } 9 \text { - análisis focus group, tabla } 27,28 \text { ). }\end{array}$ \\
\hline Inocuidad & 0.14 & $\begin{array}{l}\text { Uno de los más altos porque la limpieza e imagen de salubridad es crítico. (preg.22 - } \\
\text { análisis focus group, tabla 29). }\end{array}$ \\
\hline $\begin{array}{l}\text { Tiempo de } \\
\text { espera }\end{array}$ & 0.13 & $\begin{array}{l}\text { Segundo en importancia porque los consumidores buscan un tiempo de espera promedio } \\
\text { de } 10 \text { minutos. (preg. } 12 \text { - análisis focus group, tabla 28). }\end{array}$ \\
\hline $\begin{array}{l}\text { Calidad de los } \\
\text { productos }\end{array}$ & 0.13 & $\begin{array}{l}\text { Segundo en importancia porque es un factor que sirve de guía a los consumidores para } \\
\text { retornar al establecimiento (preg. } 5 \text { - análisis focus group propuesta de valor, tabla } 30 \text { ). }\end{array}$ \\
\hline Sabor & 0.14 & $\begin{array}{c}\text { Uno de los más altos, puesto que el sabor es determinante para la selección de un } \\
\text { restaurante conforme se obtuvo en el análisis de focus group sobre importancia de } \\
\text { factores para la selección de un fast food. }\end{array}$ \\
\hline Ubicación & 0.09 & $\begin{array}{l}\text { Cuarto en importancia porque es lo que define la cercanía y acceso al consumidor, pero } \\
\text { no determina su preferencia. (preg. } 14 \text { - análisis de focus group propuesta de valor, tabla } \\
31 \text { ). }\end{array}$ \\
\hline Precio & 0.08 & $\begin{array}{c}\text { Quinto en importancia porque va de la mano con la calidad y el sabor. Debe ser acorde al } \\
\text { producto. }\end{array}$ \\
\hline $\begin{array}{l}\text { Variedad de } \\
\text { productos }\end{array}$ & 0.08 & $\begin{array}{l}\text { Quinto en importancia porque algunas personas desean contar con variedad de productos. } \\
\text { (preg.7 - análisis focus group propuesta de valor, tabla 30). }\end{array}$ \\
\hline Ambientación & 0.07 & $\begin{array}{l}\text { Último en importancia porque el ambiente debe ser cómodo y agradable pero no es el } \\
\text { objetivo de los fast food que los clientes permanezcan mucho tiempo, la rotación de } \\
\text { mesas debe ser fluida. }\end{array}$ \\
\hline TOTAL & 1.00 & \\
\hline
\end{tabular}

Nota. Fuente: Elaboración propia. 
Tabla 13

Evaluación de factores críticos de éxito del perfil competitivo

\begin{tabular}{|c|c|c|c|c|c|c|c|c|c|c|c|}
\hline \multirow{2}{*}{$\begin{array}{l}\text { Factores } \\
\text { críticos } \\
\text { de éxito }\end{array}$} & \multirow{2}{*}{$\begin{array}{l}\text { Peso } \\
100 \%\end{array}$} & \multicolumn{2}{|c|}{$\mathrm{KFC}$} & \multicolumn{2}{|c|}{ Popeyes } & \multicolumn{2}{|c|}{ Bembos } & \multicolumn{2}{|c|}{ Burger King } & \multicolumn{2}{|c|}{ Rhupa's Diner } \\
\hline & & Calif. & $\begin{array}{c}\text { Peso } \\
\text { pondera. }\end{array}$ & Calif. & $\begin{array}{c}\text { Peso } \\
\text { pondera. }\end{array}$ & Calif. & $\begin{array}{c}\text { Peso } \\
\text { pondera. }\end{array}$ & Calif. & $\begin{array}{c}\text { Peso } \\
\text { pondera. }\end{array}$ & Calif. & $\begin{array}{c}\text { Peso } \\
\text { pondera. }\end{array}$ \\
\hline Atención & 0.14 & 3 & 0.42 & 3 & 0.42 & 3 & 0.42 & 3 & 0.42 & 3 & 0.42 \\
\hline Inocuidad & 0.14 & 3 & 0.42 & 2 & 0.28 & 3 & 0.42 & 3 & 0.42 & 2 & 0.28 \\
\hline $\begin{array}{l}\text { Tiempo de } \\
\text { espera }\end{array}$ & 0.13 & 3 & 0.39 & 3 & 0.39 & 3 & 0.39 & 3 & 0.39 & 3 & 0.39 \\
\hline $\begin{array}{l}\text { Calidad de } \\
\text { productos }\end{array}$ & 0.13 & 3 & 0.39 & 3 & 0.39 & 4 & 0.52 & 2 & 0.26 & 2 & 0.26 \\
\hline Sabor & 0.14 & 4 & 0.56 & 3 & 0.42 & 4 & 0.56 & 2 & 0.28 & 4 & 0.56 \\
\hline Ubicación & 0.09 & 4 & 0.36 & 4 & 0.36 & 4 & 0.36 & 3 & 0.27 & 2 & 0.18 \\
\hline Precio & 0.08 & 4 & 0.32 & 4 & 0.32 & 3 & 0.24 & 3 & 0.24 & 4 & 0.32 \\
\hline $\begin{array}{l}\text { Variedad de } \\
\text { productos }\end{array}$ & 0.08 & 4 & 0.32 & 3 & 0.24 & 3 & 0.24 & 2 & 0.16 & 2 & 0.16 \\
\hline Ambientación & 0.07 & 2 & 0.14 & 2 & 0.14 & 2 & 0.14 & 2 & 0.14 & 2 & 0.14 \\
\hline TOTAL & 1 & & 3.32 & & 2.96 & & 3.29 & & 2.58 & & 2.71 \\
\hline
\end{tabular}

Nota. Fuente: Elaboración propia. 


\section{Tabla 14}

Justificación de calificaciones de la Matriz del perfil competitivo

\begin{tabular}{|c|c|c|c|c|c|}
\hline Factores & $\mathrm{KFC}$ & Popeyes & Bembos & Burguer King & Rupha's Diner \\
\hline Atención & $\begin{array}{c}\text { Menor fortaleza } \\
\text { demora en horas pico. }\end{array}$ & $\begin{array}{c}\text { Menor fortaleza } \\
\text { demora en horas pico. }\end{array}$ & $\begin{array}{c}\text { Menor fortaleza } \\
\text { demora en horas pico. }\end{array}$ & $\begin{array}{l}\text { Menor fortaleza } \\
\text { demora en horas } \\
\text { pico. }\end{array}$ & $\begin{array}{c}\text { Menor fortaleza } \\
\text { demora en horas pico. }\end{array}$ \\
\hline Inocuidad & $\begin{array}{l}\text { Uso de HACCP, } \\
\text { cuidado en horas picos } \\
\text { durante manipulación. }\end{array}$ & $\begin{array}{l}\text { Uso de HACCP, } \\
\text { cuidado manipulación } \\
\text { en la entrega al } \\
\text { consumidor. }\end{array}$ & $\begin{array}{l}\text { Uso de HACCP, } \\
\text { podría mejorar } \\
\text { cuidado en horas } \\
\text { picos durante } \\
\text { manipulación. }\end{array}$ & $\begin{array}{l}\text { Uso de HACCP, } \\
\text { podría mejorar } \\
\text { cuidado en horas } \\
\text { picos durante } \\
\text { manipulación. }\end{array}$ & $\begin{array}{l}\text { No cuentan con } \\
\text { HACCP, cuidado con } \\
\text { manipulación } \\
\text { producción. }\end{array}$ \\
\hline $\begin{array}{l}\text { Tiempo de } \\
\text { espera }\end{array}$ & $\begin{array}{l}\text { Menor fortaleza, } \\
\text { problemas en horas } \\
\text { pico. }\end{array}$ & $\begin{array}{c}\text { Menor debilidad, } \\
\text { presenta } \\
\text { descoordinaciones en } \\
\text { horas pico. }\end{array}$ & $\begin{array}{c}\text { Menor debilidad, } \\
\text { presenta } \\
\text { descoordinaciones en } \\
\text { horas pico. }\end{array}$ & $\begin{array}{c}\text { Menor debilidad, } \\
\text { tiempo de espera un } \\
\text { poco mayor que los } \\
\text { demás. }\end{array}$ & $\begin{array}{c}\text { Menor fortaleza, } \\
\text { podría mejorar } \\
\text { problemas en horas } \\
\text { pico. }\end{array}$ \\
\hline $\begin{array}{l}\text { Calidad de } \\
\text { productos }\end{array}$ & $\begin{array}{l}\text { Insumos en buenas } \\
\text { condiciones. }\end{array}$ & $\begin{array}{l}\text { Insumos en buenas } \\
\text { condiciones. }\end{array}$ & $\begin{array}{l}\text { Insumos en buenas } \\
\text { condiciones, uso de } \\
\text { productos peruanos. }\end{array}$ & $\begin{array}{c}\text { Insumos en buenas } \\
\text { condiciones, sabor } \\
\text { regular. }\end{array}$ & $\begin{array}{l}\text { Buen sabor, } \\
\text { problemas con } \\
\text { manipulación. }\end{array}$ \\
\hline Sabor & $\begin{array}{l}\text { Mayor fortaleza buen } \\
\text { sabor }\end{array}$ & $\begin{array}{l}\text { Menor Fortaleza algo } \\
\text { picante }\end{array}$ & $\begin{array}{c}\text { Mayor Fortaleza } \\
\text { sabores nacionales }\end{array}$ & $\begin{array}{c}\text { Menor Fortaleza, } \\
\text { sabores clásicos } \\
\text { americanos }\end{array}$ & $\begin{array}{l}\text { Mayor fortaleza, } \\
\text { sabores nacionales }\end{array}$ \\
\hline Ubicación & $\begin{array}{l}\text { Fortaleza, plaza de } \\
\text { armas y Mall. }\end{array}$ & $\begin{array}{l}\text { Fortaleza plaza de } \\
\text { armas y Mall. }\end{array}$ & $\begin{array}{l}\text { Fortaleza, plaza de } \\
\text { armas y Mall. }\end{array}$ & $\begin{array}{c}\text { Menor fortaleza sólo } \\
\text { hay en el Mall. }\end{array}$ & $\begin{array}{l}\text { Menor debilidad, bajo } \\
\text { tránsito. }\end{array}$ \\
\hline Precio & Fortaleza & Fortaleza & Menor fortaleza & Menor fortaleza & Fortaleza \\
\hline $\begin{array}{l}\text { Variedad de } \\
\text { productos }\end{array}$ & $\begin{array}{c}\text { Fortaleza, adaptados a } \\
\text { la necesidad del } \\
\text { consumidor. }\end{array}$ & $\begin{array}{c}\text { Menor fortaleza } \\
\text {, adaptados al } \\
\text { consumidor familiar. }\end{array}$ & $\begin{array}{l}\text { Menor fortaleza, } \\
\text { combos muy } \\
\text { estáticos. }\end{array}$ & $\begin{array}{c}\text { Menor Debilidad, no } \\
\text { hay variedad, } \\
\text { productos estáticos. }\end{array}$ & $\begin{array}{l}\text { Menor Debilidad, } \\
\text { carta limitada. }\end{array}$ \\
\hline Ambientación & $\begin{array}{l}\text { Ambiente que no } \\
\text { estimula la } \\
\text { alimentación. }\end{array}$ & $\begin{array}{c}\text { Ambiente que no } \\
\text { estimula la } \\
\text { alimentación. }\end{array}$ & $\begin{array}{l}\text { mbiente que } \\
\text { no estimula la } \\
\text { alimentación. }\end{array}$ & $\begin{array}{l}\text { Ambiente que no } \\
\text { estimula la } \\
\text { alimentación. }\end{array}$ & $\begin{array}{l}\text { Menor debilidad, } \\
\text { ambiente pequeño. }\end{array}$ \\
\hline
\end{tabular}

Nota. A criterio del evaluador, se visitó establecimientos en horas pico y horas de baja afluencia. Fuente: Elaboración propia. 
Conforme la Tabla 13, se pudo determinar que el perfil competitivo de KFC es superior al de otros competidores, en segundo lugar se ubicaría Bembos, esto se explica por la preferencia del público por el pollo y las hamburguesas además del posicionamiento de la marca.

\subsection{Análisis del contexto actual y esperado.}

El instrumento del análisis PESTEL permite estudiar a una empresa en base a los factores externos de la industria o sector que influyan en el desarrollo de sus operaciones. Esta técnica permite identificar y obtener información para la toma de decisiones sobre estrategias potenciales para la empresa, en base a estudios que analizan el entorno presente en el que se desenvolverán así como las tendencias a futuro que puedan presentar, se toman en cuenta factores políticos, económicos, legales, culturales, tecnológicos y ecológicos. (Parada, 2013)

\subsubsection{Análisis político-gubernamental.}

Según Kotler \& Armstrong (2012), el medio político consiste en normas, leyes y gobiernos que en conjunto ejercen presión e intervienen en las diferentes organizaciones o sociedades. (p. 81)

“Conforme la Ley de Promoción de la Alimentación Saludable (Ley N 30021), impuesta por el Congreso de la República del Perú” (El Peruano, 2013), se establecen los lineamientos para promover y proteger el derecho a la salud de la población, al crecimiento y desarrollo apropiado para las personas, mediante la promoción de la actividad física, la implementación de establecimientos de consumo de alimentos saludables, y además asegurar la publicidad e información correctas de los productos que están dirigidas para el consumo de las personas. 
Así mismo esta ley permite reducir y controlar las enfermedades relacionados con el sobrepeso, la obesidad y las enfermedades que deriven de las mismas.

Del mismo modo, dentro del aspecto político-legal es importante destacar en relaciones al “sueldo mínimo". “Actualmente en el Perú, el mismo, se encuentra en el nivel de S/930.00 soles" (Perú21, 2018), esto influye de manera directa al proyecto, a medida que pueda verse incrementado por decisiones que tome el gobierno, afectaría por un lado, el pago de remuneraciones al personal y por el otro, la capacidad adquisitiva de la población.

Por otro lado, el índice de confianza del consumidor que mide el nivel de satisfacción del consumidor respecto a la situación económica del país y su propia situación financiera. Se obtuvo que en el tercer trimestre del año 2017 un índice de 94 puntos en Perú, superior a comparación de otros países de Latinoamérica, lo que refleja que los consumidores se encuentran del todo optimistas gracias al crecimiento económico del país y las posibilidades de trabajo e inversión que existen en el país, esto se refleja en la Figura 5, presentada a continuación. 


\section{CONFIANZA DEL CONSUMIDOR}

Q3 2017 - Latinoamérica

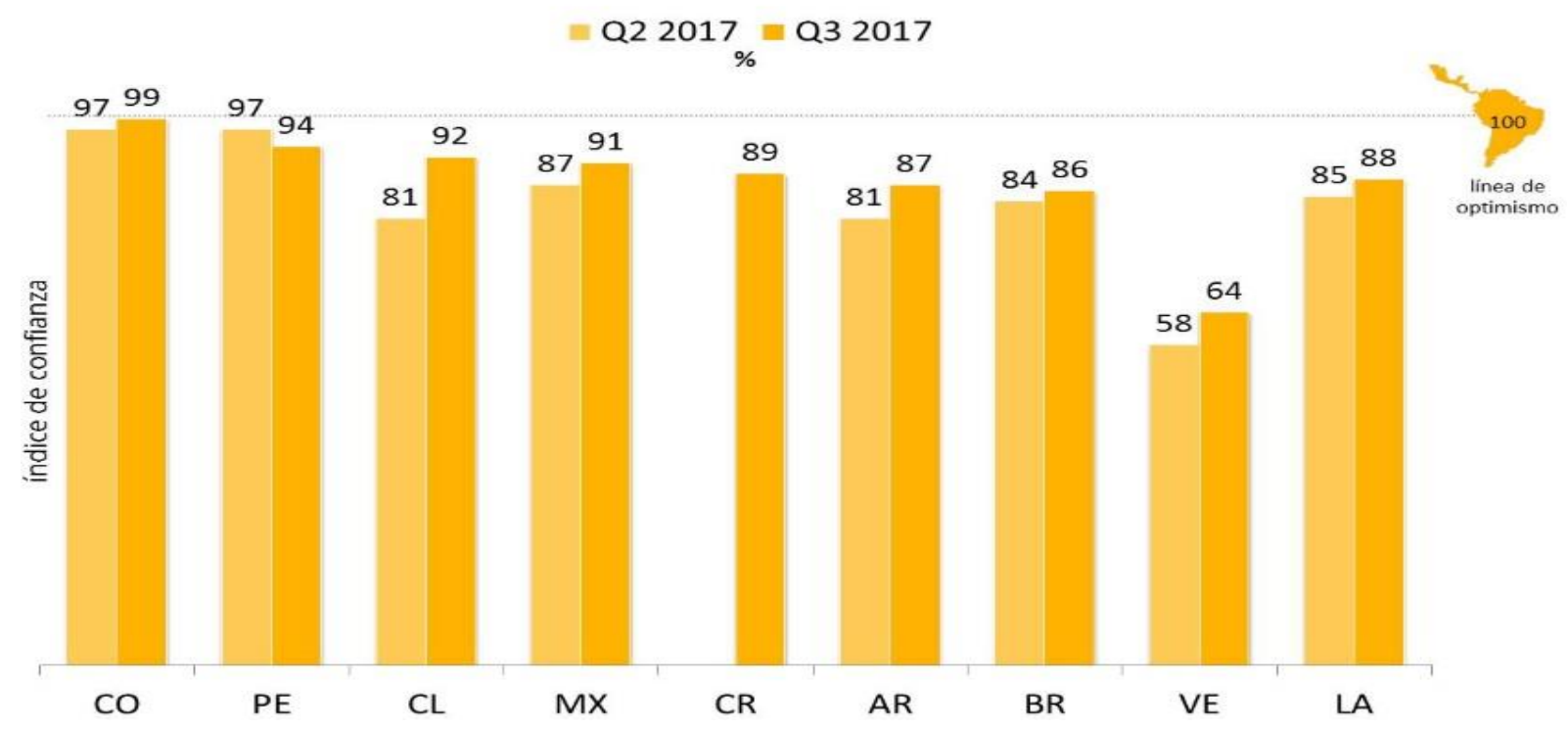

Figura 5. Índice de confianza del consumidor latinoamericano tercer trimestre 2017. Estudio global de Nielsen. (Nielsen, 2018). Recuperado de https://www.nielsen.com/ve/es/insights/news/2018/La-confianza-de-los-latinoamericanossigue-en-ritmo-de-crecimiento-con-88-puntos.print.html

Por otro lado conforme Figura 6, el nivel de confianza para la inversión en el sector empresarial de la región Cusco en Febrero 2018 se ha mantuvo sobre el tramo optimista ubicándose en 58 puntos (Banco Central de Reserva del Perú, 2018), explicado por el incremento en la explotación de hidrocarburos en 7.1\% así como el incrementó en la producción agropecuaria en $11.1 \%$ dado por la producción de Frijol de palo, papa y maíz amiláceo en dicho periodo, lo que genera la potencialidad de implementar nuevos mercado e inversiones. (Banco Central de Reserva del Perú, 2018)

A continuación, según Figura 6, se muestra gráficamente el nivel de confianza para invertir en la región Cusco. 


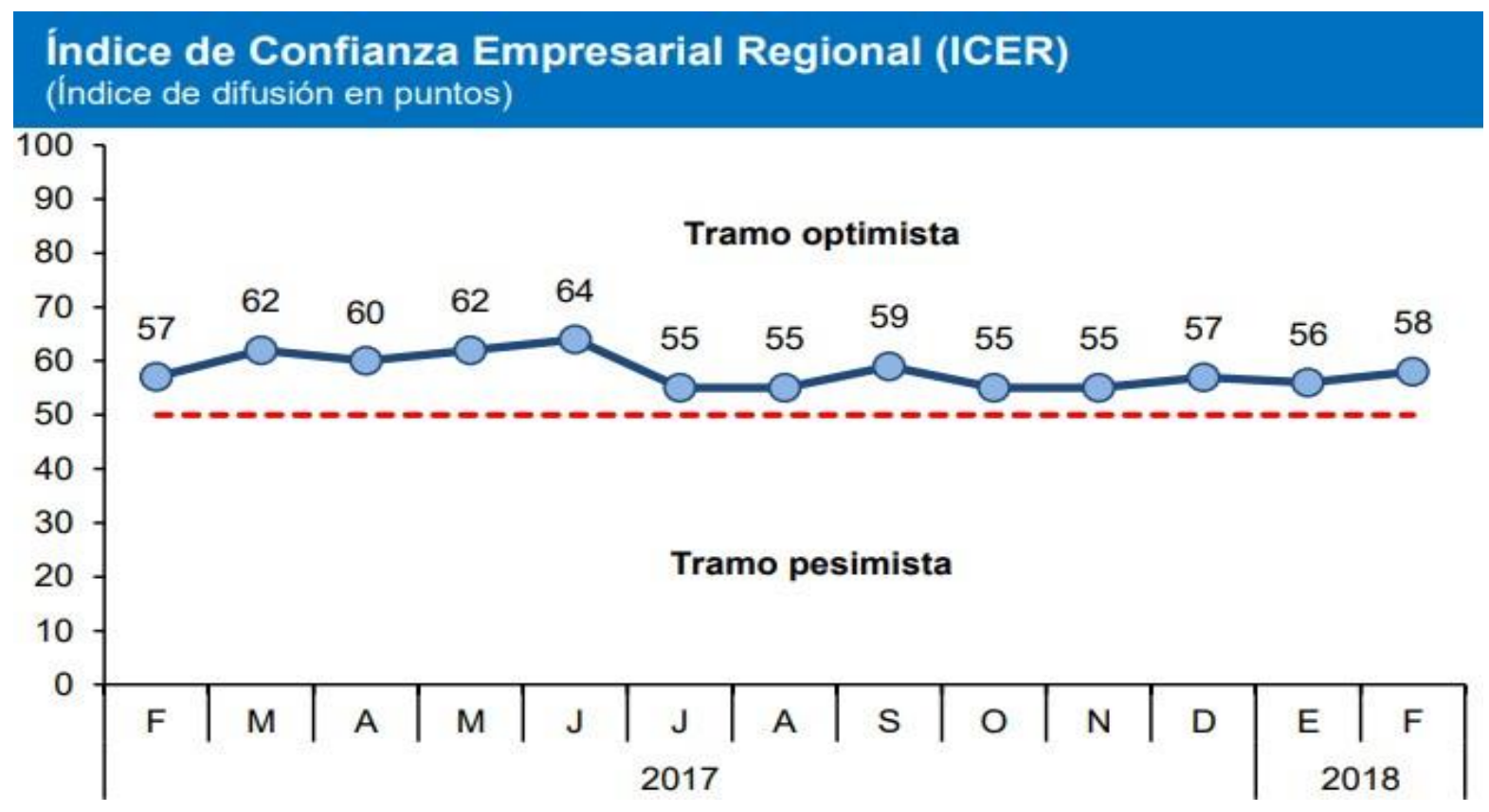

Figura 6. Cusco: Sintesis de Actividad Economica Febrero 2018, (Banco Central de Reserva del Perú, 2018). http://www.bcrp.gob.pe/docs/Sucursales/Cusco/2018/presentacion-cusco02-2018.pdf

\subsubsection{Análisis económico.}

Según Parada (2013), consiste en analizar, pensar y estudiar sobre las cuestiones económicas actuales y futuras que puedan influenciar en las decisiones futuras de la empresa.

Es notorio para la mayor parte de la población el desarrollo y crecimiento económico que ha experimentado la ciudad de Cusco en los últimos años. Sin embargo hay que considerar los factores que pueden influenciar en contracciones a la economía de la región. Por ejemplo, conforme Figura 7 se muestra el PBI per cápita de la última década en la ciudad de Cusco, donde se refleja que hubo una contracción de $3.5 \%$ en el año 2017, a pesar de que en años anteriores se evidencio un crecimiento sostenido en la región (Instituto Peruano de Economia, 2018), ello se puede explicar debido a que la producción minera e hidrocarburos cayó en 
5.3\%, además que la inversión pública se redujo en 15.3\% en dicho año, ( (Alegria, 2018); esto demuestra que las actividades extractivas y la inversión pública son determinantes para el crecimiento económico de la región, es decir estas actividad son aún más importantes que el sector turismo. (Alegria, 2018)

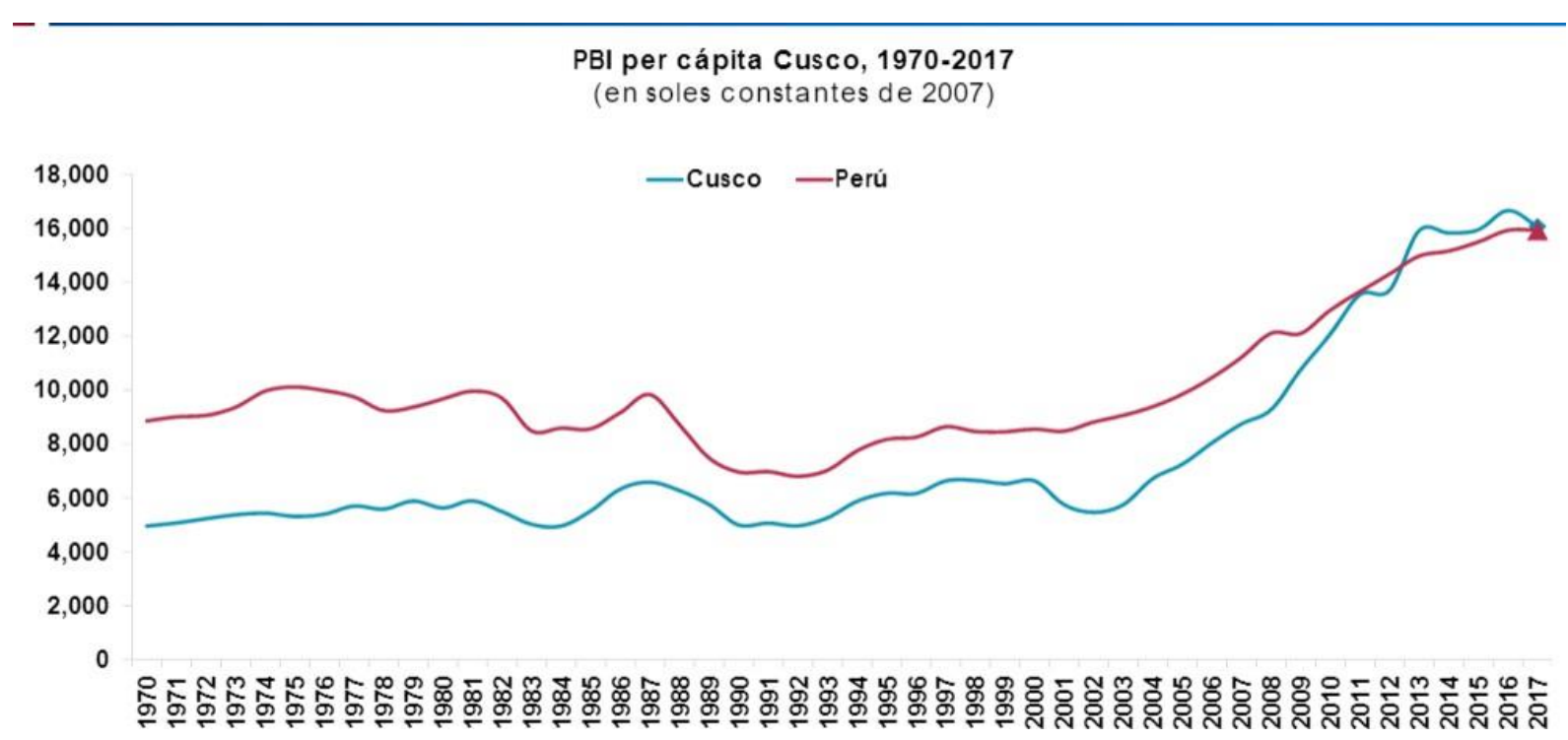

Figura 7.PBI per Capita Cusco 1970 - 2017. Perspectivas de la economía y competitividad de Perú y Cusco.Instituto Peruano de Economia, Enero 2018. Recuperado de http://www.ipe.org.pe/portal/perspectivas-de-la-economia-y-la-competitividad-de-peru-ycusco/

Del mismo modo, conforme Figura 8, se puede evidenciar el valor del costo de vida de la región de Cusco a través de la determinación del índice de precios al consumidor (IPC), en la figura en mención se evidencia que con respecto al periodo de Febrero 2017, en Enero de 2018 hubo una variación porcentual de $1.17 \%$ en el IPC, es decir menor al promedio nacional de 1.44\% (Saldaña, 2018), lo cual indica que el poder adquisitivo de la población no se vio muy afectado, puesto que la región debe contar con un nivel inflacionario estabilizado. 


\section{Índice de Precios al Consumidor de ciudades de sur, de febrero 2017 a enero de 2018 (variación \%)}

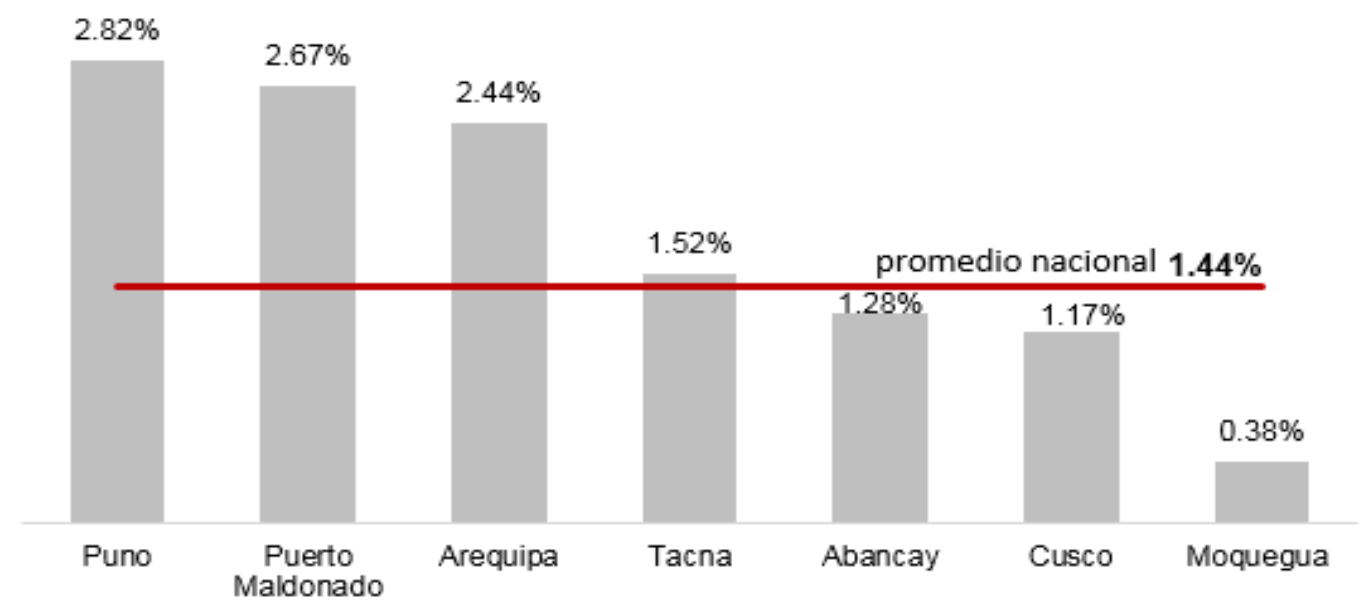

\section{Fuente: INEI.}

Elaboración: Aurum Consultoría y Mercado.

Figura 8. Índice de precios al consumidor de ciudades de sur de Febrero 2017 a Enero 2018. Moquegua con precios estancados; Puerto Maldonado con inflación encima del promedio. Mercadosyregiones.com, 2018. Recuperado de http://mercadosyregiones.com/2018/02/punocon-inflacion-por-encima-del-promedio-precios-se-estancan-en-moquegua/

Por otro lado, conforme la Figura 9, la inflación en el Perú presentó una variación entre el periodo de 2016 a 2017, lo cual indica que el valor de los algunos productos de la canasta básica de la población se ha incrementado, esto se puede explicar por las secuelas del fenómeno del niño que se dieron entre diciembre 2016 y abril 2017 en la zona norte del país. Sin embargo según las proyecciones del BCRP se prevé una disminución progresiva en 2\% de la inflación para los siguientes años, esto explicado por el incremento en los índices de confianza del consumidor y el índice de confianza a la inversión. 


\section{PROYECCIÓN DE LA INFLACIÓN, 2015-2019}

(Variación porcentual últimos doce meses)

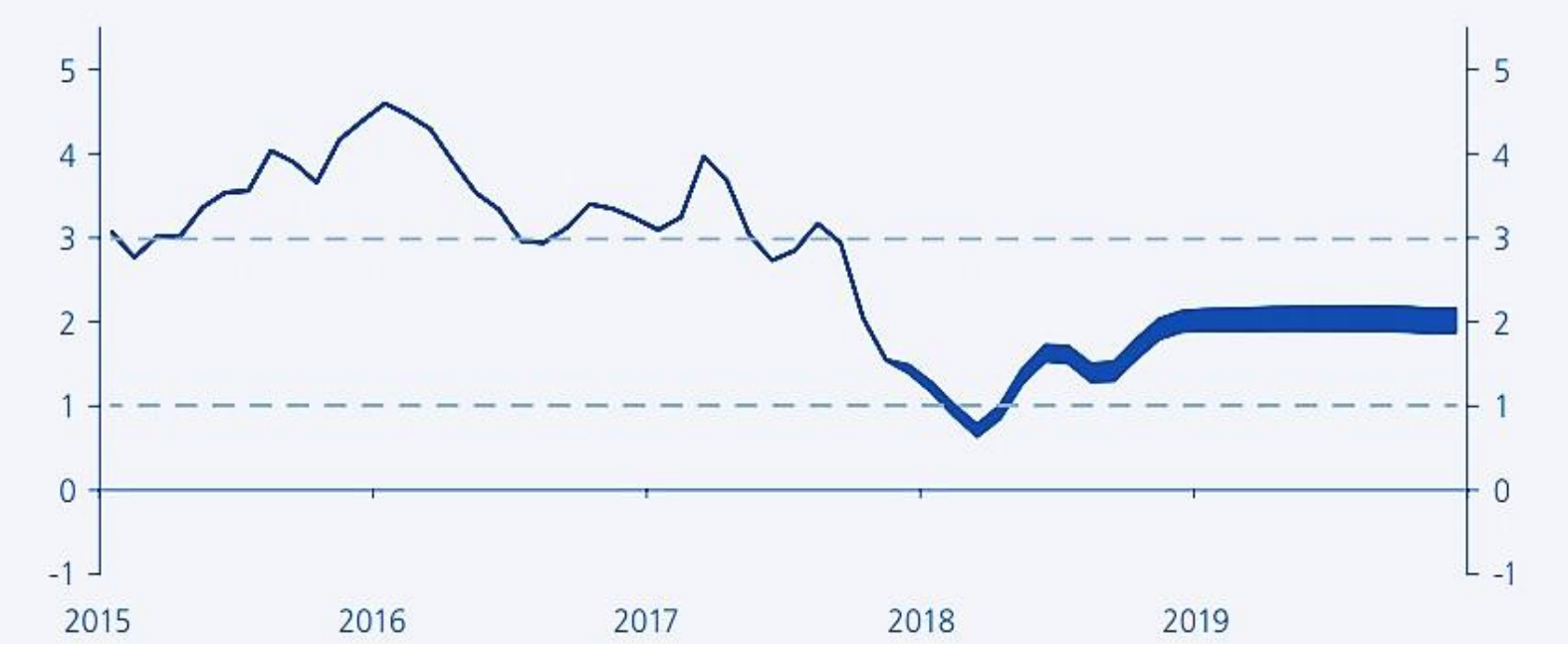

Figura 9. Proyección inflación 2015-2019. Síntesis Reporte de Inflación BCRP. Recuperado de http://www.bcrp.gob.pe/docs/Publicaciones/Reporte-Inflacion/2017/diciembre/reporte-deinflacion-diciembre-2017-sintesis.pdf

Este factor de inflación es importante para el proyecto puesto que permite determinar si la variación de los precios de los productos se mantiene o sufre fluctuaciones constantes que pueden influenciar el costo de producción y por ende el precio final al consumidor.

Por otro lado conforme la Figura 10, las proyecciones del PBI real según el MEF para la próxima década es generar un crecimiento de 4,0\% para el 2018 y que se establecerá gradualmente en un 3,5\% para el 2050. 


\section{Crecimiento del PBI real (puntos porcentuales del $\mathrm{PBI}$ )}

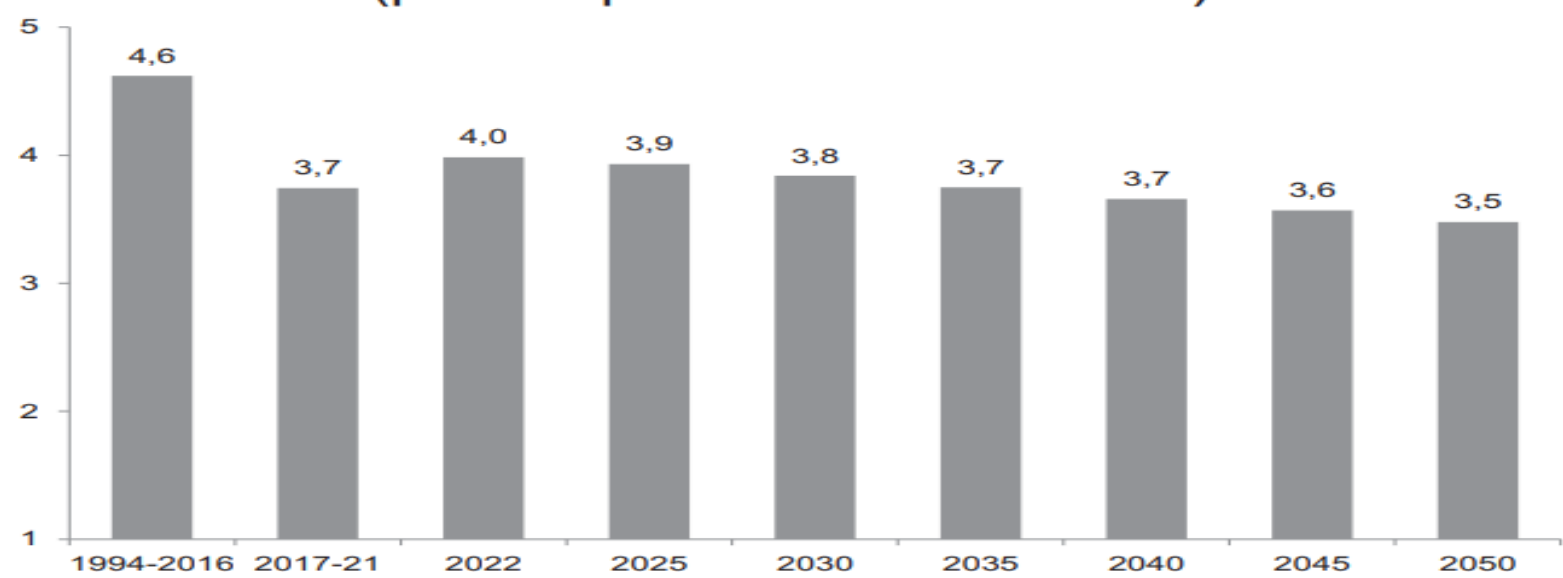

Figura 10. Crecimiento del PBI Real proyección del 2016 al 2050. Marco Macroeconómico Mundial 2018-2021, el peruano. Recuperado de https://www.mef.gob.pe/contenidos/pol_econ/marco_macro/MMM_2018_2021.pdf

Del mismo modo según Figura 11, se puede determinar que el PBI del sector servicios tendrá un importante crecimiento proyectado para los periodos del 2019 al 2021, situándose en un promedio de $4.8 \%$ con respecto al 2016 que se situó en $4.3 \%$ y superando la caída expresada en el 2017 que se posicionó en 3.1\%.

\begin{tabular}{|c|c|c|c|c|c|}
\hline & $\begin{array}{l}\text { Peso Año } \\
\text { Base } 2007\end{array}$ & 2016 & 2017 & 2018 & $\begin{array}{c}\text { Prom } \\
2019-2021\end{array}$ \\
\hline Agropecuario & 6,0 & 2,3 & 0,9 & 4,6 & 4,0 \\
\hline Agricola & 3,8 & 1,4 & $-0,5$ & 4,9 & 3,9 \\
\hline Pecuario & 2,2 & 3,7 & 3,0 & 4,2 & 4,2 \\
\hline Pesca & 0,7 & $-10,1$ & 34,7 & 5,4 & 3,5 \\
\hline $\begin{array}{l}\text { Minería e hidrocarburos } \\
\text { Minería metálica } \\
\text { Hidrocarburos }\end{array}$ & $\begin{array}{r}14,4 \\
12,1 \\
2,2\end{array}$ & $\begin{array}{l}16,3 \\
21,1 \\
-5,1\end{array}$ & $\begin{array}{l}4,9 \\
5,5 \\
2,4\end{array}$ & $\begin{array}{l}4,7 \\
4,1 \\
7,2\end{array}$ & $\begin{array}{l}1,7 \\
2,1 \\
0,0\end{array}$ \\
\hline $\begin{array}{l}\text { Manufactura } \\
\text { Primaria } \\
\text { No primaria } \\
\text { Electricidad y agua }\end{array}$ & $\begin{array}{r}16,5 \\
4,1 \\
12,4 \\
1,7\end{array}$ & $\begin{array}{r}-1,4 \\
-0,6 \\
-1,7 \\
7,3\end{array}$ & $\begin{array}{r}1,4 \\
9,7 \\
-0,6 \\
3,2\end{array}$ & $\begin{array}{l}3,4 \\
3,6 \\
3,3 \\
5,0\end{array}$ & $\begin{array}{l}3,6 \\
3,2 \\
3,7 \\
5,5\end{array}$ \\
\hline Construcción & 5,1 & $-3,1$ & $-0,1$ & 8,8 & 5,3 \\
\hline Comercio & 10,2 & 1,8 & 1,6 & 2,5 & 4,0 \\
\hline Servicios & 37,1 & 4,3 & 3,1 & 3,7 & 4,8 \\
\hline PBI & 100,0 & 4,0 & 2,8 & 4,0 & 4,0 \\
\hline
\end{tabular}

Figura 11. PBI por sectores.Marco Macroeconómico Mundial 2018-2021, el peruano. Recuperado de https://www.mef.gob.pe/contenidos/pol_econ/marco_macro/MMM_2018_2021.pdf 
Para el 2018, conforme se detalla en Figura 12, se proyecta la recuperación progresiva de la inversión privada, gracias al incremento de la demanda interna, al incremento de los precios de los metales y al desarrollo de importantes proyectos para promover la inversión minera; con ello se prevé que el PBI crecerá a 4,0\% para dicho año.

Por otro lado, para el periodo de 2019-2021 la inversión privada crecerá a tasas promedio de 5,0\% anual, encabezado por inversiones en infraestructura debido a la reconstrucción de las ciudades del norte tras los acontecimientos devastadores generados por el fenómeno del niño, además de la mejora de la infraestructura para la celebración de los juegos panamericanos a celebrarse en el país; así mismo las inversiones en el sector minero e hidrocarburos propiciarán el crecimiento de la inversión privada.

Ello motivará el incremento en la contratación formal y un entorno de inversión empresarial favorable, apoyado por la simplificación administrativa y la erradicación de barreras burocráticas. Con ello, “el Perú logrará un crecimiento potencial de 4,0\%, logrando así mantenerse como uno de los países de alto crecimiento en el mundo.” (Ministerio de economía y finanzas, 2017) 


\section{Cambio en el crecimiento del 2017-2018}

(Var. \% real anual, p.p.)

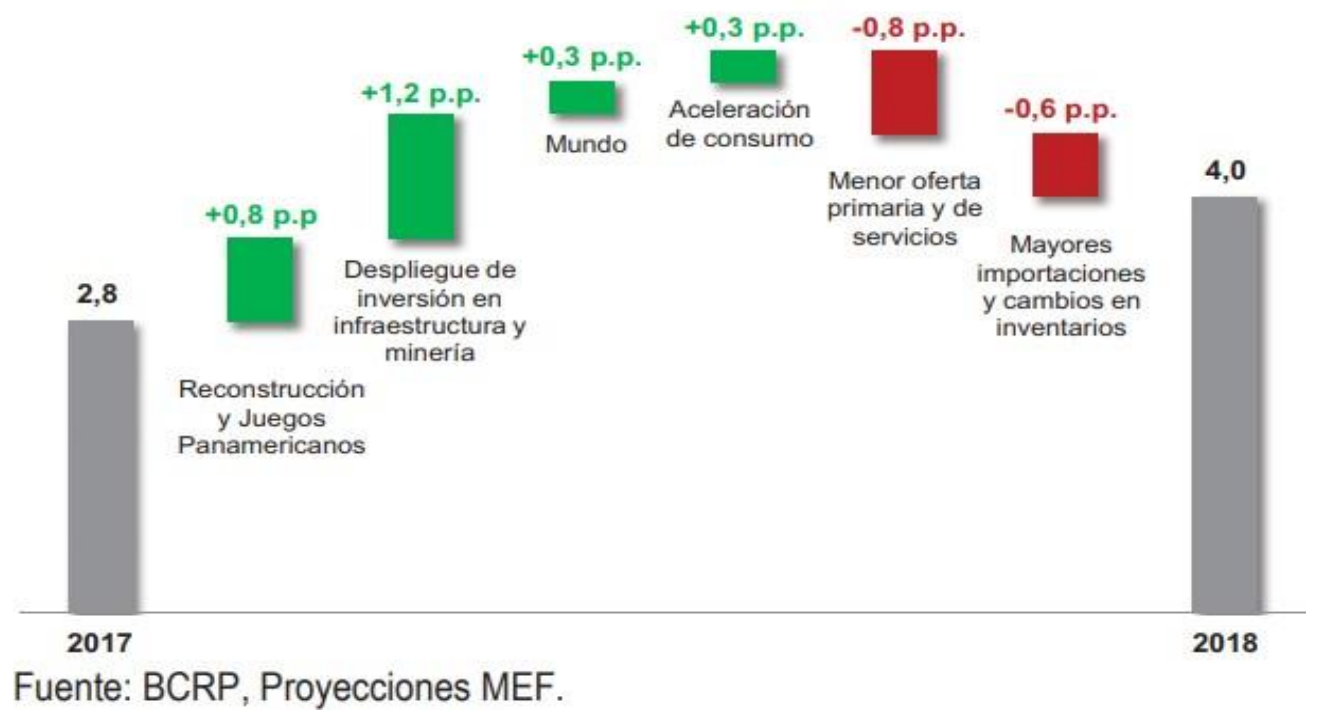

Figura 12. Cambio en el crecimiento del PBI 2017-2018. Marco macro-económico mundial 2018-2021, El Peruano. Recuperado de https://www.mef.gob.pe/contenidos/pol_econ/marco_macro/MMM_2018_2021.pdf

\subsubsection{Análisis legal.}

Según Parada (2013), estos factores se refieren a todos aquellos cambios en la normativa legal relacionada con el proyecto, que le puede afectar de forma positiva o negativa.

El primer punto a considerar es la normativa existente para restaurantes la cual es regulada por el Ministerio de Comercio Exterior y Turismo (MINCETUR) y el Ministerio de Salud (MINSA).

MINCETUR: Mediante el Decreto Supremo No. 025-2004-MINCETUR y la Resolución Ministerial No. 081-94-ITINCI, se establecen los requisitos y procedimientos necesarios para la autorización, funcionamiento y supervisión de un restaurante, así como asegurar que los 
precios que se brinden al cliente sean transparentes. También será obligatorio la presentación de la Declaración Jurada de Restaurantes, Formulario F-011. (MINCETUR, Copyright 2015)

MINSA (Ministerio de Salud): Por medio de la Norma Sanitaria para el funcionamiento de restaurantes y servicios afines, se establecen las buenas prácticas para la gestión adecuada de alimentos y bebidas para consumo humano y se determinan los parámetros de calidad así como de manipulación, infraestructura, y procedimientos para asegurar la vida y salud de la población. (El Peruano, 2014)

Por otro lado, se ha identificado potenciales barreras de entrada como la Ley de la comida chatarra - Ley 30021, donde se establece que los productos embazados deben cumplir con ciertos criterios de información en el empaque sin embargo lleva cuatro años sin contar con reglamento (Izaguirre, 2017), pero es una amenaza potencial que puede influenciar en los costos del proyecto.

Otro aspecto importante es respecto a las legislaciones municipales, tributarias y laborales. Municipalidad del Cusco: Para la obtención de licencias de funcionamiento y reglamentación sobre la disposición de letreros luminosos, el pago de arbitrios municipales, entre otros.

- SUNAT (Superintendencia Nacional de Aduanas y de Administración Tributaria): Declaración de impuestos IGV, Impuesto a la renta, registro de la propiedad jurídica. 
- MINTRA (Ministerios de Trabajo): Reglamento del Trabajo, cumplimiento de las Jornadas, salarios y beneficios de los trabajadores dispuestos por ley.

\subsubsection{Análisis cultural.}

Según Parada (2013), lo que importa especular es sobre qué elementos de la sociedad pueden afectar el proyecto y cómo están cambiando. Se busca identificar tendencias en la sociedad actual.

En la actualidad la diversidad cultural de la población cusqueña ha ido cambiando y adaptándose poco a poco debido a la migración de turistas extranjeros que pasan largas temporadas de tiempo e incluso se mudan a la ciudad de Cusco para radicar de manera permanente, sin embargo siempre se trata de mantener el legado histórico y costumbrista de la población que se revalora cada año en el mes de junio, fecha en el que la población vive el sincretismo religioso de la época de la conquista, así como se mimetiza con la simbología del patrimonio material e inmaterial de la región. La diversidad cultural genera la necesidad de formar parte del mercado mundial, así mismo el uso de tecnologías informáticas para poder comunicarse se ha vuelto cada vez más una necesidad.

Por otro lado, "el concepto de cocina novoandina permite revalorar el uso de los insumos andinos con la implantación de técnicas de cocina internacional, las nuevas fusiones gastronómicas están logrando preservar las costumbres de la región” (Instituto Latino, 2016). 
Así mismo, Cusco es la principal ciudad gastronómica y cultural del país, el uso de la papa y el maíz es prioritario y huella del legado cultural de los incas, la comida tradicional aún permanece a través de restaurantes como las picanterías y chicherías donde aún se aplican técnicas y recetas que pasan de generación en generación. (Instituto Le cordon blue, n.d)

Otro aspecto cultural predominante para el proyecto son los hábitos, gustos y preferencias del público objetivo, así como sus características demográficas; en ese sentido, conforme el estudio cualitativo llevado a cabo para el presente plan de negocio que se desarrollará en el capítulo 3, en el estudio de mercado se pudo determinar la preferencia del consumo de comida rápida por factores de tiempo, sabor y ocio; indicaron que gustan de asistir con familiares o amigos en horarios de tarde y noche, así como fines de semana, prefieren establecimientos que ofrezcan buena atención además de calidad en el producto, expresaron su preferencia por la marca KFC y las personas jóvenes entre 18 a 29 años muestran agrado y preferencia por el tipo de comida fast food estilo americano, sin embargo las personas de 30 a 45 años, indican que preferirían productos más orientados al cuidado de la salud dentro de la oferta de los fast food.

\subsubsection{Análisis tecnológico.}

Según Parada (2013), este punto es más complejo, puesto que, aunque los cambios tecnológicos siempre han existido, la velocidad con la que se producen hoy día es realmente vertiginosa.

A través del uso de las redes sociales y aplicativos móviles se pueden implementar nuevas formas y tendencias para agilizar el servicio y la calidad de atención para los clientes, se 
puede gestionar compras por delivery vía aplicativos móviles, además de compras prepagas desde los mismos aplicativos con recojo en tienda y evitar las colas. "Sistemas de fidelización a través de los códigos Quick Response (QR) vía redes sociales entre otros mecanismos que ya se aplican en el Perú.” (collectiveloudperu, 2015)

Del mismo modo otros departamentos del país, como es el caso de la ciudad de Trujillo, vienen implementando mecanismos de seguridad para el turista a través de aplicaciones móviles como es la plataforma Policetourism Perú que se trabajada en conjunto con la policía de turismo y la Asociación de Hoteles y Restaurantes, lo que permite en tiempo real comunicar sobre un agravio permitiendo a la policía contar con información precisa de localización del turista afectado. (La Industria, 2017)

Por otro lado, a través de nuevas herramientas tecnológicas como es el Big data o también conocida como minería de datos, permite la gestión y análisis de grandes volúmenes de información que se encuentra en la internet con lo que se puede crear motores de búsqueda especializados, este es el caso de la aplicación "Delectame”, creada para obtener información a nivel mundial sobre cambios en las tendencias de mercados y preferencias del público objetivo de una empresa de restauración, así como información sobre los insumos, tendencias, recetas y demanda o preferencia de los mismo, lo cual permite agilizar la toma de decisión en un restaurante para llevar a cabo la ingeniería del menú. (efeemprende, 2017)

Otros implementos tecnológicos necesarios para el proyecto son la instalación de cajas registradoras computarizadas con pantallas digitales, que permitan una gestión más eficiente de 
las ventas y que cuenten con un software especializado como es el Resprocess - SyscoPerú, dicho programa está adaptado a los negocios de restaurantes y permiten además de la facturación, el control y envío de pedidos de forma directa al área de producción y al área de despacho, unificando procesos.

\subsubsection{Análisis ecológico.}

Según Parada (2013), estos factores pueden parecer que sólo afectan a las empresas de sectores muy específicos, pero en realidad es todo lo contrario. Es de interés estar al tanto no sólo sobre los posibles cambios normativos referidos a la ecología, sino también en cuanto a la conciencia social de este movimiento.

En cuanto al impacto que genera el negocio al medio ambiente, se puede considerar las emisiones que producen los hornos, las máquinas, los freidores y planchas hacia el medio ambiente; así como, los desperdicios que se originan al desechar materias grasas, envoltorios y sobrantes de comida a la basura. Para ello se debe evaluar la posibilidad de contribuir con ONG's o empresas dedicadas al reciclaje para una mejor gestión de los residuos, así como utilizar envases, cartones y papeles que sean de fácil reciclaje, del mismo modo contribuir a un mejor manejo de los residuos grasos a través de la implementación de trampas de grasa.

Todas estas manifestaciones se deben gestionar en base al reglamento de Manejo de Residuos sólidos dispuesto por DIGESA (Dirección General de Salud Ambiental) puesto a conocimiento de la población e instituciones para un óptimo cuidado del medio ambiente. (Digesa, n.d) 


\subsection{Oportunidades y amenazas.}

Según Kotler y Armstrong (2012), la oportunidad es como una zona de necesidad e interés del comprador en la cual hay una alta probabilidad de que una empresa pueda actuar rentablemente satisfaciendo esa necesidad. Para el presente se considera al conjunto de oportunidades y amenazas obtenido como el $100 \%$ del total de factores a evaluar, a cada factor se le asignará una ponderación para poder desarrollar una Matriz EFE (Evaluación de Factores Externos) que permita determinar el índice de eficacia que tiene el proyecto para responder a los cambios en los factores externos. En la Tabla 15 se podrá visualizar las oportunidades y amenazas encontradas así como los criterios de ponderación asignados. 


\section{Tabla 15}

Oportunidades y amenazas del proyecto y justificación de ponderación

\begin{tabular}{|c|c|c|}
\hline Factores externos clave & Pond. & Criterios de ponderación \\
\hline \multicolumn{3}{|l|}{ Oportunidades } \\
\hline $\begin{array}{l}\text { Índice de Confianza empresarial } \\
\text { regional por encima del tramo } \\
\text { optimista. }\end{array}$ & $12 \%$ & $\begin{array}{l}\text { Factor atractivo puesto que refleja el crecimiento de las } \\
\text { actividades económicas en la región. }\end{array}$ \\
\hline $\begin{array}{l}\text { Índice de precios al consumidor (IPC) } \\
\text { bajo. }\end{array}$ & $5 \%$ & $\begin{array}{l}\text { Factor moderadamente atractivo puesto que refleja que } \\
\text { la región cuenta con un nivel inflacionario atractivo y la } \\
\text { capacidad de gasto del consumidor se incrementa. }\end{array}$ \\
\hline $\begin{array}{l}\text { Proyección de crecimiento del } 5 \% \\
\text { anual del sector servicios. }\end{array}$ & $15 \%$ & $\begin{array}{l}\text { Factor de alta atracción para el proyecto, alta demanda } \\
\text { del sector servicios, incentivo para la inversión privada. }\end{array}$ \\
\hline $\begin{array}{l}\text { Desarrollo de la comida novoandina, } \\
\text { insumos como legado generacional. }\end{array}$ & $8 \%$ & $\begin{array}{l}\text { Factor medianamente atractivo, es un concepto que se } \\
\text { puede mejorar }\end{array}$ \\
\hline $\begin{array}{l}\text { Uso de aplicativos móviles para } \\
\text { optimización del tiempo }\end{array}$ & $7 \%$ & $\begin{array}{l}\text { Factor medianamente atractivo, es un concepto que se } \\
\text { puede aplicar }\end{array}$ \\
\hline $\begin{array}{l}\text { Moda por la conservación del medio } \\
\text { ambiente, manejo adecuado de los } \\
\text { residuos y emisiones de los } \\
\text { restaurantes. }\end{array}$ & $2 \%$ & $\begin{array}{c}\text { Factor poco atractivo por alto costo, potencialidad para } \\
\text { aplicar programas de responsabilidad social con el } \\
\text { medio ambiente, manejo de residuos, lograr un mejor } \\
\text { posicionamiento. }\end{array}$ \\
\hline $\begin{array}{l}\text { Incremento del sueldo mínimo a } \\
\text { S/930.00 soles }\end{array}$ & $2 \%$ & $\begin{array}{l}\text { Factor poco atractivo, incrementa la capacidad de gasto } \\
\text { del consumidor pero también incrementa los gastos en } \\
\text { planilla. }\end{array}$ \\
\hline \multicolumn{3}{|l|}{ Amenazas } \\
\hline $\begin{array}{l}\text { Caída del sector agropecuario, afecta } \\
\text { el índice de confianza empresarial } \\
\text { regional para invertir. }\end{array}$ & $15 \%$ & $\begin{array}{l}\text { Factor crítico desincentiva la inversión para empresas } \\
\text { del rubro de restaurantes, se incrementa el costo de los } \\
\text { insumos y el IPC. }\end{array}$ \\
\hline $\begin{array}{l}\text { Caída de los sectores extractivos o de } \\
\text { la inversión pública genera la } \\
\text { contracción del PBI per cápita de la } \\
\text { región. }\end{array}$ & $10 \%$ & $\begin{array}{c}\text { Factor de riesgo medio, se reduce el canon minero y la } \\
\text { inversión en obras públicas, se desacelera el crecimiento } \\
\text { económico de la región, por ende se reduce la capacidad } \\
\text { de gasto del consumidor. }\end{array}$ \\
\hline Impuesto a la comida chatarra & $8 \%$ & $\begin{array}{l}\text { Factor de riesgo medio bajo porque el proyecto incluye } \\
\text { insumos nutricionales además de ser una ley que hace } \\
\text { cuatro años no se reglamenta. }\end{array}$ \\
\hline $\begin{array}{l}\text { Cambios climáticos que afectan la } \\
\text { producción agrícola }\end{array}$ & $2 \%$ & $\begin{array}{l}\text { Factor de bajo riesgo, los desastres naturales no son } \\
\text { medibles }\end{array}$ \\
\hline $\begin{array}{l}\text { Ingreso de nuevas franquicias } \\
\text { internacionales }\end{array}$ & $12 \%$ & Factor de riesgo por fuga de consumidores \\
\hline Huelgas y paros & $2 \%$ & Factores de bajo riesgo porque no son frecuentes \\
\hline Total & $100 \%$ & \\
\hline
\end{tabular}

Nota. Fuente: Elaboración propia. 
Con la determinación de las oportunidades, amenazas y las ponderaciones estimadas, se procede a realizar la matriz EFE, para lo cual se tiene que considerar los criterios de calificación en un rango del 1 a 4 que permitan estimar el nivel de respuesta del proyecto ante estos factores, donde 4=la respuesta es superior, $3=$ la respuesta esta por encima del promedio, $2=1$ a respuesta es promedio; 1= la respuesta es deficiente. (David, 2013, pág. 81)

Una vez obtenida la ponderación final el resultado indicará si el proyecto es capaz de capitalizar sus oportunidades y evitar sus amenazas, es decir si es eficaz en el tiempo. A continuación, se presenta la matriz EFE para el presente proyecto, conforme Tabla 16, además de la justificación de la ponderación asignada según la Tabla 17. 
Tabla 16

Matriz de factores externos - EFE, análisis de oportunidades y amenazas

\begin{tabular}{|c|c|c|c|}
\hline Factores externos clave & Ponderación & Calificación & Total \\
\hline \multicolumn{4}{|l|}{ Oportunidades } \\
\hline $\begin{array}{l}\text { O1. Índice de Confianza empresarial regional por } \\
\text { encima del tramo optimista. }\end{array}$ & $12 \%$ & 4 & 0.48 \\
\hline O2. Índice de precios al consumidor (IPC) bajo. & $5 \%$ & 4 & 0.2 \\
\hline $\begin{array}{l}\text { O3. Proyección de crecimiento del 5\% anual del } \\
\text { sector servicios. }\end{array}$ & $15 \%$ & 3 & 0.45 \\
\hline $\begin{array}{l}\text { O4. Desarrollo de la comida novoandina, insumos } \\
\text { como legado generacional. }\end{array}$ & $8 \%$ & 4 & 0.32 \\
\hline $\begin{array}{l}\text { O5. Uso de aplicativos móviles para optimización del } \\
\text { tiempo }\end{array}$ & $7 \%$ & 3 & 0.21 \\
\hline $\begin{array}{l}\text { O6. Moda por la conservación del medio ambiente, } \\
\text { manejo adecuado de los residuos y emisiones de los } \\
\text { restaurantes. }\end{array}$ & $2 \%$ & 2 & 0.04 \\
\hline O7. Incremento del sueldo mínimo a S/930.00 soles & $2 \%$ & 1 & 0.02 \\
\hline \multicolumn{4}{|l|}{ Amenazas } \\
\hline $\begin{array}{l}\text { A1. Caída del sector agropecuario, afecta el índice de } \\
\text { confianza empresarial regional para invertir. }\end{array}$ & $15 \%$ & 3 & 0.45 \\
\hline $\begin{array}{l}\text { A2. Caída de los sectores extractivos o de la inversión } \\
\text { pública genera la contracción del PBI per cápita de la } \\
\text { región. }\end{array}$ & $10 \%$ & 2 & 0.2 \\
\hline A3. Impuesto a la comida chatarra & $8 \%$ & 1 & 0.08 \\
\hline $\begin{array}{l}\text { A4. Cambios climáticos que afectan la producción } \\
\text { agrícola }\end{array}$ & $2 \%$ & 3 & 0.06 \\
\hline A5. Ingreso de nuevas franquicias internacionales & $12 \%$ & 1 & 0.12 \\
\hline A6. Huelgas y paros & $2 \%$ & 1 & 0.02 \\
\hline TOTAL & $100 \%$ & & 2.65 \\
\hline
\end{tabular}

Nota. Fuente: Elaboración propia. 


\section{Tabla 17}

Justificación de calificación matriz EFE

\begin{tabular}{|c|c|c|}
\hline Factores externos & Cf. & Criterios de calificación \\
\hline \multicolumn{3}{|l|}{ Oportunidades } \\
\hline $\begin{array}{l}\text { Índice de Confianza empresarial } \\
\text { regional por encima del tramo } \\
\text { optimista. }\end{array}$ & 4 & $\begin{array}{l}\text { La respuesta es superior porque el proyecto tendrá la oportunidad } \\
\text { de obtener mejores tasas para el financimiento. }\end{array}$ \\
\hline $\begin{array}{l}\text { Índice de precios al consumidor } \\
\text { (IPC) bajo. }\end{array}$ & 4 & $\begin{array}{l}\text { La respuesta es superior puesto que el consumidor tiene una } \\
\text { mayor capacidad de gasto para invertir en ocio y recreación. }\end{array}$ \\
\hline $\begin{array}{l}\text { Proyección de crecimiento del } \\
5 \% \text { anual del sector servicios. }\end{array}$ & 3 & $\begin{array}{l}\text { La respuesta es por encima del promedio puesto que se ofrecerá } \\
\text { un nuevo concepto con valor agregado al consumidor. }\end{array}$ \\
\hline $\begin{array}{l}\text { Desarrollo de la comida } \\
\text { novoandina, insumos como } \\
\text { legado generacional. }\end{array}$ & 4 & $\begin{array}{l}\text { La respuesta es superior puesto que se aprovechará el crecimiento } \\
\text { de esta nueva tendencia gastronómica que ha ganado importancia } \\
\text { en los últimos años. }\end{array}$ \\
\hline $\begin{array}{l}\text { Uso de aplicativos móviles para } \\
\text { optimización del tiempo }\end{array}$ & 3 & $\begin{array}{l}\text { La respuesta es por encima del promedio porque se pevé el uso de } \\
\text { esta tecnología para realizar el servicio delivery's. }\end{array}$ \\
\hline $\begin{array}{l}\text { Moda por la conservación del } \\
\text { medio ambiente, manejo } \\
\text { adecuado de los residuos y } \\
\text { emisiones de los restaurantes. }\end{array}$ & 2 & $\begin{array}{l}\text { La respuesta es promedio puesto que es una herramienta para } \\
\text { posicionarse a través de auspicios y responsabilidad social con el } \\
\text { medio ambiente, captando público que valore el tema. }\end{array}$ \\
\hline $\begin{array}{l}\text { Incremento del sueldo mínimo a } \\
\text { S/930.00 soles }\end{array}$ & 1 & $\begin{array}{l}\text { La respuesta es deficiente debido a que se incrementa la } \\
\text { capacidad de gasto del consumidor, pero también se incrementan } \\
\text { los gastos em planillla. }\end{array}$ \\
\hline \multicolumn{3}{|l|}{ Amenazas } \\
\hline $\begin{array}{l}\text { Caída del sector agropecuario, } \\
\text { afecta el índice de confianza } \\
\text { empresarial regional para } \\
\text { invertir. }\end{array}$ & 3 & $\begin{array}{l}\text { La respuesta es por encima del promedio debido a que se maneja } \\
\text { un margen de contribución moderado a alto que soporte esta } \\
\text { potencial caída. }\end{array}$ \\
\hline $\begin{array}{l}\text { Caída de los sectores extractivos } \\
\text { o de la inversión pública genera } \\
\text { la contracción del PBI per cápita } \\
\text { de la región. }\end{array}$ & 2 & $\begin{array}{l}\text { La respuesta es promedio para enfrentar este problema debido a } \\
\text { que se desacelera la inversión de nuevos centros comerciales y } \\
\text { ello conllevaría a menos competencia, pero también a menor } \\
\text { aparición de zonas comerciales a futuro. }\end{array}$ \\
\hline Impuesto a la comida chatarra & 1 & $\begin{array}{l}\text { La respuesta es deficiente si se aplicara este impuesto porque } \\
\text { impacta al margen de contribución ya que los envases ecológicos } \\
\text { son de alto costo. }\end{array}$ \\
\hline $\begin{array}{l}\text { Cambios climáticos que afectan } \\
\text { la producción agrícola }\end{array}$ & 3 & $\begin{array}{l}\text { La respuesta es por encima del promedio para enfrentar estas } \\
\text { situaciones porque se puede contar con proveedores de otras } \\
\text { regiones en caso de emergencias. }\end{array}$ \\
\hline $\begin{array}{l}\text { Ingreso de nuevas franquicias } \\
\text { internacionales }\end{array}$ & 1 & $\begin{array}{l}\text { La respuesta es deficiente si se incrementaran excesivamente las } \\
\text { franquicias internacionales puesto que sus economías de escala } \\
\text { los benefician en cuanto al costo. }\end{array}$ \\
\hline Huelgas y paros & 1 & $\begin{array}{l}\text { La respuesta es deficiente si se dan estas huelgas de manera } \\
\text { radical porque representan perdidas económicas. }\end{array}$ \\
\hline
\end{tabular}

Nota. Fuente: Elaboración propia. 
En base al análisis realizado se obtuvo como resultado que el total ponderado del proyecto conforme a la Matriz EFE es de 2.65, es decir está por encima de la media del rango de 1 a 4, esto indica que el proyecto es capaz de aprovechar sus oportunidades pero si presenta moderadas dificultades en enfrentar sus amenazas. 


\section{Capítulo III}

\section{Estudio De Mercado}

En el presente capítulo se elaboró un estudio del mercado actual para que de acuerdo a los resultados se puedan definir las estrategias de marketing y ventas adecuadas al proyecto. Para realizar el estudio del mercado se hizo uso de la investigación cualitativa donde se llevó a cabo 4 focus group y entrevistas a expertos con manejo de fast food, así obtener información mediante opiniones y actitudes de los participantes, también se realizaron encuestas que fueron utilizadas habiendo definido el tamaño de la muestra.

\subsection{Descripción del servicio o producto.}

Este es el primer aspecto a considerar en el estudio de mercado. Aquí se describen las características del producto, no se debe olvidar que el consumidor es el objetivo final del mercadeo y se debe procurar su satisfacción o deseo ya sea cubriendo una necesidad o creándola.

“Este producto o servicio estará siempre en función a satisfacer las necesidades del cliente o consumidor para las cuales se debe tener en consideración diferentes variables como son: calidad, tamaño, forma, diseño, marca, usos, características físicas, etc.” (Universidad Santo Tomas, n.d)

La ubicación del plan del negocio que se propone de manera preliminar, es en un local ubicado en una zona céntrica de alto tránsito o circulación que ofrezca los productos considerados de mayor demanda en el medio, como son fritura de trozos de pollo, alitas, papas 
fritas, hamburguesas de pollo y carne, ensaladas, jugos, gaseosas y refrescos, que incorporen productos andinos o de la región dentro de su preparación. Además, contará con una ambientación y decoración relacionada inspirada en la temática de la regional, con wifi gratuito, etc.

Cabe destacar, que la propuesta de diferenciación está referida al uso de insumos de la zona andina y del presente medio en particular, como es la carne de chancho, el uso de harinas de quinua y kiwicha, la muña, huacatay y el rocoto para los aderezos y cremas; bebidas de frutas y hierbas de la región.

\subsubsection{Tipo de servicio del proyecto.}

El proyecto está orientado a un tipo de servicio de comida rápida, la preparación o ensamblado del producto se elabora de forma rápida y al momento, y se entrega directamente al cliente quien lo recibe desde un mostrador. La adquisición del servicio se da en base a un sistema de prepago, es decir el cliente debe pagar primero para poder adquirir el servicio.

\subsubsection{Tipo de producto del proyecto.}

El producto que se ofrece en el presente proyecto son hamburguesas y pollos en variedades donde se incorporen ingredientes oriundos de la región conforme la Tabla 18, donde se aprecian las líneas y tamaños de producto del proyecto. 
Tabla 18

Líneas y Tamaños del producto

\begin{tabular}{|c|c|}
\hline Líneas & Tamaños \\
\hline $\begin{array}{c}\checkmark \quad \text { Línea de hamburguesas. } \\
\checkmark \quad \text { Línea de pollos } \\
\checkmark \quad \text { Línea de ensaladas } \\
\checkmark \quad \text { Línea de bebidas } \\
\checkmark \quad \text { Línea de combos } \\
\checkmark \quad \text { Línea de postres } \\
\checkmark \quad \text { Línea de adicionales o complementos }\end{array}$ & $\begin{array}{c}\checkmark \text { Tamaño de porciones de hamburguesas: } \\
\text { junior, mediano y regular } \\
\checkmark \quad \text { Tamaño de porciones de pollo: regular (1/4 de } \\
\text { pollo), junior (1/8 de pollo), porción de alitas. } \\
\checkmark \quad \text { Tamaño de porciones ensaladas: regular o } \\
\text { personal } \\
\checkmark \quad \text { Tamaño de bebidas: junior, mediana y grande. } \\
\checkmark \text { Tamaño de combos: personales y familiares. }\end{array}$ \\
\hline
\end{tabular}

Nota. Fuente: Elaboración propia.

\subsection{Selección del segmento de mercado.}

Los consumidores pertenecen a distintos segmentos de mercados. Segmentar el mercado permite a una organización considerar las acciones de la competencia así como también la fuerza de los productos existentes de la empresa con respecto a cada grupo definido de consumidores. “Al segmentar los productos de la empresa y de la competencia se puede evaluar las oportunidades de los productos que abordan mejor las debilidades de su línea de productos así como cuales explotan mejor las debilidades de la competencia.” (Ulrich \& Eppinger, 2014).

A continuación, se detallan ciertas características de la industria y del proyecto como orientación para definir las bases de segmentación del mercado, conforme la Tabla 19. 
Tabla 19

Características de la industria y del proyecto

Características Detalle

La industria de fast food es altamente atractiva por

Atractividad de la industria consumidores que buscan optimizar el tiempo por motivos de estudio, trabajo, ocio. Etc.

Las franquicias de fast food están orientadas al público juvenil y familiar. No existen en el mercado empresas de

Análisis de la competencia

fast food estilo americano que incorporen insumos originarios de la región.

El producto que se ha considerado para el proyecto

Percepción de valor representa una alta percepción del valor por ser productos que se producen en la región.

Las zonas comerciales de Cusco están localizadas en la Análisis de zonas comerciales Av. La Cultura.

Nota. Fuente: Elaboración propia.

Después del análisis anterior, que sirve como guía para definir las bases de segmentación, se procede a determinar desarrollar la Tabla 20. 
Tabla 20

Características socio-demográficas del mercado objetivo

\begin{tabular}{lc}
\hline \multicolumn{1}{c}{ Tipo de Características } & Detalle \\
\hline Geográfica: & Urbana \\
Tipo de población & Cusco \\
Región & Cusco \\
Departamento & Céntricos y aledaños a la Av. La Cultura \\
Distritos & . \\
\hline
\end{tabular}

Demográfica:

Ingresos

Edad

Género

Nivel socioeconómico

Ocupación

De S/ 850.00 soles a más

De 18 a 45 años

Femenino y masculino

A, B y C

Trabajadores dependientes o independientes, estudiantes.

\section{Psicográfica:}

Estilo de vida

Trabajo, estudio, poca disponibilidad de tiempo

Conductual:

Beneficio deseado

Optimización del tiempo, diversidad de sabores

Nota. Fuente: Elaboración propia.

En base al análisis anterior se pudo definir las características socio-demográficas del mercado al que se orientará el plan de negocio, es decir se realizó la segmentación en base a zona geográfica, características de la población, estilos de vida y valores. (Ciribeli \& Miquelito, 2014). Se determinó al segmento que está representado por la población urbana de los distritos céntricos y aledaños a la Av. La Cultura en la provincia de Cusco de los niveles socioeconómicos A, B y C entre las edades de 18 a 45 años, quienes son estudiantes y trabajadores. 
A continuación, se presenta la información estadística en base a la segmentación geográfica y psicográfica en estudio. En primer lugar, se determinó los distritos céntricos y aledaños que comprenden la Av. La Cultura según la Figura 13, posteriormente se realizó la proyección de la población al 2017 conforme Tabla 21, además de la determinación del porcentaje de población según nivel socioeconómico de acuerdo a la Figura 14 y su estimación porcentual de grupos etarios según la Tabla 22.

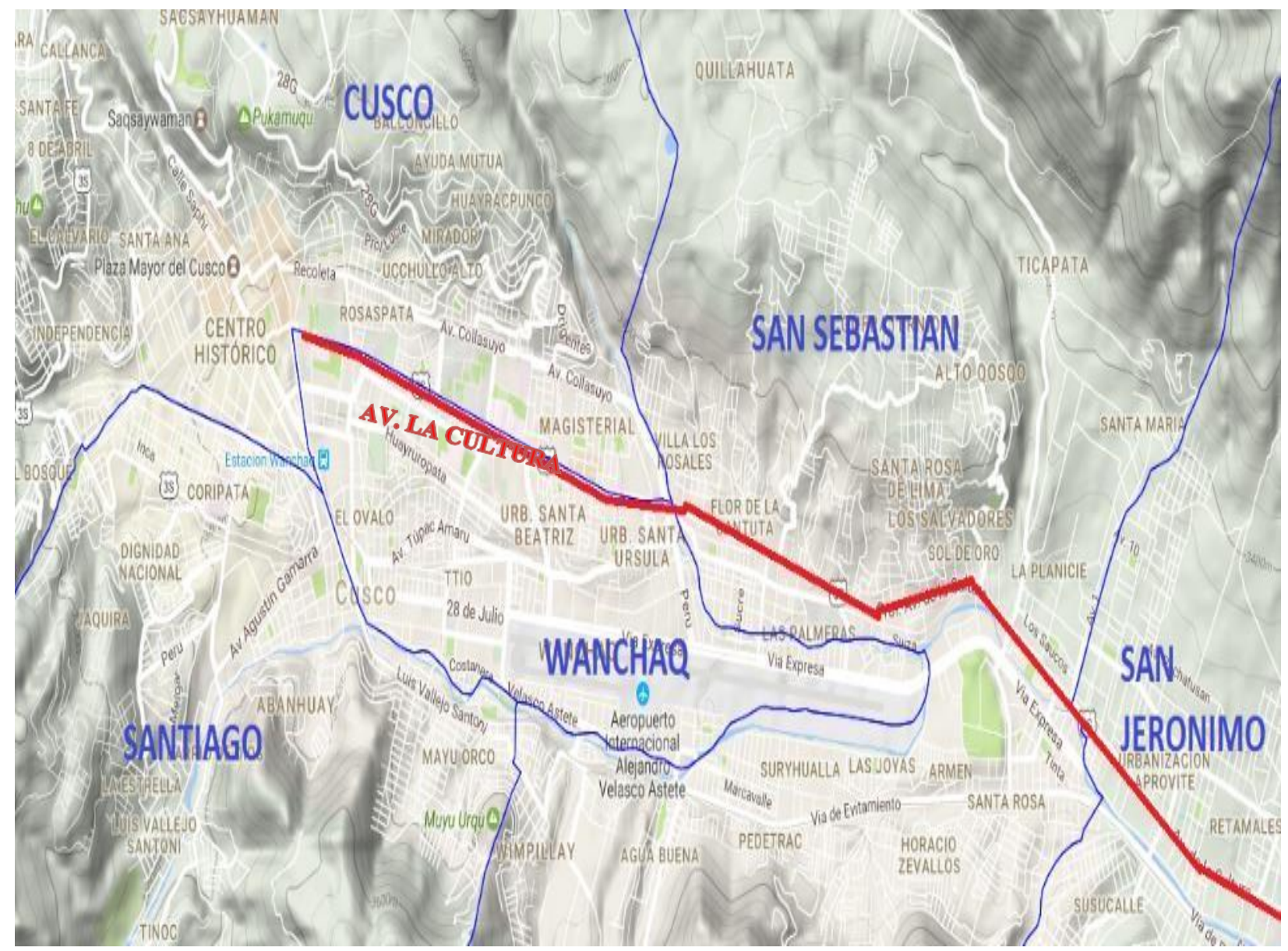

Figura 13. Mapa, Ciudad de Cusco-Distritos céntricos y aledaños a la Av. La Cultura. Adaptado de Geominsa. Recuperado de http://www.geominsa.minsa.gob.pe/geominsa/ 
Tabla 21

Segmentación geográfica: Población proyectada al 2017

\begin{tabular}{lcccccc}
\hline & 2013 & 2014 & 2015 & 2016 & $\begin{array}{c}2017 \\
\text { ( proyección) }\end{array}$ & Proporción \\
\hline Cusco & 118231 & 118322 & 118316 & 119005 & 119580 & $25.9 \%$ \\
San Jerónimo & 43406 & 45236 & 47101 & 47374 & 54072 & $11.7 \%$ \\
San Sebastián & 105388 & 110298 & 115305 & 115974 & 133927 & $29.0 \%$ \\
Santiago & 90319 & 90274 & 90154 & 90677 & 90702 & $19.6 \%$ \\
Wanchaq & 63858 & 63844 & 63778 & 64148 & 64230 & $13.9 \%$ \\
& & & & & & \\
\end{tabular}

Nota. Diresa Cusco. Adaptado de Estadísticas de población. Recuperado de http://www.diresacusco.gob.pe/estaditica/modulo7.htm

\section{Distribución de la población urbana por NSE, según departamento, 2015 (participación porcentual en cada departamento)}

\begin{tabular}{|l|c|c|c|c|}
\hline & AB & C & D & E \\
\hline Apurímac & $9.7 \%$ & $17.8 \%$ & $26.4 \%$ & $46.1 \%$ \\
\hline Arequipa & $20.9 \%$ & $35.3 \%$ & $32.6 \%$ & $11.1 \%$ \\
\hline Cusco & $17.1 \%$ & $18.9 \%$ & $32.5 \%$ & $31.6 \%$ \\
\hline
\end{tabular}

Figura 14. Segmentación demográfica - población urbana por NSE de la ciudad de Cusco. Recuperado de http://mercadosyregiones.com/niveles-socioeconomicos-yvoto-de-izquierda-en-el-sur-peruano/ 
Tabla 22

Segmentación demográfica: estimación porcentual de edades por grupo etario

\begin{tabular}{lcc}
\hline & Grupo de edades & Población \\
\hline $18-24$ & 156450 & $11.75 \%$ \\
$25-34$ & 226123 & $16.98 \%$ \\
$35-45$ & 191001 & $14.34 \%$ \\
\hline Población total departamento de Cusco & 1331758 & $100 \%$ \\
\hline
\end{tabular}

Nota. Perú: Estimaciones y proyecciones de población departamental, por año calendario y edades simples 1995 2025. INEI, 2010. Adaptado de http://proyectos.inei.gob.pe/web/biblioineipub/bancopub/Est/Lib1039/libro.pdf

\subsection{Investigación cualitativa.}

La investigación cualitativa es aquella que estudia el comportamiento hábitos humanos, permite rescatar de los consumidores su experiencia, sentir y opinión con respecto a lo que se investiga, conocer sobre sus hábitos, costumbres, cultura, maneras de pensar y proceder. La investigación cualitativa es considerada como precursora de la investigación cuantitativa ya que a menudo se utiliza para generar posibles pistas e ideas que se pueden utilizar para formular una hipótesis verificable y realista. (Shuttleworth, 2017).

\subsubsection{Proceso de muestreo.}

El muestreo es el procedimiento mediante el cual se selecciona una muestra representativa de la población objeto de estudio; para el presente caso se llevaron a cabo focus groups y entrevistas a profundidad. 


\subsubsection{Focus groups.}

Técnica que permite evaluar la interacción de un grupo de personas y promover la discusión y diálogo sobre temas personales, profundizando en el comportamiento de los individuos en base a un contexto cultural establecido del cual se pueda extraer información de relevancia para cualquier tipo de estudio. (Buss Thofehrn, y otros, 2013)

A continuación se detalla la ficha técnica del estudio cualitativo de focus group llevado a cabo para el presente proyecto, conforme la Tabla 23. 
Tabla 23

Ficha técnica de estudio cualitativo de focus group

\begin{tabular}{|c|c|}
\hline Características & Detalle \\
\hline Sesiones & Se realizaron 4 focus group con diferentes grupos de edad y NSE \\
\hline Localización & Instalaciones del campus de la Universidad San Ignacio de Loyola - Sede Cusco \\
\hline Objetivo General & $\begin{array}{c}\text { Conocer y analizar a la mayor proporción posible representativa del segmento en } \\
\text { estudio. }\end{array}$ \\
\hline $\begin{array}{l}\text { Objetivos } \\
\text { Específicos }\end{array}$ & $\begin{array}{cc}\checkmark & \text { Determinar el nivel de posicionamiento de los competidores. } \\
\checkmark & \text { Conocer las expectativas en cuanto a servicio y características del producto. } \\
\checkmark & \text { Conocer los factores determinantes para selección de un fast food } \\
\checkmark & \text { Identificar los horarios con mayor afluencia en un fast food } \\
& \checkmark \text { Determinar el nivel de aceptación del proyecto } \\
\checkmark & \text { Identificar el mejor lugar para la localización de un fast Food } \\
& \checkmark \quad \text { Conocer los gustos y preferencias de los consumidores. }\end{array}$ \\
\hline
\end{tabular}

\begin{tabular}{lcc}
\hline Perfil del & $\checkmark \quad$ Sexo: Hombres y mujeres. \\
participante & $\checkmark$ & Rango de edad entre 18 años a 45 años. \\
& $\checkmark \quad$ Nivel socioeconómico: A, B y C. \\
\hline
\end{tabular}

Se desarrollaron todos los grupos de estudio posible para la ejecución del focus group, y de ellos se seleccionó aleatoriamente a 4 grupos principales como representación de

la población cuya capacidad de gasto y perfil social permita mayor claridad al momento de la obtención de la información, de manera que dichos rangos no sean

Reclutamiento y asignación de grupos muy amplios para evitar incompatibilidades entre los entrevistados. Para la ejecución del estudio cualitativo, se convocaron a personas acorde al perfil; entre estudiante, trabajadores y padres de familia,

$\checkmark$ Primer grupo: NSE C de 18 a 29 años.

$\checkmark$ Segundo grupo: NSE B de 20 a 35 años.

$\checkmark$ Tercer grupo: NSE A 30 a 45 años.

$\checkmark \quad$ Cuarto grupo: NSE B de 30 a 45 años.

\begin{tabular}{|c|c|}
\hline Duración & 1 hora y 20 minutos en promedio por focus group \\
\hline Equipo de Trabajo & Un moderador por grupo \\
\hline Contenido & $\begin{array}{c}\checkmark \quad \text { Hábitos alimenticios en cuanto a almuerzo y cena de las personas. } \\
\checkmark \text { Concepto y percepción acerca de los fast food. } \\
\checkmark \text { Ventajas y desventajas que consideran importantes al momento de } \\
\text { consumir los productos de fast food. } \\
\checkmark \quad \text { Factores determinantes en la hora de elegir un fast food y el motivo. } \\
\checkmark \quad \text { Influencia de marcas de fast food en el consumidor. } \\
\checkmark \text { Tipos de fast food que eligen } \\
\checkmark \quad \text { Fast food de mayor concurrencia en Cusco y motivos. } \\
\checkmark \quad \text { Frecuencia de asistencia a un fast food. } \\
\checkmark \quad \text { Conocer la valoración de la nueva propuesta. } \\
\checkmark \quad \text { Preferencias de platos al momento de comprar. } \\
\checkmark \quad \text { Ticket promedio de gasto por persona en un fast food. } \\
\checkmark \text { Medios publicitarios para hacer conocida la marca. } \\
\checkmark \quad \text { Opiniones de localización. }\end{array}$ \\
\hline
\end{tabular}

Nota. Fuente: Elaboración propia. 


\subsubsection{Entrevistas a profundidad.}

Técnica que se maneja a través de dos roles en donde el encuestador elabora preguntas puntuales para obtener información sobre un tema particular de investigación y por su parte el entrevistado brinda información directa y complementaria a las preguntas en cuestión compartiendo información tanto profesional como personal. (Universidad de Alicante, n.d)

A continuación, se presenta la ficha técnica del estudio en referencia a la Entrevista a profundidad, conforme la Tabla 24.

Tabla 24

Ficha técnica de estudio cualitativo Entrevista a profundidad

\begin{tabular}{|c|c|}
\hline Características & Detalle \\
\hline Sesiones & Se realizaron 4 entrevistas a profundidad \\
\hline Localización & En las oficinas de los entrevistados \\
\hline $\begin{array}{l}\text { Perfil del } \\
\text { participante }\end{array}$ & $\begin{array}{l}\text { Persona con más de siete años de experiencia en la administración de } \\
\text { fast food (empresarios, docentes, gerentes, expertos especializados etc., } \\
\text { o que tengan manejo de temas asociados de bar y comedor). }\end{array}$ \\
\hline Reclutamiento & $\begin{array}{l}\text { Se seleccionaron gerentes y/o dueños de establecimientos tipo fast food } \\
\text { que operan en la ciudad del Cusco, principalmente competidores } \\
\text { potenciales del proyecto; a criterio del investigador. }\end{array}$ \\
\hline Duración & Media hora en promedio \\
\hline Equipo de Trabajo & Un entrevistador \\
\hline Objetivo General & Conocer a los potenciales competidores del plan de negocio. \\
\hline $\begin{array}{l}\text { Objetivos } \\
\text { específicos }\end{array}$ & $\begin{array}{c}\checkmark \text { Conocer en líneas generales la percepción del experto sobre la } \\
\text { presente investigación. } \\
\checkmark \text { Conocer la percepción real del servicio de los fast food en la } \\
\text { ciudad de Cusco. } \\
\checkmark \text { Conocer las tendencias tanto de la oferta y demanda del servicio } \\
\text { de fast food. } \\
\checkmark \text { Conocer a las competencias y/o propuestas similares. }\end{array}$ \\
\hline
\end{tabular}

Nota. Fuente: Elaboración propia. 


\subsubsection{Diseño del instrumento.}

Para llevar a cabo la investigación cualitativa se diseñó la guía de pautas para el focus group (Véase, Anexo $\mathrm{N}^{\circ} 1$ ) el cual conto con un moderador quien incentivó el flujo de la conversación en relación con los objetivos de investigación. Por otro lado, se desarrolló una guía de preguntas para las entrevistas a profundidad (Véase, Anexo $\mathrm{N}^{\circ} 2$ ) , que se aplicaron a expertos en el rubro de fast food, no se realizó degustación del producto puesto que primero se espera obtener información sobre preferencias del consumidor en cuanto a insumos regionales que serían preferidos para ser incorporados en las recetas.

\subsubsection{Guía de pautas para focus group.}

- Frase de presentación

- Diseño de fase de calentamiento

- Listado de preguntas

- Preguntas sobre percepción, preferencias y hábitos de consumo

- Preguntas sobre expectativas del consumidor en relación al servicio y al producto de un fast food

- Preguntas sobre la propuesta de valor del proyecto, nivel de aceptación

- Preguntas sobre características y cualidades que espera encontrar en el nuevo plan de negocio de fast food.

- Frase de cierre

\subsubsection{Guía de preguntas para entrevista a profundidad.}

Para elaborar la guía de preguntas se tomaron en cuenta los siguientes aspectos: 
- Frases de presentación

- Permiso para grabar

- Presentación personal y laboral del entrevistado

- Preguntas sobre percepción del entorno y visión a futuro del sector

- Preguntas sobre características y cualidades de un fast food

- $\quad$ Frase de cierre

\subsubsection{Análisis y procesamiento de datos.}

“Los datos son símbolos que describen hechos, situaciones, valores o condiciones. El análisis y procesamiento de datos en una investigación es la organización de los elementos e información obtenida durante el trabajo inquisitivo.” (Humpire, 2013). A continuación, se detalla el análisis llevado a cabo tras la ejecución de los focus group, conforme Tablas del 25 a 29. De igual forma se realizó el análisis de las entrevistas a expertos según se detalla en las tablas del 30 al 32.

Tabla 25 
Análisis de focus group preg.1 a preg. 7

Nota. Fuente: Elaboración propia.

\begin{tabular}{|c|c|}
\hline Preguntas & Resumen de análisis \\
\hline ¿Qué es para ustedes un fast food? & $\begin{array}{l}\text { Todos los participantes se refieren a fast food } \\
\text { como un lugar donde sirven comida rápida, } \\
\text { comida al instante, algunos participantes lo } \\
\text { relacionan con la grasa. }\end{array}$ \\
\hline $\begin{array}{l}\text { ¿Qué palabras se les viene a la mente cuando } \\
\text { escuchan fast food? }\end{array}$ & $\begin{array}{l}\text { La mayoría coincide con comida rápida, } \\
\text { hamburguesas, papas fritas, grasa y comida } \\
\text { chatarra. }\end{array}$ \\
\hline ¿Qué encuentran de positivo en un fast food? & $\begin{array}{c}\text { Coinciden con la rapidez y practicidad al } \\
\text { momento de satisfacer una necesidad de } \\
\text { alimentación. }\end{array}$ \\
\hline ¿Qué de negativo encuentran en un fast food? & $\begin{array}{l}\text { Todos los participantes señalan que por lo } \\
\text { general la comida rápida está relacionada a la } \\
\text { comida chatarra por su contenido en grasas y } \\
\text { puede ser perjudicial para la salud. }\end{array}$ \\
\hline $\begin{array}{l}\text { ¿Cuantas veces al mes, que días de la semana } \\
\text { y en que horarios concurren a un fast food } \\
\text { generalmente? }\end{array}$ & $\begin{array}{l}\text { Todos los participantes coinciden con los } \\
\text { fines de semana y horarios de la tarde y noche } \\
\text { en un rango de horario de } 4 \text { a } 8 \text {. }\end{array}$ \\
\hline $\begin{array}{l}\text { ¿Con quienes suelen acudir a estos centros de } \\
\text { comida rápida, solos, con la familia, con } \\
\text { amigos? }\end{array}$ & $\begin{array}{l}\text { La mayoría de los participantes indica que } \\
\text { más asisten con amistades y familias. }\end{array}$ \\
\hline $\begin{array}{l}\text { ¿Qué factores influyen para la elección de un } \\
\text { fast food determinado? }\end{array}$ & $\begin{array}{c}\text { En su mayoría para los participantes el factor } \\
\text { más importante a la hora de elegir un fast food } \\
\text { es la atención brindada y la calidad del } \\
\text { producto. }\end{array}$ \\
\hline
\end{tabular}

Tabla 26

Análisis de Focus Group preg.8 a preg. 17

Tabla 27

Análisis de focus group preg.18 a preg. 23

Nota. Fuente: Elaboración propia. 
Nota. Fuente: Elaboración propia.

\begin{tabular}{|c|c|}
\hline $\operatorname{Pr}^{P} e^{r_{g}} e_{u} g_{n} u_{t} n_{a} s^{t} a s$ & $\begin{array}{l}\text { Resumen gel anall } \mathrm{S} \\
\text { Resumen def analisis } \\
\end{array}$ \\
\hline $\begin{array}{l}\text { ¿Cuál es su fast food favorito? ¿Por qué? } \\
\text { ¿Estarían dispuestos a pagar más por }\end{array}$ & $\begin{array}{l}\text { En su mayoría señal ron que qued n con el } \\
\text { Indican que, s1 estarian dispuestos a pagar mâs, } \\
\text { KFCpgr la calidad de su prodycto. } \\
\text { nerd denendiendo del notoducto. }\end{array}$ \\
\hline $\begin{array}{l}\text { dquú le gusta má de su fast food } \\
\text { gavouririr productos frescos y naturales de } \\
\text { favogiton con valor nutritivo en un fast }\end{array}$ & 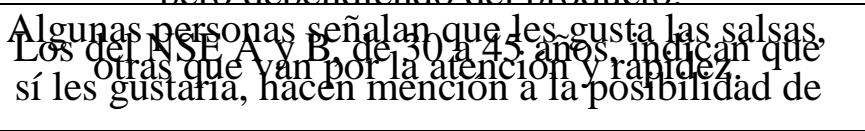 \\
\hline food? ¿Qué alimentos serian? & 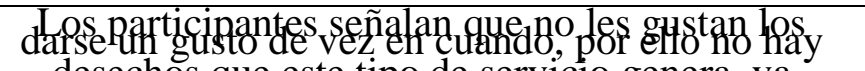 \\
\hline ¿Que no le gusta de su fast food favorito? & 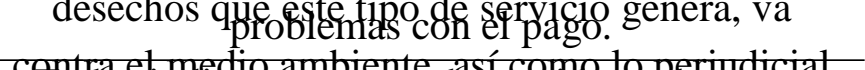 \\
\hline ¿Considerarían buena la idea el de & 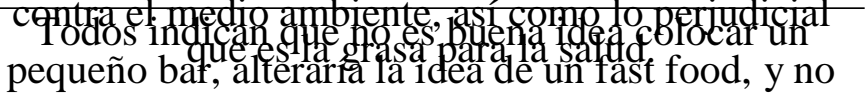 \\
\hline $\begin{array}{l}\text { colocar un pequeño bar dentro de un fast } \\
\text { fuádles su platillo preferido }\end{array}$ & 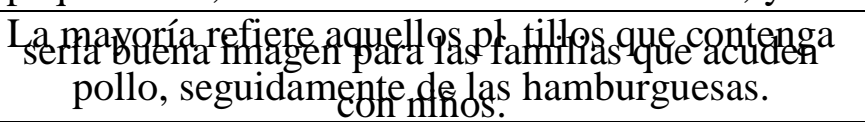 \\
\hline
\end{tabular}

¿Qué tiempo consideran ustedes que es prudente que su orden este lista?

¿Qué tipo de bebidas alcohólicas y no

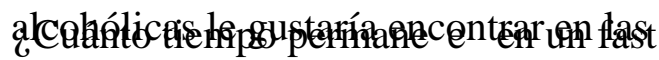
Prgaiones que ofrece un fast food?

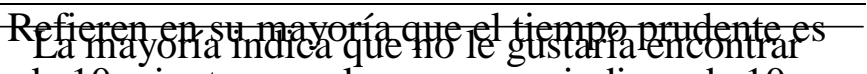
deblominutos en al gun s casos indican de 10 a

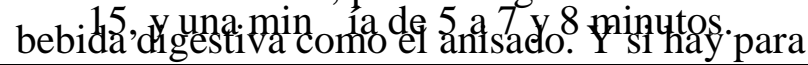

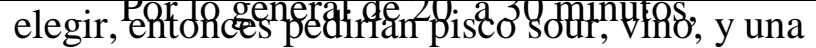
Del grupo del NSE

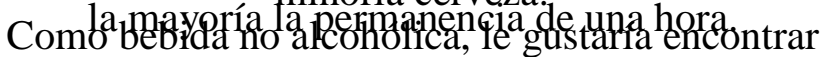

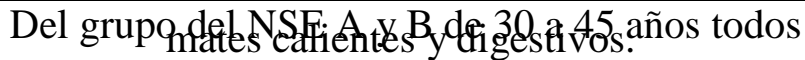

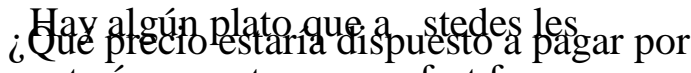
oustaría encontrar en un fast foo dy quue 円izg̨̣no lo tenga?

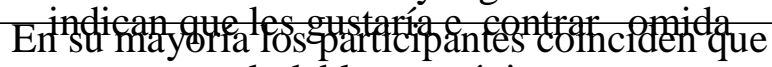
estarían dispuécsudab a le pagargánica soles, excepto el

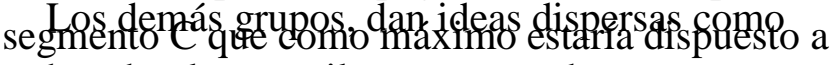
chancho, lomo pmilanesea apanados, postres en ¿Qué es calidad para ustedes en un fast Consideran que en he callfadde servicio está: Tafood? La maypría indiqa gue ne les opstaría fonsumir ¿Les gustaría consumir algún tipo de

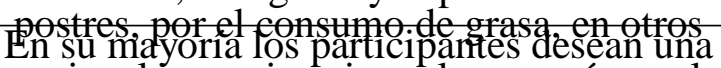
pastre después de co meren el fast fogd? de un fast food, en cuanto a decoración y inusé tipo de carnes le gustaría encontrar en un fast food? amorartosilo que si fugieren la mayoría son las crema, en cuantobid a digestivass musca de preferencia que Indican la mayoríague lefogustaría en ontrar carne

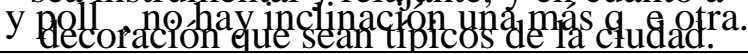
¿Les gustaría encontrar en las opciones de productos de fast food comida con valor nutritivo? Si fuese positiva la respuesta ¿Podrían mencionar algunas?

Todos refieren que si les gustaría encontrar comida con valor nutritivo, proponen, la kiwicha, maca, quinua, ensaladas, verduras, y que sean para escoger al gusto del cliente. 
Tabla 28

Análisis de focus group - propuesta valor preg.1 a preg. 10

\begin{tabular}{|c|c|}
\hline Preguntas & Resumen del análisis \\
\hline $\begin{array}{l}\text { ¿Qué opinan, piensan de este concepto de } \\
\text { fast food? }\end{array}$ & $\begin{array}{c}\text { Casi para todos los participantes les parece idea } \\
\text { innovadora por su presentación de nuevos } \\
\text { productos andinos y la variedad de ensaladas. } \\
\text { Sugieren que la papa tenga diferentes } \\
\text { presentaciones. }\end{array}$ \\
\hline ¿Han escuchado algún concepto como este? & $\begin{array}{l}\text { Todos los participantes dieron un "no" como } \\
\text { respuesta. }\end{array}$ \\
\hline $\begin{array}{l}\text { ¿Es bueno, malo? ¿Qué les gusta, que no les } \\
\text { gusta? ¿Por qué? }\end{array}$ & $\begin{array}{c}\text { A todos los participantes les parece bueno porque } \\
\text { se ofrece productos andinos y frescos. }\end{array}$ \\
\hline $\begin{array}{l}\text { ¿Asistirían o no al tipo de negocio que se les } \\
\text { está proponiendo? }\end{array}$ & $\begin{array}{l}\text { Todos los participantes dieron un "si” como } \\
\text { respuesta. }\end{array}$ \\
\hline ¿Con que frecuencia asistirían? & $\begin{array}{c}\text { En su mayoría asistirían } 2 \text { a } 3 \text { veces al mes y } \\
\text { mucho va a depender de la calidad del producto } \\
\text { para que se vuelva un cliente constante. }\end{array}$ \\
\hline $\begin{array}{l}\text { ¿En qué horario asistirían y en qué días de la } \\
\text { semana? }\end{array}$ & $\begin{array}{c}\text { La mayoría de los participantes asistirían a la hora } \\
\text { del almuerzo o por las noches, y de preferencia los } \\
\text { fines de semana. }\end{array}$ \\
\hline $\begin{array}{l}\text { ¿Qué productos no deberían faltar en el fast } \\
\text { food? }\end{array}$ & $\begin{array}{l}\text { En su mayoría los participantes piden que no falte } \\
\text { la variedad de ensaladas, y los insumos básicos } \\
\text { como el pollo y carnes. }\end{array}$ \\
\hline $\begin{array}{l}\text { ¿Qué le parece la idea de incorporar el cuy a } \\
\text { las opciones del fast food? }\end{array}$ & $\begin{array}{l}\text { La mayoría de los participantes coinciden que } \\
\text { incorporar el cuy a la carta es una buena idea pero } \\
\text { al ser un producto caro, no se animarían a } \\
\text { consumirla con mucha frecuencia. Y además que } \\
\text { sería arriesgado para el empresario. }\end{array}$ \\
\hline $\begin{array}{l}\text { ¿Creen que si el cuy es aceptado como una } \\
\text { opción a elegir, cuál debería ser el } \\
\text { acompañamiento ideal? y ¿Qué tipo de } \\
\text { verduras recomendarían? }\end{array}$ & $\begin{array}{l}\text { En su mayoría, los participantes coinciden que el } \\
\text { mejor acompañamiento para el cuy sería la papa en } \\
\text { diferentes presentaciones como la papa al horno, } \\
\text { papas andinas o papa sancochada acompañada con } \\
\text { refrescos como chicha morada o limonada. Las } \\
\text { verduras que recomendaron para acompañar el cuy } \\
\text { fueron la lechuga, el tomate y la cebolla. }\end{array}$ \\
\hline $\begin{array}{l}\text { Sobre las salsas, ¿Qué salsas son de su } \\
\text { preferencia cuando asiste a un fast food? }\end{array}$ & $\begin{array}{l}\text { Las salsas que tendrían mayor acogida frente a } \\
\text { la propuesta coinciden que sería: las salsas típicas } \\
\text { como la mayonesa, kétchup, mostaza, ají, ocopa y } \\
\text { la uchucuta. }\end{array}$ \\
\hline
\end{tabular}

Nota. Fuente: Elaboración propia. 
Tabla 29

Análisis de focus group - propuesta valor preg.11 a preg. 18

\begin{tabular}{|c|c|}
\hline Preguntas & Resumen del análisis \\
\hline $\begin{array}{l}\text { ¿Qué tipo de acompañamiento creen que deberían } \\
\text { considerar en un fast food? }\end{array}$ & $\begin{array}{l}\text { Las sugerencias en su mayoría fueron respecto a las } \\
\text { bebidas, se podría ofrecer limonada, chicha morada, } \\
\text { gaseosa y también bebidas típicas de Cusco como los } \\
\text { son la chicha de jora y la frutillada. }\end{array}$ \\
\hline ¿Qué bebidas le gustaría encontrar en la carta? & $\begin{array}{l}\text { Los participantes mostraron como preferencia los } \\
\text { refrescos, las gaseosas y de manera enfática las } \\
\text { bebidas calientes que ningún fast food lo ofrece a } \\
\text { pesar de estar situados en una región donde hace } \\
\text { mucho frío. }\end{array}$ \\
\hline $\begin{array}{l}\text { ¿Estarían dispuestos a consumir bebidas alcohólicas } \\
\text { en el fast food? Si fuese positiva su respuesta } \\
\text { ¿Cuáles? }\end{array}$ & $\begin{array}{l}\text { Existen dos grupos que coinciden en una respuesta } \\
\text { negativa frente al consumo de bebidas alcohólicas en } \\
\text { un fast food y otros dos grupos que sí consumirían y } \\
\text { estas bebidas serían aquellas elaboradas a base de } \\
\text { pisco, cerveza y al anisado pero que debería ser } \\
\text { servido en pequeñas cantidades para que los clientes } \\
\text { no permanezcan mucho tiempo en el local y se pierda } \\
\text { la idea de fast food, es decir, de comer rápido y } \\
\text { retirarse. }\end{array}$ \\
\hline
\end{tabular}

En su mayoría coinciden que el local debe estar

¿Dónde sería la ubicación óptima? ubicado en el centro de la ciudad o en un lugar que sea de mucho tránsito como la avenida La Cultura o por la plaza de armas.

¿Cuánto estaría dispuesto a gastar por persona en este servicio de fast food?

¿Cuál de estos nombres le parece la mejor opción para el fast food? Rucutu (Rocoto), Hayaq (Picante), Quncha (Fogón), otros
El precio promedio que está dispuestos a gastar los participantes por persona es de S/.17.50 soles.

Casi todos los participantes no están de acuerdo con ninguno de los nombres propuestos y los pocos que estuvieron de acuerdo escogieron el nombre de Hayaq.

La mayoría de los participantes comparten la idea que la mejor manera de informarse es por medio de internet, de formar particular mediante las redes sociales como es el Facebook y el segundo lugar, televisión, radio y los volantes.

Las recomendaciones compartidas fueron el de contar con personal capacitado para el rubro de fast food, tener especial cuidado con el cuidado del medio ambientes, es decir, tomar en cuenta el tema del reciclaje y por último que no se pierda la identidad de Cusco y que se utilicen productos propios de la región.

Nota. Fuente: Elaboración propia. 
Tabla 30

Análisis de entrevistas a profundidad preg.1 al 6

\begin{tabular}{|c|c|}
\hline Preguntas & Conclusión del análisis \\
\hline $\begin{array}{l}\text { ¿Por qué nuestra gastronomía en general } \\
\text { tiene buena percepción? }\end{array}$ & $\begin{array}{c}\text { Todos los expertos coinciden que la } \\
\text { gastronomía es una buena oportunidad para } \\
\text { generar negocios sostenibles y aún hay mucho } \\
\text { por explotar y masificar respondiendo a las } \\
\text { necesidades y exigencias de los clientes. }\end{array}$ \\
\hline $\begin{array}{l}\text { ¿Por qué la imagen de los fast food en } \\
\text { Cusco esta desarrollada? }\end{array}$ & $\begin{array}{l}\text { Son las grandes empresas de fast food las que } \\
\text { se han desarrollado en todo su potencial, todas } \\
\text { las marcas más importantes están en Cusco, } \\
\text { sin embargo hay pequeños negocios locales } \\
\text { los cuales podrían desarrollarse. }\end{array}$ \\
\hline $\begin{array}{l}\text { ¿Por qué cree que en Cusco los fast food no } \\
\text { han seguido la dinámica y tasa de } \\
\text { crecimiento similar a los de Lima? }\end{array}$ & $\begin{array}{l}\text { Los expertos coinciden que los fast food están } \\
\text { relacionados al crecimiento de los grandes } \\
\text { centros comerciales y en Cusco aún no se han } \\
\text { desarrollado, sólo existe un centro comercial. }\end{array}$ \\
\hline $\begin{array}{l}\text { ¿Qué perspectiva prevé para los fast food en } \\
\text { Cusco que no son parte de cadenas de fast } \\
\text { food internacionales? }\end{array}$ & $\begin{array}{l}\text { Las perspectivas para los fast food que no } \\
\text { pertenecen a las grandes cadenas podría ser } \\
\text { muy bueno en la medida que se ofrezca un } \\
\text { valor agregado, algo que los diferencie de las } \\
\text { demás marcas que ya existen. }\end{array}$ \\
\hline $\begin{array}{l}\text { ¿Por qué realizan solo algunos tipos de } \\
\text { promociones y cuales son? }\end{array}$ & $\begin{array}{c}\text { Los expertos de cadenas internacionales } \\
\text { señalan que las marcas como KFC y } \\
\text { McDonald's ya están posicionadas por la cual } \\
\text { no se preocupan en hacer publicidad u ofertas } \\
\text { y descuentos sino que más bien en potenciar } \\
\text { la marca, mientras que los fast food locales } \\
\text { que son negocios en desarrollo realizan } \\
\text { campañas de promoción, publicidad y ofertas } \\
\text { para poder obtener más clientela y } \\
\text { fidelizarlos. }\end{array}$ \\
\hline
\end{tabular}

Todos mencionan que las redes sociales, en

¿Por qué medios publicitarios se llega más al público objetivo? especial el Facebook, es el que tiene mayor aceptación, hoy en día todos tienen el celular

a la mano y con un clic todos se enteran rápido de todo. Seguido de la televisión y la radio respectivamente. 
Tabla 31

Análisis de entrevistas a profundidad preg.7 al 14

\begin{tabular}{lc}
\hline \multicolumn{1}{c}{ Preguntas } & Conclusión de análisis \\
\hline $\begin{array}{l}\text { ¿Cuáles son los principales fast food en el } \\
\text { Cusco? ¿Porque? }\end{array}$ & $\begin{array}{c}\text { El líder esta entre el KFC, McDonald's, Bembos, y } \\
\text { Burger King sin mayoría alguna; las mismas que } \\
\text { estarían liderando por su ubicación en la plaza y en el } \\
\text { real plaza. }\end{array}$ \\
\hline $\begin{array}{c}\text { ¿Cuál es el perfil del consumidor de este } \\
\text { producto? (rango de edad) }\end{array}$ & No hay uniformidad en las edades, como aproximado \\
& están entre: \\
15 a 40 años & 13 a 25 años \\
& De 10 años en adelante, \\
& 18 a 25 años (para Rupha’s Diner).
\end{tabular}

¿Por qué el consumidor consume alimentos bajo este formato en Cusco?

¿Por qué cree que los Fast Food en Cusco pueden mejorar su posicionamiento?

¿Considera que existe nichos de mercado para los fast food que falta explotar en la ciudad del Cusco?, ¿Por qué?
Calidad de servicio, amabilidad, cordialidad. Producto, rapidez y bajos costos.

Indican que hay muchas posibilidades, porque se abrirá otro mall, por el crecimiento de la población, también por el turismo, por las oportunidades comerciales.
¿Por qué los empresarios del rubro del servicio en especial de fast food tienen que adoptar diferentes papeles en el mercado?
Los expertos consideran que por el momento no existen nichos de mercado por explotar, y que más adelante podrían abrirse nichos de mercado si es que se llegaran a aperturar los grandes centros comerciales.

El papel que tienen que adoptar los empresarios es tener muy en cuenta la competencia, calidad, seguridad, publicidad y poseer un personal calificado para brindar este tipo de servicio.
¿Considera que existen profesionales calificados en Cusco para trabajar en el servicio de fast food? ¿Por qué?
Tres expertos aseguran que si existe profesionales calificados en Cusco y que sólo hay que capacitarlos, y uno de ellos indica que no, que aún falta conocer lo que verdaderamente es un fast food.
¿Cuáles son los factores más importantes que considera un consumidor al momento de elegir el fast food al cual asistirá y por qué?
Los expertos dicen que los principales factores son; que sea limpio, barato, y sobre todo que la atención sea rápida.

Nota. Fuente: Elaboración propia. 
Tabla 32

Análisis de Entrevistas a profundidad preg.15 al 21

\begin{tabular}{lc}
\hline \multicolumn{1}{c}{ Preguntas } & Conclusión de análisis \\
\hline $\begin{array}{l}\text { ¿Por qué el ambiente donde se brinda el } \\
\text { servicio de fast food es una parte } \\
\text { fundamental para llamar la atención del } \\
\text { cliente? }\end{array}$ & $\begin{array}{c}\text { Todos los expertos consideran que el ambiente } \\
\text { donde se brinda el servicio "si" es una parte } \\
\text { fundamental, desde el tipo de colores que se utiliza } \\
\text { para la ambientación, hasta el tipo de música que se } \\
\text { pone. }\end{array}$ \\
\hline $\begin{array}{l}\text { ¿Cuál es el plato de comida que suelen } \\
\text { pedir con más frecuencia en un fast } \\
\text { food? y ¿Por qué? }\end{array}$ & $\begin{array}{c}\text { Todos los expertos coinciden que lo más vendido } \\
\text { en sus locales son: el pollo en diversas } \\
\text { presentaciones y las hamburguesas. }\end{array}$
\end{tabular}

¿Qué tipo de bebida alcohólica considera
que es el mejor acompañamiento después
del consumo de fast food? y ¿Por qué?

¿Qué insumos son los que se compran en
cantidad y se usan más en los distintos
platos de fast food? y ¿Por qué?

¿Qué días existe mayor afluencia de consumidores? y ¿Por qué?
La mayoría menciona que no sería rentable el expendio de bebidas alcohólicas en un fast food porque la cultura peruana no lo permite en la actualidad, además porque concurren una gran cantidad de menores de edad y la venta de bebidas alcohólicas sería motivo de críticas.

\section{Los insumos que más se compran por lo general} son el pollo, las papas y las verduras como la lechuga y el tomate, por lo mismo que los platos que más suelen comprar los clientes son el pollo y las hamburguesas.

Todos coinciden que los fines de semana a partir de los jueves son los días picos así como también los feriados.

Todos los entrevistados indicaron que el horario de mayor concurrencia a los fast food que ellos dirigen es a partir de las $5 \mathrm{pm}$ en adelante ya que las personas que acudirán al local están saliendo recién de sus centros de trabajo.

¿Qué zonas dentro de la ciudad de Cusco recomendaría Ud. para iniciar con un negocio de fast food? y ¿Por qué?

¿En qué horarios existe mayor afluencia de consumidores? y ¿Por qué?

Todos los expertos coinciden que el lugar estratégico para iniciar un fast food es en la Av. La Cultura, exactamente por las zonas de Manuel Prado, Magisterio y Marcavalle, por ser una zona muy transitada y porque se encuentra el Real Plaza.

Nota. Fuente: Elaboración propia. 


\subsection{Investigación cuantitativa.}

La investigación cuantitativa permite medir de forma numérica las variables relacionadas a los objetivos de la investigación y la relación que existe entre ellas a fin de conocer en base a parámetros numéricos y estadísticas el comportamiento del mercado objetivo y con ello definir las mejores estrategias para llegar ellos (Robles, 2007). Para el presente plan se utilizó la técnica de la encuesta.

\subsubsection{Proceso de muestreo.}

Para realizar el cálculo de la muestra, primero se determina el objetivo de la investigación el cual es:

Estimar la proporción de la población urbana de residentes y flotantes en los distritos donde se ubica la Av. La Cultura en la provincia de Cusco, entre 18 y 45 años de edad de los niveles socioeconómicos A,B y C que consumirían sus alimentos en un establecimiento de comida fast food de cocina americana de pollos en variedades y hamburguesas que incorpore insumos oriundos de la región (Novoandino).

Se calculará la muestra que representa a la población de estudio haciendo uso del muestreo probabilístico sistemático, debido a que se espera obtener información de la población residente y flotante. "El muestreo sistemático conlleva la selección de un individuo de la población aleatoriamente, luego de ello se realiza el muestreo en base a un intervalo constante abarcando el volumen total de encuestas a aplicar.” (Diario Gestión, 2015) 
Se utilizará una formula estadística para el cálculo de la muestra en base a una población infinita, es decir poblaciones mayores a 100,000 habitantes, se aplica esta fórmula debido a que la cantidad de elementos que conforman la población es tan grande y variado que puede presumirse infinita, la fórmula se muestra en Figura 15:

$$
n=\frac{Z^{2} p q}{e^{2}}
$$

Figura 15. Fórmula determinación de muestra. Recuperado de https://bioestadistica1.wordpress.com/2012/11/22/formulas-poblacion-infinita/

Dónde:

$Z=1.96$ que corresponde a un nivel de confianza de $95 \%$

$\mathrm{E}=3.5 \%$ (nivel de significancia)

$\mathrm{P}=50 \%$ (probabilidad de éxito)

$\mathrm{Q}=50 \%$ (probabilidad de fracaso)

El nivel de confianza de $95 \%$ se estableció puesto que se espera que por lo menos el $95 \%$ de los casos se encuentre dentro de la proporción de personas que serían potenciales clientes para el proyecto. Al ser un proyecto nuevo con un concepto que aún no se aplica en el mercado, se estima una probabilidad de éxito o fracaso de 50\%, además al ser un proyecto que mide el nivel de consumo de la población y cuya ejecución de la muestra es bajo el muestreo probabilístico sistemático, se estima un nivel de significancia o error de $3.5 \%$ es decir que la proporción resultante del muestro sea como máximo +/-3.5\% de la proporción real de la población de estudio. 
De acuerdo a ello el cálculo de la muestra (n) es el siguiente:

La muestra (n) es: $N=784$

Para el desarrollo del muestreo sistemático se procede a determinar el intervalo constante para la aplicación de las encuestas, el factor "K" de acuerdo con la fórmula que se muestra en Figura 16.

$$
k=\left[\frac{N}{n}\right]
$$

- Donde:

$\mathrm{K}=$ Muestreo sistemático

$\mathrm{N}=$ Número de elementos de la población $\mathrm{n}=$ Tamaño de la muestra.

Figura 16. Cálculo factor K. Recuperado de http://www.espanito.com/plan-programa-lnea-de-investigacin-proyecto.html?part=8

Para determinar el intervalo, este se estimó utilizando como referencia la proporción de la población de cada distrito conforme se estimó en la Tabla 21, se dividió la población de cada distrito por el número total de encuestas, el resultado se dividió a su vez a la mitad para tener un intervalo más real en referencia al volumen de tránsito de personas en las zonas de estudio conforme la Tabla 33.

Tabla 33

Determinación del factor K/2, según población por distrito 


\begin{tabular}{lccc}
\hline Población 2017 & \% Sobre pob. Total & $\mathrm{K}$ & $\mathrm{K} / 2$ \\
\hline 119580 & $25.9 \%$ & 153 & 76 \\
54072 & $11.7 \%$ & 69 & 34 \\
133927 & $29.0 \%$ & 171 & 85 \\
90702 & $19.6 \%$ & 116 & 58 \\
64230 & $13.9 \%$ & 82 & 41 \\
\hline 462511 & $100 \%$ & & \\
\hline
\end{tabular}

Nota. Fuente: Elaboración propia.

Para desarrollar el esquema de aplicación de encuestas, se comenzó con el intervalo más bajo comenzando desde el día lunes como mecanismo de medición y se distribuyó en orden ascendente de lunes a domingo en relación al k/2 obtenido. Se determinó aleatoriamente el punto de inicio en el individuo número siete para cada día.

Se consideraron cuatro zonas diferentes de alto tránsito de la Av. La Cultura como puntos de aplicación de encuestas conforme la Figura 17, así mismo se asignó subjetivamente porcentajes de afluencia de personas estimados por día de semana que se aplicaron al número total de encuestas para obtener la distribución de encuestas por día de la semana, conforme la Tabla 34.

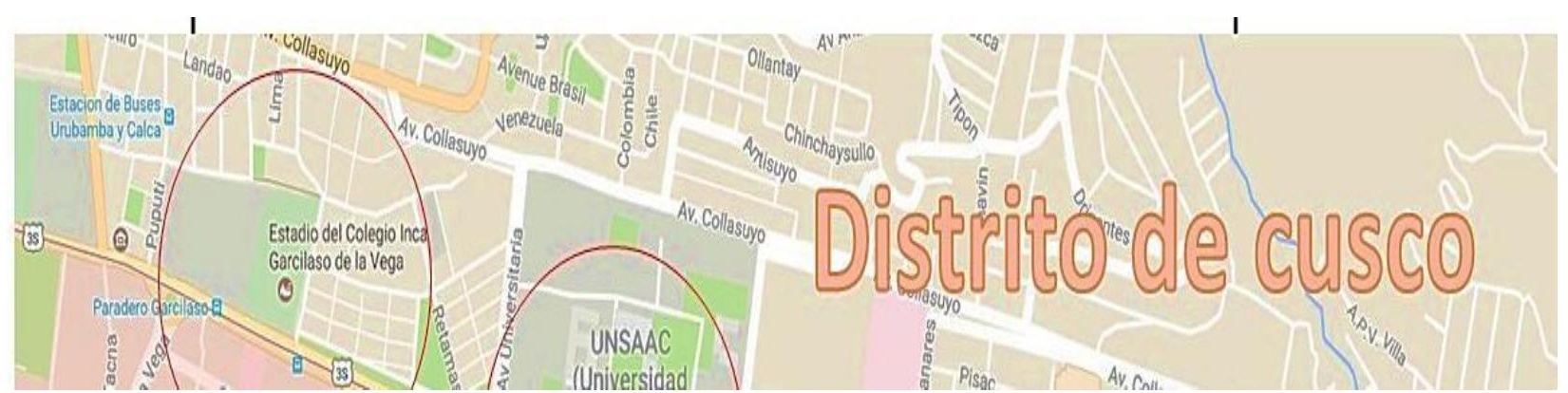


Figura 17. Puntos de aplicación de Encuestas. Adaptado de https://www.google.com.pe/maps/place/Wanchaq,+Cusco/@-13.5231733,$71.9622823,14.75 \mathrm{z} /$ data $=! 4 \mathrm{~m} 5 ! 3 \mathrm{~m} 4 ! 1 \mathrm{~s} 0 \times 916 \mathrm{e} 7 \mathrm{f} 57342 \mathrm{c} 1119: 0 \times a 62 \mathrm{~d} 8 \mathrm{cbeef} 47 \mathrm{~d} 24 \mathrm{a} ! 8 \mathrm{~m} 2$ !3d$13.5346909 ! 4 d-71.9490257$

\section{Tabla 34}

Esquema de aplicación de encuestas bajo el sistema de muestreo sistemático

\begin{tabular}{lccccccc}
\hline & Lunes & Martes & Miércoles & Jueves & Viernes & Sábado & Domingo \\
\hline $\begin{array}{l}\text { Afluencia de } \\
\text { personas } 100 \%\end{array}$ & $7 \%$ & $8 \%$ & $11 \%$ & $11 \%$ & $13 \%$ & $25 \%$ & $25 \%$ \\
$\begin{array}{l}\text { Total de } \\
\text { Encuestas }\end{array}$ & 55 & 63 & 86 & 86 & 102 & 196 & 196 \\
784 & & & & & & \\
$\begin{array}{l}\text { Intervalo } \\
\text { Constante }\end{array}$ & 34 & 41 & 58 & 76 & 85 & 85 & 85 \\
K/2 & & & & & & & \\
\hline
\end{tabular}

Horario de aplicación de encuestas

Lunes a

domingo

De 12:00pm a 10:00pm

Nota. Fuente: Elaboración propia. 


\subsubsection{Diseño de instrumento.}

Se tomó en cuenta para el diseño de la encuesta los objetivos de ventas, promoción, distribución, entre otros. Esta encuesta permitió conocer el nivel de aceptación del proyecto y la demanda potencial del mismo. El instrumento que se utilizó fue el cuestionario.

\subsubsection{Diseño de trabajo de campo.}

- Organización

El trabajo de campo se organiza en función de la cantidad de encuestas a aplicar a la población de estudio. Para ello se planifica el trabajo de la siguiente manera:

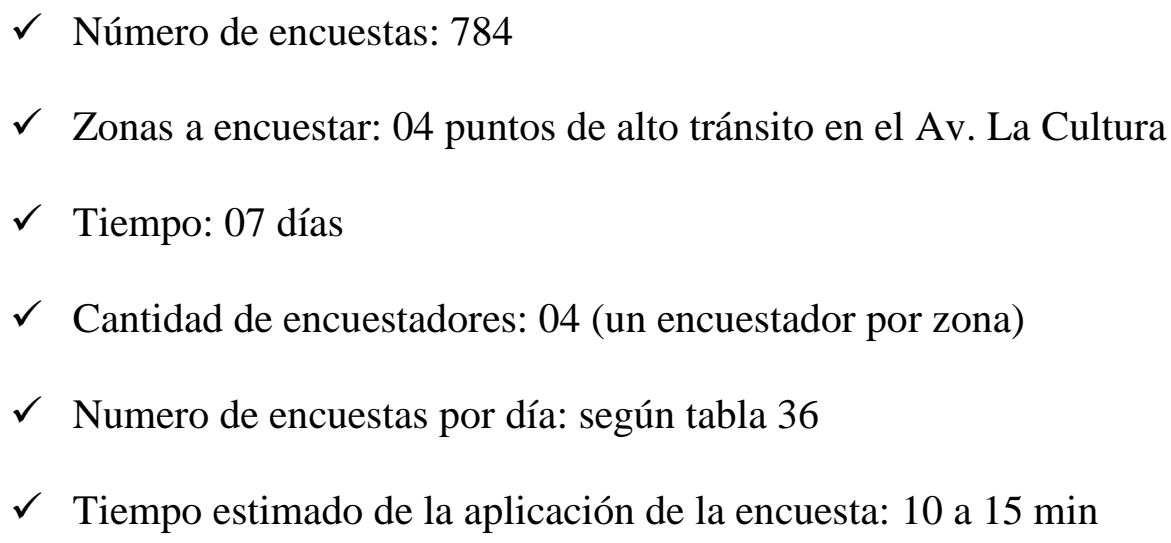

Para las acciones de coordinación y control del trabajo de campo se contará con la participación de 01 Coordinador general, 01 Supervisor de campo. Se realizaron de 6 a 8 encuestas piloto para medir si la encuesta satisface los objetivos del proyecto y si es de fácil aplicación y tabulación. 
- Requerimientos

$\checkmark$ Personal

$\checkmark$ Coordinador general (01)

$\checkmark$ Supervisor de campo (01)

$\checkmark$ Encuestadores (04)

$\checkmark$ Materiales

$\checkmark$ Tablero (08)

$\checkmark$ Lápiz (08)

$\checkmark$ Papel bond x 80 gr (1/2 millar para los cuestionarios e informes)

- Servicios de terceros

$\checkmark$ Impresiones

$\checkmark$ Movilidad

$\checkmark$ Presupuesto

Tabla 35

Presupuesto de personal para la aplicación de encuestas

\begin{tabular}{lcccc}
\hline \multicolumn{1}{c}{ Descripción } & Unidad de medida & Cantidad & Costo unitario & $\begin{array}{c}\text { Costo } \\
\text { parcial }\end{array}$ \\
\hline Coordinador general (01) & Día & 2 & 150.00 & 300.00 \\
Supervisor de campo (01) & Día & 2 & 100.00 & 200.00 \\
Encuestadores (04) & Encuesta & 784 & 0.73 & 576.00 \\
\hline Total & & & & $1,076.00$ \\
\hline Nota. Fuente: Elaboración propia. & & &
\end{tabular}


Tabla 36

Presupuesto de materiales para la aplicación de encuestas

\begin{tabular}{lcccc}
\hline \multicolumn{1}{c}{ Descripción } & Unidad de medida & Cantidad & $\begin{array}{c}\text { Costo } \\
\text { Unitario }\end{array}$ & Costo Parcial \\
\hline Tablero & Und & 8 & 11.4 & 90.00 \\
Lápiz & Und & 8 & 0.75 & 6.00 \\
Papel bond x 80 gr & Millar & 0.5 & 40.00 & 20.00 \\
\hline Total & & & & 116.00 \\
\hline
\end{tabular}

Nota. Fuente: Elaboración propia.

Tabla 37

Presupuesto servicios de terceros para aplicación de encuestas

\begin{tabular}{lcccc}
\hline \multicolumn{1}{c}{ Descripción } & Unidad de medida & Cantidad & Costo unitario & Costo parcial \\
\hline Impresiones & Glb & 1 & 100.00 & 100.00 \\
Movilidad & Glb & 1 & 50.00 & 50.00 \\
\hline Total & & & & 150.00 \\
\hline
\end{tabular}

Nota. Fuente: Elaboración propia.

Lo que suma un total presupuestado de 1, 342.00 soles.

\subsubsection{Cuestionario.}

Para el cuestionario se comenzó con la frase de presentación y luego las preguntas relevantes haciendo un total de 24 preguntas, conforme Tabla 38. 
Tabla 38

Preguntas del cuestionario base de encuesta de preg 1 a preg. 24

\section{Filtro $\mathrm{N}^{\circ} 1$}

¿Consume usted productos de comida rápida o fast food?

Datos de control

Género:

Distrito de residencia

VI. Tipo de actividad que realiza en la zona VII. Ocupación

Cuestionario-Filtro $\mathrm{N}^{\circ} 2$

$\checkmark$ ¿Asiste usted a establecimientos de comida tipo fast food?

$\checkmark$ ¿Con qué frecuencia asiste a locales de comida rápida fast food?

$\checkmark$ ¿En qué horario suele frecuentar locales de comida rápida -fast food?

$\checkmark$ Cuando asiste a un fast food, indique cuánto tiempo en promedio permanece en este tipo de establecimientos.

$\checkmark$ ¿Con quiénes suele visitar los locales de comida rápida-fast food?

$\checkmark$ ¿Qué tan importante considera usted que son algunos factores para un fast food?

$\checkmark$ Indique cuáles son los productos de su preferencia en un Fast food.

$\checkmark \quad$ ¿Cuáles son las bebidas que usted suele adquirir en un fast food?

$\checkmark$ Indique su ranking de asistencia a los establecimientos de fast food que suele visitar cuando sale a comer fuera.

$\checkmark \quad$ ¿Qué tan importante considera usted que son algunos factores para la elección de su fast food preferido?

$\checkmark$ Si se abriera un nuevo local de comida rápida - fast food donde se preparen hamburguesas y pollos y se incorpore además ingredientes andinos o de la región, tanto en la preparación de los productos principales como en las bebidas y postres

$\checkmark \quad$ ¿Qué insumos andinos le gustaría fuesen utilizados en la preparación de las hamburguesas y pollos?

$\checkmark \quad$ ¿Qué tipo de complementos o adicionales andinos le gustaría encontrar en el local?

$\checkmark \quad$ ¿Qué tipo de bebidas andinas le gustaría encontrar en local?

$\checkmark \quad$ ¿Cuánto está dispuesto a pagar en promedio por un combo personal (pollo o hamburguesa más complemento y bebida) en este tipo de local?

$\checkmark \quad$ ¿Cuánto está dispuesto a pagar por en promedio por un adicional (complemento o bebida) en este tipo de local?

$\checkmark$ ¿Qué tipo de postres andinos le gustaría encontrar en esta propuesta de fast food?

$\checkmark \quad$ ¿Cuánto está dispuesto a pagar por en promedio por un postre andino en este tipo de local?

Filtro $\mathrm{N}^{\circ} 3$ - Considera que de aperturarse este tipo de establecimiento de fast food, usted asistiría

$\checkmark$ ¿Cuánto tiempo está dispuesto a esperar por su pedido en este tipo de fast food?

$\checkmark$ Indique cuánto tiempo permanecería en este tipo de local

$\checkmark$ ¿En qué horario estaría dispuesto a frecuentar este nuevo local de comida rápida?

$\checkmark$ Ranking de medios de comunicación por el cual considera se debería realizar la promoción del nuevo local.

$\checkmark$ Indique en que zona de la Av. La Cultura le gustaría encontrar el nuevo local de comida rápida.

$\checkmark$ Nivel de importancia que tendría la implementación de los servicios o características adicionalesen este nuevo local de fast food

\footnotetext{
Nota. Ver cuestionario completo, Anexo $\mathrm{N}^{\circ} 12$. Nota. Fuente: Elaboración propia.
} 


\subsubsection{Análisis y procesamiento de datos.}

Con los datos recopilados de la encuesta se procederá a elaborar representaciones gráficas de los resultados obtenidos, procediendo a sus respectivos análisis e interpretación.

A continuación se detalla los resultados obtenidos del estudio cuantitativo llevado a cabo en base a cada pregunta del cuestionario aplicado (ver anexo $\mathrm{N}^{\circ} 12$ ).

- Filtro 1: consumo de comida rápida.

Se evidencio que el $100 \%$ de los encuestados consume productos de comida rápida.

- Datos de control 1: género de los encuestados.

Del $100 \%$ de los encuestados un $57.65 \%$ está compuesto por el público masculino y el 42.35\% restante pertenece al público femenino, conforme Tabla 39, representado gráficamente en Figura 18.

Tabla 39

Sexo de los encuestados

\begin{tabular}{lcc}
\hline & Frecuencia & Porcentaje (\%) \\
\hline Masculino & 452 & 57.65 \\
Femenino & 332 & 42.35 \\
\hline Total & 784 & 100.00 \\
\hline
\end{tabular}

Nota. Fuente: Elaboración propia. 


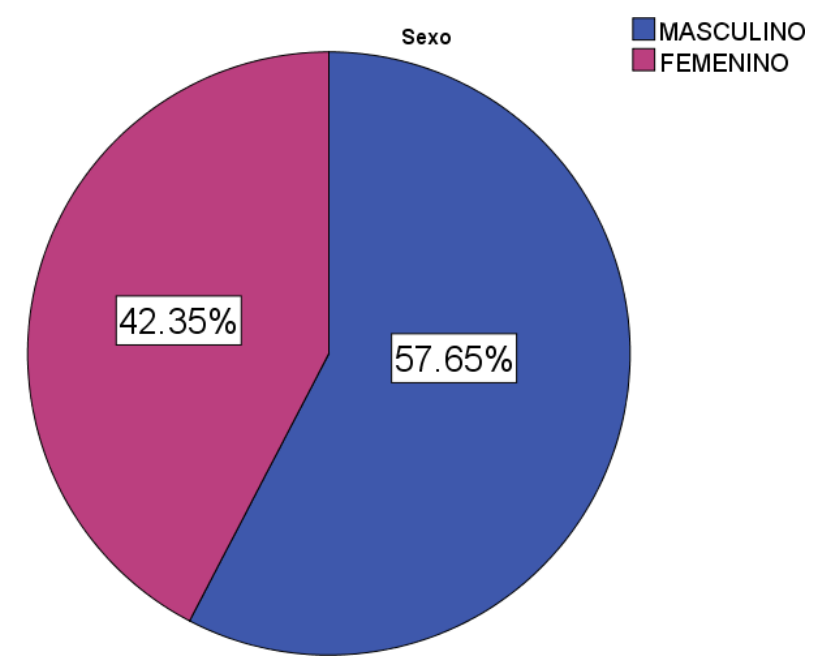

Figura 18. Género de los encuestados. Fuente: Elaboración propia.

- Datos de control 2: edad de los encuestados.

El público objetivo del proyecto está compuesto por personas que tienen entre los 18 a 45 años de edad, para efectos prácticos del estudio, se agruparon en grupos etarios de 18 a 24 años, compuestos por el $27.93 \%$ de los encuestados, de 25 a 34 años de edad, representados por el $39.03 \%$ de la población, y por último de 35 a 45 años de edad que representa el 33.04\% de la población encuestada; según Tabla 40, representado gráficamente en la Figura 19.

Tabla 40

Grupos etarios

\begin{tabular}{lcc}
\hline & Frecuencia & Porcentaje (\%) \\
\hline 18 a 24 & 219 & 27.93 \\
25 a 34 & 306 & 39.03 \\
35 a 45 & 259 & 33.04 \\
\hline Total & 784 & 100.00
\end{tabular}

Nota. Fuente: Elaboración propia. 


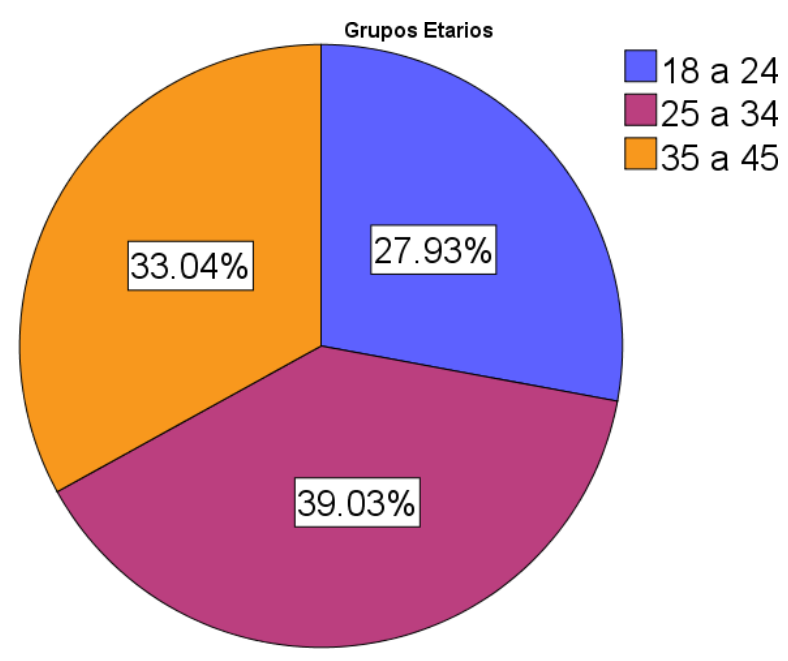

Figura 19. Grupos etarios encuestados. Fuente: Elaboración propia.

- Datos de control 3: distritos de residencia de encuestados.

Conforme la Tabla 41 y representado gráficamente en la Figura 20, se puede evidenciar que un $30.48 \%$ de los encuestados reside en el distrito de Wanchaq, el cual representa según la investigación el distrito con mayor afluencia a la zona de la Av. La Cultura, seguido por el distrito de Cusco con un 28.06\% y San Sebastián con un 17.35\%, luego le siguen los distritos de Santiago con $14.41 \%$ y San Jerónimo con $8.29 \%$, en menor proporción se evidencio público flotante de distritos alejados como son Saylla con un $1.02 \%$ y Poroy con un $0.38 \%$. 
Tabla 41

Distrito de residencia de encuestados

\begin{tabular}{lcc}
\hline & Frecuencia & Porcentaje (\%) \\
\hline Cusco & 220 & 28.06 \\
San Jerónimo & 65 & 8.29 \\
San Sebastián & 136 & 17.35 \\
Santiago & 113 & 14.41 \\
Wanchaq & 239 & 30.48 \\
Saylla & 8 & 1.02 \\
Poroy & 3 & 0.38 \\
\hline Total & 784 & 100.0
\end{tabular}

Nota. Fuente: Elaboración propia.

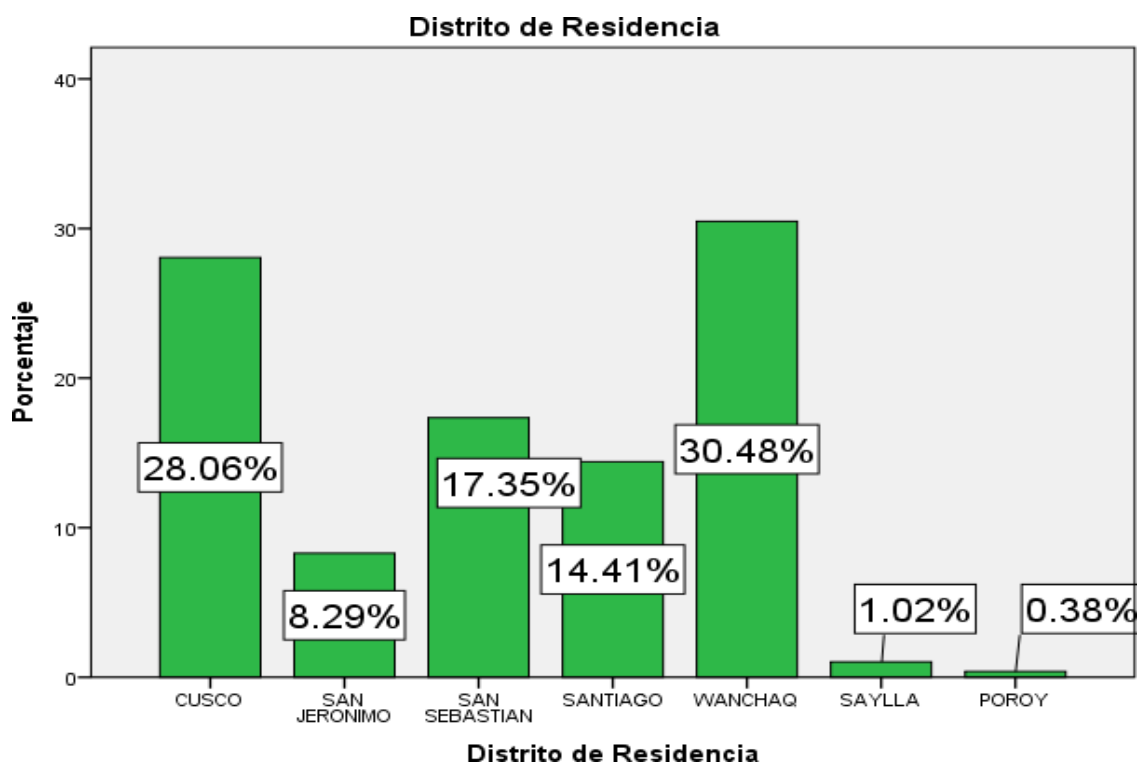

Figura 20. Distrito de residencia de encuestados. Fuente: Elaboración propia.

- Datos de control 4: nivel de ingreso familiar.

Para el estudio se consideraron del NSE A, B y C, para ello se establecieron rangos de ingresos promedio para cada nivel; NSE C compuesto por el rango de S/850 a S/1200 soles de 
ingresos mensuales que representa en la investigación cuantitativa al 52.42\% de la población de estudio, NSE B de S/1201 a S/2000 representado por el 17.98\% y de S/2001 a S/3000 representado por el $16.07 \%$ y por último NSE A de S/3001 a más, compuesto por el 13.52\%, según la Tabla 42, representado gráficamente en la Figura 21.

Tabla 42

Nivel de ingresos por NSE de encuestados

\begin{tabular}{lcc}
\hline & Frecuencia & Porcentaje $(\%)$ \\
\hline 850 a 1200 & 411 & 52.42 \\
1201 a 2000 & 141 & 17.98 \\
2001 a 3000 & 126 & 16.07 \\
3001 a más & 106 & 13.52 \\
\hline Total & 784 & 100.00
\end{tabular}

Nota. Fuente: Elaboración propia.

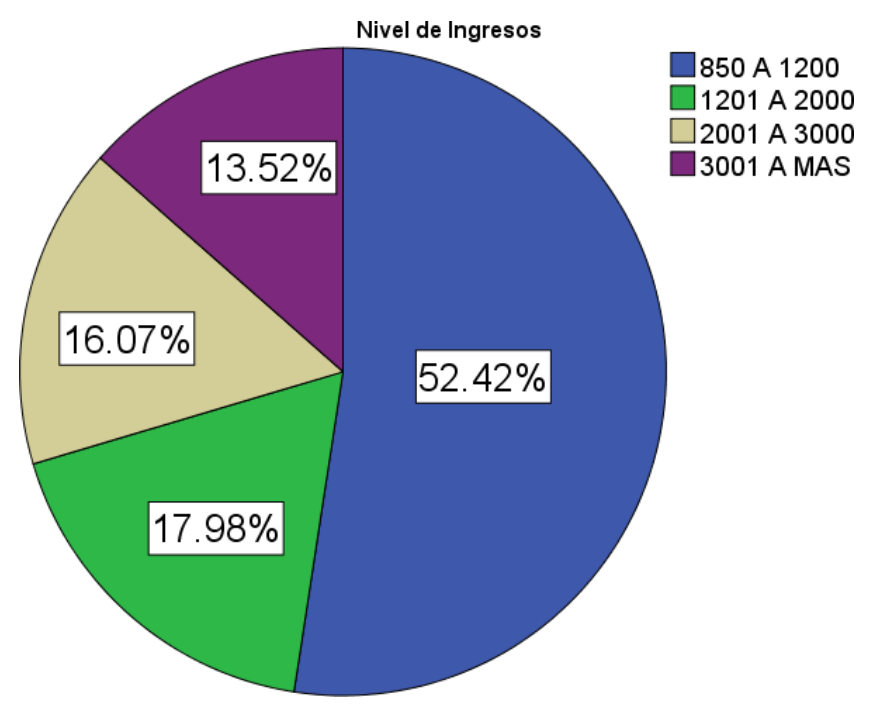

Figura 21. Nivel de ingresos por NSE de encuestados. Fuente: Elaboración propia. 
- Datos de control 5: tipo de actividad que realiza en la zona. (Opción múltiple)

Conforme Tabla 43, se observa que al ser una pregunta de respuesta múltiple, se obtuvo que hubieron 976 respuestas de las 784 personas encuestadas, resultando en que un $44.67 \%$ de las respuestas corresponde a encuestados que indican trabajar en zonas aledañas a la Av. La Cultura y un $26.84 \%$ de la respuestas representa a las personas que estudian también en dichas zonas, siendo los porcentajes más altos registrados, por otro lado, un $12.70 \%$ transitan la zona por entretenimiento y un $9.32 \%$ por comer fuera de casa. En menor proporción están las personas que visitan a familiares, o visitan la zona para hacer visita a hospitales o que van por motivos de compras, también se encuentran las personas que van a realizar deporte o escuchar música, incluso aquellas que van a realizar algún tipo de trámites. Según Figura 22 se representa gráficamente.

Tabla 43

Tipo de actividad que realiza en la zona

\begin{tabular}{lcc}
\hline & Cantidad de respuestas & Porcentaje según Total de respuestas \\
\hline Trabajo & 436 & $44.67 \%$ \\
Estudio & 262 & $26.84 \%$ \\
Entretenimiento & 124 & $12.70 \%$ \\
Alimentación fuera & 91 & $9.32 \%$ \\
Visita a familiares & 56 & $5.74 \%$ \\
Visita a hospital & 1 & $0.10 \%$ \\
Compras & 1 & $0.10 \%$ \\
Deporte & 2 & $0.20 \%$ \\
Música & 1 & $0.10 \%$ \\
Tramites & 2 & $0.20 \%$ \\
\hline Total & 976 & \\
\hline
\end{tabular}

Nota. Fuente: Elaboración propia. 


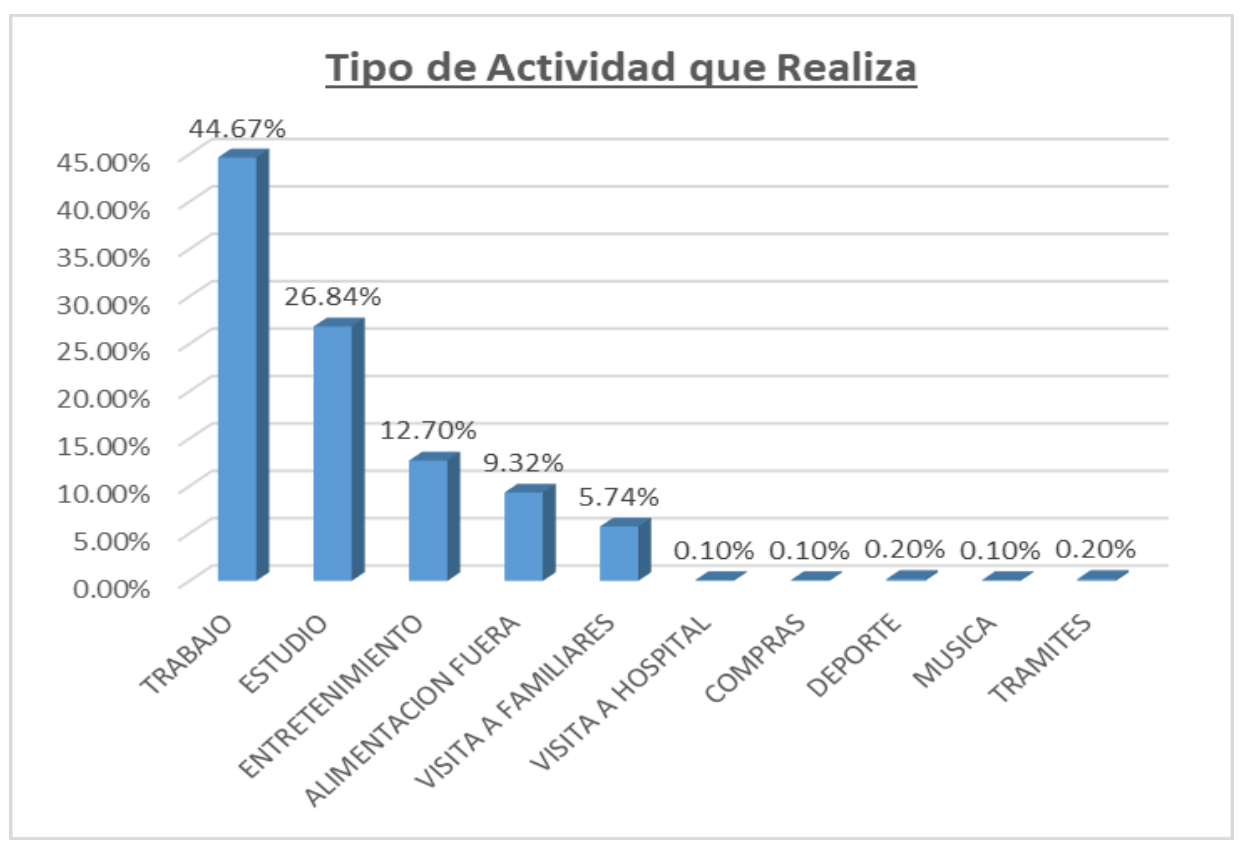

Figura 22. Tipo de actividad que realiza en la zona. Fuente: Elaboración propia.

- Datos de control 6: ocupación del encuestado. (Opción múltiple)

Como se muestra en Tabla 44 y se ilustra en Figura 23, al ser una pregunta de respuesta múltiple, se obtuvo que hubieron 880 respuestas de las 784 personas encuestadas; la mayoría de las respuestas en un $32.39 \%$ son de personas que indican ser estudiantes seguido por un $25.45 \%$ que son independientes, luego se encuentran los dependientes privados y públicos con $22.50 \%$ y 17.84\% respectivamente, así mismo existe una minoría de $1.59 \%$ de encuestados que son amas de casa, lo que refleja la necesidad de optimización de tiempo que requieren las familias para realizar sus actividades laborales y del hogar puesto que la mayoría de los miembros de las familias trabajan y estudian, cada vez hay menos amas de casa. Por último, están los músicos y vendedores con $0.11 \%$ de asistencia. Esta grafica es distinta al anterior puesto que se refiere a la ocupación o labor que realiza el encuestado en su vida diaria; por otro lado los datos de control cinco, se concentran a la actividad que ejerce el encuestado cuando concurre a la Av. La Cultura. 
Tabla 44

Ocupación de encuestados

Cantidad de respuestas Porcentaje según total de respuestas

\begin{tabular}{lcc}
\hline Dependiente publico & 157 & $17.84 \%$ \\
Dependiente privado & 198 & $22.50 \%$ \\
Independiente & 224 & $25.45 \%$ \\
Ama de casa & 14 & $1.59 \%$ \\
Estudiante & 285 & $32.39 \%$ \\
Músico & 1 & $0.11 \%$ \\
Vendedor & 1 & $0.11 \%$ \\
\hline Total & 880 & $100 \%$ \\
\hline
\end{tabular}

Nota. Fuente: Elaboración propia.

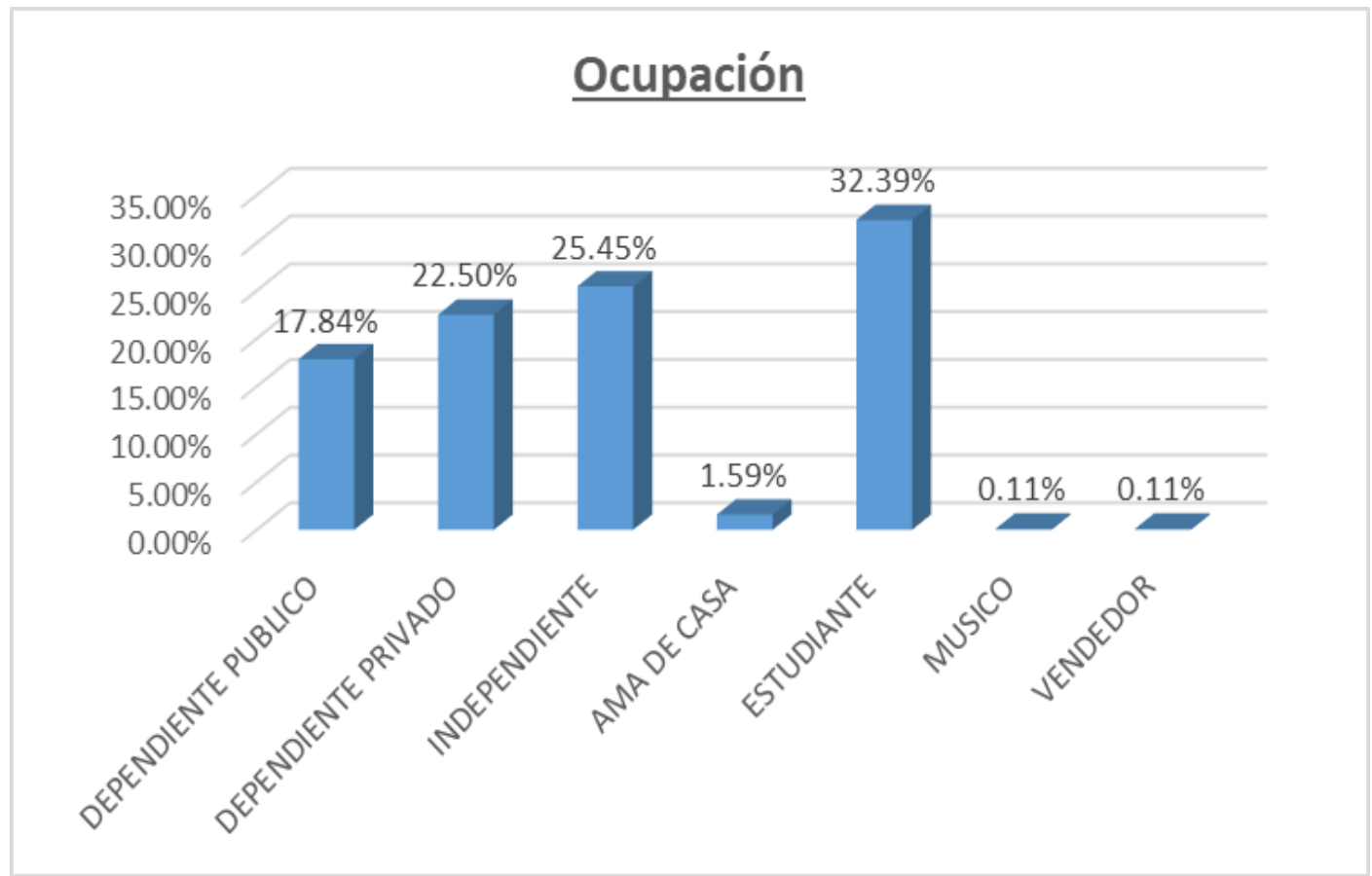

Figura 23. Ocupación de los encuestados. Fuente: Elaboración propia. 
- Filtro 2: Asistencia a establecimientos de comida rápida.

Conforme Tabla 45 y representado en Figura 24, se evidencia que un 99.36\% de los encuestados si asiste a establecimientos de comida rápida, y un $0.64 \%$ no asiste a este tipo de establecimientos, lo que refleja la alta aceptación de este tipo de comida en el mercado local.

Tabla 45

Asistencia a establecimientos de comida rápida

\begin{tabular}{lcc}
\hline & Frecuencia & Porcentaje (\%) \\
\hline $\mathrm{Si}$ & 779 & 99.36 \\
No & 5 & 0.64 \\
\hline Total & 784 & 100.00 \\
\hline
\end{tabular}

Nota. Fuente: Elaboración propia.

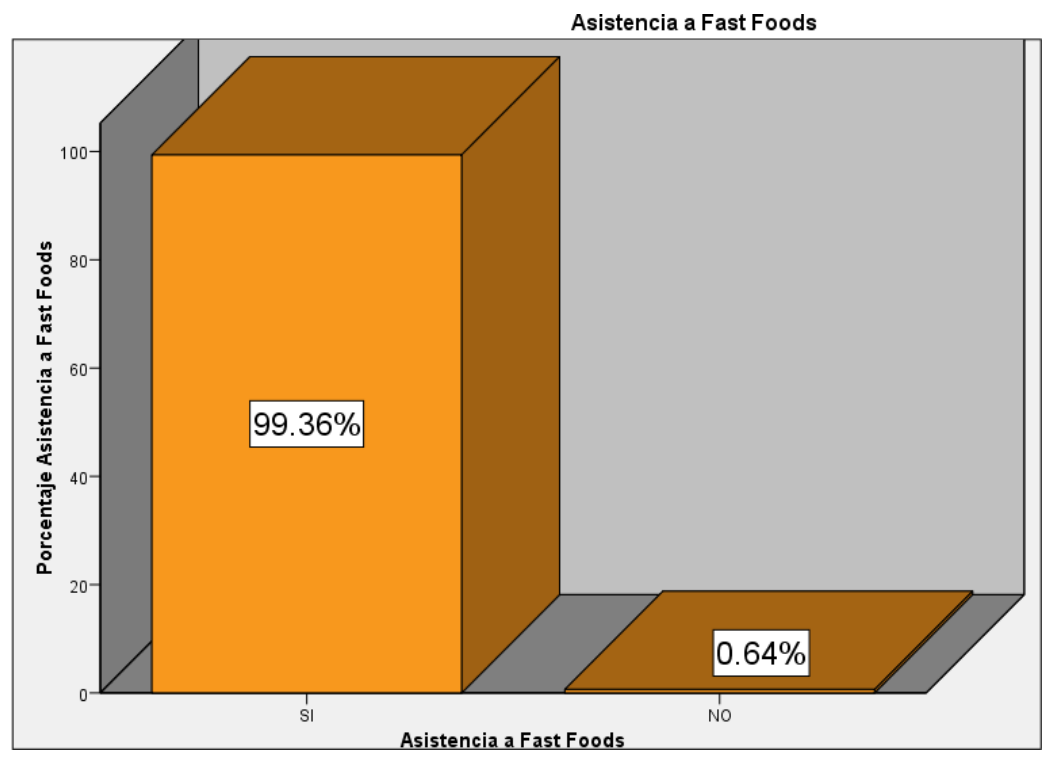

Figura 24. Asistencia a fast food. Fuente: Elaboración propia. 
- Frecuencia de asistencia a fast foods.

Para medir la frecuencia se agruparon las respuestas abiertas obtenidas en tres rangos: diario, de 1 a 5 veces a la semana, de 1 a 3 veces al mes y de 1 a 6 veces al año. Del resultado obtenido se observa que un $48.27 \%$ de los encuestados frecuenta los establecimientos de comida fast food de 1 a 5 veces a la semana y un $29.91 \%$ lo hace de 1 a 3 veces al mes, esto demuestra los hábitos de consumo de comida rápida por parte de los cusqueños, seguido se encontró que un 16.94\% asiste de 1 a 6 veces al año y una minoría de $4.88 \%$ lo hace diario, conforme Tabla 46; del mismo modo conforme Tabla 47, se estimó mediante el método de promedio ponderado la frecuencia de asistencia desagregada para la semana, mes y año, considerando pesos inversamente proporcionales a la frecuencia de asistencia de forma conservadora, considerando como base para el análisis el porcentaje de frecuencia obtenido en Tabla 46 para cada caso, los resultados finales se representan gráficamente en Figura 25.

Tabla 46

Frecuencia de asistencia a fast food según Encuesta

\begin{tabular}{lcc}
\hline & Frecuencia & Porcentaje (\%) \\
\hline Diario & 38 & 4.88 \\
De 1 a 5 veces a la semana & 376 & 48.27 \\
De 1 a 3 veces al mes & 233 & 29.91 \\
De 1 a 6 veces al año & 132 & 16.94 \\
\hline Total & 779 & 100.00 \\
\hline
\end{tabular}

Nota. Fuente: Elaboración propia. 
Tabla 47

Estimación de frecuencia semanal, mensual y anual-promedio ponderado

Semanal

\begin{tabular}{|c|c|c|c|}
\hline Veces por semana & Ponderación & $\%$ asist. Pond. & Distrib. Porcentual \\
\hline $1 \mathrm{vez}$ & 5 & $241.34 \%$ & $16.09 \%$ \\
\hline 2 veces & 4 & $193.07 \%$ & $12.87 \%$ \\
\hline 3 veces & 3 & $144.80 \%$ & $9.65 \%$ \\
\hline 4 veces & 2 & $96.53 \%$ & $6.44 \%$ \\
\hline 5 veces & 1 & $48.27 \%$ & $3.22 \%$ \\
\hline Total & 15 & $724 \%$ & $48.27 \%$ \\
\hline \multicolumn{4}{|c|}{ Mensual } \\
\hline Veces por mes & Ponderación & $\%$ asist. Pond. & Distrib. Porcentual \\
\hline $1 \mathrm{vez}$ & 3 & $89.73 \%$ & $14.96 \%$ \\
\hline 2 veces & 2 & $59.82 \%$ & $9.97 \%$ \\
\hline 3 veces & 1 & $29.91 \%$ & $4.99 \%$ \\
\hline Total & 6 & $179.46 \%$ & $29.91 \%$ \\
\hline \multicolumn{4}{|c|}{ Anual } \\
\hline Veces por año & Ponderación & $\%$ asist. Pond. & Distrib. Porcentual \\
\hline $1 \mathrm{vez}$ & 6 & $101.67 \%$ & $4.841 \%$ \\
\hline 2 veces & 5 & $84.72 \%$ & $4.034 \%$ \\
\hline 3 veces & 4 & $67.78 \%$ & $3.228 \%$ \\
\hline 4 veces & 3 & $50.83 \%$ & $2.421 \%$ \\
\hline 5 veces & 2 & $33.89 \%$ & $1.614 \%$ \\
\hline 6 veces & 1 & $16.94 \%$ & $0.807 \%$ \\
\hline Total & 21 & $355.84 \%$ & $16.94 \%$ \\
\hline
\end{tabular}

Nota. Fuente: Elaboración propia. 


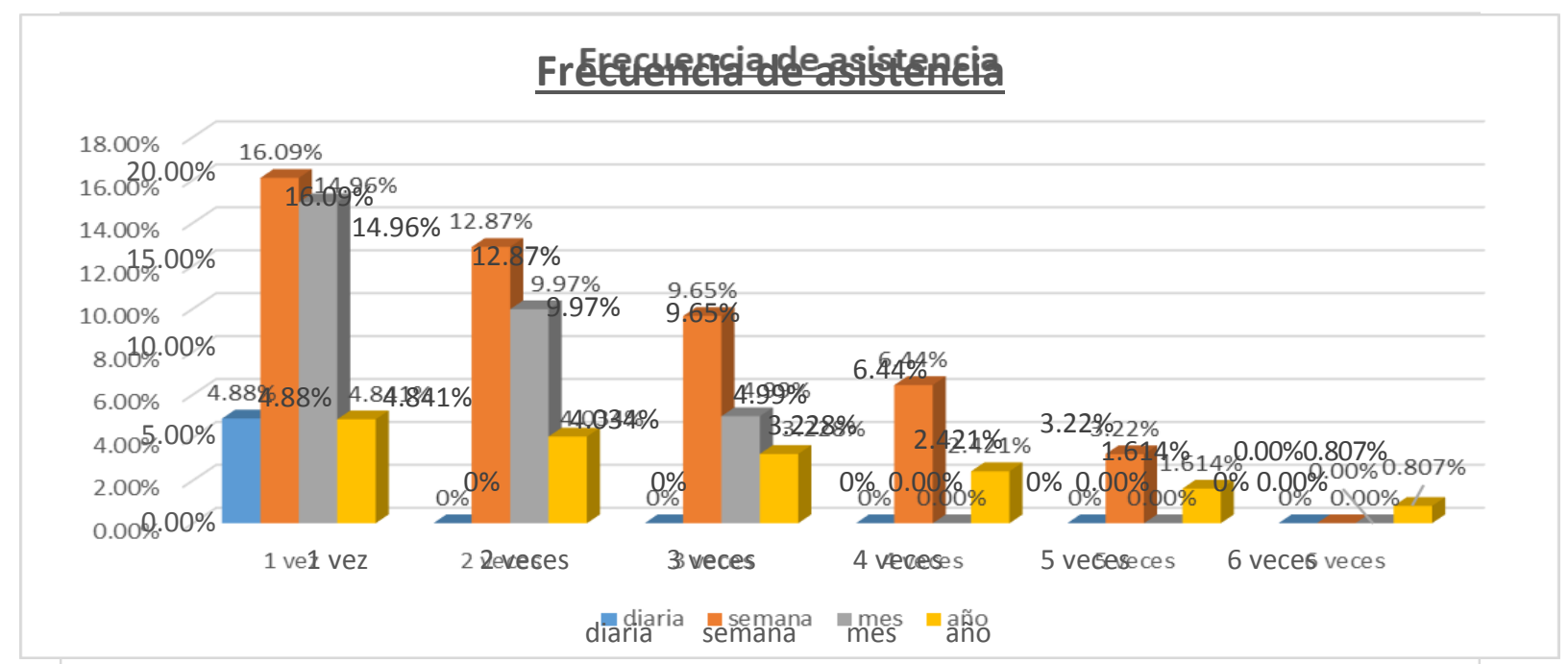

Figura 25. Frecuencia de asistencia a fast foods. Fuente: Elaboración propia.

- Horario de asistencia a establecimientos fast foods. (opción múltiple por día)

Según Figura 26 en base a Tabla 48, se puede concluir que día y el horario preferido para visitar establecimientos de comida rápida son los sábados de 6 a 9pm con un $64.3 \%$, seguido del día domingo también de $6 \mathrm{pm}$ a 9pm representado por un 56.4\%, y el día viernes con un $48.2 \%$ en el mismo horario. Por otro lado, durante los días hábiles el horario preferido es de 12pm a 3pm siendo preferidos los días lunes con un 37.9\% de preferencia y el día miércoles con un $37.8 \%$.

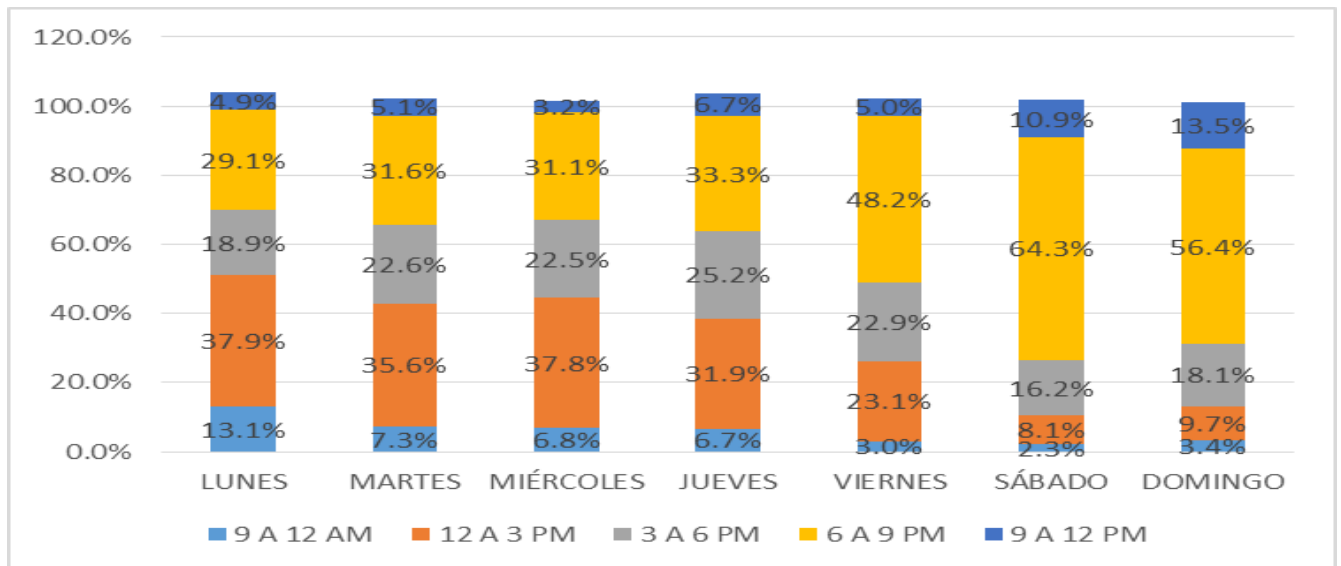

Figura 26. Horario de asistencia establecimientos de fast food. Fuente: Elaboración propia. 
Tabla 48

Horario de asistencia a establecimientos de fast food

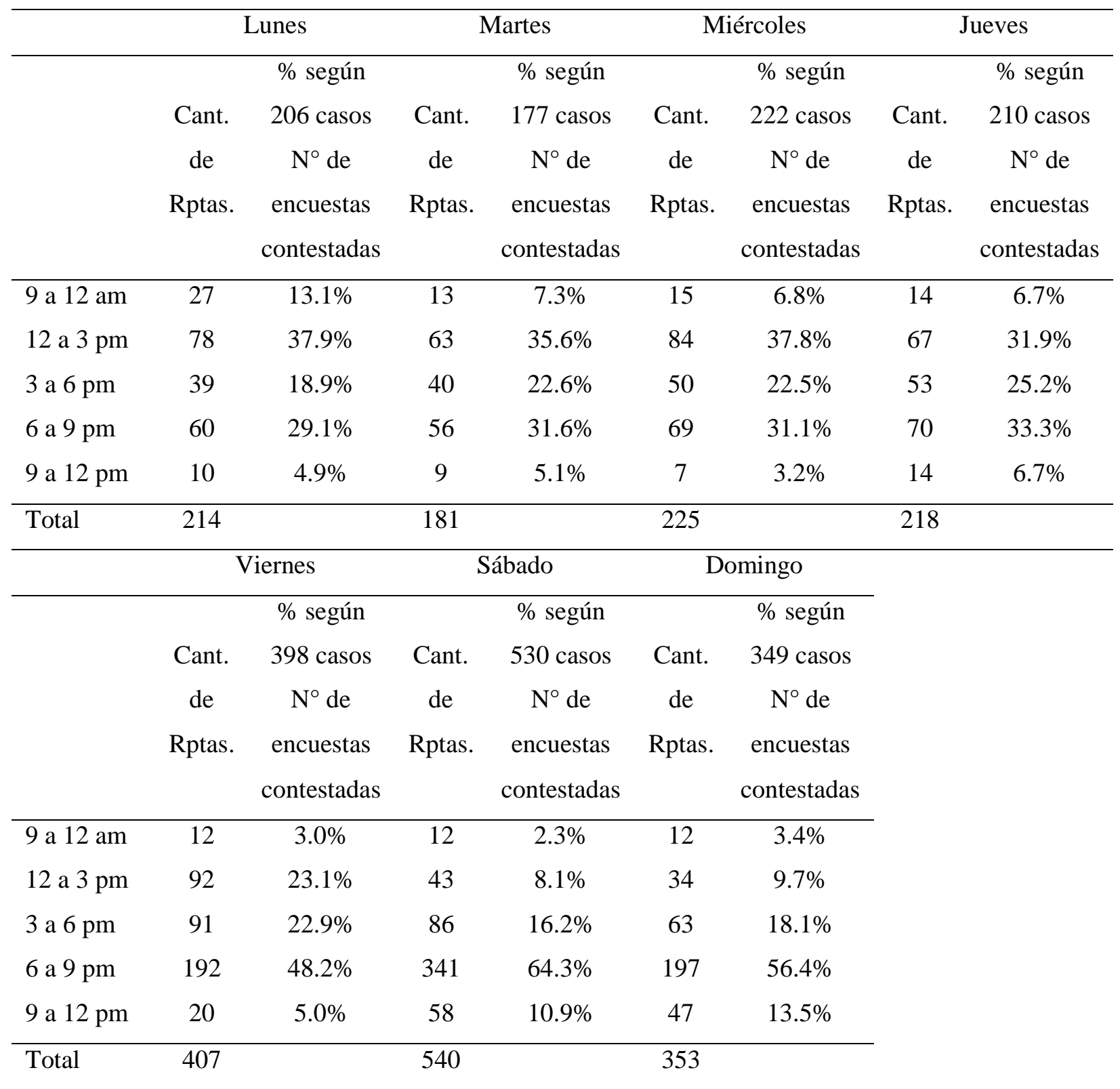

Nota. Fuente: Elaboración propia. 
- Tiempo de permanencia en fast foods.

Conforme Tabla 49 y representado gráficamente en Figura 27, se obtuvo que un $34.53 \%$ de los encuestados permanecen de 31 a 60 minutos en establecimientos de Fast Food, seguido por un $26.19 \%$ quienes permanecen de 16 a 30 minutos, así mismo existe un minoría, que permanece de 5 a 15 minutos o más de una hora con $20.28 \%$ y $19 \%$ respectivamente.

Tabla 49

Tiempo de permanencia en fast foods

\begin{tabular}{lcc}
\hline & Frecuencia & Porcentaje (\%) \\
\hline 5 a 15 minutos & 158 & 20.28 \\
16 a 30 minutos & 204 & 26.19 \\
31 a 60 minutos & 269 & 34.53 \\
Más de 1 hora & 148 & 19.00 \\
\hline Total & 779 & 100.00 \\
\hline
\end{tabular}

Nota. Fuente: Elaboración propia.

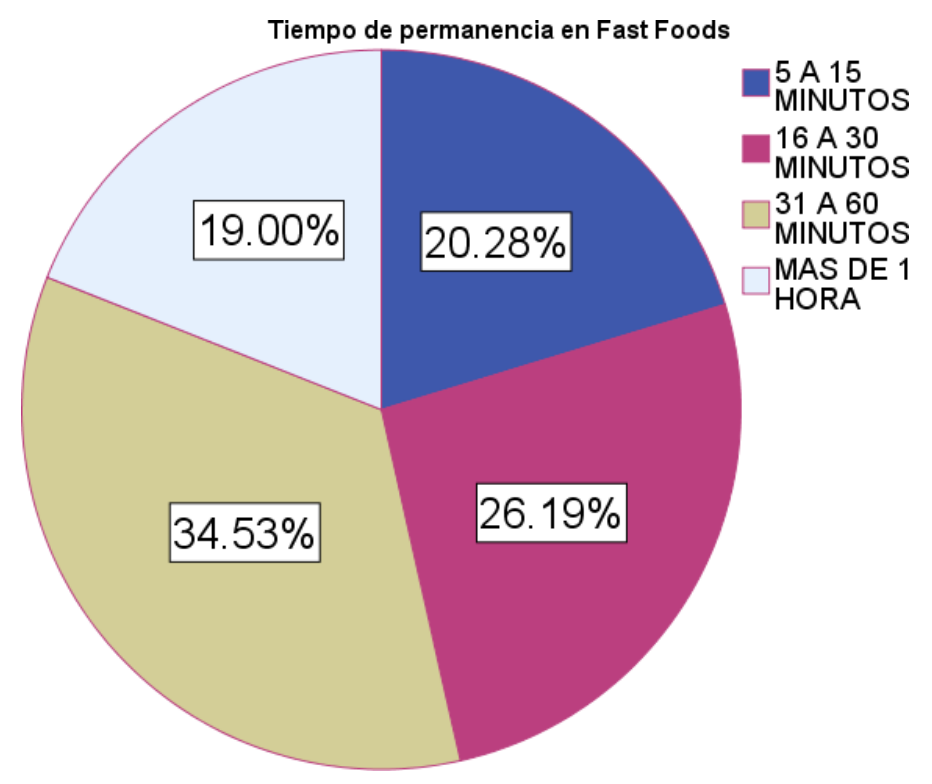

Figura 27. Tiempo de permanencia en fast food. Fuente: Elaboración propia. 
- Personas acompañantes durante visita a fast foods.

Se pudo evidenciar que un $43.26 \%$ de los encuestados visitan este tipo de establecimientos con amigos, seguido por un $36.84 \%$ quienes son acompañados por sus familiares. Por último, una minoría representada por el $11.04 \%$ acuden con sus parejas, y un $8.86 \%$ lo hacen solos, conforme la Tabla 50 y representado en la Figura 28.

Tabla 50

Personas acompañantes durante visita a establecimientos fast foods

\begin{tabular}{lcc}
\hline & Frecuencia & Porcentaje (\%) \\
\hline Solo & 69 & 8.86 \\
Familiares & 287 & 36.84 \\
Pareja & 86 & 11.04 \\
Amigos & 337 & 43.26 \\
\hline Total & 779 & 100.00 \\
\hline
\end{tabular}

Nota. Fuente: Elaboración propia.

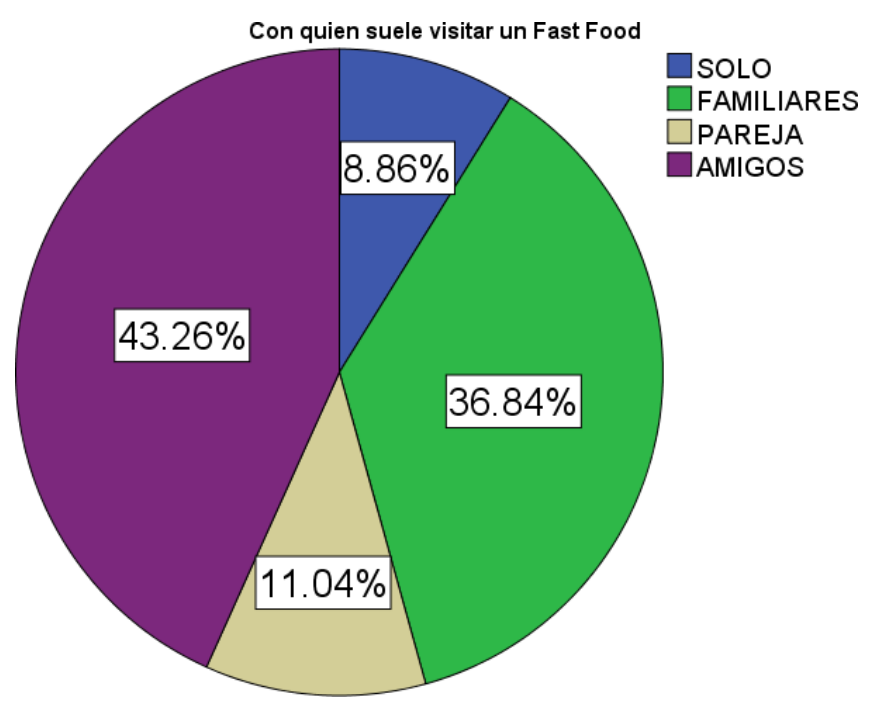

Figura 28. Personas acompañantes durante visita a fast food. Fuente: Elaboración propia. 
- Factores importantes a la hora de decidir para elegir un establecimiento de fast food. (1 menos importante a 10 más importante)

Según Tabla 51 y representado en Figura 29, conforme la frecuencia estadística de los datos obtenidos en el ranking de factores importantes a considerar en un fast food, se puede concluir con un $23.6 \%$ de votos que la calidad del producto es el factor más importante para los encuestados, seguido por el sabor con $22.6 \%$ y el precio con $16.8 \%$. Por el contrario los factores menos relevantes son: la infraestructura con $24.5 \%$ de opiniones en contra y el horario de atención con $16.7 \%$ también de opiniones en contra.

Tabla 51

Factores importantes en un fast food

\begin{tabular}{|c|c|c|c|c|c|c|c|c|c|c|}
\hline & Precio & Ubicación & $\begin{array}{l}\text { Calidad } \\
\text { de } \\
\text { product } \\
\text { os }\end{array}$ & $\begin{array}{l}\text { Calidad } \\
\text { de } \\
\text { atención }\end{array}$ & $\begin{array}{l}\text { Variedad } \\
\text { de } \\
\text { productos }\end{array}$ & Sabor & $\begin{array}{c}\text { Tamaño } \\
\text { de } \\
\text { porción }\end{array}$ & $\begin{array}{c}\text { Horario } \\
\text { de } \\
\text { atención }\end{array}$ & Ambiente & $\begin{array}{l}\text { Infrae } \\
\text { struct } \\
\text { ura }\end{array}$ \\
\hline $\begin{array}{l}1 \text { menos } \\
\text { importante }\end{array}$ & $8.7 \%$ & $12.1 \%$ & $4.2 \%$ & $3.7 \%$ & $7.4 \%$ & $3.9 \%$ & $11.4 \%$ & $16.7 \%$ & $8.5 \%$ & $\begin{array}{c}24.5 \\
\%\end{array}$ \\
\hline $\begin{array}{l}\text { 2da } \\
\text { Opción }\end{array}$ & $5.1 \%$ & $9.6 \%$ & $4.5 \%$ & $5.8 \%$ & $8.2 \%$ & $2.7 \%$ & $13.2 \%$ & $17.7 \%$ & $16.4 \%$ & $\begin{array}{c}16.4 \\
\%\end{array}$ \\
\hline 3er Opción & $4.6 \%$ & $8.7 \%$ & $6.3 \%$ & $5.9 \%$ & $8.2 \%$ & $5.8 \%$ & $13.2 \%$ & $18.7 \%$ & $14.6 \%$ & $\begin{array}{c}13.7 \\
\%\end{array}$ \\
\hline 4ta Opción & $6.4 \%$ & $10.1 \%$ & $5.9 \%$ & $8.7 \%$ & $10.9 \%$ & $5.3 \%$ & $15.9 \%$ & $10.3 \%$ & $16.0 \%$ & $\begin{array}{c}10.1 \\
\%\end{array}$ \\
\hline 5ta Opción & $8.3 \%$ & $14.2 \%$ & $5.8 \%$ & $9.0 \%$ & $10.4 \%$ & $9.2 \%$ & $12.8 \%$ & $13.1 \%$ & $10.5 \%$ & $7.3 \%$ \\
\hline 6ta Opción & $\begin{array}{c}11.7 \\
\%\end{array}$ & $11.4 \%$ & $7.7 \%$ & $11.8 \%$ & $13.6 \%$ & $\begin{array}{c}10.1 \\
\%\end{array}$ & $10.9 \%$ & $7.3 \%$ & $8.3 \%$ & $6.7 \%$ \\
\hline $\begin{array}{l}\text { 7tma } \\
\text { Opción }\end{array}$ & $\begin{array}{c}10.5 \\
\%\end{array}$ & $11.0 \%$ & $10.9 \%$ & $15.7 \%$ & $11.4 \%$ & $\begin{array}{c}13.4 \\
\%\end{array}$ & $8.0 \%$ & $5.6 \%$ & $8.2 \%$ & $4.5 \%$ \\
\hline $\begin{array}{l}\text { 8tava } \\
\text { Opción }\end{array}$ & $\begin{array}{c}10.9 \\
\%\end{array}$ & $9.5 \%$ & $14.1 \%$ & $13.4 \%$ & $16.0 \%$ & $\begin{array}{c}11.8 \\
\%\end{array}$ & $5.4 \%$ & $6.4 \%$ & $8.6 \%$ & $4.0 \%$ \\
\hline $\begin{array}{l}\text { 9na } \\
\text { Opción }\end{array}$ & $\begin{array}{c}16.8 \\
\%\end{array}$ & $8.0 \%$ & $16.9 \%$ & $16.0 \%$ & $7.4 \%$ & $\begin{array}{c}15.3 \\
\%\end{array}$ & $6.0 \%$ & $2.2 \%$ & $5.5 \%$ & $6.2 \%$ \\
\hline $\begin{array}{l}10 \text { muy } \\
\text { importante }\end{array}$ & $\begin{array}{c}16.8 \\
\%\end{array}$ & $5.3 \%$ & $23.6 \%$ & $10.0 \%$ & $6.3 \%$ & $\begin{array}{c}22.6 \\
\%\end{array}$ & $3.1 \%$ & $1.9 \%$ & $3.2 \%$ & $6.5 \%$ \\
\hline
\end{tabular}

Nota. Fuente: Elaboración propia. 


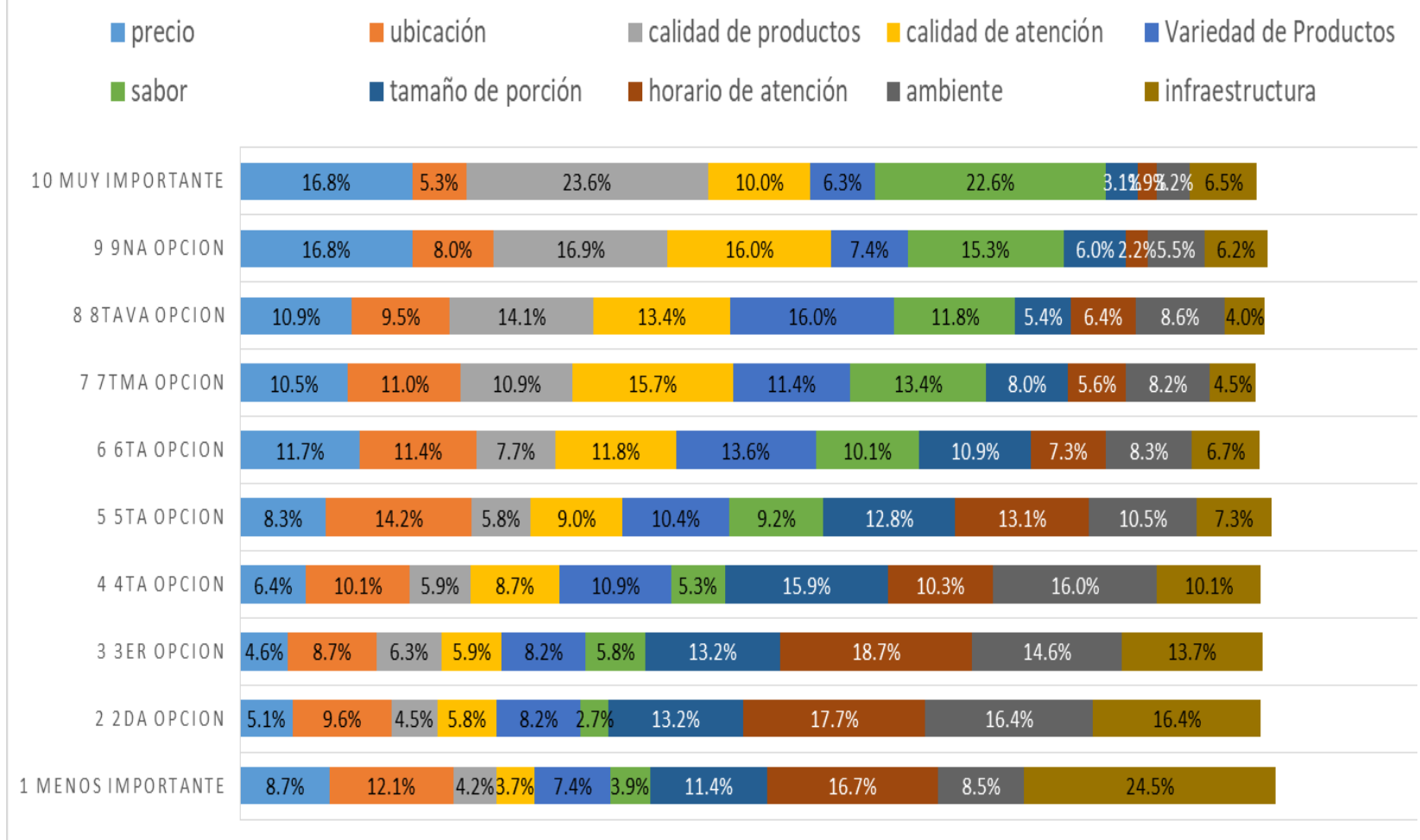

Figura 29. Factores importantes en un fast food. Fuente: Elaboración propia.

- Productos preferidos en un fast food. (Opción múltiple)

Conforme Tabla 52 y representado en Figura 30, se obtuvo que los encuestados prefieren el pollo broaster con un $57.25 \%$ de preferencia, seguido por las hamburguesas con un $53.92 \%$, pizza con un $41,34 \%$ y pollo frito con un $33.76 \%$, dentro de la categoría de pollo frito se considera a las alitas a la BBQ (Barbacoa), además de las empanadas con 15.79\% de aprobación. Lo anterior reafirma el segmento al cual se orienta el proyecto que corresponde a pollos y hamburguesas. Así mismo existen otros productos con minoría de preferencia como son el cuy, salchipapas, anticuchos, entre otros. 
Tabla 52

Productos preferidos en un fast food

\begin{tabular}{lcc}
\hline & Cantidad de respuestas & $\begin{array}{c}\text { \% según } 779 \text { casos }{ }^{\circ} \text { de } \\
\text { encuestas contestadas }\end{array}$ \\
\hline Hamburguesa & 420 & $53.9 \%$ \\
Empanada & 123 & $15.8 \%$ \\
Pollo frito & 263 & $33.8 \%$ \\
Pollo broaster & 446 & $57.3 \%$ \\
Pizza & 322 & $41.3 \%$ \\
Cuy & 2 & $.3 \%$ \\
Salchipapa & 18 & $2.3 \%$ \\
Anticucho & 1 & $.1 \%$ \\
Asado & 1 & $.1 \%$ \\
Crepes & 1 & $.1 \%$ \\
Pan con queso & 1 & $.1 \%$ \\
Piqueo & 2 & $.3 \%$ \\
\hline Total & 1600 & \\
\hline
\end{tabular}

Nota. Fuente: Elaboración propia.

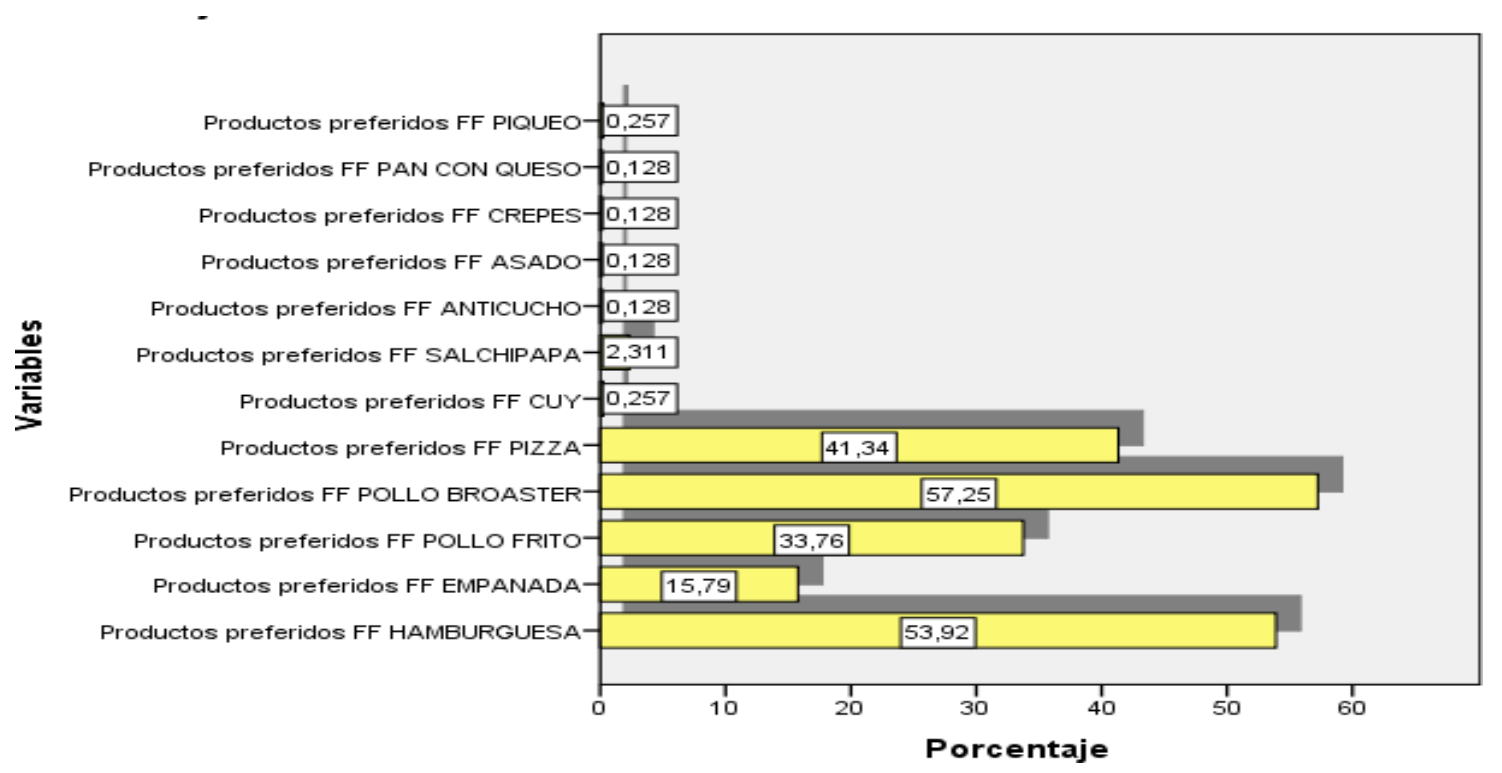

Figura 30. Productos preferidos en un fast food. Fuente: Elaboración propia. 
- Bebidas que suele adquirir en un fast food.(opción múltiple)

Según los resultados obtenidos, se identificó que la gaseosa es la bebida preferida por los encuestados con el $76.12 \%$, seguido por los jugos en un $45.06 \%$ y café con un $24.39 \%$, además de infusiones con el $12.58 \%$ de preferencia, así mismo bebidas como cerveza, agua, chicha morada entre otras cuentan con menor preferencia, conforme Tabla 53 y se representa gráficamente en Figura 31.

Tabla 53

Bebidas que suele adquirir en un fast food

\begin{tabular}{lcc}
\hline & Cantidad de respuestas & $\begin{array}{c}\text { \% según } 779 \text { casos } \mathbf{n}^{\circ} \text { de encuestas } \\
\text { contestadas }\end{array}$ \\
\hline Gaseosa & 593 & $76.12 \%$ \\
Jugos & 351 & $45.06 \%$ \\
Café & 190 & $24.39 \%$ \\
Infusiones & 98 & $12.58 \%$ \\
Cerveza & 52 & $6.68 \%$ \\
Agua & 3 & $0.39 \%$ \\
Chicha morada & 19 & $2.44 \%$ \\
Chichas variadas & 1 & $0.13 \%$ \\
Limonada & 16 & $2.05 \%$ \\
Maracuyá & 2 & $0.26 \%$ \\
Refrescos & 14 & $1.80 \%$ \\
Anisado & 1 & $0.13 \%$ \\
Cremolada & 2 & $0.26 \%$ \\
\hline Total & 1342 & \\
\hline
\end{tabular}

Nota. Fuente: Elaboración propia. 


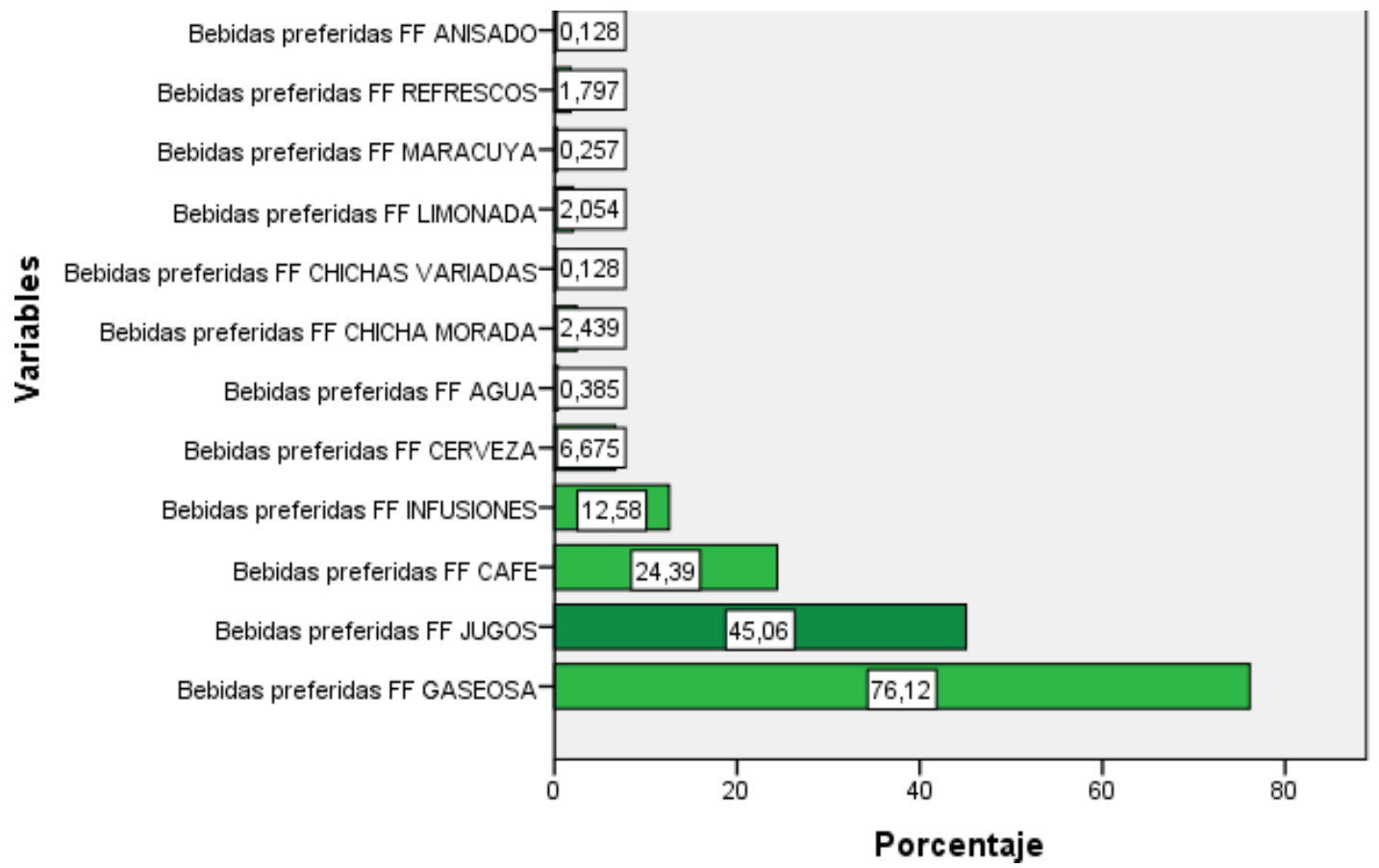

Figura 31. Bebidas que suele adquirir en un Fast Food. Fuente: Elaboración propia.

- Asistencia establecimientos de fast food. (1 menor asistencia a 5 mayor asistencia)

Conforme Tabla 54 y representado gráficamente en Figura 32, en base al ranking de asistencia se analizaron la media de los datos, para ello primero se clasifico a los establecimientos catalogado como "otros" a todas las empresas que fueron seleccionadas con dicha opción además de incorporarse a todos los datos que fueron especificados, puesto que se evidencio menor incidencia de estos datos. En base al resultado se obtuvo que con una media de 3.390, KFC es el fast food con mayor asistencia, seguido por Burguer King con 3.2 de media y Bembos con 3.107 de media. 
Tabla 54

Ranking asistencia a establecimientos de fast food

\begin{tabular}{lccc}
\hline & Estadístico & Media & Desviación estándar \\
\hline P9_Otros Preferencia por Otros & 779 & 1.041 & 2.255 \\
P9e_R_RU Preferencia por Rupha's Diner & 779 & 2.386 & 1.567 \\
P9d_R_PP Preferencia por Popeyes & 779 & 2.968 & 1.354 \\
P9c_R_BB Preferencia por Bembos & 779 & 3.107 & 1.243 \\
P9a_R_BK Preferencia por Burguer King & 779 & 3.200 & 1.291 \\
P9b_R_KF Preferencia por KFC & 779 & 3.390 & 1.420 \\
\hline N válido (por lista) & 779 & &
\end{tabular}

Nota. Fuente: Elaboración propia.

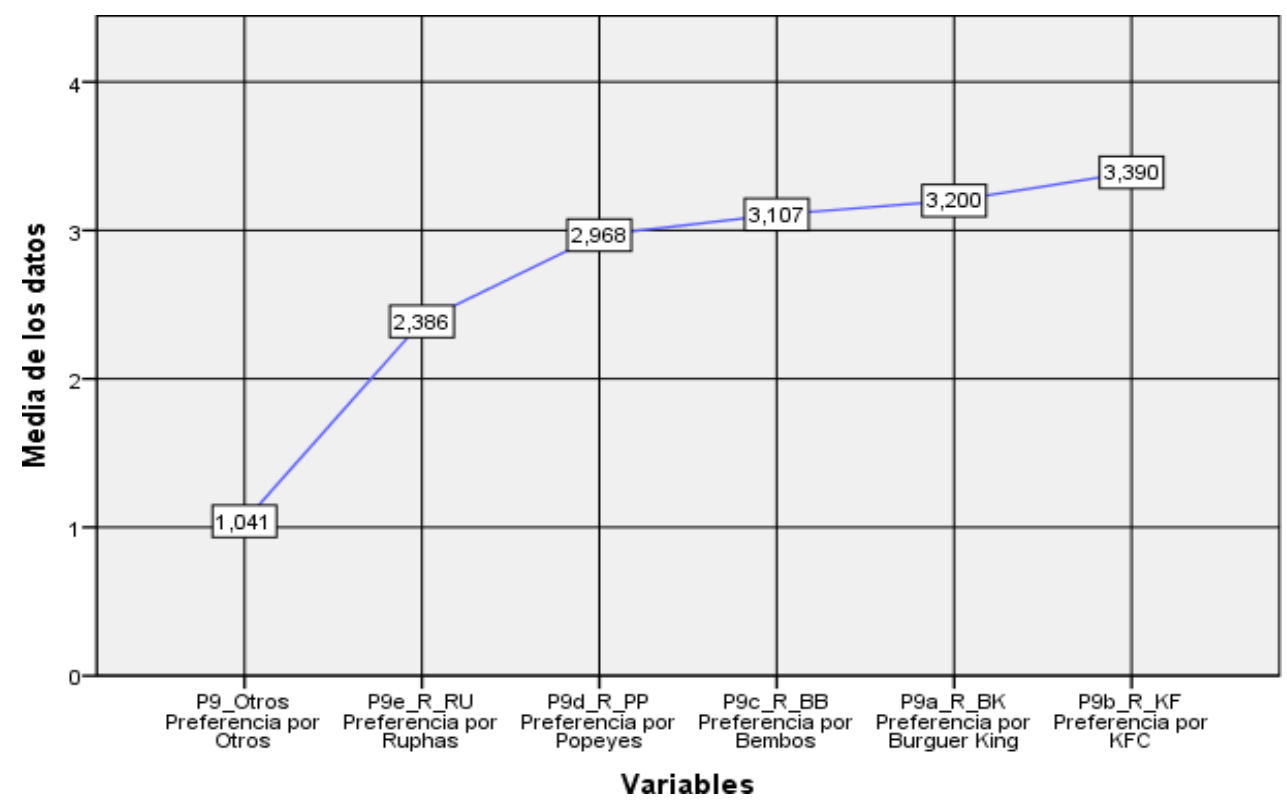

Figura 32. Ranking asistencia a establecimientos de Fast Food. Fuente: Elaboración propia.

Del mismo modo conforme la Tabla 55 y representado en Figura 33, se determinó la participación de mercado de los establecimientos de fast food más concurridos, para ello se consideró el porcentaje de frecuencia de asistencia en base a la medida de mayor asistencia (5ta opción) para cada empresa de fast food en estudio. Con ello se obtuvo que KFC cuenta con una 
participación de mercado de 30.9\%, seguido por Burguer King con 19.5\% y Popeyes con 16.7\%, por último le sigue Bembos con 16.6\% y Rupha’s con $15.5 \%$.

Tabla 55

Participación de mercado de competidores

\begin{tabular}{lcc}
\hline & Cantidad de respuestas & \% Según 779 casos ${ }^{\circ}$ de encuestas contestadas \\
\hline Burguer King & 152 & $19.51 \%$ \\
KFC & 241 & $30.94 \%$ \\
Bembos & 129 & $16.56 \%$ \\
Popeyes & 130 & $16.69 \%$ \\
Rupha's Diner & 121 & $15.53 \%$ \\
Otros & 5 & $0.64 \%$ \\
\hline Total & 778 & \\
\hline
\end{tabular}

Nota. Fuente: Elaboración propia.

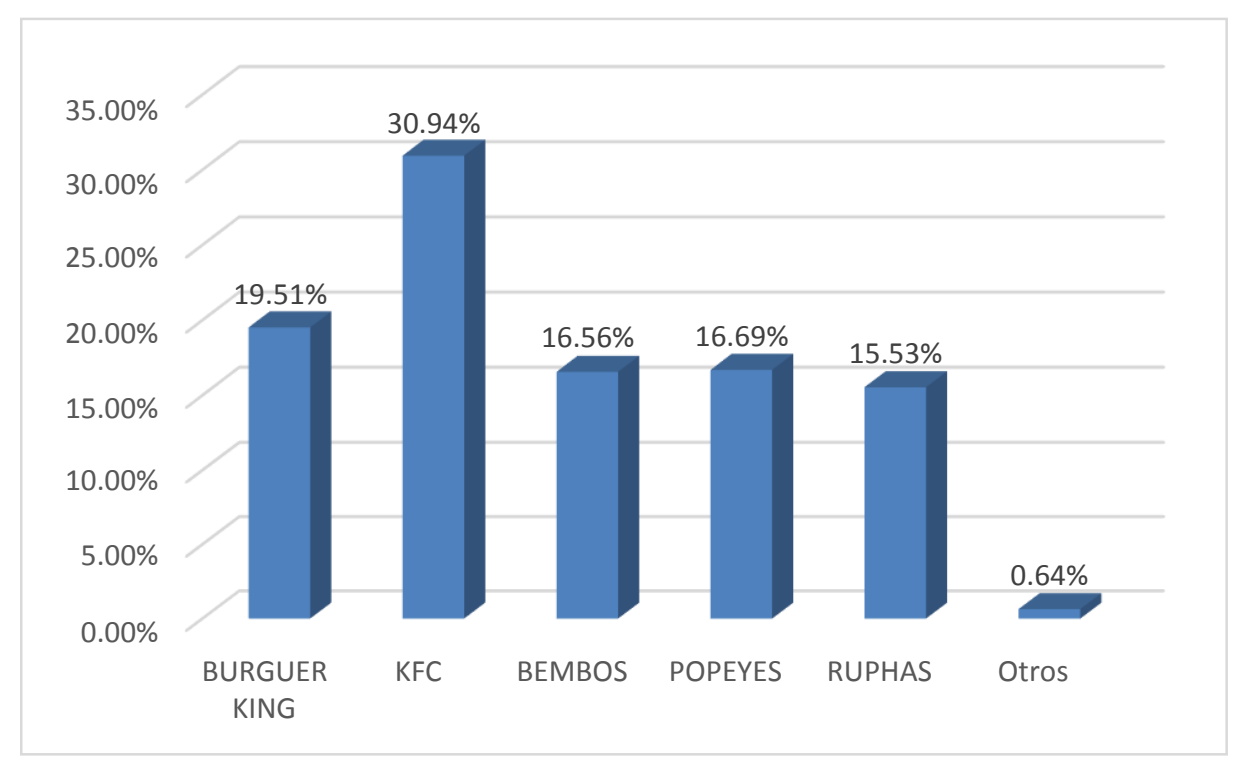

Figura 33. Participación de mercado de competidores. Fuente: Elaboración propia. 
- Factores importantes para elección de fast food preferido. (1 menos importante a 11 más importante)

Según Tabla 56 y representado en Figura 34, se determinaron la frecuencia estadística de los datos para conocer la importancia de ciertos factores para la elección del fast food preferido por los encuestados. Se obtuvo como resultado que el sabor es uno de los factores más importantes con $33.12 \%$ de los votos, seguido por la rapidez del servicio con $15.40 \%$, Tipo de producto con $10.91 \%$ y precio con $10.27 \%$. Por otro lado existen factores con menor importancia como variedad de productos con $18.61 \%$ de votos en contra, el ambiente con $13.61 \%$ y ubicación con $14.12 \%$.

\section{Tabla 56}

Factores para elección de Fast food preferido

\begin{tabular}{|c|c|c|c|c|c|c|c|c|c|c|}
\hline & $\begin{array}{c}\text { Rapid } \\
\text { ez }\end{array}$ & Precio & $\begin{array}{c}\text { Tipo de } \\
\text { producto }\end{array}$ & $\begin{array}{l}\text { Promoc } \\
\text { iones }\end{array}$ & Sabor & $\begin{array}{l}\text { Ubicac } \\
\text { ión }\end{array}$ & $\begin{array}{c}\text { Tamañ } \\
\text { o de } \\
\text { porción }\end{array}$ & $\begin{array}{l}\text { Infraest } \\
\text { ructura }\end{array}$ & Ambiente & $\begin{array}{l}\text { Variedad } \\
\text { de } \\
\text { productos }\end{array}$ \\
\hline $\begin{array}{l}1 \text { menos } \\
\text { important } \\
\mathrm{e}\end{array}$ & $\begin{array}{l}6.80 \\
\%\end{array}$ & $\begin{array}{c}7.83 \\
\%\end{array}$ & $4.75 \%$ & $\begin{array}{c}10.14 \\
\%\end{array}$ & $\begin{array}{c}2.31 \\
\%\end{array}$ & $\begin{array}{c}14.12 \\
\%\end{array}$ & $9.24 \%$ & $\begin{array}{c}13.35 \\
\%\end{array}$ & $13.61 \%$ & $18.61 \%$ \\
\hline $\begin{array}{l}\text { 2da } \\
\text { Opción }\end{array}$ & $\begin{array}{c}3.85 \\
\%\end{array}$ & $\begin{array}{c}7.57 \\
\%\end{array}$ & $8.34 \%$ & $9.50 \%$ & $\begin{array}{c}3.08 \\
\%\end{array}$ & $\begin{array}{c}15.53 \\
\%\end{array}$ & $\begin{array}{c}10.27 \\
\%\end{array}$ & $\begin{array}{c}17.33 \\
\%\end{array}$ & $13.99 \%$ & $10.40 \%$ \\
\hline $\begin{array}{l}\text { 3er } \\
\text { Opción }\end{array}$ & $\begin{array}{c}5.65 \\
\%\end{array}$ & $\begin{array}{c}6.29 \\
\%\end{array}$ & $6.55 \%$ & $8.60 \%$ & $\begin{array}{c}4.75 \\
\%\end{array}$ & $\begin{array}{c}13.86 \\
\%\end{array}$ & $\begin{array}{c}12.58 \\
\%\end{array}$ & $\begin{array}{c}15.40 \\
\%\end{array}$ & $15.02 \%$ & $11.55 \%$ \\
\hline $\begin{array}{l}\text { 4ta } \\
\text { Opción }\end{array}$ & $\begin{array}{c}6.03 \\
\%\end{array}$ & $\begin{array}{c}9.11 \\
\%\end{array}$ & $9.11 \%$ & $\begin{array}{c}10.14 \\
\%\end{array}$ & $\begin{array}{l}5.65 \\
\%\end{array}$ & $\begin{array}{c}11.68 \\
\%\end{array}$ & $\begin{array}{c}14.51 \\
\%\end{array}$ & $\begin{array}{c}13.09 \\
\%\end{array}$ & $12.84 \%$ & $7.57 \%$ \\
\hline $\begin{array}{l}\text { 5ta } \\
\text { Opción }\end{array}$ & $\begin{array}{c}8.47 \\
\%\end{array}$ & $\begin{array}{c}10.40 \\
\%\end{array}$ & $10.27 \%$ & $\begin{array}{c}11.68 \\
\%\end{array}$ & $\begin{array}{c}3.47 \\
\%\end{array}$ & $\begin{array}{c}14.12 \\
\%\end{array}$ & $\begin{array}{c}12.07 \\
\%\end{array}$ & $9.11 \%$ & $9.37 \%$ & $11.17 \%$ \\
\hline $\begin{array}{l}\text { 6ta } \\
\text { Opción }\end{array}$ & $\begin{array}{c}11.55 \\
\%\end{array}$ & $\begin{array}{c}11.42 \\
\%\end{array}$ & $11.55 \%$ & $\begin{array}{c}11.17 \\
\%\end{array}$ & $\begin{array}{c}8.86 \\
\%\end{array}$ & $9.37 \%$ & $\begin{array}{c}10.65 \\
\%\end{array}$ & $7.32 \%$ & $9.50 \%$ & $8.60 \%$ \\
\hline $\begin{array}{l}\text { 7tma } \\
\text { Opción }\end{array}$ & $\begin{array}{c}10.27 \\
\%\end{array}$ & $\begin{array}{c}11.55 \\
\%\end{array}$ & $14.38 \%$ & $\begin{array}{c}11.30 \\
\%\end{array}$ & $\begin{array}{l}9.76 \\
\%\end{array}$ & $7.57 \%$ & $9.37 \%$ & $5.78 \%$ & $7.45 \%$ & $12.32 \%$ \\
\hline $\begin{array}{l}\text { 8tava } \\
\text { Opción }\end{array}$ & $\begin{array}{c}15.79 \\
\%\end{array}$ & $\begin{array}{c}11.04 \\
\%\end{array}$ & $13.09 \%$ & $\begin{array}{c}10.27 \\
\%\end{array}$ & $\begin{array}{c}12.84 \\
\%\end{array}$ & $6.29 \%$ & $8.60 \%$ & $6.93 \%$ & $7.32 \%$ & $7.96 \%$ \\
\hline $\begin{array}{l}\text { 9na } \\
\text { Opción }\end{array}$ & $\begin{array}{c}16.17 \\
\%\end{array}$ & $\begin{array}{c}14.51 \\
\%\end{array}$ & $11.04 \%$ & $9.37 \%$ & $\begin{array}{c}16.17 \\
\%\end{array}$ & $4.75 \%$ & $8.09 \%$ & $6.42 \%$ & $6.42 \%$ & $6.42 \%$ \\
\hline $\begin{array}{l}10 \text { muy } \\
\text { important } \\
\mathrm{e}\end{array}$ & $\begin{array}{c}15.40 \\
\%\end{array}$ & $\begin{array}{c}10.27 \\
\%\end{array}$ & $10.91 \%$ & $7.83 \%$ & $\begin{array}{c}33.12 \\
\%\end{array}$ & $2.70 \%$ & $4.62 \%$ & $5.26 \%$ & $4.49 \%$ & $5.39 \%$ \\
\hline
\end{tabular}

Nota. Fuente: Elaboración propia. 


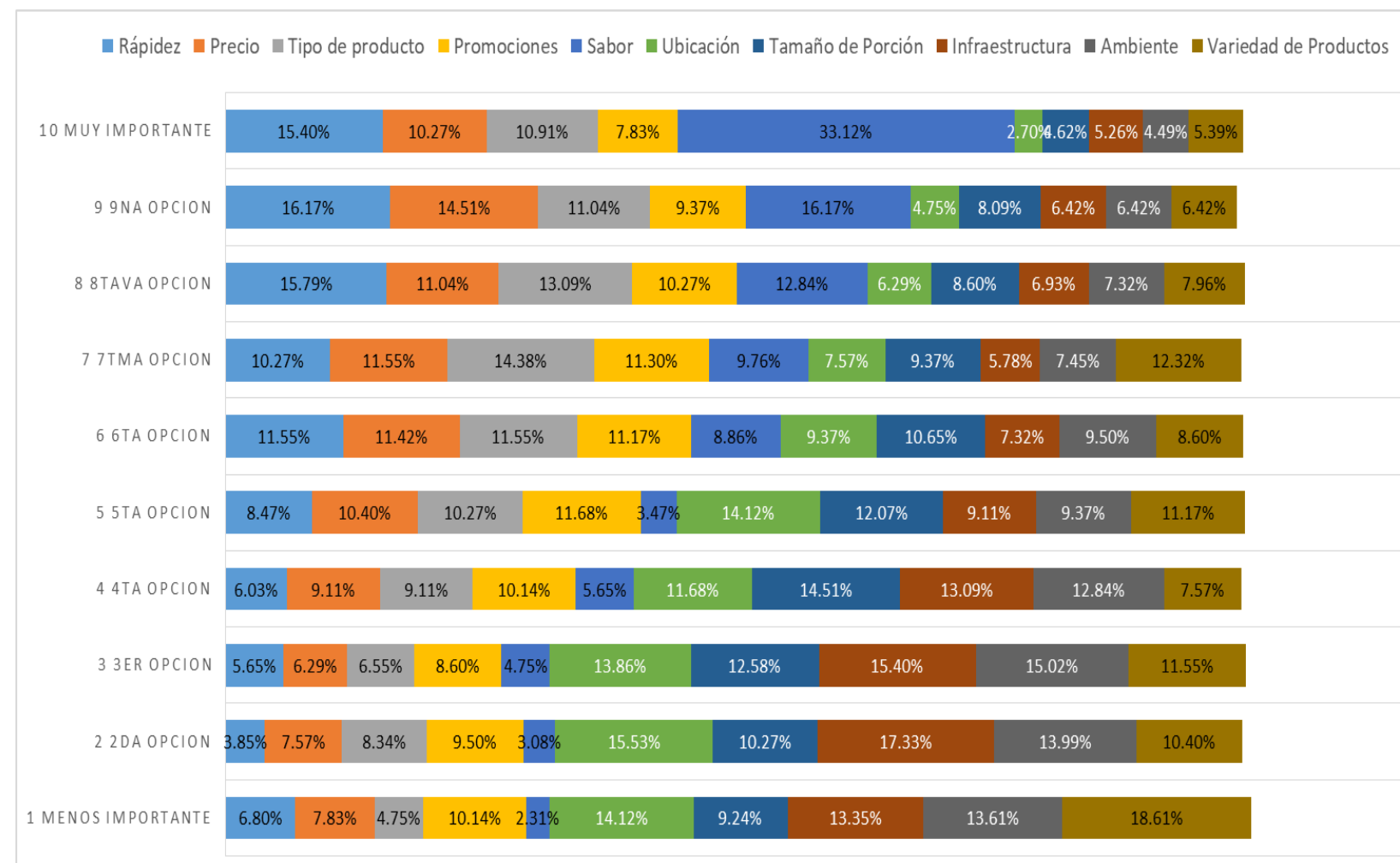

Figura 34. Importancia de factores para fast food preferido. Fuente: Elaboración propia.

- Insumos andinos preferidos para implementar un nuevo fast food novoandino. (Opción múltiple).

Los resultados en la encuesta arrojaron que la harina de quinua es la preferida por los consumidores, que sería utilizada para las preparaciones de pollo broaster en el nuevo proyecto de fast food con una preferencia de $41.08 \%$, seguido por la carne de chancho con $38.25 \%$ y harina de kiwicha con un 30.55\% de preferencia, luego se encuentra la harina de maíz con $27.60 \%$, ambas harinas tendrían el mismo uso mismo que la harina de quinua, además de aderezos de lechón y huacatay con $24.52 \%$ y $23.49 \%$ de preferencia, conforme Tabla 57 y representado en Figura 35. 


\section{Tabla 57}

Insumos andinos preferidos para nuevo fast food novoandino

\begin{tabular}{lcc}
\hline & Cantidad de respuestas & $\begin{array}{c}\text { Porcentaje según casos (779 casos - } \mathrm{n}^{\circ} \text { de } \\
\text { encuestas) }\end{array}$ \\
\hline Carne de chancho & 298 & $38.25 \%$ \\
Harina de kiwicha & 238 & $30.55 \%$ \\
Harina de quinua & 320 & $41.08 \%$ \\
Harina de maíz & 215 & $27.60 \%$ \\
Aderezo de lechón & 191 & $24.52 \%$ \\
Aderezo de huacatay & 183 & $23.49 \%$ \\
Hongos & 3 & $0.39 \%$ \\
Huevo corral & 1 & $0.13 \%$ \\
Ocopa & 1 & $0.13 \%$ \\
Res & 1 & $0.13 \%$ \\
Salsa ají amarillo & 1 & $0.13 \%$ \\
A la leña & 1 & $0.13 \%$ \\
Uchucuta & 2 & $.3 \%$ \\
\hline Total & 1455 & \\
\hline
\end{tabular}

Nota. Fuente: Elaboración propia.

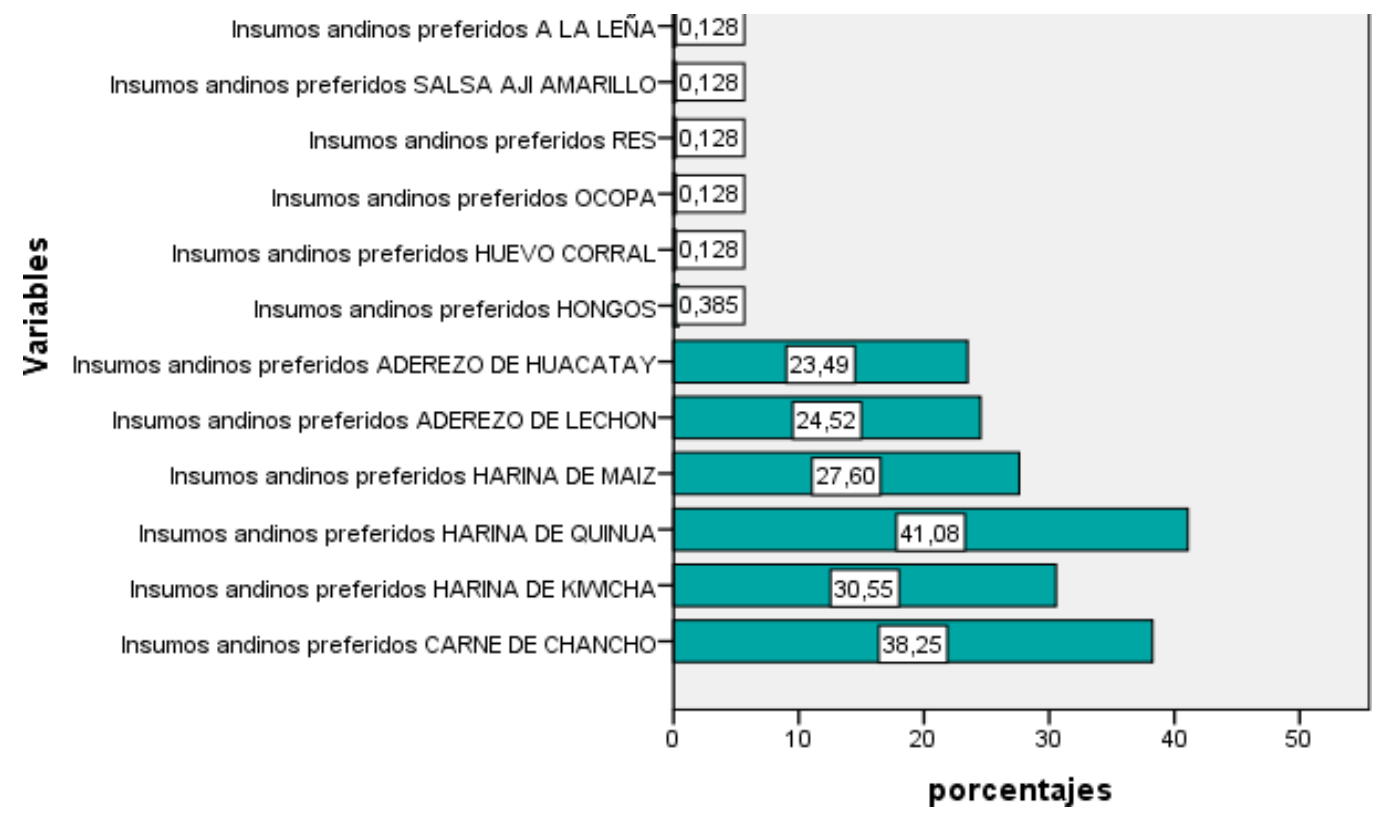

Figura 35. Insumos preferidos para nuevo fast food novoandino. Fuente: Elaboración propia. 
- Adicionales andinos que le gustaría encontrar en un nuevo fast food novoandino. (opción múltiple).

Conforme Tabla 58 y representado en Figura 36, los consumidores muestran preferencia por el ají uchucuta como complemento o adicional para el nuevo proyecto de fast food novoandino con un $55.71 \%$ de preferencia, seguido por las papas nativas con $51.35 \%$ y choclo con queso con $33.63 \%$ de preferencia, además de papa helada con queso con 32,73\%. Sin embargo existen productos con menor preferencia como son la torreja de maíz y moraya con queso con $19.90 \%$ y $19.77 \%$ de preferencia, seguidos por otros productos con más baja preferencia con índices menores a $0.5 \%$, entre estos se puede resaltar la papa frita con $0.13 \%$ de preferencia lo que da a entender que los cusqueños prefieren productos locales.

\section{Tabla 58}

Adicionales andinos preferidos para implementar un nuevo fast food novoandino

\begin{tabular}{lcc}
\hline & Cantidad de respuestas & $\begin{array}{c}\text { Porcentaje según casos (779 casos - } \mathrm{n}^{\circ} \text { de } \\
\text { encuestas) }\end{array}$ \\
\hline Ají uchucuta & 434 & $55.71 \%$ \\
Torreja de maíz & 155 & $19.90 \%$ \\
Papa helada con queso & 255 & $32.73 \%$ \\
Moraya con queso & 154 & $19.77 \%$ \\
Papas nativas & 400 & $51.35 \%$ \\
Choclo con queso & 262 & $33.63 \%$ \\
Camote & 1 & $0.13 \%$ \\
Nabo & 2 & $0.26 \%$ \\
Ocopa & 1 & $0.13 \%$ \\
Papa frita & 1 & $0.13 \%$ \\
Yuca & 3 & $0.39 \%$ \\
Rocoto relleno & 1 & $0.13 \%$ \\
\hline Total & 1669 & \\
\hline
\end{tabular}

Nota. Fuente: Elaboración propia. 


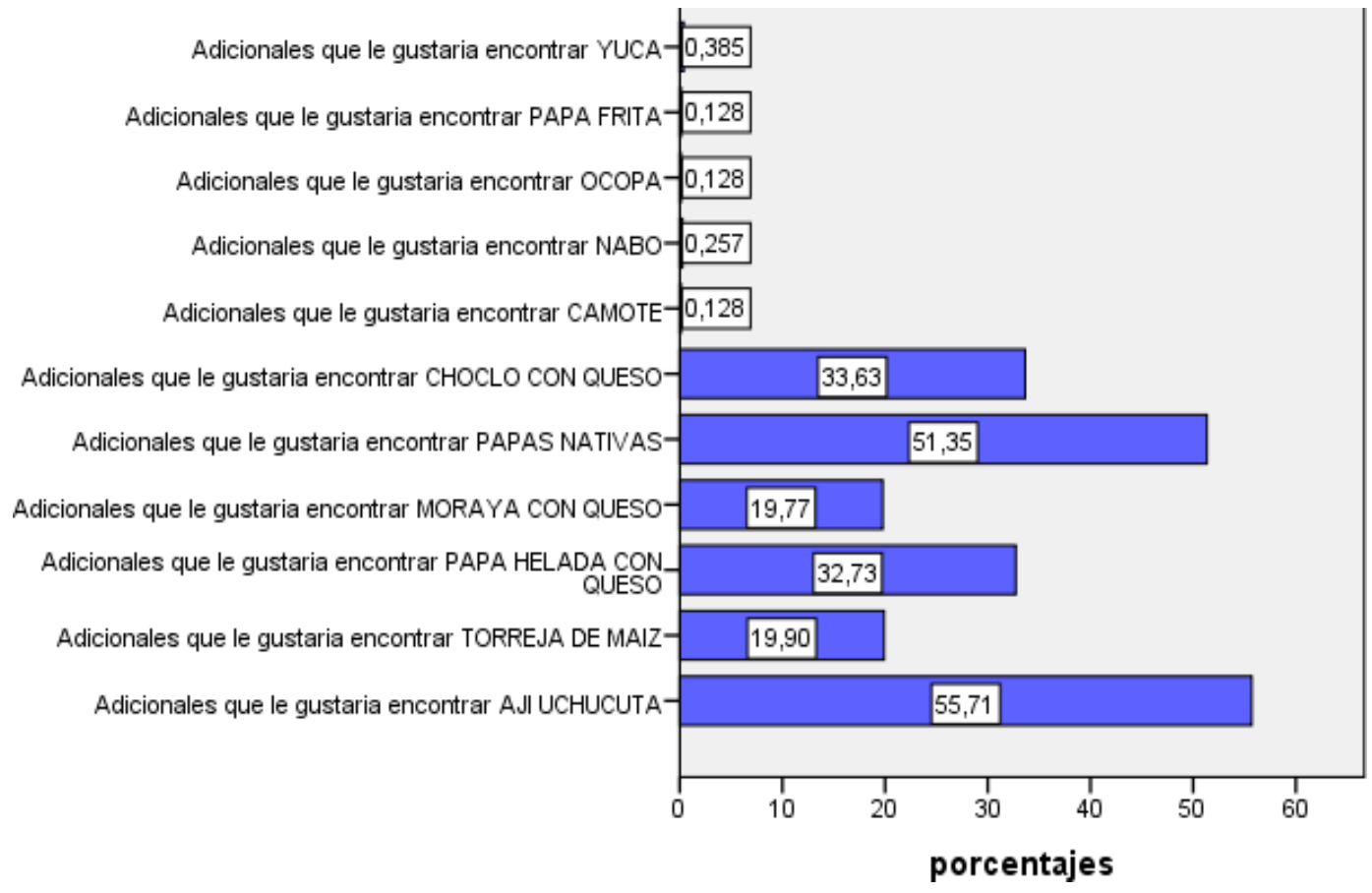

Figura 36. Adicionales andinos preferidos para implementar nuevo fast food novoandino. Fuente: Elaboración propia.

- Bebidas andinas que le gustaría encontrar en un nuevo Fast Food Novoandino.

(Opción Múltiple)

Conforme Tabla 59 y representado en Figura 37, se evidencia una alta preferencia por las bebidas emolientes con un nivel de preferencia de $53.15 \%$, seguido por la chicha de quinua con una preferencia de $52.37 \%$ y chicha de kiwicha con $30.81 \%$ de preferencia. En menor proporción se encuentran otras bebidas como anisado, cebada, jora, chicha morada, coca, infusiones, entre otras. 
Tabla 59

Bebidas andinas preferidas para nuevo fast food novoandino

\begin{tabular}{lcc}
\hline & Cantidad de respuestas & $\begin{array}{c}\text { Porcentaje según casos (779 casos - } \mathrm{n}^{\circ} \text { de } \\
\text { encuestas) }\end{array}$ \\
\hline Emoliente & 414 & $53.15 \%$ \\
Chicha de quinua & 408 & $52.37 \%$ \\
Chicha de kiwicha & 240 & $30.81 \%$ \\
Anisado & 8 & $1.03 \%$ \\
Cebada & 4 & $0.51 \%$ \\
Cerveza artesanal & 2 & $0.26 \%$ \\
Jora & 13 & $1.67 \%$ \\
Chicha morada & 17 & $2.18 \%$ \\
Chicha variedad & 18 & $2.31 \%$ \\
Coca & 1 & $0.13 \%$ \\
Infusiones & 7 & $0.90 \%$ \\
Jugos andinos & 3 & $0.39 \%$ \\
Limonada & 1 & $0.13 \%$ \\
Refresco & 5 & $0.64 \%$ \\
Agua & 3 & $0.39 \%$ \\
\hline Total & 1144 &
\end{tabular}

Nota. Fuente: Elaboración propia.

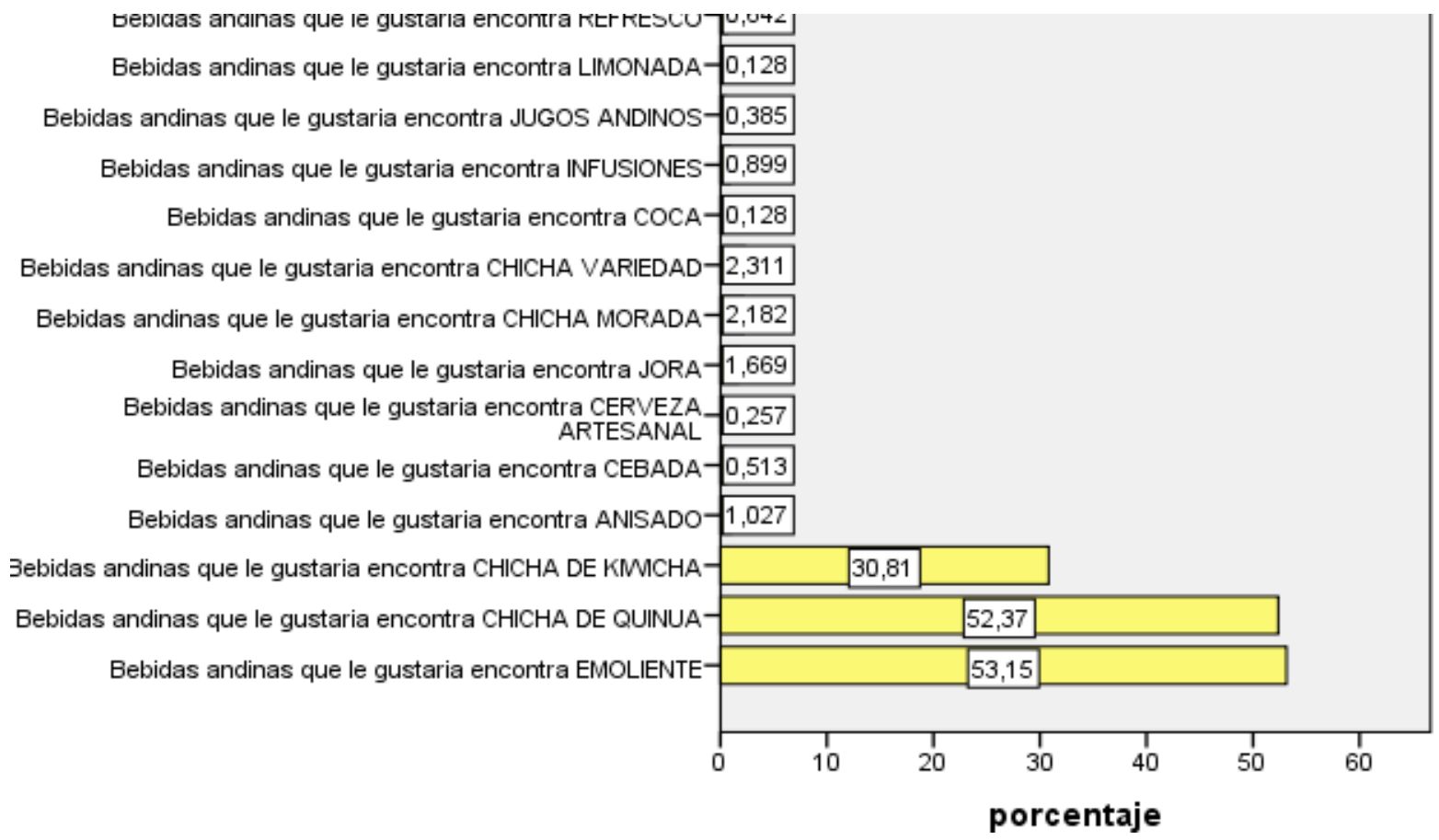

Figura 37. Bebidas andinas preferidas para implementar un nuevo fast food novoandino. Fuente: Elaboración propia. 
- Pago promedio por combo personal en un nuevo fast food novoandino.

Según Tabla 60 y representado en Figura 38, se muestra cuento estaría dispuesto a pagar el encuestado por un combo personal que incluye pollo o hamburguesa más complemento y bebida. Se obtuvo que mayoritariamente pagarían entre 10 a 15 soles con un $68.68 \%$ de preferencia seguido por el rango de 16 a 25 soles con $21.18 \%$ de preferencia.

Tabla 60

Pago promedio por combo personal en nuevo fast food novoandino

\begin{tabular}{lcc}
\hline & Frecuencia & Porcentaje $(\%)$ \\
\hline 10 a 15 soles & 535 & 68.68 \\
16 a 25 soles & 165 & 21.18 \\
26 a 35 soles & 78 & 10.01 \\
36 soles a más & 1 & 0.13 \\
\hline Total & 779 & 100.00 \\
\hline Nota. Fuente: Elaboración propia. & &
\end{tabular}

Rango promedio de pago por un combo personal en el Nuevo Fast Food

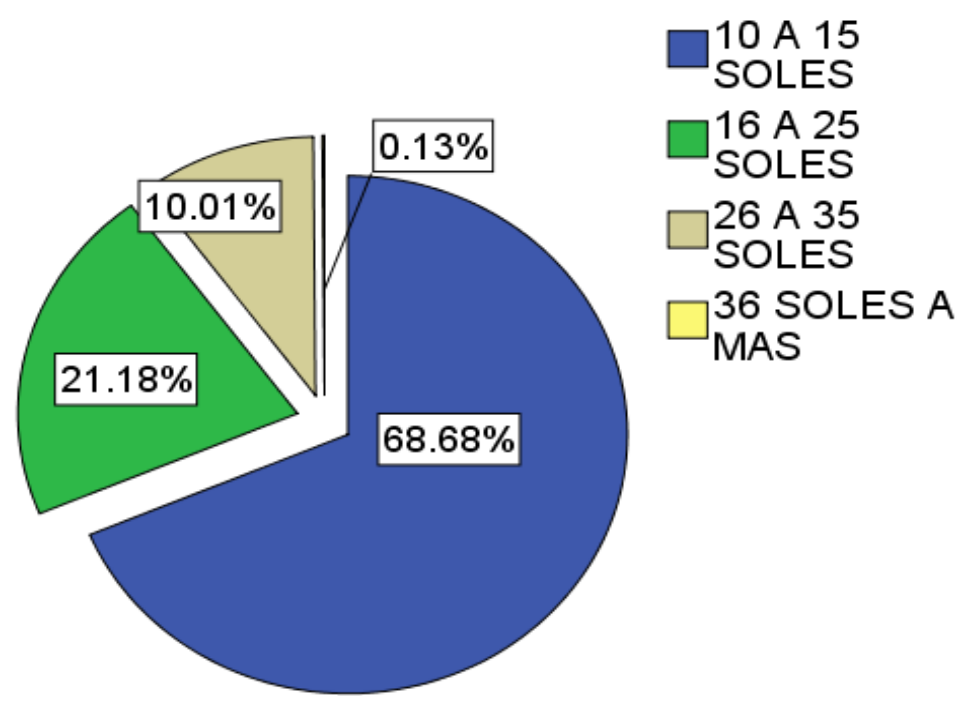

Figura 38. Pago promedio por combo personal en nuevo fast food novoandino. Fuente: Elaboración propia. 
- Pago promedio por adicionales en un nuevo fast food novoandino.

Según Tabla 61 y representado en Figura 39, los encuestados están dispuestos a pagar mayoritariamente de 5 a 7 soles por adicionales en el nuevo proyecto de fast food con una preferencia de $77.54 \%$, seguido por el rango de 8 a 10 soles con una preferencia de $17.46 \%$.

Tabla 61

Pago promedio por adicional en nuevo fast food novoandino

Frecuencia $\quad$ Porcentaje (\%)

\begin{tabular}{lcc}
\hline 5 a 7 soles & 604 & 77.54 \\
8 a 10 soles & 136 & 17.46 \\
11 a 12 soles & 35 & 4.49 \\
13 soles a más & 4 & 0.51 \\
\hline Total & 779 & 100.00 \\
\hline
\end{tabular}

Nota. Fuente: Elaboración propia.

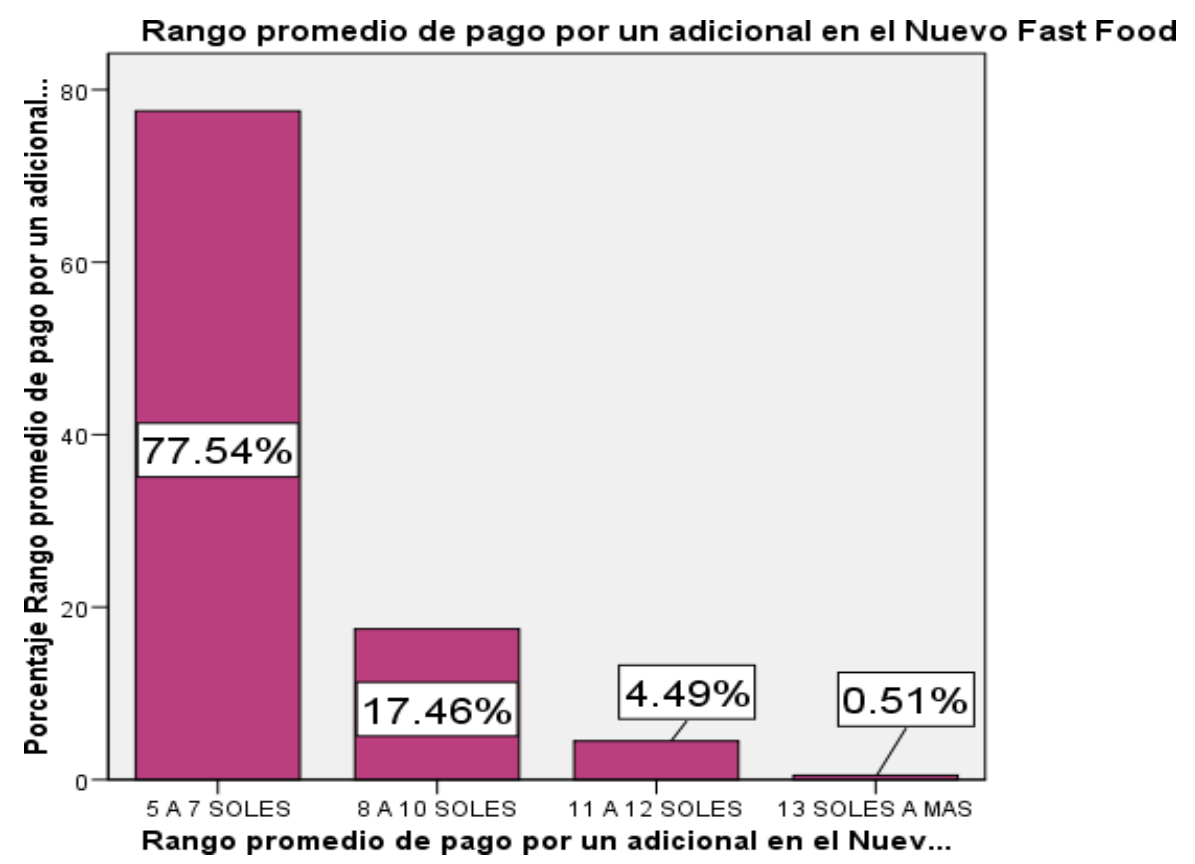

Figura 39. Pago promedio por adicional en nuevo fast food novoandino. Fuente: Elaboración propia. 
- Postres andinos para el nuevo fast food novoandino.(opción múltiple)

Como resultado de la investigación se obtuvo que el pastel de choclo es el más preferido con el $44.93 \%$ de elecciones, seguido por el budín de quinua con $44.80 \%$ de preferencia y el dulce de melocotón con $25.16 \%$, además del dulce de sacha tómate y la gelatina de pata de vaca con $19.64 \%$ y $15.66 \%$ de preferencia respectivamente. Según Tabla 62 y representado en Figura 40.

Tabla 62

Postres andinos para el nuevo fast food novoandino

\begin{tabular}{lcc}
\hline & Cantidad de respuestas & $\begin{array}{c}\text { Porcentaje según casos (779 } \\
\text { casos - nº de encuestas) }\end{array}$ \\
\hline Pastel de choclo & 350 & $44.93 \%$ \\
Dulce de sacha tómate & 153 & $19.64 \%$ \\
Budín de quinua & 349 & $44.80 \%$ \\
Gelatina de pata de vaca & 122 & $15.66 \%$ \\
Dulce de melocotón & 196 & $25.16 \%$ \\
Helado artesanal & 6 & $0.77 \%$ \\
Mazamorra de quinua & 1 & $0.13 \%$ \\
Guiso de durazno & 2 & $0.26 \%$ \\
Dulce de calabaza & 1 & $0.13 \%$ \\
Dulce de sauco & 2 & $0.26 \%$ \\
Torta & 1 & $.13 \%$ \\
\hline Total & 1183 & \\
\hline
\end{tabular}

Nota. Fuente: Elaboración propia. 


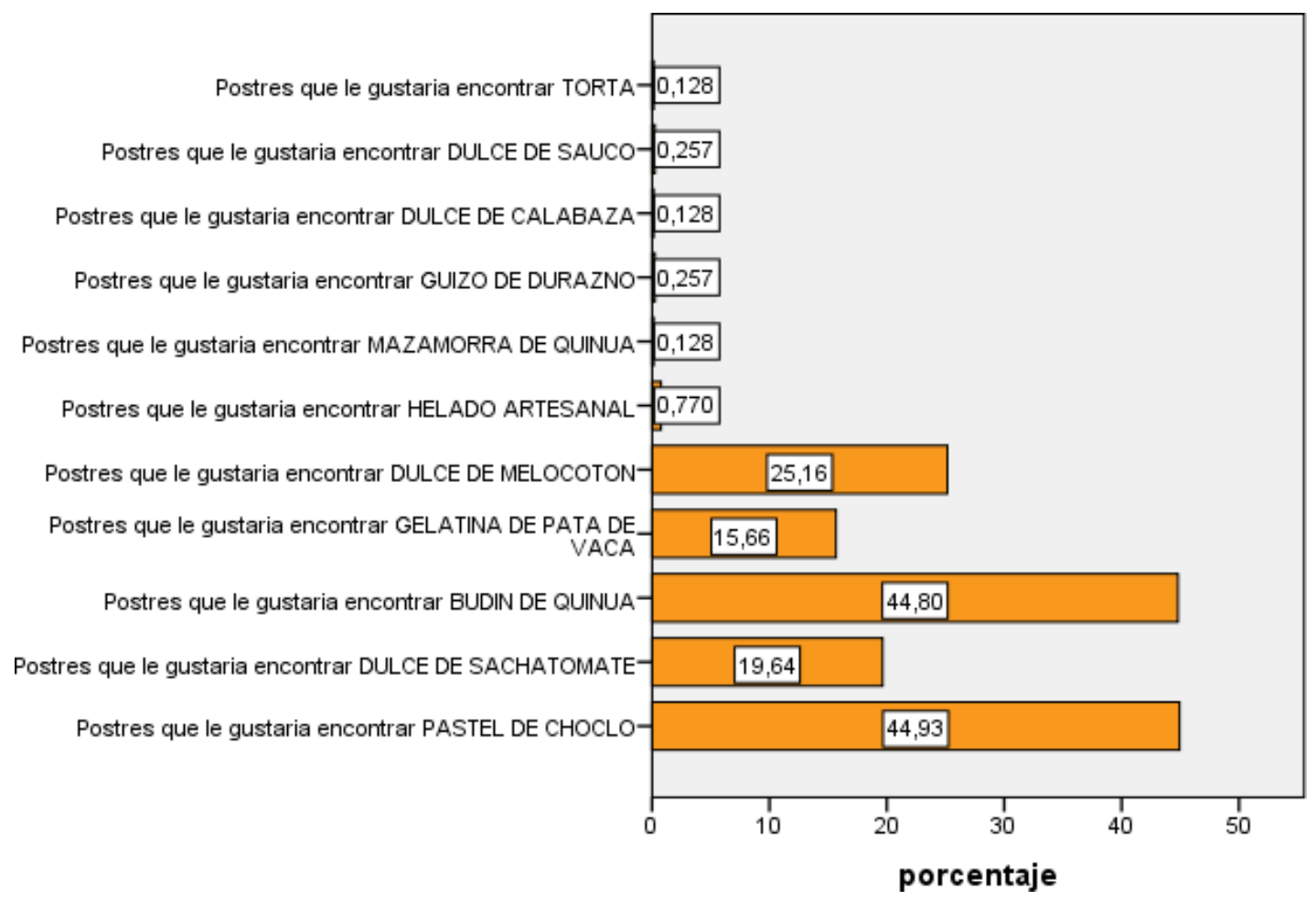

Figura 40. Postres andinos para el nuevo fast food novoandino. Fuente: Elaboración propia.

- Pago promedio por un postre andino en el nuevo fast food novoandino.

Conforme Tabla 63 y representado en Figura 41, se obtuvo que los encuestados estarían dispuestos a pagar entre 5 a 7 soles por un postre en el nuevo proyecto de fast food novoandino con una preferencia de $64.44 \%$, seguido por el rango de 8 a 10 soles con $28.88 \%$ de preferencia. 
Tabla 63

Pago promedio por postre en nuevo fast food novoandino

\begin{tabular}{lcc}
\hline & Frecuencia & Porcentaje $(\%)$ \\
\hline 5 a 7 soles & 502 & 64.44 \\
8 a 10 soles & 225 & 28.88 \\
11 soles a más & 52 & 6.68 \\
\hline Total & 779 & 100.00
\end{tabular}

Nota. Fuente: Elaboración propia.

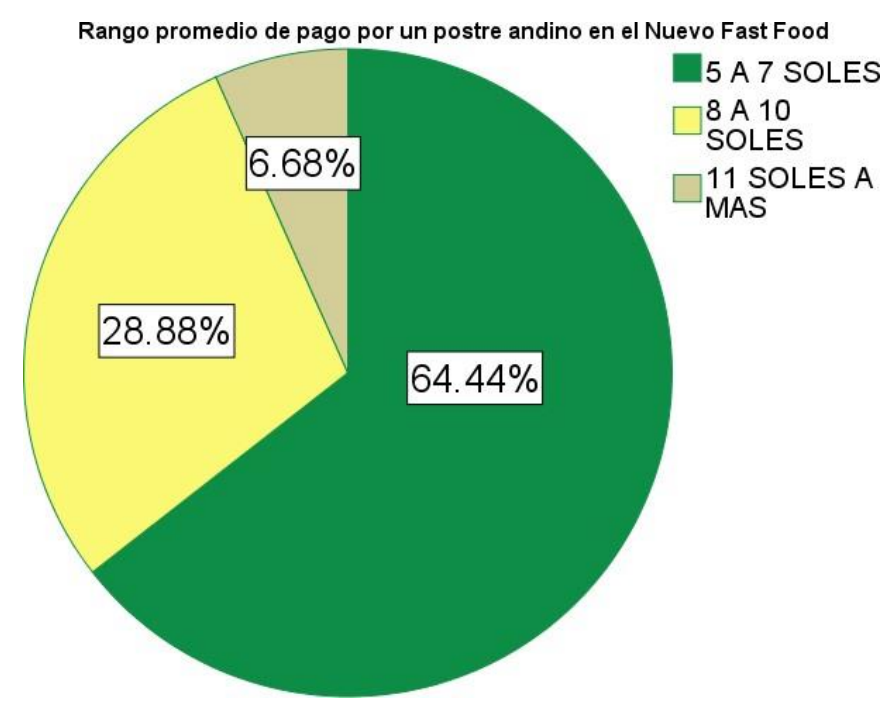

Figura 41.Pago promedio por postre andino en el nuevo fast food novoandino. Fuente: Elaboración propia.

- Filtro 3: Aceptación de un nuevo fast food novoandino.

Conforme Tabla 64 y representado en Figura 42, se determinó que los encuestado definitivamente asistirían al nuevo proyecto de fast food con una aceptación de $40.31 \%$ y existiría otro grupo con una aceptación de $55.71 \%$ que probablemente asistiría; ello refleja la potencialidad que ofrece el presente proyecto. 
Tabla 64

Aceptación de nuevo fast food novoandino

\begin{tabular}{lcc}
\hline & Frecuencia & Porcentaje (\%) \\
\hline Definitivamente asistiría & 314 & 40.31 \\
Probablemente asistiría & 434 & 55.71 \\
Indiferente & 16 & 2.05 \\
Probablemente no asistiría & 14 & 1.80 \\
Definitivamente no asistiría & 1 & 0.13 \\
(Fin de la encuesta) & 779 & 100.00 \\
\hline Total & & \\
\hline
\end{tabular}

Nota. Fuente: Elaboración propia.

Asistiría a este Nuevo Fast Food

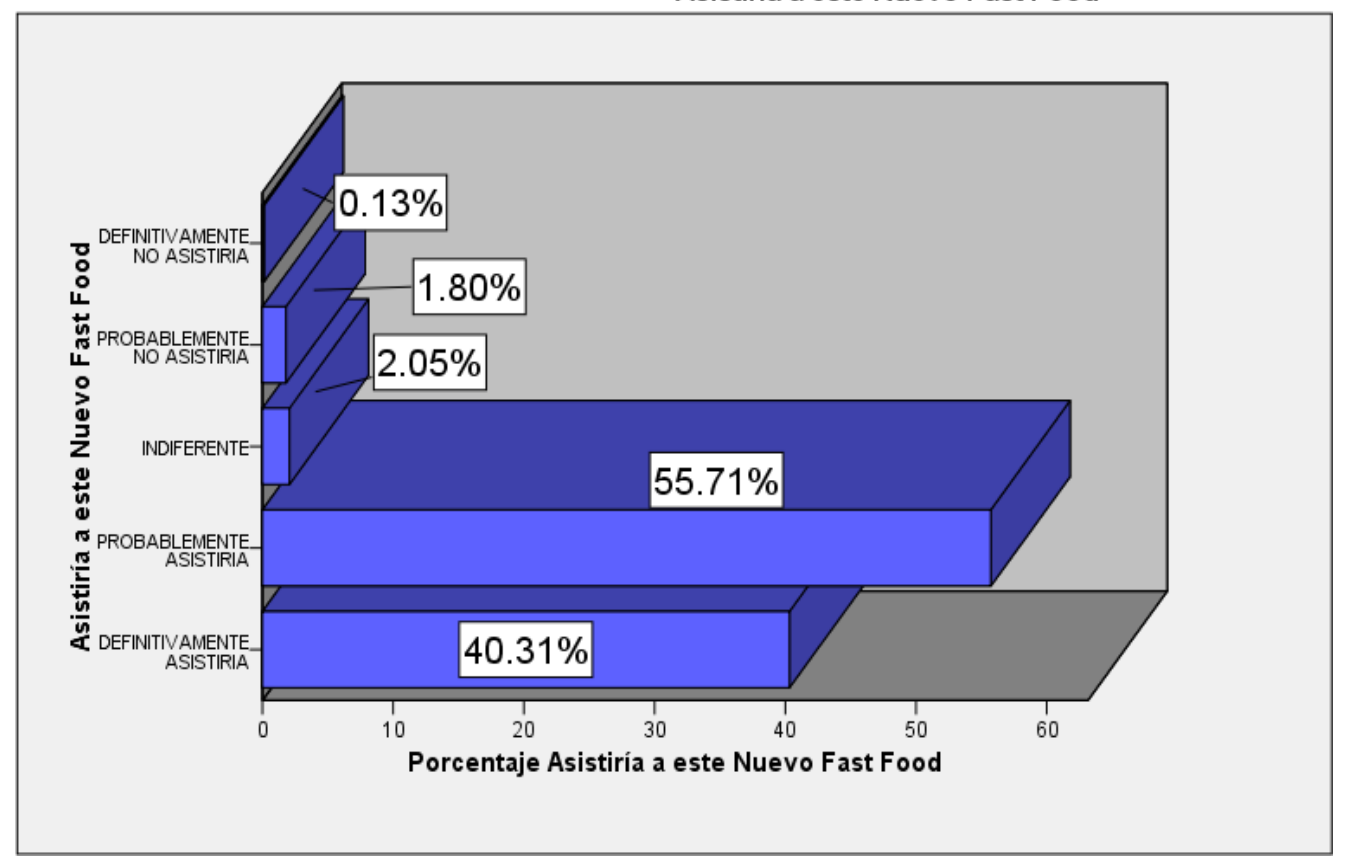

Figura 42. Aceptación de nuevo fast food novoandino. Fuente: Elaboración propia. 
- Tiempo de espera por pedido en un nuevo fast food novoandino.

Según Tabla 65 y representado en Figura 43, se pudo obtener que 81.11\% de los encuestados estarían dispuestos a esperar por sus pedidos de 10 a 15 minutos, por otro lado $16.20 \%$ de los encuestados estarían dispuestos a esperar de 16 a 20 minutos por sus pedidos. Esto establece un estándar de atención para el presente proyecto.

Tabla 65

Tiempo de espera por pedido en nuevo fast food novoandino

\begin{tabular}{lcc}
\hline & Frecuencia & Porcentaje $(\%)$ \\
\hline 10 a 15 minutos & 631 & 81.11 \\
16 a 20 minutos & 126 & 16.20 \\
21 a 25 minutos & 17 & 2.19 \\
26 minutos a más & 4 & 0.51 \\
\hline Total & 778 & 100.00
\end{tabular}

Nota. Fuente: Elaboración propia.

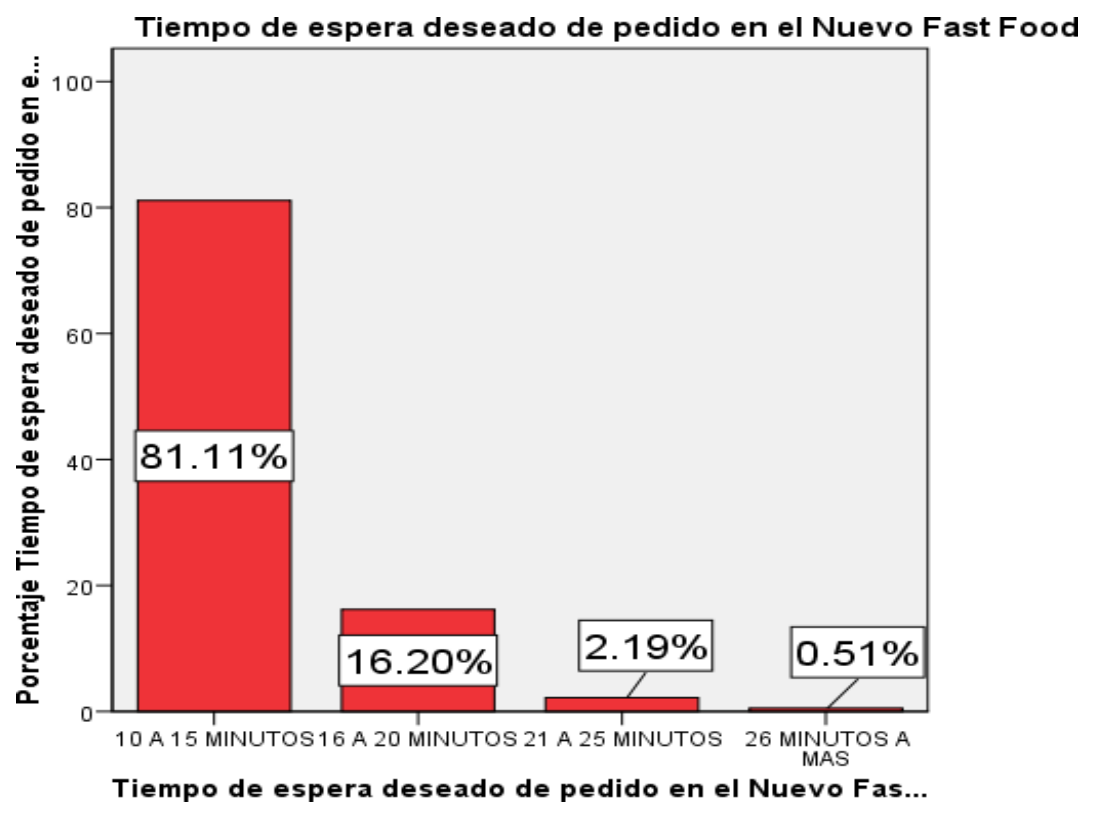

Figura 43. Tiempo de espera por pedido nuevo fast food novoandino. Fuente: Elaboración propia. 
- Tiempo de permanencia en un nuevo fast food novoandino.

Conforme Tabla 66 y representado en Figura 44, se evidencio que el 50.90\% de los encuestados permanecerían más de 31 minutos en el establecimiento del nuevo proyecto de fast food novoandino, seguido por un $31.36 \%$ quienes permanecerían entre 21 y 30 minutos en el establecimiento.

Tabla 66

Tiempo de permanencia en nuevo fast food novoandino

\begin{tabular}{lcc}
\hline & Frecuencia & Porcentaje (\%) \\
\hline 10 a 15 minutos & 97 & 12.47 \\
16 a 20 minutos & 41 & 5.27 \\
21 a 30 minutos & 244 & 31.36 \\
Más de 31 minutos & 396 & 50.90 \\
\hline Total & 778 & 100.00 \\
\hline
\end{tabular}

Nota. Fuente: Elaboración propia.

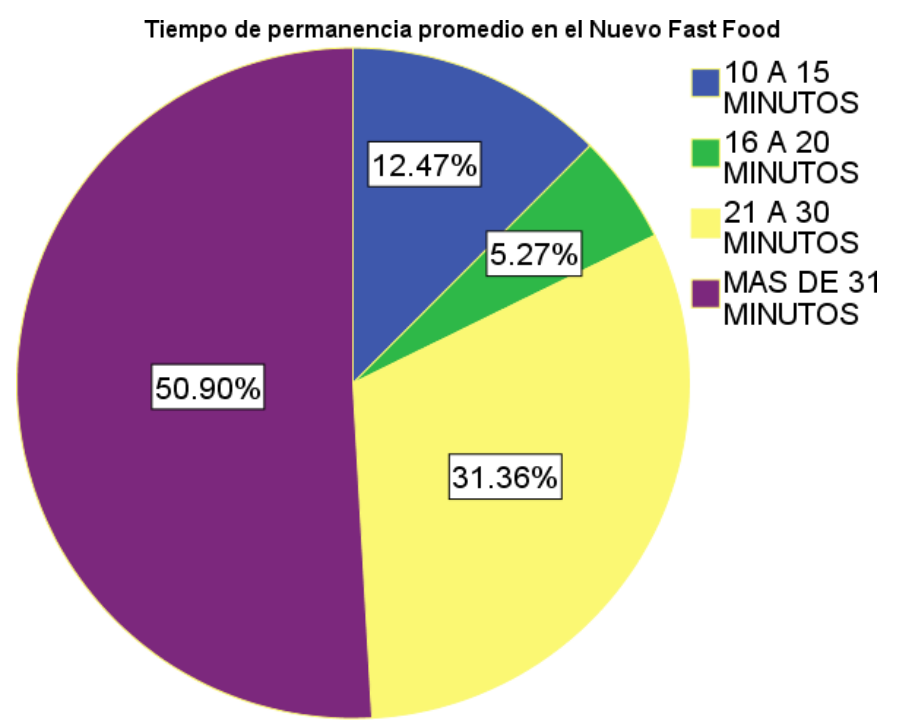

Figura 44. Tiempo de permanencia en el nuevo fast food novoandino. Fuente: Elaboración propia. 
- Horario de asistencia en un nuevo fast food novoandino.(opción múltiple por día)

Según Figura 45 y como se detalla en Tabla 67, se puede concluir que el horario preferido para visitar el nuevo establecimientos del presente proyecto es el sábado de $6 \mathrm{a} 9 \mathrm{pm}$ con un $65.3 \%$, seguido el día domingo también de 6 a 9pm representado por un $60.7 \%$, y el día viernes con un 55.2\% en el mismo horario. Por otro lado, durante los días hábiles el horario preferido es de 12 a 3pm siendo preferidos los días martes con un 37.6\% de preferencia y el día jueves con un $34.3 \%$.

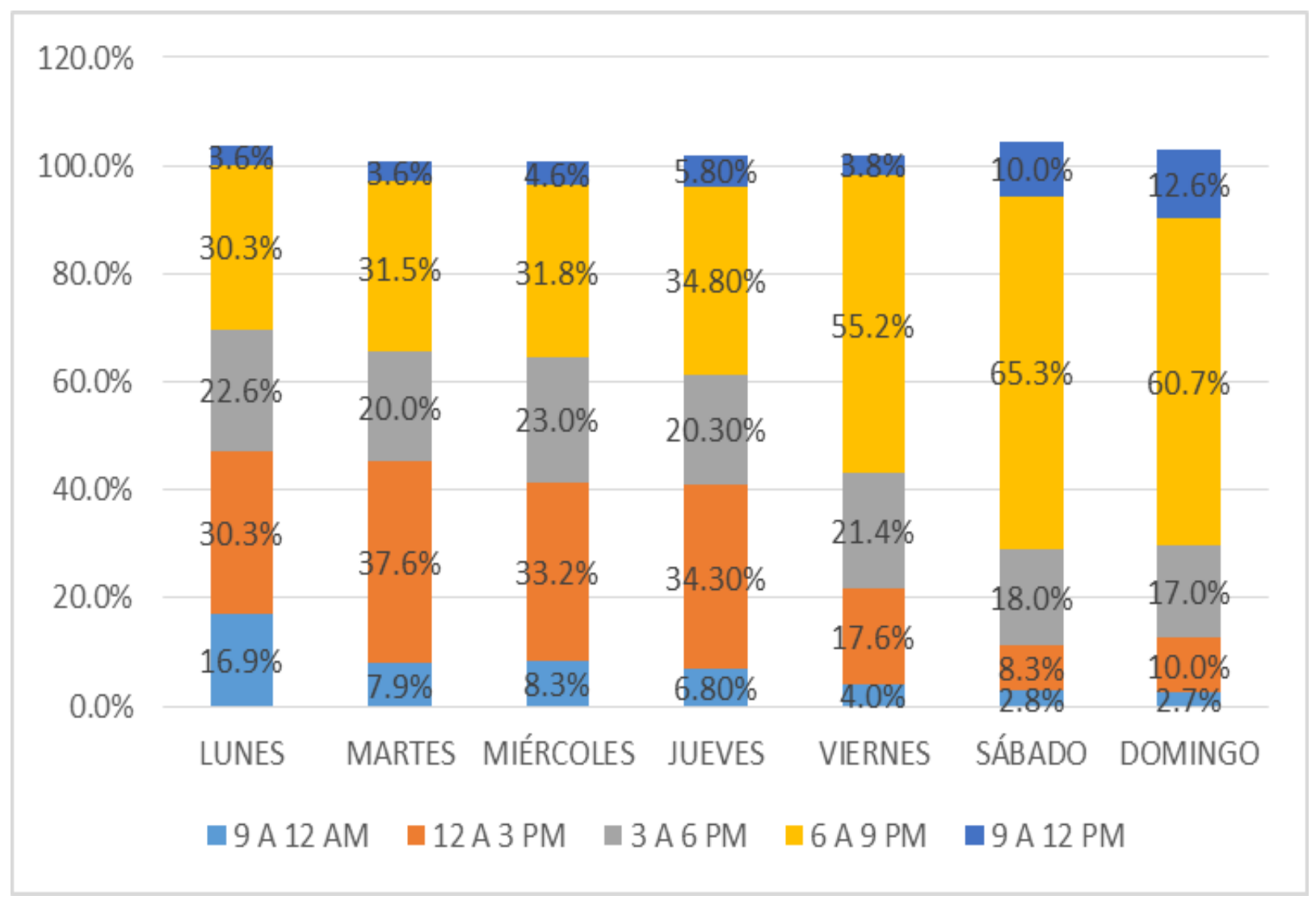

Figura 45. Horario de asistencia a nuevo fast food novoandino. Fuente: Elaboración propia. 
Tabla 67

Horario de asistencia a nuevo fast food novoandino

\begin{tabular}{|c|c|c|c|c|c|c|c|c|}
\hline & \multicolumn{2}{|c|}{ Lunes } & \multicolumn{2}{|c|}{ Martes } & \multicolumn{2}{|c|}{ Miércoles } & \multicolumn{2}{|c|}{ Jueves } \\
\hline & $\begin{array}{c}\text { Cant. } \\
\text { de } \\
\text { Rptas } \\
\text {. }\end{array}$ & $\begin{array}{c}\text { \% Según } \\
195 \text { casos } \\
\mathrm{n}^{\circ} \text { de } \\
\text { encuestas } \\
\text { contestada } \\
\mathrm{s}\end{array}$ & $\begin{array}{c}\text { Cant. } \\
\text { de } \\
\text { Rptas } \\
\text {. }\end{array}$ & $\begin{array}{c}\text { \% Según } \\
165 \text { casos } \\
\mathrm{n}^{\circ} \text { de } \\
\text { encuestas } \\
\text { contestada } \\
\mathrm{s}\end{array}$ & $\begin{array}{c}\text { Cant. } \\
\text { de } \\
\text { Rptas } \\
\text {. }\end{array}$ & $\begin{array}{c}\text { \% Según } \\
217 \text { casos } \\
\mathrm{N}^{\circ} \text { de } \\
\text { encuestas } \\
\text { contestada } \\
\text { s }\end{array}$ & $\begin{array}{c}\text { Cant. } \\
\text { de } \\
\text { Rptas } \\
\text { · }\end{array}$ & $\begin{array}{c}\text { \% Según } \\
207 \text { casos } \\
\mathrm{n}^{\circ} \mathrm{de} \\
\text { encuestas } \\
\text { contestada } \\
\mathrm{s}\end{array}$ \\
\hline $\begin{array}{l}9 \text { A } 12 \\
\text { AM }\end{array}$ & 33 & $16.9 \%$ & 13 & $7.9 \%$ & 18 & $8.3 \%$ & 14 & $6.80 \%$ \\
\hline $\begin{array}{l}12 \text { A } 3 \\
\text { PM }\end{array}$ & 59 & $30.3 \%$ & 62 & $37.6 \%$ & 72 & $33.2 \%$ & 71 & $34.30 \%$ \\
\hline $\begin{array}{l}3 \text { A } 6 \\
\text { PM }\end{array}$ & 44 & $22.6 \%$ & 33 & $20.0 \%$ & 50 & $23.0 \%$ & 42 & $20.30 \%$ \\
\hline $\begin{array}{l}6 \text { A } 9 \\
\text { PM }\end{array}$ & 59 & $30.3 \%$ & 52 & $31.5 \%$ & 69 & $31.8 \%$ & 72 & $34.80 \%$ \\
\hline $\begin{array}{l}9 \text { A } 12 \\
\text { PM }\end{array}$ & 7 & $3.6 \%$ & 6 & $3.6 \%$ & 10 & $4.6 \%$ & 12 & $5.80 \%$ \\
\hline Total & 202 & & 166 & & 219 & & 211 & \\
\hline & & iernes & & ábado & & omingo & & \\
\hline & $\begin{array}{c}\text { Cant. } \\
\text { de } \\
\text { Rptas } \\
\text {. }\end{array}$ & $\begin{array}{c}\text { \% según } \\
397 \text { casos } \\
\mathrm{n}^{\circ} \text { de } \\
\text { encuestas } \\
\text { contestada } \\
\text { s }\end{array}$ & $\begin{array}{c}\text { Cant. } \\
\text { de } \\
\text { Rptas } \\
\text {. }\end{array}$ & $\begin{array}{c}\text { \% según } \\
568 \text { casos } \\
\mathrm{n}^{\circ} \text { de } \\
\text { encuestas } \\
\text { contestada } \\
\mathrm{s}\end{array}$ & $\begin{array}{c}\text { Cant. } \\
\text { de } \\
\text { Rptas } \\
\text {. }\end{array}$ & $\begin{array}{c}\text { \% según } \\
412 \text { casos } \\
\mathrm{n}^{\circ} \mathrm{de} \\
\text { encuestas } \\
\text { contestada } \\
\mathrm{s}\end{array}$ & & \\
\hline $\begin{array}{l}9 \text { A } 12 \\
\text { AM }\end{array}$ & 16 & $4.0 \%$ & 16 & $2.8 \%$ & 11 & $2.7 \%$ & & \\
\hline $\begin{array}{l}12 \text { A } 3 \\
\text { PM }\end{array}$ & 70 & $17.6 \%$ & 47 & $8.3 \%$ & 41 & $10.0 \%$ & & \\
\hline $\begin{array}{l}3 \text { A } 6 \\
\text { PM }\end{array}$ & 85 & $21.4 \%$ & 102 & $18.0 \%$ & 70 & $17.0 \%$ & & \\
\hline $\begin{array}{l}6 \text { A } 9 \\
\text { PM }\end{array}$ & 219 & $55.2 \%$ & 371 & $65.3 \%$ & 250 & $60.7 \%$ & & \\
\hline $\begin{array}{l}9 \text { A } 12 \\
\text { PM }\end{array}$ & 15 & $3.8 \%$ & 57 & $10.0 \%$ & 52 & $12.6 \%$ & & \\
\hline Total & 405 & & 593 & & 424 & & & \\
\hline
\end{tabular}

Nota. Fuente: Elaboración propia. 
- Medios de comunicación que se debería usar para un nuevo fast food novoandino.(1 menos importantes y 5 más importante)

Conforme Tabla 68 y representado en Figura 46, se estimaron la media de los datos y se obtuvo que las redes sociales son el medio más importante para realizar la promoción de nuevo fast food novoandino con una media de 3.956, seguido por el medio televisivo con una media de 3.243 y radio con 2.938 de media.

Tabla 68

Medios de comunicación para promocionar el nuevo fast food novoandino

\begin{tabular}{|c|c|c|c|}
\hline & Estadísticos & Media & $\begin{array}{l}\text { Desviación } \\
\text { estándar }\end{array}$ \\
\hline $\begin{array}{l}\text { PV22d_R_AFI Importancia de promocionar el } \\
\text { nuevo fast food por afiche. }\end{array}$ & 778 & 2.407 & 1.326 \\
\hline $\begin{array}{l}\text { PV22c_R_PE Importancia de promocionar el } \\
\text { nuevo fast food por periódico. }\end{array}$ & 778 & 2.450 & 1.154 \\
\hline $\begin{array}{l}\text { PV22b_R_RA Importancia de promocionar el } \\
\text { nuevo fast food por radio. }\end{array}$ & 778 & 2.938 & 1.225 \\
\hline $\begin{array}{l}\text { PV22a_R_TV Importancia de promocionar el } \\
\text { nuevo fast food por televisión. }\end{array}$ & 778 & 3.243 & 1.414 \\
\hline $\begin{array}{l}\text { PV22e_R_RES Importancia de promocionar } \\
\text { el nuevo fast food por redes sociales. }\end{array}$ & 778 & 3.956 & 1.332 \\
\hline $\mathrm{N}$ válido (por lista) & 778 & & \\
\hline
\end{tabular}

Nota. Fuente: Elaboración propia. 


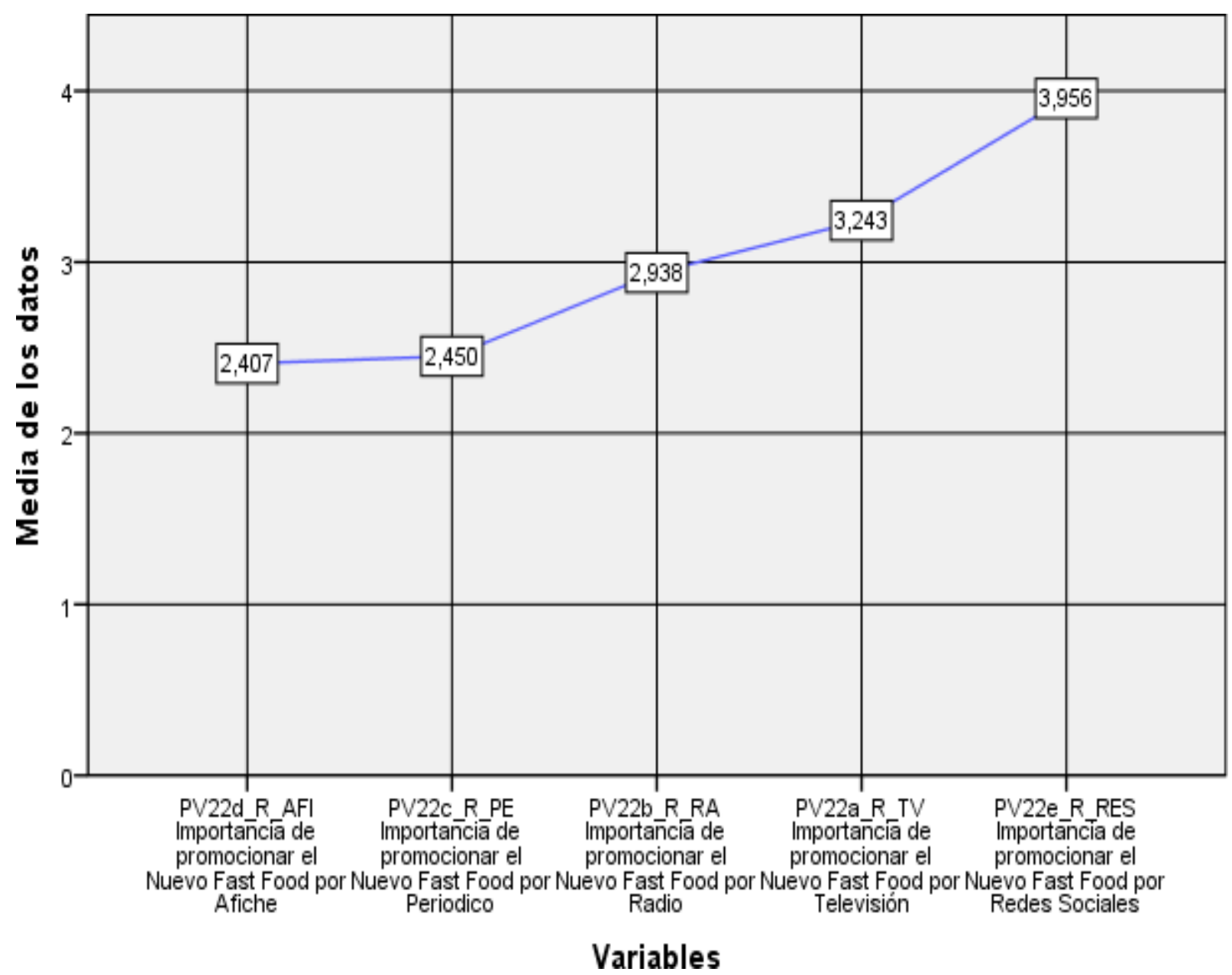

Figura 46. Medios de comunicación para promocionar el nuevo fast food novoandino. Fuente: Elaboración propia.

- Zonas de la Av. La Cultura donde se debería ubicar un nuevo fast food novoandino.

Según Tabla 69 y representado en Figura 47, se determina con un 35.7\% de preferencia el

Distrito de Wanchaq en zonas aledañas de la Av. La cultura cerca al centro comercial Real plaza como favorito para la ubicación del presente proyecto, seguido por la opción de la zona cercana a Supermercados Orión, también localizado en el distrito de Wanchaq. 
Tabla 69

Zonas de la Av. La Cultura para nuevo fast food novoandino

\begin{tabular}{|c|c|c|c|c|c|c|c|c|}
\hline & \multicolumn{2}{|c|}{ Garcilaso } & \multicolumn{2}{|c|}{ Unsaac } & \multicolumn{2}{|c|}{ Real plaza } & \multicolumn{2}{|c|}{ Orión } \\
\hline & Frecuencia & Porcentaje & Frecuencia & Porcentaje & Frecuencia & Porcentaje & Frecuencia & Porcentaje \\
\hline $\begin{array}{l}\text { Distrito } \\
\text { de Cusco }\end{array}$ & 34 & $4.34 \%$ & 124 & $15.8 \%$ & 44 & $5.6 \%$ & 13 & $1.66 \%$ \\
\hline $\begin{array}{l}\text { Distrito } \\
\text { de }\end{array}$ & 45 & $5.74 \%$ & 188 & $24.0 \%$ & 280 & $35.7 \%$ & 59 & $7.53 \%$ \\
\hline Wanchaq & & & & & & & & \\
\hline Total & 778 & $10 \%$ & 778 & $40 \%$ & 778 & $41 \%$ & 778 & $9 \%$ \\
\hline
\end{tabular}

Nota. Fuente: Elaboración propia.

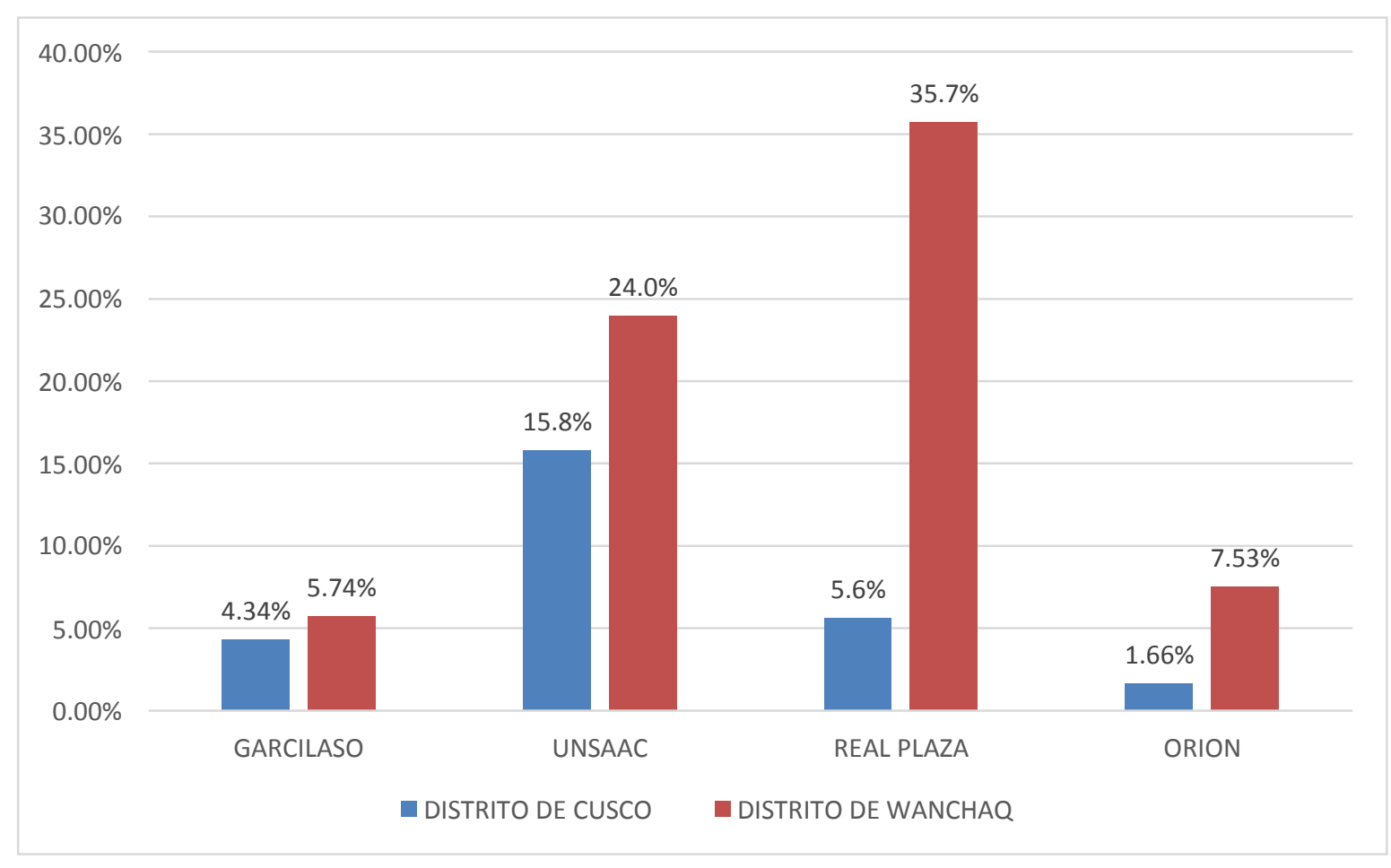

Figura 47. Zonas de la Av. La Cultura donde se ubicaría el nuevo fast food novoandino. Fuente: Elaboración propia. 
- Importancia de implementar servicios adicionales en un nuevo fast food novoandino.

Conforme Tabla 70 y representado en Figura 48, se determinó con un $44.47 \%$ de los votos que el Wi-fi es una herramienta indispensable para un Fast Food, así mismo la importancia de la entrega de pedido en mesa como servicio adicional como lo hacen por ejemplo Fast food conocidos como Otto Grill, se podría considerar como servicio complementario para ciertos productos con $36.89 \%$ de los votos. Por otro lado se evidencio que implementar servicios de cajita feliz no es tan importante para los encuestados con $11.18 \%$ de votos en contra.

\section{Tabla 70}

Importancia de servicios adicionales en nuevo fast food novoandino

\begin{tabular}{|c|c|c|c|c|c|c|c|c|}
\hline & $\begin{array}{c}\text { Música } \\
\text { Modern } \\
\text { a }\end{array}$ & Wi-fi & Delivery & $\begin{array}{l}\text { Cajita } \\
\text { Feliz }\end{array}$ & $\begin{array}{c}\text { Combos } \\
\text { familiare } \\
\mathrm{s} \\
\end{array}$ & $\begin{array}{c}\text { Zona de } \\
\text { juegos }\end{array}$ & $\begin{array}{l}\text { Entrega } \\
\text { en mesa }\end{array}$ & $\begin{array}{c}\text { Decoración } \\
\text { Temática }\end{array}$ \\
\hline $\begin{array}{l}1 \text { menos } \\
\text { important } \\
\mathrm{e}\end{array}$ & $3.21 \%$ & $3.34 \%$ & $3.73 \%$ & $11.18 \%$ & $1.54 \%$ & $8.74 \%$ & $0.77 \%$ & $1.41 \%$ \\
\hline $\begin{array}{l}\text { 2da } \\
\text { Opción }\end{array}$ & $0.90 \%$ & $0.90 \%$ & $1.67 \%$ & $6.81 \%$ & $0.51 \%$ & $3.98 \%$ & $0.13 \%$ & $1.16 \%$ \\
\hline $\begin{array}{l}\text { 3er } \\
\text { Opción }\end{array}$ & $3.21 \%$ & $2.70 \%$ & $2.83 \%$ & $9.38 \%$ & $2.70 \%$ & $6.56 \%$ & $1.41 \%$ & $2.31 \%$ \\
\hline $\begin{array}{l}\text { 4ta } \\
\text { Opción }\end{array}$ & $4.76 \%$ & $2.31 \%$ & $3.86 \%$ & $9.51 \%$ & $2.70 \%$ & $6.68 \%$ & $1.41 \%$ & $5.53 \%$ \\
\hline $\begin{array}{l}5 \text { ta } \\
\text { Opción }\end{array}$ & $9.64 \%$ & $4.88 \%$ & $11.05 \%$ & $12.98 \%$ & $6.68 \%$ & $16.84 \%$ & $6.56 \%$ & $7.84 \%$ \\
\hline $\begin{array}{l}\text { 6ta } \\
\text { Opción }\end{array}$ & $7.97 \%$ & $5.27 \%$ & $11.05 \%$ & $11.83 \%$ & $7.71 \%$ & $12.98 \%$ & $7.07 \%$ & $6.04 \%$ \\
\hline $\begin{array}{l}\text { 7tma } \\
\text { Opción }\end{array}$ & $9.00 \%$ & $8.87 \%$ & $15.04 \%$ & $13.11 \%$ & $11.70 \%$ & $10.41 \%$ & $10.80 \%$ & $12.21 \%$ \\
\hline $\begin{array}{l}\text { 8tava } \\
\text { Opción }\end{array}$ & $18.89 \%$ & $13.24 \%$ & $16.20 \%$ & $12.98 \%$ & $21.08 \%$ & $10.03 \%$ & $16.71 \%$ & $14.01 \%$ \\
\hline $\begin{array}{l}\text { 9na } \\
\text { Opción }\end{array}$ & $17.35 \%$ & $14.01 \%$ & $13.88 \%$ & $4.37 \%$ & $19.28 \%$ & $8.10 \%$ & $18.25 \%$ & $15.17 \%$ \\
\hline $\begin{array}{l}10 \text { muy } \\
\text { important } \\
\mathrm{e}\end{array}$ & $25.06 \%$ & $44.47 \%$ & $20.69 \%$ & $7.84 \%$ & $26.09 \%$ & $15.68 \%$ & $36.89 \%$ & $34.32 \%$ \\
\hline
\end{tabular}

Nota. Fuente: Elaboración propia. 


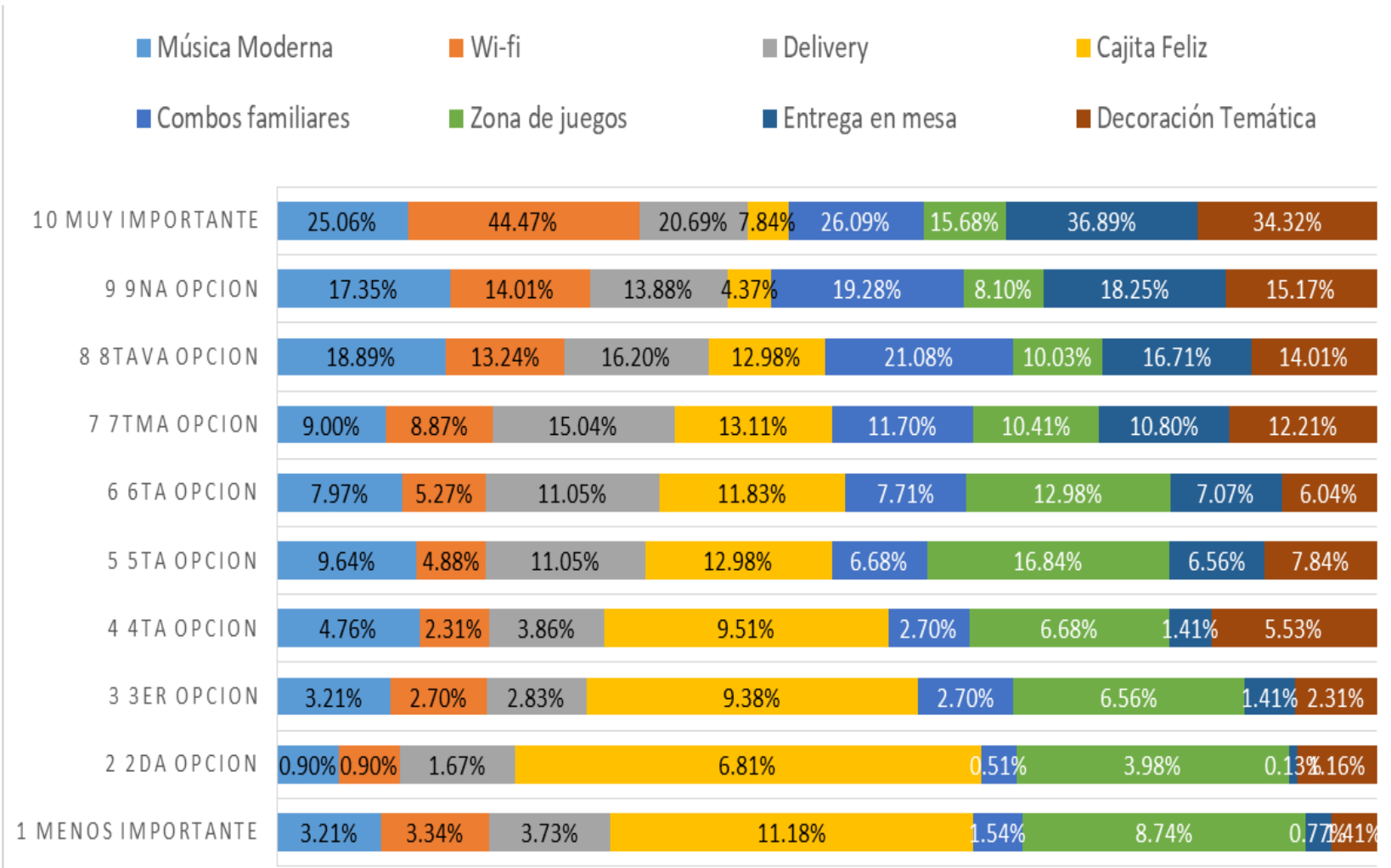

Figura 48. Importancia de servicios adicionales en nuevo Fast Food Novoandino. Fuente: Elaboración propia.

\subsection{Conclusiones y recomendaciones del estudio cualitativo y cuantitativo.}

Una vez llevado a cabo las investigaciones cualitativas y cuantitativas se podrá determinar el nivel de aceptación e influencia del proyecto con lo que se podrá definir en qué medida las características y necesidades del mercado están alineadas a los objetivos del proyecto.

En base a la información recopilada y analizada se pudo concluir que los consumidores presentan preferencia por los productos a base de pollo en primer lugar, seguido por las hamburguesas, del mismo modo para ellos el sabor, la calidad del producto y tiempo de servicio son factores muy importantes para su decisión de compra. En cuanto a su preferencia por los 
competidores potenciales se pudo obtener que el KFC es el establecimiento más visita y preferido por los cusqueños. Así mismo se pudo conocer que su frecuencia de asistencia a establecimientos de comida rápida es elevada mayoritariamente de 1 a 5 veces a la semana y en días laborales prefieren asistir a horas de almuerzo a este tipo de establecimientos, en cambio los fines de semana prefieren asistir en horario de tarde.

Por otro lado, se pudo obtener como resultado sobre la propuesta de valor que el consumidor cuenta con una gran aceptación del producto y prefiere insumos como las harinas de quinua y kiwicha, así como bebidas andinas de la región entre la más favorita se encuentra el emoliente, también se identificó que el consumidor gustaría de complementos como las papas andinas, choclo con queso y ají uchucuta.

En cuando a la disposición del gasto, el consumidor estaría dispuesto a pagar entre 10 y 15 soles por un combo personal en este tipo de establecimientos y está dispuesto a esperar de $10 \mathrm{a}$ 15 minutos por su pedido, permaneciendo en el local más de 31 minutos. Del mismo modo el consumidor considera que las redes sociales y la televisión son los mejores medios para dar a conocer el proyecto. En referencia a la ubicación se pudo concluir que los encuestados gustarían encontrar el presente proyecto cerca al centro comercial Real Plaza en el Distrito de Wanchaq.

Finalmente, se obtuvo que el consumidor le gustaría recibir como servicios adicionales principalmente el servicio en mesa a pesar de ser un servicio que no está relacionado directamente con el concepto de establecimientos fast food, además no presenta interés por la implementación de una cajita feliz para el proyecto, sin embargo, para este público es muy 
importante la instalación del servicio wifi. En cuanto a recomendaciones se podría considera que si bien el servicio en mesa el muy importante para los consumidores no se considera su implementación para el proyecto puesto que eleva la cantidad de personal y no es un sistema que se maneje frecuentemente en este tipo de establecimientos.

\subsection{Perfil del consumidor tipo y sus variantes.}

Conforme Tabla 71, se puede definir que los consumidores de 18 a 34 años tienen mayoritariamente ingresos de 850 a 2000 soles, sin embargo los consumidores de 35 a 45 años perciben en su mayoría ingresos de 850 a 1200 y de 3001 a más.

\section{Tabla 71}

Nivel de Ingresos según grupo etario

\begin{tabular}{lccccc}
\hline & & \multicolumn{3}{c}{ PC3_Etario1 grupos etarios } & Total \\
\cline { 3 - 5 } & & 18 a 24 & 25 a 34 & 35 a 45 & \\
\hline PC6_ING & 850 a 1200 & 115 & 162 & 134 & 141 \\
nivel de & 1201 a 2000 & 66 & 61 & 14 & 126 \\
ingresos & 2001 a 3000 & 25 & 51 & 50 & 106 \\
\hline
\end{tabular}

Nota. Fuente: Elaboración propia.

Del mismo modo, los consumidores de 18 a 34 años están dispuesto a pagar en su mayoría de 10 a 15 soles por un combo personal, sin embargo los consumidores de 35 a 45 años podrían pagar entre 10 a 35 soles por un combo personal, según Tabla 72. 
Tabla 72

Rango promedio de pago combo personal según grupo etario

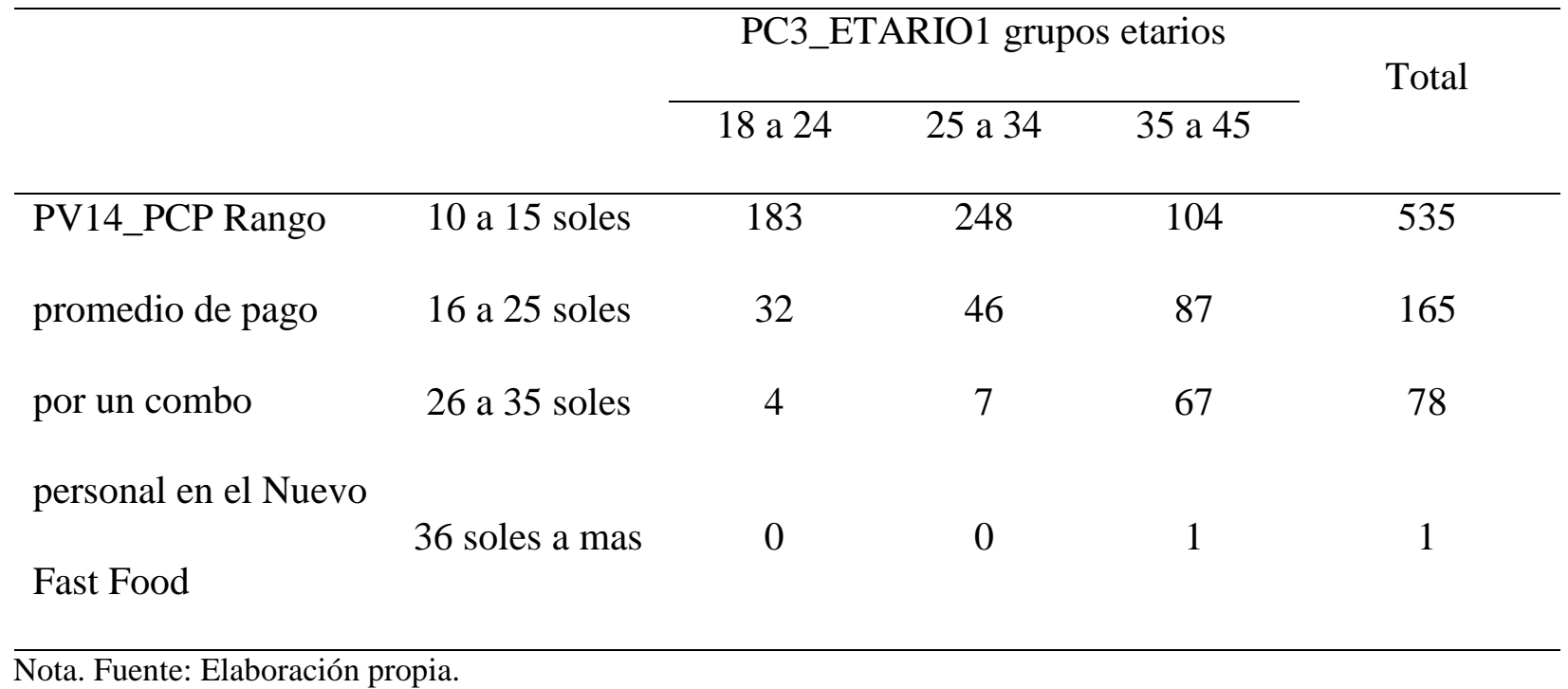

También se pudo definir que los consumidores entre 25 a 45 años prefieren asistir en su mayoría con familiares a establecimientos de comida rápida, a diferencia de los consumidores de 18 a 24 años quienes tienen preferencia por asistir con amistades, según Tabla 73.

Tabla 73

Con quien suele asistir según grupo etario

\begin{tabular}{lccccc}
\hline & & \multicolumn{2}{c}{ PC3_ETARIO1 Grupos Etarios } & Total \\
\cline { 3 - 5 } & & 18 a 24 & 25 a 34 & 35 a 45 & \\
\hline P5_AC Con & 1 solo & 14 & 25 & 30 & 287 \\
quien suele & 2 familiares & 45 & 98 & 144 & 86 \\
visitar un Fast & 3 pareja & 13 & 42 & 31 & 337 \\
Food & 4 amigos & 147 & 136 & 54 & \\
\hline
\end{tabular}

Nota. Fuente: Elaboración propia. 
Por otro lado se evidencio que los consumidores de 18 a 34 años están dispuestos a esperar de 10 a 15 minutos por sus pedidos, sin embargo un grupo de consumidores de 35 a 45 años estaría dispuesto a esperar de 10 a 20 minutos por su pedido, conforme Tabla 74 .

Tabla 74

Tiempo de espera de pedido según grupo etario

\begin{tabular}{lccccc}
\hline & & \multicolumn{3}{c}{ PC3_ETARIO1 grupos etarios } & \multirow{2}{*}{ Total } \\
\cline { 3 - 5 } & & 18 a 24 & 25 a 34 & 35 a 45 & \\
\hline PV19_TE Tiempo & 10 a 15 minutos & 203 & 250 & 178 & 631 \\
de espera deseado & 16 a 20 minutos & 14 & 41 & 71 & 126 \\
de pedido en el & 21 a 25 minutos & 2 & 7 & 8 & 17 \\
Nuevo Fast Food & 26 minutos a & 0 & 2 & 2 & 4 \\
& mas & & & & \\
\hline
\end{tabular}

Nota. Fuente: Elaboración propia.

También se pudo concluir que la mayoría de consumidores de 25 a 34 años permanecerían en el establecimiento del nuevo proyecto más de 21 minutos, así mismo la mayoría de consumidores de 18 a 24 años y de 35 a 45 años permanecerían más de 31 minutos en este establecimiento, cabe precisar que el tiempo de permanencia corresponde al tiempo que demora tomar el pedido, si existe o no colas, también incluye el tiempo de preparación y de entrega, además del tiempo de consumo según tipo de producto, conforme Tabla 75. 
Tabla 75

Tiempo de permanencia en el local según grupo etario

\begin{tabular}{lccccc}
\hline & & \multicolumn{3}{c}{ PC3_ETARIO1 Grupos Etarios } & \multirow{2}{*}{ Total } \\
\cline { 3 - 4 } & & 18 a 24 & 25 a 34 & 35 a 45 & \\
\hline PV20_TPE Tiempo de & 10 a 15 minutos & 34 & 42 & 21 & 97 \\
permanencia promedio & 16 a 20 minutos & 21 & 16 & 4 & 41 \\
en el Nuevo Fast Food & 21 a 30 minutos & 80 & 118 & 46 & 244 \\
& Más de 31 minutos & 84 & 124 & 188 & 396 \\
\hline
\end{tabular}

Nota. Fuente: Elaboración propia.

En base al análisis anterior se puede definir al consumidor de 18 a 24 años como personas con ingresos de 850 a 2000 soles y que están dispuesto a pagar de 10 a 15 soles por un combo personal, tienen preferencia por asistir con amistades a este tipo de establecimientos y están dispuestos a esperar de 10 a 15 minutos por sus pedidos permaneciendo más de 31 minutos consumiendo en restaurantes Fast Food. En cuanto a los consumidores de 25 a 34 años se le puede definir como personas con ingresos de 850 a 2000 soles dispuesto a pagar de 10 a 15 soles por un combo personal, tienen preferencia por asistir en con familiares a este tipo de establecimientos y están dispuestos a esperar de 10 a 15 minutos por sus pedidos permaneciendo en el local más de 21 minutos.

Por último el consumidor de 35 a 45 años se le puede definir como personas con ingresos de 850 a 1200 y de 3001 a más, quienes podrían pagar entre 10 a 35 soles por un combo personal y prefieren asistir con familiares a este tipo de establecimientos, estando dispuestos a esperar de 10 a 20 minutos por su pedido permaneciendo más de 31 minutos en el local. 


\section{Capítulo IV}

\section{Proyección Del Mercado Objetivo}

En el presente capítulo se tiene como fin la determinación de los cuatro tipos de mercados: el potencial, disponible, efectivo y el mercado objetivo; para conseguir un pronóstico de ventas acorde a las necesidades del cliente e identificar los posibles aspectos críticos que puedan afectar al pronóstico planteado.

\subsection{El ámbito de la proyección.}

Según Sapag Chain (2014), para que el producto resultante de la proyección permita su uso óptimo, la información deberá expresarse de la manera en la que sea más valiosa para el preparador del proyecto, por ejemplo, en algunos casos la información deberá expresarse desglosada por zona geográfica o en función de algún atributo de los clientes, como sexo, edad.

El ámbito de proyección del mercado objetivo estará basado en primer lugar en la aceptación del tipo de producto, luego de ello los resultados se expresarán en función a la edad, género, nivel socioeconómico y distrito de residencia.

\subsection{Selección del método de proyección.}

Según Sapag Chain (2014), la elección del método correcto dependerá principalmente de la cantidad y calidad de los antecedentes disponibles, así como de los resultados esperados, 
del tiempo y del nivel de precisión deseados. La efectividad del método elegido se evaluará en función de su precisión, sensibilidad y objetividad. (p.83)

Para el presente proyecto el método de proyección se realizó a través del método de encuesta de mercado a los consumidores aplicando un cuestionario de 24 preguntas para medir su comportamiento potencial de compra. A continuación, conforme Tabla 76 se determinarán los niveles de efectividad del método.

\section{Tabla 76}

Efectividad del método de encuesta del mercado

\begin{tabular}{lc}
\hline Característica & Detalle \\
\hline Precisión & $\begin{array}{r}\text { Para las encuestas se aplicó un margen de error de 3.5\%, para determinar el } \\
\text { mercado residente y flotante en un mercado de consumo. }\end{array}$ \\
& $\begin{array}{c}\text { Se determinó un nivel de confianza de 95\%, para garantizar que por lo } \\
\text { menos el 95\% de los encuestados se encuentre dentro de la proporción de } \\
\text { enstudio. }\end{array}$ \\
Objetividad & $\begin{array}{c}\text { La información obtenida es de fuente primaria, se logró recopilar diversas } \\
\text { opiniones sobre expectativas, deseos del consumidor. }\end{array}$ \\
\hline $\begin{array}{l}\text { Nota. Técnicas de proyección de mercado. Pinea, Url-Ingenieria, n.d. Adaptado de } \\
\text { http://www.fsalazar.bizland.com/pdf/05tecnicas\%20de\%20proyeccion\%20de\%20mercado.pdf }\end{array}$
\end{tabular}

\subsubsection{Mercado potencial.}

Según Kotler \& Armstrong, Marketing (2012), es el conjunto de clientes que manifiesta un grado suficiente de interés en una determinada oferta del mercado. Para el caso del proyecto se considera como mercado potencial al conjunto de consumidores que podrían necesitar el producto o servicio que queremos ofrecer, para ello primero se realizo la segmentación del 
mercado en base a las principales características de perfil del cliente que busca atender el proyecto, es decir aquellos que residen en la provincia del Cusco, en distritos aledaños a la av. La Cultura como son: Cusco, San Jerónimo, San Sebastián, Santiago y Wanchaq; además de tener entre 18 y 45 años de edad, pertenecientes a los segmentos socioeconómicos A, B y C.

En primer lugar, se tuvo que proyectar en función de los distritos mencionados, los cinco años de proyección de población para el estudio del proyecto que comprenderían del año 2019 al año 2023 a través del método de regresión lineal, puesto que ya se contaba con información estadística en referencia a los años del 2012 al 2016 como base para la proyección. Según Tabla 77, se muestra la proyección de población.

Tabla 77

Proyección población 2019 al 2023 con regresión lineal

\begin{tabular}{|c|c|c|c|c|c|c|c|c|c|c|c|c|}
\hline & 2012 & 2013 & 2014 & 2015 & 2016 & 2017 & 2018 & 2019 & 2020 & 2021 & 2022 & 2023 \\
\hline $\mathrm{x}=$ Tiempo & 1 & 2 & 3 & 4 & 5 & 6 & 7 & 8 & 9 & 10 & 11 & 12 \\
\hline $\begin{array}{l}\text { A=Poblaci } \\
\text { ón Cusco }\end{array}$ & 118052 & 118231 & 118322 & 118316 & 119005 & 119580 & 119779 & 119978 & 120177 & 120376 & 120575 & 120774 \\
\hline $\begin{array}{l}\mathrm{B}= \\
\text { Población } \\
\text { San } \\
\text { Jerónimo }\end{array}$ & 41617 & 43406 & 45236 & 47101 & 47374 & 54072 & 55593 & 57114 & 58635 & 60156 & 61677 & 63198 \\
\hline $\begin{array}{l}\mathrm{C}= \\
\text { Población } \\
\text { San } \\
\text { Sebastián }\end{array}$ & 100585 & 105388 & 110298 & 115305 & 115974 & 133927 & 137997 & 142066 & 146136 & 150205 & 154275 & 158344 \\
\hline $\begin{array}{l}\mathrm{D}=\text { Poblaci } \\
\text { ón } \\
\text { Santiago } \\
\text { E=Poblaci } \\
\text { ón } \\
\text { Wanchaq }\end{array}$ & 63825 & 63858 & 90274 & 90154 & 64148 & 90702 & 90762 & 90822 & 90881 & 90941 & 91001 & 91060 \\
\hline & & & & & & TOTAL & 468418 & 474323 & 480229 & 486135 & 492041 & 497946 \\
\hline
\end{tabular}

Nota. Ver regresión lineal Anexo $\mathrm{N}^{\circ} 13$. Datos en función de Tabla 21. Fuente: Elaboración propia. 
Con los datos proyectados por distritos del año 2019 al 2023, se realiza la segmentación según la población residente y flotante, puesto que el estudio de mercado se llevó a cabo bajo el método probabilístico sistemático ya que se seleccionaron elementos en base a una constante, se considera que la investigación llevada a cabo es representativa de la población.

Para determinar el mercado potencial se utiliza la información obtenida en los resultados del cuestionario aplicado en la etapa de estudio cuantitativo en función de los datos de control referentes al lugar de residencia de los encuestados.

Del mismo modo, cabe precisar que conforme la pregunta $\mathrm{N}^{\circ} 23$ del cuestionario se obtuvo como distrito preferido para la localización del proyecto, el distrito de Wanchaq considerándose como el mercado residente por lo que se asume para el estudio al 100\% de la población y los demás distritos se considerarán como el mercado flotante, conforme los porcentajes arrojados en la encuesta en los datos de control de la pregunta "II".

Así mismo, se consideró los datos sobre NSE (36\%) y edad (43.07\%) para determinar el mercado potencial. Conforme se detalla en Tabla 78. 
Tabla 78

Mercado potencial según mercado residente y flotante del 2019 al 2023

\begin{tabular}{|c|c|c|c|c|c|}
\hline \multicolumn{6}{|c|}{2019} \\
\hline Distritos & Población & Lugar de residencia & $18-45$ años & Nse $(a+b+c)$ & M. Potencial \\
\hline Cusco & 119978 & $41.20 \%$ & $43.07 \%$ & $36.00 \%$ & 7664 \\
\hline San Jerónimo & 57114 & $12.17 \%$ & $43.07 \%$ & $36.00 \%$ & 1078 \\
\hline San Sebastián & 142066 & $25.47 \%$ & $43.07 \%$ & $36.00 \%$ & 5611 \\
\hline Santiago & 90822 & $21.16 \%$ & $43.07 \%$ & $36.00 \%$ & 2979 \\
\hline \multirow[t]{2}{*}{$\begin{array}{l}\text { Wanchaq } \\
\text { (residentes) }\end{array}$} & 64343 & $100.00 \%$ & $43.07 \%$ & $36.00 \%$ & 9977 \\
\hline & & & & Total & 27309 \\
\hline \multicolumn{6}{|c|}{2020} \\
\hline Distritos & Población & Lugar de residencia & $18-45$ años & Nse $(a+b+c)$ & M. Potencial \\
\hline Cusco & 120177 & $41.20 \%$ & $43.07 \%$ & $36.00 \%$ & 21324 \\
\hline San Jerónimo & 58635 & $12.17 \%$ & $43.07 \%$ & $36.00 \%$ & 3074 \\
\hline San Sebastián & 146136 & $25.47 \%$ & $43.07 \%$ & $36.00 \%$ & 16033 \\
\hline Santiago & 90881 & $21.16 \%$ & $43.07 \%$ & $36.00 \%$ & 8281 \\
\hline \multirow{2}{*}{$\begin{array}{l}\text { Wanchaq } \\
\text { (residentes) }\end{array}$} & 64400 & $100.00 \%$ & $43.07 \%$ & $36.00 \%$ & 27737 \\
\hline & & & & Total & 76450 \\
\hline \multicolumn{6}{|c|}{2021} \\
\hline Distritos & Población & Lugar de residencia & 18-45 años & Nse $(a+b+c)$ & M. Potencial \\
\hline Cusco & 120376 & $41.20 \%$ & $43.07 \%$ & $36.00 \%$ & 21360 \\
\hline San Jerónimo & 60156 & $12.17 \%$ & $43.07 \%$ & $36.00 \%$ & 3154 \\
\hline San Sebastián & 150205 & $25.47 \%$ & $43.07 \%$ & $36.00 \%$ & 16480 \\
\hline Santiago & 90941 & $21.16 \%$ & $43.07 \%$ & $36.00 \%$ & 8287 \\
\hline \multirow[t]{2}{*}{$\begin{array}{l}\text { Wanchaq } \\
\text { (residentes) }\end{array}$} & 64457 & $100.00 \%$ & $43.07 \%$ & $36.00 \%$ & 27762 \\
\hline & & & & Total & 77041 \\
\hline \multicolumn{6}{|c|}{2022} \\
\hline Distritos & Población & Lugar de residencia & 18-45 años & Nse $(a+b+c)$ & M. Potencial \\
\hline Cusco & 120575 & $41.20 \%$ & $43.07 \%$ & $36.00 \%$ & 21395 \\
\hline San Jerónimo & 61677 & $12.17 \%$ & $43.07 \%$ & $36.00 \%$ & 3233 \\
\hline San Sebastián & 154275 & $25.47 \%$ & $43.07 \%$ & $36.00 \%$ & 16926 \\
\hline Santiago & 91001 & $21.16 \%$ & $43.07 \%$ & $36.00 \%$ & 8292 \\
\hline \multirow{2}{*}{$\begin{array}{l}\text { Wanchaq } \\
\text { (residentes) }\end{array}$} & 64513 & $100.00 \%$ & $43.07 \%$ & $36.00 \%$ & 27786 \\
\hline & & & & Total & 77632 \\
\hline \multicolumn{6}{|c|}{2023} \\
\hline Distritos & Población & Lugar de residencia & 18-45 años & Nse $(a+b+c)$ & M. Potencial \\
\hline Cusco & 120774 & $41.20 \%$ & $43.07 \%$ & $36.00 \%$ & 21430 \\
\hline San Jerónimo & 63198 & $12.17 \%$ & $43.07 \%$ & $36.00 \%$ & 3313 \\
\hline San Sebastián & 158344 & $25.47 \%$ & $43.07 \%$ & $36.00 \%$ & 17373 \\
\hline Santiago & 91060 & $21.16 \%$ & $43.07 \%$ & $36.00 \%$ & 8298 \\
\hline \multirow[t]{2}{*}{$\begin{array}{l}\text { Wanchaq } \\
\text { (residentes) }\end{array}$} & 64570 & $100.00 \%$ & $43.07 \%$ & $36.00 \%$ & 27810 \\
\hline & & & & Total & 78224 \\
\hline
\end{tabular}

Nota. Datos obtenidos de los resultados del cuestionario de estudio cuantitativo. Fuente: Elaboración propia. 


\subsubsection{Mercado disponible.}

Según Kotler \& Armstrong (2012), el mercado disponible es una parte del mercado potencial, referente al número de clientes que, además del interés, conoce el producto y tiene la disposición para consumirlo. Para el caso del proyecto estaría compuesto por los consumidores que tienen la necesidad específica de adquirir el producto o servicio. Sin embargo esto no todos comprarian el producto siempre, sino que una parte podría comprar en el proyecto y otra parte no. Para determinar el mercado disponible se utiliza la pregunta de asistencia a fast food aplicado en el cuestionario de la encuesta. Según Tabla 79, se define el mercado disponible.

Tabla 79

Mercado disponible del proyecto del 2019 al 2023

\begin{tabular}{|c|c|c|c|c|c|c|c|c|}
\hline \multirow{7}{*}{$\frac{N}{0}$} & Distritos & $\begin{array}{c}\text { M. } \\
\text { Potencial }\end{array}$ & $\begin{array}{c}\text { Filtro } \\
\text { :asistenci } \\
\text { a fast } \\
\text { food }\end{array}$ & $\begin{array}{c}\text { M. } \\
\text { Disponible }\end{array}$ & & $\begin{array}{c}\text { M. } \\
\text { Potencial }\end{array}$ & $\begin{array}{c}\text { Filtro } \\
\text { :asistenci } \\
\text { a fast } \\
\text { food }\end{array}$ & $\begin{array}{c}\text { M. } \\
\text { Disponible }\end{array}$ \\
\hline & Cusco & 7664 & $99.09 \%$ & 7594 & \multirow{6}{*}{ N } & 21324 & $99.09 \%$ & 7607 \\
\hline & San Jerónimo & 1078 & $100.00 \%$ & 1078 & & 3074 & $100.00 \%$ & 1107 \\
\hline & San Sebastián & 5611 & $99.26 \%$ & 5570 & & 16033 & $99.26 \%$ & 5730 \\
\hline & Santiago & 2979 & $99.12 \%$ & 2953 & & 8281 & $99.12 \%$ & 2955 \\
\hline & Wanchaq & 9977 & $99.58 \%$ & 9935 & & 27737 & $99.58 \%$ & 9944 \\
\hline & Total & 27309 & & 27130 & & 76450 & & 27341 \\
\hline \multirow{7}{*}{$\stackrel{N}{\stackrel{N}{N}}$} & Distritos & $\begin{array}{c}\text { M. } \\
\text { Potencial }\end{array}$ & $\begin{array}{c}\text { Filtro } \\
\text { :asistencia } \\
\text { fast food }\end{array}$ & $\begin{array}{c}\text { M. } \\
\text { Disponible }\end{array}$ & \multirow{7}{*}{ N } & $\begin{array}{c}\text { M. } \\
\text { Potencial }\end{array}$ & $\begin{array}{c}\text { Filtro } \\
\text { :asistencia } \\
\text { fast food }\end{array}$ & $\begin{array}{c}\text { M. } \\
\text { Disponible }\end{array}$ \\
\hline & Cusco & 21360 & $99.09 \%$ & 7620 & & 21395 & $99.09 \%$ & 7632 \\
\hline & San Jerónimo & 3154 & $100.00 \%$ & 1135 & & 3233 & $100.00 \%$ & 1164 \\
\hline & San Sebastián & 16480 & $99.26 \%$ & 5889 & & 16926 & $99.26 \%$ & 6049 \\
\hline & Santiago & 8287 & $99.12 \%$ & 2957 & & 8292 & $99.12 \%$ & 2959 \\
\hline & \multirow{2}{*}{$\begin{array}{c}\text { Wanchaq } \\
\text { Total }\end{array}$} & 27762 & $99.58 \%$ & 9952 & & 27786 & $99.58 \%$ & 9961 \\
\hline & & 77041 & & 27553 & & 77632 & & 27765 \\
\hline & \multirow{7}{*}{ స్ } & \multicolumn{2}{|c|}{ Distritos } & $\begin{array}{c}\text { M. } \\
\text { Potencial }\end{array}$ & $\begin{array}{c}\text { Filtro } \\
\text { :asistenci } \\
\text { a fast } \\
\text { food }\end{array}$ & \multicolumn{2}{|c|}{ M. Disponible } & \\
\hline & & \multicolumn{2}{|c|}{ Cusco } & 21430 & $99.09 \%$ & \multicolumn{2}{|r|}{7645} & \\
\hline & & \multicolumn{2}{|c|}{ San Jerónimo } & 3313 & $100.00 \%$ & \multicolumn{2}{|r|}{1193} & \\
\hline & & \multicolumn{2}{|c|}{ San Sebastián } & 17373 & $99.26 \%$ & \multicolumn{2}{|r|}{6208} & \\
\hline & & \multicolumn{2}{|c|}{ Santiago } & 8298 & $99.12 \%$ & \multicolumn{2}{|r|}{2961} & \\
\hline & & \multicolumn{2}{|c|}{ Wanchaq } & 27810 & $99.58 \%$ & \multicolumn{2}{|r|}{9970} & \\
\hline & & \multicolumn{2}{|c|}{ Total } & 78224 & & \multicolumn{2}{|r|}{27976} & \\
\hline
\end{tabular}

Nota. Fuente: Elaboración propia. 


\subsubsection{Mercado efectivo.}

Según Kotler \& Armstrong (2012), es la parte del mercado disponible calificado que tiene la voluntad de consumir de forma frecuente el producto o servicio. Para el proyecto está conformado por los consumidores que además de la necesidad específica, tienen la intención de comprar el bien o servicio, para ello se utilizó información proporcionada por las encuestas sobre la disposición de compra. Por ello según resultados arrojados mediante la encuesta, un total general de $40.31 \%$, de encuestados definitivamente asistirían al establecimiento del proyecto. Conforme Tabla 80, se detallada por año y porcentaje obtenido según distrito.

Tabla 80

Mercado efectivo del proyecto del 2019 al 2023

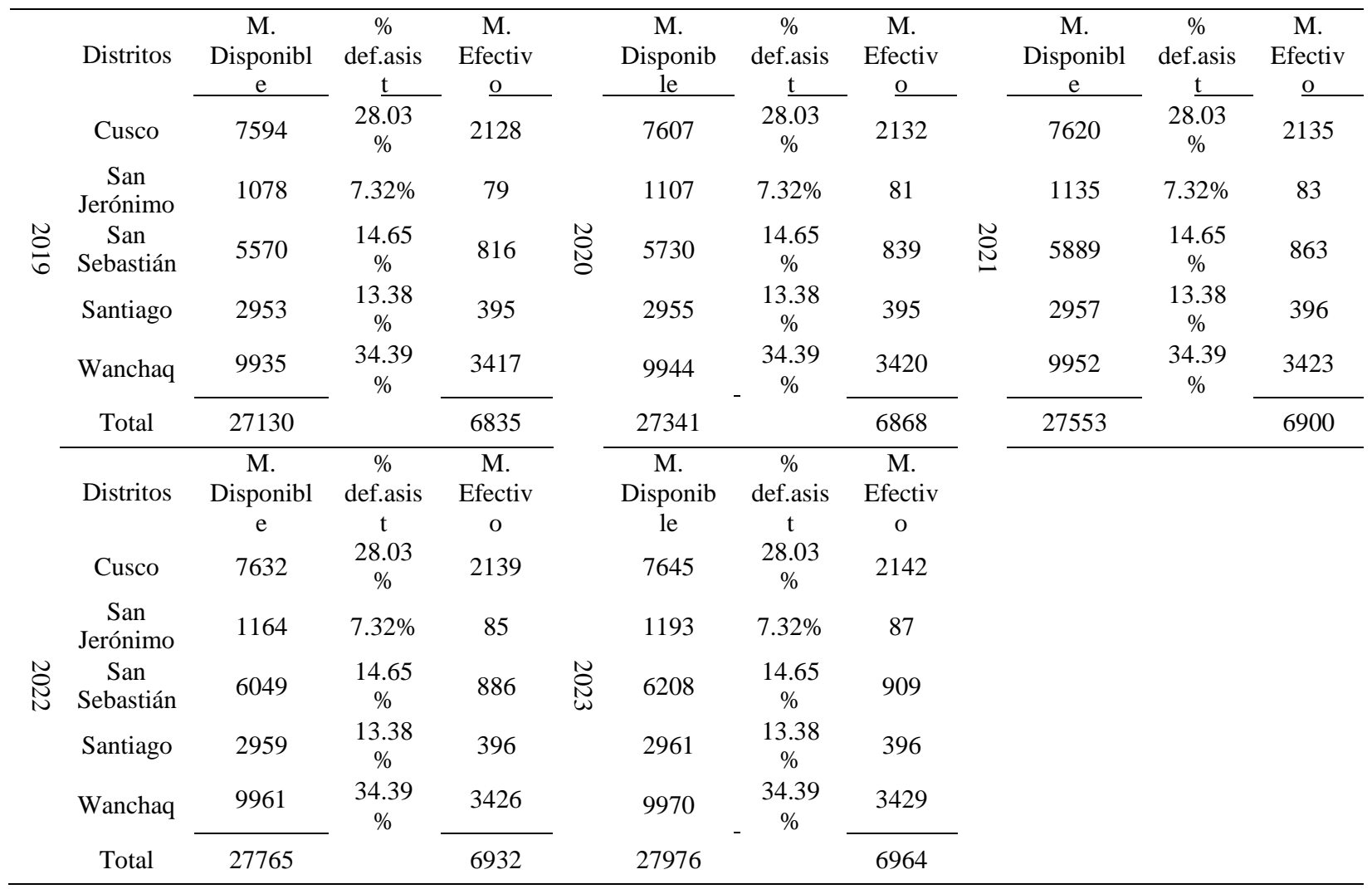

Nota. Fuente: Elaboración propia. 


\subsubsection{Mercado objetivo.}

Es una parte del mercado efectivo que la empresa espera atender, es decir la parte del mercado efectivo que se fija como meta a ser alcanzada por el negocio, donde dirigirá todos sus esfuerzos de marketing. (Rodriguez,2014)

El mercado objetivo es el resultado de la multiplicación del mercado efectivo por el porcentaje de personas que se espera captar, es decir, la participación del mercado que tendrá el negocio; para determinar este porcentaje según Figura 47, se tomó como base la participación de la empresa cusqueña Rupha's Diner de $15.53 \%$ obtenido en la evaluación de las encuestas llevadas a cabo para el presente proyecto, conforme tabla 54, para motivos de cálculo, además se tomó en cuenta, que dicha empresa lleva dos años de operación en la ciudad de Cusco, considerando también para el cálculo, el crecimiento estimado anual del mercado de fast food en la ciudad, conforme se detalla en Tabla 81.

Tabla 81

Estimación del porcentaje de crecimiento del mercado

\begin{tabular}{lc}
\hline \multicolumn{1}{c}{ Características } & S/ o \% \\
\hline Vta. Bembos 2011 por local en Lima & S/994,000a \\
Vta. Bembos 2014 por local en Lima & S/ 1,140,000a \\
\hline $\begin{array}{l}\text { Captación del mercado(tasa de crecimiento anual Bembos - 3 años) Lima } \\
\text { Postura conservadora para Cusco ( Se asume la cuarta parte de la tasa de } \\
\text { crecimiento anual de Lima) }\end{array}$ & $4.90 \%$ \\
$\begin{array}{l}\text { Postura conservadora nuevo proyecto (Se asume la octava parte de la tasa } \\
\text { de crecimiento anual de Lima) }\end{array}$ & $0.61 \%$ \\
\hline $\begin{array}{l}\text { Nota. Fuente: Elaboración propia. } \\
\text { a Chiarella, 2016. Bembos: la fast food peruana es cada vez menos rentable - Lima. Adaptad de } \\
\text { http://semanaeconomica.com/article/sectores-y-empresas/comercio/183636-bembos-la-fast-food-peruana-es-cada- vez- } \\
\text { menos-rentable/ }\end{array}$
\end{tabular}




$$
\frac{15.53 \%}{(1+1.22 \%)^{2}}=15.16 \%
$$

Figura 49. Cálculo base de participación de mercado. Adaptado de https://www.rankia.cl/blog/analisis-ipsa/3345472-valor-presente-futuro-definicion-formulasejemplos

En base al resultado obtenido de $15.16 \%$ en Figura 49, se asume la octava parte (1/8) de dicho porcentaje de forma conservadora, puesto que el proyecto en estudio es un negocio nuevo en el mercado y con un valor agregado innovador, obteniendo como participación de mercado para el proyecto un porcentaje de $1.89 \%$. Así mismo, se consideran crecimientos anuales de la participación para el presente proyecto de $0.61 \%$ asumiendo la cuarta parte de la Tasa de crecimiento anual de bembos de forma conservadora, para los cinco años de evaluación.

Por lo tanto, con los valores actuales se aplica al mercado disponible la participación de mercado obtenida de $1.89 \%$ considerando así mismo la tasa de crecimiento anual de $0.61 \%$, el resultado se divide entre el mercado efectivo para obtener el porcentaje de Captación del Mercado para cada año conforme se detalle en Tabla 82.

Tabla 82

Captación del mercado objetivo

\begin{tabular}{cccccc}
\hline Año & $\begin{array}{c}\text { Mercado } \\
\text { disponible }\end{array}$ & $\begin{array}{c}\text { Participación de } \\
\text { mercado }\end{array}$ & $\begin{array}{c}\text { Mcdo disponible } \\
\text { por Part. De } \\
\text { Mcdo }\end{array}$ & $\begin{array}{c}\text { Mercado } \\
\text { efectivo }\end{array}$ & $\begin{array}{c}\text { Porcentaje } \\
\text { captación del } \\
\text { mercado }\end{array}$ \\
\hline 2019 & 27130 & $1.89 \%$ & 513 & 6835 & $7.50 \%$ \\
2020 & 27341 & $2.50 \%$ & 684 & 6868 & $9.95 \%$ \\
2021 & 27553 & $3.11 \%$ & 857 & 6900 & $12.42 \%$ \\
2022 & 27765 & $3.72 \%$ & 1033 & 6932 & $14.90 \%$ \\
2023 & 27976 & $4.33 \%$ & 1211 & 6964 & $17.39 \%$ \\
\hline
\end{tabular}

Nota. Fuente: Elaboración propia. 
En base a la determinación de los porcentajes anteriores se calculó el mercado Objetivo, según Tabla 83.

Tabla 83

Mercado objetivo del proyecto del 2019 al 2023

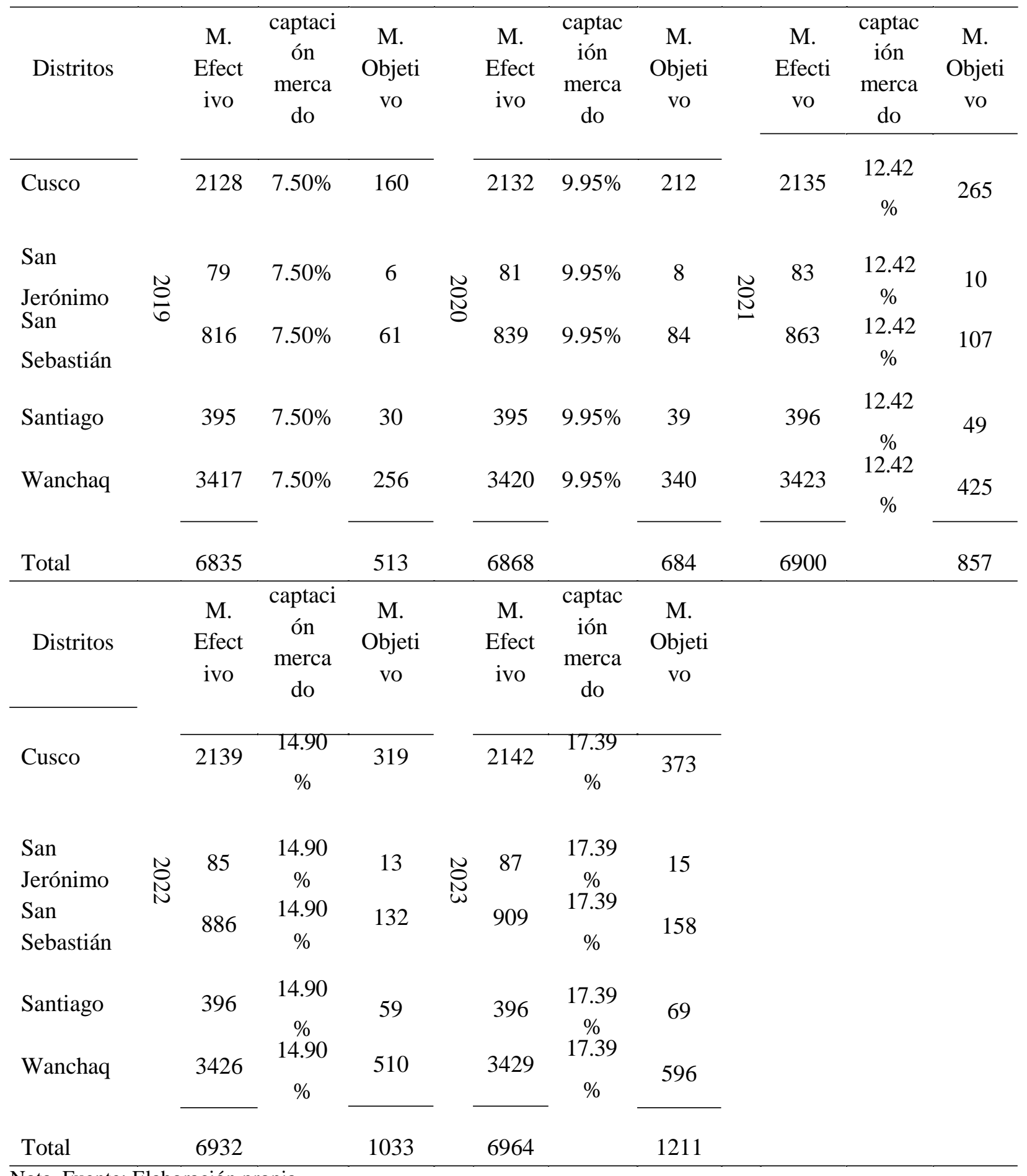

Nota. Fuente: Elaboración propia. 


\subsection{Pronostico de ventas.}

Según Kotler (2012) es el nivel esperado de ventas de la empresa, con base en un plan de mercadotecnia seleccionado y un supuesto ambiente de mercadotecnia. Las ventas de la empresa en el eje vertical y el esfuerzo en mercadotecnia en el eje horizontal.

Para el pronóstico de ventas detallado en Tabla 86, se tomó en cuenta la frecuencia de visita del consumidor y cantidad de consumo, para el cual se asume que cada cliente consume un combo por persona, cuantificado en Tabla 84 y el rango de precio promedio que está dispuesto a pagar el cliente por un combo personal y por un postre detallado en Tabla 85, asimismo para ello se consideró que la cantidad de postres a vender es el $29.59 \%$ de la cantidad de visitas por año, dicho porcentaje se estimó tomando como referencia la representación del postre más votado con respecto al total de respuestas emitidas sobre el consumo de postres según Tabla 62.

Por otro lado, en el caso de la frecuencia de visita detallada por distrito, ésta se estimó en base a los resultados obtenidos en Tabla 47 y los resultados de la encuesta en cuanto a frecuencia de asistencia y lugar de residencia conforme se detalla en Tabla 84.

Así mismo, se realiza la estimación en base al mercado objetivo aplicando la siguiente formula, según Figura 50.

Ventas $=$ Mcdo objetivo $\mathrm{x}$ frecuencia de visita $\mathrm{x}$ cantidad que consume cada vez $\mathrm{x}$ precio

Figura 50. Fórmula, cálculo de ventas. Adaptado de http://www.elcomercial.net/vendermas/formula_exito_ventas.htm 
Tabla 84

Frecuencia de asistencia y cantidad que consume cada vez por combos

\begin{tabular}{|c|c|c|c|c|}
\hline Frecuencia & $\begin{array}{l}\text { Promedio de } \\
\text { Frecuencia }\end{array}$ & $\begin{array}{c}\% \text { de } \\
\text { respuestas }\end{array}$ & $\begin{array}{c}\text { Año bancario } \\
\mathrm{n}^{\circ} \text { compras anual } \\
\text { (veces) según } \\
\text { frecuencia }\end{array}$ & Ponderado \\
\hline Diaria & 360 & $4.88 \%$ & 360 & 17.56 \\
\hline 1 a 5 veces por semana & 2.5 & $48.27 \%$ & 120 & 57.92 \\
\hline (Isenßaneades por mes & 1.5 & $29.91 \%$ & 18 & 5.38 \\
\hline (Imaeroskedès por & 3 & $16.94 \%$ & 3 & 0.51 \\
\hline año(anual) & & \multicolumn{2}{|c|}{ Promedio Ponderado anual } & 81.37 \\
\hline Cantidad de compra & $\%$ & Ponderado & & \\
\hline 1 combo por persona & $100 \%$ & 1.00 & & \\
\hline Combo cada vez & & 1.00 & & \\
\hline
\end{tabular}

Nota. Fuente: Elaboración propia.

Tabla 85

Rango de precio promedio

\begin{tabular}{|c|c|c|c|c|c|}
\hline \multicolumn{6}{|c|}{ Combos } \\
\hline Precios & Prom. & $\%$ & & Pond. & \\
\hline 10 a 15 soles & 12.5 & $68.68 \%$ & & 8.58 & \\
\hline 16 a 25 soles & 20.5 & $21.18 \%$ & & 4.34 & \\
\hline 26 a 35 soles & 30.5 & $10.01 \%$ & & 3.05 & \\
\hline \multirow[t]{4}{*}{36 soles a más } & 36 & $0.13 \%$ & - & $\underline{0.05}$ & \\
\hline & & & & 16.03 & soles \\
\hline & & & & 2.88 & IGV \\
\hline & & & & 13.14 & Sin IGV \\
\hline \multicolumn{6}{|c|}{ Postres } \\
\hline Precios & Prom. & $\%$ & & Pond. & \\
\hline 5 a 7 soles & 6 & $64.44 \%$ & & 3.87 & \\
\hline 8 a 10 soles & 9 & $28.88 \%$ & & 2.60 & \\
\hline \multirow[t]{4}{*}{11 soles a más } & 11 & $6.68 \%$ & - & 0.73 & \\
\hline & & & & 7.20 & soles \\
\hline & & & & 1.30 & IGV \\
\hline & & & & 5.90 & Sin IGV \\
\hline
\end{tabular}

Nota. Fuente: Elaboración propia. 
Tabla 86

Pronóstico de ventas combos y postres

\begin{tabular}{|c|c|c|c|c|c|}
\hline & 2019 & 2020 & 2021 & 2022 & 2023 \\
\hline Programa de ventas & 41,725 & 55,622 & 69,729 & 84046 & 98573 \\
\hline \multicolumn{6}{|l|}{ Combos (Und) } \\
\hline Programa de ventas & $\mathrm{S} / 548,350$ & $\mathrm{~S} / 730,988$ & $\mathrm{~S} / 916,386$ & $\mathrm{~S} / 1,104,541$ & $\mathrm{~S} / 1,295,458$ \\
\hline \multicolumn{6}{|l|}{ Combos (S/.) } \\
\hline $\begin{array}{l}\text { Programa de ventas Postres } \\
\text { (Und - } 29.59 \% \text { de Und de } \\
\text { venta de Combos) }\end{array}$ & 12,346 & 16,459 & 20,633 & 24,869 & 29,168 \\
\hline Programa de ventas & $\mathrm{S} / 72,895$ & $\mathrm{~S} / 97,174$ & $\mathrm{~S} / 121,821$ & $\mathrm{~S} / 146,833$ & $\mathrm{~S} / 172,213$ \\
\hline \multicolumn{6}{|l|}{ Postres(S/.) } \\
\hline $\begin{array}{l}\text { Tasa de crecimiento de las } \\
\text { ventas }\end{array}$ & & $33.307 \%$ & $25.363 \%$ & $20.532 \%$ & $17.285 \%$ \\
\hline
\end{tabular}

Nota. Fuente: Elaboración propia.

\subsection{Aspectos críticos que impactan el pronóstico de ventas.}

Existen factores que afectan el pronóstico de las ventas, las cuales se deben considerar en el proceso de planeación, estos son:

\subsubsection{Factores externos.}

Son aquellos factores no controlables y que en alguna forma inciden en las ventas, para el presente caso se considera la población económicamente activa de la región Cusco, que para el año 2017, se estimó que existen 1.2 millones de mujeres emprendedoras en el país de las cuales $7 \%$ pertenecerían a mujeres de la ciudad de Cusco (Larepública.pe, 2017). 
Esto contribuye al proyecto, se eleva la disponibilidad de ingresos para las familias. Así mismo, la tasa de ocupación de la región Cusco es de 96.8\%, elevada a comparación de la región Lima, lo cual representa la capacidad adquisitiva de la población así como la necesidad de optimización del tiempo que necesitan las familias para sus actividades domésticas, lo que influye en el incremento de las ventas conforme Figura 51.

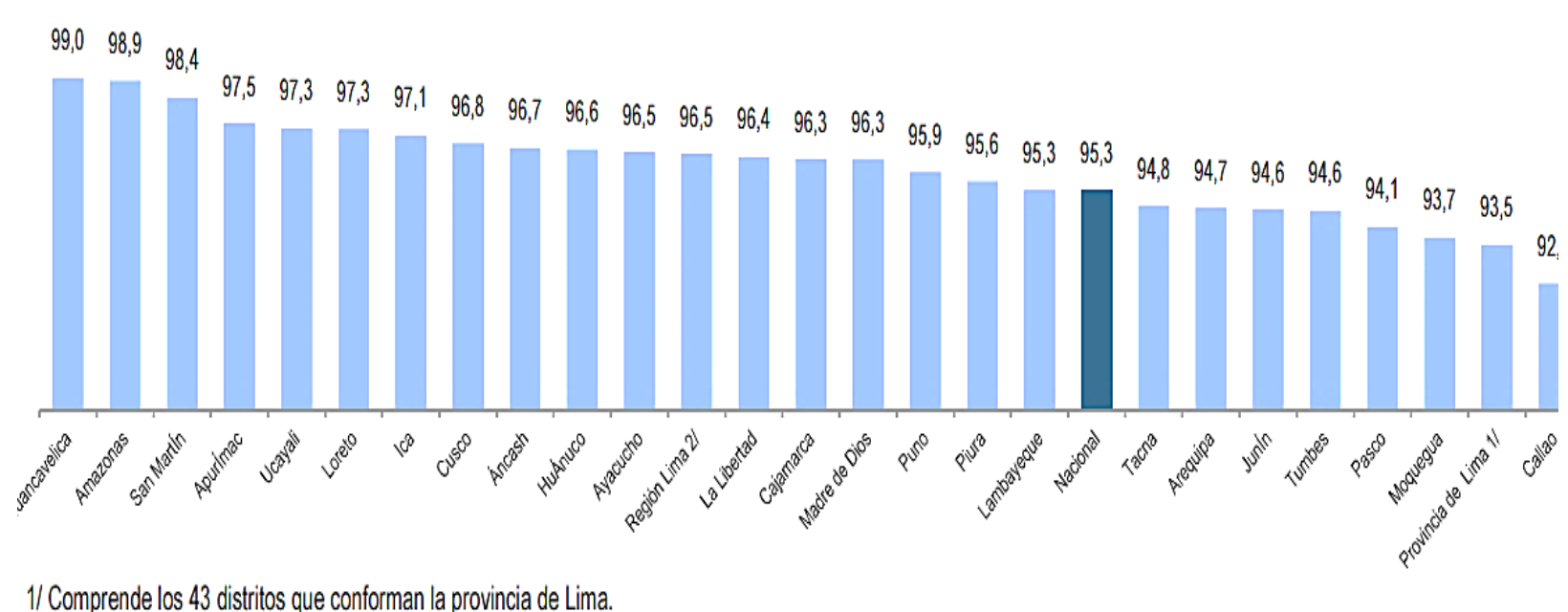

Figura 51. Tasa de ocupación por departamento 2016. Instituto Nacional de estadística - INEI. Recuperado de http://www.inei.gob.pe/media/MenuRecursivo/publicaciones_digitales/Est/Lib1391/libro.pdf

Del mismo modo el gobierno ha puesto en marcha un plan de impulso económico, que contribuirá en el desarrollo de la economía a través de herramientas fiscales, posibilidades de acceso a adquisición de viviendas, créditos para las micros y pequeñas empresas, implementación de obras públicas por impuestos y agilizando la minería (Villalobos, 2017), esto permitirá al proyecto acceder a beneficios fiscales y crediticios y mejorar los costos de los productos, ofreciendo mejores ofertas para los clientes e incentivando las ventas. 
Por otro lado, con la construcción del nuevo aeropuerto en Chincheros el gobierno espera generar 2,500 puestos de trabajo durante la etapa de construcción, lo que mejorará la calidad de vida de las familias y por ende la capacidad de gasto para actividades de recreación, entretenimiento y alimentación fuera de casa. (Andina, 2017)

Sin embargo un factor a considerar es el ingreso promedio de la región Cusco, que para inicios del 2016 ascendía a S/ 1801 soles, el cual según INEI, no es el óptimo para cubrir la canasta básica de la familiar, ya que debería ser de S/1500 soles (La República, 2016), esto impacta en el proyecto, puesto que si bien existe empleo y ocupabilidad de la población existe también una alta posibilidad que dichos ingresos se destinen para necesidades básicas y no para gastos adicionales como el consumo de alimentos fuera de casa o entretenimiento, incluso puede originar que se eleve el consumo de productos sustitutos.

Así mismo, “entre marzo del 2016 y febrero del 2017 Cusco evidenció una tasa de índice de precios al consumidor de $3.44 \%$, superior al nivel nacional que fue de $3.34 \%$ "

(Finanzasdigital.com, 2017), esto implica que los precios de los bienes y servicios que se brindan en la región se han elevado lo cual genera que la disponibilidad económica de la población esté restringida.

Finalmente, para el año 2017, entro en vigencia el nuevo régimen Mype Tributario, que beneficia a las pequeñas y medianas empresas, puesto que el impuesto ya no recae sobre los ingresos sino sobre las utilidades generadas y está orientada a empresas cuyos ingresos no 
superen las 1,700 UIT lo que beneficia a empresas que se encontraban tanto en el régimen general como en el nuevo RUS (El Comercio, 2017).

Esto permite mejorar las ofertas y promociones a través de mejores precios del producto para el cliente puesto que los ingresos no se ven afectados.

\subsubsection{Factores internos.}

Son factores donde la empresa puede ejercer control: La subida de precios de los insumos para la elaboración de algunos productos puede afectar el costo de producción, sin embargo esto se puede manejar implementando nuevas recetas que se lancen por temporadas para cubrir los cambios de precios elevados que se puedan suscitar por factores externos al negocio. Así mismo el incremento del sueldo básico también puede afectar el precio de venta del producto esto se puede sobrellevar mejorando las estrategias de ventas de la empresa.

Otro factor importante son los cambios en la tendencia de consumo de los clientes, con la aparición de nuevas ofertas de comida saludable, pero esto se puede superar puesto que como propuesta, el plan de negocio ofrece productos con valor nutricional y se pueden ajustar procesos productivos de algunos productos para acoplarse a las nuevas tendencias, claro que ello eleva los costos de producción pero esto se puede contrarrestar con la propuesta de valor que podría ofrecer.

Del mismo modo factores tecnológicos como la aparición de nuevas aplicaciones o sistemas así como nuevas redes sociales pueden influenciar en las ventas de la empresa, algunos pueden 
incrementar la inversión en tecnología, se puede superar a través de ajustes en el presupuesto de marketing y así mismo a través de la implementación de un área especializada en temas tecnológicos y sociales. 


\section{Capítulo V}

\section{Ingeniería Del Proyecto}

En el presente capítulo se definirán los aspectos técnicos, de infraestructura y estudio de localización, así como todos los recursos necesarios para llevar a cabo la constitución de la empresa, teniendo en cuenta las consideraciones legales y determinar finalmente una localización óptima.

\subsection{Ingeniería del proyecto.}

La ingeniería de un proyecto tiene por objeto cumplir una doble función:

- Primero.

"La de establecer las bases técnicas sobre las que se construirá e instalará la planta, en caso de que el proyecto demuestre" (Carro Paz \& Gonzales Gomez, n.d.).

- Segundo.

La de aportar la información que permita hacer una evaluación económica del proyecto.

\subsubsection{Modelamiento y selección de procesos productivos.}

La selección del proceso es una decisión estratégica que involucra seleccionar tipos de procesos de producción que debe considerarse. Una decisión esencial en el diseño de un sistema de producción debe en el proceso que se usará para hacer productos o brindar servicios. Esto involucra decisiones de campos tales como recursos humanos, equipos, materiales y tecnología, entre otros. (Carro Paz \& Gonzales Gomez, n.d.) 


\subsubsection{Selección de procesos.}

Para el presente proyecto se determinó elaborar el diseño de procesos en base al sistema de proceso en línea.

- Proceso en línea.

El proceso en línea está focalizado en el producto con los recursos organizados alrededor del mismo. Los volúmenes en general son altos y los productos son del tipo estandarizado. Los insumos se mueven de manera lineal de una estación a la siguiente en una secuencia ya fijada. (Carro Paz \& Gonzales Gomez, n.d.).

Debido a que el presente proyecto propone la implementación de un establecimiento de restaurante bajo el concepto de Fast Food, el sistema productivo debe llevarse a cabo de forma secuencial y estandarizada, así como la elaboración de los productos y recetas que deberán cumplir con el mismo criterio, todo ello con el objetivo de cumplir con el estándar de tiempo de servicio esperado para este tipo de establecimiento de comida rápida. En base a ello se procede a establecer el diagrama de procesos en línea (blueprint) para el proyecto (Schmal \& Olave, 2014), en primer lugar se desarrollará los diagramas de dos de las áreas críticas que ejercen mayor influencia en el proyecto. Conforme Figura 52, se visualiza el proceso general del área de servicio al cliente, seguido de Figura 53 donde se muestra el diagrama del área de producción.

En cuanto al área de servicio al cliente, este se considera critica puesto que es la primera impresión que reciben los clientes al ingresar al establecimiento propuesto en el proyecto, así mismo se debe considerar que esta área no solo involucra la venta directa al clientes sino comprende tres sub áreas claves, como son comedor, caja y despacho. 
Un aspecto a considerar en el área de servicio al cliente es que se debe asegurar cuatro aspectos fundamentales como son: limpieza, saludo, presencia y manipulación. Con ello se garantiza que la primera impresión de los clientes sea positiva y les brinde seguridad al momento de adquirir y consumir sus alimentos. Para ello el personal debe cumplir con el uso de mallas en el cabello, vestimenta con el uniforme completo, guantes de requerir la manipulación de alimentos, limpieza y buena presencia en el trabajo.

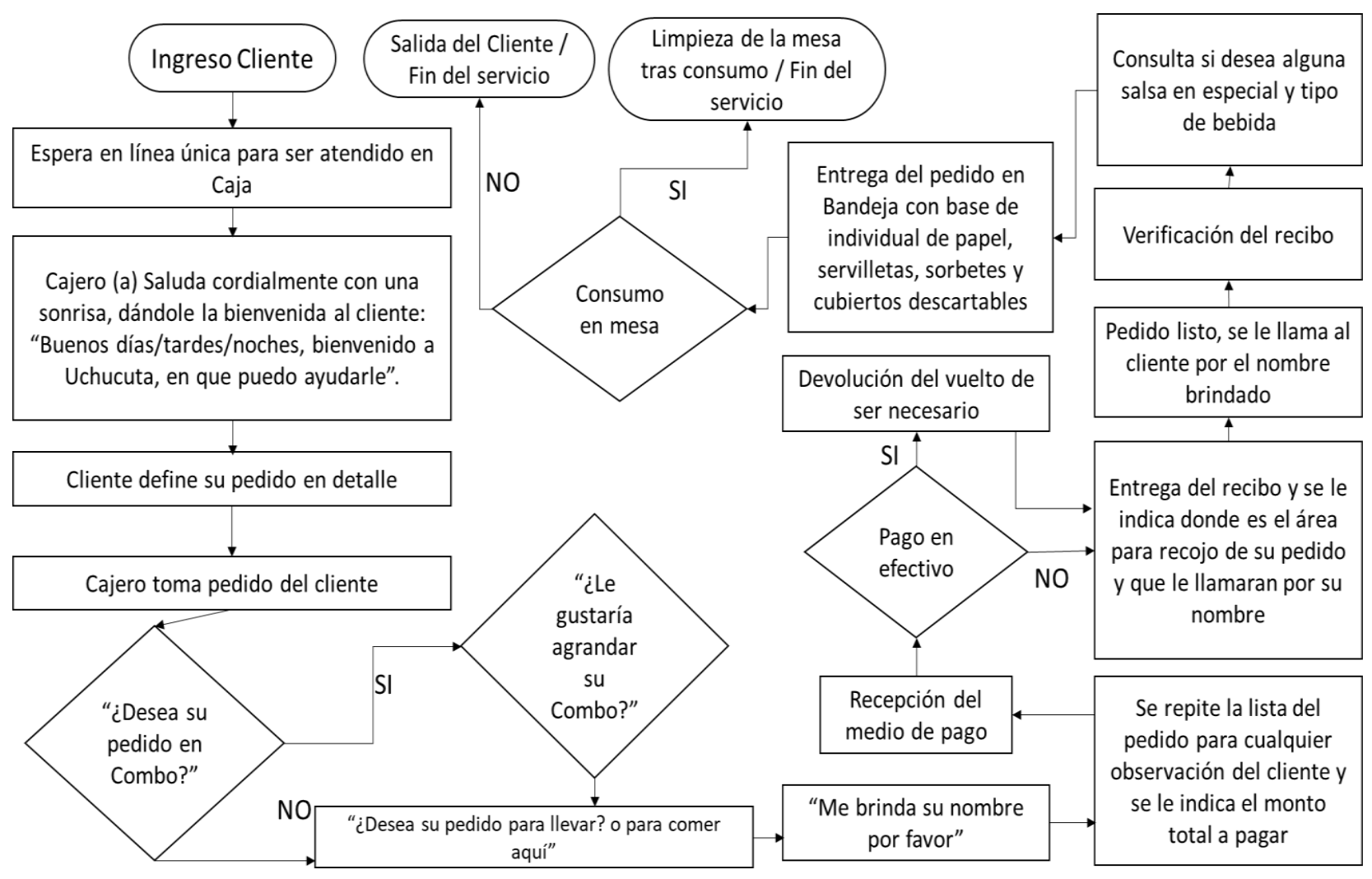

Figura 52. Diagrama del proceso del área de atención al cliente. Fuente: Elaboración propia.

Del mismo modo en cuanto al área de producción del producto esta se considera critica puesto que se debe tomar en cuenta factores como manipulación, higiene y limpieza del área de trabajo, temperaturas y control de tiempos de cocción y preparación, un error en alguno de estos aspectos 
puede poner en riesgo la operación del establecimiento y generar conflictos entre áreas e incluso con los clientes. También se debe tomar en cuenta que el área de producción depende mucho del área de abastecimiento y mantenimiento, puesto que se debe asegurar una óptima calidad de los insumos además de contar con equipamiento en buen estado y área de trabajo limpias.

A continuación según Figura 53, se considera el diagrama del proceso general de área de producción del producto.

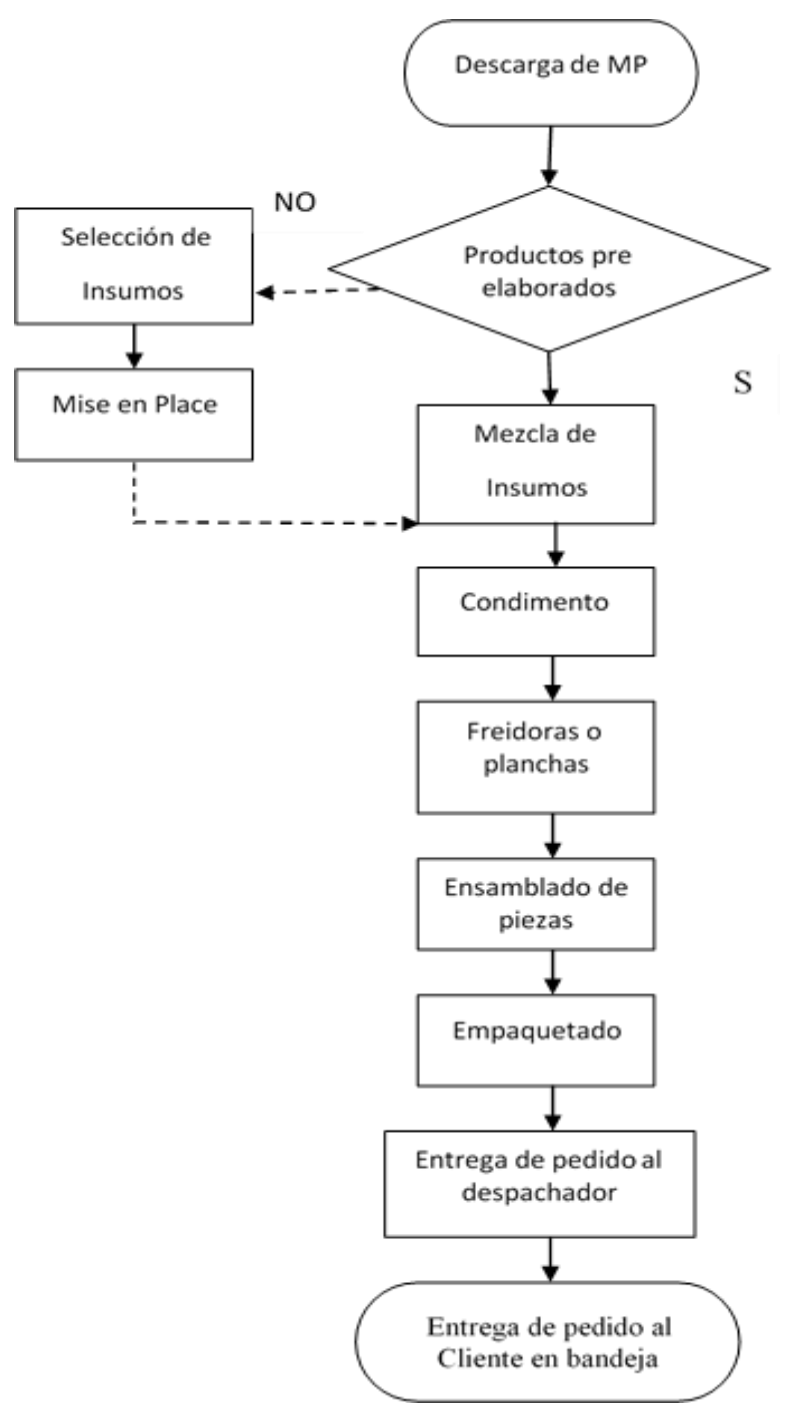

Figura 53. Diagrama del proceso productivo. Fuente: Elaboración propia. 
Así mismo para efectos de guía para las operaciones de producción del proyecto se elabora una matriz de diagrama del proceso productivo de la elaboración de las hamburguesas como guía para la producción de otros insumos y derivados. Conforme Figura 54.

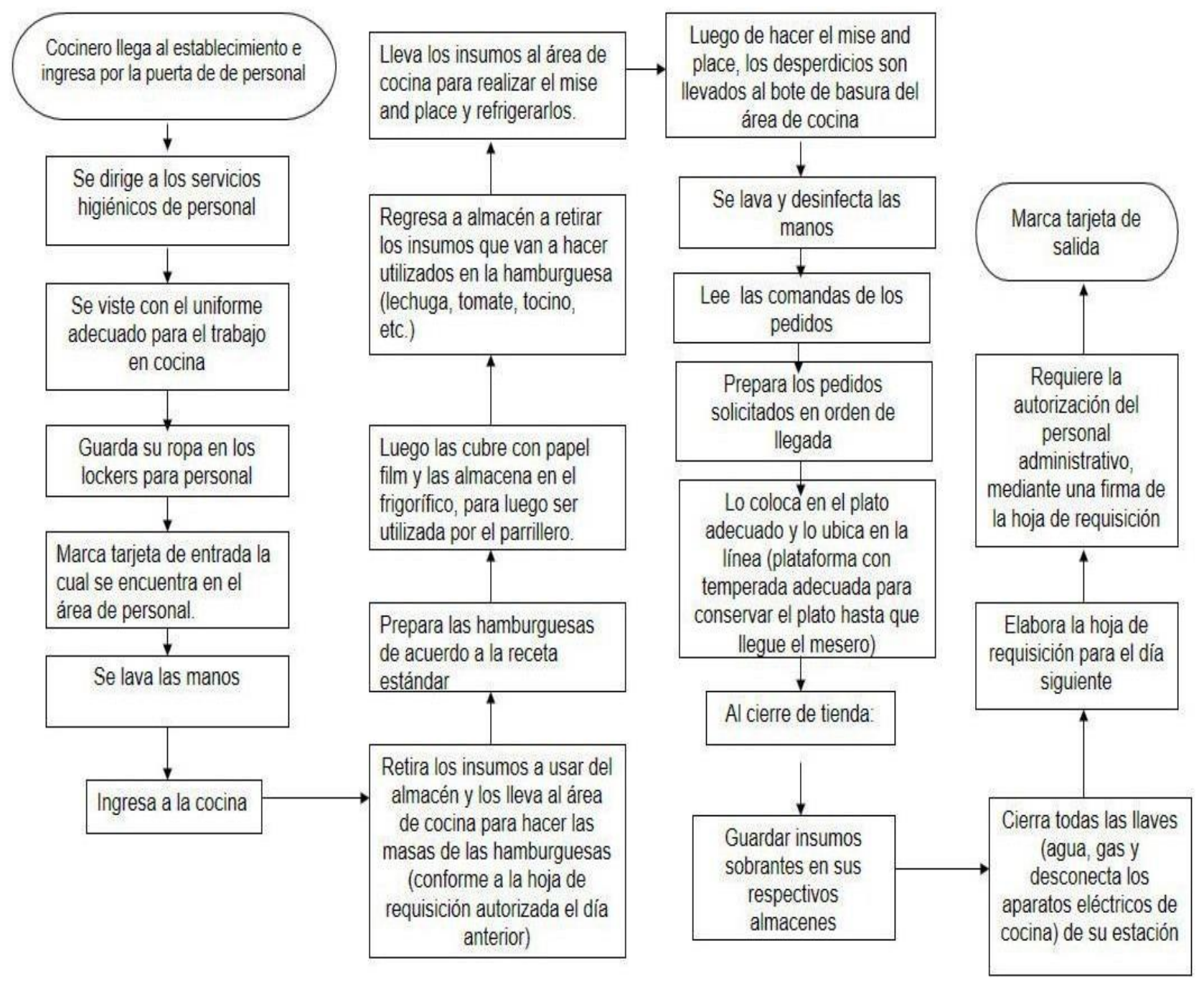

Figura 54. Diagrama del proceso de elaboración de Hamburguesas. Fuente: Elaboración Propia. 


\subsubsection{Selección del equipamiento.}

La selección de equipamiento, debe ser precedida por una adecuada tomada información a través de fabricantes de equipos, publicaciones comerciales, asociaciones de venta, archivos de las empresas, etc. y se debe distinguir las dos etapas que involucra todo proceso de selección:

\subsubsection{Elección del tipo de equipo para especificar las propuestas.}

"Selección entre los distintos equipos dentro del tipo elegido, a fin de decidir entre las propuestas." (es.scribd.com, 2017)

Para el presente proyecto los equipos a utilizar se dividen en tres áreas importantes como son: cocina, comedor y counter, y oficina administrativa. En la selección de los mismos se tomaron en cuenta factores como tamaño, dimensiones, beneficio, necesidad y precio. Conforme Tabla 87, Tabla 88 y Tabla 89. 
Tabla 87

Equipos de Cocina para el proyecto

\begin{tabular}{|c|c|c|}
\hline Equipo & Características / Especificaciones Técnicas & Precio x Und \\
\hline $\begin{array}{l}\text { Cocina industrial } \\
3 \text { hornillas }\end{array}$ & $\begin{array}{l}\text { Fabricado con planchas de Acero Inoxidable calidad AISI } 304 \text { 2B Uso } \\
\text { Gastronómico. Equipada con tres quemadores CF de fierro fundido de } \\
\text { 7" de diámetro. } 3 \text { Parrillas de fierro fundido }\end{array}$ & S/ 1300.00 \\
\hline Freidora & $\begin{array}{l}\text { Marca: Ferton. Modelo: FRP461. } \\
\text { Bandejas: 2.Capacidad: 20 Litros. } \\
\text { Voltaje: } 220 \text { Voltios. Quemadores: } 3 \text {. } \\
\text { Dimensiones: } 43 \text { x } 77 \text { x } 117 \text { cms. Peso: } 53 \text { kilos. }\end{array}$ & S/ 1100.00 \\
\hline $\begin{array}{l}\text { Plancha de } \\
\text { Hamburguesas }\end{array}$ & $\begin{array}{c}\text { Marca: Falcón } \\
\text { Todo en acero inoxidable con base. Plancha de acero. Tamaño } \\
\text { 90cmx60cm. Espesor de la plancha de } 7 \mathrm{~mm} \text { gruesa que no se deforma } \\
\text { con fibra de vidrio al contorno. }\end{array}$ & S/ 1200.00 \\
\hline $\begin{array}{l}\text { Horno para } \\
\text { carnes }\end{array}$ & $\begin{array}{c}\text { Medidas: } 1000 \text { x } 800 \text { x } 900+\text { patas de acero } \\
\text { Material: Acero inoxidable de } 1.2 \text { y } 0.9 \mathrm{~mm} \text {, calidad AISI } 430\end{array}$ & S/ 1500.00 \\
\hline Congeladora & $\begin{array}{c}\text { Medidas: } 1100 \text { x } 650 \text { x } 900 \\
\text { Material: Acero inoxidable mate de } 0.8 \mathrm{~mm} \text {, calidad AISI } 430 \\
\text { Revestimiento interno de tecnopor de } 2 " \text { densidad } 18 \\
\text { Trabaja en }-0^{\circ} \text { a }-18^{\circ}\end{array}$ & $\mathrm{S} / 2500.00$ \\
\hline $\begin{array}{l}\text { Refrigerador } \\
\text { Conservador }\end{array}$ & $\begin{array}{l}\text { Medidas: } 700 \times 700 \times 1.65 \text {. Material: Acero Inoxidable mate de } 0.6 \mathrm{~mm} \text {, } \\
\text { calidad AISI } 430 \text {. Lleva } 02 \text { puertas herméticas. Compresor hermético de } \\
1 / 4 \mathrm{H} \text {. P. de marca Tecumseh Francés, temperatura alta, refrigerante } 134^{\mathrm{a}}\end{array}$ & S/ 2850.00 \\
\hline $\begin{array}{l}\text { Horno } \\
\text { microondas }\end{array}$ & $\begin{array}{c}\text { Tiene una tecnología de Triple Distribución de Ondas } \\
\text { Pantalla tipo LED } \\
\text { Con } 10 \text { niveles de potencia } \\
\text { Potencia: } 1500 \mathrm{~W} \\
\text { Dimensiones: Alto: } 29,7 \mathrm{~cm} \text {. Ancho: } 57,7 \mathrm{~cm} \text {. Profundidad: } 38,4 \mathrm{~cm}\end{array}$ & S/ 395.00 \\
\hline
\end{tabular}

Alimentación con batería interna 6v.Autonomía aprox.12 hs. Bandeja de

Balanza acero inoxidable de 217 x $367 \mathrm{mms}$. Dimensiones generales: 380 x 387x

$467 \mathrm{~mm}$. Voltaje de alimentación: $220 \mathrm{vca}-50 \mathrm{~Hz}$. Rango de
electrónica

S/ 150.00

(Autonomía aprox. $12 \mathrm{hs}$ ). Cap. $5 \mathrm{~kg}$.

Mesas de trabajo

de acero

Mesa de 2 niveles acero inoxidable espesor $1.2 \mathrm{~mm}$ patas de 2 "

pulgadas

S/ 900.00

inoxidable

Medidas: 1.10 x $60 \mathrm{~cm}$ altura $90 \mathrm{~cm}$

Repisas de acero

inoxidable de 4

De 110x $30 \mathrm{~cm}$ espesor de los 4 niveles de $1.2 \mathrm{~mm}$

S/ 900.00

niveles

Trampa de grasa

con malla

Acero inoxidable 80x50x45 cm

S/1590.00

Extintor de

cocina

Tipo K, $2.5 \mathrm{gl}$

$\mathrm{S} / 350.00$

Nota. Ver cotizaciones en Anexo $\mathrm{N}^{\circ} 14$. Fuente: Elaboración propia. 
En Figura 55, se muestra gráficamente el tipo de equipamiento de cocina que será destinado para el proyecto indicado en Tabla 87.

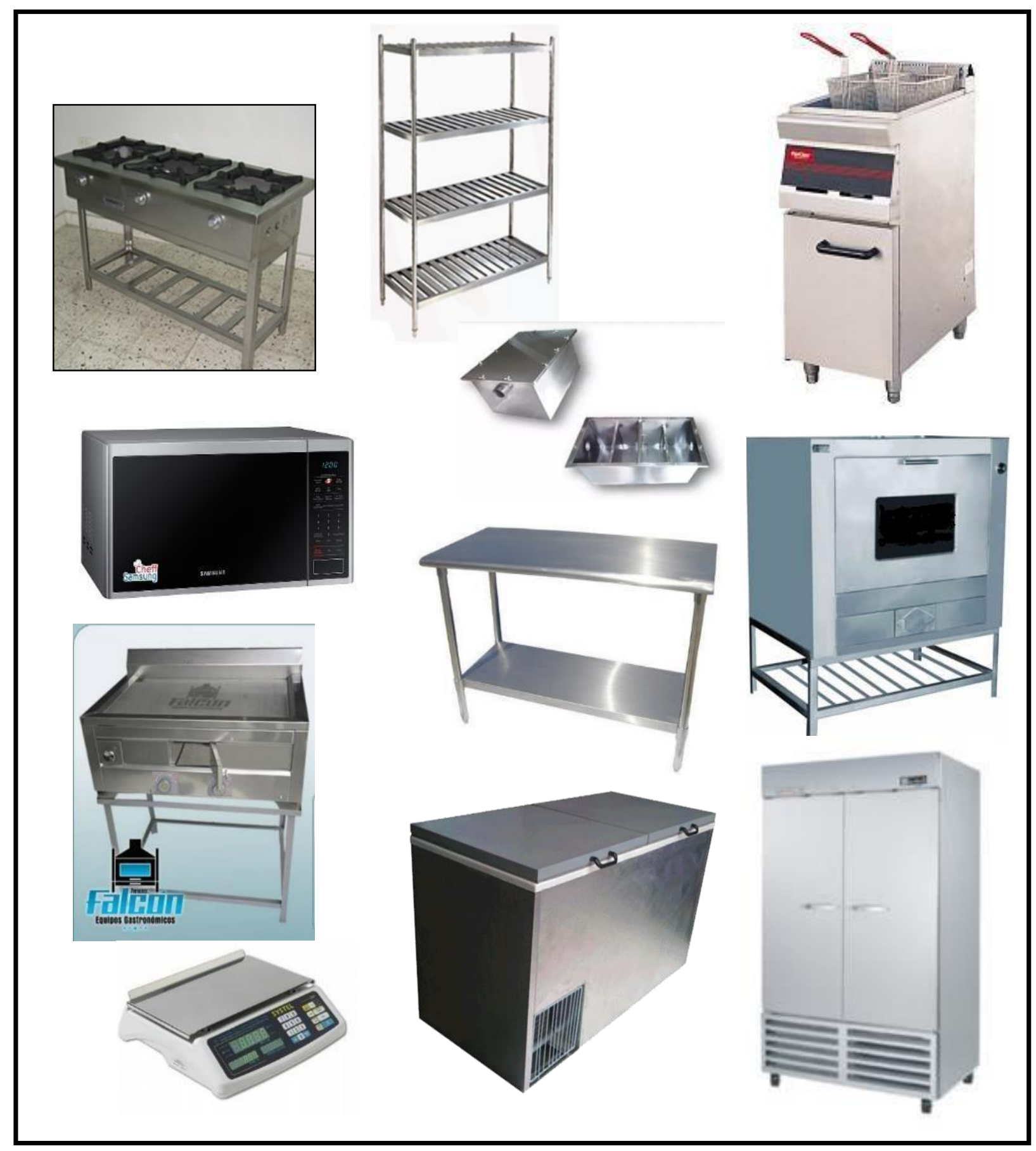

Figura 55. Equipos de cocina para el proyecto. Fuente: Elaboración propia. 
Los equipos de cocina serán necesarios para la elaboración de los productos como Hamburguesas, pollo frito y broaster, papas fritas, postres, salsas, ensaladas entre otros, por lo cual es de necesidad contar con equipos industriales o semi-industriales debido al volumen de producción que se prevé tener, del mismo modo son de utilidad para un mejor control de temperaturas y tiempos de cocción puesto que cuentan con reguladores y termostatos de mayor precisión y manejo.

Del mismo modo se seleccionaron los equipos para el área de counter y comedor conforme Tabla 88, los equipos que se tomaron en cuenta son aquellos que cumplen con las características de accesibilidad y comodidad necesarias para el proyecto, debido a que se orienta en un tipo de concepto que demanda un servicio de comida rápida. 
Tabla 88

Equipos de counter y comedor para el proyecto

\begin{tabular}{|c|c|c|}
\hline Equipo & Características / Especificaciones Técnicas & Precio x Und \\
\hline $\begin{array}{l}\text { Dispensador de salsas } \\
3 \text { Caños }\end{array}$ & 39.5 X 22 X 25 más altura de los caños. & S/ 1400.00 \\
\hline Juego de sillas y mesas & Unidad & S/ 610.00 \\
\hline $\begin{array}{l}\text { Mostradores barra } \\
\text { mostrador estilo } \\
\text { colonial madera } \\
\text { maciza }\end{array}$ & $\begin{array}{c}\text { Ancho: } 200 \mathrm{~cm} \\
\text { Altura: } 130 \mathrm{~cm} \\
\text { Profundidad: } 40 \mathrm{~cm} \\
\text { Vuelo adicional de tapa: } 20 \mathrm{~cm} \\
\text { Peso aproximado: } 50 \mathrm{~kg}\end{array}$ & S/ 2300.00 \\
\hline $\begin{array}{l}\text { Computadora } \\
\text { Caja Registradora } \\
\text { Computarizada Punto } \\
\text { de Venta Táctil Touch }\end{array}$ & $\begin{array}{l}\text { IBM } 4840 \text { TOUCH - incluye software } \\
\text { RESTPROCES - SYSCOPERU }\end{array}$ & S/ 3356.00 \\
\hline Aparadores de bebidas & & S/ 1200.00 \\
\hline POS VISA & No cobra instalación & $\begin{array}{c}\text { Cobro alquiler de POS } \\
\text { soles: } \mathrm{S} / 15.00 \\
\text { Cobro alquiler de POS } \\
\text { dólares: } \$ 8.00 \\
\text { En ambos casos cobran } 5 \% \\
\text { por transacción realizada. }\end{array}$ \\
\hline POS MasterCard & No cobra instalación ni alquiler de POS & $\begin{array}{c}\text { Para soles y dólares cobran } \\
7 \% \text { de la transacción } \\
\text { realizada. }\end{array}$ \\
\hline Extintor $\mathrm{ABC}$ de $6 \mathrm{Kg}$ & & $\mathrm{S} / 70.00$ \\
\hline
\end{tabular}

Nota. Ver cotizaciones en Anexo $\mathrm{N}^{\circ}$ 14. Fuente: Elaboración propia.

En base a lo anterior conforme a Figura 56 se muestra de forma gráfica los equipos que se seleccionaron para el área de comedor y counter. 

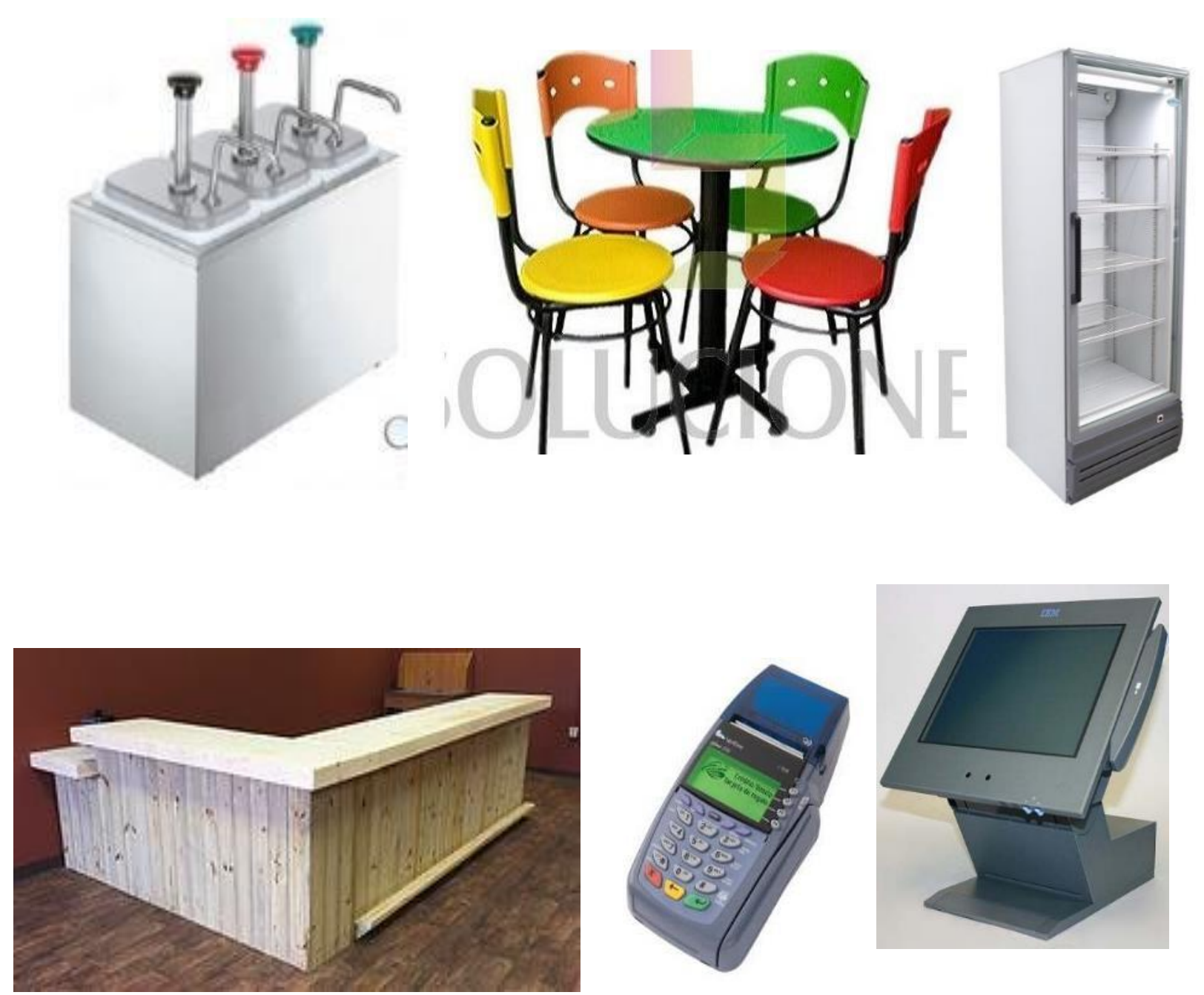

Figura 56. Equipos de comedor y counter. Fuente: Elaboración propia.

También se consideran como parte importante los equipos correspondientes al área administrativa, puesto que son necesarios para la operatividad de la empresa, para gestionar los procedimientos y llevar registros de las ventas y producción. Conforme Tabla 89 se presentan los equipos necesarios, seguido de Figura 57 donde se muestran gráficamente. 
Tabla 89

Equipos del área administrativa

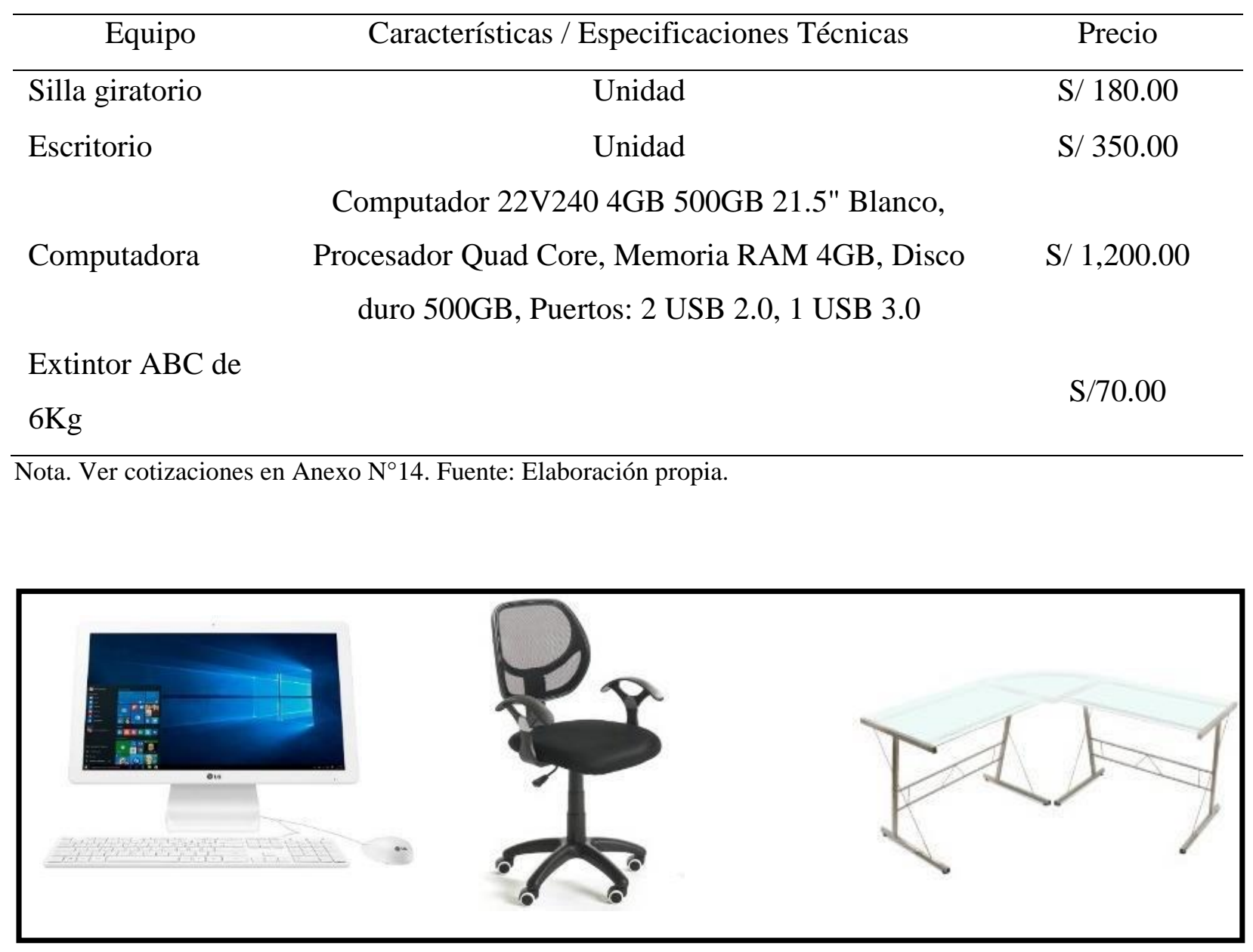

Figura 57.Equipos del área administrativo. Fuente: Elaboración propia.

\subsubsection{Lay out.}

El lay out está relacionado con el ámbito del marketing, y se vincula con la distribución de los elementos físicos en cierto espacio como parte de la estrategia empresarial de producción. 
Aunque puede parecer que la forma en la que los directivos de las organizaciones disponen los muebles y los instrumentos de trabajo es intuitiva, el estudio del lay out apunta a optimizar los tiempos y el trabajo de cada uno de los individuos y las máquinas, y quienes se ocupan de él aseguran que a la larga se notarán diferencias en los rendimientos. (Enciclopediade, 2016)

En cuanto a la determinación del Lay Out para el proyecto en primer lugar se estimó el área requerida para el local conforme los criterios establecidos en Tabla 90, para ello se tomó como base la cantidad de visitas de Combos del año 2023, es decir, el último año de evaluación del proyecto, el cual asciende a 104,420 visitas en total, a dicha cantidad se le saco el $50.90 \%$ correspondiente a los resultados de la encuesta con mayor votación en cuanto a tiempo de permanencia esperado en el nuevo proyecto de Fast Food, resultando así que el tiempo promedio de permanencia será más de 31 minutos, ello permitirá estimar la cantidad de visitas al año que permanecerían en el local para consumir sus alimentos que no sean para llevar, resultando en 53,150 visitas al año de clientes que consumirían dentro del local por año.

Tabla 90

Determinación del área de comedor del local

\begin{tabular}{lc}
\hline \multicolumn{1}{c}{ Fórmula } & \multicolumn{1}{c}{ Resultado } \\
\hline $53,150 / 12$ meses / 30 días /3 horas (duración & 49.21 comensales por hora \\
horas pico) $=$ & $49.21 \times 1.5^{\mathrm{a}}=73.82 \mathrm{~m} 2$ \\
Área de comedor del local $=$ & 4 \\
\hline
\end{tabular}

Nota. Fuente: Elaboración propia.

a Factor de Aforo para restaurantes - mesas.

http://www.cenepred.gob.pe/web/download/6.\%20ANEXO\%20CALCULO\%20DE\%20AFORO.xlsx 
El resultado anterior representa el área promedio destinada para comedor del local donde se distribuirán las sillas y mesas para consumo en tienda, para el presente caso según estándares el “área de comedor representa el 60 \% del área total, quedando el 40\% como área de producción y administración pudiendo ser este último incluso menor mientras no sea menor a la cuarta parte del área del local" (Cocinas Industriales, n.d), para efectos del estudio se determinaron dos tamaños de áreas potenciales, la primera con el estándar reglamentario y la segunda estimando que el comedor representa el 70\% del área total puesto que debido al tipo de negocio que se piensa establecer es necesario un área de comedor más amplia ya que dicha área no solo incluye la distribución de las mesas, sino también el área de espera y despacho de los pedidos, además que al elaborarse un producto estandarizado, cuyo proceso productivo de las recetas es similar entre sí, el espacio de producción directa no demanda un amplio tamaño. Este análisis se lleva a cabo para poder contar con dos opciones de áreas potenciales que se puedan ajustar a la necesidad del proyecto y así mismo para facilitar la selección del local ideal para el proyecto, conforme se detalla en Tabla 91.

Tabla 91

Estimación de áreas potenciales

\begin{tabular}{cc}
\hline Opciones & Cálculo \\
\hline Opción 1: 40\% (\% área de producción y & $(73.82 \mathrm{mts} 2 \times 40 \%) / 60 \%=49.21 \mathrm{mts}$ \\
administración), 60 \% (\% área de comedor) & $49.21 \mathrm{mts}+73.82 \mathrm{mts} 2=123.03 \mathrm{mts} 2$ \\
& \\
Opción 2: 30\% (\% área de producción y & $(73.82 \mathrm{mts} 2 \times 30 \%) / 70 \%=31.64 \mathrm{mts}$ \\
administración), 70\% (\% área de comedor) & $31.64 \mathrm{mts} 2+73.82 \mathrm{mts} 2=105.46 \mathrm{mts} 2$ \\
\hline
\end{tabular}

Nota. Fuente: Elaboración propia. 
En base a la estimación anterior y conforme el estudio de localización que se detallará más adelante se seleccionó un establecimiento con un área total de 104 mts2, conforme a la opción 2 de estimación de áreas potenciales, en base a ello se elaboró el plano del local que se piensa implementar, conforme Figura 58, en base a una escala de 1:1, asimismo se presenta el plano de zonas de seguridad y evacuación, conforme Figura 59, según las normas del Instituto Nacional de Defensa Civil. (Indeci, 2009). Asimismo, se puede validar el área y capacidad del local según el cálculo del aforo establecido por el CENEPRED (Centro Nacional de Estimación, Prevención y Reducción del Riesgo de Desastres), que determina para establecimientos de Fast Food o Comida rápida según RNE A.070 COMERCIO ART8 (CENEPRED, n.d), que se requiere como mínimo $5 \mathrm{~m} 2$ por persona para el área de Cocina y $1.5 \mathrm{~m} 2$ por persona para el área de Comedor, en ese sentido se establecio que por turno en el área de cocina deberán trabajar como máximo 4 personas puesto que el área de cocina es de $18.62 \mathrm{~m} 2$ y se estima 49.21 personas por hora en promedio que permanecen en la zona de comedor del establecimiento conforme Tabla 90, lo cual coincide con los requisitos de CENEPRED ya que se cuenta con un área de comedor de $81.38 \mathrm{~m} 2$, por lo cual podría soportar hasta 54 personas que es superior a los 49.21 personas que se tiene estimado. 


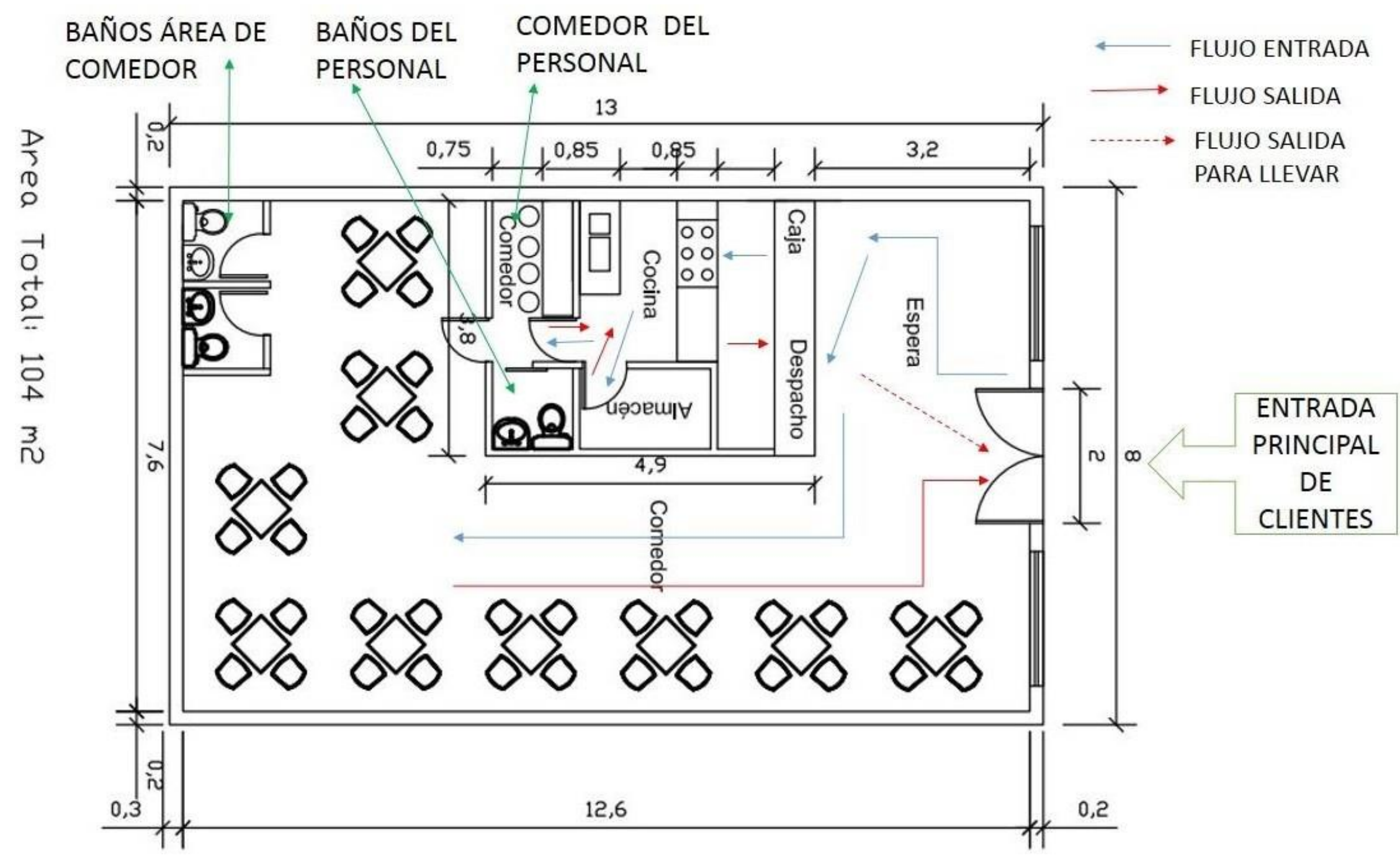

Figura 58. Lay out local del proyecto con flujos y áreas claves. Escala 1:1. Fuente: Elaboración propia. 


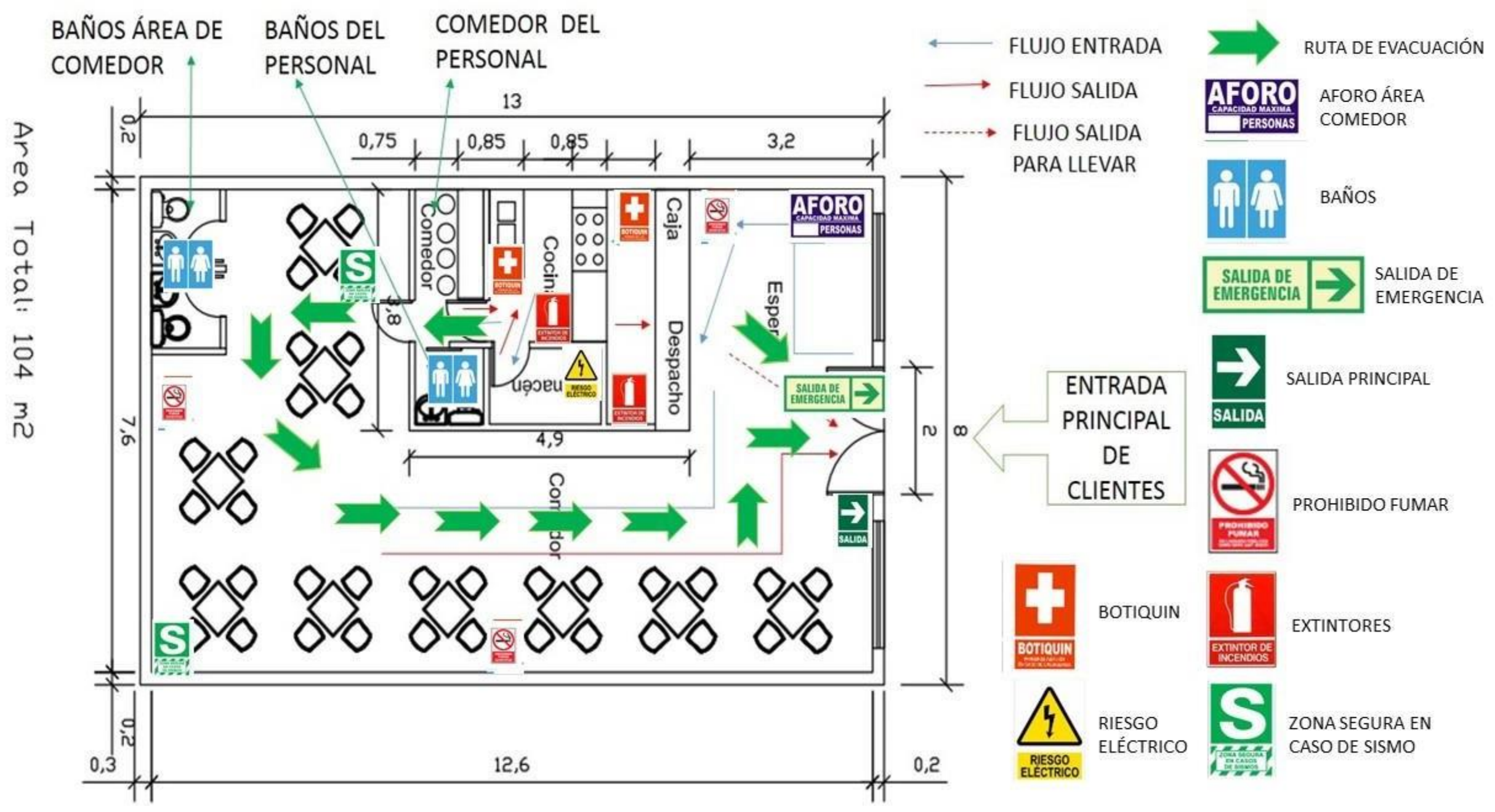

Figura 59. Plano de señalización de rutas de evacuación y zonas de seguridad. Fuente: Elaboración propia 


\subsubsection{Distribución de equipos y maquinaria.}

La distribución de la maquinaria y equipos determinará en alto grado la eficiencia de la operación de una planta industrial, ya que afecta al tiempo y la longitud de los desplazamientos de materiales y operarios, así como a las inversiones en obras civiles y en equipos de transporte. (Proyectos Ingenotas, 2009)

Para elaborar la distribución de equipos y maquinaria en primer lugar se determinó el área y dimensiones que comprende la zona de producción, en base a ello se estimó la distribución y cantidad de equipos requeridos, conforme se detalla en Figura 60.

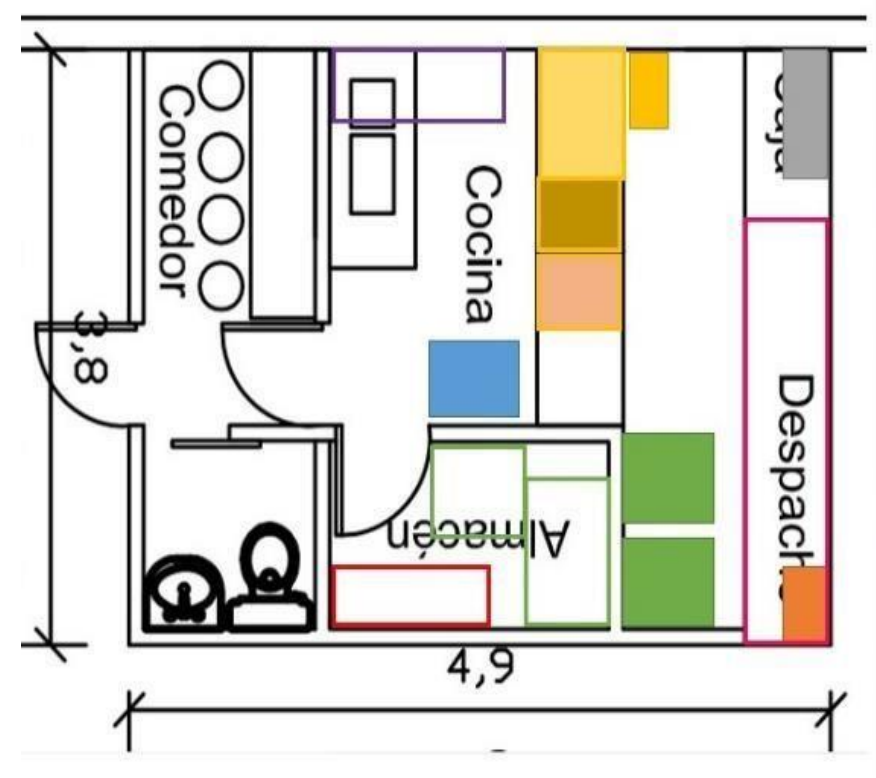

Área Zona de Cocina y Personal :

$3.8 \times 4.9=18.62 \mathrm{mts} 2$

Tamaño Almacén:

$1.2 \mathrm{~m} \times 2 \mathrm{~m}$

- 1 Repisas de acero inoxidable (4 niveles)

- 1 Refrigerador

- 1 Congelador

Tamaño de Cocina:

$2.7 \mathrm{~m} \times 2 \mathrm{~m}$

- 1 mesa de trabajo de acero inoxidable.

- 1 horno de carnes

- 1 cocina 3 hornillas

- 1 plancha de hamburguesas

- 1 freidora

Tamaño de zona de despacho:

$3.8 \mathrm{~m} \times 1.45 \mathrm{~m}$

- 2 aparadores de bebidas

- 1 caja registradora

- 1 microondas

- 1 mostrador barra de despacho

- 1 dispensador de salsas

Figura 60. Distribución de equipos y maquinaria zona de producción y personal. Fuente: Elaboración propia. 
Así mismo se procedió a realizar la distribución de la zona del comedor, para ello se tomó en cuenta el tamaño y dimensión de las mesas conforme se detalla en Tabla 92.

\section{Tabla 92}

Características de mesas y sillas

\begin{tabular}{lc}
\hline \multicolumn{1}{c}{ Características } & Especificaciones \\
\hline Tipo de mesa & Cuadrada \\
Cantidad de sillas & 4 \\
Orientación & Diagonal \\
Tamaño de Mesas & $75 \mathrm{~cm} \mathrm{x} 75 \mathrm{~cm}$ \\
Tamaño de sillas & $35 \mathrm{~cm} \mathrm{cada} \mathrm{una}$ \\
Lado de la mesa & $235 \mathrm{~cm}^{\mathrm{a}}$ \\
\hline Nota. Fuente: Elaboración propia & \\
a Lado de la mesa. https://es.slideshare.net/galgonine/calculo-de-el-aforo-y-flujo-de-clientela
\end{tabular}

En base a las especificaciones anteriores se procede a determinar la cantidad ideal de mesas para el área del local destinada al comedor principal conforme Tabla 93 y cuya distribución gráfica se observa en Figura 58.

Tabla 93

Cantidad de mesas a implementar en el local

\begin{tabular}{lc}
\hline & Estimación de cantidad de mesas \\
\hline Mesas a lo Largo: & $12.6 \mathrm{a} / 2.35=5.36$ \\
Mesas a lo Ancho: & $4 \mathrm{~b} / 2.35=1.70$ \\
Mesas a implementar: & $5.36 \times 1.70=9.112$, aprox. 9 mesas
\end{tabular}

Nota. Fuente: Elaboración propia.

a Obtenido del plano del local. Largo del Local.

b Ancho del local 8m, se considera la mitad por el área que ocupa la zona de cocina. 


\subsection{Determinación del tamaño.}

Según Sapag Chain (2014), la determinación del tamaño responde a un análisis

interrelacionado de una gran cantidad de variables de un proyecto: demanda, disponibilidad de insumos, localización y plan estratégico comercial de desarrollo futuro de la empresa que creará con el proyecto, entre otras.

El tamaño del proyecto estará determinado por el nivel de producción de combos y postres, estando éste en función al porcentaje del mercado objetivo al que se dirige donde se determinó un promedio de visitas para el último año de evaluación de 104,420 para el consumo de Combos y 30,898 para postres. Por tanto, será necesario desarrollar un volumen de producción anual en base a las características del proyecto en cuanto a tiempos de servicio.

Para este análisis se toma en cuenta que el tiempo de servicio promedio ideal resultado de la evaluación cuantitativa que es de 10 a 15 minutos con un $81.11 \%$ de aprobación, del mismo modo el tiempo de permanencia que incluye el tiempo desde la toma de pedido es más de 31 minutos conforme igualmente al resultado de las encuesta orientado al proyecto con un $50.90 \%$ de aprobación.

En base ello se elaboró la Tabla 94, para determinar la capacidad productiva máxima por día según combos y postres. 
Tabla 94

Capacidad máxima productiva

Fórmula:

Capacidad productiva máxima en comensales por día: (Capacidad Estimada de Comensales x Tiempo total del servicio)/Tiempo del ciclo del servicio.

\begin{tabular}{cc}
\hline $\begin{array}{c}\text { 104,420/ } 12 \text { meses / 30 días }=290.06 \\
\text { comensales por día de Combos }\end{array}$ & 30,898 / 12 meses / 30 días = 85.83 \\
Capacidad productiva Máxima Combos: & Capacidad productiva Máxima postres: \\
$(290.06$ x 31) /15 =599.46 - aprox. 600 & $(85.83$ x 31) /15 =177.38 - aprox. 178 \\
comensales o Combos (se asume que cada & comensales o Postres (se asume que cada \\
comensal adquiere un combo) por día. & comensal adquiere un postre) por día. \\
\hline
\end{tabular}

Nota. Fuente: Elaboración propia.

a Fórmula Capacidad productiva Máxima en comensales. https://www.asgestion.com/?p=1675

Así mismo cabe considerar que la capacidad de producción está dada también en función a la capacidad productiva de los equipamientos y la cantidad de mano de obra directa destinada a la misma, en ese sentido en el área de cocina se contará con 6 personas distribuidas en el horario de atención de 10 am a 10 pm, de forma que siempre se encuentren laborando 3 personas en la mañana, 4 en la tarde y 5 en el turno noche. Durante el horario de mayor afluencia que es durante la tarde y noche, la productividad de las máquinas y de personal será media-alta debido a que según los resultados de la evaluación cuantitativa en días de semana a la hora del almuerzo a partir del medio día es la afluencia más alta de personas, seguido por los fines de semana a partir de $6 \mathrm{pm}$. 


\subsubsection{Proyección de crecimiento.}

La cantidad demandada proyectada a futuro es quizás el factor condicionante más importante del tamaño, aunque este no necesariamente deberá definirse en función de un crecimiento esperado del mercado, ya que, el nivel óptimo de operación no siempre será el que se maximice las ventas.

Aunque el tamaño puede ir adecuándose a mayores requerimientos de operación para enfrentar un mercado creciente, es necesario que se evalué esa opción contra, la de definir un tamaño con una capacidad ociosa inicial que posibilite responder en forma oportuna a una demanda creciente en el tiempo. (Google Documents, n.d.).

Para el caso del proyecto se determinó la cantidad demandada en función de la cantidad de visitas anual de Combos y Postres proyectada del 2019 al 2023 según se aprecia en Tabla 95, cabe precisar que para determinar la cantidad de visitas de postres, se tomó en cuenta el porcentaje que representa la cantidad de respuestas de preferencias por el postre más votado sobre el total de respuestas emitidas, resultando un porcentaje de $29.59 \%$. El cual se aplicó a las visitas totales resultantes del proceso de estudio de mercado.

Tabla 95

Producción anual proyectada según número de visitas

\begin{tabular}{lccccc}
\cline { 2 - 5 } & 2019 & 2020 & 2021 & 2022 & 2023 \\
\hline Programa de ventas combos & 41,725 & 55,622 & 69,729 & 84046 & 98573 \\
Programa de ventas postres & 12,346 & 16,459 & 20,633 & 24,869 & 29,168 \\
\hline
\end{tabular}

Nota. Fuente: Elaboración propia. 


\subsubsection{Recursos.}

Se refiere a la provisión de materias primas o insumos suficientes en cantidad y calidad para cubrir las necesidades del proyecto durante los años de vida del mismo. La fluidez de la materia prima, su calidad y cantidad son vitales para el desarrollo del proyecto. (Google Documents, n.d.).

Los recursos necesarios del proyecto es la materia prima para la elaboración de las alitas, hamburguesas, broaster, papas nativas, bebidas entre otros. Para estos recursos se debe considerar en primer lugar factores como seguridad y riesgo en el manejo de los mismos, para ello se establece un sistema de manejo de alimentos óptimo conforme se detalla en Tabla 96.

Tabla 96

Manejo y manipulación de insumos

\begin{tabular}{|c|c|}
\hline Tipo de Manejo & Detalle \\
\hline $\begin{array}{l}\text { Manipulación de } \\
\text { alimentos }\end{array}$ & $\begin{array}{c}\checkmark \text { Todo el personal que manipule y/o realice actividades dentro del área de } \\
\text { cocina debe portar la indumentaria adecuada: } \\
\checkmark \text { Rejilla de cabello } \\
\checkmark \text { Guantes quirúrgicos (de manipular alimentos). } \\
\checkmark \text { Uniforme completo } \\
\checkmark \\
\end{array}$ \\
\hline $\begin{array}{l}\text { Manejo de } \\
\text { alimentos } \\
\text { alergénicos }\end{array}$ & $\begin{array}{c}\checkmark \text { Hacer de conocimiento al personal los insumos con mayor riesgo alergénico } \\
\text { en caso de consultas o preferencias particulares de algunos clientes. } \\
\checkmark \quad \text { Capacitación del personal en caso de primeros auxilios. } \\
\checkmark \quad \text { Mantener el botiquín completo y actualizado. }\end{array}$ \\
\hline $\begin{array}{l}\text { Manejo de } \\
\text { residuos }\end{array}$ & $\begin{array}{c}\checkmark \text { Capacitación del personal en temas de minimización, clasificaciones } \\
\text { (peligrosas y no peligrosas). } \\
\checkmark \quad \text { Contar con contenedores de diversos colores para el desecho de residuos } \\
\text { orgánicos (verde), plásticos (azul), papel (amarillo) y peligrosos (rojo). }\end{array}$ \\
\hline
\end{tabular}

Nota. Fuente: Elaboración propia. 
Estos productos además deberán ser adquiridos de proveedores confiables y que cumplan con la normatividad sanitaria vigente, así mismo se debe garantizar la calidad y estandarización de los insumos de manera que los clientes reciban siempre el mismo tamaño, sabor y características generales del producto que están adquiriendo. Así mismo se debe considerar que este tipo de insumos se ven afectos a la generación de mermas por sus cualidades y características por ello en base a Tabla 97 y Tabla 98, se presenta el rendimiento y las mermas por unidad de medidas que generan los insumos a utilizar en el proyecto así como sus respectivos precios.

Tabla 97

Mermas y rendimientos de insumos A

\begin{tabular}{|c|c|c|c|c|c|c|}
\hline Insumos & Unidad & Medida & Precio & Precios sin igv $18 \%$ & Merma & Rendimiento \\
\hline Sal & $\mathrm{kg}$ & 1 & $\mathrm{~S} / .1 .00$ & S/. 0.85 & 0 & $100 \%$ \\
\hline Pimienta & $\mathrm{kg}$ & 1 & S/. 10.00 & S/. 8.47 & 0 & $100 \%$ \\
\hline Comino & $\mathrm{kg}$ & 1 & S/. 12.00 & S/. 10.17 & 0 & $100 \%$ \\
\hline Mermelada de maracuyá & $\mathrm{kg}$ & 1 & S/. 12.00 & S/. 10.17 & 0 & $100 \%$ \\
\hline Harina de chuño & $\mathrm{kg}$ & 1 & S/. 5.00 & S/. 4.24 & 0 & $100 \%$ \\
\hline Azúcar blanca & $\mathrm{kg}$ & 1 & S/. 3.00 & S/. 2.54 & 0 & $100 \%$ \\
\hline Aceite & litros & 1 & S/. 6.00 & S/. 5.08 & 0 & $100 \%$ \\
\hline Mermelada de sauco & $\mathrm{kg}$ & 1 & S/. 15.00 & S/. 12.71 & 0 & $100 \%$ \\
\hline Orégano & $\mathrm{kg}$ & 1 & S/. 12.00 & S/. 10.17 & 0 & $100 \%$ \\
\hline Kétchup & litros & 1 & S/. 7.00 & S/. 5.93 & 0 & $100 \%$ \\
\hline Mostaza & $\mathrm{kg}$ & 1 & S/. 8.00 & S/. 6.78 & 0 & $100 \%$ \\
\hline Azúcar rubia & $\mathrm{kg}$ & 1 & S/. 3.00 & S/. 2.54 & 0 & $100 \%$ \\
\hline Mantequilla & $\mathrm{kg}$ & 1 & S/. 7.00 & S/. 5.93 & 0 & $100 \%$ \\
\hline Huevo & $\mathrm{kg}$ & 1 & S/. 6.00 & S/. 5.08 & 0 & $100 \%$ \\
\hline Harina de kiwicha & $\mathrm{kg}$ & 1 & S/. 7.00 & S/. 5.93 & 0 & $100 \%$ \\
\hline Kiwicha pop & $\mathrm{kg}$ & 1 & S/. 20.00 & S/. 16.95 & 0 & $100 \%$ \\
\hline Salsa de tamarindo & $\mathrm{kg}$ & 1 & S/. 5.50 & S/. 4.66 & 0 & $100 \%$ \\
\hline Jengibre en polvo & $\mathrm{kg}$ & 1 & S/. 40.00 & S/. 33.90 & 0 & $100 \%$ \\
\hline Miel & $\mathrm{kg}$ & 1 & S/. 10.00 & S/. 8.47 & 0 & $100 \%$ \\
\hline Carne de res molida & $\mathrm{kg}$ & 1 & S/. 15.00 & S/. 12.71 & 0 & $100 \%$ \\
\hline $\begin{array}{l}\text { Pan molido } \\
\end{array}$ & $\mathrm{kg}$ & 1 & S/. 3.00 & S/. 2.54 & 0 & $100 \%$ \\
\hline Quinua perlada & $\mathrm{kg}$ & 1 & S/. 6.00 & S/. 5.08 & 0 & $100 \%$ \\
\hline Queso & $\mathrm{kg}$ & 1 & S/. 14.00 & S/. 11.86 & 0 & $100 \%$ \\
\hline Harina de trigo integral & $\mathrm{kg}$ & 1 & S/. 7.00 & S/. 5.93 & 0 & $100 \%$ \\
\hline Carne de res molida & $\mathrm{kg}$ & 1 & S/. 15.00 & S/. 12.71 & 0 & $100 \%$ \\
\hline Pan molido & $\mathrm{kg}$ & 1 & S/. 3.00 & S/. 2.54 & 0 & $100 \%$ \\
\hline Quinua perlada & $\mathrm{kg}$ & 1 & S/. 6.00 & S/. 5.08 & 0 & $100 \%$ \\
\hline Queso & $\mathrm{kg}$ & 1 & S/. 14.00 & S/. 11.86 & 0 & $100 \%$ \\
\hline Harina de trigo integral & $\mathrm{kg}$ & 1 & S/. 7.00 & S/. 5.93 & 0 & $100 \%$ \\
\hline
\end{tabular}

Nota. Fuente: Elaboración propia. 


\section{Tabla 98}

Mermas y rendimientos de insumos $B$

\begin{tabular}{|c|c|c|c|c|c|c|}
\hline Insumos & Unidad & Medida & Precio & Precios sin igv $18 \%$ & Merma & Rendimiento \\
\hline Ajonjolí tostado & $\mathrm{kg}$ & 1 & S/. 15.00 & S/. 12.71 & 0 & $100 \%$ \\
\hline Cebada & $\mathrm{kg}$ & 1 & S/. 10.00 & S/. 8.47 & 0 & $100 \%$ \\
\hline Linaza & $\mathrm{kg}$ & 1 & S/. 6.00 & S/. 5.08 & 0 & $100 \%$ \\
\hline Cola de caballo & $\mathrm{kg}$ & 1 & S/. 5.00 & S/. 4.24 & 0 & $100 \%$ \\
\hline Hielo & $\mathrm{kg}$ & 1 & S/. 4.00 & S/. 3.39 & 0 & $100 \%$ \\
\hline Harina de trigo & $\mathrm{kg}$ & 1 & S/. 5.00 & S/. 4.24 & 0 & $100 \%$ \\
\hline Polvo de hornear & $\mathrm{kg}$ & 1 & S/. 10.00 & S/. 8.47 & 0 & $100 \%$ \\
\hline Leche & litros & 1 & $\mathrm{~S} / .4 .50$ & S/. 3.81 & 0 & $100 \%$ \\
\hline Anís & $\mathrm{kg}$ & 1 & S/. 10.00 & S/. 8.47 & 0 & $100 \%$ \\
\hline Pasas & $\mathrm{kg}$ & 1 & S/. 15.00 & $\mathrm{~S} / .12 .71$ & 0 & $100 \%$ \\
\hline Agua & $\mathrm{kg}$ & 1 & S/. 0.00 & $\mathrm{~S} / .0 .00$ & 0 & $100 \%$ \\
\hline Canela en polvo & $\mathrm{kg}$ & 1 & S/. 10.00 & S/. 8.47 & 0 & $100 \%$ \\
\hline Pasas & $\mathrm{kg}$ & 1 & S/. 15.00 & $\mathrm{~S} / .12 .71$ & 0 & $100 \%$ \\
\hline Bollo de pan & $\mathrm{kg}$ & 1 & S/. 4.50 & S/. 3.81 & 0 & $100.00 \%$ \\
\hline Harina de quinua & $\mathrm{kg}$ & 1 & S/. 7.00 & S/. 5.93 & 0 & $100.00 \%$ \\
\hline Harina de arroz & $\mathrm{kg}$ & 1 & S/. 14.00 & S/. 11.86 & 0 & $100.00 \%$ \\
\hline Ajo molido & $\mathrm{kg}$ & 1 & S/. 12.00 & S/. 10.17 & $43.76 \%$ & $56.24 \%$ \\
\hline Cebolla picada & $\mathrm{kg}$ & 1 & $\mathrm{~S} / .2 .50$ & S/. 2.12 & $13.91 \%$ & $86.09 \%$ \\
\hline Papas nativas & $\mathrm{kg}$ & 1 & S/. 3.00 & S/. 2.54 & $10.34 \%$ & $89.66 \%$ \\
\hline Apio & $\mathrm{kg}$ & 1 & S/. 2.50 & S/. 2.12 & $36.15 \%$ & $63.85 \%$ \\
\hline Zumo de limón & litros & 1 & S/. 4.00 & S/. 3.39 & $42.86 \%$ & $57.14 \%$ \\
\hline Ají limo & $\mathrm{kg}$ & 1 & S/. 10.00 & S/. 8.47 & $14.78 \%$ & $85.22 \%$ \\
\hline Pimentón & $\mathrm{kg}$ & 1 & S/. 2.00 & S/. 1.69 & $19.05 \%$ & $80.95 \%$ \\
\hline Tomate & $\mathrm{kg}$ & 1 & $\mathrm{~S} / .2 .50$ & S/. 2.12 & $32.26 \%$ & $67.74 \%$ \\
\hline Lechuga & $\mathrm{kg}$ & 1 & S/. 2.00 & S/. 1.69 & $22.22 \%$ & $77.78 \%$ \\
\hline Carne de cerdo picada & $\mathrm{kg}$ & 1 & S/. 18.00 & S/. 15.25 & $17.14 \%$ & $82.86 \%$ \\
\hline Perejil fresco & $\mathrm{kg}$ & 1 & S/. 3.00 & S/. 2.54 & $73.24 \%$ & $26.76 \%$ \\
\hline Pechuga de pollo & $\mathrm{kg}$ & 1 & S/. 12.00 & S/. 10.17 & $28.79 \%$ & $71.21 \%$ \\
\hline Kion rallado & $\mathrm{kg}$ & 1 & S/. 10.00 & S/. 8.47 & $22.16 \%$ & $77.84 \%$ \\
\hline Carne de res picada & $\mathrm{kg}$ & 1 & S/. 15.00 & S/. 12.71 & $21.70 \%$ & $78.30 \%$ \\
\hline Cebolla china & $\mathrm{kg}$ & 1 & S/. 1.00 & S/. 0.85 & $24.30 \%$ & $75.70 \%$ \\
\hline Ají verde & $\mathrm{kg}$ & 1 & S/. 6.00 & S/. 5.08 & $16.00 \%$ & $84.00 \%$ \\
\hline Maíz morado & $\mathrm{kg}$ & 1 & S/. 2.50 & S/. 2.12 & 0 & $100.00 \%$ \\
\hline Chicha de jora & litros & 1 & S/. 2.00 & S/. 1.69 & 0 & $100.00 \%$ \\
\hline Alitas & $\mathrm{kg}$ & 1 & S/. 8.00 & S/. 6.78 & $12.33 \%$ & $87.67 \%$ \\
\hline Poro & $\mathrm{kg}$ & 1 & S/. 3.00 & S/. 2.54 & $57.61 \%$ & $42.39 \%$ \\
\hline Dientes de ajo & $\mathrm{kg}$ & 1 & S/. 4.50 & S/. 3.81 & $34.90 \%$ & $65.10 \%$ \\
\hline Culantro & $\mathrm{kg}$ & 1 & S/. 2.00 & S/. 1.69 & $72.73 \%$ & $27.27 \%$ \\
\hline Acelga & $\mathrm{kg}$ & 1 & S/. 3.00 & S/. 2.54 & $53.10 \%$ & $46.90 \%$ \\
\hline Huacatay & $\mathrm{kg}$ & 1 & S/. 5.00 & S/. 4.24 & $69.99 \%$ & $30.01 \%$ \\
\hline Hierba buena & $\mathrm{kg}$ & 1 & S/. 6.00 & S/. 5.08 & $66.77 \%$ & $33.23 \%$ \\
\hline Muña & $\mathrm{kg}$ & 1 & S/. 4.00 & S/. 3.39 & $64.00 \%$ & $36.00 \%$ \\
\hline $\begin{array}{l}\text { Choclo desgranado } \\
\text { pelado }\end{array}$ & $\mathrm{kg}$ & 1 & S/. 5.00 & S/. 4.24 & $62.23 \%$ & $37.77 \%$ \\
\hline Choclo desgranado & $\mathrm{kg}$ & 1 & S/. 5.00 & S/. 4.24 & $52.77 \%$ & $47.23 \%$ \\
\hline Zumo de naranja & litros & 1 & S/. 5.00 & S/. 4.24 & $47.23 \%$ & $52.77 \%$ \\
\hline $\begin{array}{l}\text { Papa helada (variedad de } \\
\text { papa) }\end{array}$ & $\mathrm{kg}$ & 1 & S/. 10.00 & S/. 8.47 & $29.51 \%$ & $70.49 \%$ \\
\hline Piña & $\mathrm{kg}$ & 1 & S/. 3.00 & S/. 2.54 & $34.70 \%$ & $65.30 \%$ \\
\hline Manzana de agua & $\mathrm{kg}$ & 1 & S/. 6.00 & S/. 5.08 & $27.86 \%$ & $72.14 \%$ \\
\hline
\end{tabular}

Nota. Fuente: Elaboración propia. 


\subsubsection{Tecnología.}

El tamaño también está en función del mercado de maquinarias y equipos, porque el número de unidades que pretende producir el proyecto depende de la disponibilidad y existencias de activos de capital.

En algunos casos el tamaño se define por la capacidad estándar de los equipos y maquinarias existentes, las mismas que se hallan diseñadas para tratar una determinada cantidad de productos, entonces, el proyecto deberá fijar su tamaño de acuerdo a las especificaciones técnicas. (Google Documents, n.d.).

Para el proyecto se considerará el área de la cocina representada por el 30\% del área total del proyecto para ello se estableció la cantidad y capacidad de equipamiento necesaria conforme Tabla 99.

Tabla 99

Cantidad y capacidad de equipos a implementar 


\begin{tabular}{lcc}
\hline & Equipos de Cocina para el proyecto & \\
\hline Equipo & Cantidad requerida & Capacidad \\
\hline Cocina industrial & 1 & 3 hornillas \\
Freidora & 1 & 20 litros \\
Plancha de hamburguesas & 1 & $90 \mathrm{~cm} \mathrm{x} 60 \mathrm{~cm}$ \\
Horno para carnes & 1 & Medidas: $1 \mathrm{~m} \mathrm{x} 80 \mathrm{~cm} \mathrm{x}$ \\
& & $90 \mathrm{~cm}$ \\
Congeladora & 1 & Medidas: $1.10 \mathrm{~m} \mathrm{x} 0.65 \mathrm{~m} \mathrm{x}$ \\
Refrigerador Conservador & 1 & $0.90 \mathrm{~m}$ \\
Horno microondas & 1 & Medidas: 0.7 x $0.7 \times 1.65$ \\
Balanza electrónica & 2 & Profundidad: $38,4 \mathrm{~cm}$ \\
Mesas de trabajo de acero inoxidable & 1 & Medidas: $1.10 \times 60$ \\
Repisas de acero inoxidable de 4 niveles & 1 & cm altura $90 \mathrm{~cm}$ \\
\hline
\end{tabular}

Equipos de counter y comedor para el proyecto

\begin{tabular}{|c|c|c|}
\hline Dispensador de salsas & 1 & $39.5 \mathrm{~m} \times 22 \mathrm{~cm} \mathrm{X} 25 \mathrm{~cm}$ \\
\hline Juego de sillas y mesas & 9 & $75 \times 75 \mathrm{~cm}$ \\
\hline $\begin{array}{l}\text { Mostradores barra mostrador estilo } \\
\text { colonial madera maciza }\end{array}$ & 1 & $2 \mathrm{~m} \times 1.30 \mathrm{~m} \times 40 \mathrm{~cm}$ \\
\hline
\end{tabular}

Nota. Fuente: Elaboración propia.

Adicionalmente se implementará una máquina registradora digital de marca IBM 4840 touch, para el manejo de los pedidos y comandas que serán enviadas al área de la cocina, además de contar con sistemas de pago vía POS para los pagos con crédito o débito. 


\subsubsection{Flexibilidad.}

La flexibilidad debe estar presente en el tamaño, localización, tecnología, crecimiento y recursos que se establecieron para la empresa o negocio ya que puede variar de acuerdo a las circunstancias.

El presente proyecto presenta la flexibilidad de adaptarse a las nuevas tendencias e implementación de nuevos insumos andinos o regionales, por otro lado el proyecto permite variar la capacidad productiva dependiendo del nivel de captación de mercado que pueda lograr en el largo o mediano plazo, en cuanto al largo plazo se puede implementar un nuevo local con mayores dimensiones y mayor capacidad productiva, así mismo puede adaptar nuevos servicios como son las cajitas felices o los delivery’s a través de aplicativos móviles.

\subsubsection{Selección del tamaño ideal.}

Analizados los puntos anteriores, se determina el tamaño del proyecto considerando: El volumen de producción, cuyo componente deberá encontrarse dentro de los márgenes de la demanda insatisfecha del mercado. Los aspectos relacionados con el abastecimiento de materia prima, insumos, materiales, equipos, personal suficiente, etc. (Google Documents, n.d.).

Para determinar el tamaño ideal del proyecto se determinó la capacidad productiva del mismo en base al volumen de visitas anual por año que se obtuvo como resultado de las encuestas y posteriores filtros para determinar el mercado objetivo así como la frecuencia de visita, con ello se elaboró la Tabla 100, donde se presenta el detalle y de la producción anual según tipo de 
producto, los porcentaje fueron tomados de los resultados de la encuesta y aplicadas al volumen de visitas según combos o postres.

Tabla 100

Programa de producción anual por combos y postres

\begin{tabular}{|c|c|c|c|c|c|c|}
\hline Programa de producción & & 2019 & 2020 & 2021 & 2022 & 2023 \\
\hline \multicolumn{7}{|c|}{ Programa de producción combos } \\
\hline Alitas/pollo frito & $23.29 \%$ & 9720 & 12957 & 16243 & 19578 & 22963 \\
\hline $\begin{array}{l}\text { Alitas en salsa de } \\
\text { maracuyá }\end{array}$ & $14.29 \%$ & 1389 & 1851 & 2320 & 2797 & 3280 \\
\hline Alitas en salsa de sauco & $14.29 \%$ & 1389 & 1851 & 2320 & 2797 & 3280 \\
\hline Alitas en salsa de bbq & $14.29 \%$ & 1389 & 1851 & 2320 & 2797 & 3280 \\
\hline Alitas búfalo & $14.29 \%$ & 1389 & 1851 & 2320 & 2797 & 3280 \\
\hline Alitas empanizadas & $14.29 \%$ & 1389 & 1851 & 2320 & 2797 & 3280 \\
\hline $\begin{array}{l}\text { Alitas con salsa de } \\
\text { tamarindo }\end{array}$ & $14.29 \%$ & 1389 & 1851 & 2320 & 2797 & 3280 \\
\hline Alitas dulces & $14.29 \%$ & 1389 & 1851 & 2320 & 2797 & 3280 \\
\hline Hamburguesas & $37.20 \%$ & 15522 & 20692 & 25940 & 31266 & 36670 \\
\hline Hamburguesa clásica & $16.67 \%$ & 2587 & 3449 & 4323 & 5211 & 6112 \\
\hline Hamburguesa de cerdo & $16.67 \%$ & 2587 & 3449 & 4323 & 5211 & 6112 \\
\hline Hamburguesa de pollo & $16.67 \%$ & 2587 & 3449 & 4323 & 5211 & 6112 \\
\hline Hamburguesa de quinua & $16.67 \%$ & 2587 & 3449 & 4323 & 5211 & 6112 \\
\hline Hamburguesa paypi fast & $16.67 \%$ & 2587 & 3449 & 4323 & 5211 & 6112 \\
\hline $\begin{array}{l}\text { Hamburguesa } \\
\text { vegetariana }\end{array}$ & $16.67 \%$ & 2587 & 3449 & 4323 & 5211 & 6112 \\
\hline Broaster & $39.50 \%$ & 16483 & 21973 & 27546 & 33201 & 38940 \\
\hline Emoliente & $38.33 \%$ & 15994 & 21322 & 26729 & 32218 & 37786 \\
\hline Chicha de quinua & $37.78 \%$ & 15763 & 21013 & 26342 & 31751 & 37239 \\
\hline Chicha de kiwicha & $22.22 \%$ & 9272 & 12360 & 15495 & 18677 & 21905 \\
\hline Chicha morada & $1.57 \%$ & 657 & 876 & 1098 & 1323 & 1552 \\
\hline Limonada & $0.09 \%$ & 39 & 52 & 65 & 78 & 91 \\
\hline Limonada frozzen & $33.33 \%$ & 13 & 17 & 22 & 26 & 30 \\
\hline $\begin{array}{l}\text { Limonada con } \\
\text { hierbabuena }\end{array}$ & $33.33 \%$ & 13 & 17 & 22 & 26 & 30 \\
\hline Limonada con muña & $33.33 \%$ & 13 & 17 & 22 & 26 & 30 \\
\hline Papas nativas & $43.62 \%$ & 18201 & 24263 & 30416 & 36661 & 42998 \\
\hline Choclo con queso & $28.57 \%$ & 11921 & 15892 & 19923 & 24013 & 28164 \\
\hline Papa helada con queso & $27.81 \%$ & 11603 & 15467 & 19390 & 23372 & 27411 \\
\hline \multicolumn{7}{|c|}{ Programa de producción postres } \\
\hline Pastel de choclo & $50.07 \%$ & 6182 & 8241 & 10331 & 12452 & 14605 \\
\hline Budín de quinua & $49.93 \%$ & 6164 & 8217 & 10302 & 12417 & 14563 \\
\hline
\end{tabular}

Nota. Fuente: Elaboración propia. 


\subsection{Estudio de localización.}

“El estudio de la localización es el análisis de las posibles localizaciones para elegir aquella que permita las mayores ganancias entre las alternativas que se consideren factibles." (Sapag Chain, 2014, p.166)

Para el presente caso se realiza el estudio a través del método de Ranking de factores para determinar qué local es el indicado para el proyecto y cumple con las características técnicas esperadas para el mismo.

\subsubsection{Definición de factores locacionales.}

Según Sapag Chain (2014), las alternativas de instalación de la planta deben considerarse en función de las fuerzas locacionales típicas de los proyectos.

Para el presente caso conforme a la investigación llevada a cabo para la selección del local y considerando la preferencia de los consumidores a través de la encuesta, el local debe localizarse en el Distrito de Wanchaq, cerca al centro comercial Real Plaza.

En base a dichos criterios se contó con dos potenciales establecimientos, los cuales a través del método de Ranking de Factores se sometieron a evaluación conforme Tabla 101. 
Tabla 101

Estudio de localización del proyecto

\begin{tabular}{|c|c|c|c|c|c|}
\hline \multirow{3}{*}{ Factor Localización } & \multirow{3}{*}{ Peso } & \multicolumn{4}{|c|}{ Wanchaq } \\
\hline & & \multicolumn{2}{|c|}{ Clle. Gordon Magne } & \multicolumn{2}{|c|}{$\begin{array}{c}\text { Av. La Cultura c/ Clle. } \\
\text { Gordon Magne }\end{array}$} \\
\hline & & Calificación & Ponderado & Calificación & Ponderado \\
\hline Costo de Alquiler & 0.15 & 4 & 0.60 & 3 & 0.45 \\
\hline Área del Local & 0.15 & 4 & 0.60 & 5 & 0.75 \\
\hline Accesibilidad & 0.20 & 3 & 0.60 & 4 & 0.80 \\
\hline Visibilidad del Local & 0.15 & 3 & 0.45 & 5 & 0.75 \\
\hline $\begin{array}{l}\text { Cercanía de } \\
\text { Proveedores }\end{array}$ & 0.15 & 3 & 0.45 & 3 & 0.45 \\
\hline $\begin{array}{l}\text { Cercanía de } \\
\text { Competidores }\end{array}$ & 0.10 & 4 & 0.40 & 4 & 0.40 \\
\hline Seguridad & 0.10 & 3 & 0.30 & 3 & 0.30 \\
\hline Total & 1.00 & & 3.40 & & 3.90 \\
\hline Calificación & Leyenda & & & & \\
\hline 1 & Muy Mala & & & & \\
\hline 2 & Mala & & & & \\
\hline 3 & Regular & & & & \\
\hline 4 & Buena & & & & \\
\hline 5 & Muy Buena & & & & \\
\hline
\end{tabular}

Nota. Fuente: Elaboración propia.

Conforme la Tabla 101, se determinó como el local ideal para el proyecto el local ubicado en la Av. La Cultura, para ello se tomó en cuenta los siguientes factores:

- Costo del local: este factor es importante en temas de costos para el establecimiento, puesto que tiene que ser accesible para la operatividad del proyecto. Para el caso del estudio se determinó un peso de 0.15 debido a la importancia de mismo para la toma de decisión del local, es importante más no determinante, puesto que también depende 
mucho de la necesidad a la capacidad o área del local. El local de la Calle. Magne ofrecía un mejor precio que el local seleccionado. Una diferencia de S/ 200.00 soles.

- Área del local: Este factor va de la mano con el Costo del local y la zona de ubicación del mismo es decir su visibilidad y accesibilidad por lo que se le asigna un peso de 0.15. Para el caso se consideró que el local de Av. La Cultura era 10 mts 2 más grande que el local de la Av. Magne, además que cumplía con la segunda opción del estudio del tamaño del local detallado en Tabla 101.

- Accesibilidad: A este factor se le asignó el peso más alto 0.20 puesto que es un factor importante para asegurar la circulación y visita de comensales al establecimiento, debido a que debe asegurar la transitabilidad hacia el local además de circulación automotor cerca de la misma. Para el presente caso se le dio más peso al local de la Av., la cultura puesto que se ubica en una esquina frente a un parque colindante a la Av. Principal y a un paradero público, lo que lo hace zona de alto tránsito.

- Visibilidad: Este factor es igualmente importante y va de la mano con la accesibilidad por lo que se le asignó un peso de 0.15 . El local de la Av. La cultura obtuvo mayor peso, puesto que al encontrarse en esquina y colindante a la Av. Principal es altamente visible por las personas que transitan y circulan por la zona.

- Cercanía de los Proveedores: Factor importante por lo que se le asignó un peso de 0.15, puesto que en Cusco los mercados no se encuentran tan distantes y la Av. La 
cultura se encuentra cerca al centro de Cusco en cuestiones de tiempo de traslado. Al encontrarse ambos locales en la misma calle, se les asigna el mismo peso.

- Cercanía de Competidores: Este factor es medianamente importante puesto que la competitividad genera el mejoramiento continuo de la empresa. Para el caso se le asignó el mismo peso puesto que son locales que se ubican en la misma calle.

- Seguridad: Así mismo este factor es medianamente importante, puesto que en la Ciudad de Cusco los casos de robos a establecimiento son poco frecuentes además que dicho tema depende más de la empresa de establecer sus propios mecanismos de seguridad para proteger sus activos. Por ello se le asignó el peso de 0.1 y la misma calificación para ambos locales.

\subsubsection{Consideraciones legales.}

“La Empresa es un conjunto de recursos organizados, con el fin de realizar actividades de producción o intercambio de bienes o servicios, que satisfacen las necesidades de un mercado en particular.” (dspace.ups.edu.ec, n.d.)

\subsubsection{Identificación del marco legal.}

La estructura organizacional es la "suma total de las formas en que su trabajo es dividido entre las diferentes áreas y luego es lograda su coordinación entre estas tareas” (Mintzberg, n.d). 
Para iniciar con el diseño de la estructura organizacional se identifica los tipos de empresas, para luego acogernos a la que más se ajusta a la necesidad del plan de negocio.

- Tipos de empresa

$\checkmark$ Natural: Requiere solo de la inscripción en el Registro Único del Contribuyente, (a) ventajas: cuenta con un dueño, puede ejercer cualquier actividad. (b) ante deudas debe responder no solo con el patrimonio, sino también con los propios bienes.

- Persona jurídica: Requiere de escritura pública ante registros públicos, habiendo cuatro modalidades como se muestra en Figura 61.

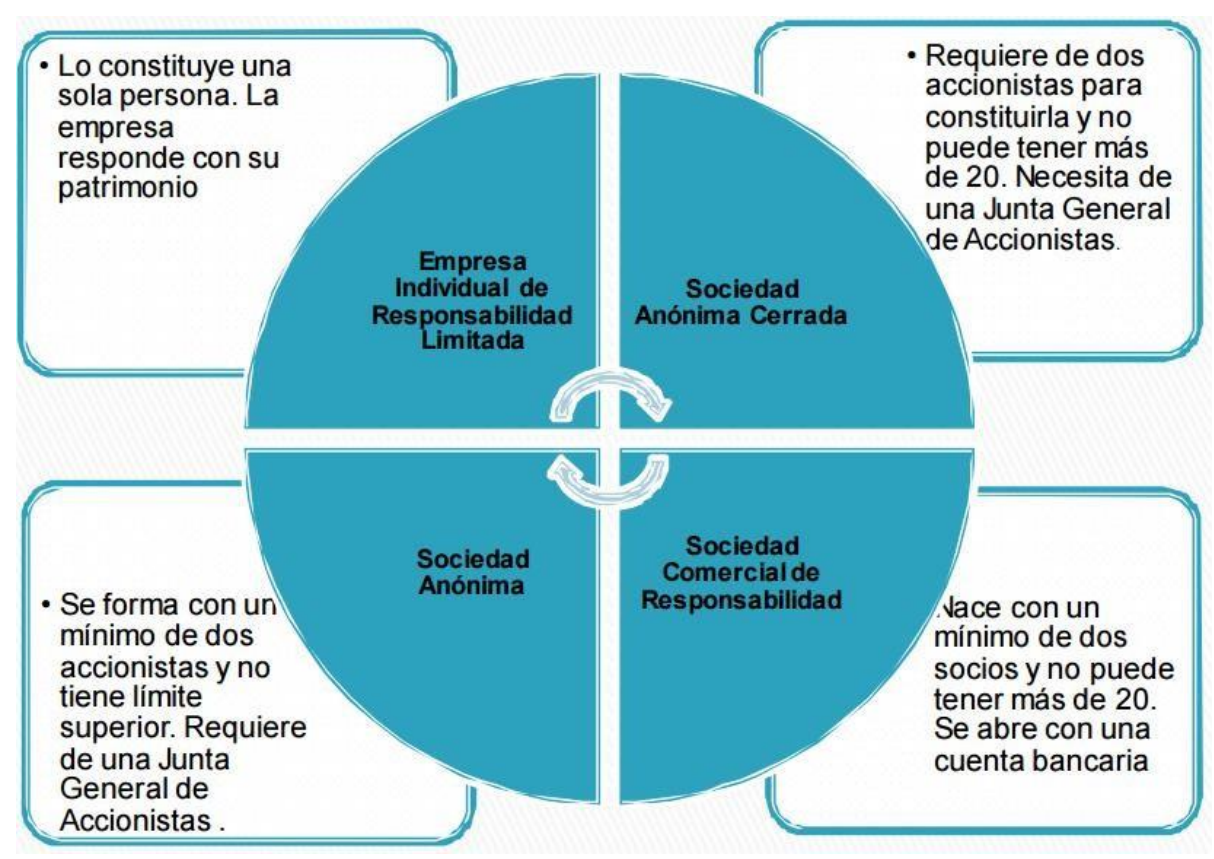

Figura 61. Modalidades de tipos de empresa como persona jurídica. Tomado de "Constitución y formalización," por el ministerio de la producción Recuperado de http://www2.produce.gob.pe/RepositorioAPS/3/jer/-1/Italler/02\%20Importancia\%20del\%20establecimiento\%20de\%20MYPES\%20de\%20acuicultura.p df 
Según el decreto legislativo que aprueba la ley de promoción de la competitividad, formalización y desarrollo de la micro y pequeña empresa y del acceso al empleo decente, en el marco del proceso de promoción del empleo, inclusión social y formalización de la economía, para el acceso a condiciones de dignidad respalda el desarrollo de las micro y pequeñas empresas para la ampliación del mercado interno y externo.

La micro y pequeña (MYPE) empresa es la unidad económica instaurada por una persona natural o jurídica, en cualquiera de sus formas o gestión empresarial aprobada en la legislación vigente, con finalidad lucrativa pudiendo desarrollarse actividades de extracción, transformación, producción, comercialización de bienes o prestación de servicios. (Castillo Gamarra, n.d.).

Según la ley $\mathrm{N}^{\mathrm{0}}$ 28015, ley de promoción y formalización de la micro y pequeña empresa, las características de la MYPE según la Tabla 102.

Tabla 102

Características de la MYPE

$$
\mathrm{N}^{\circ} \text { Trabajadores Ventas anuales }
$$

\begin{tabular}{lll}
\hline Microempresa & 1 hasta 10 trabajadores $\quad$ Hasta el monto de 150 UIT $(\mathrm{S} / 607,500)$
\end{tabular}

Pequeña empresa 1 hasta 100 trabajadores Hasta 1700 UIT $(6,885,000)$

Nota. "Principales beneficios de la ley MYPE". Adaptado de: http://www.prompex.gob.pe/Miercoles/Portal/MME/descargar.aspx?archivo=C1DED215-5C9C-44B1-9CE010484048C5F1.PDF 
El incremento den el monto máximo de ventas anuales es determinado por el decreto supremo refrendado por el Ministro de Economía y Finanzas cada dos años.

\subsubsection{Ordenamiento jurídico de la empresa.}

Está compuesto por un complejo conjunto de normales legales o políticas de gobierno que rigen las actividades del tipo de sector al que se enfoca el proyecto y las cuales se deben respetar. (Cordero Quinzacara, 2009)

La empresa se formará bajo el régimen de Sociedad Anónima Cerrada (S.A.C.); debido a que los accionistas buscan tener la primera opción de compra de las acciones en el caso que estas estén a la venta, además de cumplir con las restricciones características de esta sociedad, no se contara con más 20 socios accionistas, así mismo las acciones no se encuentran inscritas en los registros públicos. (PQS, 2017)

- Organismo.

$\checkmark$ Junta General de Socios. Esta junta representa a todos los socios de la empresa.

$\checkmark$ Administrador. Es el que reemplaza al gerente en caso de ausencia.

- Proceso de constitución.

$\checkmark$ Elaboración de minuta de constitución

$\checkmark$ Elaboración de Escritura pública (Notaria)

$\checkmark$ Inscripción en Registros Públicos de Personas Jurídicas (SUNARP)

$\checkmark$ Inscripción en la SUNAT (RUC, RUS O RER) 
$\checkmark$ Licencia Municipal de Funcionamiento

$\checkmark$ Autorización de libros de Planillas

$\checkmark$ Legalización de libros contables

La constitución de la empresa debe realizarse siguiendo una serie de pasos que aquí se detallan a continuación.

- Denominación social. Una empresa como la que plantea el proyecto no se le puede dar cualquier tipo de denominación, debe ser una denominación nueva ya que no se permite la repetición de nombres. Para el caso el nombre elegido ha sido el de Uchucuta, sabiendo que la empresa es una Sociedad Anónima Cerrada pasará a tener como nombre final el de Uchucuta S.A.C

- Elaboración de la minuta. La Minuta debe contener el pacto social y el estatuto. El Pacto Social debe contener de manera obligatoria, los datos de identificación de los fundadores, la manifestación expresa de la voluntad de los accionistas de constituir una sociedad anónima, el monto del capital y las acciones que se van a dividir. (PQS.pe, 2017)

- Elaboración de escritura pública. La Minuta será remitida al Colegio de Notarios, la cual es la institución encargada de elegir la Notaria que elevara la minuta a Escritura Pública, y luego derivarla a la Oficina de Registros Públicos, condicionado al pago previo de los derechos notariales y registrales correspondientes. (PQS, 2017) 
- Inscripción en registros públicos. La inscripción de la persona jurídica en la SUNARP (Superintendencia Nacional de los Registros Públicos) cuando el parte notarial ingresa a Registros Públicos este se puede hacer a través del SID-SUNARP un aplicativo que permite realiza el trámite en 24 horas. (PQS, 2017)

- Inscripción en la Sunat. En la SUNAT (Superintendencia Nacional de Administración Tributaria) se llenan los formularios correspondientes para solicitar un RUC (Régimen General del Contribuyente) provisional (como persona jurídica), el cual será regularizado una vez emitida la inscripción de la empresa en los Registros Públicos. Regularizando de esta manera el número de partida y ficha registrada de la empresa en la SUNAT y regularizando así de esta manera el RUC. La obtención del R.U.C. permite emitir comprobantes de pago, a la par de estar obligado a pagar los impuestos de ley. (SUNAT, 2017)

- Licencias municipales. Requisitos indispensables para que los dueños de distintos tipos de establecimientos (restaurantes, tiendas) puedan obtener su licencia de funcionamiento y en el caso de restaurantes y cafeterías obtengan además el registro de sanidad correspondiente. La municipalidad demora siete días hábiles para otorgar una Licencia Provisional previa conformidad de la zonificación y compatibilidad de uso correspondiente. Vencido los siete días hábiles se entregará la Licencia de Funcionamiento Provisional que tendrá una validez de 12 meses contados, contando desde la fecha de presentación de la solicitud. Vencido el plazo y sin ninguna anomalía presente se emite la Licencia Municipal de Funcionamiento definitiva. 
(Certificado de Compatibilidad de Uso y Autorización Municipal de Funcionamiento). (Municipalidad del Cusco, 2018)

- Certificado de defensa civil. En lo que respecta a Defensa Civil, se deberá presentar el plan de contingencia firmado por el gerente general y visado en todas las páginas por él mismo y por el profesional en la especialidad responsable. Asimismo, se deberá mostrar los planos de ubicación del establecimiento, de arquitectura, de instalaciones eléctricas y los de evacuación (salidas de emergencia). Se debe presentar además el Protocolo de Pruebas y Mantenimiento de los Sistemas contra Incendios, como certificado de operatividad de extintores, pruebas hidrostáticas de Sistemas de extinción (gabinetes y rociadores). Firmados por la empresa responsable de dichos mantenimientos. El propietario y/o conductor deberá solicitar la renovación del certificado de Seguridad en Defensa Civil antes de su vencimiento. (Indeci, 2018)

- Carnet de sanidad. Este documento es indispensable para toda persona encargada de la elaboración y expendio de alimentos. Es una constancia de que el personal que trabaja en el rubro de alimentos y bebidas, se encuentra en perfecto estado de salud, y cumple con los requisitos para elaborar en algún establecimiento del sector.

- Registro de marca. Dentro de la lista de productos y servicios considerados por INDECOPI en la clasificación de NIZA para el registro de marcas (Instituto Nacional de Defensa del Consumidor y de la Propiedad Intelectual), el local estaría dentro de la denominada "Clase 43: Servicios de restauración (alimentación); hospedaje temporal", 
porque se brindará servicios de alimentos y bebidas. El registro incluye el logotipo y el nombre del restaurante que lo identificará, estos dos elementos se registrarán en la oficina de OSD de INDECOPI, a favor de diferenciarse y proteger el nombre comercial del negocio y/o la propiedad del mismo. (Indecopi, 2017)

- Libros contables. Los registros de ingresos y gastos de la empresa deberán ser llevados por un Contador Colegiado.

Conforme Tabla 103, se presenta el diagrama de Gantt del proyecto que permite visualizar el tiempo y secuencia de las actividades que se llevaran a cabo en la parte pre-operativa del mismo. 
Tabla 103

Diagrama de Gantt del proyecto

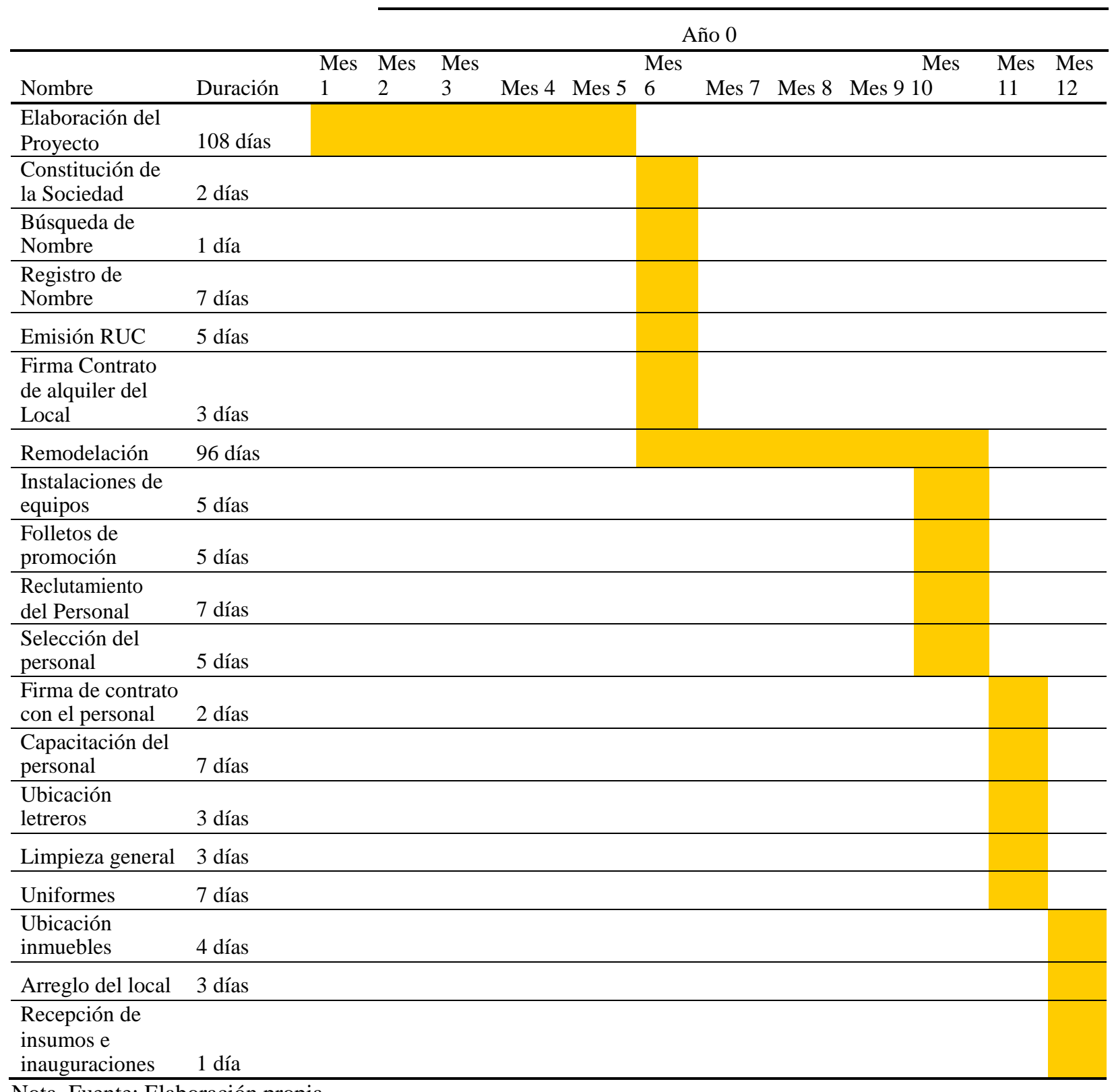

Nota. Fuente: Elaboración propia.

\subsection{Determinación de la localización óptima.}

En este caso, se trata simplemente de establecer el sitio donde se hará el emplazamiento final de la planta industrial, con el fin de que todos los análisis económico-financieros se refieran a 
dicha localización. (Universidad privada de la Selva, n.d.) . En base al estudio de localización se seleccionó el local de la Av. La Cultura el cual cuenta con las características que se detallan en Tabla 104 y se representa gráficamente en Figura 62.

Tabla 104

\section{Características local seleccionado}

\begin{tabular}{|c|c|}
\hline Características & Detalle \\
\hline Dirección & Av. La Cultura Cdra. 24 cruce con Calle. Calle Gordon Magne \\
\hline Precio de Alquiler & S/ 2000.00 \\
\hline Área del local y Dimensiones & $\begin{array}{c}\text { Garantía de } 3 \text { meses, renovación de contrato anual. } \\
\checkmark \quad \text { Área Total: 104 mts2 } \\
\checkmark \quad \text { Largo o Fondo:12.6mts } \\
\checkmark \quad \text { Ancho Frente: 8mts } \\
\checkmark \quad \text { Ancho Fondo: 7.6mts } \\
\checkmark \quad \text { Área de zona de Cocina y personas: } \\
\checkmark \quad 18.62 \mathrm{mts} 2\end{array}$ \\
\hline Zona de ubicación del local & $\begin{array}{l}\text { Esquina Frente a un parque colindante al paradero de la Urb. Magisterio en la } \\
\text { Av. La Cultura. }\end{array}$ \\
\hline $\begin{array}{l}\text { Lugares o establecimientos } \\
\text { cercanos }\end{array}$ & 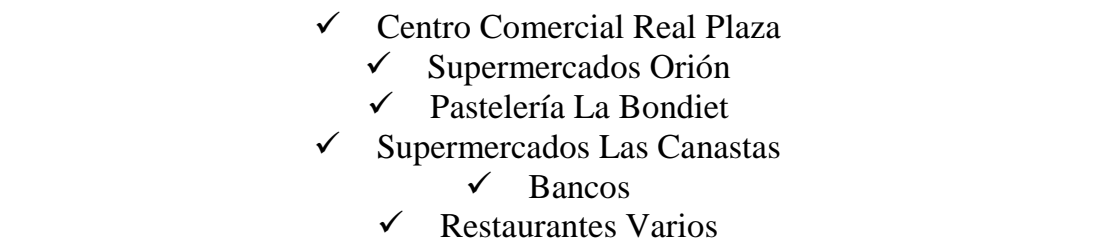 \\
\hline
\end{tabular}

Nota. Fuente: Elaboración propia.

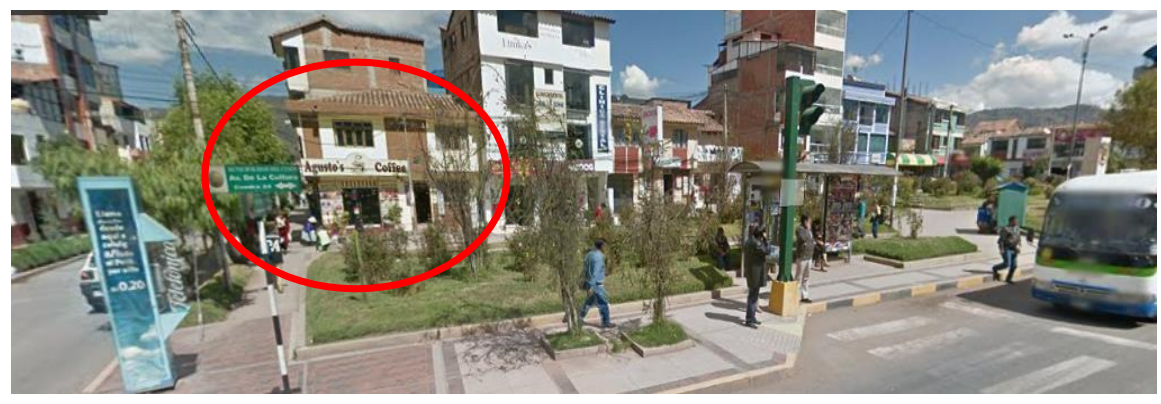

Figura 62. Local seleccionado para el proyecto. 


\section{Capítulo VI}

\section{Aspectos Organizacionales}

En este capítulo se determinará la planeación y formulación de una cultura organizacional, teniendo en consideración tres puntos que definen a una empresa: Misión, visión y principios. Así como la definición de la normativa y políticas de acuerdo a la constitución de la empresa.

\subsection{Caracterización de la cultura organizacional deseada.}

Ante los cambios cada vez más frecuentes de paradigma de negocio, o fusiones y adquisiciones asociadas a procesos de consolidación, existen recetas para que la experiencia no sea tan traumática. Planificar y no perder de vista el factor humano resulta fundamental. (Gestión.pe, 2015)

La cultura estará orientada inicialmente a los clientes internos (colaboradores), quienes estarán en permanente capacitación en relación a temas técnicos y de desarrollo personal para el buen desempeño de las funciones que les serán asignadas; a su vez serán evaluados periódicamente para su respectivo reconocimiento, la misma que permitirá a la motivación.

\subsubsection{Visión.}

La visión debe responder a la pregunta: ¿En qué quiere convertirse la empresa?, por lo que se debe tomar importancia a las siguientes consideraciones para su elaboración: debe ser de breve redacción y contar con la aportación de tantos directivos como sea necesario, así mismo "una 
visión bien desarrollada es utilizada como base para el planteamiento de una misión detallada" (Fred R., 2013)

. A continuación se realizará el análisis y se definirá la visión propuesta.

¿En qué quiere convertirse la empresa? La empresa quiere ser reconocida por su innovación y calidad, además de la dedicación a sus clientes.

- Visión propuesta.

Ser la marca de comida rápida líder en Cusco, reconocida por su innovación en la incorporación de ingredientes regionales, por sus productos de calidad y la dedicación a satisfacer a sus clientes. Logrando la competitividad y rentabilidad de sus operaciones.

\subsubsection{Misión.}

(Fred R., 2013) refiere que: La declaración de misión “es la expresión perdurable del propósito que distingue a una organización de otras empresas similares; es la declaración de la “razón de ser” de una organización y la respuesta a esta pregunta fundamental: ¿cuál es el negocio?”. (p. 45).

A continuación conforme Tabla 105, se determinó los componentes para desarrollar la misión de la empresa. 
Tabla 105

Componentes de la declaración de misión

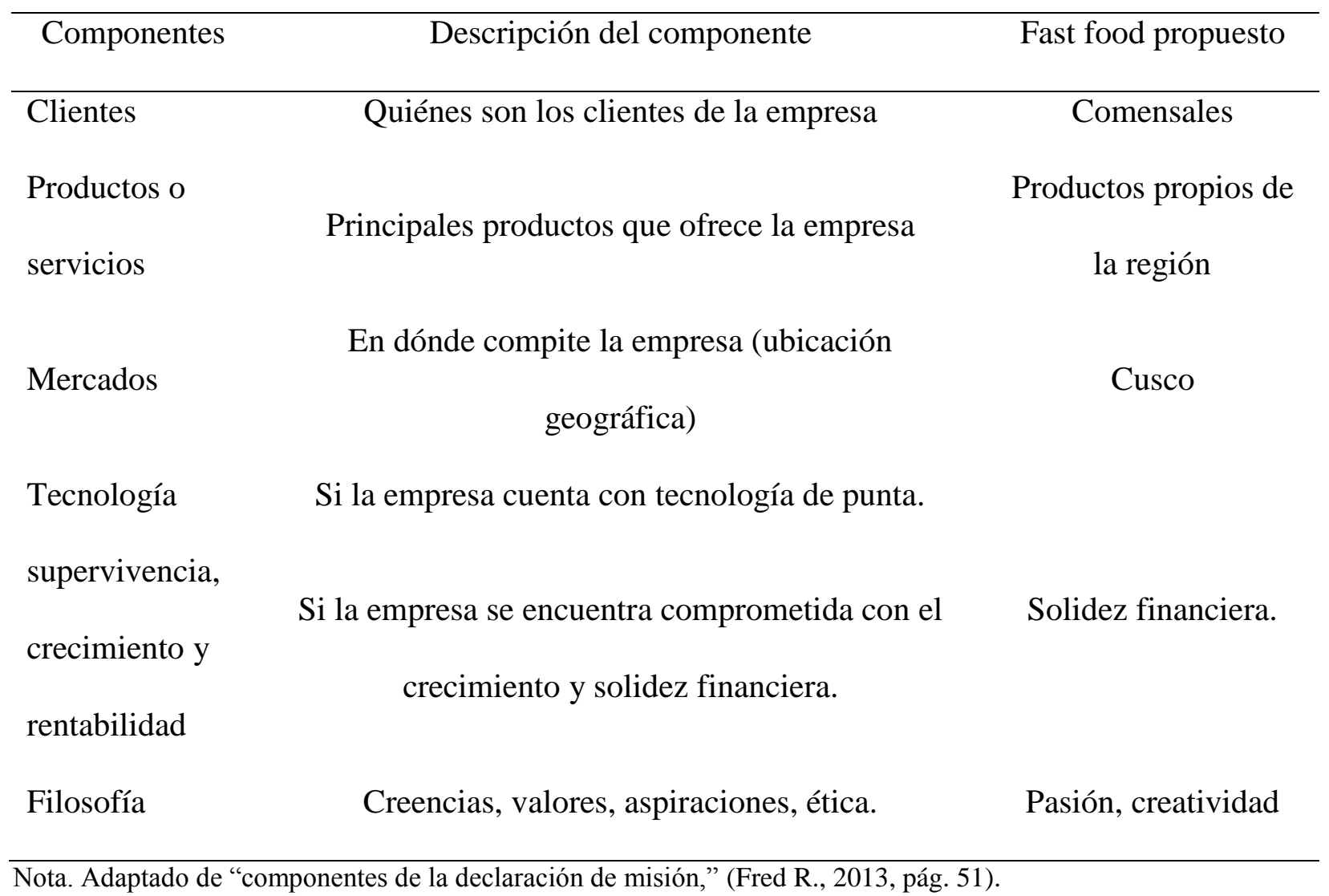

Nota. Adaptado de “componentes de la declaración de misión,” (Fred R., 2013, pág. 51).

La misión debe ser inspiradora, conciliadora, con alto alcance, sin incluir montos monetarios, cifras, objetivos, la extensión debe ser menor a 250 palabras, considerando estos puntos, a continuación se formula la propuesta.

- Misión Propuesta. 
Brindar una experiencia única de comida rápida, mediante el uso de productos propios de la región, preparando alimentos de calidad con pasión y creatividad, aplicando técnicas innovadoras en un espacio de trabajo que permita el desarrollo de sus colaboradores, brindando un servicio de excelencia a los clientes, generando solidez financiera.

Como se puede apreciar, de los seis componentes, el componente de tecnología no fue incluido, la propuesta del negocio no será centrada en tecnología, sino más bien en los productos de la región.

\subsubsection{Principios.}

"Los principios o valores son la base cultural de una empresa, que permite establecer la guía para el correcto comportamiento de una organización.” (Espinoza, 2012)

La cultura organizacional para el proyecto estará basada en principios éticos y morales sólidos, que incentiven a los colaboradores a crecer dentro de la empresa y se sientan parte de ella.

Se consideran los siguientes principios como importantes en la organización:

- Vocación de servicio: Tener la predisposición de ayudar o servir a los clientes que necesiten asistencia es lo que se busca en una empresa que brinda servicios pero para que se cumpla este principio es necesario que se asista al cliente de forma desinteresada con la única satisfacción de sentirse bien con uno mismo. 
- Trabajo en equipo: Para que la organización marche adecuadamente es necesario que todos los miembros que la conforman realicen sus propias actividades con el fin de alcanzar un solo objetivo, el trabajo en equipo influye de manera positiva porque debe existir una comunicación fluida y por ende se origina el compañerismo entre todos.

- Respeto: El respeto a la integridad es la consideración e incluso la valoración que se merecen las personas en la organización por el hecho de ser humanos y estar amparados bajo leyes que respaldan el bienestar, es por ello que dentro de una empresa debe existir siempre el respeto mutuo para mantener una buena armonía.

- Excelencia: La palabra calidad con el tiempo está siendo reemplazada por la excelencia empresarial, mediante la cual se busca sobresalir en los resultados obtenidos, los cuales tienen que conducir al objetivo trazado inicialmente por la organización, la excelencia se debe conseguir principalmente en la atención de los clientes y la calidad de los productos, servicios y recursos humanos.

- La mejora continua: Para que la organización sea exitosa en las actividades que desempeña, es necesaria la innovación de productos que estén adaptados a las necesidades del cliente que por el hecho de estar cada vez más informado por la tecnología tiende a ser más exigente.

- Veracidad: Es importante dar la información que necesita el cliente de los productos que ofrece la organización con transparencia y veracidad sin mostrar ningún tipo de 
alteración que pueda perjudicar en un futuro la reputación y buena imagen que cuesta muchas veces obtenerlo.

\subsection{Formulación de estrategias de negocio.}

Permite "mejorar la posición competitiva de los productos o servicios de una empresa o unidad de negocios, en la industria o en el segmento especifico del mercado al que están dirigidos". (Wheelen, Wheelen, \& Hunger, 2013).

Plantear la estrategia es muy importante, permite tener impacto sobre el rendimiento global de la empresa y el efecto sobre la industria en general. Para el presente proyecto se tomarán en cuenta las estratégicas competitivas de Porter, puesto que pueden ser implementadas por cualquier empresa o negocio sin importar su tipo o tamaño, estas se detallan a continuación:

La estrategia de menor costo (liderazgo en costos); capacidad para diseñar, producir y comercializar un producto comparable más eficientemente que sus competidores para el mercado masivo, minimiza costos en I + D (investigación y desarrollo)

La estratégica de diferenciación; mercado masivo, crear productos o servicios únicos con características especiales en el mercado. La empresa puede cobrar más por un producto o servicio.

Enfoque de costos; estratégica de bajo costo, la cual se centra en un determinado grupo de compradores o mercado geográfico con el objetivo de servir solamente a un nicho (porción de un segmento de mercado). 
Enfoque de diferenciación; se centra en un nicho ya sea en el segmento para una línea de producto o un mercado geográfico.

Ninguna de estas estratégicas competitivas garantiza el éxito, las investigaciones afirman que empresas que las implementaron con éxito no la pudieron sostener, esto porque cada una de las estrategias cuenta con sus riesgos, como se resumen en la Figura 63.

\begin{tabular}{|c|c|c|}
\hline Riesgos del liderazgo en costos & Riesgos de la diferenciación & Riesgos del enfoque \\
\hline $\begin{array}{l}\text { El liderazgo en costos no es } \\
\text { sostenible cuando: } \\
\text { Los competidores imitan. } \\
\text { La tecnología cambia. } \\
\text { Otra clase de liderazgo en costos } \\
\text { lo remplaza. }\end{array}$ & $\begin{array}{l}\text { La diferenciación no es sostenible } \\
\text { cuando: } \\
\text { = Los competidores imitan. } \\
\text { = Los criterios para la diferenciación } \\
\text { llegan a ser menos importantes para } \\
\text { los compradores. }\end{array}$ & $\begin{array}{l}\text { Se imita el enfoque estratégico. } \\
\text { El segmento objetivo pierde atractivo } \\
\text { estructuralmente: } \\
\text { — La estructura se erosiona. } \\
\text { La demanda desaparece. }\end{array}$ \\
\hline $\begin{array}{l}\text { La proximidad en la diferenciacion } \\
\text { se pierde. }\end{array}$ & La aproximación en costos se pierde. & $\begin{array}{l}\text { Generalmente el nivel de competencia } \\
\text { satura el segmento de mercado: } \\
\text { La diferencia entre segmentos de } \\
\text { mercado es menos notoria. } \\
\text { Las ventajas de una línea amplia de } \\
\text { productos se incrementa. }\end{array}$ \\
\hline $\begin{array}{l}\text { Quienes se enfocan en los costos } \\
\text { aún pueden reducir los costos en } \\
\text { ciertos segmentos. }\end{array}$ & $\begin{array}{l}\text { Quienes se enfocan en la diferenciación } \\
\text { aún pueden diferenciarse en ciertos } \\
\text { segmentos. }\end{array}$ & $\begin{array}{l}\text { Nuevas empresas se enfocan } \\
\text { en subsegmentos del mercado. }\end{array}$ \\
\hline
\end{tabular}

Figura 63.Riesgos de las estratégicas competitivas genéricas. Recuperado de "administración estratégica y política de negocios" (p.203.), por Wheelen,et al, 2013, Colombia por Pearson.

En cuanto al presente proyecto se considera que el tipo de producto que se ofrecerá es de consumo masivo, sin embargo el público objetivo del proyecto se encuentra enfocado en un segmento del mercado, por ello el nivel de competitividad del mercado se analiza en base al segmento objetivo. La principal ventaja competitiva de este proyecto es el concepto innovador y único que aún no se aplica en el mercado de fast food como es la comida Novoandina, en ese 
sentido se determinó que la mejor estrategia competitiva de Porter a implementar es el Enfoque en Diferenciación, como se muestra en la Figura 64.

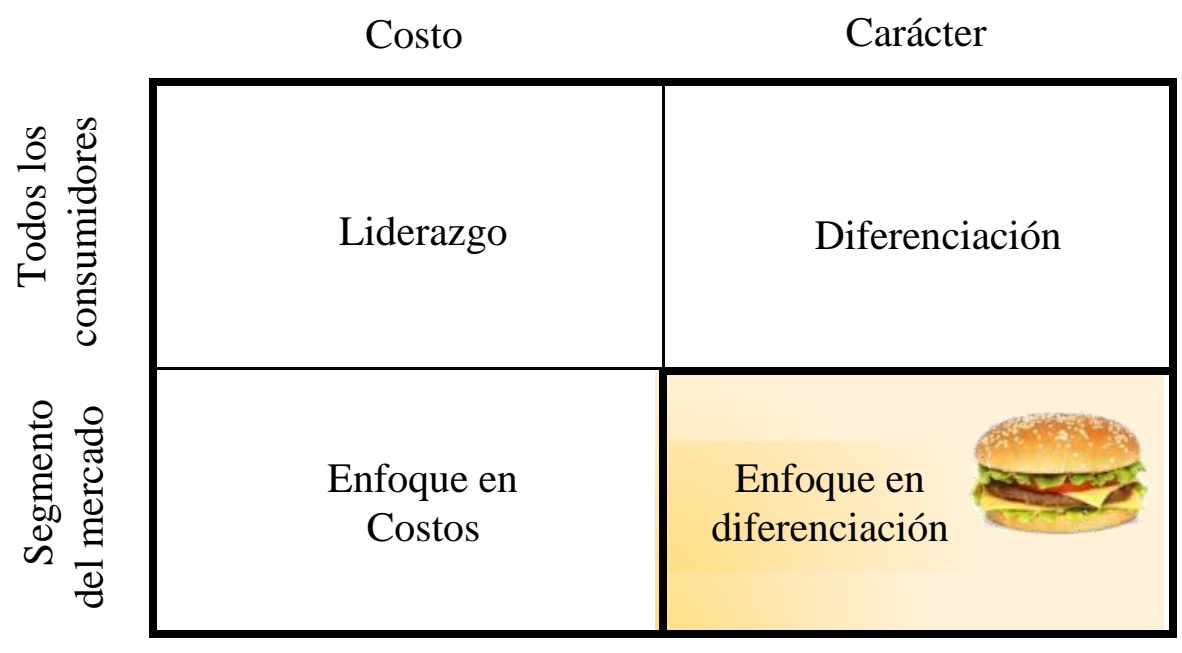

Figura 64. Determinación de la estrategia competitiva de Porter para el proyecto. Adaptado de "Las estrategias competitivas genéricas". Recuperado de http://maestriaengerenciaestrategica.blogspot.pe/2011/03/informacion-complementariametodologia.html

La estrategia de Enfoque en Diferenciación se reflejara en el uso de insumos de la región, procesos productivos innovadores y servicio de atención eficaz, diferenciándose positivamente de la competencia.

A través de la aplicación de esta estrategia, se pretende en un inicio el incremento de consumidores y su posterior estabilidad; una vez logrado la preferencia de los consumidores, será posible llegar al punto de incremento razonable de precios manteniendo la calidad del producto y de los servicio de atención al cliente. Del mismo modo, con el fin de sostener los riesgos que derivan de una estrategia de enfoque en diferenciación, se realizaran estudios 
periódicos de las tendencias del mercado objetivo y satisfacción de los clientes, para mantener el nivel de innovación y cumplir con las expectativas de los consumidores.

\subsubsection{Algunas acciones a considerarse.}

- Posicionar a la empresa como el único fast food que utiliza insumos naturales de la región con alto valor nutricional.

- Establecer alianzas estratégicas con instituciones públicas y privadas para la promoción de la marca orientado al incremento de consumidores.

- Establecer convenios o alianzas estratégicas con proveedores de insumos para asegurar los volúmenes, calidad y continuidad de provisión de insumos a ser utilizados.

- Fidelizar a los clientes mediante descuentos por acumulación de puntos en consumo.

- Reducir costos, mediante precios de insumos y la mayor eficiencia de la mano de obra.

- Permanente capacitación y motivación del personal mediante incentivos por productividad.

- Evaluación permanente de las preferencias y observaciones de los clientes para la mejora permanente del producto ofrecido y la calidad del servicio.

- Oferta de carnes y verduras frescas con insumos naturales de la región como harinas integrales y hortalizas frescas y saludables; refrescos y bebidas preparados con insumos adecuados y de calidad, utilización de artefactos, utensilios y accesorios de cocina de calidad, como se aprecia en la Tabla 106. 
Tabla 106

Características de los bienes e insumos en producción

\begin{tabular}{ccc}
\hline Insumos / Ingredientes & Utensilios y accesorios & Artefactos \\
\hline Carnes frescas y de calidad & Menajeria de acero & \\
garantizadas & inoxidable (cubiertos, & Cocina industrial (freidora) \\
Papas andinas de la región & bandejas, cuchillos, ollas) & Horno microondas \\
Refrescos preparados con & Cucharones & Licuadora \\
insumos naturales y & Bandejas de acero & Congeladora \\
saludables & Cuchillos de acero inoxidable & Mesas y sillas de madera \\
Uso de aceites de calidad & & \\
garantizado & & \\
\end{tabular}

Nota. Fuente: Elaboración propia.

Adicionalmente se consideran las características y recursos que se ejecutaran en la etapa de operación como se presenta en la Tabla 107.

Tabla 107

Características y recursos que se ejecutaran en la etapa de operación

\begin{tabular}{lc}
\hline \multicolumn{1}{c}{ Recursos } & Características \\
\hline Tangibles & Capacidad para obtener financiamiento \\
& Decoración típica de Cusco \\
& Ubicación privilegiada, av. La cultura. \\
\hline Intangibles & Motivación al equipo de trabajo \\
& Procedimientos propios en la elaboración de los productos. \\
Capacidad de innovación, con insumos propios de la región.
\end{tabular}

Nota. Fuente: Elaboración propia. 
A continuación se detallas las estrategias del negocio tomando en cuenta las oportunidades, amenazas, fortaleza y debilidades a las que se ve afecto el desarrollo del proyecto, es decir los factores externos e internos del mismo y que herramientas o estrategias se piensan implementar, conforme Tabla 108. 


\section{Tabla 108}

\section{Matriz FODA del proyecto}

\begin{tabular}{|c|c|c|}
\hline & Fortalezas & Debilidades \\
\hline \multirow{5}{*}{ Factores } & F1.Aportes de los accionistas & \multirow{6}{*}{$\begin{array}{c}\text { D1.Capacidad de Financiamiento } \\
\text { D2.Empresa Rhupa's Diner ya cuenta con reconocimiento como } \\
\text { empresa cusqueña. }\end{array}$} \\
\hline & F2.Ubicación en zona comercial & \\
\hline & $\begin{array}{l}\text { F3.Acceso a wifi para los clientes } \\
\text { F4.Servicio de delivery } \\
\text { F5.Precios accesibles por tamaño de porción }\end{array}$ & \\
\hline & F6.Capacidad de innovación & \\
\hline & F7.Calidad de los insumos por su origen regional & \\
\hline Oportunidades & F8.Brindar nuevas experiencias para el consumidor & \\
\hline $\begin{array}{l}\text { O1. Índice de Confianza empresarial regional por encima del } \\
\text { tramo optimista. }\end{array}$ & $\begin{array}{c}\text { O1, F6, F7 Incorporación de insumos de la región como } \\
\text { ingredientes principales. }\end{array}$ & O7, D2 Sorteos para los clientes más frecuentes \\
\hline O2. Índice de precios al consumidor (IPC) bajo. & $\begin{array}{c}\text { O1, F1 Potencial para invertir en nuevas líneas de producto en } \\
\text { el futuro. }\end{array}$ & D2 Actividades de Responsabilidad social con la comunidad \\
\hline $\begin{array}{l}\text { O3. Proyección de crecimiento del } 5 \% \text { anual del sector } \\
\text { servicios. }\end{array}$ & $\begin{array}{c}\text { O2, O7, F5 Diseñar productos como combos familiares, } \\
\text { combos infantiles, dúos, tríos que satisfagan todas las } \\
\text { capacidades de gasto del consumidor. }\end{array}$ & $\begin{array}{c}\text { O1, D2 Auspicios de eventos regionales, ferias, conciertos, teatro, } \\
\text { etc. }\end{array}$ \\
\hline $\begin{array}{l}\text { O4. Desarrollo de la comida novoandina, insumos como legado } \\
\text { generacional. }\end{array}$ & $\begin{array}{c}\text { O3, F2 Potencial para invertir a futuro en impementar más } \\
\text { locales. }\end{array}$ & O4 Generar una receta única que permita posicionar la marca. \\
\hline O5. Uso de aplicativos móviles para optimización del tiempo & $\begin{array}{c}\text { O4, F8 Actualizar periódicamente los productos para ofrecer } \\
\text { nuevas experiencias. }\end{array}$ & $\begin{array}{l}\text { D2 Crear una campaña publicitaria creativa para captar nuevos } \\
\text { consumidores. }\end{array}$ \\
\hline $\begin{array}{l}\text { O6. Moda por la conservación del medio ambiente, manejo } \\
\text { adecuado de los residuos y emisiones de los restaurantes. }\end{array}$ & $\begin{array}{l}\text { O5, F4 Implementar el uso de aplicativo mobil para el } \\
\text { servicio de delivery. }\end{array}$ & $\begin{array}{c}\text { D2 Crear una página web interactiva e implementar el uso de } \\
\text { Facebook, twitter, Instagram. }\end{array}$ \\
\hline O7. Incremento del sueldo mínimo a S/930.00 soles & O6 Implementar trampa de grasa para el manejo de residuos. & \\
\hline \multicolumn{3}{|l|}{ Amenazas } \\
\hline $\begin{array}{l}\text { A1. Caída del sector agropecuario, afecta el índice de confianza } \\
\text { empresarial regional para invertir. } \\
\text { A2. Caída de los sectores extractivos o de la inversión pública } \\
\text { genera la contracción del PBI per cápita de la región. }\end{array}$ & $\begin{array}{l}\text { A1, A4 Permanecer alertas ante los cambios de legislación o } \\
\text { factores climatologicos que afectan drasticamente al sector } \\
\text { agropecuario en la región. }\end{array}$ & $\begin{array}{l}\text { A5, D2 Implementación de estándares de servicio y producción en } \\
\text { cuanto a buenas prácticas de manipulación. }\end{array}$ \\
\hline A3. Impuesto a la comida chatarra & $\begin{array}{l}\text { A4 Contar con proveedores de respaldo en provincias } \\
\text { cercanas en caso de contingencias. }\end{array}$ & \multirow{4}{*}{$\begin{array}{c}\text { A5, D2 Capacitación del personal en temas de servicio y } \\
\text { manipulación de alimentos }\end{array}$} \\
\hline A4. Cambios climáticos que afectan la producción agrícola & A6, F1 Contar con un buen sistema de seguridad. & \\
\hline A5. Ingreso de nuevas franquicias internacionales & A5, F1 Alianzas con empresas del rubro entretenimiento para & \\
\hline A6. Huelgas y paros & & \\
\hline
\end{tabular}




\subsection{Determinación de las ventajas competitivas crítica.}

Para determinar el potencial competitivo, se realizará el análisis VRIO, para estipular si los recursos que se implementarán en el proyecto pueden representar una ventaja competitiva.

Primero se determinará los criterios de evaluación según Tabla 109 y posteriormente se llevará a cabo la matriz VRIO conforme Tabla 110, además de su respectivo análisis.

Tabla 109

Justificación de asignación de valor Sí o No, matriz VRIO

\begin{tabular}{|c|c|c|}
\hline & Sí & No \\
\hline Valor & $\begin{array}{l}\text { Recursos que dan la potencialidad de abrir } \\
\text { oportunidades en el mercado. }\end{array}$ & $\begin{array}{l}\text { Recursos que no brindan ningún } \\
\text { valor al proyecto. }\end{array}$ \\
\hline Raro & $\begin{array}{l}\text { Recursos que pueden ser difíciles para otros } \\
\text { competidores en la industria de imitar. }\end{array}$ & Recursos fáciles de copiar. \\
\hline Inimitable & $\begin{array}{l}\text { Recursos únicos que otros nunca podrán } \\
\text { igualar }\end{array}$ & $\begin{array}{l}\text { Recursos que otros competidores } \\
\text { pueden buscar otra forma para } \\
\text { imitar. }\end{array}$ \\
\hline Organización & $\begin{array}{l}\text { Recursos que forman parte de los objetivos } \\
\text { del proyecto }\end{array}$ & $\begin{array}{l}\text { Recursos que podrían formar parte } \\
\text { de los objetivos del proyecto }\end{array}$ \\
\hline
\end{tabular}

Nota. Fuente: Elaboración propia.

Conforme a la Figura 64, se asignará la calificación de ventaja competitiva correspondiente a cada recurso.

\begin{tabular}{|c|c|c|c|c|c|}
\hline $\begin{array}{l}\text { Dónde poner } \\
\text { foco }\end{array}$ & VALOR & RARO & INIMITABLE & ORGANIZACIÓN & IMPLICACIÓN ESTRATÉGICA \\
\hline Recurso 1 & $\mathrm{NO}$ & & & & Desventaja Competitiva \\
\hline Recurso 2 & Sí & $\mathrm{NO}$ & & & $\begin{array}{l}\text { Paridad competitiva. Ni suma ni } \\
\text { resta. }\end{array}$ \\
\hline Recurso 3 & Sí & Sí & $\mathrm{NO}$ & & Ventaja competitiva temporalmente \\
\hline Recurso 4 & Sí & Sí & Sí & $\mathrm{NO}$ & Ventaja competitiva aun por explotar \\
\hline Recurso 5 & Sí & Sí & Sí & Sí & Ventaja competitiva sostenida \\
\hline
\end{tabular}

Figura 65. Asignación de ventajas competitivas a los recursos. Análisis de capacidades VRIO. Recuperado de https://docs.google.com/spreadsheets/d/15d2h8F73jUdT5iTABILuRRET2HHmb-3m9QaOy3S53w/edit\#gid=0 
Tabla 110

Recursos o capacidades que generan ventaja competitiva, matriz VRIO

\begin{tabular}{|c|c|c|c|c|c|}
\hline Recurso / capacidad & Valor & Raro & Inimitable & Organización & Ventaja competitiva \\
\hline \multicolumn{6}{|c|}{ Recursos tangibles } \\
\hline Aportes de los accionistas & Sí & No & & & Paridad competitiva \\
\hline Ubicación en zona comercial & Sí & No & & & Paridad competitiva \\
\hline Acceso a wifi para los clientes & Sí & No & & & Paridad competitiva \\
\hline Servicio de delivery & Sí & No & & & Paridad competitiva \\
\hline Precios accesibles por tamaño de porción & Sí & No & & & Paridad competitiva \\
\hline $\begin{array}{l}\text { Ambientación del local acorde a la temática } \\
\text { regional }\end{array}$ & Sí & Sí & No & & $\begin{array}{l}\text { Ventaja competitiva } \\
\text { temporalmente }\end{array}$ \\
\hline Capacidad de Financiamiento & Sí & Sí & No & & $\begin{array}{l}\text { Ventaja competitiva } \\
\text { temporalmente }\end{array}$ \\
\hline \multicolumn{6}{|c|}{ Recursos intangibles } \\
\hline Capacidad de innovación & Sí & Sí & Sí & Sí & $\begin{array}{l}\text { Ventaja competitiva } \\
\text { sostenida }\end{array}$ \\
\hline Insumos oriundos de la región & Sí & Sí & No & & $\begin{array}{l}\text { Ventaja competitiva } \\
\text { temporalmente }\end{array}$ \\
\hline $\begin{array}{l}\text { Calidad de los insumos por su valor } \\
\text { nutricional }\end{array}$ & Sí & Sí & Sí & Sí & $\begin{array}{l}\text { Ventaja competitiva } \\
\text { sostenida }\end{array}$ \\
\hline $\begin{array}{l}\text { Brindar nuevas experiencias para el } \\
\text { consumidor }\end{array}$ & Sí & Sí & Sí & Sí & $\begin{array}{l}\text { Ventaja competitiva } \\
\text { sostenida }\end{array}$ \\
\hline Reconocimiento por ser empresa cusqueña & Sí & Sí & No & & $\begin{array}{l}\text { Ventaja competitiva } \\
\text { temporalmente }\end{array}$ \\
\hline Patentar la marca & Sí & No & & & Paridad competitiva \\
\hline Patentar una receta & Sí & Sí & Sí & No & $\begin{array}{l}\text { Ventaja competitiva } \\
\text { aún por explotar }\end{array}$ \\
\hline $\begin{array}{l}\text { Atención enfocada en la satisfacción al } \\
\text { cliente }\end{array}$ & Sí & No & & & Paridad competitiva \\
\hline Estándares de limpieza y manipulación altos & Sí & No & & & Paridad competitiva \\
\hline $\begin{array}{l}\text { Trabajo en equipo sincronización de } \\
\text { actividades }\end{array}$ & Sí & No & & & Paridad competitiva \\
\hline Sorteos para los clientes más frecuentes & Sí & No & & & Paridad competitiva \\
\hline $\begin{array}{l}\text { Actividades de Responsabilidad social con la } \\
\text { comunidad }\end{array}$ & Sí & No & & & Paridad competitiva \\
\hline $\begin{array}{l}\text { Auspicios de eventos regionales, ferias, } \\
\text { conciertos, teatro, etc. }\end{array}$ & Sí & Sí & No & & $\begin{array}{l}\text { Ventaja competitiva } \\
\text { temporalmente }\end{array}$ \\
\hline \multicolumn{6}{|c|}{ Recursos humanos } \\
\hline Personal Calificado para los puestos & Sí & No & & & Paridad competitiva \\
\hline Beneficios educativos para los empleados & Sí & No & & & Paridad competitiva \\
\hline Beneficios económicos para los empleados & Sí & No & & & Paridad competitiva \\
\hline Beneficios de salud para los empleados & Sí & No & & & Paridad competitiva \\
\hline Actividades de integración laboral & Sí & No & & & Paridad competitiva \\
\hline
\end{tabular}

Nota. Fuente: Elaboración propia. 
Conforme a la elaboración de la Matriz VRIO, se pudo determinar que los siguientes recursos representan las principales ventajas competitivas del proyecto:

- Capacidad de innovación. El proyecto cuenta con un amplio potencial para innovar constantemente. Cusco cuenta con una gran variedad de productos naturales con muchas propiedades nutricionales, muchas de ellas comestible y de buen sabor.

- Calidad de los insumos por su valor nutricional. Esto permite tener una ventaja sobre otros establecimientos de fast food de pollo y hamburguesa, puesto que estos solo buscan optimizar sus costos pero no buscan alternativas a sus productos que contengan mejores contenidos nutricionales.

- Brindar nuevas experiencias para el consumidor. Los consumidores de comida fast food buscan cada vez más nuevos sabores. En Cusco, la mayoría de la población tiene un gusto prioritario por sus productos regionales y complementar sus gustos con técnicas y cocinas de otros países, les llama mucho la atención, el proyecto buscara a través de sus productos, brindar nuevas experiencias en sabores. La competencia no hace uso de este recurso puesto que implica tiempo, dedicación e inversión.

- Patentar una receta. Esta es una ventaja aún por explotar, el proyecto puede buscar la oportunidad de crear una receta única y especial que pueda patentar, de forma que genere un posicionamiento de la marca y eleve el nivel de recordación del producto. 


\subsection{Diseño de la estructura organizacional deseada.}

La estructura organizacional es la "suma total de las formas en que su trabajo es dividido entre las diferentes áreas y luego es lograda su coordinación entre estas tareas”. (Mintzberg, n.d)

Para el presente proyecto la empresa a conformar será una persona Jurídica en la modalidad de Sociedad Anónima Cerrada, puesto que contará con cuatro accionistas quienes aportarán capital para el financiamiento del proyecto. Así mismo, las decisiones que adopte la junta de socios serán por mayoría de acuerdo al porcentaje de participación del capital social. El objetivo inicial del proyecto es conformar una pequeña empresa, por lo que se propone el siguiente esquema de organigrama según la ley general de sociedades y el ordenamiento legal de la empresa, Figura 66.

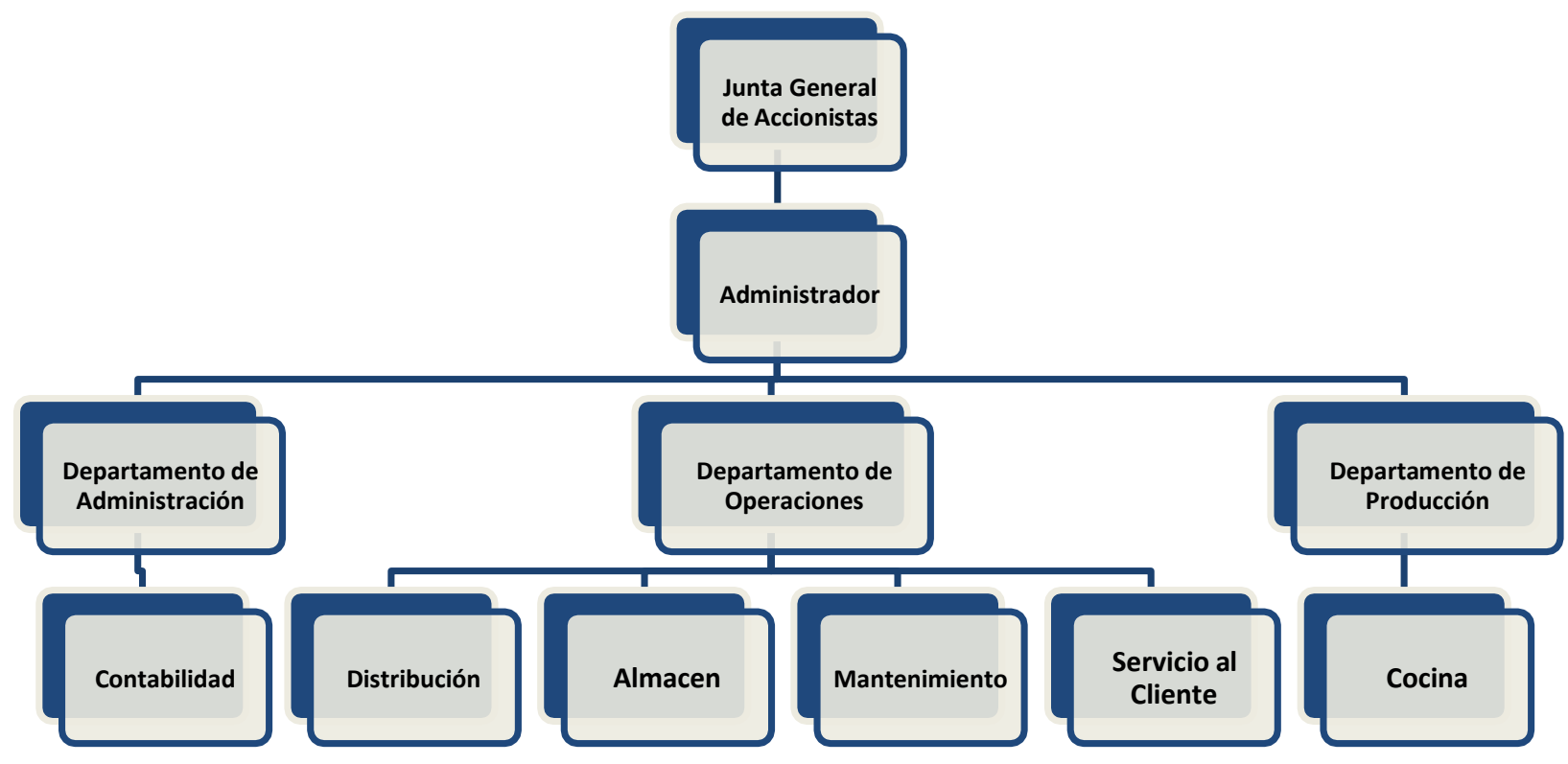

Figura 66.Organigrama funcional del proyecto. Fuente: Elaboración propia. 


\subsection{Diseño de los Perfiles de Puesto Claves}

A continuación se detallaran los perfiles de todos los puestos claves para la operatividad del

proyecto, además de los requisitos y funciones de los mismo conforme se detallan de la Tabla

111 a la Tabla 143. 


\section{Tabla 111}

Perfil puesto clave - Contador

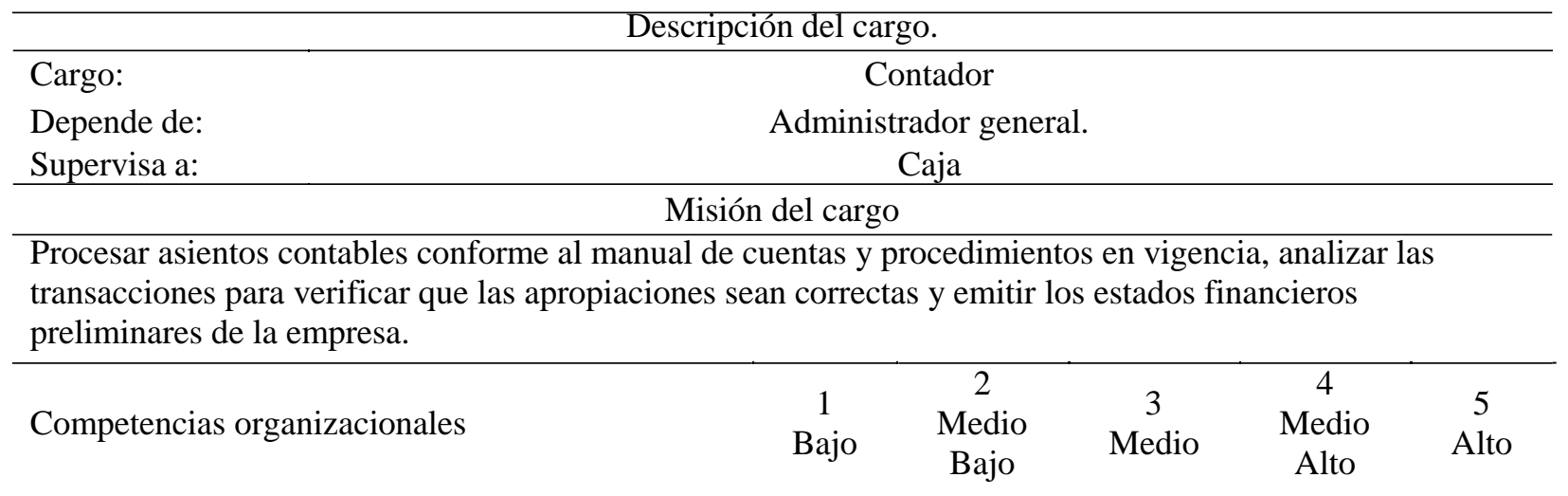

\section{Genéricas de la organización}

Integridad: Actuar con ética, transparencia, honradez y responsabilidad en el cumplimiento de todos los compromisos.

Compromiso: Asumir como propio los intereses de la empresa siguiendo los mismo objetivos.

Laboriosidad

Productividad: Capacidad para fijarse objetivos y alcanzarlos exitosamente, en el tiempo y con la calidad requerida, controlando el curso de acción y

la optimización de recursos e insumos

\section{Funcionales del área}

Trabajo bajo presión: Dar soluciones rápidas, ser

prácticos para solucionar problemas de inmediato.

Capacidad para trabajar manteniendo un buen

nivel de energía. Controlar las emociones

Orientación al cliente: Actitud permanente de

ayudar y servir a los clientes internos y externos:

se esfuerza por conocer sus problemas, los

escucha, da respuestas adecuadas.

\begin{tabular}{ll}
\hline \multicolumn{1}{c}{ Individuales del puesto } & \multicolumn{1}{c}{} \\
\hline Planificación y organización: Capacidad para & \\
ordenar una tarea o serie de tareas y establecer un & $\mathrm{x}$ \\
plan de trabajo que dé respuesta al requerimiento & \\
para el cumplimiento de metas. & \\
Capacidad de análisis y síntesis & \\
Capacidad para comprender una situación, & $\mathrm{x}$ \\
identificar sus partes, organizarlas & \\
sistemáticamente, y extraer conclusiones nuevas & \\
de los datos obtenidos. Métodos de inducción- & \\
deducción o viceversa &
\end{tabular}

Nota. Fuente: Elaboración propia. 
Tabla 112

Perfil puesto clave - Contador, requisitos del cargo

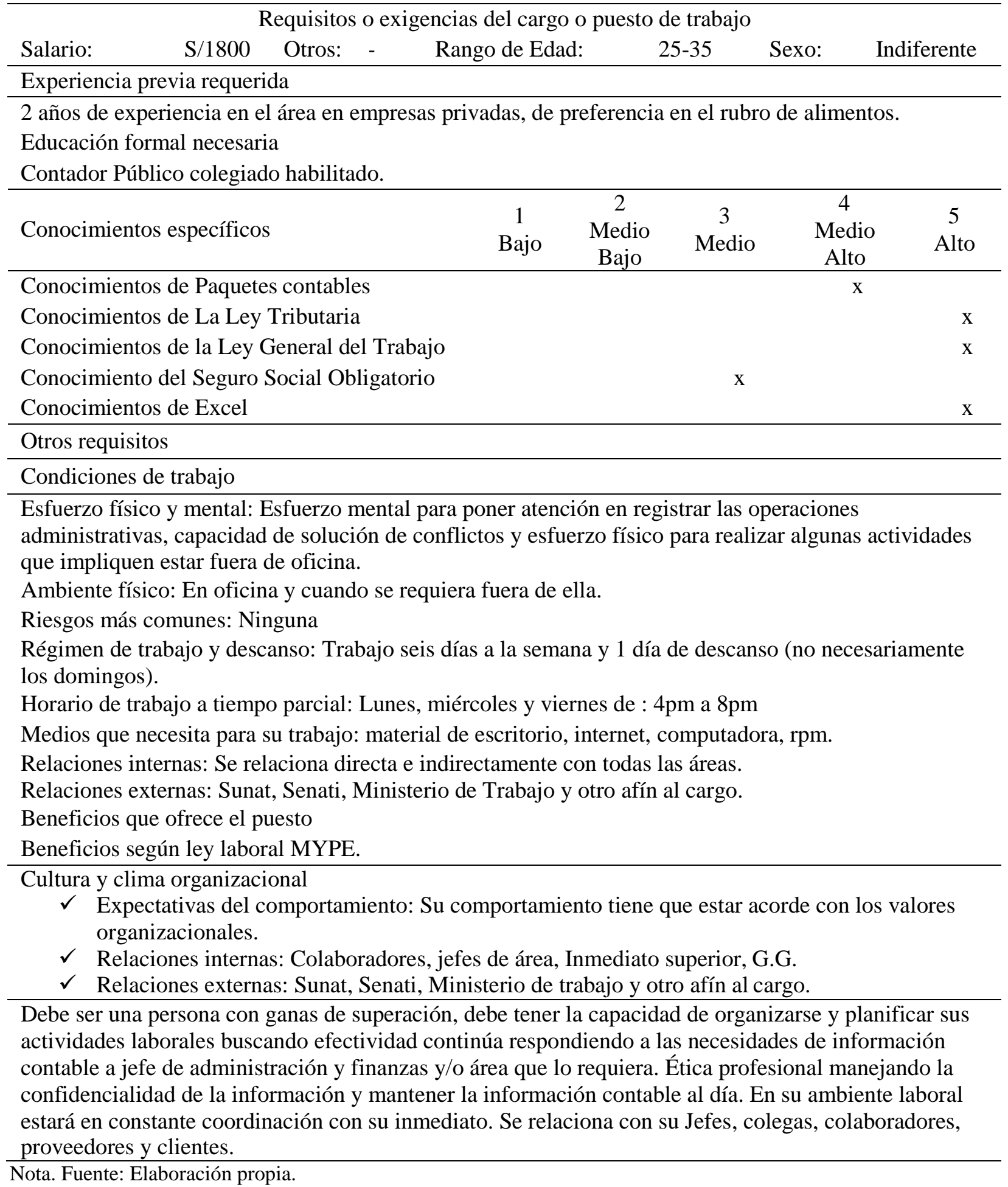




\section{Tabla 113}

Perfil puesto clave - Contador, funciones

\begin{tabular}{|c|c|}
\hline \multicolumn{2}{|c|}{ Principales funciones } \\
\hline Tareas & Indicadores de control \\
\hline $\begin{array}{l}\text { Revisar el cálculo de las planillas de retención de } \\
\text { impuesto sobre la renta del personal emitidas por los } \\
\text { empleados, y realizar los ajustes en caso de no } \\
\text { cumplir con las disposiciones. }\end{array}$ & $\begin{array}{l}\text { Declaración de impuestos según cronogramas } \\
\text { establecidos, emisión de planilla de } \\
\text { remuneraciones sin errores de cálculo. }\end{array}$ \\
\hline $\begin{array}{l}\text { Programar y cumplir la emisión de estados } \\
\text { financieros mensuales, supervisando el estricto } \\
\text { cumplimiento de los cronogramas. }\end{array}$ & $\begin{array}{l}\text { Entrega oportuna de estados financieros al } \\
\text { administrador para su análisis y toma de } \\
\text { decisiones. }\end{array}$ \\
\hline $\begin{array}{l}\text { Coordinar las labores de las diferentes áreas } \\
\text { encargadas de efectuar registros contables conforme } \\
\text { a normas y procedimientos vigentes. }\end{array}$ & $\begin{array}{l}\text { Mantener actualizado el registro de información } \\
\text { según formato Excel. }\end{array}$ \\
\hline $\begin{array}{l}\text { Verificar que las facturas recibidas contengan } \\
\text { correctamente los datos fiscales de la empresa que } \\
\text { cumplan con las formalidades requeridas. }\end{array}$ & $\begin{array}{c}\text { Asegurar que las operaciones sean fehacientes y } \\
\text { que permitan sustentar costo/gasto. }\end{array}$ \\
\hline
\end{tabular}

Nota. Fuente: Elaboración propia. 
Tabla 114

Perfil del Administrador

\begin{tabular}{|c|c|c|c|c|c|}
\hline \multicolumn{6}{|c|}{ Descripción del cargo } \\
\hline \multicolumn{6}{|c|}{ Administrador } \\
\hline Depende de: & \multicolumn{5}{|c|}{ Socios } \\
\hline \multirow{2}{*}{\multicolumn{6}{|c|}{$\begin{array}{r}\text { Todos las áreas } \\
\text { Misión del cargo }\end{array}$}} \\
\hline & & & & & \\
\hline \multicolumn{6}{|c|}{$\begin{array}{l}\text { Planificar, organizar, dirigir y controlar todas las actividades de carácter administrativo financiero } \\
\text { responsabilizándose en forma directa e indirecta, de la consecución de márgenes de rentabilidad y } \\
\text { asegurar la liquidez de la empresa. }\end{array}$} \\
\hline Competencias organizacionales & $\begin{array}{c}1 \\
\text { Bajo }\end{array}$ & $\begin{array}{c}2 \\
\text { Medio } \\
\text { Bajo }\end{array}$ & $\begin{array}{c}3 \\
\text { Medio }\end{array}$ & $\begin{array}{l}4 \\
\text { Medio } \\
\text { Alto }\end{array}$ & $\begin{array}{c}5 \\
\text { Alto }\end{array}$ \\
\hline \multicolumn{6}{|c|}{ Genéricas de la organización } \\
\hline $\begin{array}{l}\text { Compromiso: Asumir como propio los intereses } \\
\text { de la empresa siguiendo los mismo objetivos. } \\
\text { Laboriosidad } \\
\text { Productividad: Capacidad para fijarse objetivos y } \\
\text { alcanzarlos exitosamente, en el tiempo y con la }\end{array}$ & & & & & $\mathrm{x}$ \\
\hline $\begin{array}{l}\text { calidad requerida, controlando el curso de acción } \\
\text { y la optimización de recursos e insumos }\end{array}$ & & & & & $\mathrm{x}$ \\
\hline $\begin{array}{l}\text { Funciona } \\
\text { Orientación al cliente: Actitud permanente de } \\
\text { ayudar y servir a los clientes internos y externos: } \\
\text { se esfuerza por conocer sus problemas, los } \\
\text { escucha, da respuestas adecuadas. }\end{array}$ & del ár & & & & $\mathrm{x}$ \\
\hline \multicolumn{6}{|c|}{$\begin{array}{ll}\text { Individuales del puesto } \\
\end{array}$} \\
\hline $\begin{array}{l}\text { Planificación y organización: Capacidad para } \\
\text { ordenar una tarea o serie de tareas y establecer un } \\
\text { plan de trabajo que dé respuesta al requerimiento } \\
\text { para el cumplimiento de metas. }\end{array}$ & & & & & $\mathrm{x}$ \\
\hline
\end{tabular}

Nota. Fuente: Elaboración propia. 
Tabla 115

Perfil puesto clave - Administrador, requisitos del cargo

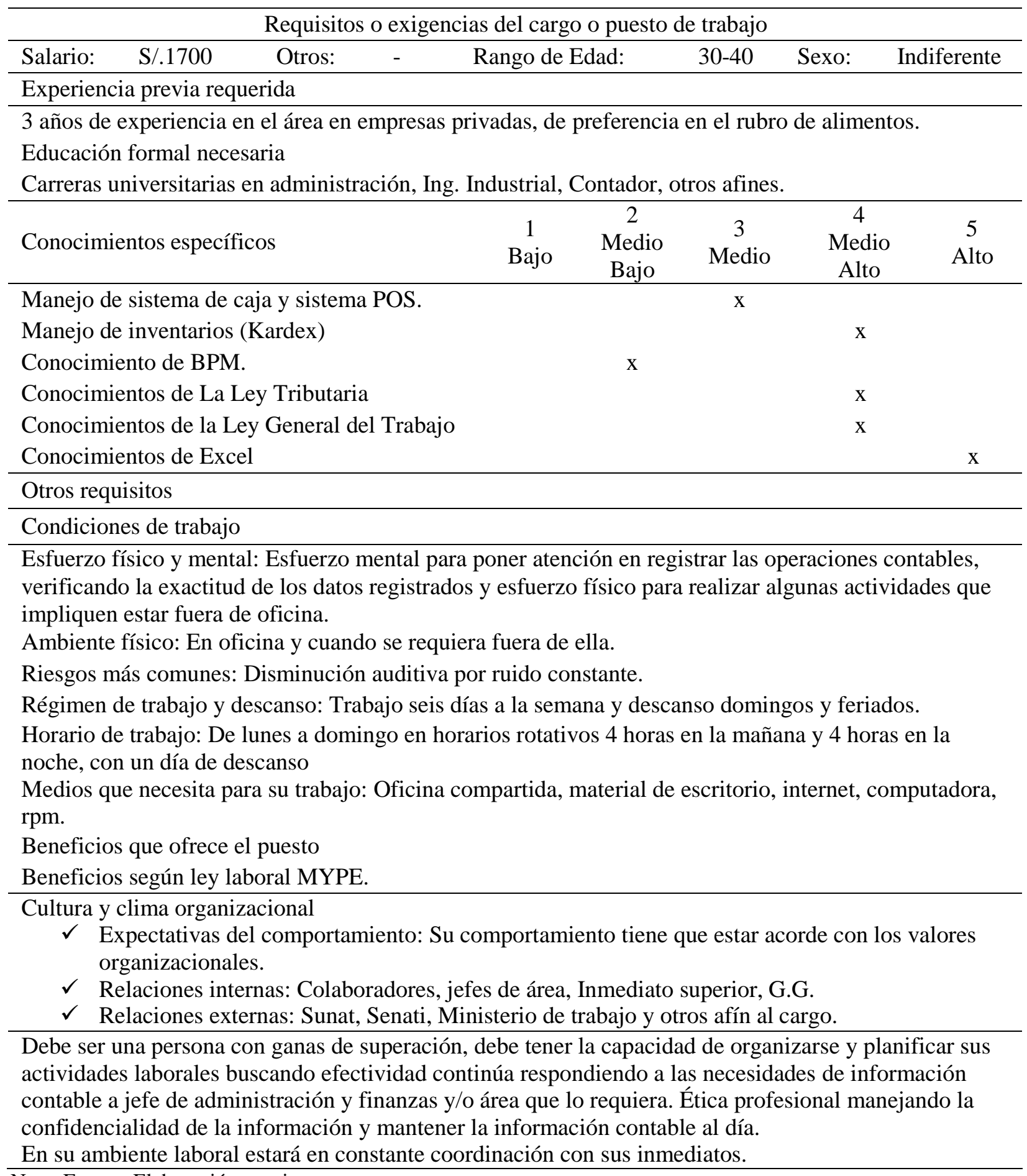

Nota. Fuente: Elaboración propia. 
Tabla 116

Perfil puesto clave - Administrador, funciones

\begin{tabular}{|c|c|}
\hline \multicolumn{2}{|c|}{ Principales funciones } \\
\hline Tareas & Indicadores de control \\
\hline $\begin{array}{l}\text { Planificar, dirigir, y ejecutar las actividades } \\
\text { financieras en coordinación con socios, en base al } \\
\text { flujo de caja con seguimiento mensual, controlando y } \\
\text { supervisando la evolución del flujo proyectado. }\end{array}$ & $\begin{array}{l}\text { Evaluación de estados financieros cada fin de } \\
\text { mes. }\end{array}$ \\
\hline $\begin{array}{l}\text { Realizar análisis de costos de producción y } \\
\text { determinar el punto de equilibrio de la empresa. }\end{array}$ & Mediante el uso de las estadísticas de ventas. \\
\hline $\begin{array}{l}\text { Analizar el presupuesto de compra de insumos, } \\
\text { materiales, suministros, materia prima, mano de obra } \\
\text { directa, repuestos y otros antes de su incorporación al } \\
\text { presupuesto general de la empresa. }\end{array}$ & Estado de ganancias y pérdidas. \\
\hline $\begin{array}{l}\text { Estudiar, proponer y definir en conjunto con socios } \\
\text { todos los aspectos relacionados con los regímenes de } \\
\text { precio, descuentos y servicios en el mercado local. }\end{array}$ & Planes de acción por áreas. \\
\hline $\begin{array}{l}\text { Autorizar las órdenes de compra, órdenes de pago, } \\
\text { comprobantes de ingresos, egresos, traspasos, y } \\
\text { cotizaciones diariamente verificando los } \\
\text { comprobantes elaborados en el día por caja. }\end{array}$ & Registro de gastos, inventarios. \\
\hline $\begin{array}{l}\text { Gestionar, verificar y cumplir con las vigencias de: } \\
\text { licencias, permisos, autorizaciones de las actividades } \\
\text { de la empresa, equipos y sus establecimientos. }\end{array}$ & $\begin{array}{l}\text { Hacer seguimiento cada fin de mes en las } \\
\text { reuniones que se programarán con todo su } \\
\text { equipo de trabajo. }\end{array}$ \\
\hline $\begin{array}{l}\text { Planificar, dirigir, y ejecutar las actividades } \\
\text { financieras en coordinación con socios, en base al } \\
\text { flujo de caja con seguimiento mensual, controlando y } \\
\text { supervisando la evolución del flujo proyectado. }\end{array}$ & $\begin{array}{l}\text { Evaluación de estados financieros cada fin de } \\
\text { mes. }\end{array}$ \\
\hline
\end{tabular}


Tabla 117

Perfil puesto clave - Jefe de Cocina

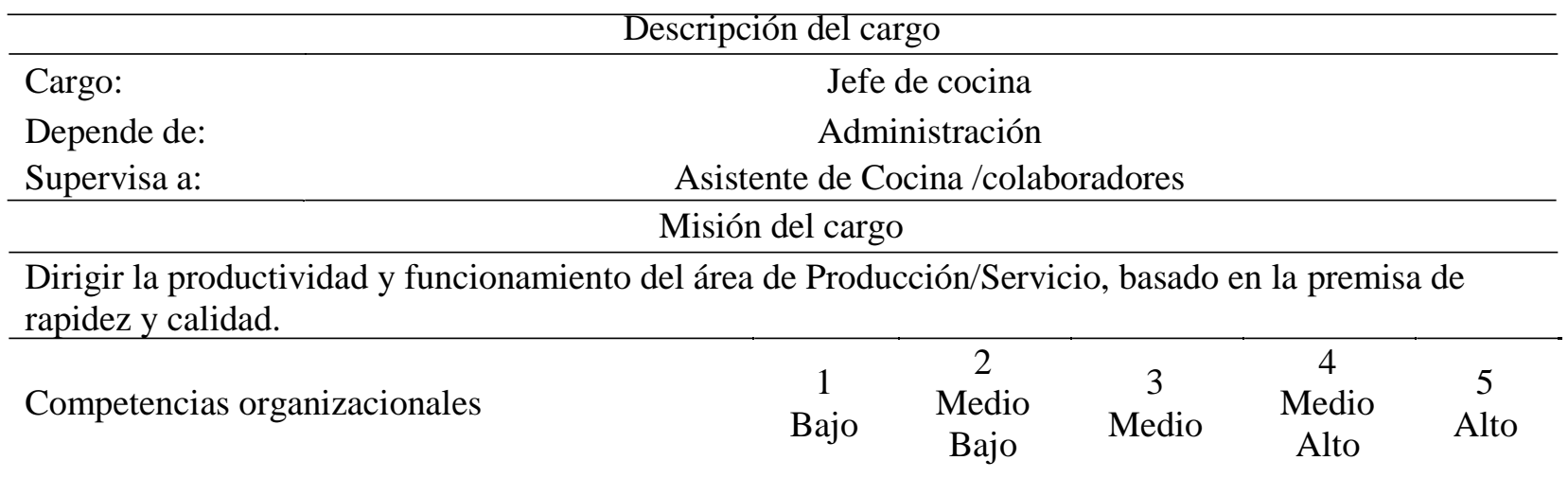

Genéricas de la organización

Compromiso: Asumir como propio los intereses

de la empresa siguiendo los mismo objetivos.

Laboriosidad

Productividad: Capacidad para fijarse objetivos

y alcanzarlos exitosamente, en el tiempo y con

la calidad requerida, controlando el curso de

X acción y la optimización de recursos e insumos

\section{Funcionales del área}

Trabajo bajo presión: Dar soluciones rápidas, ser prácticos para solucionar problemas de inmediato. Capacidad para trabajar manteniendo un buen nivel de energía. Controlar las emociones

Individuales del puesto

Orientación al cliente: Actitud permanente de ayudar y servir a los clientes internos y externos: se esfuerza por conocer sus problemas, los escucha, da respuestas adecuadas.

Nota. Fuente: Elaboración propia. 
Tabla 118

Perfil puesto clave - Jefe de Cocina, requisitos del cargo

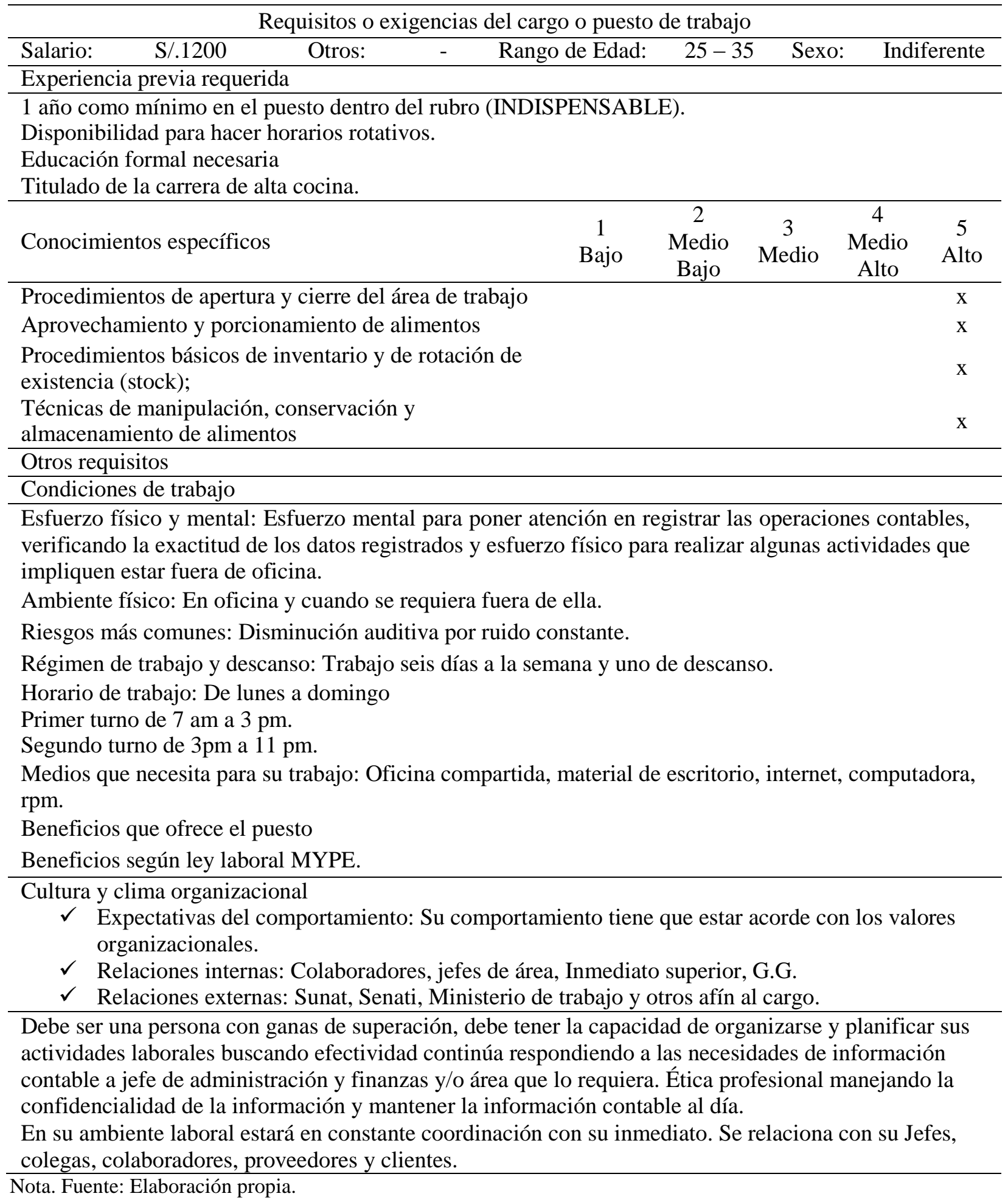




\section{Tabla 119}

Perfil puesto clave - Jefe de Cocina, funciones

\begin{tabular}{lc}
\hline \multicolumn{1}{c}{ Principales funciones. } \\
\hline \multicolumn{1}{c}{ Tareas } & Indicadores de control \\
\hline $\begin{array}{l}\text { Realizar inducción a su personal, toda vez que } \\
\text { ingrese un nuevo colaborador, u otros temas según } \\
\text { programa de capacitación. }\end{array}$ & Evaluaciones de inducción. \\
$\begin{array}{l}\text { Supervisar la limpieza de todos los ambientes que } \\
\text { todo esté impecable. }\end{array}$ & Inspección visual. \\
$\begin{array}{l}\text { Gestionar el orden en la cocina, desde horarios, } \\
\text { perfiles de empleados, posibles imprevistos, } \\
\text { colocación de todas las cosas según corresponda. } \\
\begin{array}{l}\text { Realizar inducción a su personal, toda vez que } \\
\text { ingrese un nuevo colaborador, u otros temas según } \\
\text { programa de capacitación. }\end{array}\end{array}$ \\
$\begin{array}{l}\text { Nota. Fuente: Elaboración propia. } \\
\text { Registro según programa de obligaciones y } \\
\text { funciones del personal a su cargo. }\end{array}$ \\
\end{tabular}


Tabla 120

Perfil puesto clave - Asistente de Tienda

\begin{tabular}{|c|c|c|c|c|c|}
\hline \multicolumn{6}{|c|}{ Descripción del cargo } \\
\hline Cargo: & \multirow{3}{*}{\multicolumn{5}{|c|}{$\begin{array}{c}\text { Asistente de Tienda } \\
\text { Administración } \\
\text { Caja /Colaboradores }\end{array}$}} \\
\hline Depende de: & & & & & \\
\hline Supervisa a: & & & & & \\
\hline \multicolumn{6}{|c|}{ Misión del cargo } \\
\hline \multicolumn{6}{|c|}{$\begin{array}{l}\text { Dirigir la productividad y funcionamiento del área de Servicio, basado en la premisa de rapidez y } \\
\text { calidad. }\end{array}$} \\
\hline Competencias organizacionales & $\begin{array}{c}1 \\
\text { Bajo }\end{array}$ & $\begin{array}{c}2 \\
\text { Medio } \\
\text { Bajo }\end{array}$ & $\begin{array}{l}3 \\
\text { Medio }\end{array}$ & $\begin{array}{c}4 \\
\text { Medio } \\
\text { Alto }\end{array}$ & $\begin{array}{c}5 \\
\text { Alto }\end{array}$ \\
\hline
\end{tabular}

Genéricas de la organización

Compromiso: Asumir como propio los

intereses de la empresa siguiendo los mismo

objetivos. Laboriosidad

Productividad: Capacidad para fijarse

objetivos y alcanzarlos exitosamente.

Trabajo bajo presión: Dar soluciones rápidas, ser prácticos para solucionar problemas de inmediato. Capacidad para trabajar

manteniendo un buen nivel de energía.

Controlar las emociones

Orientación al cliente: Actitud permanente de

Individuales del puesto

ayudar y servir a los clientes internos y

externos: se esfuerza por conocer sus

problemas, los escucha, da respuestas

adecuadas.

Nota. Fuente: Elaboración propia. 
Tabla 121

Perfil puesto clave - Asistente de Tienda, requisitos del cargo

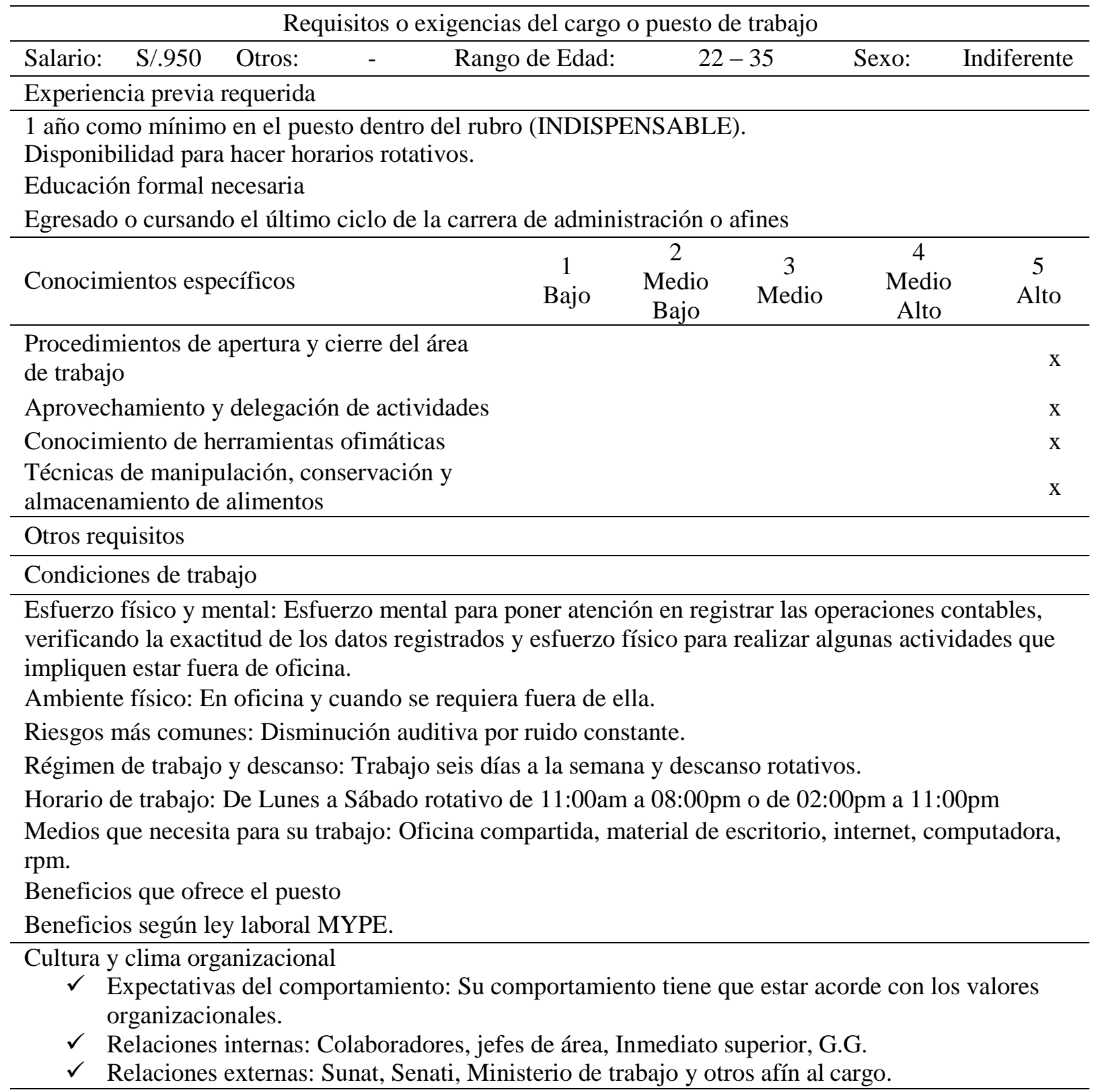

Debe ser una persona con ganas de superación, debe tener la capacidad de organizarse y planificar sus actividades laborales buscando efectividad continúa respondiendo a las necesidades de información contable a jefe de administración y finanzas y/o área que lo requiera. Ética profesional manejando la confidencialidad de la información y mantener la información contable al día.

En su ambiente laboral estará en constante coordinación con su inmediato. Se relaciona con su Jefes, colegas, colaboradores, proveedores y clientes.

Nota. Fuente: Elaboración propia. 
Tabla 122

Perfil puesto clave - Asistente de Tienda, funciones

Tareas

Realizar inducción a su personal, toda vez que ingrese un nuevo colaborador, u otros temas según programa.

Supervisar la hora del servicio

Supervisar la limpieza de todos los ambientes que todo esté impecable.

Apoyar al administrador en labores archivísticas, manejo de las estadísticas de producción y ventas.

Control del acervo documentario.

Estar en contacto directo con los clientes, verificar que se esté brindando un buen servicio.

Nota. Fuente: Elaboración propia.

Tabla 123

Perfil puesto clave - Jefe de Almacén, distribución y mantenimiento

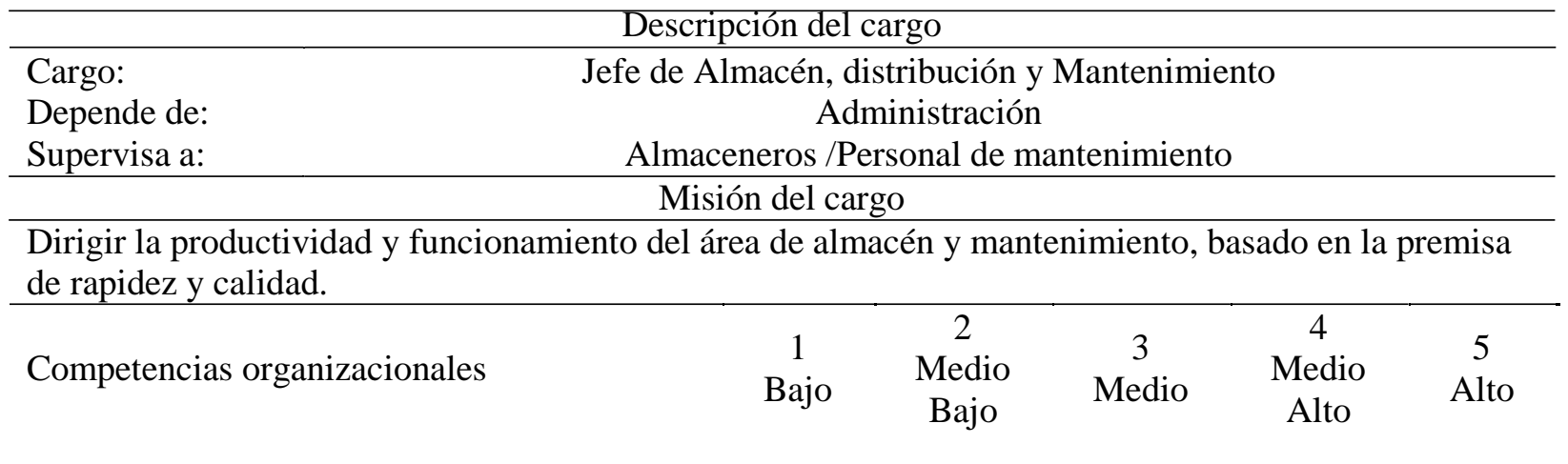

Genéricas de la organización

Compromiso: Asumir como propio los

intereses de la empresa siguiendo los mismo

objetivos. Laboriosidad

Productividad: Capacidad para fijarse

objetivos y alcanzarlos exitosamente, en el

tiempo y con la calidad requerida,

controlando el curso de acción y la

optimización de recursos e insumos

Funcionales del área

Trabajo bajo presión: Dar soluciones rápidas, ser prácticos para solucionar problemas de inmediato. Capacidad para trabajar

manteniendo un buen nivel de energía.

Controlar las emociones

Nota. Fuente: Elaboración propia. 
Tabla 124

Perfil puesto clave - Jefe de Almacén, requisitos del cargo

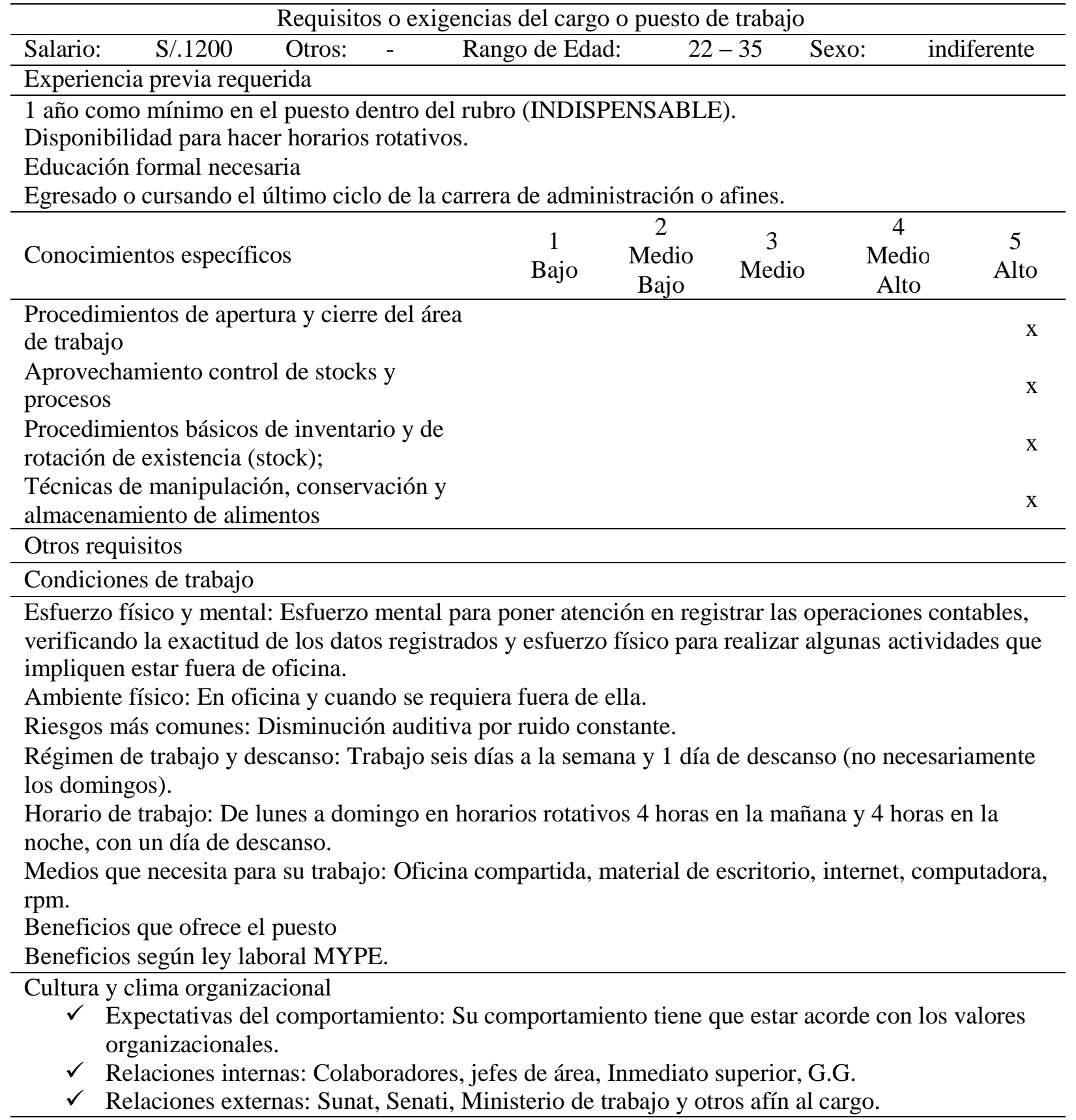

Debe ser una persona con ganas de superación, debe tener la capacidad de organizarse y planificar sus actividades laborales buscando efectividad continúa respondiendo a las necesidades de información contable a jefe de administración y finanzas y/o área que lo requiera. Ética profesional manejando la confidencialidad de la información y mantener la información contable al día.

En su ambiente laboral estará en constante coordinación con su inmediato. Se relaciona con su Jefes, colegas, colaboradores, proveedores y clientes.

Nota. Fuente: Elaboración propia. 
Tabla 125

Perfil puesto clave - Jefe de Almacén, funciones

\begin{tabular}{lc}
\hline \multicolumn{1}{c}{ Tareas } & \multicolumn{1}{c}{ Principales funciones } \\
\hline $\begin{array}{l}\text { Supervisar las entradas y salidas del insumos y/o } \\
\text { diversos productos de almacén. }\end{array}$ & $\begin{array}{c}\text { Reporte mensual mediante estadísticas del flujo } \\
\text { de entrada y salida de insumos y/o diversos } \\
\text { productos. }\end{array}$ \\
$\begin{array}{l}\text { Coordinaciones con proveedores y el jefe de cocina } \\
\text { y supervisar la optimización de los insumos y/o } \\
\text { diversos productos que cuenta bajo su custodia. }\end{array}$ & $\begin{array}{c}\text { Llenado de registro de control de solicitud de } \\
\text { pedido. }\end{array}$ \\
$\begin{array}{l}\text { Estar en contacto directo con los proveedores, para } \\
\text { solicitar determinados insumos y/o diversos } \\
\text { productos. }\end{array}$ & $\begin{array}{l}\text { Reporte de entrega de las solicitudes de pedido. } \\
\begin{array}{l}\text { Estar pendiente de las refacciones y mejoras de la } \\
\text { infraestructura. }\end{array}\end{array}$ \\
\hline
\end{tabular}

Nota. Fuente: Elaboración propia.

Tabla 126

Perfil puesto clave - Asistente de Cocina

\begin{tabular}{lc}
\hline & Descripción del cargo \\
\hline Cargo: & Asistente de Cocina \\
Depende de: & Jefe de Cocina \\
\hline & Misión del cargo \\
\hline
\end{tabular}

Asegurar el mise en place de los alimentos

Nota. Fuente: Elaboración propia.

Tabla 127

Perfil puesto clave - Asistente de Cocina, requisitos del cargo

\begin{tabular}{lllll}
\hline \multicolumn{5}{c}{ Requisitos o exigencias del cargo o puesto de trabajo } \\
\hline Salario: S/.950 Otros: $\quad-\quad$ Rango de Edad: & $18-30$ & Sexo: & indiferente \\
\hline Experiencia previa requerida & & \\
\hline 6 meses como mínimo en el puesto dentro del rubro (indispensable). & \\
Disponibilidad para hacer horarios rotativos. & \\
Educación formal necesaria & & \\
Egresado o cursando el último ciclo de la carrera de alta cocina. & \\
\hline
\end{tabular}

Nota. Fuente: Elaboración propia. 
Tabla 128

Perfil puesto clave - Asistente de Cocina, funciones

\section{Tareas}

Limpieza de los insumos para uso en producción

Picar, trozar y dejar los insumos listo para producción

Elaboración de Cremas y salsas especiales

Evitar la contaminación cruzada y cuidar la temperatura de los alimentos

Nota. Fuente: Elaboración propia.

Tabla 129

Perfil puesto clave - Cajero

\begin{tabular}{lc}
\hline & Descripción del cargo \\
\hline $\begin{array}{l}\text { Cargo: } \\
\text { Depende de: }\end{array}$ & Cajero \\
& Asistente de Tienda \\
\hline Gestionar el cobro de los productos, brindar un buen trato al cliente \\
\hline Nota. Fuente: Elaboración propia.
\end{tabular}

Tabla 130

Perfil puesto clave - Cajero, requisitos del cargo

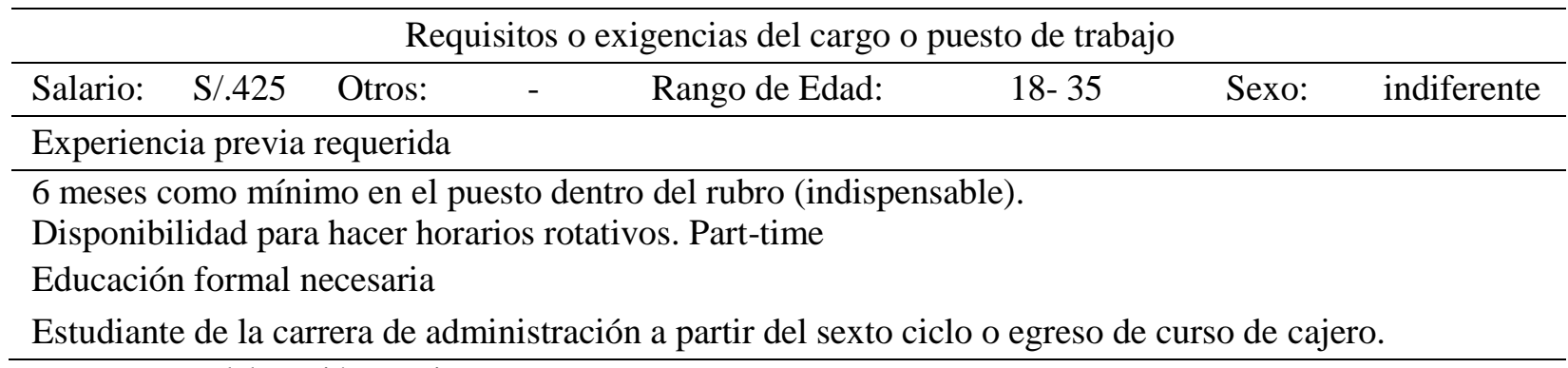

Nota. Fuente: Elaboración propia.

Tabla 131

Perfil puesto clave - Cajero, funciones

Tareas

Manejo de caja, reconocimiento de monedas y billetes falsos.

Manejo de POS y atención al cliente. Apertura y cierre de caja.

Nota. Fuente: Elaboración propia. 
Tabla 132

Perfil puesto clave - Almacenero

\begin{tabular}{lc}
\hline & Descripción del cargo \\
\hline Cargo: & Almacenero/volantero \\
Depende de: & Jefe de Almacén y Mantenimiento \\
\hline & Misión del cargo \\
\hline
\end{tabular}

Asegurar el traslado de insumos y mantener el inventario.

Nota. Fuente: Elaboración propia.

Tabla 133

Perfil puesto clave - Almacenero, requisitos del cargo

\begin{tabular}{llllll}
\hline \multicolumn{5}{c}{ Requisitos o exigencias del cargo o puesto de trabajo } \\
\hline Salario: $\quad$ S/.425 $\quad$ Otros: & - & Rango de Edad: & $18-35$ & Sexo: & Varón \\
\hline Experiencia previa requerida & & & & \\
\hline 3 meses como mínimo en el puesto. & & & \\
Disponibilidad para hacer horarios rotativos. Part-time & & & \\
Educación formal necesaria & & & \\
Secundaria completa & & & & \\
Nota. Fuente: Elaboración propia.
\end{tabular}

Tabla 134

Perfil puesto clave - Almacenero, funciones

Tareas

Asegurar el traslado de los insumo al almacén principal

Realizar el inventario semanal de insumos y mensual de bienes.

Asegurar el stock de folletería, distribución de la folletería en la entrada del local.

Nota. Fuente: Elaboración propia.

Tabla 135

Perfil puesto clave - Colaboradores

\begin{tabular}{lc}
\hline & Descripción del cargo \\
\hline Cargo: & Colaboradores \\
Depende de: & Jefe de cocina/ asistente de tienda \\
\hline & Misión del cargo \\
\hline Apoyar en labores de atención al cliente & \\
\hline Nota. Fuente: Elaboración propia. &
\end{tabular}


Tabla 136

Perfil puesto clave - Colaboradores, requisitos del cargo

\begin{tabular}{lllll}
\hline \multicolumn{4}{c}{ Requisitos o exigencias del cargo o puesto de trabajo } & \\
\hline Salario: $\quad$ S/.850 y 425 Otros: & $-\quad$ Rango de Edad: & $18-30$ & Sexo: & indiferente \\
\hline Experiencia previa requerida & & & & \\
\hline Con o sin experiencia & & & \\
Disponibilidad para hacer horarios rotativos. & & & \\
Educación formal necesaria & & & \\
Estudiante técnico o universitario desde el tercer ciclo. & &
\end{tabular}

Nota. Fuente: Elaboración propia.

Tabla 137

Perfil puesto clave - Colaboradores, funciones

\section{Tareas}

Recepción de los clientes, atención de consultas y reclamos.

Despacho de los productos y ensamblado de los productos rotativo.

Mantener la limpieza de su área. Lavado de bandejas y utensilios.

Nota. Fuente: Elaboración propia.

Tabla 138

Perfil puesto clave - Personal de Delivery

\begin{tabular}{lc}
\hline & Descripción del cargo. \\
\hline Cargo: & Personal de Delivery \\
Depende de: & Jefe de Almacén, distribución y mantenimiento \\
\hline & Misión del cargo \\
\hline Entregar los pedidos telefónicos & \\
\hline
\end{tabular}

Nota. Fuente: Elaboración propia.

Tabla 139

Perfil puesto clave - Personal de Delivery, requisitos del cargo

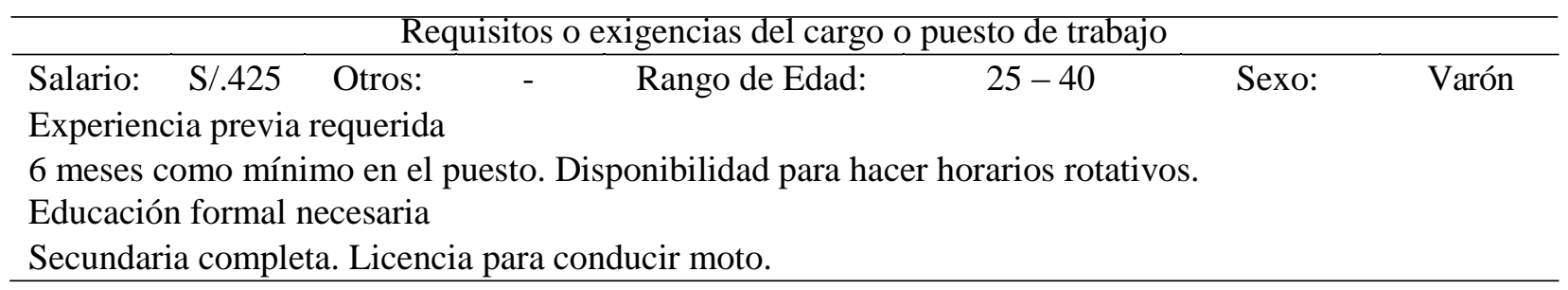

Nota. Fuente: Elaboración propia. 
Tabla 140

Perfil puesto clave - Personal de Delivery, funciones

Tareas

Entregar los pedidos en el tiempo establecido por las políticas de la empresa

Nota. Fuente: Elaboración propia.

Tabla 141

Perfil puesto clave - Personal de Mantenimiento

\begin{tabular}{lc}
\hline & Descripción del cargo \\
\hline Cargo: & Personal de mantenimiento \\
Depende de: & Jefe de Almacén y mantenimiento \\
\hline \multicolumn{2}{c}{ Misión del cargo } \\
\hline Mantener la limpieza y la buena imagen del establecimiento \\
\hline Nota. Fuente: Elaboración propia.
\end{tabular}

Nota. Fuente: Elaboración propia.

Tabla 142

Perfil puesto clave - Personal de Mantenimiento, requisitos del cargo

\begin{tabular}{|c|c|c|c|c|c|c|c|}
\hline \multicolumn{8}{|c|}{ Requisitos o exigencias del cargo o puesto de trabajo } \\
\hline Salario: & $\mathrm{S} / .425$ & Otros: & - & Rango de Edad: & $18-40$ & Sexo: & Varón \\
\hline \multicolumn{8}{|c|}{ Experiencia previa requerida } \\
\hline \multicolumn{8}{|c|}{$\begin{array}{l}3 \text { meses como mínimo en el puesto. Disponibilidad para hacer horarios rotativos. Part-time } \\
\text { Educación formal necesaria }\end{array}$} \\
\hline \multicolumn{8}{|c|}{ Secundaria completa } \\
\hline
\end{tabular}

\section{Tabla 143}

Perfil puesto clave - Personal de Mantenimiento, funciones

\section{Tareas}

Mantener la limpieza de las áreas de entrada, comedor, baños e internas.

Asegurar el correcto manejo de la basura.

Recoger bandejas para el área de lavado.

Nota. Fuente: Elaboración propia. 


\subsection{Remuneraciones, compensaciones e incentivos.}

La remuneración es el proceso que contiene todas las representaciones de retribución o recompensas que se otorgan a los colaboradores y que provienen de su trabajo.

Las condiciones laborales se detallan en la Tabla 144.

Tabla 144

Datos Laborales - Condiciones

\begin{tabular}{lc}
\hline \multicolumn{1}{c}{ Datos laborales } & Condiciones \\
\hline Tipos de trabajadores & Empleados \\
Régimen laboral & Micro y pequeña empresa Decreto legislativo 1086 \\
Periodicidad de pago & Mensual \\
Tipo de pago & Deposito a cuenta \\
\hline
\end{tabular}

Nota. Fuente: Elaboración propia.

La empresa estará conformada por más de 10 colaboradores por lo que las condiciones de contratación estarán estipuladas bajo las condiciones de la ley MYPE (micro y pequeña empresa). A continuación se indicarán los principales derechos de los trabajadores de la pequeña empresa según Figura 67. 


\begin{tabular}{|c|c|}
\hline \multicolumn{2}{|c|}{ DERECHOS DE LOS TRABAJADORES DE LA PEQUEÑA EMPRESA } \\
\hline REMUNERACIÓN MÍNIMA VITAL & Remuneración Minima Vital como mínimo. \\
\hline $\begin{array}{l}\text { PROTECCIÓN DE LA JORNADA MÁXIMA } \\
\text { DE TRABAJO. HORARIO DE TRABAJOY } \\
\text { HORAS EXTRAS }\end{array}$ & 8 Horas Diarias 048 horas Semanales. \\
\hline DESCANSO SEMANAL & 24 horas consecutivas semanales \\
\hline DESCANSO VACACIONAL & $\begin{array}{l}15 \text { días calendarios de descanso por cada } \\
\text { año completo de servicios }\end{array}$ \\
\hline DESCANSO POR LOS DIAS FERIADOS & Igual que el Régimen General \\
\hline GRATIFICACIÓN & $\begin{array}{l}1 \text { Gratificación por Fiestas Patrias y Por } \\
\text { Navidad ( } 50 \% \text { de la Remuneración) }\end{array}$ \\
\hline $\begin{array}{l}\text { COMPENSACIÓN POR TIEMPO DE } \\
\text { SERVICIOS }\end{array}$ & $\begin{array}{l}15 \text { Remuneraciones diarias por año } \\
\text { completo de servicios con un máximo de } 90 \\
\text { remuneraciones. }\end{array}$ \\
\hline UTILIDADES & Io previsto para el Ré gimen Laboral General \\
\hline $\begin{array}{l}\text { INDEMNIZACIÓN POR DESPIDO } \\
\text { INJUSTIFICADO }\end{array}$ & $\begin{array}{l}10 \text { Remuneraciones diarias por cada año } \\
\text { completo de servicios con un máximo de } 90 \\
\text { remunerciones diarias }\end{array}$ \\
\hline \begin{tabular}{|l|} 
INDEMNIZACIÓN POR VACACIONES NO \\
GOZADAS
\end{tabular} & $\begin{array}{l}\text { Lo previsto para el Régimen Laboral General } \\
\text { pero en funcion de los } 15 \text { días de vacaciones } \\
\text { no gozados. }\end{array}$ \\
\hline SEGUROS & $\begin{array}{l}\text { Seguro de Vida } \\
\text { Seguro Complementario de Trabajao }\end{array}$ \\
\hline
\end{tabular}

Figura 67.Derechos de los trabajos de las pequeñas empresas. Tomado de "Régimen laboral aplicable a la micro y pequeña empresa". Recuperado de http://www.asecoint.com.pe/laboral/regimen-laboral-aplicable-a-la-micro-y-pequena-empresa/

En base a las consideraciones anteriores se procede a armar el cuadro de remuneraciones previsto para el presente proyecto, ver Tabla 145 y Horario según Tabla 146. 


\section{Tabla 145}

\section{Esquema de Remuneraciones}

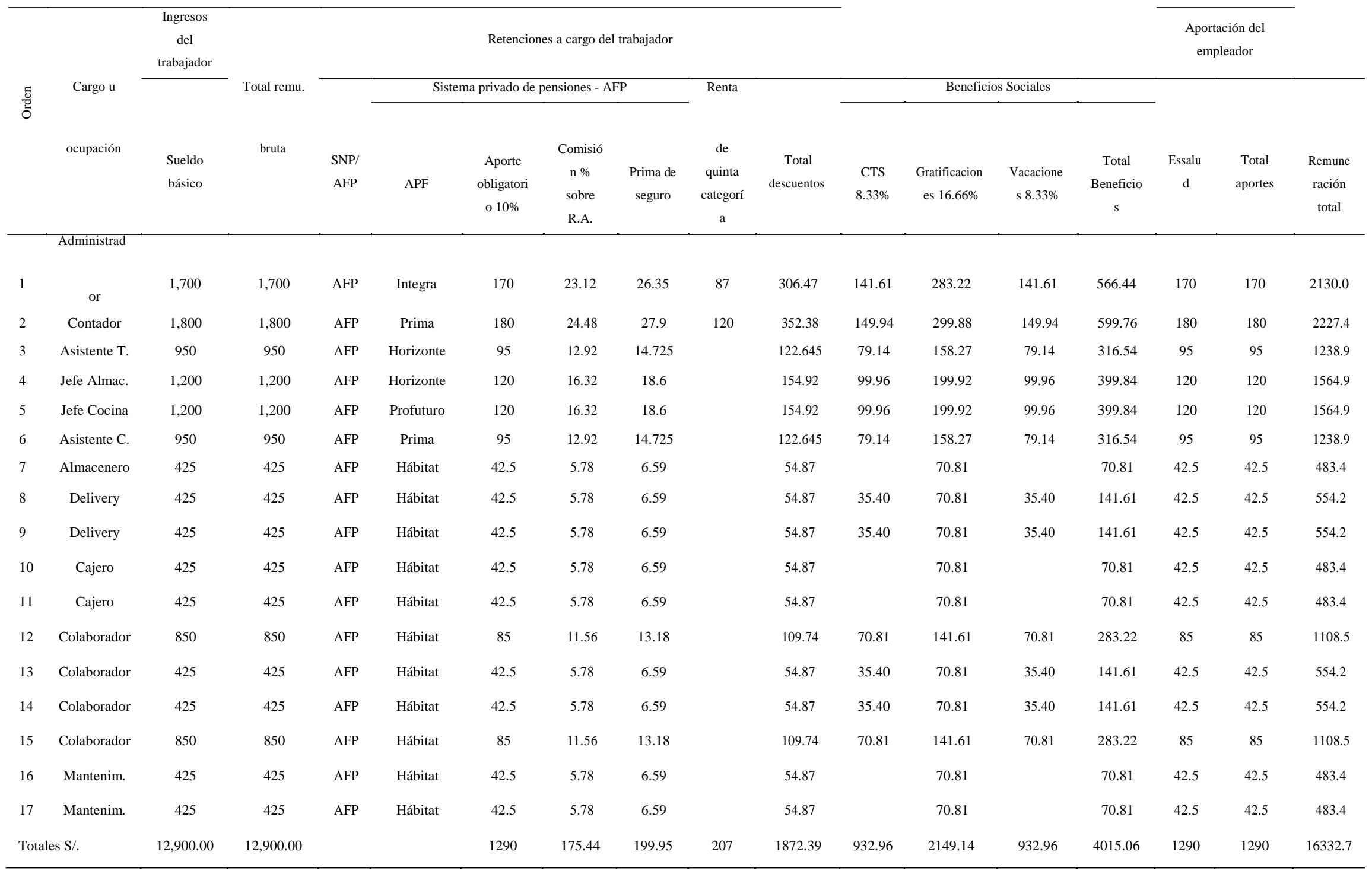

Nota. Fuente: Elaboración propia. 


\section{Tabla 146}

Horarios del personal para el proyecto

\begin{tabular}{|c|c|c|c|c|c|c|c|c|c|c|c|c|c|}
\hline Horario & $\begin{array}{l}10 \mathrm{am} \mathrm{a} \\
11 \mathrm{am}\end{array}$ & $\begin{array}{l}11 \mathrm{am} \mathrm{a} \\
12 \mathrm{pm}\end{array}$ & $\begin{array}{l}12 \mathrm{pm} \mathrm{a} \\
1 \mathrm{pm}\end{array}$ & $\begin{array}{l}1 \mathrm{pm} \mathrm{a} \\
2 \mathrm{pm}\end{array}$ & $\begin{array}{l}2 \mathrm{pm} \mathrm{a} \\
3 \mathrm{pm} \\
\end{array}$ & $\begin{array}{l}3 \mathrm{pm} \mathrm{a} \\
4 \mathrm{pm}\end{array}$ & $\begin{array}{l}4 \mathrm{pm} \mathrm{a} \\
5 \mathrm{pm}\end{array}$ & $\begin{array}{l}5 \mathrm{pm} \mathrm{a} \\
6 \mathrm{pm} \\
\end{array}$ & $\begin{array}{l}6 \mathrm{pm} \text { a } 7 \\
\mathrm{pm}\end{array}$ & $7 \mathrm{pm}$ a $8 \mathrm{pm}$ & $8 \mathrm{pm}$ a $9 \mathrm{pm}$ & $9 \mathrm{pm}$ a $10 \mathrm{pm}$ & $10 \mathrm{pm}$ a $11 \mathrm{pm}$ \\
\hline \multicolumn{14}{|l|}{ Administrador } \\
\hline \multicolumn{14}{|l|}{ Asistente de Tienda } \\
\hline \multicolumn{14}{|l|}{ Jefe de Cocina } \\
\hline \multicolumn{14}{|l|}{ Jefe de Almacén } \\
\hline \multicolumn{14}{|l|}{ Asistente de Cocina } \\
\hline \multicolumn{14}{|l|}{ Almacenero Part Time } \\
\hline \multicolumn{14}{|c|}{ Colaborador 1 Part Time } \\
\hline \multicolumn{14}{|l|}{ Colaborador 2} \\
\hline \multicolumn{14}{|c|}{ Colaborador 3 Part Time } \\
\hline \multicolumn{14}{|l|}{ Colaborador 4} \\
\hline \multicolumn{14}{|c|}{ Mantenimiento 1 Part Time } \\
\hline \multicolumn{14}{|c|}{ Mantenimiento 1 Part Time } \\
\hline \multicolumn{14}{|l|}{ Cajera 1 Part Time } \\
\hline \multicolumn{14}{|l|}{ Cajera 2 Part Time } \\
\hline \multicolumn{14}{|l|}{ Delivery 1 Part Time } \\
\hline Delivery 2 Part Time & & & & & & & & & & & & & \\
\hline
\end{tabular}

Nota. Fuente: Elaboración propia. 


\subsubsection{Compensaciones e incentivos.}

- Se entregaran entradas gratis al cine, así como descuentos en A\&B como incentivo a los mejores índices de atención.

- Se premiara al "empleado del mes" cada mes, y los requisitos serán:

$\checkmark \quad$ Llegar puntual.

$\checkmark \quad$ Vestirse correctamente y portando uniforme completo.

$\checkmark$ Ayuda a sus compañeros.

- Deseos de aprender más.

- Asimismo se le dará un regalo representativo que se le será entregado con públicamente.

- Celebración de cumpleaños mensuales

- Se publicará mensualmente los cumpleaños del mes, que se festejaran a fines de cada mes.

- Se organizarán encuentros deportivos una vez al año para que todas las áreas se puedan reunir y así lograr integración entre todos.

\subsubsection{Política de recursos humanos.}

- Reclutamiento.

$\checkmark$ Se colocara avisos en Rueda de Negocios, en la sección empleos con el perfil del puesto que se requiera.

$\checkmark$ Se colora anuncios en páginas web de empleos como bumerán, aptitus, laborum y computrabajo. 
$\checkmark$ La bolsa laboral en universidades e institutos como Universidad Andina del Cusco, Universidad Nacional San Antonia Abad del Cusco, etc.

- Selección.

$\checkmark$ Se seleccionara a las personas que cumplan con el perfil necesario para cada puesto.

- Análisis de curriculums

$\checkmark$ Se analizaran los curriculums y se tomarán en cuenta las personas que se relacionen más con el puesto buscado.

- Entrevistas Preliminares

$\checkmark \quad$ Investigar e identificar si el candidato cumple con las características que el puesto solicita.

- Entrevistas de Selección

$\checkmark$ Conocer las aptitudes del candidato, intereses, antecedentes, etc. Se le pregunta sobre su trabajo anterior, a que dedica su tiempo libre, sus gustos, sus proyectos, etc. Se trata de llevar una comunicación fluida sin que el entrevistado se sienta presionado.

- Pruebas Psicológicas

$\checkmark$ Se realizarán tests de inteligencia, de rendimiento, de aptitudes, de personalidad y de interés.

- Entrevista Final

$\checkmark$ Se citará al seleccionado y se le hará mención de los documentos que debe entregar. 
- Contratación

$\checkmark$ Cuando pase el proceso de selección, se le comunicara al empleado que debe de traer después de una semana algunos documentos para ser contratados como, copia de DNI, copia de recibo de agua, luz o teléfono y certificado original de antecedentes policiales, carnet de sanidad.

- Inducción.

$\checkmark$ Se le realiza una visita guiada por las instalaciones del establecimiento.

$\checkmark$ Presentación de sus compañeros de trabajo y de su jefe inmediato

$\checkmark$ Entrega de manual del trabajador donde constan todos sus deberes, responsabilidades, funciones y actividades, así como las políticas de la empresa.

- Capacitación.

$\checkmark$ Dentro del restaurante se llevarán a cabo charlas grupales, seminarios, conferencias, cursos, estos se llevaran a cabo en el restaurante, según disponibilidad de este.

- Entrenamiento.

$\checkmark$ Entrenar al personal en el mismo restaurante para la pre- apertura en sus puestos, los entrenamientos que se darán son los siguientes:

- Calidad de los servicios

- Manipulación de alimentos

- Seguridad en el restaurante 
- Evaluación.

$\checkmark$ La evaluación de desempeño se realizara tres veces al año, variando de fecha según los eventos y ocupabilidad del restaurante. Esto se dará para todo el personal que trabaje en el restaurante incluyendo el personal administrativo, estas evaluaciones se harán escritas y orales.

- Objetivos Específicos.

$\checkmark$ Contribuir al mejoramiento de las relaciones humanas, facilitando la comunicación positiva y productiva entre jefes y empleados.

$\checkmark$ Ubicar a los colaboradores en puestos o cargos compatibles con sus conocimientos habilidades y destrezas. 


\section{Capítulo VII}

\section{Plan De Marketing}

En el presente capítulo se desarrollarán diversas estrategias de marketing para la determinación óptima de servicios a implementar y proponer el plan de ventas y políticas de servicio acorde al cliente objetivo.

\subsection{Estrategia de marketing.}

Según señalan Kotler \& Armstrong (2012), la estrategia de marketing es la habilidad y creatividad que la empresa tiene para generar valor en el cliente y así poder alcanzar beneficios rentables. La empresa es quien determina su público objetivo mediante la segmentación y nicho de mercado si fuese necesario; y la empresa es quien decide cuál será su posicionamiento en el mercado y su valor de diferenciación.

Para el caso del proyecto se determinó aplicar una estrategia de marketing Indiferenciado o Masivo, es decir que todos los esfuerzos de marketing y estrategias estarán dirigidos de forma general al segmento determinado durante la etapa de estudio de mercado del proyecto, que esta conformado por la población urbana de los distritos céntricos y aledaños a la Av. La Cultura en la provincia de Cusco de los niveles socioeconómicos A, B y C entre las edades de 18 a 45 años, quienes son estudiantes y trabajadores. Asimismo, se determinó como ventaja competitiva la diferenciación del producto a través de la incorporación de insumos andinos en productos o platos de la cocina americana, en ese sentido cabe precisar que la propuesta de valor que ofrece el proyecto al segmento objetivo es la creación de un restaurante tipo fast food que fusione el estilo de cocina americana con los insumos andinos que se producen en la ciudad del Cusco 
(novoandino), donde se preparen productos como: hamburguesas, pollo broaster, bebidas y postres que incorporen insumos oriundos de la región.

Conforme a ello, para el presente proyecto, se determinó como marca comercial el nombre "Uchucuta" perteneciente a la empresa Uchucuta S.A.C, el nombre proviene del nombre de un ají típico elaborado en la región Cusco que lleva dicho nombre y cuyos ingredientes incluyen insumos oriundos de la región, conforme Figura 68, se muestra el logo de la empresa.

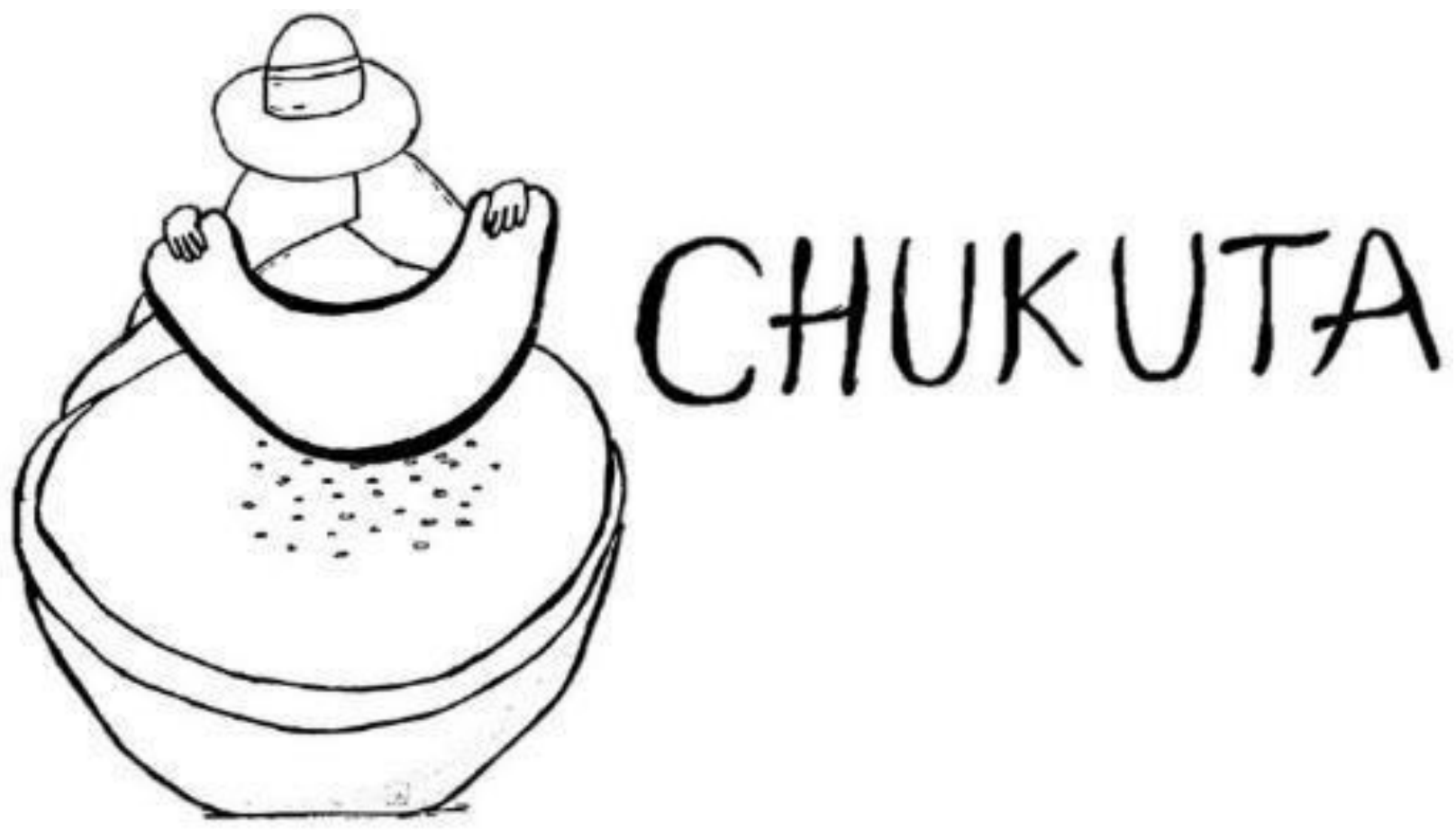

Figura 68.Logo del proyecto - Uchucuta S.A.C. Fuente: Elaboración propia.

El logo representa a la mujer cusqueña con la vestimenta típica de la región utilizando un batan de piedra usado antiguamente para realizar la mezcla y preparación del ají uchucuta. 
Por otro lado, conforme Tabla 147, se desarrollo la matriz de Ansoff (matriz producto) que permite determinar las principales estrategias que servirán como herramientas para la puesta en marcha del proyecto, estas son las estrategias de penetración de mercado y el desarrollo de nuevos productos, ello debido a que el proyecto prevé la viabilidad de una propuesta de negocio nueva para el mercado. Por ello, estrategias como desarrollo del mercado y diversificación no podrían contemplarse en el corto y mediano plazo. Asi mismo cabe precisar que debido a que el proyecto ofrece un servicio, se realizó el análisis de las estrategias a aplicar de acuerdo a las 7P's del Marketing, es decir: Producto, Precio, Plaza, Promoción, Personas, Procesos y Presencia Fisica. 
Tabla 147

Matriz de Ansoff, principales estrategias de marketing

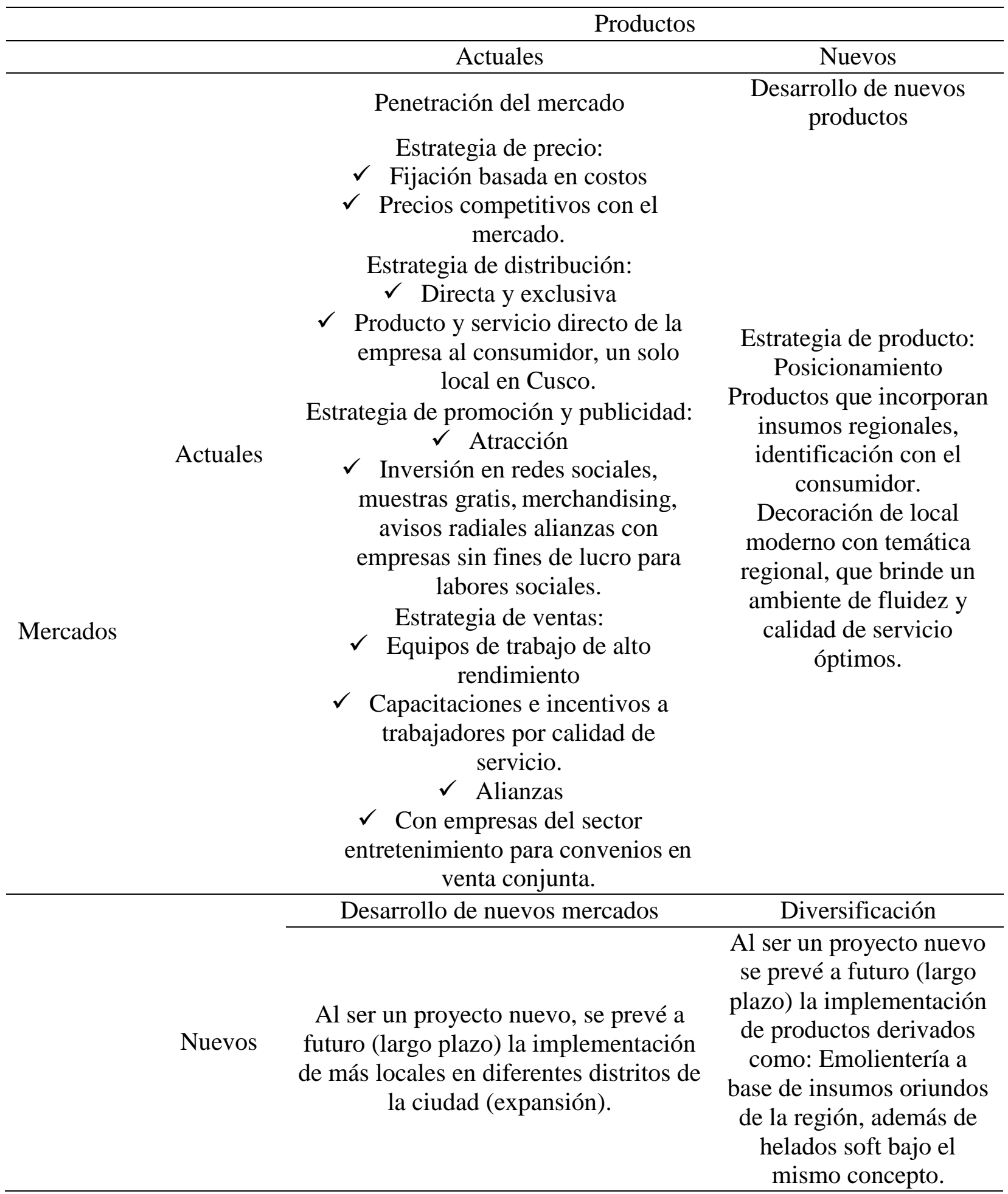

Nota. Fuente: Elaboración propia. 


\subsubsection{Estrategia de producto.}

Kotler \& Armstrong (2012), definen el producto como todo aquel objeto que se puede ofrecer en el mercado para su venta, uso o consumo de tal forma que se pueda satisfacer el deseo o necesidad del consumidor.

Para definir la oferta del proyecto primero se realizará un análisis de los niveles de productos con los que contará el proyecto. Los niveles de producto son la suma de los valores agregados del proyecto que conforman el paquete de la oferta o experiencia que obtiene el consumidor. (Kotler \& Armstrong, Marketing, 2012). A continuación se detallan gráficamente los niveles de productos del proyecto, según Figura 69.

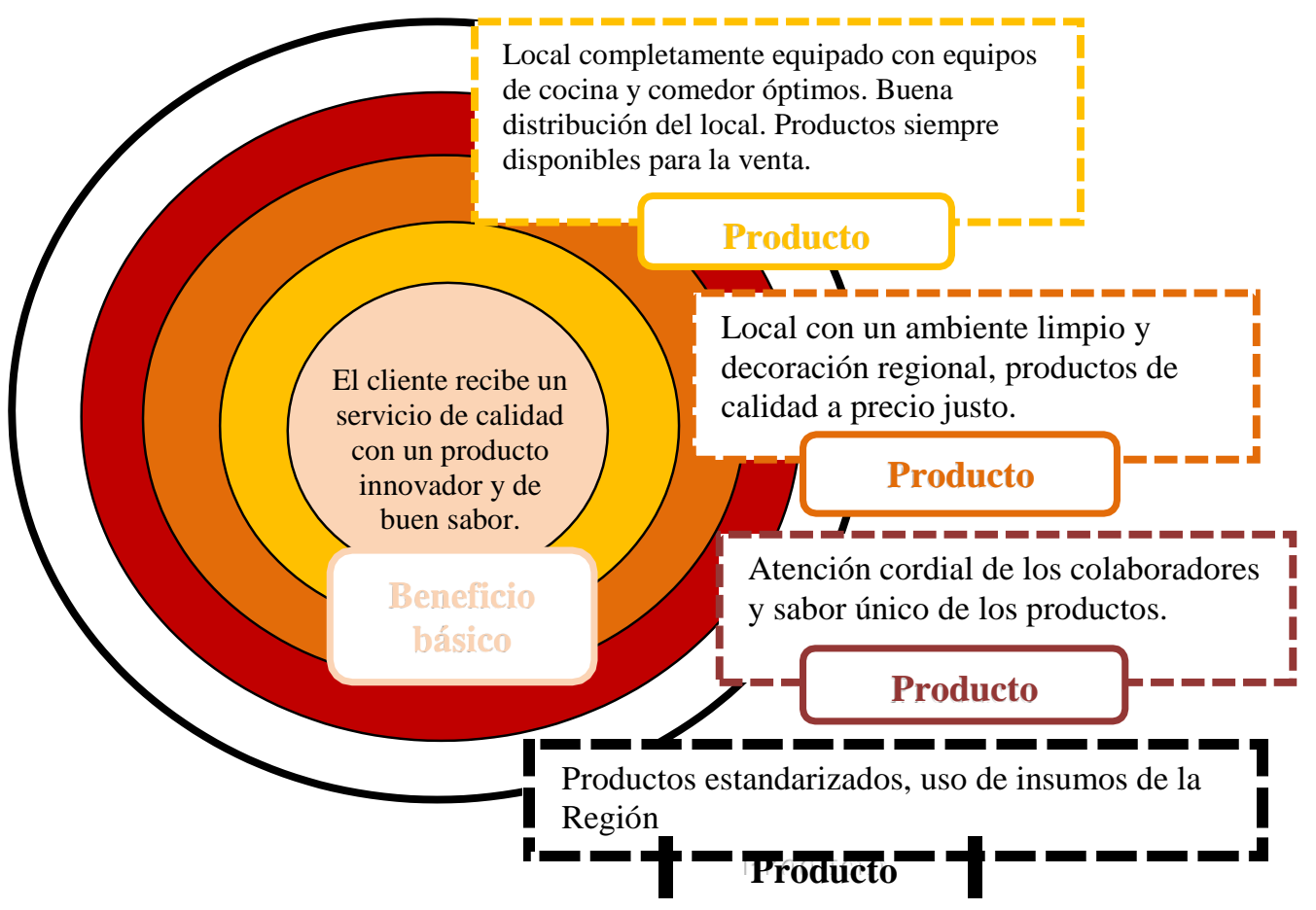

Figura 69.Niveles de productos del proyecto. Adaptado de Niveles de productos. Ing. Romina Daza (2016). Tomado de http://www.slideshare.net/RominaDazaRamos/tema-1-estrategia-deproductos. (p.8) 
Luego de identificar los niveles de producto, se puede reconocer que el beneficio básico, es decir, lo que el consumidor realmente adquiere en este establecimiento es la experiencia de alimentarse con un producto innovador, que le permita identificarse con el mismo, puesto que incorpora en su elaboración insumos regionales, brindándole adicionalmente un servicio de calidad.

Por otro lado, se analizará la mezcla de producto a utilizar en el proyecto en base a las dimensiones potenciales del negocio como se detalla en la Tabla 148.

Tabla 148

Mezcla del producto en base a sus dimensiones

\begin{tabular}{|c|c|}
\hline Dimensiones & Detalle \\
\hline Amplitud & $\begin{array}{c}\checkmark \\
\qquad \quad \text { Línea de hamburguesas. } \\
\checkmark \checkmark \text { Línea de pollos. } \\
\checkmark \text { Línea de ensaladas } \\
\checkmark \text { Línea de bebidas } \\
\checkmark \text { Línea de combos } \\
\checkmark \text { Línea de postres } \\
\checkmark \text { Línea de adicionales o complementos }\end{array}$ \\
\hline Longitud & $\begin{array}{c}\checkmark \text { Tamaño de porciones de hamburguesas: junior, mediano y regular } \\
\checkmark \text { Tamaño de porciones de pollo: regular (1/4 de pollo), junior (1/8 de pollo), } \\
\text { porción de alitas. } \\
\checkmark \quad \text { Tamaño de porciones ensaladas: regular o personal } \\
\checkmark \text { Tamaño de bebidas: junior, mediana y grande. } \\
\checkmark \quad \text { Tamaño de combos: personales y familiares. }\end{array}$ \\
\hline Profundidad & $\begin{array}{l}\checkmark \text { Hamburguesas de pollo y carne, con o sin queso andino. } \\
\checkmark \text { Pollo con quinua, kiwicha o salsas andinas. } \\
\checkmark \quad \text { Ensaladas clásicas o regionales. } \\
\checkmark \text { Bebidas clásicas o regionales. } \\
\checkmark \quad \text { Postres clásicos o regionales. } \\
\checkmark \quad \text { Complementos clásicos o regionales. }\end{array}$ \\
\hline
\end{tabular}


En relación al tema de envases, se determinó utilizar contenedores y bolsas de papel y cartón, para facilitar su posterior reciclaje. En base al beneficio básico del producto y las dimensiones del mismo, se determinó que la principal estrategia del producto es la de posicionamiento, cuyo objetivo será el de posicionarse en la mente del consumidor y marcar una diferencia que cree valor, debido a que el producto que ofrece este proyecto es una nueva propuesta de valor al incluir los productos propios de la región en la preparación de los productos, así mismo se le dará la opción de armar sus propios combos, conforme se detalla en Tabla 149.

El posicionamiento del producto es necesario cuando se agrupa dos o más características de diversos productos creando un nuevo producto, el nuevo producto que es la creación de un producto innovador conteniendo un gran valor percibido por el consumidor. (Ancona, Canul, Martinez, \& Nah, 2012)

Tabla 149

Combos que se ofrecerán en el proyecto

\begin{tabular}{|c|c|c|c|c|}
\hline 01 bebida al escoger & & 01 plato de fondo al escoger & & 01 complemento al escoger \\
\hline $\begin{array}{ll}\checkmark & \text { Emoliente } \\
\checkmark & \text { Chicha de quinua } \\
\checkmark & \text { Chicha de kiwicha } \\
\checkmark & \text { Chicha morada } \\
\checkmark & \text { Limonada frozen } \\
\checkmark & \text { Limonada con muña } \\
\checkmark & \text { Limonada con hierba } \\
& \text { buena }\end{array}$ & + & $\begin{array}{cc}\checkmark & \text { Alitas en salsa de maracuyá } \\
\checkmark & \text { Alitas en salsa de sauco } \\
\checkmark & \text { Alitas en salsa de bbq } \\
& \checkmark \quad \text { Alitas búfalo } \\
& \checkmark \text { Alitas empanizadas } \\
\checkmark & \text { Alitas con salsa de tamarindo } \\
& \checkmark \text { Alitas dulces } \\
\checkmark & \text { Hamburguesa clásica } \\
\checkmark & \text { Hamburguesa de cerdo } \\
\checkmark & \text { Hamburguesa de pollo } \\
\checkmark & \text { Hamburguesa de quinua } \\
\checkmark & \text { Hamburguesa paypi fast } \\
\checkmark & \text { Hamburguesa vegetariana } \\
& \checkmark \text { Broaster }\end{array}$ & + & $\begin{array}{c}\checkmark \quad \text { Papas nativas } \\
\checkmark \quad \text { Choclo con queso } \\
\checkmark \quad \text { Papa helada con queso }\end{array}$ \\
\hline
\end{tabular}

Nota. Fuente: Elaboración propia. 
Adicionalmente se venderán 2 tipos de postre como son: pastel de choclo y budín de quinua.

Otro aspecto importante para el posicionamiento es el ambiente que ofrecerá el local, el cual incluirá en parte de su decoración la temática regional además que la iluminación y la distribución del mismo permitirán fluidez y vistosidad para los visitantes.

\subsubsection{Estrategia de precio.}

Kotler \& Armstrong (2012) indican que, si los clientes observan que el producto posee un precio superior al que ellos consideran su valor, definitivamente no lo adquirirán, es por ello que los costos son con seguridad los límites mínimos del precio y si la empresa aplica precios por debajo de los costos sus ganancias se verán afectadas.

Primero se realizará un benchmarking de los precios que ofrecen los principales competidores del proyecto, conforme Tabla 150.

Tabla 150

Precio promedio de combos de competidores directos

\begin{tabular}{lc}
\hline \multicolumn{1}{c}{ Competidores directos } & Precio promedio de combos \\
\hline KFC & $\mathrm{S} / 15.50 \mathrm{a}$ \\
Popeyes & $\mathrm{S} / 14.90 \mathrm{~b}$ \\
Bembos & $\mathrm{S} / 16.90 \mathrm{c}$ \\
Burguer King & $\mathrm{S} / 15.00 \mathrm{~d}$ \\
Rupha's Diner & $\mathrm{S} / .16 .00 \mathrm{e}$ \\
\hline
\end{tabular}

Nota. Fuente: Elaboración propia.

a KFC. Productos, promociones. https://www.kfc.com.pe/Online/Productos/Productos?idCodigo=1 b Popeyes. Promociones Online. http://www.popeyes.com.pe/promociones-online c Bembos. Delivery. http://www.bembos.com.pe/hamburguesas/bembos-clasica d Buguer King. Jueves de XT. https://es-la.facebook.com/notes/burger-king-per\%C3\%BA/jueves-de-xt2018/224747924526600/

e Rupha’s Diner. Por observación directa, se visitó establecimiento. 
Así mismo, conforme los resultados de la investigación cuantitativa, se obtuvo que el 68.68\% de los encuestados están dispuestos a pagar entre S/10.00 y S/15.00 soles por combo, además de un $21.18 \%$ que podrían pagar entre 16 a 25 soles.

A continuación se detallan los criterios determinantes para la fijación de precios según Tabla 151.

Tabla 151

Criterios para la fijación de precios

\begin{tabular}{lc}
\hline \multicolumn{1}{c}{ Costo del producto } & $\begin{array}{c}\text { El costo de este tipo de producto por los insumos que } \\
\text { intervienen es moderado-alto. }\end{array}$ \\
\hline $\begin{array}{l}\text { Percepción del valor del } \\
\text { producto }\end{array}$ & $\begin{array}{c}\text { Conforme al estudio cualitativo, se determinó que los } \\
\text { consumidores si estarían moderadamente dispuestos a pagar } \\
\text { más por un producto, como el propuesto en el proyecto. }\end{array}$ \\
$\begin{array}{l}\text { Característica genuina del } \\
\text { producto } \\
\begin{array}{l}\text { Barreras de entrada del } \\
\text { producto }\end{array}\end{array}$ & $\begin{array}{c}\text { Uso de insumos de la región } \\
\text { Concepto de fácil imitación, pero difícil implementación, el } \\
\text { sabor es lo que predomina. }\end{array}$ \\
\hline
\end{tabular}

Nota. Fuente: Elaboración propia.

Entre las principales estrategias de fijación de precios y lo obtenido en la Tabla 151, se puede determinar que la mejor estrategia para el proyecto es la siguiente:

- Fijación de precios basada en el costo: Esta estrategia es la más utilizada por las empresas y consiste en determinar el precio según los costos de producción, distribución y venta del bien o servicio, a todo ello se debe considerar de manera adicional un margen de utilidad por todos los esfuerzos empleados para la elaboración 
del producto. Esta estrategia se implementará en todos los productos del proyecto, ello debido a que al basar el precio en función de costos se asegura el cubrir los costos fijos del negocio, además de poder ser más competitivos con respecto a precio, ajustando los márgenes de contribución según convenga. Para ello, en base al costeo de las recetas, véase Anexo $\mathrm{N}^{\circ} 18$, se le asignará un factor multiplicador de 2.5 al costo de producción unitario por receta, para determinar el precio de venta unitario sin IGV.

\subsubsection{Estrategia de distribución.}

Según Kotler \& Armstrong (2012), la estrategia de distribución se define como los medios que son utilizados para unir los productos que ofrece la empresa con los clientes, creando así una cadena de suministros que implica todos los procesos desde el hacer y vender del producto, todo este concepto surge a partir de la necesidad del cliente.

A continuación se determinará los criterios de evaluación para fijar la mejor estrategia de distribución del proyecto, ver Tabla 152.

\section{Tabla 152}

Criterios para definir las estrategias de distribución

\begin{tabular}{|c|c|}
\hline Criterio & Estrategia \\
\hline $\begin{array}{l}\text { Concentración geográfica de } \\
\text { clientes }\end{array}$ & $\begin{array}{l}\text { El mercado objetivo del proyecto está enfocado en los } \\
\text { distritos de Cusco, Wanchaq y San Sebastián. }\end{array}$ \\
\hline Canales de distribución & Venta directa al consumidor y delivery. \\
\hline Frecuencia de compra & Alta \\
\hline Tipo de producto & Perecedero \\
\hline Proyecciones a futuro & $\begin{array}{l}\text { Ingresar a nuevos segmentos de mercado y aperturar } \\
\text { nuevos locales en Cusco y provincias. }\end{array}$ \\
\hline
\end{tabular}

Nota. Fuente: Elaboración propia. 
Conforme a la Tabla 152, se puede determinar que el canal de distribución del proyecto es directo, es decir, el producto se procesa y vende directamente al cliente sin intermediarios, debido al tipo de producto y frecuencia de consumo, en la Figura 69 se presenta gráficamente el canal de distribución.

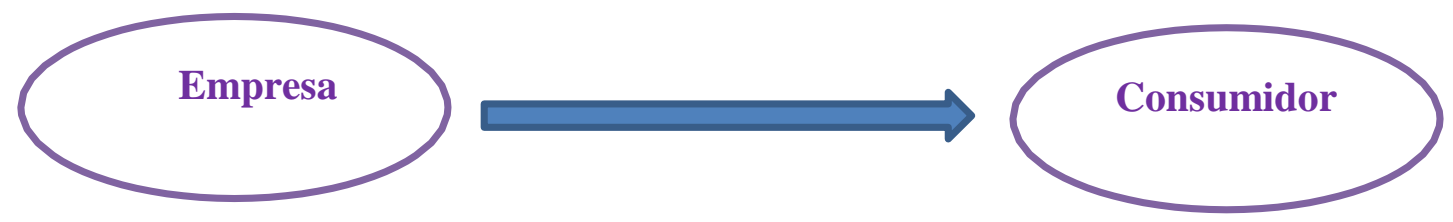

Figura 70.Canal de distribución del proyecto. Fuente: Elaboración propia.

Conforme a las proyecciones futuras del proyecto se podría implementar la siguiente estrategia.

- Cobertura de mercado: se divide en tres estrategias de cobertura, como la distribución intensiva en la cual existen varios puntos de venta en donde el producto está más expuesto al cliente y por lo tanto, conlleva a una mayor eficacia en transmisión del mensaje publicitario. La distribución selectiva tiene un número reducido de distribuidores, poca cobertura de venta y menor costo de distribución ya que no posee muchos puntos de venta. La distribución exclusiva por su parte se da cuando los productos tienen una venta exclusiva por su elevado costo, del mismo modo que la distribución selectiva, tiene poca cobertura y oportunidad de venta. 
Para el proyecto se consideró una distribución exclusiva, puesto que se contará con un solo

local, que ofrece productos innovadores, que no se ofrecen actualmente en ningún fast food de la ciudad de Cusco.

\subsubsection{Estrategia de promoción y publicidad.}

Según Kotler \& Armstrong (2012), una de las decisiones más difíciles por las que atraviesa una organización es asignar un presupuesto adecuado para la promoción, es por ello que las empresas consideran diversos métodos para la determinación de dicho presupuesto.

En primer lugar se desarrollará el programa de publicidad del proyecto que consta de cuatro pasos:

- Formulación de objetivos. El presente plan de marketing tiene como objetivo determinar la mejor combinación de producto, precio, plaza y promoción, que permita una óptima penetración en el mercado cusqueño con el desarrollo de un producto innovador.

- Establecimiento del presupuesto. El método para la fijación del presupuesto de promoción y publicidad estará basado en el método de objetivo y tarea; es el método más coherente que deberían emplear las organizaciones ya que permite trazar objetivos y definir logros específicos para luego realizar un costeo que dichas necesidades implica. En base al objetivo señalado en el inciso anterior, el presupuesto 
debe ser elaborado en función de incrementar las ventas y captar al público objetivo, logrando el posicionamiento en el mercado.

- Mensaje publicitario. El mensaje será informativo, dando a conocer el producto innovador que ofrece el presente proyecto. Fast food novoandino, hamburguesas y pollo broaster con insumos de la región.

- Medios. A través de volantes, afiches, banners, aviso radial, muestra gratis, redes sociales.

Del mismo modo se definirán las estrategias básicas de promoción entre las cuales la organización debe elegir para captar a su mercado.

Para fines de propuesta de proyecto, la estrategia considerada como la más adecuada acorde al funcionamiento de sus actividades es la estrategia de atracción, esta estrategia emplea la publicidad y promoción para promover la ventas de productos a los consumidores finales, al sentirse motivados y atraídos por lo ofrecido, los consumidores acudirán a los locales de expendio. Esta estrategia se aplicará puesto que en primera instancia se hará uso de las redes sociales como el Facebook e Instagram para dar a conocer el producto y porque según los focus group y entrevistas realizadas a expertos, las redes sociales son el medio por el cual las personas se enteran de nuevos productos o acontecimientos importantes en cuestión de minutos, en segundo lugar se considerarán los anuncios por radios locales, ya que el público objetivo de la propuesta son los residentes de la ciudad de Cusco. 
Según Kotler \& Armstrong (2012), consideran que la publicidad es todo aquel medio pagado que se utiliza a modo de representación y promoción no personales para informar, persuadir y recordar a los consumidores sobre un producto o servicio, además cabe resaltar que la publicidad es llevada a cabo sólo por un tiempo determinado y a un segmento de consumidores específico.

La evaluación de los resultados obtenidos por la implantación de estas estrategias, será de forma trimestral, para medir los efectos en el mercado y su crecimiento.

A continuación se detalla en la Tabla 153, el plan de publicidad para el periodo de evaluación del proyecto. 


\section{Tabla 153}

Plan de promoción y publicidad para el periodo de evaluación del proyecto

\begin{tabular}{|c|c|c|c|c|c|}
\hline Recursos & Actividades & Objetivo & Cantidad & Años & $\begin{array}{l}\text { Periodicidad } \\
\text { /Renovación }\end{array}$ \\
\hline \multirow{4}{*}{ Afiches } & \multirow{4}{*}{$\begin{array}{l}\text { Colocación en paraderos de transporte } \\
\text { público y postes de los distritos objetivo. }\end{array}$} & \multirow{4}{*}{$\begin{array}{c}\text { Dar a conocer la existencia del negocio en la } \\
\text { zona. }\end{array}$} & \multirow{4}{*}{ Medio millar } & Año 1 & Trimestral \\
\hline & & & & Año 2 & Cuatrimestral \\
\hline & & & & Año 3 & Semestral \\
\hline & & & & Año 4 y Año 5 & Anual \\
\hline \multirow{3}{*}{ Volantes } & \multirow{3}{*}{$\begin{array}{l}\text { Cupones de descuento en combos, } \\
\text { repartición manual en cruces y avenidas } \\
\text { principales, institutos y universidades } \\
\text { cerca al local. }\end{array}$} & \multirow{3}{*}{$\begin{array}{c}\text { Incentivar la asistencia de consumidores al } \\
\text { local. }\end{array}$} & \multirow{3}{*}{ Medio millar } & Año del 1 al 3 & Cuatrimestral \\
\hline & & & & & \\
\hline & & & & Año del 4 al 5 & Semestral \\
\hline Banners & En la puerta de entrada del local & $\begin{array}{c}\text { Resaltar las cualidades de negocio y general } \\
\text { visibilidad del local. }\end{array}$ & Dos unidades & Del año 1 al 5 & Anual \\
\hline \multirow{3}{*}{$\begin{array}{l}\text { Aviso radial } \\
\text { (radio salkantay } \\
92.7 \mathrm{FM} \text { ) }\end{array}$} & \multirow{3}{*}{2 veces al día mañana y tarde } & \multirow{3}{*}{$\begin{array}{c}\text { Incentivar el nivel de recordación de la } \\
\text { marca. }\end{array}$} & \multirow{3}{*}{$\begin{array}{l}\text { Duración } 3 \text { veces por } \\
\text { semana por un mes }\end{array}$} & Año 1 & Bimestral \\
\hline & & & & Año 2 y Año 3 & Cuatrimestral \\
\hline & & & & Año 4 y Año 5 & Semestral \\
\hline Redes sociales & $\begin{array}{l}\text { Imágenes de los productos, atención de } \\
\text { sugerencias, notas de novedades y } \\
\text { publicación de eventos en la región. }\end{array}$ & $\begin{array}{l}\text { Mantener contacto directo con los clientes, } \\
\text { obtener retroalimentación. }\end{array}$ & $\begin{array}{l}\text { Facebook } \\
\text { Instagram } \\
\text { Twitter } \\
\text { Canal de YouTube }\end{array}$ & $\begin{array}{l}\text { Del año } 1 \text { al año } \\
5\end{array}$ & $\begin{array}{l}\text { Actualización } \\
\text { constante }\end{array}$ \\
\hline Muestras gratis & $\begin{array}{l}\text { Degustación de pequeñas porciones de } \\
\text { productos en los exteriores del local. }\end{array}$ & $\begin{array}{l}\text { Incentivar la aceptación del producto y } \\
\text { asistencia de consumidores. }\end{array}$ & Un ciento & Año 1 & Trimestral \\
\hline Página web & Contratación de un web master & $\begin{array}{l}\text { Reconocimiento de la marca e identificación } \\
\text { con el público objetivo. }\end{array}$ & 1 & Años del 1 al 5 & anual \\
\hline Merchandising & $\begin{array}{l}\text { Llaveros, polos, gorras, libretas, etc. con el } \\
\text { logo de marca y frase. }\end{array}$ & $\begin{array}{c}\text { Publicidad indirecta en las calles, recordación } \\
\text { de la marca }\end{array}$ & Medio millar & Años del 1 al 3 & Semestral \\
\hline
\end{tabular}

Nota. Fuente: Elaboración propia. 


\subsubsection{Estrategia de Personas.}

Para el presente proyecto se considera a los colaboradores y personal de atención al cliente, como la fuerza de ventas del negocio, por ello se dará importancia a la implementación de las estrategias en la Tabla 154, en cuanto el manejo de la fuerza de ventas.

Tabla 154

Estrategias para el manejo de la fuerza de ventas

\begin{tabular}{|c|c|}
\hline Estrategias & Detalle \\
\hline $\begin{array}{l}\text { Que los colaboradores } \\
\text { conformen equipos de trabajo de } \\
\text { alto rendimiento }\end{array}$ & $\begin{array}{c}\checkmark \quad \text { Conocimiento del producto. } \\
\checkmark \quad \text { Saber sugerir a los consumidores. } \\
\checkmark \quad \text { Mantener orden y limpieza. } \\
\checkmark \quad \text { Atentos a las necesidades del consumidor. } \\
\checkmark \quad \text { Tolerancia a la presión. } \\
\checkmark \quad \text { Trabajo en equipo. } \\
\checkmark \quad \text { Saber escuchar, empatía. }\end{array}$ \\
\hline $\begin{array}{l}\text { Diseñar sistemas de capacitación } \\
\text { periódica }\end{array}$ & $\begin{array}{c}\text { Los expertos de fast food señalan que en la ciudad de Cusco no se } \\
\text { cuenta con personal capacitado, es por ello que se capacitará a los } \\
\text { colaboradores de forma quincenal en cuanto a la atención de los } \\
\text { clientes, tomando en cuenta el respeto, la consideración y } \\
\text { cordialidad. }\end{array}$ \\
\hline $\begin{array}{l}\text { Generar incentivos para mejorar } \\
\text { la calidad de atención }\end{array}$ & $\begin{array}{c}\text { Se realizan breves encuestas por calidad de servicio a los clientes, } \\
\text { en ese sentido, el colaborador que durante un periodo de tiempo } \\
\text { reciba mejores resultados, recibirá un incentivo económico como } \\
\text { bonos y cupones o incentivo no económico como diplomas o } \\
\text { reconcomiendo público. }\end{array}$ \\
\hline
\end{tabular}

Nota. Fuente: Elaboración propia.

\subsubsection{Estrategia de Procesos.}

En el caso de los procesos del proyecto, cabe resaltar que el servicio brindado en el establecimiento sera tipo fast food americano, esto conlleva a que se estándarizen los procesos para brindar al cliente la misma calidad de producto y servicio siempre, a través de la elaboración de recetas estándares en caso de los productos y elaboración de brueprints de 
procesos de servicio para el personal encargado. Del mismo modo se aplicaran encuestas de satisfacción a los consumidores para asegurar que los procesos se estén aplicando de forma uniforme y continua.

\subsubsection{Estrategia de Presencia Fisica.}

Para el caso del proyecto, se considerará la aplicación de una ambientación tematizada de acuerdo a una fusión moderna conforme el estilo americano y colores, telas y texturas acordes a la Región del Cusco, del mismo modo se incluirá música de fondo con sonidos latinoamericanos de artistas como Paqarina, Los Jarkas, Antologia, Alborada entre otros exponentes de la música andina instrumental, para brindar un entorno acorde al producto a ofrecer.

\subsection{Estrategia de Ventas.}

De acuerdo con Kotler \& Armstrong (2012), los gerentes del departamento de marketing tiene la gran responsabilidad de buscar estrategias de ventas adecuadas para obtener la mayor rentabilidad en la organización, es así que algunas de las disyuntivas presentes al momento de decidir sobre las estrategias son el tamaño de la fuerza de venta, el medio por el cual se debe realizar la venta, la cantidad y forma de estructurar a los vendedores, entre otras.

\subsubsection{Plan de ventas.}

Según Kotler \& Armstrong (2012), el plan de ventas incluye una serie de procesos que los vendedores deben conocer muy bien, estos procesos deberían tener como objetivo alcanzar nuevos clientes y también formar relaciones a largo plazo. 
A continuación se menciona los procesos a tener en consideración para obtener un plan de ventas exitoso:

- Definir el público potencial, es decir, a que segmento de mercado se va a dirigir la empresa.

- Plantear precios, acorde al tipo de producto que se tiene y al valor de percepción que consideren los clientes.

- Identificar a la competencia, para conocer quienes ofrecen el mismo o similar producto y además para poder identificar las debilidades que pueden tener.

- Determinar el precio de venta, que dejará a la empresa un margen de utilidad previa realización de los procesos anteriores.

- Previsión de ventas, teniendo en consideración que el año tiene temporadas altas y bajas.

- Identificar la forma de distribución, es decir, saber con qué canales se va a llevar a cabo la entrega del producto a su destino final.

- Dar a conocer el producto, análisis previo de las estrategias de promoción y publicidad que se ajusten más a las necesidades de la empresa. (García, 2016).

En base a lo anterior se puede determinar los criterios que servirán para definir el plan de ventas del proyecto conforme Tabla 155, con ello se desarrolló el plan de venta según Tabla 156; además según Tabla 157 a Tabla 159 se estimó el presupuesto del plan de Marketing. 
Tabla 155

Criterios para definir el plan de ventas

\begin{tabular}{lc}
\hline \multicolumn{1}{c}{ Procesos } & Características \\
\hline $\begin{array}{l}\text { Público objetivo } \\
\text { Estrategia de precios }\end{array}$ & Personas de 18 a 45 años de los NSE A, B y C, que residen \\
en los distritos de Wanchaq, San Sebastián y Cusco. & Valor agregado y costo. \\
Debilidades de la competencia & Productos conocidos bajo nivel de innovación, no cuentan \\
Canales de distribución & con alianzas con empresas de la región. \\
Previsión de ventas & Directo. \\
Alianzas estratégicas & Aldeas infantiles, centros geriátricos, cinerama (cine). \\
\hline
\end{tabular}

Nota. Fuente: Elaboración propia. 
Tabla 156

Plan de ventas

\begin{tabular}{|c|c|c|c|c|c|c|}
\hline Objetivo & Estrategia & Táctica & Actividad & Periodo & Responsables & Medición \\
\hline $\begin{array}{l}\text { Definir una } \\
\text { estrategia de } \\
\text { precios acorde al } \\
\text { público objetivo } \\
\text { y al valor de } \\
\text { innovación del } \\
\text { proyecto }\end{array}$ & $\begin{array}{l}\text { Establecer el } \\
\text { precio de venta } \\
\text { considerando } \\
\text { costo y valor } \\
\text { agregado }\end{array}$ & $\begin{array}{l}\text { Determinar un } \\
\text { margen de } \\
\text { contribución } \\
\text { sobre el costo de } \\
\text { producción } \\
\text { unitario. }\end{array}$ & $\begin{array}{l}\text { Costeo de los } \\
\text { producto y } \\
\text { estimaciones de } \\
\text { volúmenes de } \\
\text { venta, factor } \\
\text { multiplicador de } \\
2.5\end{array}$ & Actividad pre-operativa & $\begin{array}{l}\text { Jefe de cocina y } \\
\text { producción. } \\
\text { Administrador. }\end{array}$ & $\begin{array}{l}\text { Encuestas } \\
\text { de } \\
\text { satisfacción } \\
\text { del cliente }\end{array}$ \\
\hline $\begin{array}{l}\text { Contribuir a la } \\
\text { comunidad con } \\
\text { actividades de } \\
\text { responsabilidad } \\
\text { social }\end{array}$ & $\begin{array}{c}\text { Generar alianzas } \\
\text { estratégicas con } \\
\text { empresas sin } \\
\text { fines de lucro }\end{array}$ & $\begin{array}{c}\text { Convenio con } \\
\text { Aldeas infantiles } \\
\text { Convenio con } \\
\text { Centros } \\
\text { geriátricos }\end{array}$ & $\begin{array}{c}\text { Por cada } 50 \\
\text { soles de } \\
\text { consumo está } \\
\text { donando el } 10 \% \\
\text { de su compra. }\end{array}$ & $\begin{array}{l}\text { Abril, agosto, diciembre } \\
\text { de cada año } \\
\text { Recaudación de un mes }\end{array}$ & Administrador & $\begin{array}{c}\text { Volumen } \\
\text { de } \\
\text { recaudación } \\
\text { durante los } \\
\text { periodos de } \\
\text { aplicación }\end{array}$ \\
\hline $\begin{array}{l}\text { Fidelizar a los } \\
\text { clientes }\end{array}$ & $\begin{array}{c}\text { Generar alianzas } \\
\text { estratégicas con } \\
\text { empresas del } \\
\text { sector } \\
\text { entretenimiento }\end{array}$ & $\begin{array}{l}\text { Convenio con } \\
\text { cinerama } \\
\text { imperial plaza }\end{array}$ & $\begin{array}{l}\text { Una entrada } \\
\text { gratis por } \\
\text { consumo de } \\
\text { combos } \\
\text { personales }\end{array}$ & $\begin{array}{c}\text { Febrero y noviembre año } 2 \\
\text { Febrero y noviembre año } 4 \\
\text { Stock máx. } 100 \text { und por } \\
\text { mes. }\end{array}$ & Administrador & $\begin{array}{c}\text { Tasa de } \\
\text { crecimiento } \\
\text { de las } \\
\text { ventas } \\
\text { durante los } \\
\text { periodos de } \\
\text { aplicación }\end{array}$ \\
\hline
\end{tabular}

Nota. Fuente: Elaboración propia. 
Tabla 157

Presupuesto del plan de marketing año 1 y año 2

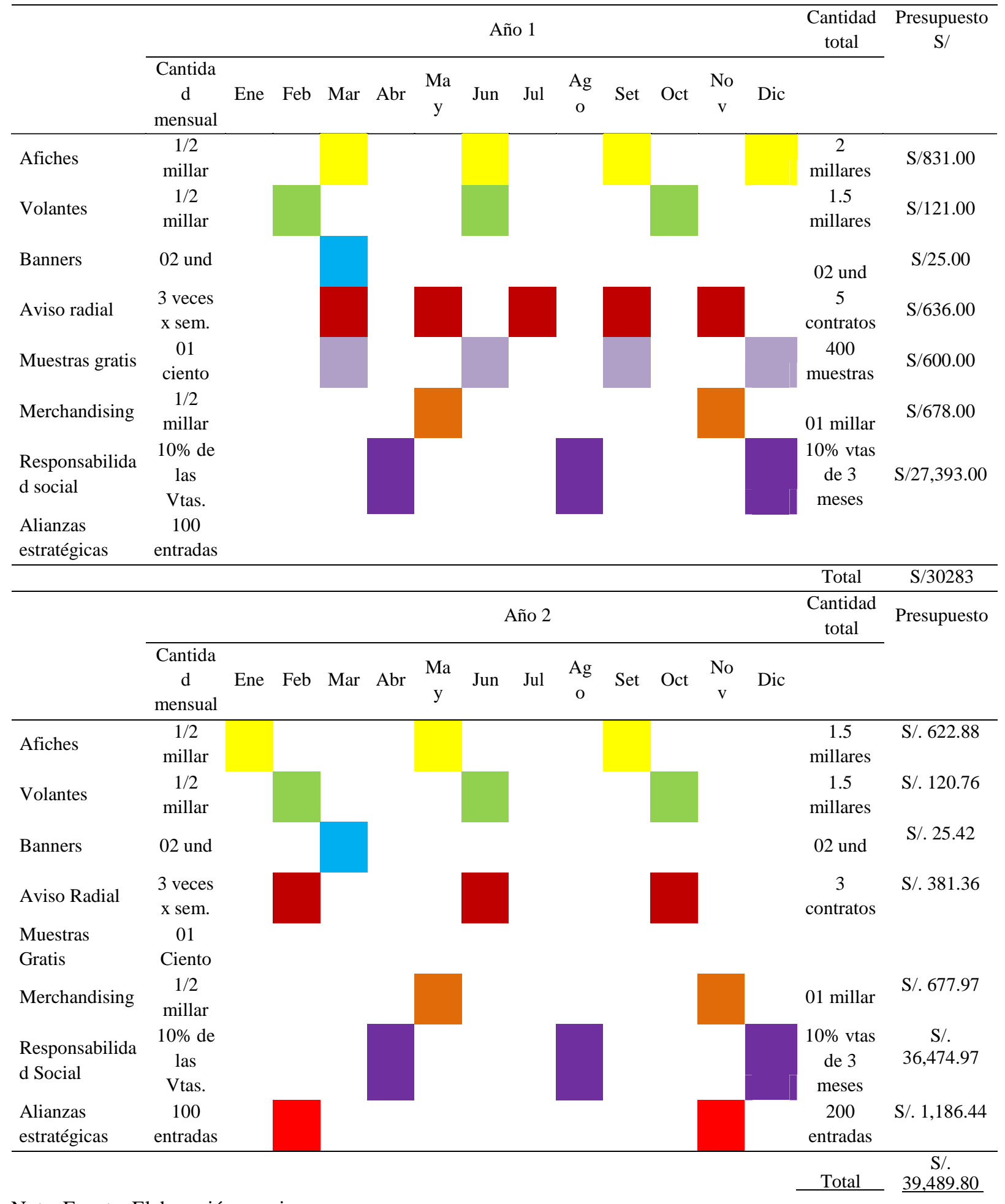

Nota. Fuente: Elaboración propia. 
Tabla 158

Presupuesto del plan de marketing Año 3 y Año 4

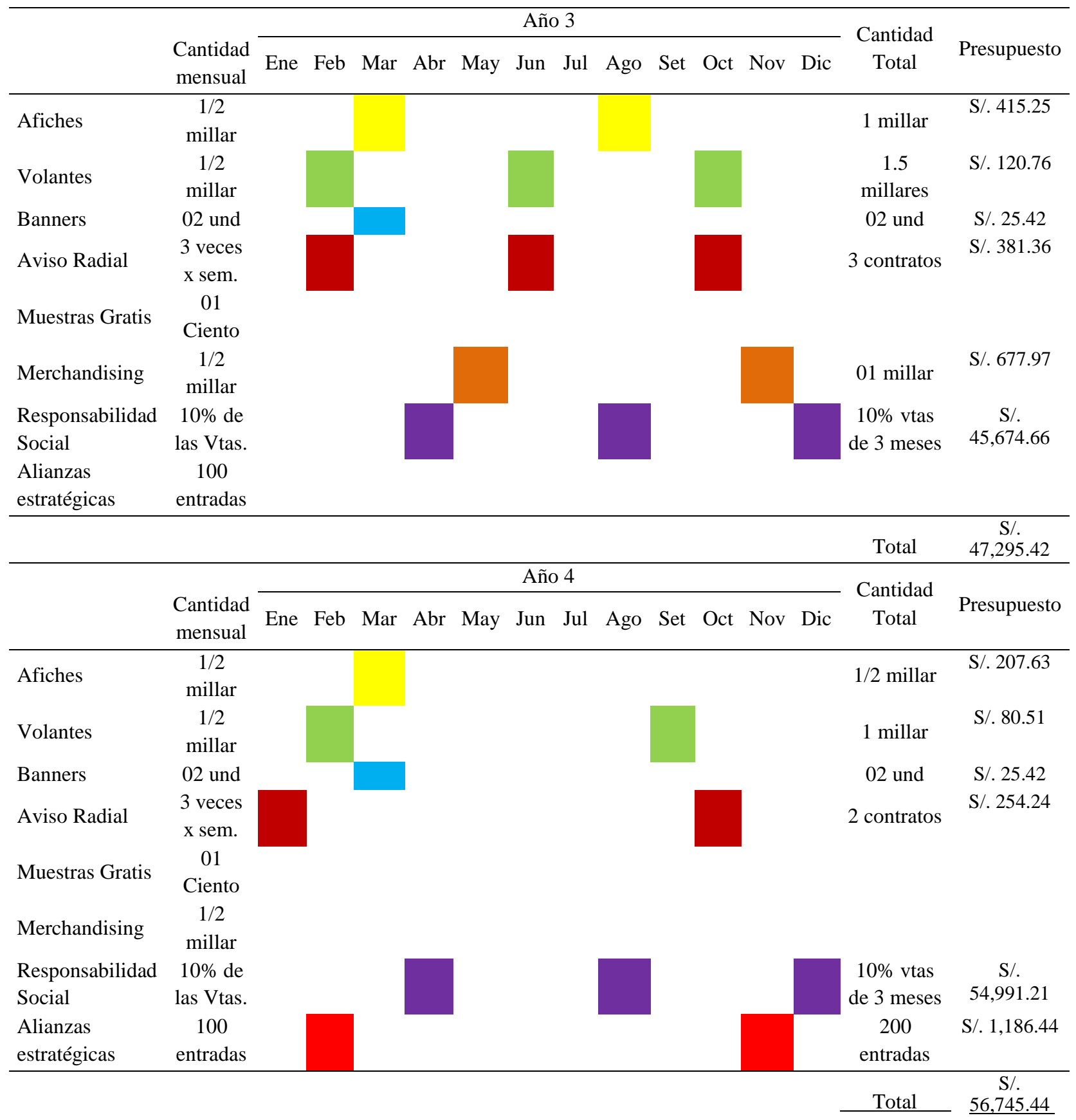

Nota. Fuente: Elaboración propia. 
Tabla 159

Presupuesto del plan de marketing Año 5

\begin{tabular}{|c|c|c|c|c|c|c|c|c|c|c|c|c|c|c|}
\hline & & & & & & & io 5 & & & & & & & \\
\hline & $\begin{array}{l}\text { Cantidad } \\
\text { mensual }\end{array}$ & Ene Feb & Mar & Abr & May & Jun & Jul & Ago & Set & Oct & Nov & Dic & Total & Presupuesto \\
\hline Afiches & $\begin{array}{c}1 / 2 \\
\text { millar }\end{array}$ & & & & & & & & & & & & $\begin{array}{c}1 / 2 \\
\text { millar }\end{array}$ & S/. 207.63 \\
\hline Volantes & $\begin{array}{c}1 / 2 \\
\text { millar }\end{array}$ & & & & & & & & & & & & 1 millar & S/. 80.51 \\
\hline Banners & 02 und & & & & & & & & & & & & 02 und & S/. 25.42 \\
\hline Aviso Radial & $\begin{array}{l}3 \text { veces } \\
\mathrm{x} \text { sem. }\end{array}$ & & & & & & & & & & & & $\begin{array}{c}2 \\
\text { contratos }\end{array}$ & S/. 254.24 \\
\hline Muestras Gratis & $\begin{array}{c}01 \\
\text { Ciento }\end{array}$ & & & & & & & & & & & & & \\
\hline Merchandising & $\begin{array}{c}1 / 2 \\
\text { millar }\end{array}$ & & & & & & & & & & & & & \\
\hline $\begin{array}{l}\text { Responsabilidad } \\
\text { Social }\end{array}$ & $\begin{array}{l}10 \% \text { de } \\
\text { las Vtas. }\end{array}$ & & & & & & & & & & & & $\begin{array}{c}10 \% \\
\text { vtas de } 3 \\
\text { meses }\end{array}$ & S/. $64,425.08$ \\
\hline $\begin{array}{l}\text { Alianzas } \\
\text { estratégicas }\end{array}$ & $\begin{array}{l}100 \\
\text { entradas }\end{array}$ & & & & & & & & & & & & & \\
\hline
\end{tabular}

Nota. Fuente: Elaboración propia.

\subsubsection{Política de servicios y garantías.}

Las políticas de servicio son las orientaciones, comportamientos y procedimientos que una empresa debe tomar en cuenta al momento de brindar atención al cliente. Las políticas de servicio ayudan a mantener una estandarización en los procesos de atención al cliente, así mismo mediante las políticas, el cliente está informado acerca de aquello que tiene que esperar de la empresa. 
Para realizar las políticas de servicio se debe considerar los siguientes pasos:

- Definir los objetivos a los que se quiere llegar, como el trato cordial, la forma de comunicarse y transmitir el mensaje a los clientes.

- Evaluación de la competencia, en la cual se hace una evaluación de las políticas de la competencia las cuales servirán para determinar las propias políticas y lo más interesante es que se puede aprovechar ello para darle un valor agregado a las políticas de la empresa propia.

- Documentar los procedimientos, para tener de forma más clara los detalles y actividades que cada colaborador debe cumplir para ofrecer un buen servicio al cliente.

- Evaluación, para este penúltimo paso es necesario poner a prueba todo aquello que se ha plasmado mediante un documento para obtener resultados realistas e identificar fallas en el proceso si es que las hubiera.

- Publicación, luego de "corregir las fallas encontradas en el proceso sigue el paso de la publicación de las políticas, es decir, dar a conocer a todos los colaboradores mediante charlas o capacitaciones para su posterior aplicación y mantener a un cliente satisfecho." (Safi, 2014)

A continuación se detalla la política de servicio al cliente definido para el presente proyecto, según Tabla 160. 
Tabla 160

Políticas de servicio

Políticas

Calidad de servicio

Relación con el cliente

Protección del cliente

Gestión de reclamos

Promesas cumplidas

Actitud del personal de servicio

Infraestructura
Comprometidos y enfocados en la satisfacción del cliente en concordancia con la cultura y principios institucionales.

Construcción de relaciones sólidas y de largo plazo con los clientes, pendientes a sus necesidades y brindando un trato amable y cordial.

Preservar la salud e integridad de los clientes con productos de calidad y cuidando la higiene y salubridad de todos los ambientes y procesos productivos.

Estar en constante contacto con los clientes, aplicar la escucha activa y garantizar que sientan que sus sugerencias o reclamos son tomados en cuenta.

Brindar productos de calidad y garantía, asegurando que el cliente vea que está consumiendo productos que contribuyen al desarrollo de su comunidad y cuidado de su salud. Colaboradores con actitud proactiva, trato amable, cordial y con vocación de servicio.

Instalación amplia, limpia y adecuada con todas las facilidades de acceso a los clientes. 


\section{Capítulo VIII}

\section{Planificación Financiera}

La planeación financiera establece la manera de cómo se lograrán las metas, es la base de toda la actividad económica de la empresa. Ayuda a mitigar las necesidades futuras de modo que las presentes puedan ser satisfechas de acuerdo a un fin determinado que se establece en las acciones de la empresa.

Morales Castro \& Morales Castro (2014) señalo que para desarrollar las actividades de corto y largo plazo se necesita proporcionar los activos de maquinaria, equipo, capital de trabajo, etc., de tal manera que se desarrollan dos actividades fundamentales el financiamiento y la inversión.

\subsection{La inversión.}

La inversión es todo aquel desembolso de recursos financieros para adquirir bienes concretos o instrumentos de producción que la empresa utilizará durante varios años para el logro de sus objetivos, así como también engloba la adquisición de mercaderías, materias primas, de consumo y prestaciones de servicio al personal y terceros.

"Una empresa incrementa sus inversiones cuando adquiere maquinaria o cuando amplía su producción, sus instalaciones o sus centros de venta.” (Iborra, Dasí, Dolz, \& Ferrer, 2014). 
Para el presente estudio, la inversión está representada por los activos fijos y activos intangibles que demanda el proyecto, así como el capital de trabajo necesario para iniciar las operaciones del establecimiento, además de los gastos pre-operativos.

\subsubsection{Gastos pre-operativos.}

La mayoría de gastos iniciales en un proyecto están concentrados en aquellos que se realizan antes del inicio de la operación, constituyen lo que los textos denominan calendario de inversiones previas a la puesta en marcha. (Sapag Chain, 2011)

Para el caso del proyecto los gastos pre-operativos se dan dos meses antes del inicio de operaciones, con la contratación del personal y la implementación del local. Conforme Tabla 161 se detalla los gastos pre-operativos.

Tabla 161

Gastos pre-operativos del proyecto 


\begin{tabular}{|c|c|}
\hline Gastos Pre-operativos & Año 0 \\
\hline Costos de producción & S/. 32,900.10 \\
\hline Total cif & S/. 14,067.06 \\
\hline Botiquín & S/. 70.99 \\
\hline Otros útiles de aseo & S/. 8,056.76 \\
\hline Útiles de cocina & S/. $4,876.00$ \\
\hline Gas & S/. 565.00 \\
\hline Uniformes & S/. 498.31 \\
\hline Total mano de obra & S/. $18,833.05$ \\
\hline Mano de obra directa & S/. $12,258.54$ \\
\hline Mano de obra indirecta & S/. 6,574.51 \\
\hline Gastos generales & S/. 50,969.79 \\
\hline Total gastos adm & S/. $40,117.17$ \\
\hline Planilla & S/. $12,865.42$ \\
\hline Telefonía más internet & S/. 750.00 \\
\hline Servicio de agua & S/. 2,447.00 \\
\hline Servicio de luz & S/. 4,322.76 \\
\hline Uniformes & S/. 762.71 \\
\hline Útiles de oficina & S/. 2,627.28 \\
\hline Investigación de mercado & S/. $1,342.00$ \\
\hline Alquiler & S/. $15,000.00$ \\
\hline Total gastos vtas & S/. $10,852.63$ \\
\hline Marketing y publicidad & S/. 210.00 \\
\hline Web master & S/. $1,950.00$ \\
\hline Planilla ventas & S/. $1,933.75$ \\
\hline Utensilios descartables & S/. 675.89 \\
\hline Servilletas & S/. 405.53 \\
\hline Bolsas blancas $16 \times 19$ & S/. 5,677.46 \\
\hline Total costos y gastos pre-operativo & S/. 83,869.90 \\
\hline
\end{tabular}
Nota. Fuente: Elaboración propia.

Del mismo modo, las inversiones en Activos intangibles y Activos tangibles también se llevaran a cabo como parte de los gastos pre-operativos del proyecto, conformes Tabla 162 y Tabla 163. 
Tabla 162

Inversiones en Activos Intangibles

\begin{tabular}{lcccc}
\hline \multicolumn{1}{c}{ Activos intangibles } & Cantidad & $\begin{array}{c}\text { Costo } \\
\text { unitario }\end{array}$ & Total & Amortización \\
\hline Licencia de funcionamiento & 1 & S/. 645.00 & S/. 645.00 \\
Elaboración de la minuta & 1 & S/. 350.00 & S/. 350.00 \\
Escritura pública por notario & 1 & S/. 250.00 & S/. 250.00 \\
Costo de registros públicos & 1 & S/. 374.00 & S/. 374.00 \\
Derecho de tramite & 1 & S/. 84.00 & S/. 84.00 \\
Costo de libros contables & 1 & S/. 50.00 & S/. 50.00 \\
Minuta & 1 & S/. 220.00 & S/. 220.00 \\
Sunarp & 1 & S/. 393.00 & S/. 393.00 \\
Remodelación del Local & & S/. 23,590.00 & S/. 23,590.00 \\
Gastos pre-operativos & & S/. 83,869.90 & S/. 83,869.90 \\
Software Administrativo & 1 & S/. 983.05 & S/. 983.05 & S/. 22, 161.79 \\
Total intangibles & & S/. 110,808.95 &
\end{tabular}

Conforme Tabla 87, Tabla 88 y Tabla 89 se determinó el requerimiento de equipos y maquinarias necesarias para el proyecto en base a ello se elaboró Tabla 163 y Tabla 164 donde se define la inversión Total de equipos y maquinarias por áreas además de su respectiva depreciación y valor de rescate o desecho futuro. 


\section{Tabla 163}

\section{Inversión Activo Tangible A}

\begin{tabular}{|c|c|c|c|c|c|c|c|c|c|c|c|c|}
\hline \multirow[b]{2}{*}{ Área de Producción } & \multirow{2}{*}{$\begin{array}{c}\text { Cant } \\
.\end{array}$} & Costo & Tasa & años & Deprec & al $5^{\circ}$ año & v.libros & $\begin{array}{l}\mathrm{v} . \\
\text { reventa }\end{array}$ & valor & VM - VL & $29.5 \%$ & Valor \\
\hline & & $\begin{array}{c}\text { adquisició } \\
n\end{array}$ & $\begin{array}{c}\text { Deprec } \\
.\end{array}$ & $\begin{array}{c}\text { Vid } \\
\text { a } \\
\text { útil }\end{array}$ & anual & dep acum & $\begin{array}{c}\text { v.residua } \\
1\end{array}$ & $\begin{array}{c}\text { v.salva } \\
\mathrm{m}\end{array}$ & mercado & $\begin{array}{l}\text { Util / } \\
\text { Perd }\end{array}$ & $\mathrm{IR} / \mathrm{EF}$ & Desecho \\
\hline Cocina industrial 3 hornillas & 1 & $\begin{array}{c}\mathrm{S} / . \\
1,101.69\end{array}$ & $10 \%$ & 10 & $\begin{array}{c}\text { S/. } \\
110.17\end{array}$ & $\begin{array}{c}\mathrm{S} / . \\
550.85\end{array}$ & $\begin{array}{c}\mathrm{S} / . \\
550.85\end{array}$ & $35 \%$ & $\begin{array}{c}\text { S/. } \\
385.59\end{array}$ & $\begin{array}{c}-S / . \\
165.25\end{array}$ & $\begin{array}{c}-\mathrm{S} / . \\
48.75\end{array}$ & $\begin{array}{c}\text { S/. } \\
434.34\end{array}$ \\
\hline Freidora & 1 & S/. 932.20 & $10 \%$ & 10 & $\begin{array}{c}\mathrm{S} / . \\
93.22\end{array}$ & $\begin{array}{c}\mathrm{S} / . \\
466.10\end{array}$ & $\begin{array}{c}\mathrm{S} / . \\
466.10\end{array}$ & $35 \%$ & $\begin{array}{c}\mathrm{S} / . \\
326.27\end{array}$ & $\begin{array}{c}-S / . \\
139.83\end{array}$ & $\begin{array}{c}-\mathrm{S} / . \\
41.25\end{array}$ & $\begin{array}{c}\mathrm{S} / . \\
367.52\end{array}$ \\
\hline Plancha de Hamburguesas & 1 & $\begin{array}{c}\mathrm{S} / . \\
1,016.95\end{array}$ & $10 \%$ & 10 & $\begin{array}{c}\text { S/. } \\
101.69\end{array}$ & $\begin{array}{c}\text { S/. } \\
508.47\end{array}$ & $\begin{array}{c}\text { S/. } \\
508.47\end{array}$ & $35 \%$ & $\begin{array}{c}\text { S/. } \\
355.93\end{array}$ & $\begin{array}{c}-\mathrm{S} / . \\
152.54\end{array}$ & $\begin{array}{c}-\mathrm{S} / . \\
45.00\end{array}$ & $\begin{array}{c}\text { S/. } \\
400.93\end{array}$ \\
\hline Horno para carnes & 1 & $\begin{array}{c}\text { S/. } \\
1,271.19\end{array}$ & $20 \%$ & 10 & $\begin{array}{c}\text { S/. } \\
254.24\end{array}$ & $\begin{array}{c}\text { S/. } \\
1,271.19\end{array}$ & S/. 0.00 & $35 \%$ & $\begin{array}{c}\text { S/. } \\
444.92\end{array}$ & $\begin{array}{c}\text { S/. } \\
444.92\end{array}$ & $\begin{array}{c}\text { S/. } \\
131.25\end{array}$ & $\begin{array}{c}\text { S/. } \\
313.67\end{array}$ \\
\hline Congeladora & 1 & $\begin{array}{c}\text { S/. } \\
2,118.64\end{array}$ & $10 \%$ & 10 & $\begin{array}{c}\text { S/. } \\
211.86\end{array}$ & $\begin{array}{c}\text { S/. } \\
1,059.32\end{array}$ & $\begin{array}{c}\text { S/. } \\
1,059.32\end{array}$ & $30 \%$ & $\begin{array}{c}\text { S/. } \\
635.59\end{array}$ & $\begin{array}{c}-S / . \\
423.73\end{array}$ & $\begin{array}{c}-\mathrm{S} / . \\
125.00\end{array}$ & $\begin{array}{c}\text { S/. } \\
760.59\end{array}$ \\
\hline Refrigerador Conservador & 1 & $\begin{array}{c}\text { S/. } \\
2,415.25\end{array}$ & $10 \%$ & 10 & $\begin{array}{c}\text { S/. } \\
241.53\end{array}$ & $\begin{array}{c}\text { S/. } \\
1,207.63\end{array}$ & $\begin{array}{c}\text { S/. } \\
1,207.63\end{array}$ & $30 \%$ & $\begin{array}{c}\text { S/. } \\
724.58\end{array}$ & $\begin{array}{c}-S / . \\
483.05\end{array}$ & $\begin{array}{c}-\mathrm{S} / . \\
142.50\end{array}$ & $\begin{array}{c}\text { S/. } \\
867.08\end{array}$ \\
\hline Horno microondas & 1 & S/. 334.75 & $10 \%$ & 5 & $\begin{array}{c}\text { S/. } \\
33.47\end{array}$ & $\begin{array}{c}\text { S/. } \\
167.37\end{array}$ & $\begin{array}{c}\text { S/. } \\
167.37\end{array}$ & $20 \%$ & S/. 66.95 & $\begin{array}{c}-S / . \\
100.42\end{array}$ & $\begin{array}{c}-\mathrm{S} / . \\
29.63\end{array}$ & S/. 96.57 \\
\hline Balanza electrónica & 2 & S/. 254.24 & $10 \%$ & 5 & $\begin{array}{c}\mathrm{S} / . \\
25.42\end{array}$ & $\begin{array}{c}\text { S/. } \\
127.12\end{array}$ & $\begin{array}{c}\text { S/. } \\
127.12\end{array}$ & $30 \%$ & S/. 76.27 & $\begin{array}{c}-\mathrm{S} / . \\
50.85\end{array}$ & $\begin{array}{c}-\mathrm{S} / . \\
15.00\end{array}$ & S/. 91.27 \\
\hline $\begin{array}{l}\text { Mesas de trabajo de acero } \\
\text { inoxidable }\end{array}$ & 1 & S/. 762.71 & $10 \%$ & 5 & $\begin{array}{c}\text { S/. } \\
76.27\end{array}$ & $\begin{array}{c}\mathrm{S} / . \\
381.36\end{array}$ & $\begin{array}{c}\mathrm{S} / . \\
381.36\end{array}$ & $30 \%$ & $\begin{array}{c}\mathrm{S} / . \\
228.81\end{array}$ & $\begin{array}{c}-\mathrm{S} / . \\
152.54\end{array}$ & $\begin{array}{c}-\mathrm{S} / . \\
45.00\end{array}$ & $\begin{array}{c}\text { S/. } \\
273.81\end{array}$ \\
\hline $\begin{array}{l}\text { Repisas de acero inoxidable de } 4 \\
\text { niveles }\end{array}$ & 1 & S/. 762.71 & $10 \%$ & 5 & $\begin{array}{c}\text { S/. } \\
76.27\end{array}$ & $\begin{array}{c}\text { S/. } \\
381.36\end{array}$ & $\begin{array}{c}\text { S/. } \\
381.36\end{array}$ & $30 \%$ & $\begin{array}{c}\text { S/. } \\
228.81\end{array}$ & $\begin{array}{c}-\mathrm{S} / . \\
152.54\end{array}$ & $\begin{array}{c}-\mathrm{S} / . \\
45.00\end{array}$ & $\begin{array}{c}\text { S/. } \\
273.81\end{array}$ \\
\hline Trampa de grasa con malla & 1 & $\begin{array}{c}\text { S/. } \\
1,347.46\end{array}$ & $10 \%$ & 5 & $\begin{array}{c}\mathrm{S} / . \\
134.75\end{array}$ & $\begin{array}{c}\text { S/. } \\
673.73\end{array}$ & $\begin{array}{c}\text { S/. } \\
673.73\end{array}$ & $35 \%$ & $\begin{array}{c}\text { S/. } \\
471.61\end{array}$ & $\begin{array}{c}-\mathrm{S} / . \\
202.12\end{array}$ & $\begin{array}{c}-\mathrm{S} / . \\
59.63\end{array}$ & $\begin{array}{c}\text { S/. } \\
531.24\end{array}$ \\
\hline Extintor de cocina tipo $\mathrm{K}, 2.5 \mathrm{gl}$ & 1 & S/. 296.61 & & & & & & & & & & \\
\hline Total Año & & $\begin{array}{c}\mathrm{S} / . \\
12,614.41\end{array}$ & & & $\begin{array}{c}\mathrm{S} / . \\
1,358.9 \\
0\end{array}$ & $\begin{array}{c}\mathrm{S} / . \\
6,794.49\end{array}$ & $\begin{array}{c}\mathrm{S} / . \\
5,523.31\end{array}$ & & $\begin{array}{c}\text { S/. } \\
3,945.34\end{array}$ & $\begin{array}{c}-\mathrm{S} / . \\
1,577.97\end{array}$ & $\begin{array}{c}-\mathrm{S} / . \\
465.50\end{array}$ & $\begin{array}{c}\text { S/. } \\
4,410.84\end{array}$ \\
\hline
\end{tabular}

Nota. Fuente: Elaboración propia. 


\section{Tabla 164}

\section{Inversión Activo Tangible B}

\begin{tabular}{|c|c|c|c|c|c|c|c|c|c|c|c|c|}
\hline \multirow[b]{2}{*}{ Área de Administración } & \multirow[b]{2}{*}{ Cant. } & Costo & Tasa & años & Deprec & al $5^{\circ}$ año & v.libros & v. reventa & valor & VM - VL & $29.5 \%$ & Valor \\
\hline & & adquisición & Deprec. & $\begin{array}{l}\text { Vida } \\
\text { útil }\end{array}$ & anual & dep acum & v.residual & v.salvam & mercado & Util / Perd & $\mathrm{IR} / \mathrm{EF}$ & Desecho \\
\hline Silla giratorio & 1 & S/. 152.54 & $10 \%$ & 5 & S/. 15.25 & S/. 76.27 & S/. 76.27 & $20 \%$ & S/. 30.51 & $-\mathrm{S} / .45 .76$ & $-S / .13 .50$ & S/. 44.01 \\
\hline Escritorio & 1 & S/. 296.61 & $10 \%$ & 5 & S/. 29.66 & S/. 148.31 & S/. 148.31 & $20 \%$ & S/. 59.32 & $-\mathrm{S} / .88 .98$ & $-\mathrm{S} / .26 .25$ & S/. 85.57 \\
\hline Computadora & 1 & S/. 1,016.95 & $25 \%$ & 4 & $\begin{array}{c}\text { S/. } \\
254.24\end{array}$ & $\begin{array}{c}\mathrm{S} / . \\
1,016.95\end{array}$ & S/. 0.00 & $10 \%$ & S/. 101.69 & S/. 101.69 & S/. 30.00 & S/. 71.69 \\
\hline Extintor $\mathrm{ABC}$ de $6 \mathrm{Kg}$ & 1 & S/. 59.32 & & & & & & & & & & \\
\hline Total & & S/. $1,525.42$ & & & $\begin{array}{c}\text { S/. } \\
299.15\end{array}$ & $\begin{array}{c}\mathrm{S} / . \\
1,241.53\end{array}$ & S/. 224.58 & & S/. 191.53 & $-\mathrm{S} / .33 .05$ & $-\mathrm{S} / .9 .75$ & S/. 201.28 \\
\hline \multirow[b]{2}{*}{ Área de Ventas } & \multirow[b]{2}{*}{ Cant. } & Costo & Tasa & años & Deprec & al $5^{\circ}$ año & v.libros & v. reventa & valor & VM - VL & $29.5 \%$ & Valor \\
\hline & & adquisición & Deprec. & $\begin{array}{l}\text { Vida } \\
\text { útil }\end{array}$ & anual & dep acum & v.residual & v.salvam & mercado & Util / Perd & $\mathrm{IR} / \mathrm{EF}$ & Desecho \\
\hline Dispensador de salsas & 1 & S/. 1,186.44 & $10 \%$ & 5 & $\begin{array}{c}\mathrm{S} / . \\
118.64\end{array}$ & S/. 593.22 & S/. 593.22 & $30 \%$ & S/. 355.93 & $\begin{array}{c}-\mathrm{S} / . \\
237.29\end{array}$ & $-\mathrm{S} / .70 .00$ & S/. 425.93 \\
\hline Juego de sillas y mesas & 9 & S/. 4,652.54 & $10 \%$ & 5 & $\begin{array}{c}\mathrm{S} / . \\
465.25\end{array}$ & $\begin{array}{c}\text { S/. } \\
2,326.27\end{array}$ & $\begin{array}{c}\text { S/. } \\
2,326.27\end{array}$ & $25 \%$ & $\begin{array}{c}\mathrm{S} / . \\
1,163.14\end{array}$ & $\begin{array}{c}-\mathrm{S} / \\
1,163.14\end{array}$ & $\begin{array}{c}-\mathrm{S} / . \\
343.13\end{array}$ & $\begin{array}{c}\mathrm{S} / . \\
1,506.26\end{array}$ \\
\hline $\begin{array}{l}\text { Mostradores barra mostrador estilo } \\
\text { colonial madera maciza }\end{array}$ & 1 & S/. $1,949.15$ & $10 \%$ & 5 & $\begin{array}{c}\text { S/. } \\
194.92\end{array}$ & S/. 974.58 & S/. 974.58 & $30 \%$ & S/. 584.75 & $\begin{array}{c}-\mathrm{S} / . \\
389.83\end{array}$ & $\begin{array}{c}-\mathrm{S} / . \\
115.00\end{array}$ & S/. 699.75 \\
\hline $\begin{array}{l}\text { Caja Registradora Computarizada Punto } \\
\text { de Venta Táctil Touch incluye software } \\
\text { RESTPROCES - SYSCOPERU }\end{array}$ & 1 & S/. 2,844.07 & $25 \%$ & 4 & $\begin{array}{c}\text { S/. } \\
711.02\end{array}$ & $\begin{array}{c}\mathrm{S} / . \\
2,844.07\end{array}$ & S/. 0.00 & $10 \%$ & S/. 284.41 & S/. 284.41 & S/. 83.90 & S/. 200.51 \\
\hline Aparadores de bebidas & 2 & S/. 2,033.90 & $10 \%$ & 5 & $\begin{array}{c}\text { S/. } \\
203.39\end{array}$ & $\begin{array}{c}\mathrm{S} / . \\
1,016.95\end{array}$ & $\begin{array}{c}\text { S/. } \\
1,016.95\end{array}$ & $25 \%$ & S/. 508.47 & $\begin{array}{c}-\mathrm{S} / . \\
508.47\end{array}$ & $\begin{array}{c}-\mathrm{S} / . \\
150.00\end{array}$ & S/. 658.47 \\
\hline Extintor $\mathrm{ABC}$ de $6 \mathrm{Kg}$ & 1 & S/. 59.32 & & & & & & & & & & \\
\hline Total & & $\begin{array}{c}\mathrm{S} / . \\
12,725.42\end{array}$ & & & $\begin{array}{c}\mathrm{S} / . \\
1,693.22\end{array}$ & $\begin{array}{c}\mathrm{S} / . \\
7,755.08\end{array}$ & $\begin{array}{c}\mathrm{S} / . \\
4,911.02\end{array}$ & & $\begin{array}{c}\mathrm{S} / . \\
2,896.69\end{array}$ & $\begin{array}{c}-\mathrm{S} / . \\
2,014.32\end{array}$ & $\begin{array}{c}-\mathrm{S} / . \\
594.23\end{array}$ & $\begin{array}{c}\mathrm{S} / . \\
3,490.92\end{array}$ \\
\hline
\end{tabular}

Nota. Fuente: Elaboración propia. 


\subsubsection{Inversión en capital de trabajo.}

Una inversión muy importante para el éxito o fracaso de una organización es la que se hace en capital de trabajo.

El proyecto puede considerar la inversión en activos fijos necesario para poder funcionar adecuadamente, pero si no contempla la inversión en capital de trabajo para financiar los errores o desfases de caja durante su operación es probable que fracase. (Sapag Chain, Proyectos de Inverion Formulacion y Evaluacion, 2014)

Para el presente estudio el capital de trabajo está constituido por la cantidad de dinero necesaria para cubrir los activos corrientes necesarios para la operatividad del mismo.

En este caso al ser un negocio de restaurantes se asume una rotación de efectivo semanal debido a que los insumos son altamente perecederos y demandan una alta rotación de los mismos, además de no contar con información estadística de estacionalidad de las ventas en empresas iguales o similares en la Región.

En base a dicha premisa se elabora el capital de Trabajo conforme se detalla en Tabla 166, cabe considerar que se asume que no se cuenta con ingresos la primera semana por temas de inauguración y las ventas y egresos proyectados del año 2019 se deben estimar de forma semanal, conforme Tabla 165, para la elaboración del capital de trabajo se utilizó el método del déficit acumulado semanal. 
Llevado a cabo el análisis se obtuvo como capital de trabajo S/ 13,413.98 soles, al cual se agrega el monto mínimo para dar vuelto a los clientes de S/.3, 500 soles, haciendo un capital de trabajo Total de S/. 16,913.98.

Tabla 165

Ingresos y Egresos semanales

\begin{tabular}{lccc}
\hline & Año & Mes & Semana \\
\hline Ingresos 2019 & S/753,529.11 & S/62,794.09 & S/15,698.52 \\
\hline Egresos 2019 & & & \\
Materia Prima & $\mathrm{S} / 318,448.39$ & $\mathrm{~S} / 26,537.37$ & $\mathrm{~S} / 6,634.34$ \\
Mano de Obra directa & $\mathrm{S} / 112,998.27$ & $\mathrm{~S} / 9,416.52$ & $\mathrm{~S} / 2,354.13$ \\
Costos indirectos fabricación & $\mathrm{S} / 14,887.59$ & $\mathrm{~S} / 1,240.63$ & $\mathrm{~S} / 310.16$ \\
Gastos Administrativos y Ventas & $\mathrm{S} / 197,536.88$ & $\mathrm{~S} / 16,461.41$ & $\mathrm{~S} / 4,115.35$ \\
\hline
\end{tabular}

Nota. Fuente: Elaboración propia. 


\section{Tabla 166}

\section{Capital de trabajo del proyecto}

\begin{tabular}{|c|c|c|c|c|c|c|}
\hline Concepto / Sem & & Sem 1 & Sem2 & Sem3 & Sem4 & \\
\hline Total Ingresos & & S/. 0.00 & S/. $15,698.52$ & S/. $15,698.52$ & S/. $15,698.52$ & \\
\hline \multicolumn{7}{|l|}{ Egresos } \\
\hline Costos de materia prima & & S/. $6,634.34$ & S/. 6,634.34 & S/. 6,634.34 & S/. 6,634.34 & \\
\hline Costo de mano obra directa & & S/. $2,354.13$ & S/. $2,354.13$ & S/. $2,354.13$ & S/. 2,354.13 & \\
\hline Costos indirectos fabricación & & S/. 310.16 & S/. 310.16 & S/. 310.16 & S/. 310.16 & \\
\hline Gastos Admin. y Ventas & & S/. 4,115.35 & S/. 4,115.35 & S/. 4,115.35 & S/. 4,115.35 & \\
\hline Pago a cta. Imp. a la Renta & $1.5 \%$ & & S/. 0.00 & S/. 235.48 & S/. 235.48 & \\
\hline Total Egresos & & S/. $13,413.98$ & S/. $13,413.98$ & S/. 13,649.46 & S/. 13,649.46 & \\
\hline Flujo de Operaciones & & $-\mathrm{S} / .13,413.98$ & S/. 2,284.54 & S/. 2,049.06 & S/. 2,049.06 & \\
\hline Flujo Acumulado & & $-\mathrm{S} / .13,413.98$ & $-\mathrm{S} / .11,129.44$ & $-\mathrm{S} / .9,080.38$ & $-\mathrm{S} / .7,031.31$ & \\
\hline Capital de Trabajo & -S/. 13,413.98 & & & & & \\
\hline Caja min. Vuelto Clientes sem. & S/. 3,500.00 & & & & & \\
\hline Capital de trabajo anual & Año 0 & A1 & A2 & A3 & A4 & A5 \\
\hline Ventas & & S/. 753,529.11 & S/. 1,004,505.34 & S/. $1,259,274.84$ & S/. $1,517,831.49$ & S/. $1,780,184.78$ \\
\hline Req KW & $2.24 \%$ & S/. $16,913.98$ & S/. 22,547.48 & S/. $28,266.13$ & S/. $34,069.78$ & S/. 39,958.66 \\
\hline Tasa de crecimiento Ventas & & & $33.31 \%$ & $25.36 \%$ & $20.53 \%$ & $17.28 \%$ \\
\hline Variaciones & & S/. $16,913.98$ & S/. 5,633.50 & S/. 5,718.65 & S/. 5,803.65 & S/. 5,888.88 \\
\hline Inv. KW & -S/. 16,913.98 & $-S / .5,633.50$ & $-S / .5,718.65$ & $-S / .5,803.65$ & $-\mathrm{S} / .5,888.88$ & S/. 0.00 \\
\hline
\end{tabular}

Nota. Fuente: Elaboración propia. 


\subsubsection{Costo del proyecto.}

"Estimar los costos del proyecto consiste en desarrollar una aproximación de los recursos monetarios necesarios para completar las actividades del plan. La estimación de costos es una predicción que se basa en la información disponible en un momento dado.” (Sánchez, n.d)

Para la determinación de los costos del proyecto se estimaron en primer lugar las inversiones en activo fijo y en activo intangible además del capital de trabajo del negocio conforme se presenta en Tabla 167, con la suma de estos se determinó el costo total del proyecto.

Tabla 167

Costo del proyecto

\begin{tabular}{lcc}
\hline \multicolumn{1}{c}{ Descripción } & Inversión Total & \\
\hline & & Monto \\
\hline Inversión Activo Fijo Tangible & $\mathrm{S} / .26,865.25$ & $17.38 \%$ \\
Inversión Activo Intangible & $\mathrm{S} / .110,808.95$ & $71.68 \%$ \\
Capital de Trabajo & $\mathrm{S} / .16,913.98$ & $10.94 \%$ \\
\hline Total S/. & $\mathrm{S} / .154,588.19$ & $100.00 \%$ \\
\hline
\end{tabular}

Nota. Fuente: Elaboración propia.

\subsubsection{Inversiones futuras.}

Son las inversiones previstas para la implementación del negocio referido a maquinarias, equipos y otros bienes para la producción del negocio. Incluye los costos de reposición durante la etapa de operación del proyecto. 
Las inversiones futuras que se realizarán en el proyecto corresponden a la estructura del capital que se piensa aplicar, el cual se detalla en Tabla 168.

Tabla 168

Estructura de capital del proyecto

Estructura de capital y prestamos

Inversiones/Fuente Total Capital Propio Préstamo

\begin{tabular}{lccc}
\hline I.- Activos fijos tangibles & S/. 26,865.25 & & S/. 26,865.25 \\
Activos fijos del Área Producción & S/. 12,614.41 & S/. 12,614.41 \\
Activos fijos del Área Administración & S/. 1,525.42 & S/. 1,525.42 \\
Activos fijos del Área Ventas & S/. 12,725.42 & & S/. 12,725.42 \\
\hline II.-Activos fijos intangibles & S/. 110,808.95 & S/. 110,808.95 & \\
\hline Total inversión Fija: I+II & S/. 137,674.20 & S/. 110,808.95 & S/. 26,865.25 \\
\hline III.- KW & S/. 16,913.98 & & S/. 16,913.98 \\
\hline Inversión Total & S/. 154,588.19 & S/. 110,808.95 & S/. 43,779.24 \\
Participación financiamiento & $100 \%$ & $71.68 \%$ & $28.32 \%$
\end{tabular}

Nota. Fuente: Elaboración propia.

\subsection{Financiamiento.}

Financiamiento está referido al conjunto de recursos monetarios y de crédito que se destinan a una empresa, organización, actividad para que estos lleven a cabo una determinada actividad o concreten algún proyecto, uno de los más habituales es la apertura de un nuevo negocio. (Definicionabc, Definición de Financiamiento, n.d) 


\subsubsection{Endeudamiento y condiciones.}

El endeudamiento son los recursos de capital adquiridos mediante crédito para fines de inversión y costos de operación, estas inversiones están sujetas a condiciones que determinan las entidades que otorgan el préstamo, estas condiciones están referidas a plazos de amortización, intereses, periodos de gracia.

Para el presente proyecto se prevé financiar S/. 43,779.24 soles a 2 años a través de un Crédito de la Cooperativa Santo Domingo de Guzmán quienes ofrecen una TCEA de $36.03 \%$ a través de un préstamo empresarial.

A continuación, conforme Tabla 169 se presenta el esquema de financiamiento del préstamo que se solicitará para el proyecto, estableciendo una cuota de S/ 2,474.23 soles. 
Tabla 169

Financiamiento del proyecto

\begin{tabular}{|c|c|c|c|c|}
\hline Monto s/. & $43,779.24$ & & & \\
\hline Tea & $36.03 \%$ & & & \\
\hline Tem & $2.60 \%$ & & & \\
\hline Periodos & 24 & & & \\
\hline Modalidad & Cuotas fijas & & & \\
\hline Servicio deuda & $\mathrm{A} 0$ & A1 & A2 & \\
\hline Préstamo & S/. 43,779.24 & & & \\
\hline Cuota & & -S/. 29,690.74 & -S/. 29,690.74 & \\
\hline Amortización & & $-\mathrm{S} / .18,548.17$ & $-\mathrm{S} / .25,231.07$ & \\
\hline Intereses & & $-S / .11,142.58$ & $-S / .4,459.67$ & \\
\hline Escudo fiscal & & S/. 3,287.06 & S/. 1,315.60 & \\
\hline Mes & Saldo & Intereses & Amortización & Cuota \\
\hline 0 & $43,779.24$ & & & \\
\hline 1 & $42,442.12$ & $1,137.11$ & $1,337.12$ & $2,474.23$ \\
\hline 2 & $41,070.27$ & $1,102.38$ & $1,371.85$ & $2,474.23$ \\
\hline 3 & $39,662.78$ & $1,066.75$ & $1,407.48$ & $2,474.23$ \\
\hline 4 & $38,218.74$ & $1,030.19$ & $1,444.04$ & $2,474.23$ \\
\hline 5 & $36,737.20$ & 992.68 & $1,481.55$ & $2,474.23$ \\
\hline 6 & $35,217.17$ & 954.20 & $1,520.03$ & $2,474.23$ \\
\hline 7 & $33,657.66$ & 914.72 & $1,559.51$ & $2,474.23$ \\
\hline 8 & $32,057.65$ & 874.21 & $1,600.01$ & $2,474.23$ \\
\hline 9 & $30,416.07$ & 832.66 & $1,641.57$ & $2,474.23$ \\
\hline 10 & $28,731.86$ & 790.02 & $1,684.21$ & $2,474.23$ \\
\hline 11 & $27,003.91$ & 746.27 & $1,727.96$ & $2,474.23$ \\
\hline 12 & $25,231.07$ & 701.39 & $1,772.84$ & $2,474.23$ \\
\hline 13 & $23,412.19$ & 655.34 & $1,818.88$ & $2,474.23$ \\
\hline 14 & $21,546.06$ & 608.10 & $1,866.13$ & $2,474.23$ \\
\hline 15 & $19,631.46$ & 559.63 & $1,914.60$ & $2,474.23$ \\
\hline 16 & $17,667.13$ & 509.90 & $1,964.33$ & $2,474.23$ \\
\hline 17 & $15,651.79$ & 458.88 & $2,015.35$ & $2,474.23$ \\
\hline 18 & $13,584.09$ & 406.53 & $2,067.69$ & $2,474.23$ \\
\hline 19 & $11,462.69$ & 352.83 & $2,121.40$ & $2,474.23$ \\
\hline 20 & $9,286.19$ & 297.73 & $2,176.50$ & $2,474.23$ \\
\hline 21 & $7,053.16$ & 241.20 & $2,233.03$ & $2,474.23$ \\
\hline 22 & $4,762.13$ & 183.20 & $2,291.03$ & $2,474.23$ \\
\hline 23 & $2,411.59$ & 123.69 & $2,350.54$ & $2,474.23$ \\
\hline 24 & 0.00 & 62.64 & $2,411.59$ & $2,474.23$ \\
\hline
\end{tabular}

Nota. Ver Anexo 15, Requisitos, Tasas y características del Crédito empresarial. Fuente: Elaboración propia. 


\subsubsection{Capital y costo de oportunidad.}

"El costo de oportunidad es el valor máximo sacrificado alternativo de tomar una decisión económica, también es llamado costo alternativo o costo económico.” (Gestiopolis, n.d)

Para establecer el costo de oportunidad o Cok, este se elaboró determinando primero el COK real de Estados Unidos para luego agregarle el riesgo país y el riesgo del negocio que se asume es de $15.53 \%$, en función de la participación del mercado de la empresa cusqueña, Fast Food Rhupa’s Diner, para obtener así el Cok real de Perú conforme Tabla 170.

Tabla 170

Determinación del costo de oportunidad del negocio

\section{Cok real Perú}

$$
\text { Cokr perú }=\text { cokr usa }+ \text { riesgo país }+ \text { Riesgo negocio }
$$

\begin{tabular}{lc}
\hline Cokr usa & $8.74 \%$ \\
Riesgor país & $1.86 \%$ \\
Riesgor negocio & $15.53 \%$ \\
\hline Cokr perú & $26.13 \%$
\end{tabular}

Nota. Ver determinación del COK real Estados Unidos, Riesgo país y Riesgo del negocio, Anexo 16. Fuente: Elaboración propia.

\subsubsection{Costo de capital promedio ponderado.}

El costo de capital promedio ponderado refleja el costo futuro promedio esperado del costo del capital a largo plazo. Se calcula ponderando el costo de cada tipo específico de capital de 
acuerdo con su proporción en la estructura de capital de la compañía. (Lawrence J. \& Chad J., 2012, pág. 332)

Para determinar el costo de capital promedio ponderado se procedió a aplicar la formula conforme se detalla en Figura 70, resultando en un WACC de 25.07\%, conforme Tabla 171.

$$
\text { WACC }=\frac{D}{D+E} \times \quad \text { i } \times(1-\operatorname{tax})+\frac{E}{D+E} \times \quad \operatorname{coK}
$$

Figura 71. Fórmula para el cálculo del WACC. Recuperado de https://www.quora.com/Doesanyone-know-how-to-calculate-the-weighted-average-cost-of-capital-using-the-dividenddiscount-model

Tabla 171

Determinación del Costo de Capital promedio ponderado

\begin{tabular}{lccc}
\hline \multicolumn{1}{c}{ Datos } & \multicolumn{2}{c}{ Resolución } \\
\hline Deuda $^{\mathrm{a}}$ & $28.32 \%$ & Interes real & $31.77 \%$ \\
Patrimonio $^{\mathrm{a}}$ & $71.68 \%$ & $(\mathrm{D} / \mathrm{D}+\mathrm{E}) * \mathrm{i}$ r & $9.00 \%$ \\
$\begin{array}{l}\text { Impuesto (Imp. A la } \\
\text { Renta) }\end{array}$ & $29.50 \%$ & $(1-\mathrm{TAX})$ & $70.50 \%$ \\
$\begin{array}{l}\text { Interés (Del } \\
\text { financiamiento) }\end{array}$ & $36.03 \%$ & $(\mathrm{E} / \mathrm{D}+\mathrm{E}) * \mathrm{COK}$ & $18.73 \%$ \\
COK & $26.13 \%$ & & $25.07 \%$ \\
\cline { 2 - 3 } & & WACC & \\
\hline
\end{tabular}

Nota. Fuente: Elaboración propia.

a Conforme Tabla 167, Estructura del Capital del proyecto

b Tasa del Impuesto a la Renta. SUNAT. Recuperado de http://orientacion.sunat.gob.pe/index.php/empresas-

menu/impuesto-a-la-renta-empresas/regimen-general-del-impuesto-a-la-renta-empresas/calculo-anual-del-impuesto- a-larenta-empresas/2900-03-tasas-para-la-determinacion-del-impuesto-a-la-renta-anual c Conforme Tabla 168, Financiamiento del proyecto (TCEA) 


\subsection{Presupuestos base.}

Este tipo de presupuesto se hace antes de que dé inicio el periodo correspondiente y requiere que los encargados de cada área hagan un análisis de los gastos que tendrán y los den a conocer.

La finalidad pura de estos presupuestos es lograr que las dependencias lleven a cabo todas sus actividades y sean igual de productivas sin desperdiciar tantos recursos. De este modo se consigue que las dependencias que cumplen con el objetivo del presupuesto cero representen un verdadero ahorro a la empresa. (Zúñiga, n.d)

Para determinar el presupuesto base se tuvo que estructurar todos los gastos en lo que debe incurrir el negocio en base a las áreas funcionales del mismo como son las áreas de Administración, ventas, producción entre otros.

\subsubsection{Presupuesto de ventas.}

El presupuesto de ventas representa todas las estimaciones en términos cuantitativos de futuros ingresos de una organización a través del pronóstico de ventas.

"El presupuesto de ventas se complementa con el de gastos y debe incluir los productos y servicios que comercializa la empresa en unidades y volúmenes de ingresos y precios unitarios de cada producto.” (Bermúdez Talavera, 2013)

Para establecer el presupuesto de ventas en primera instancia se determinó el costo de producción unitario por receta al cual se le aplico un factor multiplicador de 2.5 que permita 
considerar un margen de contribución que brinde utilidades positivas al proyecto, al precio resultante se le multiplicó la cantidad de ventas en combos y postres para determinar las ventas anuales por producto y luego los totales, dicho proceso se detalla en Anexo $\mathrm{N}^{\circ} 17$, conforme Tabla 172 se presenta el presupuesto de Ventas para el proyecto.

Tabla 172

Presupuesto de Ventas

\begin{tabular}{|c|c|c|c|c|c|c|}
\hline & & 2019 & 2020 & 2021 & 2022 & 2023 \\
\hline Ingresos & & $\mathrm{S} /$. & $\mathrm{S} /$. & $\mathrm{S} /$. & $\mathrm{S} /$. & $\mathrm{S} /$. \\
\hline por venta & & $753,529.11$ & $1,004,505.34$ & $1,259,274.84$ & $1,517,831.49$ & $1,780,184.78$ \\
\hline $\begin{array}{l}\text { Ingresos } \\
\text { por combos }\end{array}$ & $90.0 \%$ & $\begin{array}{c}\text { S/. } \\
678,141.24\end{array}$ & $\begin{array}{c}\text { S/. } \\
904,008.20\end{array}$ & $\begin{array}{c}\mathrm{S} / . \\
1,133,288.92\end{array}$ & $\begin{array}{c}\mathrm{S} / . \\
1,365,977.91\end{array}$ & $\begin{array}{c}\mathrm{S} / . \\
1,602,083.70\end{array}$ \\
\hline $\begin{array}{l}\text { Ingresos } \\
\text { por postres }\end{array}$ & $10.0 \%$ & $\begin{array}{c}\text { S/. } \\
75,387.88\end{array}$ & $\begin{array}{c}\text { S/. } \\
100,497.15\end{array}$ & $\begin{array}{c}\text { S/. } \\
125,985.92\end{array}$ & $\begin{array}{c}\text { S/. } \\
151,853.58\end{array}$ & $\begin{array}{c}\text { S/. } \\
178,101.08\end{array}$ \\
\hline
\end{tabular}

Nota. Fuente: Elaboración propia.

\subsubsection{Presupuesto de costos de producción.}

Son los requerimientos financieros necesarios para la etapa de producción que considera los insumos para la elaboración del producto, mano de obra, servicios, alquileres, impuestos y otros gastos. En cuanto a los costos de materia primera en primer lugar se determinaron los costos totales de producción conforme a los productos que se piensa ofrecer, para ello primero se toma en cuenta que la proyección de visitas generada es en función de Combos, en ese sentido los combos están compuestos por un alimento con un complemento y una bebida, así se determinó en primer lugar los productos que se piensan implementar para los combos las cuales se presentan en Tabla 173. 
Tabla 173

Productos que se ofrecerán en el Proyecto

\begin{tabular}{|c|c|c|c|c|}
\hline \multicolumn{3}{|c|}{ Alimentos } & Bebidas & Complementos \\
\hline Alitas/pollo frito & Hamburguesas & Broaster & Emoliente & Papas nativas \\
\hline $\begin{array}{l}\text { Alitas en salsa de } \\
\text { maracuyá }\end{array}$ & $\begin{array}{l}\text { Hamburguesa } \\
\text { clásica }\end{array}$ & & Chicha de quinua & Choclo con queso \\
\hline $\begin{array}{l}\text { Alitas en salsa de } \\
\text { sauco }\end{array}$ & $\begin{array}{c}\text { Hamburguesa de } \\
\text { cerdo }\end{array}$ & & Chicha de kiwicha & $\begin{array}{c}\text { Papa helada con } \\
\text { queso }\end{array}$ \\
\hline $\begin{array}{l}\text { Alitas en salsa de } \\
\text { BBQ }\end{array}$ & $\begin{array}{l}\text { Hamburguesa de } \\
\text { pollo }\end{array}$ & & Chicha morada & \\
\hline Alitas búfalo & $\begin{array}{c}\text { Hamburguesa de } \\
\text { quinua }\end{array}$ & & Limonada frozzen & \\
\hline Alitas empanizadas & $\begin{array}{l}\text { Hamburguesa paypi } \\
\text { fast }\end{array}$ & & $\begin{array}{l}\text { Limonada con } \\
\text { hierbabuena }\end{array}$ & \\
\hline $\begin{array}{l}\text { Alitas con salsa de } \\
\text { tamarindo }\end{array}$ & $\begin{array}{c}\text { Hamburguesa } \\
\text { vegetariana }\end{array}$ & & Limonada con muña & \\
\hline Alitas dulces & & & & \\
\hline
\end{tabular}

Nota. Ver Recetas y Costeo de recetas Anexo n ${ }^{\circ} 18$. Fuente: Elaboración propia.

En base al desarrollo de las recetas y sus respectivas cantidades de insumos demandados, se determinó por insumo sus precios, rendimientos y mermas, conforme Tabla 97 y 98, que se expusieron en el Capítulo 5 del presente proyecto. Del mismo modo, se realizó la determinación del programa de producción anual por producto detallado en Tabla 100. Conforme a ambos estudios, se elaboró el programa de compras de materia prima según se detallará en Tabla 174, además de los costos generales de materia prima directa e indirecta (envases que contendrán el producto), según la Tabla 175. 


\section{Tabla 174}

Programa de costo de Materia prima directa del proyecto

\begin{tabular}{|c|c|c|c|c|c|c|}
\hline \multirow[b]{2}{*}{ Alitas/pollo frito } & \multirow{2}{*}{$\begin{array}{l}\text { Costo } \\
\text { prod.unit }\end{array}$} & \multicolumn{5}{|c|}{ Costo de ventas } \\
\hline & & 2019 & 2020 & 2021 & 2022 & 2023 \\
\hline Alitas en salsa de maracuyá & S/. 3.18 & S/. 4,412.93 & S/. 5,882.73 & S/. 7,374.75 & S/. $8,888.95$ & S/. $10,425.38$ \\
\hline Alitas en salsa de sauco & S/. 3.06 & S/. 4,242.30 & S/. 5,655.28 & S/. 7,089.61 & S/. 8,545.26 & S/. 10,022.29 \\
\hline Alitas en salsa de bbq & S/. 2.89 & S/. 4,012.84 & S/. 5,349.39 & S/. 6,706.14 & S/. 8,083.06 & S/. 9,480.19 \\
\hline Alitas búfalo & S/. 2.99 & S/. 4,150.92 & S/. 5,533.46 & S/. 6,936.90 & S/. 8,361.19 & S/. 9,806.40 \\
\hline Alitas empanizadas & S/. 2.76 & S/. 3,831.08 & S/. 5,107.09 & S/. 6,402.38 & S/. 7,716.93 & S/. 9,050.78 \\
\hline $\begin{array}{l}\text { Alitas con salsa de } \\
\text { tamarindo }\end{array}$ & S/. 3.06 & S/. 4,249.88 & S/. 5,665.38 & S/. 7,102.27 & S/. 8,560.52 & S/. 10,040.19 \\
\hline Alitas dulces & S/. 3.00 & S/. 4,159.64 & S/. 5,545.08 & S/. 6,951.46 & S/. 8,378.75 & S/. 9,827.00 \\
\hline \multicolumn{7}{|c|}{ Hamburguesas } \\
\hline Hamburguesa clásica & S/. 3.72 & S/. 9,623.83 & S/. $12,829.22$ & S/. 16,083.05 & S/. 19,385.26 & S/. 22,735.95 \\
\hline Hamburguesa de cerdo & S/. 4.91 & S/. $12,710.78$ & S/. $16,944.33$ & S/. 21,241.87 & S/. 25,603.29 & S/. 30,028.75 \\
\hline Hamburguesa de pollo & S/. 4.09 & S/. $10,580.62$ & S/. $14,104.68$ & S/. 17,682.01 & S/. 21,312.51 & S/. 24,996.32 \\
\hline Hamburguesa de quinua & $\mathrm{S} / .2 .07$ & S/. 5,355.23 & S/. 7,138.88 & S/. 8,949.49 & S/. $10,787.02$ & S/. $12,651.52$ \\
\hline Hamburguesa paypi fast & S/. 5.38 & S/. $13,918.15$ & S/. $18,553.84$ & S/. 23,259.59 & S/. 28,035.29 & S/. 32,881.12 \\
\hline Hamburguesa vegetariana & $\mathrm{S} / .3 .83$ & S/. 9,915.89 & S/. $13,218.56$ & S/. $16,571.14$ & S/. $19,973.56$ & S/. 23,425.93 \\
\hline Broaster & S/. 2.24 & S/. $36,945.90$ & S/. 49,251.39 & S/. $61,742.86$ & S/. 74,420.02 & S/. 87,283.33 \\
\hline Emoliente & S/. 0.84 & S/. 13,419.09 & S/. $17,888.55$ & S/. 22,425.57 & S/. 27,030.03 & S/. 31,702.10 \\
\hline Chicha de quinua & S/. 0.51 & S/. 7,992.65 & S/. $10,654.74$ & S/. 13,357.07 & S/. 16,099.57 & S/. $18,882.34$ \\
\hline Chicha de kiwicha & S/. 0.51 & S/. 4,701.56 & S/. $6,267.50$ & S/. 7,857.10 & S/. 9,470.34 & S/. 11,107.26 \\
\hline Chicha morada & S/. 0.48 & S/. 317.28 & S/. 422.95 & S/. 530.22 & S/. 639.09 & S/. 749.56 \\
\hline \multicolumn{7}{|c|}{ Limonada } \\
\hline Limonada frozzen & S/. 0.84 & S/. 10.80 & S/. 14.40 & S/. 18.06 & S/. 21.76 & S/. 25.53 \\
\hline Limonada con hierbabuena & S/. 0.19 & S/. 2.47 & S/. 3.29 & S/. 4.12 & S/. 4.97 & S/. 5.83 \\
\hline Limonada con muña & S/. 0.18 & $\mathrm{~S} / .2 .32$ & S/. 3.09 & S/. 3.87 & S/. 4.67 & S/. 5.47 \\
\hline Papas nativas & S/. 1.21 & S/. $22,038.77$ & S/. 29,379.17 & S/. $36,830.52$ & S/. 44,392.63 & S/. 52,065.78 \\
\hline Choclo con queso & S/. 3.73 & S/. 44,505.72 & S/. 59,329.14 & S/. 74,376.61 & S/. 89,647.75 & S/. $105,143.13$ \\
\hline Papa helada con queso & S/. 4.32 & S/. $50,155.84$ & S/. $66,861.13$ & S/. $83,818.91$ & S/. $101,028.76$ & S/. $118,491.33$ \\
\hline \multicolumn{7}{|c|}{ Programa de producción POSTRES } \\
\hline Pastel de choclo & $\mathrm{S} / .2 .36$ & S/. $14,566.72$ & S/. $19,418.43$ & S/. $24,343.47$ & S/. 29,341.71 & S/. $34,413.35$ \\
\hline Budín de quinua & S/. 0.82 & S/. 5,065.30 & S/. $6,752.39$ & S/. 8,464.97 & S/. 10,203.02 & S/. $11,966.58$ \\
\hline Total Costo de Materia Prim & irecta & S/. 290,888.52 & S/. $387,774.10$ & S/. 486,124.01 & S/. 585,935.89 & S/. $687,213.41$ \\
\hline
\end{tabular}

Nota. Fuente: Elaboración propia. 
Tabla 175

Costo de Materia prima directa e indirecta

\begin{tabular}{|c|c|c|c|c|c|c|c|}
\hline Unidades & $\begin{array}{l}\text { Q por } \\
\text { paquete }\end{array}$ & merma & 2019 & 2020 & 2021 & 2022 & 2023 \\
\hline $\begin{array}{l}\text { Envase cuadrado } \\
10 \times 10 \text { (postres) }\end{array}$ & 100 & $2 \%$ & 126 & 168 & 211 & 254 & 298 \\
\hline $\begin{array}{l}\text { Envase redondo } \\
20 \mathrm{CM}\end{array}$ & 100 & $2 \%$ & 426 & 568 & 712 & 858 & 1006 \\
\hline Soles & Cost.paq & & 2019 & 2020 & 2021 & 2022 & 2023 \\
\hline $\begin{array}{l}\text { Envase cuadrado } \\
10 \times 10\end{array}$ & C/ $48 \cap 0$ & & $\begin{array}{c}\mathrm{S} / . \\
6,059.12\end{array}$ & $\begin{array}{c}\mathrm{S} / . \\
8,077.21\end{array}$ & $\begin{array}{c}\mathrm{S} / . \\
10,125.81\end{array}$ & $\begin{array}{c}\text { S/. } \\
12,204.86\end{array}$ & $\begin{array}{c}\text { S/. } \\
14,314.44\end{array}$ \\
\hline $\begin{array}{l}\text { Envase redondo } \\
10 \times 10\end{array}$ & S/. 50.50 & & $\begin{array}{c}\text { S/. } \\
21,500.76\end{array}$ & $\begin{array}{c}\mathrm{S} / . \\
28,661.96\end{array}$ & $\begin{array}{c}\mathrm{S} / . \\
35,931.41\end{array}$ & $\begin{array}{c}\text { S/. } \\
43,308.91\end{array}$ & $\begin{array}{c}\text { S/. } \\
50,794.74\end{array}$ \\
\hline Total & & & $\begin{array}{c}\mathrm{S} / . \\
27,559.87\end{array}$ & $\begin{array}{c}\mathrm{S} / . \\
36,739.18\end{array}$ & $\begin{array}{c}\mathrm{S} / . \\
46,057.22\end{array}$ & $\begin{array}{c}\mathrm{S} / . \\
55,513.77\end{array}$ & $\begin{array}{c}\text { S/. } \\
65,109.19\end{array}$ \\
\hline \multicolumn{3}{|c|}{ Materia prima } & 2019 & 2020 & 2021 & 2022 & 2023 \\
\hline $\begin{array}{l}\text { Mp directa } \\
\text { (insumos) }\end{array}$ & & & $\begin{array}{c}\text { S/. } \\
290,888.52\end{array}$ & $\begin{array}{c}\mathrm{S} / . \\
387,774.10\end{array}$ & $\begin{array}{c}\mathrm{S} / . \\
486,124.01\end{array}$ & $\begin{array}{c}\mathrm{S} / . \\
585,935.89\end{array}$ & $\begin{array}{c}\mathrm{S} / . \\
687,213.41\end{array}$ \\
\hline Mp combos & & & $\begin{array}{c}\text { S/. } \\
271,256.49\end{array}$ & $\begin{array}{c}\mathrm{S} / . \\
361,603.28\end{array}$ & $\begin{array}{c}\text { S/. } \\
453,315.57\end{array}$ & $\begin{array}{c}\text { S/. } \\
546,391.16\end{array}$ & $\begin{array}{c}\text { S/. } \\
640,833.48\end{array}$ \\
\hline Mp postres & & & $\begin{array}{c}\mathrm{S} / . \\
19,632.02\end{array}$ & $\begin{array}{c}\mathrm{S} / . \\
26,170.82\end{array}$ & $\begin{array}{c}\mathrm{S} / . \\
32,808.44\end{array}$ & $\begin{array}{c}\mathrm{S} / . \\
39,544.73\end{array}$ & $\begin{array}{c}\text { S/. } \\
46,379.93\end{array}$ \\
\hline $\begin{array}{l}\text { Mp indirecta( } \\
\text { envases) }\end{array}$ & & & $\begin{array}{c}\text { S/. } \\
27,559.87\end{array}$ & $\begin{array}{c}\mathrm{S} / . \\
36,739.18\end{array}$ & $\begin{array}{c}\mathrm{S} / . \\
46,057.22\end{array}$ & $\begin{array}{c}\mathrm{S} / . \\
55,513.77\end{array}$ & $\begin{array}{c}\text { S/. } \\
65,109.19\end{array}$ \\
\hline Total mp & & & $\begin{array}{c}\mathrm{S} / . \\
318,448.39\end{array}$ & $\begin{array}{c}\text { S/. } \\
424,513.27\end{array}$ & $\begin{array}{c}\mathrm{S} / . \\
532,181.23\end{array}$ & $\begin{array}{c}S / . \\
641,449.66\end{array}$ & $\begin{array}{c}S / . \\
752,322.60\end{array}$ \\
\hline
\end{tabular}

Nota. Fuente: Elaboración propia.

Una vez establecidos los costos de materia prima se procede a determinar los costos de mano de obra directa e indirecta conforme Tabla 176, estos costos derivan de la planilla de sueldos elaborada en Tabla 145. 
Tabla 176

Costo de mano de obra Directa e Indirecta

\begin{tabular}{lccccc}
\hline & 2019 & 2020 & 2021 & 2022 & 2023 \\
\hline $\begin{array}{l}\text { Mano de obra } \\
\text { directa }\end{array}$ & S/. 73,551.24 & S/. 73,551.24 & S/. 73,551.24 & S/. 73,551.24 & S/. 73,551.24 \\
$\begin{array}{l}\text { Mano de obra } \\
\text { indirecta }\end{array}$ & S/. 39,447.03 & S/. 39,447.03 & S/. 39,447.03 & S/. 39,447.03 & S/. 39,447.03 \\
\hline $\begin{array}{l}\text { Total mano de } \\
\text { obra }\end{array}$ & S/. 112,998.27 & S/. 112,998.27 & S/. 112,998.27 & S/. 112,998.27 & S/. 112,998.27 \\
\hline
\end{tabular}

Nota. Fuente: Elaboración propia.

Así mismo se determinaron los costos indirectos de Fabricación conforme Tabla 177.

Tabla 177

Otros Costos indirectos de Fabricación

\begin{tabular}{|c|c|c|c|c|c|}
\hline & 2019 & 2020 & 2021 & 2022 & 2023 \\
\hline Botiquín & S/. 425.93 & S/. 425.93 & S/. 425.93 & S/. 425.93 & S/. 425.93 \\
\hline $\begin{array}{l}\text { Otros útiles de aseo } \\
\text { (producción) }\end{array}$ & S/. 9,262.76 & S/. 9,262.76 & S/. 9,262.76 & S/. 9,262.76 & S/. 9,262.76 \\
\hline Gas (Balones de 45kg) & S/. 3,840.00 & S/. 3,840.00 & S/. 3,840.00 & S/. 3,840.00 & S/. 3,840.00 \\
\hline Uniformes (producción) & & & S/. 498.31 & & \\
\hline $\begin{array}{l}\text { Depreciación } \\
\text { (producción) }\end{array}$ & $\mathrm{S} / 1,358.90$ & $\mathrm{~S} / 1,358.90$ & $\mathrm{~S} / 1,358.90$ & $\mathrm{~S} / 1,358.90$ & $\mathrm{~S} / 1,358.90$ \\
\hline Total Cif & $\begin{array}{c}\text { S/. } \\
14,887.59\end{array}$ & $\begin{array}{c}\text { S/. } \\
14,887.59\end{array}$ & $\begin{array}{c}\text { S/. } \\
15,385.89\end{array}$ & $\begin{array}{c}\text { S/. } \\
14,887.59\end{array}$ & $\begin{array}{c}\text { S/. } \\
14,887.59\end{array}$ \\
\hline
\end{tabular}

Nota. Fuente: Elaboración propia.

Una vez determinados estos tres costos se procede a determinar los costos totales de producción del proyecto según se muestra en Tabla 178. 
Tabla 178

Costos de producción del Proyecto

\begin{tabular}{|c|c|c|c|c|c|}
\hline $\mathrm{S} /$. & A1 & A2 & A3 & A4 & A5 \\
\hline $\begin{array}{l}\text { Inv. Inicial Productos } \\
\text { en Proceso }\end{array}$ & 0 & 0 & 0 & 0 & 0 \\
\hline \multicolumn{6}{|l|}{ Más: } \\
\hline MPD & $\mathrm{S} / 290,888.52$ & $\mathrm{~S} / 387,774.10$ & $\mathrm{~S} / 486,124.01$ & $\mathrm{~S} / 585,935.89$ & $\mathrm{~S} / 687,213.41$ \\
\hline MOD & $\mathrm{S} / 73,551.24$ & $\mathrm{~S} / 73,551.24$ & $\mathrm{~S} / 73,551.24$ & $\mathrm{~S} / 73,551.24$ & $\mathrm{~S} / 73,551.24$ \\
\hline CIF: & $\mathrm{S} / 81,894.49$ & $\mathrm{~S} / 91,073.79$ & $\mathrm{~S} / 100,890.14$ & $\mathrm{~S} / 109,848.39$ & $\mathrm{~S} / 119,443.80$ \\
\hline MPI & $\mathrm{S} / 27,559.87$ & $\mathrm{~S} / 36,739.18$ & $\mathrm{~S} / 46,057.22$ & S/55,513.77 & S/65,109.19 \\
\hline MOI & $\mathrm{S} / 39,447.03$ & $\mathrm{~S} / 39,447.03$ & $\mathrm{~S} / 39,447.03$ & $\mathrm{~S} / 39,447.03$ & $\mathrm{~S} / 39,447.03$ \\
\hline Otros CIF & $\mathrm{S} / 14,887.59$ & $\mathrm{~S} / 14,887.59$ & $\mathrm{~S} / 15,385.89$ & $\mathrm{~S} / 14,887.59$ & $\mathrm{~S} / 14,887.59$ \\
\hline $\begin{array}{l}\text { (-) Inv. Final Productos } \\
\text { en Proceso }\end{array}$ & 0 & 0 & 0 & 0 & 0 \\
\hline $\begin{array}{l}\text { Total costo de } \\
\text { producción }\end{array}$ & S/446,334.25 & $\mathrm{S} / 552,399.13$ & $\mathrm{~S} / 660,565.39$ & $\mathrm{~S} / 769,335.52$ & S/880,208.46 \\
\hline Costo de prod. Unitario & $\mathrm{S} / 8.25$ & S/7.66 & $\mathrm{S} / 7.31$ & $\mathrm{~S} / 7.06$ & $\mathrm{~S} / 6.89$ \\
\hline
\end{tabular}

Nota. Fuente: Elaboración propia.

\subsubsection{Presupuesto de compras.}

Es la previsión de requerimiento financiero necesario para las adquisiciones de bienes y servicios durante la etapa de producción, puede ser diario, semanal o mensual.

Para el caso del proyecto, según Tabla 179 se determinó el presupuesto de compras, para lo cual se consideró la cantidad de combo y postres al año que se proyectan vender conforme Tabla 86, a ello se le aplica el costo de producción unitario obtenido en Tabla 178, para así obtener el Presupuesto de compras, cabe resaltar que al ser un proyecto nuevo no se cuenta con inventario final ni inicial de materias primas. 
Tabla 179

Presupuesto de compras

\begin{tabular}{lccccc}
\hline & $\mathrm{A} 1$ & $\mathrm{~A} 2$ & $\mathrm{~A} 3$ & $\mathrm{~A} 4$ & $\mathrm{~A} 5$ \\
\hline Unidades (Combos) a consumir & 54071.03 & 72080.35 & 90361.86 & 108915.13 & 127740.83 \\
(+) Inv. Final de Materia prima & - & - & - & - & - \\
(-) Inv. Inicial de Materia Prima & - & - & - & - & - \\
(*)Costo de prod. Unitario & $\mathrm{S} / 8.25$ & $\mathrm{~S} / 7.66$ & $\mathrm{~S} / 7.31$ & $\mathrm{~S} / 7.06$ & $\mathrm{~S} / 6.89$ \\
\hline Presupuesto de compras & $\mathrm{S} / 446,334.25$ & $\mathrm{~S} / 552,399.13$ & $\mathrm{~S} / 660,565.39$ & $\mathrm{~S} / 769,335.52$ & $\mathrm{~S} / 880,208.46$
\end{tabular}

Nota. Fuente: Elaboración propia.

\subsubsection{Presupuesto de costo de ventas.}

El presupuesto de costo de ventas presenta una visión completa de todo el proceso presupuestario descrito hasta este punto, partiendo de las materias primas, siguiendo a través de la elaboración de las mismas y concluyendo en el almacén de productos terminados. Es decir, es un presupuesto que permite una apreciación general de la actividad fabril en términos de unidades monetarias. (Rivadeneyra Unda, n.d)

Para determinar el costo de ventas del proyecto primero se llevó a cabo el costo de cada receta considerando las medidas o peso de insumos, equivalencias y mermas, para determinar la cantidad ideal de materia prima por insumo conforme se presenta en Anexo $\mathrm{N}^{\circ} 18$.

En base a lo obtenido se múltiplo el costo de producción unitario por receta por la cantidad de platos o visitas esperado para cada año resultando la Tabla 180, donde se detalla el costo de venta del proyecto, cabe precisar que por el tipo de negocio en estudio, no se cuenta con inventarios iniciales, productos en proceso o finales puesto que los productos alimenticios se 
elaboran en el día, para garantizar su calidad, por ello se considera a las compras de materia prima como parte del costo de ventas .

Tabla 180

Costo de Ventas

\begin{tabular}{lccccc}
\hline & A1 & A2 & A3 & A4 & A5 \\
\hline Total Costo de Producción & $\mathrm{S} / 446,334.25$ & $\mathrm{~S} / 552,399.13$ & $\mathrm{~S} / 660,565.39$ & $\mathrm{~S} / 769,335.52$ & $\mathrm{~S} / 880,208.46$ \\
(+) Inv. Inicial Productos & & & & & \\
terminados & - & - & - & - & - \\
$\begin{array}{l}\text { (-) Inv. Final Productos } \\
\text { terminados }\end{array}$ & - & - & - & - & - \\
\hline Costo de Ventas & $\mathrm{S} / 446,334.25$ & $\mathrm{~S} / 552,399.13$ & $\mathrm{~S} / 660,565.39$ & $\mathrm{~S} / 769,335.52$ & $\mathrm{~S} / 880,208.46$ \\
\hline
\end{tabular}

Nota. Fuente: Elaboración propia.

\subsubsection{Presupuesto de gastos de administrativos.}

Son las previsiones presupuestales para la gestión del negocio, se considera la administración del negocio (mano de obra calificada) y los bienes y servicios que demanda esta área.

Para el caso se consideró en el presupuesto de gastos administrativos todos aquellos gastos que debe asumir la administración del negocio y que son básicos para el funcionamiento de las instalaciones y correcto desenvolvimiento en las funciones de las diversas áreas, conforme Tabla 181. 
Tabla 181

Presupuesto de gastos administrativos

\begin{tabular}{|c|c|c|c|c|c|}
\hline & 2019 & 2020 & 2021 & 2022 & 2023 \\
\hline $\begin{array}{l}\text { Planilla } \\
\text { Administrativa }\end{array}$ & S/. 77,192.52 & S/. 77,192.52 & S/. 77,192.52 & S/. 77,192.52 & S/. 77,192.52 \\
\hline Telefonía + internet & S/. 3,000.00 & S/. 3,000.00 & S/. 3,000.00 & S/. 3,000.00 & S/. 3,000.00 \\
\hline Servicio de agua ${ }^{a}$ & S/. 9,787.98 & S/. 9,787.98 & S/. 9,787.98 & S/. 9,787.98 & S/. 9,787.98 \\
\hline Servicio de luz ${ }^{\mathrm{a}}$ & S/. 17,291.03 & S/. 17,291.03 & S/. 17,291.03 & S/. 17,291.03 & S/. 17,291.03 \\
\hline Uniformes & & & S/. 762.71 & & \\
\hline Útiles de oficina ${ }^{b}$ & $\mathrm{~S} / 2,627.28$ & S/. 2,627.28 & S/. 2,627.28 & S/. 2,627.28 & S/. 2,627.28 \\
\hline Alquiler Local & S/. $15,000.00$ & S/. $30,000.00$ & S/. 30,000.00 & S/. $30,000.00$ & S/. $30,000.00$ \\
\hline $\begin{array}{l}\text { Alquiler de POS } \\
\text { VISA }^{c}\end{array}$ & S/. 180.00 & S/. 180.00 & S/. 180.00 & S/. 180.00 & S/. 180.00 \\
\hline Arbitrios $^{\mathrm{a}}$ & S/. 120.00 & S/. 120.00 & S/. 120.00 & S/. 120.00 & S/. 120.00 \\
\hline Depreciación (adm.) & S/. 299.15 & S/. 299.15 & S/. 299.15 & S/. 299.15 & S/. 299.15 \\
\hline Total gastos adm. & $\begin{array}{c}\text { S/. } \\
125,497.97\end{array}$ & $\begin{array}{c}\text { S/. } \\
140,497.97\end{array}$ & $\begin{array}{c}\text { S/. } \\
141,260.68\end{array}$ & $\begin{array}{c}\text { S/. } \\
140,497.97\end{array}$ & $\begin{array}{c}\text { S/. } \\
140,497.97\end{array}$ \\
\hline
\end{tabular}

Nota. Fuente: Elaboración propia.

a Ver detalle en Anexo 19. Estimaciones de servicios.

b Ver detalle en Anexo 14. Cotizaciones.

c Ver detalle Tabla 88. Equipos de counter y comedor para el proyecto.

La planilla administrativa corresponde a las remuneraciones que percibirá el personal administrativo al igual que los uniformes destinos a los mismos. Por otro lado, se debe tomar en cuenta que el alquiler asciende a S/ 2500.00 soles mensuales y se pagará como garantía seis meses de alquiler antes del inicio de operaciones, que se reflejan en el presupuesto pre-operativo, la diferencia se abonara en el primer año. 


\subsubsection{Presupuesto de marketing y ventas.}

El presupuesto de marketing y ventas es uno de los componentes del plan de marketing, define cuanto y como se va a gastar en cuanto a temas de distribución, promoción e implementación de estrategias de ventas.

Conforme Tabla 181, se detalla el presupuesto de marketing y ventas del proyecto, cabe precisar que el detalle del presupuesto de "Marketing y Publicidad" se presenta en Tablas 157, 158 y Tabla 159. Así mismo, en el presente presupuesto se considera el monto de comisión por el POS, para el cual se estimó el promedio de la comisión VISA y MasterCard, resultando en 6\% de las Ventas. Además se incorporó los utensilios descartables que acompañan al producto al momento de la venta, así como el sueldo de un Web master para el soporte de la página web.

Tabla 182

Presupuesto de Marketing y Ventas

\begin{tabular}{lccccc}
\hline & 2019 & 2020 & 2021 & 2022 & 2023 \\
\hline Marketing y publicidad & S/. $30,382.94$ & S/. $39,489.80$ & S/. $47,295.42$ & S/. $56,745.44$ & S/. 64,992.87 \\
Web master & S/. 11,700.00 & S/. 11,700.00 & S/. 11,700.00 & S/. 11,700.00 & S/. 11,700.00 \\
Planilla ventas (cajero) & S/. 11,602.50 & S/. 11,602.50 & S/. 11,602.50 & S/. 11,602.50 & S/. 11,602.50 \\
Comisión POS Visa y & & & & & \\
MasterCard & S/. 9,901.37 & S/. 13,199.20 & S/. 16,546.87 & S/. 19,944.31 & S/. 23,391.63 \\
Utensilios descartables & S/. 675.89 & S/. 1,351.78 & S/. 1,351.78 & S/. 1,351.78 & S/. 1,351.78 \\
Servilletas & S/. 405.53 & S/. 811.07 & S/. 811.07 & S/. 811.07 & S/. 811.07 \\
Bolsas Blancas 16x19 & S/. 5,677.46 & S/. 11,354.92 & S/. 11,354.92 & S/. 22,709.83 & S/. 22,709.83 \\
Depreciación(vtas) & S/. 1,693.22 & S/. 1,693.22 & S/. 1,693.22 & S/. 1,693.22 & S/. 1,693.22 \\
Total gastos vtas & S/. 72,038.92 & S/. 91,202.48 & S/. 102,355.77 & S/. 126,558.15 & S/. 138,252.90
\end{tabular}

Nota. Fuente: Elaboración propia. 


\subsubsection{Presupuesto de gastos financieros.}

"Este presupuesto comprende el gasto en que se incurre por concepto de financiamientos realizados, suele realizarse al final del estudio financiero.” (Herrera, 2013)

Para el presupuesto de gastos financieros se considera a los gastos por amortización de intangibles según Tabla 162, además de los intereses generados por el financiamiento bancario expresado en Tabla 169, ambos gastos se reflejan en Tabla 183, correspondiente al presupuesto de gastos financieros.

Tabla 183

Presupuesto de gastos financieros

\begin{tabular}{lccccc}
\hline & 2019 & 2020 & 2021 & 2022 & 2023 \\
\hline Amortización de & S/. 22,161.79 & S/. 22,161.79 & S/. 22,161.79 & S/. 22,161.79 & S/. 22,161.79 \\
$\begin{array}{l}\text { Intangibles } \\
\text { Interés Financiamiento }\end{array}$ & S/. 11,142.58 & S/. 4,459.67 & S/. 0.00 & S/. 0.00 & S/. 0.00 \\
\hline Total Gastos Financieros & S/. 33,304.37 & S/. 26,621.46 & S/. 22,161.79 & S/. 22,161.79 & S/. 22,161.79
\end{tabular}

Nota. Fuente: Elaboración propia.

\subsection{Presupuesto de resultados.}

Es el presupuesto que refleja los resultados obtenidos por el proyecto, es decir conocer si genera o no utilidades en función de sus ventas, costos y gastos, además del beneficio obtenido.

\subsubsection{Estado de ganancias y pérdidas proyectado.}

Es un estado financiero que permite determinar el resultado de la empresa en función de un periodo de tiempo determinado. El mismo se detalla en Tabla 184. 


\section{Tabla 184}

\section{Estado de Resultados proyectado}

\begin{tabular}{|c|c|c|c|c|c|c|c|c|c|c|}
\hline & 2019 & $\%$ & 2020 & $\%$ & 2021 & $\%$ & 2022 & $\%$ & 2023 & $\%$ \\
\hline Ventas & $\begin{array}{c}\text { S/. } \\
753,529.11\end{array}$ & $100.00 \%$ & $\begin{array}{c}\text { S/. } \\
1,004,505.34\end{array}$ & $100.00 \%$ & $\begin{array}{c}\text { S/. } \\
1,259,274.84\end{array}$ & $100.00 \%$ & $\begin{array}{c}\text { S/. } \\
1,517,831.49\end{array}$ & $100.00 \%$ & $\begin{array}{c}\text { S/. } \\
1,780,184.78\end{array}$ & $100.00 \%$ \\
\hline Combos & $\begin{array}{c}\text { S/. } \\
678,141.24\end{array}$ & $90.00 \%$ & S/. 904,008.20 & $90.00 \%$ & $\begin{array}{c}\text { S/. } \\
1,133,288.92\end{array}$ & $90.00 \%$ & $\begin{array}{c}\text { S/. } \\
1,365,977.91\end{array}$ & $90.00 \%$ & $\begin{array}{c}\mathrm{S} / . \\
1,602,083.70\end{array}$ & $90.00 \%$ \\
\hline Postres & S/. 75,387.88 & $10.00 \%$ & S/. 100,497.15 & $10.00 \%$ & S/. $125,985.92$ & $10.00 \%$ & S/. $151,853.58$ & $10.00 \%$ & S/. 178,101.08 & $10.00 \%$ \\
\hline Costos de producción & $\begin{array}{c}\text { S/. } \\
446,334.25\end{array}$ & $59.23 \%$ & S/. 552,399.13 & $54.99 \%$ & S/. 660,565.39 & $52.46 \%$ & S/. 769,335.52 & $50.69 \%$ & S/. 880,208.46 & $49.44 \%$ \\
\hline Utilidad bruta & $\begin{array}{c}\text { S/. } \\
307,194.86\end{array}$ & $40.77 \%$ & S/. 452,106.21 & $45.01 \%$ & S/. 598,709.45 & $47.54 \%$ & S/. $748,495.97$ & $49.31 \%$ & S/. 899,976.33 & $50.56 \%$ \\
\hline $\begin{array}{l}\text { Gastos } \\
\text { Administración y } \\
\text { Generales }\end{array}$ & $\begin{array}{c}\text { S/. } \\
125,198.81\end{array}$ & $16.61 \%$ & S/. 140,198.81 & $13.96 \%$ & S/. 140,961.52 & $11.19 \%$ & S/. $140,198.81$ & $9.24 \%$ & S/. 140,198.81 & $7.88 \%$ \\
\hline Gastos de Ventas & S/. 70,345.70 & $9.34 \%$ & S/. 89,509.26 & $8.91 \%$ & S/. 100,662.55 & $7.99 \%$ & S/. $124,864.92$ & $8.23 \%$ & S/. 136,559.68 & $7.67 \%$ \\
\hline Depreciación & S/. 3,351.27 & $0.44 \%$ & S/. 3,351.27 & $0.33 \%$ & S/. 3,351.27 & $0.27 \%$ & S/. 3,351.27 & $0.22 \%$ & S/. 3,351.27 & $0.19 \%$ \\
\hline Amortización & S/. 22,161.79 & $2.94 \%$ & S/. 22,161.79 & $2.21 \%$ & S/. 22,161.79 & $1.76 \%$ & S/. 22,161.79 & $1.46 \%$ & S/. 22,161.79 & $1.24 \%$ \\
\hline Utilidad operativa & S/. 86,137.30 & $11.43 \%$ & S/. 196,885.08 & $19.60 \%$ & S/. 331,572.31 & $26.33 \%$ & S/. 457,919.17 & $30.17 \%$ & S/. 597,704.78 & $33.58 \%$ \\
\hline Gastos financieros & S/. $-11,142.58$ & $-1.48 \%$ & S/. $-4,459.67$ & $-0.44 \%$ & S/. 0.00 & $0.00 \%$ & S/. 0.00 & $0.00 \%$ & S/. 0.00 & $0.00 \%$ \\
\hline $\begin{array}{l}\text { UTILIDAD antes de } \\
\text { impuestos }\end{array}$ & S/. 74,994.72 & $9.95 \%$ & S/. 192,425.41 & $19.16 \%$ & S/. 331,572.31 & $26.33 \%$ & S/. 457,919.17 & $30.17 \%$ & S/. 597,704.78 & $33.58 \%$ \\
\hline $\begin{array}{l}\text { Impuesto a la Renta } \\
(29.5 \%)\end{array}$ & S/. $-22,123.44$ & $-2.94 \%$ & S/. $-58,081.10$ & $-5.78 \%$ & S/. $-97,813.83$ & $-7.77 \%$ & S/. $-135,086.15$ & $-8.90 \%$ & S/. $-176,322.91$ & $-9.90 \%$ \\
\hline Utilidad neta & S/. 52,871.28 & $7.02 \%$ & S/. 134,344.31 & $13.37 \%$ & S/. 233,758.48 & $18.56 \%$ & S/. 322,833.01 & $21.27 \%$ & S/. 421,381.87 & $23.67 \%$ \\
\hline
\end{tabular}

Nota. Fuente: Elaboración propia. 
En el estado de ganancias y pérdidas cabe precisar que según SUNAT, la tasa actual para el presente año del impuesto a la renta es de $29.5 \%$, porcentaje que se utilizó para la proyección de estado de ganancias y pérdidas conforme Tabla 183.

Así mismo otro aspecto importante a denotar es que las utilidades del proyecto son positivas, lo cual indica que los ingresos por ventas cubren los costos y gastos del proyecto. También se puede detallar que los costos de producción representan en promedio el 50\% de los ingresos y los gastos administrativos son los más altos a comparación de otros gastos que genera el proyecto.

Para el 2019 se prevé una utilidad neta que represente el $7.02 \%$ de las ventas, dicho margen se incrementa para los siguientes años, obteniendo un $13.37 \%$ para el 2020, $18.56 \%$ para el 2021, $21.27 \%$ para el 2022 y $23.67 \%$ para el 2023, es decir en cinco años las utilidades se incrementan en $16.65 \%$ respecto a las ventas.

\subsubsection{Balance proyectado.}

Es el flujo periódico del resultado generado a partir de la diferencia de beneficios y costos. Conforme se detalla en Tabla 185. 


\section{Tabla 185}

Balance de situación financiera

\begin{tabular}{|c|c|c|c|c|c|c|}
\hline & Año 0 & 2019 & 2020 & 2021 & 2022 & 2023 \\
\hline \multicolumn{7}{|c|}{ Activos } \\
\hline \multicolumn{7}{|l|}{ Activos Corrientes } \\
\hline Efectivo & S/16,913.98 & S/16,913.98 & S/16,913.98 & S/16,913.98 & S/16,913.98 & S/16,913.98 \\
\hline Bancos & & $\mathrm{S} / 26,403.68$ & $\mathrm{~S} / 81,246.42$ & $\mathrm{~S} / 187,215.59$ & S/420,974.06 & $\mathrm{S} / 743,807.08$ \\
\hline Otros Activos corrientes & & $\mathrm{S} / 78,384.34$ & S/159,857.37 & $\mathrm{S} / 259,271.54$ & $\mathrm{~S} / 348,346.07$ & S/446,894.93 \\
\hline Total Activos Corrientes & S/16,913.98 & $\mathrm{S} / 121,702.00$ & $\mathrm{~S} / 258,017.77$ & $\mathrm{~S} / 463,401.11$ & $\mathrm{~S} / 786,234.12$ & $\mathrm{~S} / 1,207,615.99$ \\
\hline \multicolumn{7}{|c|}{ Activos No Corrientes } \\
\hline $\begin{array}{l}\text { Inmuebles, maquinaria y } \\
\text { equipo }\end{array}$ & $S / 26,865.25$ & $\mathrm{~S} / 26,865.25$ & $\mathrm{~S} / 26,865.25$ & $\mathrm{~S} / 26,865.25$ & $\mathrm{~S} / 26,865.25$ & $\mathrm{~S} / 26,865.25$ \\
\hline Intangibles & S/110,808.95 & S/110,808.95 & S/110,808.95 & S/110,808.95 & $\mathrm{S} / 110,808.95$ & S/110,808.95 \\
\hline $\begin{array}{l}\text { Depreciación y } \\
\text { amortización }\end{array}$ & & $-\mathrm{S} / 25,513.06$ & $-\mathrm{S} / 25,513.06$ & $-\mathrm{S} / 25,513.06$ & $-\mathrm{S} / 25,513.06$ & $-\mathrm{S} / 25,513.06$ \\
\hline $\begin{array}{l}\text { Total activos no } \\
\text { corrientes }\end{array}$ & S/137,674.20 & $\mathrm{S} / 112,161.14$ & S/112,161.14 & $\mathrm{S} / 112,161.14$ & $\mathrm{~S} / 112,161.14$ & $\mathrm{~S} / 112,161.14$ \\
\hline Total de activos & S/154,588.19 & $\mathrm{S} / 233,863.14$ & $\mathrm{~S} / 370,178.91$ & $\mathrm{~S} / 575,562.25$ & S/898,395.26 & $\mathrm{S} / 1,319,777.13$ \\
\hline \multicolumn{7}{|c|}{ Pasivos y Patrimonio } \\
\hline \multicolumn{7}{|c|}{ Pasivos Corrientes } \\
\hline $\begin{array}{l}\text { Parte corriente Deuda a } \\
\text { Largo plazo }\end{array}$ & & $S / 26,403.68$ & $\mathrm{~S} / 28,375.14$ & $\mathrm{~S} / 0.00$ & $\mathrm{~S} / 0.00$ & $\mathrm{~S} / 0.00$ \\
\hline Total Pasivos Corrientes & & $\mathrm{S} / 26,403.68$ & $\mathrm{~S} / 28,375.14$ & $\mathrm{~S} / 0.00$ & $\mathrm{~S} / 0.00$ & $\mathrm{~S} / 0.00$ \\
\hline \multicolumn{7}{|l|}{ Pasivos No Corrientes } \\
\hline Deuda a largo Plazo & $\mathrm{S} / 43,779.24$ & $\mathrm{~S} / 43,779.24$ & $\mathrm{~S} / 43,779.24$ & $\mathrm{~S} / 0.00$ & $\mathrm{~S} / 0.00$ & $\mathrm{~S} / 0.00$ \\
\hline $\begin{array}{l}\text { Total Pasivos No } \\
\text { Corrientes }\end{array}$ & $\mathrm{S} / 43,779.24$ & $\mathrm{~S} / 43,779.24$ & $\mathrm{~S} / 43,779.24$ & $\mathrm{~S} / 0.00$ & $\mathrm{~S} / 0.00$ & $\mathrm{~S} / 0.00$ \\
\hline Total Pasivos & S/43,779.24 & $\mathrm{S} / 70,182.92$ & S/72,154.37 & $\mathrm{S} / 0.00$ & $\mathrm{~S} / 0.00$ & $\mathrm{~S} / 0.00$ \\
\hline \multicolumn{7}{|c|}{ ?atrimonio } \\
\hline Capital Emitido & S/110,808.95 & S/110,808.95 & S/110,808.95 & S/110,808.95 & S/110,808.95 & S/110,808.95 \\
\hline Capital Suscrito & & $\mathrm{S} / 0.00$ & $\mathrm{~S} / 0.00$ & S/43,779.24 & $\mathrm{S} / 43,779.24$ & $\mathrm{~S} / 43,779.24$ \\
\hline Resultados Acumulados & & $\mathrm{S} / 52,871.28$ & S/187,215.59 & S/420,974.06 & $\mathrm{S} / 743,807.08$ & S/1,165,188.94 \\
\hline Total Patrimonio & S/110,808.95 & $\mathrm{S} / 163,680.23$ & $\mathrm{~S} / 298,024.53$ & S/575,562.25 & S/898,395.26 & $\mathrm{S} / 1,319,777.13$ \\
\hline $\begin{array}{l}\text { Total pasivo y } \\
\text { patrimonio }\end{array}$ & S/154,588.19 & $\mathrm{S} / 233,863.14$ & $\mathrm{~S} / 370,178.91$ & $\mathrm{~S} / 575,562.25$ & $\mathrm{~S} / 898,395.26$ & $\mathrm{~S} / 1,319,777.13$ \\
\hline
\end{tabular}

Nota. Fuente: Elaboración propia. 
El balance permite analizar si los pasivos y patrimonios cubren o respaldan a los activos fijos de la empresa. Se obtuvo que el total de Activos coincide con el total de Pasivo y Patrimonio que asciende a S/ 154,588.19 para el Año 0, que es la etapa pre-operativa del proyecto, así mismo en el siguiente año los Activo, pasivo y patrimonio ascienden a S/ 233,863.14 soles, y se mantiene la equivalencia para los subsiguientes años.

Sin embargo, se debe resaltar que en el concepto 'Efectivo' se consideró a los montos correspondientes al capital de trabajo, que es el efectivo más líquido que necesita la empresa para sus operaciones; en el concepto 'Bancos' se considera a los ingresos líquidos que ingresan a las cuentas Bancarias del negocio es decir la utilidad de años anteriores.

Del mismo modo, el concepto 'Deuda a largo plazo', para el Año 0 que es la etapa preoperativa donde se realiza el financiamiento considera los S/ 43,770.24 soles que se planea solicitar en calidad de préstamo bancario para pagar a dos años.

\subsubsection{Flujo de caja proyectado.}

Es el flujo periódico de costos y beneficios que incluye la inversión inicial, los costos de operación, los costos de reposición, los costos financieros y de los beneficios que genera el proyecto que será determinado por las ventas durante el horizonte de evaluación del proyecto. Según Tabla 186 se presenta el flujo para el proyecto. 


\section{Tabla 186}

Flujo económico y financiero del proyecto

\begin{tabular}{|c|c|c|c|c|c|c|}
\hline & Año 0 & 2019 & 2020 & 2021 & 2022 & 2023 \\
\hline Utilidad neta & & $\begin{array}{c}\text { S/. } \\
52,871.28\end{array}$ & $\begin{array}{c}\text { S/. } \\
134,344.31\end{array}$ & $\begin{array}{c}\text { S/. } \\
233,758.48\end{array}$ & $\begin{array}{c}\text { S/. } \\
322,833.01\end{array}$ & $\begin{array}{c}\text { S/. } \\
421,381.87\end{array}$ \\
\hline Depreciación(+) & & $\begin{array}{c}\text { S/. } \\
3,351.27\end{array}$ & $\begin{array}{c}\text { S/. } \\
3,351.27\end{array}$ & $\begin{array}{c}\text { S/. } \\
3,351.27\end{array}$ & $\begin{array}{c}\text { S/. } \\
3,351.27\end{array}$ & $\begin{array}{c}\text { S/. } \\
3,351.27\end{array}$ \\
\hline Amortización (+) & & $\begin{array}{c}\text { S/. } \\
22,161.79\end{array}$ & $\begin{array}{c}\text { S/. } \\
22,161.79\end{array}$ & $\begin{array}{c}\text { S/. } \\
22,161.79\end{array}$ & $\begin{array}{c}\text { S/. } \\
22,161.79\end{array}$ & $\begin{array}{c}\text { S/. } \\
22,161.79\end{array}$ \\
\hline Flujo operativo & & $\begin{array}{c}\text { S/. } \\
78,384.34\end{array}$ & $\begin{array}{c}\text { S/. } \\
159,857.37\end{array}$ & $\begin{array}{c}\text { S/. } \\
259,271.54\end{array}$ & $\begin{array}{c}\text { S/. } \\
348,346.07\end{array}$ & $\begin{array}{c}\text { S/. } \\
446,894.93\end{array}$ \\
\hline Activo fijo tangible & $\begin{array}{c}\text { S/. - } \\
26,865.25\end{array}$ & & & & & \\
\hline Activo fijo intangible & $\begin{array}{c}\text { S/. - } \\
110,808.95\end{array}$ & & & & & \\
\hline Capital de trabajo & $\begin{array}{c}\text { S/. - } \\
16,913.98\end{array}$ & $\begin{array}{c}\text { S/. - } \\
5,633.50\end{array}$ & $\begin{array}{c}\text { S/. - } \\
5,718.65\end{array}$ & $\begin{array}{c}\text { S/. - } \\
5,803.65\end{array}$ & $\begin{array}{c}\text { S/. - } \\
5,888.88\end{array}$ & S/. 0.00 \\
\hline Liquidación de valor de rescate & & & & & & $\begin{array}{c}\text { S/. } \\
8,103.03\end{array}$ \\
\hline Recuperación de capital de trabajo & & & & & & $\begin{array}{c}\text { S/. } \\
39,958.66\end{array}$ \\
\hline Flujo de inversiones & $\begin{array}{c}\text { S/. - } \\
154,588.19\end{array}$ & $\begin{array}{c}\text { S/. } \\
5,633.50\end{array}$ & $\begin{array}{c}\text { S/. - } \\
5,718.65\end{array}$ & $\begin{array}{c}\text { S/. } \\
5,803.65\end{array}$ & $\begin{array}{c}\text { S/. - } \\
5,888.88\end{array}$ & $\begin{array}{c}\text { S/. } \\
48,061.69\end{array}$ \\
\hline Flujo de caja económico & $\begin{array}{c}\text { S/. - } \\
154,588.19\end{array}$ & $\begin{array}{c}\text { S/. } \\
72,750.84\end{array}$ & $\begin{array}{c}\text { S/. } \\
154,138.72\end{array}$ & $\begin{array}{c}\text { S/. } \\
253,467.89\end{array}$ & $\begin{array}{c}\text { S/. } \\
342,457.20\end{array}$ & $\begin{array}{c}\text { S/. } \\
494,956.62\end{array}$ \\
\hline Préstamo & $\begin{array}{c}\text { S/. } \\
43,779.24\end{array}$ & & & & & \\
\hline Servicio de la deuda & & & & & & \\
\hline Capital & & $\begin{array}{c}\text { S/. - } \\
18,548.17\end{array}$ & $\begin{array}{c}\text { S/. - } \\
25,231.07\end{array}$ & S/. 0.00 & $\mathrm{~S} / .0 .00$ & S/. 0.00 \\
\hline Interés & & $\begin{array}{c}\text { S/. - } \\
11,142.58\end{array}$ & $\begin{array}{c}\text { S/. - } \\
4,459.67\end{array}$ & S/. 0.00 & S/. 0.00 & S/. 0.00 \\
\hline Escudo fiscal & & $\begin{array}{c}\text { S/. } \\
3,287.06\end{array}$ & $\begin{array}{c}\text { S/. } \\
1,315.60\end{array}$ & S/. 0.00 & S/. 0.00 & S/. 0.00 \\
\hline Flujo servicio a la deuda & & $\begin{array}{c}\text { S/. - } \\
26,403.68\end{array}$ & $\begin{array}{c}\text { S/. - } \\
28,375.14\end{array}$ & S/. 0.00 & S/. 0.00 & S/. 0.00 \\
\hline Flujo de caja financiero & $\begin{array}{c}\text { S/. - } \\
110,808.95\end{array}$ & $\begin{array}{c}\text { S/. } \\
46,347.16\end{array}$ & $\begin{array}{c}\mathrm{S} / . \\
125,763.58\end{array}$ & $\begin{array}{c}\text { S/. } \\
253,467.89\end{array}$ & $\begin{array}{c}\text { S/. } \\
342,457.20\end{array}$ & $\begin{array}{c}\text { S/. } \\
494,956.62\end{array}$ \\
\hline
\end{tabular}

Nota. Fuente: Elaboración propia. 
El flujo Operativo del proyecto se ha realizado partiendo del Estado de ganancias y Pérdidas Proyectado previamente elaborado en el punto anterior, y añadiendo a la utilidad después de impuesto la depreciación y amortización de intangibles.

El flujo de capital así mismo se ha realizado tomando en cuenta los datos obtenidos en los puntos referentes a los activos fijos tangibles, los activos fijos intangibles, la inversión en capital de trabajo, el valor de rescates de los activos fijos y la recuperación del capital del trabajo. La mayor inversión de activos fijos tangibles se realiza en el año cero, año en que se considera toda la inversión necesaria que se ha de realizar para el futuro funcionamiento de la empresa. En el año 2023, se está considerando la respectiva liquidación del valor de rescate y la recuperación del Capital del trabajo.

Además, el flujo de caja económico se obtiene al sumar el flujo de caja operativo más el flujo de capital. En cuanto al flujo económico lo que se busca es evaluar el proyecto en sí. El importe del momento cero (etapa pre-operativa) representa el total de la inversión a realizar; y los importes de los siguientes años representan lo que el proyecto devuelve.

Por otro lado el flujo de servicio de la deuda se realizó consolidando en un solo cuadro el cronograma de pagos del financiamiento realizado, el cual se presenta en forma anualizada. El préstamo representa la cantidad que se requirió financiar para llevar a cabo el proyecto, por lo cual representa un ingreso en el año cero (etapa pre-operativa). El escudo fiscal es un beneficio, ya que su operación conduce al ahorro de impuestos, razón por la cual se trabajó con signo positivo. 
Finalmente el flujo de caja financiero se realizó sumando los respectivos flujos de caja económica y del servicio de la deuda. El monto del año cero representa el aporte que realizan los inversionistas. Los siguientes años representan el monto neto que los inversionistas recibirán llegando así cubrir todos los costos, gastos y el servicio de la deuda. 


\section{Capítulo IX}

\section{Evaluación Económica Financiera}

En este capítulo se realizara el análisis o estudio económico financiero del proyecto mediante las inversiones estimadas del proyecto, el financiamiento y el presupuesto determinara la rentabilidad del capital invertido del proyecto, así como los flujos financieros y la capacidad financiera del proyecto, todo este análisis permitirá reflejar el costo real del proyecto, las fuentes los ingresos y gastos de operación y todos los esquemas de financiamiento que requiere el proyecto, así como la estimación económica de los resultados futuros de la empresa, así mismo la rentabilidad del proyecto con o sin financiamiento para definir su viabilidad y rentabilidad.

\subsection{Evaluación financiera.}

La evaluación financiera es el análisis detallado de costos, beneficios y riesgos de una propuesta de inversión (proyecto o negocio) antes de su implementación; su objetivo principal es la determinación del rendimiento o rentabilidad de la inversión, que permita tomar la decisión adecuada para la ejecución del negocio o proyecto. Sin éste análisis o investigación, la entidad que lleva adelante un negocio no tendría la información de consistencia necesaria para llevar adelante el negocio.

\subsubsection{Tasa interna de retorno (TIR).}

"El criterio de la tasa interna de retorno evalúa el proyecto en función de una única tasa de rendimiento por periodo, con la cual la totalidad de los beneficios actualizados son exactamente 
iguales a los desembolsos en moneda actual." (Sapag Chain, 2014). La misma se detalla en Tabla 187.

Tabla 187

Tasa interna de retorno del proyecto

\begin{tabular}{cc}
\hline \multicolumn{1}{c}{ Tipo } & $\%$ \\
\hline TIRE & $94 \%$ \\
TIRF & $108 \%$ \\
\hline
\end{tabular}

Nota. Fuente: Elaboración propia.

La TIR es la tasa interna de retorno, que iguala a cero el valor presente neto, así según la TIRF el proyecto es aceptado puesto que el porcentaje obtenido de $108 \%$ es mayor al COK de $26.13 \%$, y por otro lado el TIRE de $94 \%$ es mayor al WACC de $25.07 \%$ por lo que por ese lado el proyecto se acepta.

\subsubsection{Valor actual neto (VAN).}

El valor actual neto es un método generalmente aceptado para la evaluación de proyectos.

Mide el excedente que resulta después de obtener la rentabilidad deseada o exigida y después de recuperar toda la inversión.

Se calcula el valor actual de todos los flujos futuros de caja, proyectados a partir del primer periodo de operación, y resalta la inversión total expresada en el momento cero. 
"El criterio del VAN plantea que el proyecto debe aceptarse si su valor actual neto es igual o superior a cero, donde VAN es la diferencia entre todos sus ingresos y egresos expresados en moneda actual.” (Sapag Chain, 2014).

Para el caso del proyecto el valor actual se determinó conforme se detalla en Tabla 188.

Tabla 188

Valor actual neto del proyecto

\begin{tabular}{lc}
\hline \multicolumn{1}{c}{ Tipo } & Monto \\
\hline VANE & S/. $416,643.11$ \\
VANF & S/. 437,830.76 \\
\hline
\end{tabular}

Nota. Fuente: Elaboración propia.

El VANF que fue obtenido del flujo financiero descontado con el COKreal indica que el proyecto es rentable considerando el financiamiento externo con el que se va a contar, por otro lado el VANE que se obtuvo del flujo económico descontado con el WACC también indica que sin financiamiento externo también puede ser rentable.

\subsubsection{Rentabilidad del capital (ROE).}

El ROE (Return Over Equity) es la tasa de retorno sobre el patrimonio en un periodo determinado. Para efectos del proyecto este se presente en Tabla 189. 
Tabla 189

Rentabilidad del capital (ROE)

\begin{tabular}{lccccc}
\hline & 2019 & 2020 & 2021 & 2022 & 2023 \\
\hline k1 & S/. 0.07 & S/. 0.13 & S/. 0.19 & S/. 0.21 & S/. 0.24 \\
k3 & S/. 4.87 & S/. 6.50 & S/. 8.15 & S/. 9.82 & S/. 11.52 \\
ROE & S/. 0.34 & S/. 0.87 & S/. 1.51 & S/. 2.09 & S/. 2.73 \\
& $50 \%$ & $127 \%$ & $222 \%$ & $306 \%$ & $400 \%$ \\
\hline
\end{tabular}

Nota. Fuente: Elaboración propia.

Se analiza cada factor para la obtención del ROE, el factor k1 indica que por cada sol de venta la empresa genera una utilidad de S/0.07 soles, para el año 2019, así mismo conforme el factor $\mathrm{K} 2$, indica que por cada sol del activo total la empresa genera S/.4.87 de ventas, es decir un alto rendimiento de los activos, del mismo modo está el factor $\mathrm{K} 3$, el cual indica que la empresa genera un valor de S/0.34 soles por cada sol del Activo Total.

En base a los tres indicadores se determina que el apalancamiento del ROE es de $50 \%$ es decir el retorno de la inversión sobre el patrimonio es elevado. El producto que se ofrece es de alta rentabilidad.

\subsubsection{Ratios.}

Los ratios son un conjunto de indicadores que comparan las ganancias de una empresa en un determinado periodo con determinadas partidas del Estado de Resultado y de Situación. 
Sus resultados materializan la eficiencia en la gestión de la empresa, es decir, la forma en que los directivos han utilizado los recursos, ofrecen respuestas más completas acerca de qué tan efectivamente está siendo manejada la empresa.

Un ratio puede ser por ejemplo el margen de beneficio neto o Rentabilidad de los Ingresos que indica cuánto beneficio se obtiene por cada sol de venta, en otras palabras, cuánto gana la empresa por cada sol que vende.

Conforme a Tabla 190 se presentan los ratios resultados del estudio del proyecto. 


\section{Tabla 190}

\section{Ratios del proyecto}

\begin{tabular}{|c|c|c|c|c|c|}
\hline & & 2019 & 2020 & 2023 & Análisis \\
\hline \multirow{2}{*}{ Índices de Liquidez } & Razón corriente & 4.61 & 9.09 & 0.00 & $\begin{array}{l}\text { En el 2020, por cada sol que la empresa debe, puede pagar } 9.09 \text { soles, es decir le queda } 8.90 \text { soles. Con } \\
\text { respecto al } 2019 \text { a aumentado su capacidad de pago. }\end{array}$ \\
\hline & $\begin{array}{l}\text { Capital de Trabajo } \\
\quad \text { Neto }\end{array}$ & 95298 & 229643 & 1207616 & $\begin{array}{l}\text { En el 2020, la empresa cuenta con } 229643 \text { soles para cubrir sus obligaciones. Con respecto al } 2019 \text { ha } \\
\text { aumentado su capacidad para cubrir sus obligaciones y para el } 2023 \text { sigue incrementándose. }\end{array}$ \\
\hline $\begin{array}{l}\text { Índices de Rotación- } \\
\text { Gestión }\end{array}$ & $\begin{array}{l}\text { Rotación de } \\
\text { Inventarios }\end{array}$ & 7.00 & 7.00 & 7.00 & $\begin{array}{c}\text { En promedio en el año los inventarios han rotado en } 7 \text { días. El producto desde que se compra y vende demora } 7 \\
\text { días. Ello se estima debido a que las compras de materia prima directa se realizan de forma semanal. }\end{array}$ \\
\hline \multirow{3}{*}{ Índices de Solvencia } & $\begin{array}{l}\text { Endeudamiento a } \\
\text { corto plazo }\end{array}$ & 0.16 & 0.10 & 0.00 & $\begin{array}{l}\text { En el 2019, por un sol que posee el accionista } 0.16 \text { soles está comprometido con deuda a corto plazo, lo que } \\
\text { tiene para garantizar su deuda. Con respecto al } 2020 \text { su capacidad de endeudamiento a corto plazo ha } \\
\text { disminuido. }\end{array}$ \\
\hline & $\begin{array}{l}\text { Endeudamiento a } \\
\quad \text { largo plazo }\end{array}$ & 0.27 & 0.15 & 0.0 & $\begin{array}{l}\text { En el 2019, por un sol que posee el accionista } 0.27 \text { soles está comprometido con deuda a largo plazo, lo que } \\
\text { tiene para garantizar su deuda. Con respecto al } 2020 \text { su capacidad de endeudamiento a corto largo ha } \\
\text { disminuido. }\end{array}$ \\
\hline & Endeudamiento total & 0.43 & 0.24 & 0.00 & $\begin{array}{l}\text { En el 2020, por un sol que posee el accionista } 0.24 \text { soles está comprometido con el total de la deuda. Con } \\
\text { respecto al } 2019 \text { su capacidad de endeudamiento ha disminuido. }\end{array}$ \\
\hline \multirow{3}{*}{$\begin{array}{l}\text { Índices de } \\
\text { Rentabilidad }\end{array}$} & Rentabilidad bruta & 0.41 & 0.45 & 0.51 & $\begin{array}{l}\text { En el 2020, por cada sol se ha obtenido } 45 \% \text { de rentabilidad bruta. Con respecto al } 2019 \text { a mejorado su } \\
\text { rentabilidad en } 4 \% \text { y para el } 2023 \text { aumenta en } 6 \% \text { más. }\end{array}$ \\
\hline & Rentabilidad neta & 0.07 & 0.13 & 0.24 & $\begin{array}{l}\text { En el } 2020 \text {, por cada sol se ha obtenido } 13 \% \text { de rentabilidad neta. Con respecto al } 2019 \text { hubo un incremento de } \\
\qquad 6 \% \text { y se prevé un incremento de } 11 \% \text { más para el } 2023 .\end{array}$ \\
\hline & $\begin{array}{r}\text { Rentabilidad } \\
\text { patrimonial }\end{array}$ & 0.32 & 0.45 & 0.32 & $\begin{array}{l}\text { En el 2020, por cada sol que invirtió el accionista, obtuvo } 45 \% \text { de rentabilidad. Con respecto al } 2019 \text { el } \\
\text { accionista incremento su rentabilidad en } 13 \% \text { y para el } 2023 \text { obtendrá una rentabilidad de } 32 \% \text {. }\end{array}$ \\
\hline
\end{tabular}

Nota. Fuente: Elaboración propia. 


\subsection{Análisis de riesgo.}

El riesgo de un proyecto se define como la variabilidad que presentan los componentes del flujo de caja efectivo respecto de los estimados en el caso base. El riesgo se manifiesta en la variabilidad de los rendimientos del proyecto, puesto que se calculan sobre la proyección de los flujos de caja.

El riesgo define una situación donde el comportamiento de un resultado está sujeto a un conjunto de resultados posibles cada uno de los cuales con una probabilidad asignada. (Sapag Chain, 2014)

\subsubsection{Análisis de punto de equilibrio.}

Punto de Equilibrio está referido al punto de una actividad empresarial o negocio en el cual los ingresos totales son exactamente iguales a los costos totales asociados a la creación del valor de una empresa, actividad, proyecto o negocios. Es aquel punto de la actividad o empresa en el cual no existe utilidad, ni pérdida.

El análisis del punto de equilibrio considera la relación que existe entre costos y gastos fijos, costos y gastos variables, volumen de ventas o de producción y utilidades de las operaciones. Es importante el conocimiento precisa, la naturaleza y el comportamiento de los costos del proceso productivo y financiero. Para la determinación del punto de equilibrio es necesario clasificar los costos y gastos en 2 grupos; los fijos y variables. 
El análisis de punto de equilibrio es conocido también como análisis de costo-volumenutilidad, muestra las relaciones básicas entre costos e ingresos para diferentes niveles de producción y ventas, asumiendo valores constantes de ingresos y costos dentro de rangos razonables de operación. (Sapag Chain, 2014).

Conforme Tabla 191 se presenta el punto de equilibrio según Combos y según Tabla 192 se muestra el punto de equilibrio en base a postres. 
Tabla 191

Punto de equilibrio en Combos

\begin{tabular}{|c|c|c|c|c|c|}
\hline \multicolumn{5}{|c|}{ Combos } & \multirow{2}{*}{$\begin{array}{c}77.17 \% \\
2023\end{array}$} \\
\hline Costos fijos & 2019 & 2020 & 2021 & 2022 & \\
\hline M.o.d & 56,757 & 56,757 & 56,757 & 56,757 & 56,757 \\
\hline G. Administración y ventas & 150,895 & 177,258 & 186,453 & 204,540 & 213,565 \\
\hline C.i.f (sin depreciación) & 10,440 & 10,440 & 10,824 & 10,440 & 10,440 \\
\hline Depreciación (anual) y amortización & 19,688 & 19,688 & 19,688 & 19,688 & 19,688 \\
\hline G. Financiero (intereses) & 8,598 & 3,441 & 0 & 0 & 0 \\
\hline Total costo fijo & 246,377 & 267,583 & 273,721 & 291,424 & 300,449 \\
\hline Costos variables & 2019 & 2020 & 2021 & 2022 & 2023 \\
\hline Materia prima & 245,735 & 327,582 & 410,665 & 494,984 & 580,541 \\
\hline Total costo variable & 245,735 & 327,582 & 410,665 & 494,984 & 580,541 \\
\hline \multicolumn{6}{|l|}{ (cf)/(valor de venta-cv unit) } \\
\hline Punto equilibrio económico & 2019 & 2020 & 2021 & 2022 & 2023 \\
\hline Ventas unidades & 41,725 & 55,622 & 69,729 & 84,046 & 98,573 \\
\hline Precio promedio & 20.64 & 19.16 & 18.28 & 17.66 & 17.23 \\
\hline Ventas & 678,141 & 904,008 & $1,133,289$ & $1,365,978$ & $1,602,084$ \\
\hline Costo fijo & 246,377 & 267,583 & 273,721 & 291,424 & 300,449 \\
\hline Costo variable & 245,735 & 327,582 & 410,665 & 494,984 & 580,541 \\
\hline Costo variable unitario & 5.89 & 5.89 & 5.89 & 5.89 & 5.89 \\
\hline Pto. Equil. Unid & 16,707 & 20,165 & 22,099 & 24,761 & 26,502 \\
\hline Pto. Equil. S/. & 344,771 & 386,343 & 403,872 & 437,251 & 456,528 \\
\hline Comprobación & 2019 & 2020 & 2021 & 2022 & 2023 \\
\hline Ingreso & 344,771 & 386,343 & 403,872 & 437,251 & 456,528 \\
\hline Materia prima & 98,394 & 118,760 & 130,151 & 145,827 & 156,080 \\
\hline Costo fijo & 246,377 & 267,583 & 273,721 & 291,424 & 300,449 \\
\hline Total & 0 & 0 & 0 & 0 & 0 \\
\hline
\end{tabular}

Nota. Fuente: Elaboración propia. 
El punto de equilibrio ayuda a determinar cuál es la cantidad mínima de ventas que se debe realizar con el fin de mantener el equilibrio, es decir no perder ni ganar, donde la utilidad es cero y los ingresos son iguales a los costos, este punto permite determinar cómo orientar los esfuerzos de ventas del proyecto para incentivar el crecimiento de las ventas (Buenaventura Vera, 2002), así mismo se pudo determinar que el costo variable unitario es en promedio de $\mathrm{S} / 5.89$ soles, lo cual es menos de la mitad del precio promedio del producto lo cual indica que el producto tiene una tendencia a tener más costos variables que lo influencian esto se podría explicar por el nivel de rotación de inventarios al comercializarse productos perecederos. 
Tabla 192

Punto de Equilibrio en Postres

\begin{tabular}{|c|c|c|c|c|c|}
\hline & Postres & & & & $22.83 \%$ \\
\hline Costos fijos & 2019 & 2020 & 2021 & 2022 & 2023 \\
\hline M.o.d & 16,794 & 16,794 & 16,794 & 16,794 & 16,794 \\
\hline G. Administración y ventas & 44,650 & 52,451 & 55,171 & 60,523 & 63,194 \\
\hline C.i.f (sin depreciación) & 3,089 & 3,089 & 3,203 & 3,089 & 3,089 \\
\hline Depreciación (anual) y amortización & 5,826 & 5,826 & 5,826 & 5,826 & 5,826 \\
\hline G. Financiero (intereses) & 2,544 & 1,018 & 0 & 0 & 0 \\
\hline Total costo fijo & 72,903 & 79,178 & 80,994 & 86,232 & 88,903 \\
\hline Costos variables & 2019 & 2020 & 2021 & 2022 & 2023 \\
\hline Materia prima & 72,713 & 96,931 & 121,516 & 146,466 & 171,782 \\
\hline Total costo variable & 72,713 & 96,931 & 121,516 & 146,466 & 171,782 \\
\hline Punto equilibrio económico & 2019 & 2020 & 2021 & 2022 & 2023 \\
\hline Ventas unidades & 12,346 & 16,459 & 20,633 & 24,869 & 29,168 \\
\hline Precio promedio & 6.11 & 5.67 & 5.41 & 5.23 & 5.10 \\
\hline Ventas & 75,388 & 100,497 & 125,986 & 151,854 & 178,101 \\
\hline Costo fijo & 72,903 & 79,178 & 80,994 & 86,232 & 88,903 \\
\hline Costo variable & 72,713 & 96,931 & 121,516 & 146,466 & 171,782 \\
\hline Costo variable unitario & 5.89 & 5.89 & 5.89 & 5.89 & 5.89 \\
\hline Pto. Equil. Unid & 336,132 & $-359,483$ & $-168,140$ & $-129,843$ & $-112,231$ \\
\hline Pto. Equil. S/. & $2,052,532$ & $-2,037,979$ & $-909,255$ & $-678,470$ & $-572,078$ \\
\hline Comprobación & 2019 & 2020 & 2021 & 2022 & 2023 \\
\hline Ingreso & $2,052,532$ & $-2,037,979$ & $-909,255$ & $-678,470$ & $-572,078$ \\
\hline Materia prima & $1,979,629$ & $-2,117,157$ & $-990,249$ & $-764,703$ & $-660,981$ \\
\hline Costo fijo & 72,903 & 79,178 & 80,994 & 86,232 & 88,903 \\
\hline Total & 0 & 0 & 0 & 0 & 0 \\
\hline
\end{tabular}

Nota. Fuente: Elaboración propia.

Del mismo modo en cuanto a la venta de postres se puede ver que el costo variables unitario es más bajo que el de los Combos y también inferior al precio de venta promedio unitario lo cual 
se puede explicar cómo en el caso anterior que muchos de los productos de repostería al contar con fecha de caducidad tienen un nivel de rotación moderado.

\subsubsection{Análisis de sensibilidad.}

El análisis de sensibilidad, considera que en cualquier emprendimiento, proyecto o negocio, en el futuro siempre existe elementos de incertidumbre, por ello permite determinar el punto de equilibrio y como varían los indicadores al cambiar los costos, ingresos e inversión. (Torres Fernández, Almazán del Olmo, \& Hernández, 2015)

"Es importante el análisis de la sensibilidad ya que los valores de las variables que se utilizaron para la evaluación del proyecto pueden presentar desviaciones con efectos de consideración en la medición de resultados.” (Sapag Chain, 2014)

Los resultados de la evaluación del proyecto son sensibles a las variaciones de uno o más parámetros si la decisión inicial cambia al incluir estas variaciones en el criterio de evaluación empleado.

En este punto se presenta un modelo de sensibilización que puede aplicarse directamente a las mediciones del valor actual neto, TIR, y de otros parámetros que se deben sensibilizar. En base a ello para casos del proyecto se determina Tabla 193 donde se detalla el análisis de sensibilización. 


\section{Tabla 193}

Análisis de sensibilidad del proyecto

Análisis de sensibilidad - variación en costos

\begin{tabular}{|c|c|c|c|c|c|c|}
\hline & \multicolumn{3}{|c|}{ Pesimista } & \multicolumn{3}{|c|}{ Optimista } \\
\hline & Costos $+5 \%$ & costos $+10 \%$ & costos $+15 \%$ & costos $-5 \%$ & costos- $10 \%$ & costos $-15 \%$ \\
\hline VANE & S/. 359,891.68 & S/. 303,140.25 & S/. 246,388.81 & S/. 470,692.10 & S/. 519,827.54 & S/. 564,690.33 \\
\hline VANF & S/. 379,684.91 & S/. 321,539.07 & S/. 263,393.22 & S/. 493,207.76 & S/. 543,550.48 & S/. 589,515.57 \\
\hline TIRE & $85 \%$ & $76 \%$ & $67 \%$ & $103 \%$ & $111 \%$ & $119 \%$ \\
\hline TIRF & $96 \%$ & $85 \%$ & $74 \%$ & $119 \%$ & $129 \%$ & $139 \%$ \\
\hline
\end{tabular}

Análisis de sensibilidad - variación en ingresos

\begin{tabular}{lcccccc}
\hline & \multicolumn{3}{c}{ Optimista } & & Pesimista \\
\hline & Beneficios+5\% & beneficios+10\% & beneficios+15\% & beneficios-5\% & beneficios-10\% & beneficios-15\% \\
\hline VANE & S/. 522,876.66 & S/. 629,110.21 & S/. 735,343.75 & S/. 315,468.31 & S/. 223,491.21 & S/. 139,512.13 \\
VANF & S/. 546,754.21 & S/. 655,677.65 & S/. 764,601.10 & S/. 334,094.14 & S/. 239,788.13 & S/. 153,682.64 \\
TIRE & $111 \%$ & $128 \%$ & $144 \%$ & $78 \%$ & $64 \%$ & $50 \%$ \\
TIRF & $129 \%$ & $150 \%$ & $172 \%$ & $88 \%$ & $70 \%$ & $54 \%$ \\
\hline
\end{tabular}

Nota. Fuente: Elaboración propia.

Para el análisis de sensibilidad se evaluaron dos posturas o escenarios, se les llamo optimistas y pesimistas, en el caso del escenario optimista se efectuaron cambios en el costo de producción y en los ingresos por ventas aumentando en tres diferentes niveles para ver cómo reacciona el flujo del proyecto, como se observa, en el escenario optimista al incrementarse los costos el valor actual neto fue disminuyendo al igual que la TIRE, y la TIRF, de forma inversa sucede de incrementarse las ventas donde dichos valores van en aumento. De igual forma en el escenario pesimista se da de forma inversa. Sin embargo algo que se debe resaltar es que el proyecto no soportaría si los ingresos disminuyeran más de $15 \%$ puesto que esto podría generaría perdida. 


\subsubsection{Análisis de escenarios.}

El análisis de escenarios es un proceso que intenta predecir y analizar posibles acontecimientos futuros considerando diferentes escenarios, tomando en cuenta factores disruptivos que transciendan en diversos resultados, teniendo como objetivo diseñar diferentes estrategias para cada posible escenario que se considere. De esta forma, este análisis tiene el objetivo de presentar varios posibles futuros alternativos. (Tuespuntoes, 2012)

Aun cuando se cuenta con información precisa, se sabe que los sistemas complejos tienen comportamientos inestables, son extremadamente sensibles a las condiciones iniciales y tienen comportamientos erráticos en umbrales críticos, y todo ello hace imposible la predicción. Además, es imposible conocer el futuro, ya que éste depende de decisiones humanas que aún no se han tomado. Ante semejante incertidumbre, el análisis de escenarios ofrece un medio para explorar diversas alternativas de largo alcance, sabiendo que la incertidumbre acerca del futuro aumenta de manera proporcional a lo lejano que está del presente.

Los escenarios son relatos cuidadosamente construidos acerca del futuro. Incluyen una interpretación del presente, una visión a futuro y un recuento internamente sistemático de la trayectoria entre el presente los diversos futuros posibles. Pueden aplicarse a cualquier escala geográfica o temporal, pero tienden a ser más útiles con respecto a otros métodos para considerar el futuro a medida que los horizontes temporales adquieren mayor alcance. Quizás su aspecto más importante sea que la perspectiva que aportan es relevante para las decisiones que se toman hoy. Conforme Tabla 194 se detalla el análisis de escenarios. 
Tabla 194

Análisis de escenarios

\begin{tabular}{lcc}
\hline & Escenario 1 & Escenario 2 \\
\hline VANE & S/. $458,855.90$ & S/. 515,100.69 \\
TIRE & $100 \%$ & $110 \%$ \\
VANF & S/. $481,240.11$ & S/. 539,019.08 \\
TIRF & $115 \%$ & $127 \%$ \\
\hline
\end{tabular}

Nota. Fuente: Elaboración propia.

Para el presente caso se estimaron dos casos potenciales que podrían influenciar en las ventas , el primer escenario seria en caso las ventas se incrementen en $10 \%$ pero del mismo modo los costos se eleven en $15 \%$, esto debido a que muchas veces se generan grandes volúmenes de ventas y los administradores se confían sin percatarse que los costos pueden también estar aumentando, por lo que se debe saber que pasaría de darse dicho escenario, en el caso de estudio se obtuvo que a pesar del incremento de las ventas, el que los costos se incrementen más que las ventas genera que el Valor actual neto aumente al igual que la TIRE.

El segundo escenario es el caso en que el precio del pollo subiera en 50\% que es un escenario altamente probable al ser un producto que pertenece a la canasta básica de población y es de alto consumo además de ser uno de los insumos principales para el establecimiento. Como se observa en los resultados se puede ver que esto no impacta considerablemente a las ventas puesto que el margen de contribución que se considera por producto es elevado lo cual permite amortiguar las contingencias en los cambios fluctuantes de los precios de los insumos de primera necesidad. 


\section{Conclusiones}

Se puede concluir que el proyecto es viable puesto que cuenta con una idea innovadora única en el mercado que aún no se encuentra en aplicación, si bien es una idea fácil de imitar, el reto está en mantener un alto grado de innovación constante. Por otro lado una de las desventajas seria el costo de los insumos eso se puede minimizar gracias al valor agregado que brinda el producto para la percepción de valor del consumidor.

Del mismo modo, conforme a la investigación y análisis llevado a cabo para el presente proyecto, se puede determinar que la puesta en marcha de un negocio de Fast Food americano que incorpere insumos de la región Cusco es altamente viable, los resultados de evaluación financiera llevados a cabo demuestran de forma cuantitativa la rentabilidad del proyecto según la TIRF el proyecto es aceptado puesto que el porcentaje obtenido de $108 \%$ es mayor al COK de $26.13 \%$, y por otro lado el TIRE de $94 \%$ es mayor al WACC de $25.07 \%$.

Por otro lado, se pudo determinar la viabilidad del proyecto a través de la determinación de un mercado objetivo compuesto por la población urbana de residentes y flotantes en los distritos donde se ubica la Av. La Cultura en la provincia de Cusco, entre 18 y 45 años de edad de los niveles socioeconómicos A,B y C que consumirían sus alimentos en un establecimiento de comida fast food de cocina americana de pollos en variedades y hamburguesas que incorpore insumos oriundos de la región (Novoandino). 
En cuanto a la ingeniería del proyecto se pudo diseñar la infraestructura y equipamiento ideal para el proyecto, a través de la determinación de la cantidad de visitas proyectadas al año y el tiempo de permanencia en el establecimiento, al cual se le incorporo el estándar de $70 \%$ espacio de comedor y $30 \%$ área de cocina, con ello se obtuvo un área ideal de local de 104mts2, realizando con ello el estudio de localización en base a método de promedios ponderados, obteniendo como ganador un local ubicado en la Av. La Cultura, cerca al Centro Comercial Real Plaza Cusco. Asimismo, se pudo determinar la cantidad de maquinarias y equipamiento necesarios para el proyecto, así como el plan de seguridad adecuado según la normativa de INDECI, lo cual garantiza la viabilidad del proyecto al contar con un local que cumpla con los requisitos minimos del proyecto y de las entidades públicas relacionadas

Otro aspecto importante del proyecto es que se pudo definir y analizar a los principales competidores del proyecto obteniendo como principal competidor a KFC con una participación de $30.9 \%$, seguidamente se presenta Burguer King con 19,5\% en contraste se encuentra la empresa Popeyes con $16.7 \%$ y Bembos con $16.6 \%$, por último se encuentra la empresa Rupha's Diner que va abriendo paso en el mercado local con un $15.5 \%$ de participación, lo cual garantiza la viabilidad del proyecto debido a que el principal competidor del mismo es Rhupa's Dinner el cual cuenta con un nivel importante de participación en el mercado.

Por otro lado se pudo realizar un análisis externo del segmento para conocer el nivel de influencia de factores políticos, económicos, legales, culturales, tecnológicos y ecológicos en el proyecto, donde se evidencio que en la región Cusco existe confianza hacia la inversión, además de contar con un PBI per cápita estable y un Índice de precios al consumidor (IPC) bajo, que 
asegura una inflación regional estabilizada; asimismo se pudo asegurar que el crecimiento del sector servicios con miras al 2021 proyectaba un crecimiento promedio de 5\% anual, lo que incentiva la inversión privada en dicho sector. Del mismo modo, se obtuvo oportunidades para el posicionamiento a través de la implementación de estrategias de responsabilidad social con el manejo adecuado de los residuos. Otro aspecto es que se encontraron nuevas técnicas tecnológicas para conocer y llegar más directamente al consumidor y también se determinaron las instituciones públicas que tienen injerencia en el desarrollo del proyecto. Ello ayuda a demostrar que el proyecto es viable puesto que el entorno externo brinda garantías para un desarrollo sostenible.

También se pudo determinar la estructura legal, organizacional y funcional necesaria para la implementación de un negocio de comida rápida, con lo cual se determinó conformar un Sociedad Anónima Cerrada (SAC) con el nombre de Uchucuta SAC y se determinó los procedimientos legales de constitución de este tipo empresas así como se diseñó el organigrama funcional del mismo.

Se logró también diseñar el plan de marketing del proyecto, para lo cual se creó el logo del proyecto y se determinaron las principales estrategias de marketing como son la penetración del mercado con una estrategia de precio a través de la fijación basada en costos y precios competitivos con el mercado. Así como una estrategia de distribución directa y exclusiva con un producto y servicio directo de la empresa al consumidor, usando una estrategia de promoción y publicidad donde se invierta en redes sociales, muestras gratis, merchandising, avisos radiales alianzas con empresas sin fines de lucro para labores sociales. También diseñaron estrategias de 
ventas con equipos de trabajo de alto rendimiento, capacitaciones e incentivos a trabajadores por calidad de servicio y alianzas estratégicas con empresas del sector entretenimiento para convenios en venta conjunta. Asimismo se implementó el desarrollo de nuevos productos con una estrategia de producto con enfoque en posicionamiento a través de productos que incorporan insumos regionales, identificación con el consumidor y decoración de local moderno con temática regional. En ese sentido el plan de marketing permite demostrar que las estrategias son óptimas para garantizar la viabilidad del proyecto.

Por último se realizó la evaluación económica y financiera del proyecto que dio como resultado un VANF que indica que el proyecto es rentable considerando el financiamiento externo con el que va a contar, y un VANE que indica que sin financiamiento externo también puede ser rentable. Del mismo modo se obtuvo que el apalancamiento del ROE es de $50 \%$ es decir el retorno de la inversión sobre el patrimonio es elevado es decir el producto que se ofrece es de alta rentabilidad. También se pudo determinar que el proyecto es poco sensible a los cambios fluctuantes de precios de los insumos de primera necesidad, explicado por el alto margen de contribución por producto que asegura un soporte para situaciones inesperadas. 


\section{Recomendaciones}

Se debe tomar en cuenta el tiempo de vida del producto para asegurar la calidad del mismo. Por otro lado es necesario evaluar la posibilidad de generar una receta única y patentada, que sea el sello o marca de la empresa que permita el posicionamiento en la mente del consumidor.

Es necesario proyectar a futuro la potencialidad de contar con un nuevo local, la cocina si bien cumple con las características técnicas necesarias para efectos del estudio presente, no permite el incremento de la producción a futuro debido al tamaño.

Se debe evaluar la posibilidad de habilitar servicio en mesa, puesto que es un punto de alto interés y preferencia para los consumidores, podría destinarse de preferencia al traslado de los pedidos a la mesa en horas de baja rotación, el cliente siempre tendría que solicitar su pedido en caja para agilizar la atención. 
Anexos 
Anexo 1. Ficha Técnica de Investigación Cualitativa - Focus Group

Ficha Técnica de Investigación Cualitativa: Focus Group

\section{A. Objetivo de la investigación}

El propósito de llevar a cabo el focus group es averiguar, interpretar y comprender aquello que los participantes tengan que opinar con relación a la creación de un fast food y conocer las razones de sus respuestas respecto a las preguntas que se formularán en el desarrollo del focus group.

\section{B. Contenido}

- Hábitos alimenticios en cuanto a almuerzo y cena de las personas.

- Concepto y percepción acerca de los fast food.

- Ventajas y desventajas que consideran importantes al momento de consumir los productos de fast food.

- Factores determinantes en la hora de elegir un fast food y el motivo.

- Influencia de marcas de fast food en el consumidor.

- Tipos de fast food que eligen

- fast food de mayor concurrencia en Cusco y motivos.

- Frecuencia de asistencia a un fast food.

- Conocer la valoración de la nueva propuesta.

- Preferencias de platos al momento de comprar.

- Percepción de las personas frente a la comida saludable.

- Importancia de incorporar comida saludable en la carta y aceptación.

- Preferencias de menú para incorporar al fast food. 
- Ticket promedio de gasto por persona en un fast food.

- Propuesta de precio.

- Medios publicitarios para hacer conocida la marca.

- Test de marca para la determinación del nombre del fast food.

- Opiniones de localización.

\section{Perfil del participante}

- Sexo: Hombres y mujeres.

- Rango de edad entre 18 años a 45 años.

- Nivel socioeconómico: A, B y C.

\section{Determinación de número de focus group que se realizarán}

Se llevarán a cabo cuatro focus group de ocho participantes por cada grupo para poder analizar opiniones y comportamientos acerca del tema a desarrollar; y obtener información más concisa.

- El primer focus group será realizado con personas de nivel socioeconómico C con rango de edad entre 18 años a 29 años,

- El segundo focus group será realizado con personas de nivel socioeconómico A con rango de edad entre 30 años a 45 años.

- El tercer focus group se llevará a cabo personas de nivel socioeconómico B con rango de edad entre 20 y 35 años.

- El tercer focus group se llevará a cabo personas de nivel socioeconómico B con rango de edad entre 30 y 45 años. 


\section{E. Guía de pautas}

\section{- Frase de presentación}

Buenas tardes, primero agradecerles por la asistencia y apoyo en esta investigación que se está llevando a cabo mi nombre es (...) y seré la moderadora del grupo. El tema que se desarrollará durante esta dinámica es la apertura de un nuevo fast food en la ciudad del Cusco donde, ustedes ya saben, existen algunas cadenas internacionales y otras empresas locales, con diversas opciones a escoger y con precios accesibles para todos.

\section{- Diseño de fase de calentamiento}

Antes de comenzar con el desarrollo del focus group y entrar un poco en confianza, voy a presentarme de forma breve. Como ya les mencioné al inicio, mi nombre es (...), soy licenciada en Turismo y Hotelería, trabajo en una empresa propia que es un hotel y en mi día libre me gusta disfrutar con mi familia al aire libre. Ahora me gustaría conocerlos; por favor, preséntese cada uno de forma breve contándonos un poco acerca de su trabajo, dónde viven, cuál es su pasatiempo y algún otro tema que ustedes quisieran compartir con todos nosotros.

\section{- Listado de preguntas}

Antes de comenzar con las preguntas, debo indicarles que no hay preguntas correctas e incorrectas, deben ser veraces con sus respuestas, deben participar una persona a la vez, en orden y debemos escuchar a los demás.

1. ¿Qué es para ustedes un fast food?

2. ¿Qué palabras se les viene a la mente cuando escuchan el término fast food?

3. ¿Qué encuentran de positivo en un fast food? 
4. ¿Qué de negativo encuentran en un fast food?

5. ¿Cuántas veces al mes, qué días de la semana y en qué horario concurren a un fast food generalmente?

6. ¿Con quiénes suelen acudir a estos centros de comida rápida, solos, con la familia, con los amigos?

7. ¿Qué factores influyen para la elección de un fast food determinado?

\begin{tabular}{|l|l|}
\hline VARIABLES & CALIFICACION $1-10$ \\
\hline Ubicación & \\
\hline Ambientación & \\
\hline Tipo de producto & \\
\hline Calidad de productos & \\
\hline Variedad de productos & \\
\hline Atención & \\
\hline Precio & \\
\hline Otros & \\
\hline
\end{tabular}

Donde uno es menor importancia y diez mayor importancia.

8. ¿Cuál es su fast food favorito? ¿Por qué?

9. ¿Qué les gusta más de su fast food favorito?

10. ¿Qué no le gusta de su fast food favorito?

11. ¿Cuál es su platillo preferido?

12. ¿Qué tiempo consideran ustedes que es prudente para que su orden esté lista?

13. ¿Cuánto tiempo permanece en un fast food?

14. ¿Hay algún plato que a ustedes les gustaría encontrar en un fast food y qué ningún local lo tenga?

15. ¿Les gusta consumir algún tipo de postre después de comer en el fast food?

16. ¿Qué tipo de carnes le gustaría encontrar en un fast food? 
17. ¿Les gustaría encontrar en las opciones de productos de fast food comida con valor nutritivo? Si fuese positiva la respuesta, ¿Podrían mencionar algunas opciones?

18. estarían dispuestos a pagar más por adquirir productos frescos y naturales de la región con valor nutritivo en un fast food? ¿qué alimentos serian?

19. ¿Considerarían buena idea el de colocar un pequeño bar dentro de un fast food?

20. ¿Qué tipo de bebidas alcohólicas y no alcohólicas le gustaría encontrar en las opciones que ofrece un fast food?

21. ¿Qué precio estaría dispuesto a pagar por un plato personal en un servicio de fast food?

22. ¿Qué es calidad para ustedes en un fast food?

23. ¿Cómo debería estar ambientado un local de fast food, en cuanto a decoración y música?

\section{Propuesta de valor}

Un fast food donde se brinde piqueos a base de pollo, cerdo y cuy empanizadas con harina de kiwicha selecta de San Salvador y con toque de hiervas finas y salsas acompañadas de papas nativas fritas, sanguches y hamburguesas a base de pollo, carne de res acompañadas de verduras frescas de la zona, tales como lechuga, apio, zanahoria, tomate, cebolla, brócoli y papas andinas fritas.

Con relación a las bebidas, podrá encontrar las clásicas limonadas, y bebidas especiales a base de frutas y gaseosas también aperitivos con alcohol como el mojito, chilcano, con hierbas aromáticas frescas, cerveza y gaseosa.

1. ¿Qué opinan/piensan de este concepto de fast food?

2. ¿Han escuchado algún concepto como este?

3. ¿Es bueno, malo? ¿Qué les gusta, que no les gusta? ¿Por qué? 
4. ¿Asistirían o no al tipo de negocio que se está proponiendo?

5. ¿Ustedes lo tomarían como una opción entre sus alternativas de fast food?

6. ¿Con qué frecuencia asistirían?

7. ¿En qué horario asistirían? ¿Días de la semana?

8. ¿Qué productos no deberían faltar en el fast food?

9. ¿Qué le parece la idea de incorporar el cuy a las opciones del fast food?

10. ¿Creen que si el cuy es aceptado como una opción a elegir, deberían ir acompañas de verduras? ¿Qué tipo de verduras recomendarían?

11. Sobre las salsas ¿qué salsas son de su preferencia cuando asiste a un fast food?

12. ¿Qué tipo de acompañamiento creen q deberían considerar en un fast food?

13. ¿Qué bebidas le gustaría encontrar en la carta?

14. ¿estarían dispuestos a consumir bebidas alcohólicas en el fast food? Si fuese positiva su respuesta ¿cuáles?

15. ¿Dónde seria la ubicación optima?

16. ¿Cuánto estaría dispuesto a gastar por persona en este servicio de fast food?

17. ¿Cuál de estos nombres le parece la mejor opción para el fast food?

○ Rucutu (Rocoto)

○ Hayaq (Picante)

○ Quncha (Fogón)

○ Otros $\ldots \ldots \ldots \ldots \ldots \ldots \ldots$

18. ¿Por qué medios le gustaría informarse sobre la publicidad y/o promociones de este nuevo negocio? 
19. ¿Les gustaría dar alguna recomendación o sugerencia con relación a este proyecto de fast food?

\section{F. Bibliografía}

Carl McDaniel, Jr. \& Roger Gates Investigación de Mercados (Octava edición 
Anexo 2. Ficha Técnica de Investigación Cualitativa - Entrevista a Profundidad

Ficha Técnica de Investigación Cualitativa: Entrevista a Profundidad

\section{A. Objetivo de la investigación}

El propósito de llevar a cabo la entrevista a profundidad es conocer el mercado de principales competidores del proyecto, además de tener información sobre la percepción de estos hacia el desenvolvimiento y crecimiento del sector.

\section{B. Contenido}
a. Frases de presentación
b. Permiso para grabar
c. Presentación personal y laboral del entrevistado
d. Preguntas sobre percepción del entorno y visión a futuro del sector
e. Preguntas sobre características y cualidades de un fast food
f. Frase de cierre

\section{Perfil del participante}

Persona con más de siete años de experiencia en la administración de fast food (empresarios, docentes, gerentes, expertos especializados etc., o que tengan manejo de temas asociados de bar y comedor).

\section{Determinación de número de entrevistas que se realizarán}

Se llevarán a cabo cuatro entrevistas a profundidad para poder analizar opiniones e información de crecimiento y desenvolvimiento del mercado. 


\section{E. Reclutamiento}

Se seleccionaron gerentes y/o dueños de establecimientos tipo fast food que operan en la ciudad del Cusco, principalmente competidores potenciales del proyecto; a criterio del investigador, los seleccionados fueron los siguientes:

- Gerente de Tienda KFC

- Gerente de Rhupa's Diner

- Gerente de Turno McDonald's

- Gerente de Native Restaurants

\section{F. Guía de pautas}

\section{- Frase de presentación}

Buenos días/tardes.

Mi nombre

es.

Soy estudiante de la Maestría en Ciencias Empresariales de la Universidad San Ignacio de Loyola, y en esta ocasión nos encontramos realizando una investigación de mercado sobre los fast food en la ciudad del Cusco"

- Permiso para grabar.

La información que nos facilite en esta entrevista será tratada para fines exclusivamente de la investigación, no pudiendo ser utilizada de forma nominal ni facilitada a terceros.

- Listado de preguntas

1. ¿Qué percepción tiene de nuestra gastronomía en general? 
2. ¿Considera que está suficientemente desarrollada la imagen de los fast food en Cusco?

3. ¿Por qué cree que en Cusco los fast food no han seguido la dinámica y tasa de crecimiento similar a los de Lima?

4. ¿Qué perspectiva prevé para los fast food en Cusco que no son parte de cadenas de fast food internacionales?

5. ¿Qué promociones e iniciativas se están llevando o se han llevado a cabo para potenciar los fast food (ofertas)?

6. ¿Cuáles son los medios publicitarios por el cual se llega más al público objetivo?

7. ¿Cuáles son los principales fast food en el Cusco? ¿Cuál cree Ud. que es el líder?

8. ¿Cuál es el perfil del consumidor de este producto? (rango de edad)

9. ¿Cuál es la motivación del consumidor que impulsa el consumo bajo este formato en Cusco?

10. ¿Cuáles son las posibilidades de lograr un mayor posicionamiento de fast food en Cusco a futuro?

11. ¿Considera que existe nichos de mercado para los fast food que falta explotar en la ciudad del Cusco?, si su respuesta es sí ¿Cuáles?

12. ¿Cuál es el papel que tienen que adoptar los empresarios del rubro del servicio en especial de fast food?

13. ¿Considera que existen profesionales calificados en Cusco para trabajar en el servicio de fast food? 
14. ¿Cuáles son los factores más importantes que considera un consumidor al momento de elegir el fast food al cual asistirá?

15. ¿Considera que el ambiente donde se brinda el servicio de fast food es una parte fundamental para llamar la atención del cliente?

16. ¿Cuál es el plato de comida que suelen pedir con más frecuencia en un fast food?

17. ¿Qué tipo de bebida alcohólica considera que es el mejor acompañamiento después del consumo de fast food?

18. ¿Qué insumos son los que se compran en cantidad y se usan más en los distintos platos de fast food?

19. ¿Qué días existe mayor afluencia de consumidores?

20. ¿En qué horarios existe mayor afluencia de consumidores?

21. ¿Qué zonas dentro de la ciudad de Cusco recomendaría Ud. para iniciar con un negocio de fast food? y ¿Por qué? 


\section{Anexo 3.Transcripción Focus Group NSE B, de 30 a 45 años}

Moderador 1: buenos días primero agradecer por la participación en esta actividad mi nombre es Pilar voy a hacer la moderadora del grupo y me acompaña mi compañera

Moderador 2: buenos días yo soy Marita que voy a apoyar en esta ocupación a pilar que es la moderadora

JUEGO:

\section{PRESENTACION DE LOS INVITADOS}

Moderadora 1: el tema que se desarrollara durante esta dinámica es sobre la apertura de un nuevo Fast Food en la ciudad de Cusco, Ud. Ya saben q existen cadenas internacionales y otras empresas locales con diversas opciones con precios accesibles para todos. Antes de empezar con las preguntas quiero decir que no hay preguntas correctas e incorrecta deben ser veraces con sus respuestas, deben participar una persona a la vez, vamos a empezar con la primera pregunta ¿Qué es para ustedes un fast food?

-bueno es un conjunto de palabras más relacionado al idioma ingles que significa comida rápida, enfocada a un segmento y enfocada que la vida es más agitada, estos restaurantes deben optimizar tiempos, pero también tienen sus contras

- comida rápida

- comida al paso

-una forma de comer fuera de casa o tomarla como un vicio para salir de casa

-comida rápida o al paso, y que te sirven rápido

- comida rápido o al paso, tiene particulares el fast food, con comida no saludable pero no van orientadas a preservar la salud, la gente lo relaciona como comida chatarra 
- fast food comida rápida comida al paso comida chatarra, algo que no está muy aplicada aun en la ciudad de Cusco y que para comer algo no saludable aún existe demora

- como la mayoría lo determino comida rápida, como empresa lo considero, es que esa comida es para personas que coman eso, pero personas que tienen económicamente pueden comer algo más sano

Moderadora 1: gracias vamos con la siguiente

¿Qué palabras se les viene a la mente cuando escuchan el término fast food?

Pollo a la braza

Grasa

Chatarra

Papas fritas

Mayonesa complementos

Moderadora 1: Bien ¿Qué encuentran de positivo en un fast food?

Negocio

Yo tengo una pregunta. La palabra fast food comida rápida al paso, pero una cafetería que prepara jugos también está considerado dentro de los fast food

Es un snack porque te dan frutos y en un fast food te van a dar comida que almacenas grasas en tu cuerpo

Moderadora 2: Influye el tipo de servicio en una jugueria te sientas y te dan la carta y en un fast food esperas tu comida y te lo llevas

La disponibilidad en el momento, la particular que es rápido entre comillas, si nos ponemos analizar en la ciudad de Cusco, los feriados te pasas haciendo cola, cuando deberías ir mejor a un restaurant normal. Todo bajo condiciones normales si funciona el servicio 
Moderadora 1: Con que más nos quedamos con lo positivo el tiempo, tal vez el precio algo positivo en un restaurante

Moderadora 1: yéndonos a la parte contraria Qué de negativo encuentran en un fast food?

Salud

No es rápida, por la demanda que existe en la ciudad

Grasa

Yo pienso por el tema de la sociedad, el consumir comida chatarra te quita tiempo para hacer algo de comida sana.

Se refiere a que quita tiempo de unión familiar o de un compartir familiar. Y no simboliza a la unión familiar.

Particularmente bajo en mi concepto, voy a que me sirvan, no para servirme, ir llevar tu bandeja no me parece un buen concepto de servicio

Moderadora 1: ¿Cuántas veces al mes, qué días de la semana y en qué horario concurren a un fast food generalmente? O recurren a un fast food

Recurren en un feriado por las tardes

Mayormente por las tardes más o menos a las horas de 5 o 6

Uno sale del cine o una discoteca, y uno acude a un fast food.

El consumo se da más por la noche.

Uno va por la facilidad, y consume lo que ya está servido

Por la facilidad y por la noche, al momento que uno va a distraerse por la noche, ese horario es el favorito para la distracción y con lleva a comer.

Son momentos en lo cual uno frecuenta a esos lugares y seria de concurrir por las tardes Yo no voy, una vez me dijeron para ir, pero no me llama la atención. 
Moderadora 1: no es atractivo para usted Alguien que quiera compartir y si van por las tardes o por las noches ¿Con quiénes suelen acudir a estos centros de comida rápida, solos, con la familia, con los amigos?

Creo que más se basa en la amistad o en lo familiar, uno queda más por las diversión y el cine, más que todo la amistad

Coincido con Betty, mayormente vas con amigos y familias para momentos para pasarla bien

Algunos por tema de amistad, familiar y unos amigos de minas, la mayoría de esos lugares va por el wifi y disfrutan más por el chat

Por la amistad, familia y compañeros de trabajo

Moderadora 1: la gran mayoría coincidimos con esa jerarquía con las amistades y familia y compañeros de trabajo

Moderadora 2: pasamos a la segunda pregunta les voy a mencionar algunos factores que influyen en un fast food y Uds. le van a dar una clasificación del 1- 10 por favor iremos en orden ¿Qué factores influyen para la elección de un fast food determinado?

\begin{tabular}{lc}
\hline \multicolumn{1}{c}{ Variables } & Calificación \\
\hline Ubicación & $8-6-8-8-8-8$ \\
Ambientación & $5-4-5-4-4-6-6-5$ \\
Tipo de producto & $7-4-8-7-8-8-10-9$ \\
Calidad de productos & $7-5-8-7-8-6-10-10$ \\
Variedad de productos & $8-6-8-7-7-6-7-7$ \\
Atención & $10-9-9-10-10-10-10$ \\
Precio & $8-9-8-7-8-8-7-8$ \\
Otros & Tiempo, el stock del producto, el espacio.
\end{tabular}

Nota. Fuente: Elaboración propia. 
Moderadora 1: pasamos al siguiente punto ¿Cuál es su fast food favorito? ¿Por qué?

Acá no hay no se acá hay un mall por mi falta de experiencia quede impresionado pero favorito no.

Antes de ir al real plaza, prefiero ir a la bendita gula, tiene buen servicio y el ambiente es acogedor y limpio, prefiero muchas veces ir ahí, que el del real plaza. Porque es atención personalizada.

En lo particular me gusta las papas fritas, yo consumo más que un pollo, creo que mi favorito es el McDonald's

Creo que personalmente me gusta ir al KFC por los juguetitos que dan y promociones por mi hijo, y le llama la atención a mi niño, más que todo por eso.

Yo voy poquísimas veces a un fast food, pero de las pocas veces que fui me quedo con KFC, por la atención, porque yo valoro mucho el tiempo y no espere tanto y por la calidad del producto

A ver que me gusta, huevo frito con la hamburguesa, no le presto mucha atención, Favorito no existe, porque se me antoja cualquier tipo de comida y vario mucho en la comida. Moderadora 1: Ahora el contrario de esta pregunta ¿Qué no le gusta de su fast food favorito? La basura que genera y es mucho por las servilletas, una de las cremas que dio KFC y no fue muy agradable

\section{La grasa}

Yo si me fijo mucho en el tema, de la calidad del producto, si tengo que criticar algo, es la porción de papas, en un mega te dan una porción pequeña, lo que sirven no es acorde al producto que venden

Creo q en esa parte los dueños hacen para que puedan comprar un poco más de su producto. 
En mi caso es la distancia, si hubiera cerca seria genial

Grasa mucha grasa

Moderadora 1: de la experiencia de los fast food ¿Cuál es su platillo preferido?

La gran mayoría va por el pollo y por la papa

Por el pollo

La gran mayoría va por lo crocante del pollo

Por el pollo crispí

A mi si me gusta las hamburguesas, para mí es generoso, hamburguesa o mollejitas

Por lo crujiente que uno puede sentir del pollo

Restaurante por las hamburguesas

Pollo y papa frita

Moderadora 1: bueno ¿Qué tiempo consideran ustedes que es prudente para que su orden esté lista?

5 min

Yo no quiero que todo tenga frito, y me lo den así tome o no tome, daría 15 min.

5 min

Moderadora 1: en su experiencia ¿Cuánto tiempo permanece en un fast food?

1 hora

1 hora un selfie por ahí

Cual sea el motivo en lo cual estas ahí, conversas y se te pasa la hora, dependiendo de la circunstancia, pero normalmente con amistades $40 \mathrm{~min}$.

1 hora tal vez pueda ser más, o tal vez por el cine, 
Moderadora 1: ¿Hay algún plato que a ustedes les gustaría encontrar en un fast food y qué no lo tenga ningún otro?

Yo espero que incluyan comida saludable y que sea rápido

Ensalada orgánica que ningún fast food ofrece, ensalada orgánica frescas

Comida tipo vegetariana

Por la tendencia algo orgánico, todavía ese concepto aun no es bien asimilado, solo es cuestión de atrevimiento. Me gustaría que incluyan alitas picantes.

Moderadora 1: ¿Les gusta consumir algún tipo de postre después de comer en el fast food?

No se encuentra variedad en el fast food

Mucho cargo de conciencia que lo que espero es otra cosa

Mucha grasa como para comer un helado

Fuera de lo que ya haya consumido, tal vez en otro horario si podría ser, pero después de comer creo que no.

Uno toma conciencia después de comer semejante comida y comer un postre es abusar del organismo.

Más que todo no es un tema de combinación si no un tema de conciencia. Y hay mucha gente que va a almorzar pero no encuentra mucha diversidad de postre.

Particularmente lo que yo esperaría no necesariamente un postre, si no más que todo una bebida fuera de las gaseosas, una limonada, me interesaría q haya variedades de bebidas.

Bebidas digestivas

Moderadora 1: Qué tipo de carnes le gustaría encontrar en un fast food? Más te irías por la res, el pollo.

Carne roja 
Res

La carne roja

La carne de res

Carne también

Ambas carnes, normalmente uno se cansa de uno y es necesario cambiar

Los dos tipos de carne

Moderadora 1: algo que ya estamos tocando ¿Les gustaría encontrar en las opciones de productos de fast food comida con valor nutritivo? ¿Ya lo estuvimos tocando algunas cosas?

Montar a elegir entre papas fritas o una ensalada

Tipo Belisario para poder elegir que se alterne, siempre tengan otras alternativas le da un valor agregado

Moderadora 1: entonces si les gustaría tener variedades

Definitivamente para mí el valor o la diferencia será cuando ofrezca o alterne su producto estrella, y será más variedad

Moderadora 1: algún producto fuera de las ensaladas

Un producto puede ser la quinua, el producto va a subir.

Hablando de pollo y las papas, podemos ofrecer la yuca, el camote, no ofrecen palitos de yuca, es una buena opción porque en casa gusta mucho.

La forma como se prepare, yuquitas porque tiene fibras al horno y las ofrezco porque son más nutritivas más hervidas

Productos a vapor

Moderadora 1: con lo que mencionan estarían dispuestos a pagar más por adquirir productos frescos y naturales de la región con valor nutritivo en un fast food? ¿Qué alimentos serian? 
Hay q ser conscientes que los productos, aparecen en temporadas, y cuales se produce, la yuca nos va a dar, en el tiempo que se almacena ya tiene otro sabor. Cuando se guarda ya es muy distinto.

Yo si estoy dispuesta claro que si por que va estar dirigido a un público que va a querer esa variedad, no se almacena grandes variedades, porque lo harán de acuerdo a lo uno va a consumir.

Creo que más que pagar algo más, es un precio justo porque quien no desea comer algo sano Claro que si por la variedad

Si es algo saludable para mí, si agregar la diferencia

Claro que sí.

A medida que el precio sea razonable yo creo q si

Moderadora 1: ¿Considerarían buena idea el de colocar un pequeño bar dentro de un fast food?

¿Bar de qué? De bebidas alcohólicas de una barra, yo creo que no, no en mi punto de vista En mi concepto de vista ya altera con lo que tengo conocimiento de fast food Yo vi que ofrecen hamburguesas piqueos alitas picantes, pero son bares que ofrecen no fast food que ofrecen tragos.

Podría darse el caso, pero si hablamos de un fast food que pasamos familiar con niños no me parece correcto tener un bar.

Como tema de espacio, ese espacio ocuparía un poco más, a las personas que quiera comer, los que quieren comer ocupan mucho espacio

Dependería mucho del horario en la que esté abierto, y con limitaciones de la cantidad que se sirva siempre y cuando solo este abierto en un horario 
Moderadora 1: Qué tipo de bebidas alcohólicas y no alcohólicas le gustaría encontrar en las opciones que ofrece un fast food?

Para mi bebida no alcohólica, a mí me gustaría que tenga una limonada con stevia, combinaciones que puedan dirigir esta grasa que se ha consumido.

Tal vez una cervecita, o de repente por ahí un shot de anisado para la grasa, o un mate.

Te comiste tanta grasa, y tomar una limonada frozzen no te ayuda con la grasa pero una bebida caliente si te ayuda

Bebidas alcohólicas no, pero si una bebida digestiva sí, pero la temperatura de la bebida no tiene nada que ver, más que todo el componente de la bebida

Bebidas alcohólicas no, pero si infusiones

Filtrantes digestivos, vi en una pollería, te servían un té sea de manzanilla u otros.

Siempre queremos una bebida calienta más aun con el frio cuzqueño, nos dura como 6 meses.

La gaseosa que nos ofrece no es gaseosa a comparación a una botella embotellada, lo único que vemos es lo q presionan.

En mi caso voy al tema del horario, como empresaria pondría bebidas en la noche para un público determinado, en horario en la tarde, bebidas calientes o frías

No alcohólicas mates, los calientes digestivos

Infusiones bebidas calientes, refrescos con componentes digestivos

Moderadora 1: ¿Qué precio estaría dispuesto a pagar por un plato personal en un servicio de fast food? Solo pondremos el precio

$\mathrm{S} / 15$

Moderadora 1: en una sola palabra que es ¿Qué es calidad para ustedes en un fast food? Eficiencia 


\section{Servicio}

\section{Satisfacción}

Buen servicio

\section{Rapidez}

Moderadora 1: también en una sola palabra ¿Cómo debería estar ambientado un local de fast food, en cuanto a decoración y música?

Amigable no solo en la decoración si no en el ambiente, y todo también como te recibe el staff, el color blanco para mi está bien

Queremos comer algo rápido y tranquilo y con el color algo blanco

Moderadora 1: ¿con respecto a la música?

La música debe ser suave para poder conversar, donde puedas tener dialogo

Más que color la iluminación, que el ambiente sea cómodo, que sea espacioso, y la música suave no tan alta. El color blanco

\section{Color marfil}

Los tonos de blanco que son suaves, que tengan ventanas y no se vea tan cerrados

Los colores vivos, el blanco amarillo verdes claro dependen del tema que se basa el fast food Moderadora 1: bueno ahora le daremos a conocer nuestra propuesta de valor Un fast food donde se brinde piqueos a base de pollo, cerdo y cuy empanizadas con harina de kiwicha selecta de San Salvador y con toque de hiervas finas y salsas acompañadas de papas nativas fritas, sanguches y hamburguesas a base de pollo, carne de res acompañadas de verduras frescas de la zona, tales como lechuga, apio, zanahoria, tomate, cebolla, brócoli y papas andinas fritas. 
Con relación a las bebidas, podrá encontrar las clásicas limonadas, y bebidas especiales a base de frutas y gaseosas también aperitivos con alcohol como el mojito, chilcano, con hierbas aromáticas frescas, cerveza y gaseosa.

Moderadora 1: ¿Qué opinan/piensan de este concepto de fast food?

Seguimos en lo mismo no llegamos a cambiar

A mí me atrae mucho lo del cuy, y comer el bracito así todo crujiente, la kiwicha ya para mi es agradable, ya tendré el crujiente que a mí me gusta, y la guarnición está el brócoli, y si le quitaría las bebidas alcohólicas

Seguimos con el concepto de papas fritas, una papa al horno o papa hervida.

Ampliar los acompañamientos papa al horno, gratinadas, que le dará un valor más, pero ya en la encuesta, una bebida alcohólica te demanda mucho tiempo, y en un fast food necesitamos que sea rápido

Me parece muy buena propuesta, con incorporar el cuy con lo nutritivo ya que es muy nutritivo, y algunas acompañamientos, algunos platos a base de ellos e incorporar la variedades de bebidas y las bebidas alcohólicas no pero las infusiones. Y el diferenciador es el cuy.

Moderadora 1: ¿Han escuchado algún concepto como este?

En la canasta como Nuggets, que te lo llevas y te lo preparas pero así no

No

No

No

No

Moderadora 1: Han mencionado un poco ya lo que ¿Es bueno, malo? ¿Qué les gusta, que no les gusta? ¿Por qué? ¿Asistirían o no al tipo de negocio que se está proponiendo? 
Si definitivamente si

Como cualquier persona cuando se abre algo nuevo quiero probar

$\mathrm{Si}$

Si

Si

Si añadiría algo más de los complementarios

Si

Si

Moderadora 1: ¿Con qué frecuencia asistirían?

Va a depender mucho de la ubicación, una vez al mes

A medida que el producto sea bueno, y la ubicación si el producto me gusta me convence y no está muy lejos una vez a la semana

Si asistiría

Una vez a la semana, si encuentro el gusto, es como el pollo a la brasa una vez a la semana y si satisface mi tiempo la distancia y mi paladar

Como están ofreciendo la variedad, y el precio aumenta asistiría una vez cada 15 días

Una vez al mes

Depende del servicio y como esta, y puedo estar todo los días dependerá si me gusta o no.

Moderadora 1: En cortas palabras ¿En qué horario asistirían y en qué días de la semana?

En la tarde a partir de las 6, generalmente los viernes sábados

De 6 -10 sábados y domingos

4 a 5 fines de semana

Fines de semana por las tardes 
Preferiría a mitad de semana por la tarde

Sábados y domingos, horario de almuerzo puede ser 12 o 6

Cualquier día de la semana por la tarde, un gusto no tiene horario

Moderadora 1: ok ¿Qué productos no deberían faltar en el fast food?

Carnes no debería faltar

Su stock que siempre esté abastecido

Carne

Carne

Alitas picantes

Moderadora 1: Un poco para reforzar que les había parecido el cuy, algo más que se podría incorporar una idea más sobre la incorporación del cuy.

La incorporación seria el cuy al horno con papa al horno

Empanizado

El cuy es deshuesado o con hueso, un cuy chaqtado en miniatura con una guarnición de papas horneadas o aromatizadas

Salsas de aguaymanto, salsa de quinua

Cuy empanizado al estilo crispí acompañado de salsa de aguaymanto me parece fuera de lo común para un fast food y creo que podría tener éxito.

Moderadora 1: La mayoría o el 100\% considera que el cuy es muy buena opción en considerar el fast food, y el acompañamiento de papa al horno y yuquitas al horno,

¿Qué tipo de verduras recomendarían?

La quinua que tipo de preparación le podrían dar 
Moderadora 1: Sobre las salsas ¿qué salsas son de su preferencia cuando asiste a un fast food? ¿Que ustedes Hayan visto y de su preferencia?

Ají amarillo

Ají criollo

Salsa de aceituna

Salsa de palta

Orégano

Moderadora 1: Algún otro acompañamiento

Uchucuta que ofrecen

Uchucuta el verdecito que comemos en casa

Moderadora 1: Una sola bebida que le gustaría encontrar en su fast food?

Limonada

Algo con menta

Gaseosa

Limonada refrescos

Bebidas calientes

Maracuyá

Café

Moderadora 1: En una sola palabra en el caso si ¿estarían dispuestos a consumir bebidas alcohólicas en el fast food? ¿Cuál sería?

Pisco sour

Cerveza artesanal

Cuba libre 
Pisco

Pisco en las variedades que existe

Moderadora 1: En una sola palabra ¿Dónde seria la ubicación optima?

Centro

Centro

Centro

Centro o plaza vea

Moderadora 1: Dado a conocer nuestra propuesta de valor ¿Cuánto estaría dispuesto a gastar por persona en este servicio de fast food?

$\mathrm{S} / 15$ a 20

Moderadora 1: Bien les voy a mencionar algunos nombres ¿Cuál de estos nombres le parece la mejor opción para el fast food?

Rucutu (Rocoto)

Hayaq (Picante)

Quncha (Fogón)

Creo q los nombres no van con las comidas que se van ofreciendo, debería ser algo como fast cuy, tantas ideas que podrían pensar

Moderadora 1: Otras ideas que se les viene a la mente

Una combinación de palabras entre el inglés y el quechua

Creo debería comenzar con el fast y luego siguiente la palabra quechua

La propuesta el cuy la química algo con lo que se vende.

Moderadora 1: Entonces rucutu, quncha

No tiene relación con lo que venden u ofrecen 
No tienen nada que ver con lo que ofrecen

Moderadora 1: Ya estamos en la penúltima ¿Por qué medios le gustaría informarse sobre la publicidad y/o promociones de este nuevo negocio?

Internet

Volantes

No todos tienen acceso a la virtual

La manera que puedes promocionar es vocalmente, conversando que comemos, por contactos Por medios de comunicación, tv, radial, creo que mayormente por la televisión

De alguna manera más, es hacerlo por un trato directo, aprovechar con los parlantes haciendo anuncios, personalmente por internet no miraría nada.

Muy aparte de las redes sociales, creo que ir a sitios de mayor frecuencia de personas, por ejemplo en un gimnasio muchos dejan promociones para personas que van ahí y de curiosos van ahí, y de ahí llevan a familiares, amigos y pareja

Moderadora 1: En nuestra última pregunta ¿Les gustaría dar alguna recomendación o sugerencia con relación a este proyecto de fast food?

Ya se dio las sugerencias aparte, durante toda la entrevista

Deberían reciclar

Deberían mantener la imagen de la ciudad de Cusco

Que no sea un negocio alienado que mantenga la esencia que nosotros tengamos

Moderadora 1: Bien hemos finalizado, muchas gracias por su participación

Moderadora 2: Muchas gracias por su asistencia estas preguntas y respuesta nos va ayudar para las dudas que teníamos para nuestro proyecto.

GRACIAS!! 


\section{Anexo 4. Transcripción Focus Group NSE B, de 20 a 35 años}

Buenas tardes

Primero agradecerles por la asistencia y el apoyo en esta investigación que se está llevando a cabo. Mi nombre es Pilar y seré la moderadora de este grupo y me está acompañando mi compañera Marita eh bien para efectos de la investigación y de respaldo este proceso de entrevista va a ser grabada.

Bien el tema que se va a, bueno antes de empezar este vamos a identificarnos

Para mayor facilidad en el momento de preguntas vamos a tomar nuestros nombres y lo vamos a pegar en el pecho.

Silvia, Anahí, Beatriz, Priscila, Priscila por favor pásale,

Ok se lo pegan en la medida que no se caiga y si se creen que se les va a caer

Tenemos unos prendedores, creo que serían mejor chinche. Le pasas por favor. Alfiler a ok, Bien ok, el tema que se desarrollara durante esta dinámica. Ahora es la apertura

Donde ustedes ya saben que existen unas cadenas internacionales y otras empresas locales con diversas opciones a escoger con precios accesibles

Con precios accesibles bien, antes de comenzar, este el desarrollo del focus group y entrar un poco más de confianza voy a presentarme en forma breve como ya les indique mi nombre es Pilar soy psicóloga Aquí me acompaña Marita. Mi nombre es Marita Ccahua yo soy licenciada en turismo y hotelería, actualmente soy administradora, bueno en mis ratos libres me gusta salir al campo ir al campo pasar con la familia.

Y del mismo modo que por favor nos gustaría que cada uno se presente a que se dedican que están estudiante que les gusta hacer en sus ratos libres a ver si empezamos contigo: 
Yo me llamo ... vivo en la ciudad de Cusco, he estudiado en el colegio Sagrado Corazón de Jesús, actualmente en el instituto Khipu digo Tuinen Star y estoy en el tercer semestre de administración de empresas.

Mi nombres es Anahí, estudié en el colegio Humberto Luna, estoy en el instituto Tuinen Star, yo escucho música en mis tiempos libres, gracias.

Buenas tardes, mi nombre es Silvia, estudié en santa teresa que es virgen del Carmen de Suyuncuyo, ahora por el momento estoy en el instituto de Tuinen Star en el tercer semestre, gracias.

Mi nombre es... Cruz, he estudiado en dos colegios, primaria lo hice en...

Secundaria lo hice en...

Buenas tardes con todos, mi nombre es Jessica estudié en el colegio Sagrado Corazón de Jesús y en mis ratos libres me gusta escuchar música ver televisión y estudiar un poco y estoy estudiando ahorita en el instituto Tuinen Star la carrera de administración de empresas, gracias.

Buenas tardes, soy Beatriz, bueno yo si ya trabajo actualmente en una empresa, estoy estudiando administración para reforzar las cosas que creo que me falta, en mis ratos libres trabajo y estudio y vine a hacer empresa, gracias.

Bueno ante todo buenas tardes, yo me llamo Irene, yo ahorita estoy estudiando en el instituto Tuinen Star por la carrera de administración de empresas, en mis ratos libres leo, a veces hago mis tareas, me dedico a hacer mis cosas eso es todo, gracias.

Ante todo buenas tardes, mi es nombres Víctor, soy de Quillabamba, estoy realizando mi tercera carrera ahora. Soy técnico en forestales y tengo otra carrera de topografía, mi tercera es administración de empresas en Tuinen Star, en mis ratos libres leo libros, es todo gracias. 
Bien, antes de comenzar con las preguntas debo indicarles que no hay preguntas correctas e incorrectas, deben ser veraces con sus respuestas, deben participar una persona a la vez en forma ordenada y escuchar a los demás.

Bien vamos con la primera pregunta ¿Qué es para ustedes un fast food?

Un servicio de comida rápida

Anahí

Priscila

Comida rápida

Jesica

Servicio ágil

Ok

Beatriz

Las personas que trabajamos nos aligera el tiempo de cocinar vamos a comer.

Ok

Que es menor tiempo no

Y es todo

Comida rápida es un lugar donde se gana el tiempo, es al toque.

A ver Yesica y Beatriz

Cuando alguien esté hablando vamos a escuchar a los demás para no perdernos, ¿ya?

Bien vamos con la segunda pregunta

¿Qué palabras se les viene a la mente cuando escuchan el termino fast food?

Ahorro de tiempo para las personas que trabajan es que los tienen ocupados todo el día Anahí 
Fácil, Más sencillo, Más rápido

Comida veloz, fácil y simple hacer las cosas fáciles, es una comida un bar con Carne o algo así con alguna verdura.

Ok

Vamos con nuestra Tercera pregunta

¿Qué encuentran de positivo en un fast food? ¿Qué cosas positivas hay?

Ahorro de dinero para otras necesidades.

El ahorro de tiempo

Ahorro de tiempo

Algo de economía

Beneficios que pueden darnos Algunos carbohidratos algunas carnes, que tiene saludables algunas verduras carnes de buena calidad. Ya

Anahí

¿Qué de positivo encuentras?

La economía,

Ahorro de dinero,

Irene

La economía

Ahora vamos con la contraparte

¿Qué de negativo ven o encuentran en un fast food?

Por favor si levantamos un poquito la voz tal vez

Lo negativo sería que es comida chatarra y que no nos alimenta bien que no tiene muchas, Muchos beneficios para nuestro cuerpo, nos hace engordar, también no nos mantiene bien, 
No es una comida que deberíamos de consumir todo el rato todos los días porque no nos trae beneficios.

No tiene calidez

La pregunta es ¿Qué de negativo encuentran en un fast food?

Negativo

Alguien tiene alguna idea hasta que Irene aclare sus ideas

Creo que también no es una alimentación adecuada

Tiene muchos químico tal vez nos pueda hacer daño

No

Y también a parte van a ir a

No comparten con toda la familia como debería ser.

Moderadora: Gracias.

Jessica

Y aparte cuando no nos alimentamos bien estamos con malestar después y nos accidentamos.

Víctor, Irene está todavía pensando.

La Contaminación más que todo

Cuando ellos preparan y luego están cobrando

Un poquito que sería negativo

Ósea Venden y te cobran al mismo tiempo también ósea al mismo tiempo las 2 cosas hacen.

Considero que es cualquier tipo de negocio, se podría decir que la contaminación.

Claro algunos de los servicios como Bembos, McDonald's tienen una caja que les reservas con ticket, tú ya te sirves el producto. 
Ya tiene listo el producto en un lado y ya estas cancelado y ya estas pidiendo lo que tú quieres y te llaman a tu nombre y te entregan.

Considero que la comida hechas con químicos y al momento de consumir nosotros, nosotros mismos conseguimos eso. Eso no nos beneficia a nosotros

Beatriz.

Considero que la comida rápida como se dice tiene más ingredientes químicos creo que deberíamos de comer al mes o tal vez una vez al mes para darnos el gusto y no una comida diaria.

Es una pregunta que viene posterior.

Silvia algo que tengas que comentar nada

Entonces nos pasamos a la siguiente

¿Cuántas veces al mes, qué días de semana y en qué horarios concurren a un fast food?

Generalmente ustedes en caso de en forma particular en vuestros casos no en lo que hayan vista en otras personas como personas. Si no ustedes como consumidores.

De noche

Beatriz tú de noche

3 de la tarde 4 de la tarde

Voy al cine y descanso

Claro Como tomarse un tiempo de receso

Un poquito para este entrar en uniformidad

Van a mencionar cuantas veces al mes y en qué días en que horarios han frecuentado.

Son 3 preguntas cuantas veces al mes y en qué días en que horarios han frecuentado

¿Cuantas veces? ¿Qué días de la semana y en que horario concurren a un fast food? 
Los sábados

Todos los sábados

Algunos días algún miércoles o jueves puede ser a las 4 de la tarde o a las 7 de la noche Yo creo normalmente entre amigos a partir de las 6 de la tarde domingos. Domingos.

Anahí

Todos los domingos van al fast food

Silvia

Con consumes.

Priscila, ya comentaste

Jessica

Una vez a la semana los miércoles,

Los miércoles

¿En qué horario?

A las 6

Una vez al mes

Horario

Sábado en la noche o domingo en la noche

Una vez al mes, Solo los miércoles podría ser 11.30 de la mañana

Los miércoles

Yo tampoco consumo

¿Con quiénes sueles acudir a estos centros de comida rápida solos con familia con amigos?

Con amigos

Irene 
Hijos

Con mi hermanito, Hermano

Familia entonces

Más que todo con la familia,

Entonces cuando van con la familia el papa paga y cuando van con amigos hacen chancha.

Irene

Los mismos

Que las comidas son así, hechas con químicos y bueno al momento de consumir nosotros

Beatriz

Considero que la comida rápida como usted dice tiene más elementos químicos, no como una comida diaria.

Silvia algo que tengas que comentar

En la siguiente pregunta

Calificar del 1 al 10 donde el 1 es menor importancia y 10 es de mayor importancia.

La primera

La ubicación

Cuán importante es la ubicación de

Vanesa

Mucho, Que este más ubicado, la gente más transcurra este centro comercial,

Solo mencionamos los números.

$98,9,9,7,5,8$

Del mismo modo 
La importancia que ustedes le considerar a la ambientación, me refiero a la decoración del lugar

101099710910 (que sea llamativo)

El tipo de producto.

Cuán importante es para ustedes.

6 porque como es comida rápida no tiene muchas vitaminas

5. 5.7.610510

La calidad del producto

Como lo valoran ustedes del producto

8776810710

En cuanto a la atención que ustedes reciben cuán importante es la atención

10. 10. 10. 10101010

En cuanto al precio

Cuan importantes es

8. 10.9.10.9.89

Tal vez tengan variable o concepción

Que considere importante en un fast food

Los servicios calidad y atención

La limpieza cuan importancia es la limpieza para ustedes

Todos 10

Alguna otra variable que tal vez nos esté pasando por allí

Tal vez me haya olvidado de colocar el tiempo

Ustedes valoran el tiempo 
Cuanto le ponen de valoración

8. 8. 7. 7.9.5. 8.6.8.

Moderadora: ¿Cuál es su fast food favorito? y ¿Por qué?

La Bembos

¿Por qué?

Por sus hamburguesas, y la oferta.

Por la atención dice.

¿Qué fast food?

Bembos

También

El café de Choquechaca

No

No está considerada con comida rápida

La Bembos

Porque te agrada bembos.

Las cremas.

Irene.

¿Qué les gusta más de este fast food a los que mencionaron el fast food favorito?

El local

Te refieres a que

La estructura como es

Los colores, la atención

El tipo de promoción que dan 
Te refieres al ambiente.

También es por la ubicación de local también por la atención lo que nos ofrecen las cremas.

Jessica no tengo conocimiento

Beatriz, la comida es agradable, la contextura

Víctor

Ahora vamos a mencionar lo contrario

¿Qué no nos gusta de este fast food favorito?

Que a veces el precio no es muy cómodo, para algunos

En tu caso para ti Vanesa

Suele pasar que está en promoción la tele y cuando llegas al lugar no es el mismo precio

Parece que estás ahorrando pero no estás ahorrando mucho

La economía

Que a veces está muy lleno y tienes que esperar.

Dentro de sus fast food ¿Cuál sería el platillo preferido? Qué platillo preferido tienen.

Hamburguesa, la fritura, el pollo.

Cualquier pollo que te dan.

Más con pollo.

¿Qué tiempo en forma general que tiempo considerar ustedes para que este su comida lista?

5 minutos

8 minutos

9 minutos

7 minutos

10 minutos 
8 minutos

En vuestra experiencia ¿Cuánto tiempo permanecen en un fast food?

1 hora

1 hora y media

1 hora

1 hora

1 hora

1 hora

También de forma general ¿Hay algún plato que les gustaría encontrar en un fast food, una comida favorita?

Un saltado, eso te gustaría encontrar.

Verduras

Más variedad

Ensaladas

Algún plato en específico

Agridulces

Ok

Les gusta consumir algún tipo de postre

Helado, helado....

¿Qué tipos de carnes les gustaría encontrar en un fast food?

A parte del pollo, el cordero.

Res

Pollo 
Y también el cuy

Bistec y parrillas

Cordero

Pollo y res

Un poco para hacer break, pueden consumir sus bebidas o galletas también, siéntanse en la libertad de poder compartir.

Buenos vamos continuando mientras van compartiendo.

¿Les gustaría encontrar en las opciones de fast food alimentos con valor nutritivo? Si fuese positiva su respuesta ¿Podrían mencionar algunas opciones?

Sí, el escabeche, como ensaladas, frutas

Frutas

Frutas

Mucha ensalada

Víctor: Ensalada

Verduras

Moderadora: Entonces a todos les gustaría encontrar valor nutritivo

Todos: Sí

¿Estarían dispuestos a pagar más por adquirir productos frescos y naturales de la región con valor nutritivo en un fast food?

Sí, si encontrara productos más de acá, de la sierra.

Moderadora: los productos frescos, ¿cuáles serían?

Brócoli, lechuga, en carnes sería del campo como las gallinas de chacra.

Anahí: las gallinas, el tomate, la lechuga, sí pagaría un poco más. 
Silvia: Las lechugas y sí pagaría un poco más.

Priscila: Sí

Jessica: Sí

Beatriz: Que las carnes sean frescas y sin químicos. Sí pagaría más.

Sí estaría dispuesta a pagar por los productos naturales y por ejemplo verduras, como dijo mi compañera, gallinas de casa.

Víctor: Sí estoy dispuesto a pagar un poco más.

¿Considerarían buena idea el de colocar un pequeño bar o una barra dentro de un fast food?

Sí, de jugos, jugos nutritivos, cremoladas, refrescos de la sierra como la cebada, el trigo, ya que no solo es consumir gaseosa.

Moderadora: ¿Bebidas alcohólicas también?

No.

Participante: ¿Por qué no?

Moderadora: A ver tal vez alguien esté de acuerdo, vamos a escuchar en orden

Víctor: Un anisado

Tragos.

Pisco

Pero estaríamos contradiciendo lo que hemos dicho en antes que si queremos ahorrar tiempo y nos ponemos a tomar entonces ya no estaríamos ganando tiempo, nos estaríamos contradiciendo.

Moderadora: Entonces ¿Sería una buena idea?

Víctor: No, porque se come la comida rápido y el refresco se toma rápido, entonces ganas tiempo y entras a trabajar. 
Vanessa: Pero si vas días feriados o fines de semana si podrías tomar. En el McDonald’s también hay bebidas y no solo es comida, para acompañar siempre.

Moderadora: ¿Pero cómo cliente te gustaría encontrar este tipo de bebidas alcohólicas?

Víctor: No

Irene: no

No

$\mathrm{Si}$

$\mathrm{Si}$

¿Qué tipo de bebidas alcohólicas y no alcohólicas les gustaría encontrar en las opciones que ofrece un fast food?

Un pisco sour

Vino

Jugos y refresco tipo cremolada y ahorramos el helado.

Jugos

Chicha morada, chicha de jora.

Moderadora: ¿Y les gustaría encontrar tal vez alguna bebida caliente?

Café

Ponche

Infusiones

Es lo menos que podrían ofrecer

Capuchino

Té 
Ponche de castañas, de habas, para que la gente de Cusco también conozca algo fuera de lo convencional, para que se sientan identificados y no consuman lo mismo de siempre, la gente quiere ver productos nuevos.

Moderadora: Bien, pasamos a la siguiente pregunta ¿Qué precio estaría dispuesto a pagar por un plato personal en un servicio de fast food?

15 soles

15 soles

10 soles

15 soles

10 soles

15 soles

12 soles

15 soles

Moderadora: En una sola palabra ¿Qué es calidad para ustedes en un fast food?

La forma de elaboración del producto

La variedad de los productos

Variedad de productos

Un servicio óptimo podría ser.

Moderadora: ¿Cómo sería un servicio óptimo?

Que implique un buen servicio, que el cliente salga satisfecho del lugar.

Irene: Que brinden un buen servicio de acuerdo a los productos, que sean eficientes.

Víctor: Proceso del producto, como se hace el producto.

Moderadora: Ya estamos en la última fase de esta primera etapa 
¿Cómo debería estar ambientado un local de fast food en cuanto a decoración y música?

De lujo

El color amarillo con rojo

El color naranja

Colores vivos que te incentiven a entrar, que se vea más amplio

Yo opino que la música debería ser suave, sin canto, solo ritmo, porque con tanta bulla de la gente estresa la música fuerte, tipo instrumental, como en las tiendas Orión.

Debería estar con sillas pequeñas porque si vas a poner sofás la gente no va a querer moverse.

Moderadora: ¿Pero tú como consumidor?

Beatriz: Ah me gustaría que sea cómodo.

También que tenga afiches grandes porque a veces ponen afiches pequeños y no llama la atención del cliente

Irene: La imágenes que sean con colores referentes a la empresa

El nombre que sea llamativo, porque hay clientes que miran el nombre e inspira a entrar.

Colocar imágenes de comida, imágenes llamativas.

Música suave.

Moderadora: Les vamos a dar a conocer nuestra propuesta de valor. Un fast food donde se brinde piqueos a base de pollo, cerdo y cuy empanizadas con harina de kiwicha selecta de San Salvador y con toques de hierbas finas y salsas acompañadas de papas nativas fritas, sanguches y hamburguesas a base de pollo, carne de res acompañadas con verduras frescas de la zona, tales como lechuga, apio, zanahorias, tomates, cebolla, brócoli y papas fritas andinas. 
Con relación a las bebidas podrá encontrar la clásica limonada y bebidas especiales a base de frutas y gaseosas, también aperitivos con alcohol como el mojito, el chilcano con hierbas aromáticas frescas, cerveza y gaseosas.

Con relación a nuestra propuesta de valor, ¿Qué opinan sobre este concepto de fast food?

Lo siento familiar porque solamente en mi casa las carnes son aromatizadas con hierbas finas, voy a mi casa coloco hierbas finas a la carne y lo frio en poco aceite, siento familiar la propuesta.

Para mí es buena la propuesta.

Está bien la propuesta.

Las frutas y verduras me parecen bien considerarlo en la propuesta.

Víctor: Esta bien porque también lo siento familiar

Vanessa: Esta bien la propuesta, porque frente a Plaza Vea hay un restaurante que ofrece papas fritas con cáscara, tiene comidas de aquí como la moralla con queso, también tiene como entrada mote con queso y como bienvenida mientras eliges tu pedido te traen una jarra de limonada.

¿Han escuchado algún concepto como este?

No

No

No

No

En comida rápida, no.

¿Es bueno, malo? ¿Qué les gusta? ¿Qué no les gusta? Y ¿Por qué?

Es buena la propuesta 
Para mí es bueno

Es bueno

Víctor: Está bien, ofrecen productos naturales

Beatriz: Es una buena propuesta, pero sigue siendo grasa, no me gusta que todo siga siendo frituras, pero si es empanizado con kiwicha eso lo arregla todo.

¿Asistirían o no al tipo de negocio que se está proponiendo?

Todos: Sí

Vanessa: Sí iría, porque tiene productos innovadores.

¿Con qué frecuencia asistirían?

Dos veces a la semana

Tres veces a la semana

Dos veces al mes

Todos los domingos

Dos veces a la semana

Los sábados

Los viernes y domingos

¿E qué horario asistirían y en qué días de la semana?

Iría el jueves a las 4pm y los domingos también, después del partido

Viernes y domingos a las $6 \mathrm{pm}$

Domingos a las $7 \mathrm{pm}$

Viernes 12pm

Domingos en la noche

Domingos a las 6pm 
Domingos a las 7pm o después del cine o los jueves a las 4pm después de pasear con el enamorado.

¿Qué productos no deberían faltar en el fast

food? Lechuga, tomates, verduras y ensaladas.

Verduras y frutas

Verduras y frutas

Variedad de ensaladas y jugos

Verduras y frutas

Verduras y frutas.

¿Creen que si el cuy es aceptado como una opción a elegir, cuál debería ser el acompañamiento ideal? ¿Qué tipo de verduras recomendaría?

Con ensalada de chicharrón

Moderadora: Para ir pensando un poco en la respuesta, ¿Qué les parece la idea de incorporar el cuy?

Es buena idea

Es buena idea

Me parece buena idea

Para mí no es buena idea porque el cuy se come al horno o chactado

Es arriesgado pero sería innovador y como consumidora sí me gustaría

Depende de cómo se ofrezca el producto, por ejemplo si es con pan, no sería buena idea.

Moderadora: L presentación del cuy sería como el pollo, es decir, crocante.

Beatriz que no estaba de acuerdo con la idea: Yo una vez probé el cuy empanizado y no me gustó. 
¿Creen que si el cuy es aceptado como una opción a elegir, cuál debería ser el acompañamiento ideal? ¿Qué tipo de verduras recomendaría?

Acompañar el cuy con papa, con cremas de uchucuta.

Cuy con lechuga y tomate

Cuy con papa

Cuy con papa, pepino, tomate

Con papa y rocoto relleno

Cuy con ocopa de huacatay o ensalada con cebolla.

Cuy con papas sancochadas y ají con sacha tómate.

Moderadora: Ahora vamos a continuar sobre las salsas ¿Qué salsas son de su preferencia cuando asisten a un fast food?

Mayonesa

Mayonesa

Mayonesa

Mayonesa

Mayonesa

Una salsa mayonesa tipo agridulce con pimienta, que no recuerdo el nombre, lo encontré en una pollería, hay otra salsa amarilla también con maní y orégano.

¿Qué tipo de acompañamiento creen que se debe considerar en un fast food?

Una bebida, chicha morada o Coca Cola.

Refresco

Mates calientes.

Cremoladas 
Té helado

Refrescos

Hidromiel

¿Estarían dispuestos a consumir bebidas alcohólicas en el fast food? Si fuese positiva su respuesta ¿Cuáles?

Vino

Mojito

Té macho

Té macho

Anisado

¿Dónde sería la ubicación óptima del fast food?

Por el centro

Por el centro

Por el centro

Por el centro

Por mi casa, por el Molino

Por el centro

Por el centro

¿Cuánto estaría dispuesto a pagar por persona en este servicio de fast food?

15 soles

25 soles

20 soles

20 soles 
15 soles

20 soles con bebida

20 soles con bebida

Moderadora: Les voy a mencionar algunos nombres ¿Cuál de estos nombres le parece la mejor opción para el fast food?

Rucutu (Rocoto)

Hayaq (Picante)

Quncha (Fogón)

Otras.

Todos: No estamos de acuerdo con los nombres propuestos.

Moderadora: ¿Tal vez algún nombre que se les ocurra a ustedes?

Yo pienso que debería ser un nombre más para jóvenes porque ellos son los que más van a los fast food.

Bells tal vez que significa belleza y comodidad, si el local es atractivo.

¿Por qué medios les gustaría informarse sobre publicidad y promociones de este nuevo negocio?

Internet

Internet

Redes sociales

Facebook

Internet

Facebook

Afiches en bicicleta que pasan por las calles. 
Letreros en la calle, gigantografías.

¿Les gustaría dar alguna recomendación o sugerencia con relación a este proyecto de fast food? ¿Cuál sería?

Yo como consumidora asidua en la calle, recomendaría la buena atención, que haya un buen producto. Por ejemplo hace poco fui a comer, el producto es bueno y les cuento una experiencia, le dije a la moza que me trajera una gaseosa y una cerveza, era una cena con socios y la señorita me responde: ¿No ves que estoy ocupada? Y yo le respondí pero es tu trabajo y ya no pedimos bebidas, como comimos y nos retiramos. Contratan a gente no calificada, para ser mozos no los capacitan, comes bien pero te atienden mal y ya no regresas, ósea si tienes buena atención y buen producto creo que el local lo podemos obviar. Yo les recomendaría la atención.

La vez pasada fui al Paisa, no me atendieron, me hicieron hora, me trajeron la comida fría y ese es el recuerdo que te llevas y ya no quieres regresar.

Jessica: Cuando hay buena atención nosotros mismo podemos recomendar a que la gente vaya, a nuestros amigos y conocidos, marketing boca a boca, la atención al cliente es importante, yo me puedo fidelizar.

Si no me atienden bien ya no regreso.

Moderadora: Bien, hemos finalizado con las preguntas, muchas gracias por su participación, la opinión de cada uno es valiosa para nosotros.

Marita: Gracias chicos por sus respuestas, nos va a ayudar mucho a lo que es nuestra investigación de nuestro proyecto y bueno eso sería todo, muchas gracias 


\section{Anexo 5.Transcripción Focus Group NSE C, de 18 a 29 años}

MODERADORA: Buenas noches rimero agradecerles por la asistencia en el apoyo de esta investigación que se está llevando a cabo. Mi nombre es Marita Cahua y ere la moderadora del grupo, el tema que se desarrollara durante esta dinámica es la apertura de un nuevo fast food en la ciudad de Cusco, donde ustedes ya saben que existen algunas cadenas internacionales y otras empresas locales con diversas opciones a escoger y con precios accesibles para todos.

Antes de comenzar con el desarrollo del focus group y entrar un poco en confianza voy a presentarme de forma breve, luego de ello les pediré a todos ustedes que lo hagan; bueno como ya les mencione mi nombre es Marita Cahua, soy licenciada en turismo y hotelería y bueno yo soy la administradora en este hotel y en mis ratos libres, me gusta ir al campo y disfrutar con la familia o ir al cine de vez en cuando. Ahora yo les voy a agradecer que ustedes también se presenten del mismo modo.

LESLIE: "Mi nombre es Leslie, soy estudiante tengo 19 años y los fines de semana me gusta pasar con mi familia"

MANUEL: "Mi nombre es Manuel bueno ahora estoy trabajando en un restaurante, bueno soy bar tender y todos los días chambeando"

DENILSON: "Buenas noches mi nombre es Denilson ahorita me dedico externamente con mi empresa a hacer proyectos y varias cosas, me gusta jugar futbol y salir al campo e ir al cine"

DIEGO: "Buenas noches mi nombre es Diego, estudio la carrera de administración de empresas, tengo la edad de 19 años y en mis días libre me gusta jugar futbol y leer la palabra de Dios.

CARMEN: Buenas noches mi nombre es Carmen Rosa, yo soy estudiante de administración de empresas y tengo 20 años y en mis ratos libre me gusta escuchar música y cantar. 
SOLEDAD: Buenas noches mi nombre es Soledad, estudio administración, en mis horas libre me gusta leer y jugar.

MODERADORA: Muchas gracias a todos, antes de empezar con la entrevista debo indicarles que no hay preguntas correctas e incorrectas, deben ser veraces con sus respuestas, deben participar una persona a la vez en orden y debemos escuchar a los demás.

Ahora voy a comenzar con la primera pregunta:

¿Qué es para ustedes un fast food?

MANUEL: Comida rápida al instante, hamburguesas, churritos, picarones cosas que sean al instante.

DIEGO: Comida rápida, por lo que yo sé el concepto es como un restaurante donde venden comida rápida y delivery’s.

CARMEN: Creo que el fast food como es comida rápida la mayoría de las personas tienen muy poco tiempo para poder comer y lo que necesitan es comida rápida.

DENILSON: Creo que todos tenemos una idea de fast food y creo que están con la comida precosida.

LESLIE: Comida rápida.

SOLEDAD: Comida rápida algo que sea al instante.

MODERADORA: Bien vamos con la segunda pregunta:

¿Qué palabra se les viene a la mente cuando escuchan el termino fast food?

MANUEL: papas fritas, anticuchos, bembos, McDonald's, rocoto relleno.

LESLIE: Hamburguesas

MANUEL: cosas que encuentras en el camino.

MODERADORA: Vamos con la tercera pregunta: 
¿Qué encuentran de positivo en un fast food?

DIEGO: Primeramente la rapidez con la que te atienden el tiempo creo que es de 2 a 5 minutos.

LESLIE: También te lo puedes llevar.

DENILSON: Calmar las ansias, el antojo.

MODERADORA: Creen que la parte del precio puede ser algo positivo.

DENILSON: De acuerdo donde esté ubicado

MANUEL: Por ejemplo en una carreta y una empresa como Bembos hay mucha diferencia, Bembos te pone una cantidad bien elevada y no es muy bueno para mí, prefiero una señora de una carreta.

DIEGO: Tiene que ver también el servicio y la calidad.

MODERADORA: Vayamos a parte contraria:

¿Qué de negativo encuentran en un fast food?

CARMEN: Calorías, la mayoría de los fast food es grasa.

DIEGO: Comida chatarra, cuando está lleno el tiempo de espera.

DENILSON: Todo fast food es anti higiénico debido a que en una carreta por ejemplo no sabemos en qué condiciones está el aceite, puede ser de días anteriores, no nos fijamos en eso solo en el producto.

MANUEL: También es depende de donde es, por ejemplo si vamos a Lima y es un lugar en malas condiciones nos pueden dar carne de perro, pero viendo aquí que estamos en Cusco la gente es más humilde, más sencilla entonces tratan de hacerlo más limpio. 
MODERADORA: Ahora, aquí vamos a tener tres preguntas en una sola, por favor tomen atención. ¿Cuántas veces al mes, en que días de la semana y en que horario concurren a un fast food generalmente?

MANUEL: En horario a veces paso cualquier rato y se antoja, 1 a 2 veces al mes y meses en que no y otros que sí, viernes o sábado un fin de semana.

DIEGO: yo consumo casi diario 20 días al mes, de 11 a 11:30 de la mañana.

DENILSON: Yo me veo obligado a consumir, estoy acostumbrado a comer comida chatarra.

LESLIE: Al mes 2 a 3 veces, los fines de semana y por las noches.

CARMEN: En mi instituto hamburguesas

SOLEDAD: Raras veces no 2 a 3 veces, viernes o sábado, por las noches

MODERADORA: Bien pasamos a la siguiente pregunta:

¿Con quienes suelen acudir a estos centros de comida rápida? ¿Solos, con familia, con amigos?

MANUEL: Mas con amigos.

DENILSON: Mas con amigos que con la familia.

TODOS: Con amigos.

MODERADORA: bueno pasamos a la siguiente pregunta:

Yo les voy a mencionar unas variables y ustedes me van a dar el grado de importancia que tienen para ustedes, cada variable que les voy a presentar, donde 1 tiene el puntaje más bajo y 10 el más alto.

Vamos con la ubicación:

¿Cuán importante es para ustedes la ubicación?

DIEGO: 5 
CARMEN: 5

MANUEL: 3

SOLEDAD: 4

LESLIE: 5

DENILSON: 10

¿Cuán importante es ambientación del local?

DIEGO: 7

CARMEN: 8

LESLIE: 9

SOLEDAD: 10

MANUEL: 5

DENILSON: 7

¿Tipo de producto?

SOLEDAD: 9

CARMEN: 6

DENILSON: 10

MANUEL: 10

DIEGO: 10

LESLIE: 10

¿La calidad del producto?

SOLEDAD: 8

LO DEMAS: 10

¿La atención que ustedes reciben? 
TODOS: 10

¿Precio?

DENILSON: 5

LOS DEMAS: 10

MODERADORA: De las variables que yo haya mencionado hay alguna otra que tal vez no lo dije y ustedes os consideren importante.

DENILSON: Creo que no consideraron higiene.

MODERADORA: Ahora vamos con la higiene entonces:

¿Cuán importante es la higiene para ustedes?

TODOS: 10

¿Tiempo de espera?

DIEGO: 7

CARMEN: 7

SOLEDA: 8

LESLIE: 8

MANUEL: 7

DENILSON: 5

MODERADORA: Continuamos:

¿Cuál es su fast food favorito y por qué?

DENILSON: KFC porque es agradable el pollo y las papas.

MANUEL: El fast food de la universidad porque es económico y lo hacen en 5 minutos

LESLIE: El local del instituto.

SOLEDAD: KFC porque me gusta su pollo crocante. 
CARMEN: McDonald's porque me atendieron rápido y porque me hicieron descuento.

DIEGO: La salchipaperia de mi barrio por la calidad y la atención es buena y es económico.

¿Qué les gusta más de su fast food favorito?

DENILSON: Las cremas

SOLEDAD: Las cremas

DIEGO: La comida

¿Que no les gusta de su fast food favorito?

DENILSON: El como lo hacen.

DIEGO: Publicidad engañosa.

MANUEL: La demora y la publicidad engañosa.

LESLIE: La higiene porque no vemos como lo preparan.

¿Cuáles su platillo favorito cuando van al fast food?

DIEGO: Salchipapas

CARMEN: Hamburguesas

LESLIE: Salchipapas

SOLEDAD: Hamburguesas

MANUEL: Hamburguesas y pollo

DENILSON: Nuggets

¿Qué tiempo consideran prudente para que su orden este lista?

TODOS: de 5 a $10 \mathrm{~min}$

¿Cuánto tiempo permanecen en un fast food considerando desde la entrada?

MANUEL: 10 a $15 \mathrm{~min}$ 
CARMEN: 20 min si no estaría apurada

DENILSON: 15 min

DIEGO: $30 \mathrm{~min}$

SOLEDAD: $20 \mathrm{~min}$

LESLIE: $20 \mathrm{~min}$.

¿Hay algún plato que a ustedes les gustaría encontrar en un fast food y que en ningún local lo tenga?

MANUEL: Ceviche, hamburguesas con lomo saltado, hamburguesa de chicharrón.

DIEGO: Hamburguesas de lomo saltado, milanesa, combinados clásicos.

¿Les gusta consumir algún tipo de postre después de comer en el fast food?

DENILSON: Helado

¿Qué tipo de carnes les gustaría encontrar en un fast food?

CARMEN: Chancho

SOLEDAD: Chancho

DENILSON: Cuy

¿Les gustaría encontrar en las opciones de productos de fast food comida con valor nutritivo? ¿Si fuese positiva la respuesta mencione algunas opciones?

DIEGO: Si, quinua, kiwicha

MANUEL: Maca, quinua

DENILSON: No

LESLIE: Ensaladas y verduras

SOLEDAD: Verduras 
CARMEN: Verduras

¿Estarían dispuestos a pagar más por adquirir productos frescos y naturales de la región con valor nutritivo en un fast food?

DIEGO: De acuerdo al producto

MANUEL: Depende del momento

LESLIE: Si, si me dan un pollo fresco y bastante ensalada

SOLEDAD: ¿De acuerdo al producto?

CARMEN: Por las ensaladas

¿Consideran una buena idea colocar un bar dentro del fast food?

MANUEL: No si es un fast food

CARMEN: Seria un cambio de ambiente.

DENILSON: Creo que sí.

DIEGO: Por ejemplo Rhupa's en un lugar donde te ofrecen música electrónica y también creo que venden tragos.

DENILSON: Si

LESLIE: No

¿Qué tipo de bebidas alcohólicas y no alcohólicas les gustaría encontrar en las opciones que ofrece fast food?

DIEGO: Agua, bebidas calientes.

DENILSON: Gaseosas.

CARMEN: Refrescos.

MANUEL: Principalmente café y agua mineral, pisco, jugos

DENILSON: Pisco sour 
LESLIE: Agua, bebidas calientes y Machupicchu.

SOLEDAD: Agua mineral y bebidas calientes.

¿Qué precio estaría dispuesto a pagar por un plato personal en un fast food?

DIEGO: 4 soles

LESLIE: 8 a 10 soles

CARMEN: 8 a 10 soles

MANUEL: 8 soles

SOLEDAD: 5 A 10 soles

DENILSON: 3 a 4 soles

¿Qué es calidad para ustedes en un fast food?

DIEGO: Según a la expectativa del cliente, cuando una persona quiere comprar y aprobar ese producto el cliente se ve asombrado, que me ofrezca un valor agregado, primeramente la atención y la higiene.

CARMEN: Que nos ofrezcan un producto de calidad, que nos ofrezcan un producto nutritivo, el ambiente, la comodidad y la atención.

LESLIE: Buena atención y la comodidad y el ambiente.

SOLEDAD: La comodidad y el ambiente.

DENILSON: Higiene.

¿Cómo debería estar ambientado un fast food en cuanto a decoración y música?

DIEGO: Pintado color blanco.

CARMEN: Pintado color crema.

MANUEL: Color crema.

DENILSON: Colores claros. 
SOLEDAD: Color crema o blanco.

DIEGO: la música depende la ubicación.

MODERADORA: Bueno vamos a pasar ahora a la propuesta de valor que es un fast food donde se va brindar piqueos a base de pollo, cerdo y cuy, empanizados con harina de kiwicha selecta de san salvador con un toque de hierbas finas, salsas acompañadas de papas nativas fritas, sándwiches y hamburguesas a base de pollo, carne de res acompañadas con ensaladas frescas como lechuga, zanahoria, apio, tomate, cebolla, brócoli y papas andinas fritas. Con relación a las bebidas podrá encontrar las típicas limonadas y bebidas especiales a base de frutas y gaseosas y también aperitivos con alcohol como el mojito el chilcano con hierbas aromáticas frescas, cerveza y gaseosas. Es nuestra propuesta que les estamos sugiriendo a ustedes y muy aparte lo que se come convencionalmente, pollo broaster, hamburguesa. Ahora voy a la pregunta.

¿Qué opinan de este concepto de fast food?

DIEGO: Creo que esa propuesta de fast food sería muy innovador porque es algo andino, con productos adicionales, para mí sería una buena idea, es algo más nutritivo e innovador.

SOLEDAD: Esta bueno porque ofrecen productos frescos, y ofrecen verduras.

LESLIE: Seria algo novedoso e innovador.

MANUEL: Creo que los precios de la carne en todo aspecto son muy elevados y para un fast food no creo que sería, pero viendo los precios de la empresa y la dueña pienso que se iría a la quiebra.

DENILSON: Me parece muy innovador y me gustaría consumir y probar.

MODERADORA: ok gracias ¿Han escuchado algún concepto como este?

DIEGO: Si yo escuche por ejemplo en los papachos creo que es de Gastón Acuario en la cual hizo una promoción en la plaza san pedro en la cual vinieron los del local. 
MANUEL: Hay un restaurant que se llama nunataymi y trabaja con la gente de Pisac y ellos le dan lo que verduras.

CARMEN: Yo creo que las personas quieren consumir más lo nutritivo y eso es lo que más busca la gente.

DENILSON: La gente siempre busca algo innovador.

MODERADORA: Papachos está considerado como un restaurante porque más venden platos a la carta.

MODERADORA: ¿La propuesta que les menciona es buena es mala, que les gusta y que no les gusta?

DIEGO: Para mí es muy buena tiene que estar bien ubicado si quieres hacer conocer a la población.

CARMEN: Si me parece buena y se tendría que hacer conocer.

SOLEDAD: Sería muy bueno porque tiene productos como verduras.

MANUEL: Sería muy bueno, porque a quien no les gustaría encontrar papas nativas y si es en un fast food seria genial.

DENILSON: También tiene que ver mucho la ubicación y el costo ¿Asistirían o no al tipo de negocio que se les está proponiendo?

TODOS: Si asistirían

¿Con que frecuencia asistirían?

DIEGO: Depende del lugar.

MANUEL: Depende del lugar.

CARMEN: Depende del ambiente

DENILSON: Si es bueno y hay variedad todos los días. 
¿En qué horario asistirían y que días de la semana?

DIEGO: En las tardes

CARMEN: Fin de semana

SOLEDAD: Fin de semana

MANUEL: Los martes que es mi libre por la tarde

DENILSON: 3 a 4 veces a la semana

LESLIE: Fin de semana a partir de las 8

¿Qué productos no deberían faltar en un fast food?

MANUEL: papas fritas

CARMEN: Agua

SOLEDAD: Pollo

DENILSON: Pollo

LESLIE: Carne

¿Qué les parece la idea de incorporar el cuy en las opciones del fast food?

DIEGO: Sería muy interesante y tiene mucho valor nutricional

TODOS: Muy bueno

¿Creen que si el cuy es aceptado como una opción a elegir cual sería el acompañamiento ideal?

MANUEL: Papa al horno y su rocoto relleno, choclo también.

DENILSON: Chicha morada.

LESLIE: Limonada

CARMEN: Ensalada y papas

DIEGO: Camote 
SOLEDAD: Papa y rocoto relleno

MODERADORA: ¿Y sobre las salsas?

MANUEL: UCHUCUTA, AJI

CARMEN: Salsa picante

SOLEDAD: Mostaza, kétchup.

DENILSON: Lo típico

DIEGO: Ocopa

¿Qué tipo de acompañamiento debería considerarse en un fast food?

MANUEL: Chicha de jora

LESLIE: Frutilla da

DIEGO: Chicha morada y chicha blanca

MODERADORA: ¿Qué bebidas les gustaría encontrar en la carta?

DIEGO: Gaseosas y agua.

LESLIE: Bebidas calientes

MANUEL: Café o ponche de habas

¿Estarían dispuestos a consumir bebidas alcohólicas en el fast food?

TODOS: No

MODERADORA: ¿Dónde seria la ubicación óptima para este fast food?

CARMEN: En el centro

MANUEL: En el centro los locales son caros

DIEGO: Por la plaza San Francisco

DENILSON: En un lugar transitado porque si no va a ver gente que conozca.

SOLEDAD: Por la cultura 
¿Cuánto estaría dispuesto a gastar por persona en este fast food?

MANUEL: 15 soles

CARMEN: 15 soles

SOLEDAD: 15

LESLIE: 15

DENILSON: 30

DIEGO: 15

MOERADORA: ¿Cuál de estos nombres le parece una mejor opción para el fast food?

- RUCUTU

- JAYAC

- CONCHA

DIEGO: Jayac

MANUEL: Jayac

LESLIE: Jayac

DENILSON: Concha porque tiene varios significados

CARMEN: Jayac pero le aumentarían algo mas

SOLEDAD: Concha

MODERADORA: ¿Por qué medio les gustaría informarse sobre la publicidad y/o

promociones de este nuevo negocio?

DIEGO: Facebook ya que sería una forma de digitalizar

CARMEN: Redes sociales

LESLIE: Redes sociales

MANUEL: Facebook 
DENILSON: Volantes y redes sociales

MODERADORA: ¿Les gustaría dar alguna recomendación o sugerencia con relación a este proyecto de fast food?

DENILSON: Bueno mi sugerencia, yo lo pondría como andino para llamar la atención

DIEGO: Que lleve algún nombre típico de la región de Cusco.

MANUEL: Algo que vaya con el cuy

MODERADORA: Bueno chicos hemos culminado con este focus group, agradecerles nuevamente por la asistencia y por todos los comentarios que me han hecho saber, nos va ayudar mucho a nuestro proyecto y bueno eso sería todo. 


\section{Anexo 6.Transcripción Focus Group NSE A, de 30 a 45 años}

Moderador 1: buenas noches a todos, primero agradecer por el apoyo y asistencia en esta investigación que estamos llevando a cabo, mi nombre es Marita voy a hacer la moderadora en este oportunidad junto con Lisbeth. El tema que se va a desarrollar durante esta dinámica es la apertura de un nuevo fast food en la ciudad de Cusco como ustedes ya saben existen cadenas internacionales y otras que son empresas locales y como ustedes ya saben con diversas opciones a escoger y con precios accesibles a todos. .

Voy a empezar a presentarme primero, y luego presentarse ustedes.

Mi nombre es Marita, soy Lic. En turismo y hotelería, soy administradora en el hotel Antahuasi, en mis ratos libres me gusta ir al campo, al cine, y en la actualidad estoy estudiando una maestría.

Moderador 2: Buenas noches con todos, mi nombre es Lisbeth, soy contadora de profesión, trabajo en una entidad financiera en el área de créditos, actualmente vengo estudiando una maestría, y en mis ratos libres me gusta estar con mi familia.

Luis Fernando: buenas noches con todos, soy bachiller en contabilidad, trabajo en la cooperativa santo domingo, en el área de créditos, me gusta escuchar música.

Bryan: de profesión soy ing. Geólogo, vengo cursando mi segunda carrera de Ing. Civil, en ratos libres con familia, primos, y viajar.

Yamil: bach. en arqueología trabajo en ministerio de cultura, en mis ratos libres me gusta hacer deporte y estar con la familia.

Karina: soy tec. en administración de hoteles, trabajo en el hotel Antahuasi, en ratos libres con mi familia, salir de viaje.

Jesús: estudiante de instituto de música en ratos libres, estar en familia y compartir con ellos. 
Francia: trabajo en una entidad financiera, en mis ratos me gusta leer.

Elvis: trabajo en la empresa rico pollo, soy analista de desarrollo organizacional y en ratos libres me gusta hacer deportes y ver películas.

Ana: estoy estudiando de contabilidad en un instituto, en mis ratos libres me gusta escuchar música.

Moderador 1: Antes de empezar con las preguntas quiero decir que no hay preguntas correctas e incorrecta deben ser veraces con sus respuestas, deben participar una persona a la vez, vamos a empezar con la primera pregunta

¿Qué es para ustedes un fast food?

Luis Fernando: un lugar de atención, donde puedes encontrar comida, algo al paso, algo apetecible, puedes adquirir en el momento y deja seguir con tu rutina.

Bryan: es un centro o un lugar donde podemos ir con nuestras familias, tipos de comida en menos tiempo y te dan a cómodo precio.

Yamil: para mi es rico, accesible y bueno compartimos bastante con la familia o en momentos agradables, pasar un rato.

Elena: dan porciones, las personas van conversan un rato, y así mismo no puedan gastado tanto, de acuerdo a la porción.

Jesús: para compartir con la familia, amigos, accesible, mayormente para disfrutar.

Elvis: un centro de comidas rápidas, la idea que se me viene es encontrar comidas apetecibles, que te permitan ahorrar tiempo.

Ana: puedes ir con la familia cuando descansan.

Luis Fernando. Un centro de expendio de comida, para mi es rico, compartimos bastante con mi familia o en momentos que tenemos libres. 
Jesús: accesible para diversas posibilidades económicas.

Moderadora 1: gracias vamos con la siguiente

¿Qué palabras se les viene a la mente cuando escuchan el término fast food?

Luis Fernando: papitas

Bryan: Hamburguesa

Yamil: pollo

Elena: papitas, acompañada de alguna fritura.

Jesús: grasa

Elvis: comida chatarra

Ana: gaseosa

Jamil: grasa

Moderadora 1: bien ¿Qué encuentran de positivo en un fast food?

Luis Fernando: un lugar para comer

Bryan: economía

Yamil: variedad

Elena: para comer más rápido

Jesús: comida agradable

Elvis: apetecible

Ana: accesible

Moderadora 1: yéndonos a la parte contraria ¿Qué de negativo encuentran en un fast food?

Luis Fernando: azucares, y grasa

Bryan: en contra de la salud

Yamil: en contra de la salud 
Elena: en contra de la salud

Jesús: grasa, harina para la salud, en contra de la salud

Elvis: mucha hormona

Ana: en contra de la salud, de acuerdo al grado de consumo.

Moderadora 1: pasamos a la 5ta pregunta, van a haber 3 preguntas, tomen atención por favor. ¿Cuántas veces al mes, qué días de la semana y en qué horario concurren a un fast food generalmente? O recurren a un fast food generalmente.

Luis Fernando: 2 a 3 veces los fines de semana.

Yamil: consideramos dentro del fast food el pollo a la brasa o chifa?

Moderadora 1: No, porque el pollo a la brasa y el chifa tienen otra forma de servicio, en un fast food mayormente espera su comida, y te vas a sentar en una mesa, en una pollería o chifa te llevan la carta y te reciben el pedido tienen otro tipo de servicio

Bryan: entonces viendo esa categoría, las hamburguesas son también fast food, eso quiere decir que los estudiantes o hemos trabajado hemos concurrido muchas veces, muchas veces no alcanza para el almuerzo en el trabajo o algo, y muchas veces lo primero que nos compramos es una hamburguesa de frente te vas a tu of.

Elena: 2 o 3 veces, rutinariamente sábado o domingo entre las 7 y 9 de la noche

Jesús: mayormente los fines de semana, por ejemplo cuando vemos una película, y nos vamos a comer algo hasta esperar, 2 veces al mes.

Elvis: prácticamente los fines de semana, promedio 1 vez por fines de semana, es decir 4 veces al mes, 5, 67 de la noche.

Ana: 1 vez al mes 5 a 7 de la noche, puede ser un miércoles, sábado. 
Moderadora 2: ¿Con quiénes suelen acudir a estos centros de comida rápida, solos, con la familia, con los amigos?

Luis Fernando: con mi enamorada

Yamil: con la familia.

Bryan: amigos y con la familia.

Elena: con mis amigos y mi novio.

Elvis: solo, acompañado, con la familia, depende, por ejemplo tengo que supervisar otras ciudades y por mi trabajo tiendo a comer solo.

Ana: amigos y familia.

Moderadora 2: pasamos a la segunda pregunta les voy a mencionar algunos factores que influyen en un fast food y Uds. le van a dar una clasificación del 1- 10 por favor iremos en orden ¿Qué factores influyen para la elección de un fast food determinado?

\begin{tabular}{|c|c|}
\hline VARIABLES & CALIFICACION \\
\hline $\begin{array}{l}\text { Ubicación } \\
\text { Ambientación }\end{array}$ & $\begin{array}{c}8-6-8-8-8-8 \\
5-4-5-4-4-6-6-5\end{array}$ \\
\hline Tipo de producto & $10-10-10-10-10-10-10-10$ \\
\hline Calidad de productos & $10-10-10-10-10-10-10$ \\
\hline Variedad de productos & 8-10-10-8-8-7-9- \\
\hline $\begin{array}{l}\text { Atención } \\
\text { Precio } \\
\text { Otros }\end{array}$ & $\begin{array}{c}10-10-10-10-10-10-10 \\
10-9-9-9-9-9-9\end{array}$ \\
\hline Limpieza & $10-10-10-10-10-10-10-10$ \\
\hline Cantidad & $10-8-8-6-8-8-8-7-8$ \\
\hline Tiempo de espera & $7-8-8-7-8-8-8-8-9$ \\
\hline
\end{tabular}

Nota. Fuente: Elaboración propia 
Pero la persona que te atiende, y te atiende mal y te atiende seriamente ya no dan ganas de volver.

Moderador 1: Algún otro punto,

Moderador 2: Tal vez sería en el servicio o parte de la atención

Moderadora 1: entonces pasamos a la siguiente pregunta ¿Cuál es su fast food favorito? ¿Por qué?

Elena, KFC porque su sazón es un poco más agradable

Jamil Popeyes, porque me gusta el picante, por las papitas también picantes, aumento 4 soles y me aumentan una caja de papitas.

Bryan Otogril por la calidad del servicio

Elvis: Otogril por la calidad del servicio

Jesús: Otogril por el sabor

Luis Fernando KFC por el sabor

Ana: Popeyes porque te dan la opciones de mesclar picante y no picante, porción de arroz, adiciones, tiene variedad

Moderadora 1: ahora el contrario de esta pregunta ¿Qué no le gusta de su fast food favorito?

El tiempo de espera

El tiempo de espera

El tiempo de espera

El tiempo de espera

El precio

El ambiente, como dejan las demás personas los ex clientes, muchas veces dejan sucias, muchas veces cada uno tiene que estar limpiando su propia mesa o las sillas. 
Moderadora 1: bueno ¿Qué tiempo consideran ustedes que es prudente para que su orden esté lista?

10 minutos, de 5 a 10 minutos

5 a 10 minutos

5 a 6 minutos a más tardar 10 minutos, si no ya no sería comida rápida, si estas yendo al cine y quieres aprovechar ese tiempo. Sino después sin sabor, ya no se disfruta

Unos 8 minutos

5 a 7

También de 5 a 7

De 5 a 10

3 minutos

Moderadora 1: en su experiencia ¿Cuánto tiempo permanece en un fast food?

dependiendo

20 minutos

En el real plaza por lo general 20 a 30 hora, si recurrimos a la esquina es menos tiempo, puede ser 4 minutos, pero si se trata del tiempo de permanencia 20 minutos

Es variable, por lo general 15 minutos

Por lo general 20 a 30 minutos

20 a 25 minutos

De 20 a 30 minutos

20 a 30 minutos

15 minutos 
Moderadora 1: ¿Hay algún plato que a ustedes les gustaría encontrar en un fast food y qué no lo tenga ningún otro?

Cuy

Chancho

Chicarrones podría ser (2 precitas), ajicito.

Milanesa de pollo, carne no las encuentras, y también no las encuentras.

También apanado

Dulces también,

Postres también

Pero no puedes encontrar un solo lugar no se encuentra dulce y salado.

Pero en cada stand, si es dulce dulce, pero si quieres algo salado que haya el salado, que estén juntas pero no revueltos, pero ya se tiene la variedad y si está a la vista mejor.

Por ejemplo en KFC tienen sus helados, pero no le damos importancia, pero ahí están sus helados, pero de repente alguna propuesta nueva, tal vez un combo ya se tienen algo nuevo, a veces cuando vas en familia, tu prefieres algo salado pero el niño quiere helado, entonces ya tienes esa variedad

Moderadora: 1 ¿Algo más?

Los Dispensadores automático de gaseosa como cuando fui al Burguer King, como cuando estuve en Madrid y consumes la cantidad que quieras, a un solo precio

Moderadora 1: ¿Les gusta consumir algún tipo de postre después de comer en el fast food?

Creo que bebidas calientes, por el tipo de comida que se sirven.

Si bebidas calientes

Digestivos 
Café o mate

Les vuelvo a repetir ¿Les gusta consumir algún tipo de postre después de comer en el fast food?

No

No

Si

No

No

No

Si, helados.

Moderadora 1: Qué tipo de carnes le gustaría encontrar en un fast food?

Carne de pollo y res

Pollo, res y cerdo

Pollo, res y cerdo

Pollo, res y cerdo

También pollo res y cerdo

Pollo

También pollo

Moderadora 1: algo que ya estamos tocando ¿Les gustaría encontrar en las opciones de productos de fast food comida con valor nutritivo? Si fuera positivo cual sería estas opciones.

Por ejemplo yo como en oto grill, depende de lo que pidas 
Hace poco vi un reportaje a base de fruta orgánica, las ensaladas, los jugos, sé que cuesta más, pero se incentiva por ejemplo la exportación, productos como kiwicha, quinua, maca, podría ser, a mí me gustaría si encontrar

También estuve viendo en internet, se puede sustituir la harina, se puede poner otros productos naturales, meterle mucha harina, poner otros productos naturales.

Revalorar la quinua, se puede tener diferentes variedades, pasteles, comida, empanadas, alternativas diferentes.

También varias las ensaladas, lo que te dan es col, mayonesa

Moderadora 2: que te gustaría encontrar

Por ejemplo el brócoli, betarraga, u otros que comemos a diario

Pero cuando es en la práctica, cuando escuchamos fast food ya sabemos que es pollo frito, papa, y esos productos como que se pueden encontrar en el mercado y más económico, desde mi punto de vista voy a consumir pollo.

La idea es no perder el sabor del producto. Pero podríamos darle un valor agregado

Moderadora 1: podría ser, igual vas a consumir pollo, papas fritas, pero si vas con una persona vegetariana no va a poder consumir.

Ensaladas

De quinua

Moderadora 1: con lo que mencionan estarían dispuestos a pagar más por adquirir productos frescos y naturales de la región con valor nutritivo en un fast food? ¿Qué alimentos serian?

Claro si es un producto bueno, tú vas, así sea el precio.

Pero el factor precio muchas veces no es un determinante para ir a un fast food. 
Igual pero si vas a comer algo que te guste así te cueste, igual lo vas a pagar.

Pero estando en el nivel que quieras siempre vas a querer darte tu trabajo.

No es determinante, pero si tienes la posibilidad te vas a dar el gusto dependiendo de tus posibilidades económicos

Moderadora 2 la pregunta es estarían dispuestos a pagar más

Si en realidad sí.

$\mathrm{Si}$

$\mathrm{Si}$

$\mathrm{Si}$, si te quieres dar tu trato

Moderadora 1: ¿Que alimentos serían?

Quinua

Maca

Quinua

Ensalada de frutas también

Moderadora 1: Les escuche bastante hablar del precio, ¿Consideran ustedes que los precios son accesibles a todos?

$\mathrm{Si}$

Sí, pero si quieres algo, aumentas algo y listo.

Creo que sí, que están estandarizadas, por lo menos en Cusco, creo que es de 9.50.

Si son accesibles para todos.

Moderadora 1: ¿Considerarían buena idea el de colocar un pequeño bar dentro de un fast food?

Eso dependiendo 
En una carreta no

Pero para bajar la grasa

¿Sería buena idea implementar?

No

No

No

No

No

Hay pero no

Moderadora 2: ¿pero te gustaría un bar?

Pero un fast food es para comida rápida, es para comer, se caracteriza por el local y todo.

Y también la comida de un restaurant que se consume puedes acomodar tragos

Si quieres ir a un bar, piensas comes y te vas a un bar.

También dependerá de la cultura.

Pero si uno quiere tomar un trago, no se si sea relevante, si está a un lado quien quiere va y quien no quiere no va.

En un bar normalmente se fuma y se toma más hasta $3^{\text {a }} 4$ horas. Podría ser para una previa.

Un bar en un local aparte podría ser. Aquí van a tomar y se quedan de largo, depende de la cultura.

Moderadora 1: Qué tipo de bebidas alcohólicas y no alcohólicas le gustaría encontrar en las opciones que ofrece un fast food?

Pisco sour

Pisco sour 
Vino

Pisco

Pisco

Cerveza

Vino

Vino y pisco

Moderadora 2: Y bebidas no alcohólicas

Jugos

Mates

Mates y refrescos

Mates

Mates y refrescos

Jugos y mates

Jugos y mates, chicha morada.

Infusiones también

Moderadora 1: ¿Qué precio estaría dispuesto a pagar por un plato personal en un servicio de fast food?

15

Unos 15

Gual 15, variable hasta 18 o 20

20

Máximo 20

$15-20$ 
De 10 a 15

Moderadora 1: ¿Qué es calidad para ustedes en un fast food?

Abarca limpieza, y de acuerdo como te ha ido, desde el trato, hasta el sabor y la limpieza

Más al sabor y la cantidad

Estamos acostumbrado que sea arto, rico y barato, también cuenta la limpieza, el trato,

O que sea descortés, pero si es con sonrisa y te atienden con unas ganas.

También en la variedad de los insumos, que no te cambien a última hora.

Platos con chorizos y otras cosas, no lo que tienen a su disposición si no lo que tu estas comprando

Moderadora 2 ¿Algo más?

La limpieza ante todo, si es un lugar sucio, no sería agradable.

Limpieza, atención, y el sabor

Moderadora 1: también en una sola palabra ¿Cómo debería estar ambientado un local de fast food, en cuanto a decoración y música?

\section{Colorido}

Colores vivos

Que sea variado en música, pero no reggaetón

Moderadora 2: ¿Que colores les gustaría?

Amarillo

Verde

Verde limón

Rojo pastel 
Moderadora 2: ¿Qué tipo de música?

Las baladitas, música tranquila

Instrumental, se conversa agradablemente.

Buena opción, música instrumental

Rock alternativo

La de $\operatorname{los} 80$

Moderadora 2: cuales son los fast food que conocen

KFC, bembos

McDonald's, Bembos

Popeyes, todos

En amauta, hay hamburguesas de pollos deshilachados, no tiene nombre, pero si es fast food.

Frente a la Unsaac, donde venden butifarra

$\mathrm{La}$ arequipeñita, el nombre es lo de menos.

Los que conocemos es porque los hemos visto en alguna publicidad.

Hay una que es nueva Rupha’s Diner, buena música, para lleno, es rica, sobre todo las empanadas, cafés, limonadas.

Moderadora 1: bueno ahora le daremos a conocer nuestra propuesta de valor Un fast food donde se brinde piqueos a base de pollo, cerdo y cuy empanizadas con harina de kiwicha selecta de San Salvador y con toque de hiervas finas y salsas acompañadas de papas nativas fritas, sanguches y hamburguesas a base de pollo, carne de res acompañadas de verduras frescas de la zona, tales como lechuga, apio, zanahoria, tomate, cebolla, brócoli y papas andinas fritas. 
Con relación a las bebidas, podrá encontrar las clásicas limonadas, y bebidas especiales a base de frutas y gaseosas también aperitivos con alcohol como el mojito, chilcano, con hierbas aromáticas frescas, cerveza y gaseosa.

Moderadora 1: ¿Qué opinan/piensan de este concepto de fast food?

Interesante, al menos por el cuy, ya es otra variedad, lo que se me viene a la mente, es la presentación

Podría ser en trozos

Creo que sería interesante, en Cusco la gente usualmente piensa en cuy y lechón, y si se tiene ese plato, te va a llamar la atención, particularmente me llama la atención

También me llama la atención, a otras personas llamaría la atención.

Es algo interesante, por la variedad que ofrecen, básicamente es una buena alternativa, es un beneficio no solo para los productores sino porque se utilizarían productos de la zona, sería más rara, pero buena

Propuesta nueva, innovadora, interesante, me gustaría verla plasmada, yo sí.

Creo que por la opción tan novedosa, la mayoría va a querer probar, es algo diferente, es otra opción, es diferente a lo clásico, ya no va a ver necesidad de bajar hasta saylla, quien sabe que no sea tan caro, dependiendo también de los precios.

Moderadora 2: ¿Han escuchado algún concepto como este?

No

No

No

$\mathrm{Al}$ menos con el cuy no, pero con el pollo y res y lo sabemos. 
Moderadora 2: ¿Es bueno, malo? ¿Qué les gusta, que no les gusta? ¿Por qué? ¿Asistirían o no al tipo de negocio que se está proponiendo?

El concepto está bien, en principio variedad, lo que han mencionado me gusta la variedad del cuy, también están innovando en bebidas, alcohólicas, y no alcohólicas

También me gusta lo de las papas andinas.

Coincido con mis compañeros, es muy novedosa, la variedad es tanto, la quinua, kiwicha, ya no solamente el clásico de la fritura si no un valor agregado.

Aparte que genera trabajo, el punto seria el lugar, donde estaría ubicada.

Podría darme un gusto, mi trato, por lo menos una vez al mes.

Moderadora 2: ¿asistirían o no?

$\mathrm{Si}$

$\mathrm{Si}$

$\mathrm{Si}$

De hecho

Es llamativo desde todo punto de vista

Me gustaría verlo, como lo preparan

También va a depender mucho del precio, porque si se va a tener acceso, va a ser concurrido si va a tener precios cómodos, pero si va a ser tipo restaurant, puede ser una vez al mes o cada quincena, pero también va a depender del sabor.

Pero como idea innovadora va a llamar mucho la atención.

Moderadora 1: ¿Con qué frecuencia asistirían?

Si el sabor es agradable y no es tan caro, lo puedes recomendar.

Mínimamente una vez por semana. 
En mejor de los casos, 2 veces por semana, y los fines de semana.

Pero también hay que ver el tema de la salud.

2 a 3 veces por semana

2 veces por semana, pero también puede ser dañino para la salud

1 o 2 veces por semana.

1 vez por semana

2 a 3 veces por semana

2 a 3 veces por semana

Moderadora 2: en cortas palabras ¿En qué horario asistirían y en qué días de la semana?

Hora de almuerzo

Hora de almuerzo

Hora de almuerzo o en la tarde al salir del trabajo 6 a 7 pm, miércoles, jueves, viernes o sábado.

A partir de las $6,7,8 \mathrm{pm}$

Usualmente viernes sábado domingo 7 a $9 \mathrm{~m}$

Viernes o sábado de 7 a 9

Los fines de semana, en el almuerzo, o cena

Viernes después del trabajo $7 \mathrm{~m}$

Fines de semana medio día.

Moderadora 2: ¿Qué productos no deberían faltar en el fast food?

Refrescos,

Variedad de carnes

Carnes 
Bebidas calientes y ensalada

Bebidas calientes y ensalada

Gaseosa

Bebidas calientes

Moderadora 1: algo más que se podría incorporar una idea más sobre la incorporación del cuy.

Choclo partido

Brócoli

Zanahorias,

Betarraga

Alternativa de ensalada.

Moderadora 2: sobre las salsas ¿qué salsas son de su preferencia cuando asiste a un fast food? ¿Que Uds. Hayan visto y de su preferencia?

La mayonesa

Mayonesa y mostaza

Kétchup

Ají y mayonesa

Ají panca

Ahora hay una combinación de mayonesa con una especie de verdurita, salsa de no se... salsa de ajo

Salsa de aceituna

Moderadora 2: ¿Algo que hayan probado?

Ají, uchucuta 
Moderadora 1: algún otro acompañamiento ¿Qué tipo de acompañamiento creen que debería tener?

Pequeña entrada como mote

Queso

El mote es nativo y consumible, y acompaña al cuy, cuando se va a provincia, al valle se consume mote.

Pero la idea central es fast food, hablar de otros acompañamientos seria para un restaurant.

Por ejemplo inventamos un combo, (ensalada rusa; pero no va con cuy, y de repente un agregado más).

Moderadora 1: que bebida que le gustaría encontrar en su fast food?

Todas las infusiones

Limonadas

Chichas

Refrescos (chicha morada, refrescos)

Igual refrescos, anisado de cortesía.

Mates, vino

Yo pienso el pisco, el anisado y los mates.

Mate de coca, es muy importante, también la muña.

Moderadora 2: ¿estarían dispuestos a consumir bebidas alcohólicas en el fast food? ¿Cuál sería?

$\mathrm{Si}$

Sí, claro

De repente un pisco sour, un vasito pequeño 
El área de sus áreas alcohólicas debería ser en porciones pequeñas, solo para acompañamiento, no para quedarse.

Mientras la porción sea pequeña la gente también va a comprar.

Quien no ha ido a comer chicharrones, y caballero uno tiene que consumir anisado.

Si consumiría

$\mathrm{Si}$, va a depender mucho del plato, porque hay platos que no ameritan acompañar con bebida, a no ser de estar con la predisposición.

También depende del tiempo.

Moderadora 2: ¿Dónde seria la ubicación óptima?

Túpac Amaru

Por el centro

Por la plaza, también le llamaría la atención a los turistas

Por la municipalidad, por regocijo

Si no es céntrico, por la cultura, por Manuel prado, por el real plaza; el real plaza se ha vuelto bastante movido, o por san Sebastián también.

Entre comillas es relevante, si el producto es bueno, la gente donde sea va a ir, si le comentas a tu papa, él va ir, y va a volver a ir, la primera impresión es la que vale, es muy importante.

Moderadora 2: ¿Cuánto estaría dispuesto a gastar por persona en este servicio de fast food? Igual, hasta 20

Unos 20

Unos 25 a 30 soles

30 mucho, mejor me voy a comer cuy a otro lado. 
Moderadora 1: es la opinión de él y la vamos a respetar.

Desde 8 soles como básico, máximo hasta 15 soles.

Yo como base 12.90 hasta 18 soles

Desde 10 hasta 15 a 18 soles.

De 11.90 hasta 15 soles

Mínimo 10 y máximo 20

Moderadora 2: ¿Cuál de estos nombres le parece la mejor opción para el fast food?

Rucutu (Rocoto)

Hayaq (Picante)

Quncha (Fogón)

Creo q los nombres no van con las comidas que se van ofreciendo, debería ser algo como fast cuy, tantas ideas que podrían pensar

Moderadora 1: algunos de los que hemos mencionado tal vez.

Hayaq me parece más llamativo

Hayaq

Hayaq podría ser

Hayaq o rucutu

Moderadora 1: o tal vez otro nombre

Hayaq

Hayaq

Moderadora 2: ¿Por qué medios le gustaría informarse sobre la publicidad y/o promociones de este nuevo negocio?

Redes sociales 
Redes, radio, televisión

Redes

Redes sociales

Redes sociales y radio, porque radios circula en las combis, en la calle, donde estemos la estamos escuchando.

Radio y redes sociales

Radio y redes

Moderadora 2: en nuestra última pregunta ya para terminar ¿Les gustaría dar alguna recomendación o sugerencia con relación a este proyecto de fast food?

Primero preocuparse porque salga bien el producto, la ubicación y la atención al cliente, nada cuesta una sonrisa.

Garantizar la calidad en cada proceso que van a utilizar, no se olviden que hay calidad en cada uno de los procesos, no descuidarla.

El tiempo de atención, la rapidez

Tener que estandarizar el tiempo para que las personas vayan motivadas por el producto y que vayan a obtener más rápido el producto.

Moderadora 1: Algo más

Creo que el tema de costos, creo que el cuy elevaría los costos.

Ver el tema de costos, y tamaños.

Moderadora 1: bueno chicos, agradecerles por su participación, por cada una de sus respuestas, nos va a ayudar con el estudio de mercado, a ver precios, u otros. Agradecerles por sus comentarios.

GRACIAS!! 


\section{Anexo 7.Transcripción Entrevista Gerente de Tienda KFC}

FICHA TÉCNICA ENTREVISTA A PROFUNDIDAD: EXPERTOS DEL SECTOR

Buenos días/tardes.

Mi nombre es

Soy estudiante de la Maestría en Ciencias Empresariales de la Universidad San Ignacio de

Loyola, y en esta ocasión nos encontramos realizando una investigación de mercado sobre los fast food en la ciudad de Cusco"

Permiso para grabar.

La información que nos facilite en esta entrevista será tratada para fines exclusivamente de la investigación, no pudiendo ser utilizada de forma nominal ni facilitada a terceros.

\section{OBJETIVO DE LA INVESTIGACIÓN}

El objetivo de llevar a cabo la entrevista a expertos, es conocer la opinión sobre la dinámica y crecimiento en el sector de fast food en estos últimos tiempos, y como se vería este sector de acá a tres años en la ciudad de Cusco.

\section{OBJETIVOS ESPECÍFICOS}

Conocer en líneas generales la percepción del experto sobre la presente investigación.

Conocer la percepción real del servicio de los fast food en la ciudad de Cusco.

Conocer las tendencias tanto de la oferta y demanda del servicio de fast food.

Conocer a las competencias y/o propuestas similares.

\section{PERFIL DEL ENTREVISTADO}

Persona con más de tres años de experiencia en la administración de fast food (empresarios, docentes, gerentes, expertos especializados etc., o que tengan manejo de temas asociados de bar y comedor). 
En la invitación, decir que se mantendrá una conversación, en la cual se les van a compartir los resultados preliminares que se han ido obteniendo y conocer su opinión al respecto.

Moderador: buenas tardes, mi nombre es Pilar Apaza, soy estudiante de la Maestría en Ciencias Empresariales de la Universidad San Ignacio de Loyola, y en esta ocasión nos encontramos realizando una investigación de mercado sobre los fast food en la ciudad de Cusco.

Antes de iniciar la información que nos va a brindar en esta entrevista será tratada para fines exclusivamente de investigación, la misma que va a ser publicada; bien, para continuar deseo que Ud. se presente, que nos comente un poco de su experiencia, de su nivel de educación.

Experto: Que tal Pilar, mi nombre es Israel Carpio Urday, tengo 25 años, soy bachiller en Administración de Negocios del a Universidad Católica de San Pablo de la ciudad de Arequipa, trabajo en el grupo DELOSI SA. El grupo de franquicias más grande del Perú que representa a 8 marcas internacionales de mayor renombre y de mayor movimiento de operaciones del país, trabajo en esta empresa 6 años, empecé a trabajar en el puesto de cocinero en Pizza Hut y poco a poco hice línea de carrera a la par estudiando también, entonces conozco muy bien este negocio he pasado por tres marcas y bueno eso sería parte de mi experiencia laboral.

Moderador: ok, me comentabas que habías empezado en el puesto de cocina haciendo línea de carrera, ¿actualmente cuál es tu cargo oficial?

Experto: bueno el proceso de línea de carrera se divide en las siguientes partes; la primera es de part time, en áreas de cocina o servicio al cliente, después le sigue el puesto de entrenador full time (tiempo completo) quien está encargado del entrenamiento a los colaboradores, de ahí sigue el puesto de asistente de gerente que tiene funciones tanto operativas como administrativas, que dan soporte al gerente de tienda; ahora soy gerente de tienda ya hace año y medio, y es el puesto que estoy ocupando ahora. 
Moderador: ok, vamos a empezar con la primera pregunta.

Moderador: ¿Por qué nuestra gastronomía en general tiene buena percepción?

Experto: viendo en general la gastronomía nacional peruana, yo creo que es una de las mejores del mundo, he tenido la oportunidad de probar la comida de muchos países, y me quedo con la peruana, sin embargo actualmente la población está variando bastante, la gente está optando por este tipo de comida, por este tipo de negocios, por este tipo de comida rápida que por la comida tradicional, he visto a lo largo de la evolución de esta empresa la preferencia de la gente ha ido cambiando, y sé que va seguir cambiando.

Moderador: ¿Por qué la imagen de los fast food en Cusco esta desarrollada?

Yo creo que sí, porque las marcas que trabajan en esta ciudad son marcas de mucho renombre, KFC (Kentucky Fried Chicken) no necesita publicidad de la que lanzamos en televisión ¿porque?, porque toda la gente viene, y año a año el crecimiento de la venta se va dando de $15 \%$ al 19\% anual desde que estamos en la ciudad de Cusco, hablamos de la apertura del real plaza en el Cusco en el año 2014, la gente si tiene bien claro metido en su cabeza la imagen de un fast food y cada año aumenta la preferencia.

Moderador: bien, para nuestra tercera pregunta, maso menos se dice que en Lima se ha evidenciado el crecimiento de estas cadenas de fast food, la pregunta es: ¿Por qué cree que en Cusco los fast food no han seguido la misma dinámica y la tasa de crecimiento similar a los de Lima?

El crecimiento nacional en el año 2015, 2016 no ha sido tan grande como se cree en nivel de apertura de tiendas, ¿Por qué crece una cadena de fast food? Uno, nosotros estamos anclados a centros comerciales, entonces es más rentable abrir una tienda en un centro comercial que abrir 
una tienda con puerta a calle por muchos motivos; cuando abres una tienda en un centro comercial tienes asegurada transacciones, gente va a ir a un centro comercial, a las tiendas ancla como son Oeshle, Saga Falabella, Ripley, entonces el principal crecimiento de una cadena de franquicias de restaurant es que está anclado a centros comerciales. Punto número 2 como se van generando competencias, hay tiendas que se van cerrando porque no son rentables, los años pasados en vez de haber muchos crecimiento se ha buscado la rentabilidad, hacer rentable el negocios que ya están aperturadas, en Cusco mientras no se haya abierto un centro comercial, te aseguro que no se abrirá una tienda con puerta a calle, estoy seguro.

Moderador: ¿Qué perspectiva prevé para los fast food en Cusco que no son parte de cadenas de fast food internacionales?

Experto: mira, todo fast food que hay en Cusco del nivel de KFC, Popeyes son operador por capitales nacionales y siempre van a estar anclados en un centro comercial, el crecimiento de una franquicia nacional aunque tú no creas, China Wok, Bembos, Otto Grill, Montao son cuatro franquicias nacionales pero son operadas por un operador que es un grupo de la otra competencia que se llama NGR, trabajan en un grupo de franquicias, entonces si te das cuenta, tenemos la mitad del centro comercial son franquicias nacionales e internacionales sólo son Popeyes , Papa Jhons, KFC, Burger King igual son operadas por capitales totalmente nacionales. Entonces el crecimiento de una franquicia nacional está ligada también como te digo, si es operada por DE LOSI, por NGR o por cualquier otro operador importante ligada a un centro comercial, está muy muy relacionada, es una alianza estratégica que no se va a romper. Moderador: ¿Por qué realizan solo algunos tipos de promociones y cuáles son? 
Experto: En el caso del KFC que es una marca que está ya está ya muy posicionada en la mentalidad de los peruanos tanto así que a veces yo bromeo KFC deberían declararlo un plato nacional porque te digo, navidad, año nuevo la gente en vez de ir a comer su tradicional pavo, lechón, esta acá reventando la tienda, entonces KFC es una marca muy posicionada, la pregunta va a ¿qué hemos llevado para potenciar las ofertas?, es un proceso histórico como todo negocio, en el caso de KFC ahorita lo único que estamos lanzando este año, es una campaña del fortalecimiento de marca, ya no necesitamos generar promociones por venta ni oferta, solamente potenciar la marca, hay otras franquicias como Burger King por ejemplo que están ofertando como precio, ellos si están preocupados por promoción, ellos están lanzando comerciales con oferta, combos, igual que Pizza Hut que también están en ese mismo nivel de crecimiento, KFC ahorita está destinado orientado a fortalecer la marca, a fortalecer la experiencia a ser parte de las familias de los peruanos todos los comerciales que van a ver este año que van a estar centrados en la familia, buscar la conexión familia con KFC, porque hay muchas familias en especial de Lima que desde niños han crecido con KFC, aquí en Cusco es 4, 5, 10 años pero en Lima KFC es la marca de muchos limeños, entonces ahora estamos en proceso de fortalecer la marca y buscar sus conexiones.

Moderador: ¿Cuáles son los principales fast food en el Cusco? ¿Porque?

Experto: bueno como tenemos un solo centro comercial, todos los fast food están en el centro comercial, los principales son los mismos que operan en todo el Perú, en todo el Perú vas a encontrar un China Wok, Popeyes, Papa Jhons, Burger King, pero como dije antes pertenecen a cadenas importantes, el principal en el Perú y en Cusco es KFC, es el líder en ventas, a nivel gente, a nivel posicionamiento, es la marca top of mind de las personas de lo que es restaurant de comida rápida, hay muchos estudios que lo dicen. 
Moderador: ¿Cuál es el perfil del consumidor de este producto? (rango de edad).

Experto; es un perfil muy variado, como la coca cola que lo consumen todo el mundo, o sea desde niños hasta grandes pero depende de la localización de la tienda es que el mercado de edades varían, por ejemplo en este real plaza es una tienda de combos familiares, el promedio de personas que vienen a consumir, el mayor volumen de personas son personas de 30 a 40 años que consumen, son capaces de adquirir un producto de 40 a 60 soles, hay tiendas con otro formato que tiene unos clientes distintos como la tienda de la plaza de armas, es una tienda destinada netamente a un ticket promedio de 20 soles, sus focus son turistas $50 \%$ - $55 \%$ de sus clientes son turistas, pero en si KFC creo que es un producto de consumo masivo, no hay una edad especifica.

Moderador: entonces, aquí el establecimiento permite captar clientes locales y nacionales.

Experto: si real plaza es un negocio netamente para cusqueños, la gente aquí son el 98\% cusqueños y familias.

Moderador: si tuvieras que lanzar un rango de edad en promedio.

Experto: yo creo que en la tienda que yo gestiono a) el $70 \%$ es entre 30 a 40 años, b) $20 \%$ de 10 a 30 años, y el c) $10 \%$ que queda es gente de 40 años para arriba.

Modelador: ¿Por qué el consumidor consume alimentos bajo este formato en Cusco?

Experto: mira, KFC es un producto rico, es un producto barato relativamente, nos esforzamos por potenciar el servicio, a nivel corporativo manejamos una ecuación que es la que da respuesta a esa pregunta, porque el consumidor viene a Kentucky y viene otra vez, creemos que el 56\% de la decisión para que la persona regrese es por la amabilidad, el servicio y la hospitalidad que ha recibido, la calidad de la atención. El otro $31 \%$ corresponde a la calidad del producto $13 \%$ al valor, en base a esas tres premisas o esas 3 variables es que el cliente decide volver, ¿entonces 
porque la gente tiene preferencia por esta comida? Tiene preferencia por esta comida porque es rápida, es una comida que máximo esperas 10 minutos o en realidad debe ser menos, son los estándares que manejamos, aunque en realidad debe ser menos, precio asequible, es rica y además con la seguridad que estamos operando bajo muchos estándares, es un producto muy bien operado, muy bien tratado y de calidad.

Experto: ¿Por qué cree que los Fast Food en Cusco pueden mejorar su posicionamiento?

Experto: Cusco es un mercado que ha sorprendido mucho a la empresa donde trabajo, porque ambas tiendas, como te dije hace un rato, sobre todo la del real plaza, tenemos un crecimiento de $15 \%$ a $19 \%$ anual, o sea año tras año crece en promedio el $17 \%$, es mucho dinero, no hay ninguna posibilidad de una tienda con puerta a calle, hay muchas negociaciones con posibilidad a una apertura de un nuevo centro comercial aquí en Cusco, estamos a la espera de eso, a parte hay contratos, y tenemos contratos si un centro comercial decide abrir un centro comercial en la punta del cerro, si o si KFC tiene que estar ahí, hay contrato de por medio que tiene determinadas acciones, además los centros comerciales piden que KFC trabajen con ellos, y facilitan como con temas de alquiler, mantenimiento.

Moderador: ¿Considera que existe nichos de mercado para los fast food que falta explotar en la ciudad del Cusco?, ¿Por qué?

Experto: ahorita no, no hay ningún otro nicho que se pueda explotar, si se abriera un centro comercial, ese sería nuestro nicho, en Cusco no tenemos como en la ciudad de Lima o Arequipa, boulevard, la única zona peatonal, cerrada que tiene transacciones es la plaza de armas, hay negocios, por eso hay un KFC hay, después de eso no hay otro lugar donde se pueda aperturar negocio como este. Solo convendría cuando se abra un centro comercial. 
Moderador: ¿Por qué los empresarios del rubro del servicio en especial de fast food tienen que adoptar diferentes papeles en el mercado?

Experto: El negocio de la comida rápida en nuestro país, viene creciendo muy rápidamente en los últimos años entonces los líderes de esas empresas, los empresarios que manejan el capital de este rubro básicamente tienen que apuntar a mejorar cada vez sus estándares de calidad, estándares de seguridad, los estándares en la operaciones de los alimentos, ¿porque? Porque hay demasiada competitividad además que cada mes a mes, año a año, siguen aumentando las regulaciones por parte del estado, en base a los controles que se deben manejar en un restaurant, entonces en este negocio, básicamente se debe apuntar a ser mejor a la competitividad al aseguramiento de estándares a la búsqueda de la rentabilidad y sobre todo al compromiso del equipo teniendo en cuenta que el principal recurso de toda empresa de todo negocio es la gente

Moderador: ¿Considera que existen profesionales calificados en Cusco para trabajar en el servicio de fast food? ¿Por qué?

Experto: Si sino no operaríamos nosotros, cada ciudad, cada cultura tiene perfiles distintos de cómo es la gente, la ciudad de Cusco es una ciudad con muchas oportunidades, es un reto, ya tenemos 6 años en Cusco porque la tienda del real plaza se abrió el año 2010, hemos podido generar gente de aquí, educar gente de aquí.

Moderador: ¿crees que ya estaban educados y faltaba solo amoldarlos?

Experto: depende de los niveles en primer lugar la gente de Cusco recién se está acomodando a cómo funciona, los 3 años que llevamos en el real plaza la gente maso menos ya sabe cómo funciona un centro comercial, como funciona un restaurant de comida rápida, por ejemplo cuando yo he llegado acá, la gente esperaba que le traiga la comida a la mesa, no hay, no había una cultura de cómo funciona un restaurant de comida rápida, entonces ahora ya la gente está 
entendiendo, ya lo conoce mejor, entonces a raíz de eso también la gente ha empezó a trabajar con nosotros, actualmente ha sido un reto, a través de entrevistas procesos de contratación, en la ciudad de Cusco son bastante más detallados que otras ciudades. Sin embargo para puestos gerenciales se están dando muchas oportunidades a la gente que empezó a trabajar aquí, se está buscando gente que conozca todo el negocio, que haga línea de carrera ¿porque? Porque de alguna manera ya están más inmersos en la operación y van a ser más capaces de llevar el negocio adelante, te comento eso porque actualmente en las tiendas operamos 6 gerenciales, de los seis, tres somos arequipeños y tres son cusqueños, eso no puede seguir así, entonces el objetivo que tenemos es que los seis sean cusqueños porque talento hay acá, sólo que tenemos que ir trabajando, comprometerlos más con el trabajo, los principales pilares son la gente, fortalecer a la gente y que ellos sean los que trabajen, lo ideal es que cusqueños trabajen.

Cuando ha iniciado la tienda todo el equipo gerencial era gente de afuera, a lo largo de los años, ha ido cambiando; en conclusión estamos dando preferencia la gente interna, porque ha habido mucho personal calificado en papel, pero no ha encajado adecuadamente en el perfil, entonces todos los esfuerzo en este 2016, ha sido entrenar, desarrollar el talento.

Moderador: ¿Cuáles son los factores más importantes que considera un consumidor al momento de elegir el fast food al cual asistirá y por qué?

Experto: un consumidor lo que va a buscar cómo te dije enantes es el tema de cuál es el más rico, cual es el más barato, en cual me van a atender más rápido, cual he venido antes y me ha gustado, la experiencia en base a esos atributos el consumidor va a decidir.

Moderador: ¿Por qué el ambiente donde se brinda el servicio de fast food es una parte fundamental para llamar la atención del cliente? 
Experto: sí, es la parte principal, la experiencia, atención, amabilidad, cordialidad, es donde concentramos la mayor parte de nuestros esfuerzos.

Moderador: ¿Cuál es el plato de comida que suelen pedir con más frecuencia en un fast food? y ¿Por qué?

Experto: En mi marca yo vendo pollo, pollo frito, el producto que más sale es el producto regional que lo hemos llamado mega cusqueño, la gente se siente identificado con ese producto, porque es un producto completo, un tamaño familiar, de un precio económico, de 29 soles, es un producto abundante, es un producto que la gente se identifica mucho con ese producto quizá por el nombre y justo lo hemos dado porque está destinado a nuestros clientes meta, porque siempre vienen 2, 3, 4 personas, y este es un producto de 6 piezas y encaja para esa cantidad de personas. En mi caso es un producto bandera en Cusco.

Moderador: ¿considera conveniente la venta de bebidas alcohólicas en un fast food? $\boldsymbol{y}$ ¿Por qué?

Experto: no hay ningún fast food con formato de bebidas todavía en Perú porque la cultura etílica de Perú es diferente al de otras culturas, porque en la cultura europea tu encuentras mojitos, cocteles, en formatos ya pre ensamblados, refrigerados, es todo un tema, es otra cultura, en Perú todavía no se ha lanzado fast food que venda bebidas alcohólicas.

Moderador. ¿Esto por la cultura?

Experto: Es un tema yo creo cultural, además seguramente se han hecho estudios de mercado y la gente no va a comer, por ahí cada país, cada cultura es diferente.

Experto: entonces no creo que pegaría el tema de licor con comida rápida, lo que si pega es el tema de las gaseosas, el Perú es un país muy gaseoso, por ejemplo hay muchas campañas ligadas a nuestros proveedores de la gaseosa. 
Moderador: ¿Qué tipo de bebida alcohólica considera que es el mejor acompañamiento después del consumo de fast food? $\boldsymbol{y}_{\boldsymbol{i}}$ PPor qué?

Experto: yo creo que ninguna bebida alcohólica para mí, y para la actualidad del mercado se considera como mejor acompañamiento para un fast food. Para mí, para el mercado, para el actual todavía no se puede acompañar, la gente no asocia fast food con bebidas alcohólicas. La gente asocia al fast food, como comida rápida, comida luego de la chamba, no lo ve como un destino final, como el Chilis, Belisario donde si vas a comer y pides una bebida, no hay el concepto ligado.

Moderador: ¿Qué insumos son los que se compran en cantidad y se usan más en los distintos platos de fast food? $\boldsymbol{y}_{\boldsymbol{i}}$ Por qué?

Bueno depende de qué tipo de fas food sea, tenemos en el Perú más de 20 marcas de comida rápida, y cada negocio independientemente tiene un distinto tipo de insumo clave, en el caso del KFC el insumo clave es el pollo, la papa y los diferentes insumos que nosotros llamamos no controlables, que acompañan al producto final, entonces esta pregunta es relativa de acuerdo a cada negocio, en el caso del KFC el principal producto es la papa, el pollo que manejamos de acuerdo a nuestros productos, y bueno la papa que es importada, esos son los principales insumos

Moderador: ¿Qué días existe mayor afluencia de consumidores? y ¿Por qué?

Experto: como la mayoría de negocios y como la mayoría de centros comerciales yo creo que los fines de semana, nuestra partición de ventas está así: los feriados si son picos, la venta es 
50\% de lunes a viernes, y 50\% de sábados a domingos, o sea así de marcada es la diferencia en los centros comerciales.

Moderador: ¿en qué horarios existe mayor afluencia de consumidores? y ¿Por qué?

Experto: es variable en base a la participación de ese momento, La afluencia está en base a eso también, por ejemplo en fines de semana las horas pico que tenemos son de 1 a $3 \mathrm{pm}$ y de 6pm a 10pm, un sábado; y de 3pm a 6pm la afluencia es menos.

Moderador: ¿Cual crees que sea el indicador?

Experto: porque la gente a la 1 a 3 la gente está almorzando la gente está terminando sus compras, y en la tarde la hora que la gente viene a comprar, la gente viene al cine, la hora que la gente sale de la chamba se dan una vuelta, esa proporción se da casi todos los días feriados, a excepción de los feriados donde la afluencia es de 11 am a 5pm es una hora pico bastante larga, porque la gente sale de su casa hacer compras. Esto es en centros comerciales, son los datos que te he dado.

Moderador: ¿Cuáles son los medios publicitarios que se llegan más al público? $\boldsymbol{y}$ ¿Por qué?

Actualmente se está dando mucho punche a lo que son las redes sociales, ay muchas promociones por redes sociales, nuestro comunity manager está muy activo, entonces se está dando mucho refuerzo por ahí, lanzando promociones, comunicados, también se llega incluso a comunidades, que te dan sus opiniones, ahorita lo que está en moda son las redes sociales; la publicidad televisiva es muy impactante también.

Moderador: dentro de vuestro presupuesto ¿dentro de su presupuesto cual es el que ha representado mayor costo?

Experto: ahorita la publicidad televisiva, ahorita estamos trabajando con una nueva agencia publicitaria que es CIRCUS y la mejor del Perú no solo con el grupo que tengo sino trabaja con 
todo el grupo de LOSI es una fuerte inversión, pero la calidad de los comerciales que están saliendo en la televisión todo el arte de las vallas, bueno en Cusco no se ve muchas vallas, en Lima y Arequipa hay calles grandes en Cusco no hay mucha normativa, se está dando mucha inversión en eso, es toda una inversión que si ha dado resultados, ¿Qué hacemos nosotros? Cuando hay comerciales de promoción, después se hace una evaluación comercial, se evalúa que tanto el comercial ha pegado en la gente, se ha obtenido muy buenas puntuaciones en cuanto a las muestras que se han hecho no que no son pequeñas, son grandes, entonces la inversión es fuerte que abarca muchas áreas, no solamente televisiva. En Cusco no tenemos vallas, además Kentucky no necesita publicidad.

Moderador: aquí en Cusco no hay un tema económico destinado a la publicidad.

Experto: tenemos la publicidad que se maneja en Cusco es centralizado, un cartel que coloquemos en el centro comercial, es centralizado, nada se maneja aquí en Cusco.

Moderador ¿Qué opinión tienes en relación a la apertura de un fast food local producto de un emprendimiento?, una marca local. De alguien que quiera aperturar un fast food por ejemplo en la avenida de la cultura. ¿Crees que se pueda competir con los fast food internacionales?

Experto: yo creo que para que un fast food sea competitivo tiene que venir con un concepto muy innovador, punto número uno, punto dos, tiene que tener una muy fuerte inversión de respaldo, porque las cadenas o los grupos de franquicias del país manejamos muy altos estándares dentro de nuestros equipos, operaciones, y un respaldo de procesos internacionales que nos dan mucha seguridad, no es por nada, pero un snack en la esquina, también es un restaurant de comida rápida, entonces tenemos que ver qué tipo de restaurant, yo conozco restaurant, chiferias, muy exitosos, dentro de sus metas, de sus objetivos, sin embargo dentro de aquí, ha habido varias marcas cusqueñas que han pasado por aquí por el real plaza , por ejemplo 
raymi, cerró ha estado operando todo el año 2016, ahora no sabemos quién entre en ese espacio, pero le fue bien un tiempo, pero no era un producto innovador, no era competitivo, era pollo contra pollo, carecía de ciertos estándares de seguridad, de operatividad, entonces hay que entrar, un negocio como este, hay que tocarlo con mucha pinza para que sea realmente rentable, y sobre todo que la gente lo decida captar, yo creo que si hay una marca que quiera entrar en el real plaza, por ahora es muy difícil, pero si si hay mucho mercado de fast food tal vez en otras ubicaciones de la ciudad, de hecho que sí, pero la cuestión es cómo te dije, que el producto sea innovador, la gente para un restaurant de comida rápida, te va a pedir un buena atención, producto bueno, que sea a un precio competitivo, si está dentro de esos tres atributos y lo orienta bien al mercado objetivo que tiene pensado, si se enfoca bien, creo que si puede tener éxitos.

Moderador: proponemos hacer algo innovador, algo que llame, queremos incursionar con el cuy, en vez de pollo.

Experto: Yo no creo que el kilo de pollo sea igual al del cuy, hay tienes un costo de venta te va a dar un margen bastante delicado, vas a tener que manejar con mucho cuidado, porque siempre se tiene que buscar en negocios como este que tu costo de venta sea el más apretado posible, porque nosotros vendemos por volumen. Eso es uno, ahora que tanta gente vendría a comer cuy en el real plaza en realidad no creo, ahora el cuy, es un plato que se come en picantería, son platos tradicionales o en lugares turísticos, y son caros, dar un formato de comida rápida tendría que salir quizá trozado, quizá armarle combos, quizá fusionarlo ya no con papa hervida, sancocharlo, y no meterle papas fritas, es una idea bastante explotable pero a mí lo que no me animaría es el costo del cuy, y no todos los peruanos consumen cuy, yo soy arequipeño y nunca en mi vida he comida un cuy, mucha gente que no come un cuy entonces, no es como el 
pollo, donde todos levantamos la mano y en un restaurant de comida rápida, es rápido y tiene a enfocarse a ser masivo, si no va a ser rentable.

Moderador: bien ya hemos finalizado, muchas gracias por los datos que nos has brindado, para nosotros es muy importante cada información para poderla analizar.

Experto: gracias a ti más bien. 


\section{Anexo 8.Transcripción Entrevista Gerente de Rhupa's}

\section{FICHA TÉCNICA ENTREVISTA A PROFUNDIDAD: EXPERTOS DEL SECTOR}

Buenos días/tardes.

Mi nombre es...

Soy estudiante de la Maestría en Ciencias Empresariales de la Universidad San Ignacio de

Loyola, y en esta ocasión nos encontramos realizando una investigación de mercado sobre los fast food en la ciudad del Cusco"

Permiso para grabar.

La información que nos facilite en esta entrevista será tratada para fines exclusivamente de la investigación, no pudiendo ser utilizada de forma nominal ni facilitada a terceros.

\section{OBJETIVO DE LA INVESTIGACIÓN}

El objetivo de llevar a cabo la entrevista a expertos, es conocer la opinión sobre la dinámica y crecimiento en el sector de fast food en estos últimos tiempos, y como se vería este sector de acá a tres años en la ciudad de Cusco.

\section{OBJETIVOS ESPECÍFICOS}

Conocer en líneas generales la percepción del experto sobre la presente investigación.

Conocer la percepción real del servicio de los fast food en la ciudad de Cusco.

Conocer las tendencias tanto de la oferta y demanda del servicio de fast food.

Conocer a las competencias y/o propuestas similares.

\section{PERFIL DEL ENTREVISTADO}

Persona con más de tres años de experiencia en la administración de fast food (empresarios, docentes, gerentes, expertos especializados etc., o que tengan manejo de temas asociados de bar y comedor). 
En la invitación, decir que se mantendrá una conversación, en la cual se les van a compartir los resultados preliminares que se han ido obteniendo y conocer su opinión al respecto.

Moderador: buenas tardes, mi nombre es Marita Ccahua, soy estudiante de la Maestría en Ciencias Empresariales de la Universidad San Ignacio de Loyola, y en esta ocasión nos encontramos realizando una investigación de mercado sobre los fast food en la ciudad de Cusco.

Antes de iniciar la información que nos va a brindar en esta entrevista será tratada para fines exclusivamente de investigación, la misma que va a ser publicada; bien, para continuar deseo que Ud. se presente, que nos comente un poco de su experiencia, de su nivel de educación.

Experto: Mi nombre es Martín Jiménez, soy chef corporativo de profesión, estudié en la ciudad de Lima en la escuela de alta cocina D'Galia, de eso me especialicé en otros países con un poco de esfuerzo y algo de mucha experiencia lograron hacer el Martín Jiménez que ahora está frente a ti.

Moderadora: ¿Cuántos años de experiencia tiene usted?

Experto: 20 años, 21 años trabajando en lo mismo

Moderadora: Bien vamos a empezar entonces con lo que es la primera pregunta ¿Por qué nuestra gastronomía en general tiene buena percepción?

Experto: Muy buena, la gastronomía peruana para mi es algo que es exportable, es algo que el mundo debe enterarse, la gastronomía peruana puedes llevarla a niveles muy altos en sistema gourmet o puedes llevarlo a un fast food, se acomoda muy rápidamente y es de gusto de todo el mundo, de todo el mundo.

Moderadora: Vamos con la segunda pregunta ¿Por qué la imagen de los fast food en Cusco esta desarrollada? 
Experto: No, tenemos una cultura muy fuerte, una tradición muy fuerte y gracias no? Por eso, inclusive nuestra cadena cierra los días más tradicionales de Cusco, respetamos a la ciudad, creo que por eso las grandes cadenas no se han arriesgado en invertir mucho dinero en esta ciudad, porque ellos lo ven más por el dinero, en cuánto es lo que se va a ganar, nosotros lo hacemos por brindar un servicio al Cusco.

Moderadora: Ahora vamos con la tercera pregunta ¿Por qué cree que en Cusco los fast food no han seguido la dinámica y tasa de crecimiento similar a los de Lima?

Experto: Porque somos una ciudad que estamos recién creciendo, somos una ciudad tradicional como te digo, Arequipa o algunas otras ciudades grandes siguen su tradicionalismo pero son ciudades ya muy dinámicas y grandes a lo que recién estamos apuntando nosotros, es por ello que las grandes cadenas no han ingresado aún acá.

Moderadora: ¿Qué perspectiva prevé para los fast food en Cusco que no son parte de cadenas de fast food internacionales?

Experto: No sabría decirte, qué perspectivas tienen.

Moderadora: ¿Usted como empresario?

Experto: Yo tengo, sí una perspectiva, tengo un plan de crecimiento ya para este año, vamos a ingresar al valle, vamos a abrir dentro de nuestro plan de crecimiento para esta zona del país es abrir uno en el valle, uno en Quillabamba, uno en Abancay y uno en Puerto Maldonado, ¿Por qué? Porque las grandes cadenas internacionales no se arriesgan a invertir dinero donde va ser muy difícil la recuperación de inversión, nosotros no estamos buscando la recuperación de inversión, sabemos que va ser a muy largo plazo pero estamos buscando brindar un mejor servicio y solidificar la marca en el país y empezamos de donde nadie ha empezado. Moderadora: ¿Por qué realizan solo algunos tipos de promociones y cuáles son? 
Experto: En las marcas internacionales no han hecho mucho o nada, solo han abierto una tienda o dos que estaba dirigida para el turista que llegaba de la ciudad sin importarles mucho el nacional, el nacional empezó a probar y vio que el producto es bueno y empezó a ir, ellos empezaron a hacer volantes por ahí, nosotros como marca, sí estamos muy interesados que nuestra marca se diga que nacimos en Cusco, que somos cusqueños somos Rupha's Diner, un clásico dinner americano nacida en la ciudad de Cusco, de acá a unos 15 días o 20 abrimos nuestra primera tienda en Máncora, fuera de la ciudad de Cusco y llegamos como empresa cusqueña y eso es lo que estamos proporcionando, a partir del día de mañana estamos en una radio conocida que es de acá, nacional, radio Veritas pero vamos al enfoque de decir ya que la marca es cusqueña, que estamos saliendo a nivel nacional.

Moderadora: ¿El nombre también es cusqueño?

Experto: Por supuesto. Rupha's, caliente en quechua Moderadora: ¿Por qué medios publicitarios se llega más al público objetivo?

Experto: Facebook, ahorita redes sociales, el 90\% sino es exagerado tiene un celular en la mano y tiene el Facebook en la mano, solamente es un clic de una tarjeta de crédito y más de 25000 personas en menos de 24 horas se van a enterar de lo que estás haciendo.

Moderadora: ¿Y luego del Facebook?

Experto: Radio.

Moderadora: ¿Cuáles son los principales fast food en el Cusco? ¿Porque?

Experto: Bueno los que hay Kentucky, McDonald's, Chilli's y nosotros que recién nos estamos abriendo como cadena he visto sus ventas y yo creo que aún sigue liderando Kentucky, porque es una marca internacional muy poderosa, el sabor es bueno para un público en general, la gente que conoce un poco de sabores sabe que te están dando, te están manipulando el paladar, 
a la primera mordida dices juy que rico! Y ya te olvidaste de la cantidad de grasa que estas comiendo porque han abierto tus cinco sentidos y la comida ahora ingresa por eso, es psicológica, ahora la comida ha sido creada psicológicamente ya más que el aderecito de la mamá, esa papita que la sembró en campesino o que se dedicó en recolectar y cuidarla para que llegue a nuestro paladar, para muchas cadenas eso ya murió, todo es industrial y todo es psicológico y la presentación también.

Moderadora: ¿Cuál es el perfil del consumidor de este producto? (rango de edad)

Experto: El fast food es desde los 13 años, muchos fast food llaman a familias por medio de los niños, ahí tienes una payaso en alguna cadena, el tema de los juegos de los fast food, porque por medio de los niños atraes gente, atraes a familias completas, a eventos, algunas cadenas sí se han dedicado más al segmento de 13 a 25, puedes disfrutar de una buena comida, una buena conversación con una compañera o en amigos.

Moderadora: ¿Y en el caso de Rupha’s? ¿Cuál es el rango de edad?

Experto: de 13 a 25 años pero nos hemos dado cuenta de que nos hemos ido acogiendo a los muy niños hasta gente de muy alta edad.

Moderadora: ¿Por qué cree que los Fast Food en Cusco pueden mejorar su posicionamiento?

Experto: Mucha porque somos una ciudad que está creciendo a paso agigantado, sabemos que dentro de muy poco tiempo va a haber dos malls más, la ciudad está siendo presionada para crecer por parte del turismo, por el tema comercial, van a venir marcas muy grandes que van a necesitar traer gente de afuera, eso significa mucho más población, significa gente que va a necesitar comida rápida, ahí viene la inversión del fast food.

Moderadora: ¿Considera que existe nichos de mercado para los fast food que falta explotar en la ciudad del Cusco?, ¿̈Por qué? 
Experto: Por ahora no, la población de Cusco está creo bastante abastecida con lo que hay en este momento, falta un poco pero el plan a cinco años por lo que yo he entendido económicamente sí va a tener un crecimiento pero va a demorar un poquito, va a demorar por lo menos dos años a que se termine y unos tres a los centros comerciales para que la ciudad se poblé más y ahí saldrán otros nichos posiblemente, muchos nichos, va a venir Tanta, Friday’s, va a venir muchas marcas que aún no están y nosotros como Rupha's nos estamos preparando para eso, cuando ellos lleguen, nuestros clientes prefieran Rupha's, prueben sus marcas pero sepan que acá hay un producto $100 \%$ calidad y mucho cariño y cusqueño sobretodo.

Moderadora: ¿Por qué los empresarios del rubro del servicio en especial de fast food tienen que adoptar diferentes papeles en el mercado?

Experto: Abordar un poco más con la publicidad, el tema publicitario en fast food, le da la oportunidad a la gente que coma algo bueno y rápido y no lo saben mucho, se sorprende mucha gente que un plato de comida salga al minuto de haberlo pedido, mucha gente se sorprende pero eso es el fast food, tener la operatividad tan bien diseñada para que el producto esté muy fresco y se sirva muy muy rápido eso falta comunicar, esos dos falta comunicar y eso es competitividad.

Moderadora: ¿Considera que existen profesionales calificados en Cusco para trabajar en el servicio de fast food? ¿Por qué?

Experto: No, la verdad es que no, lo he analizado bastante y al no tener experiencia en este mercado, no conocer muchos no se han dedicado en indagar, en ver el potencial económico que hay en esta línea de negocio, creemos que el sistema hotelero lo es todo o es lo mejor que se puede hacer, muchos chefs tienen la oportunidad de ser los mejores chefs hoteleros o hasta ganar estrellas Michelin pero algunos como yo nos dedicamos a este mundo, investigamos y dedicamos nuestra vida a esto a crear nuestra propia empresa a ser profesionales dentro de un fast food, 
cuando vimos estos y la oportunidad en Cusco, empezamos a buscar a los administradores y pensábamos ya en crear una escuela de administradores de esta línea porque no hay ni en las escuelas gastronómicas quien te enseñe realmente que un plato tiene que salir en un minuto y cómo hacerlo. Es fast food, es rápido tienes que hacerlo rápido, tus márgenes son muy bajos, nuestros márgenes son bajísimos y el fast food tiene ese diseño que seas margen bajo y que vendas mucho, que tengas mucha rotación, si no creas esa rotación vas a comenzar a tener pérdidas, sino vas a tener que innovar o reinvertir, entonces para eso tienes que entrenar gente para que sea rápida.

Moderadora: ¿Cuáles son los factores más importantes que considera un consumidor al momento de elegir el fast food al cual asistirá $y$ por qué?

Experto: El sabor de la comida, yo creo que mucho es el sabor de la comida y la rapidez en la atención, por ejemplo aquí tenemos Kentucky y Popeyes no? Uno va al mal ve las colas, porque el mal profesionalismo de estas personas, yo he comido Popeyes en América y en otros países y no es lo que te venden acá, no es lo que venden acá y me he quejado, he dicho esto no es Popeyes, este pollo no ha sido escurrido de tal manera porque yo lo sé cómo chef, el arroz no se sirve de esta manera, entonces que es lo que han creado, por obtener mayor margen, porque se demoran 15 minutos en botar un plato y creen ahora que ahorro para tener más margen están matando el producto, eso lo asume el cliente y dice: el producto es malo y no es así, tienes un gerente malo que no supo atender rápido y por ahorrar compró productos más baratos o te dio cualquier cosa o hasta un pollo crudo, entonces falta instruir más a la gente de fast food.

Moderadora: ¿Por qué el ambiente donde se brinda el servicio de fast food es una parte fundamental para llamar la atención del cliente? 
Experto: Sí, yo creo que el ambiente donde se ponga un fast food es muy importante, tiene que ser una zona muy comercial no solo un centro comercial, sino muy comercial o de mucha población, por ejemplo nosotros elegimos Ttio, donde a ninguna cadena se le ocurriría poner un fast food ahí y nosotros hemos logrado un crecimiento de casi el 200\% desde que hemos abierto hasta el día de hoy en esa tienda, porque hay mucha población, hay mucha población en esa zona entonces la gente ya no necesita subir al mal, subir al centro para comer algo bueno, ya les pusimos una tienda ahí, entonces llegan, salen, en sport, en su short, en sandalias, bien abrigados si es que está lloviendo, compran una alitas, una hamburguesa y van a casa a comerlo y lo pueden comer caliente porque todos los Rupha's son calientes y tienen un ambiente muy caliente.

Moderadora: Una pregunta, ¿Y respecto al ambiente interno, cuán importante es?

Experto: La decoración, la música es muy importante nosotros elegimos ser un fast food que difunde la música electrónica, muy rápidamente apenas abrimos conectamos con la isla Ibiza que es la principal difusora de música y conectamos radios directamente, en la misma hora en la que se están produciendo las fiestas allá y la gente disfruta de eso, a muchos no les gusta pero creo que lo viven cómodamente dentro de los Rupha's, tiene que tener una ambientación cómoda donde por más que sea una comida rápida, no puedes estar sentado en un lugar incómodo o en una mesa donde a las justas entra tu plato, si en algún momento nosotros cometimos ese error, no lo vamos a volver a hacer, no te preocupes que no lo vamos a volver a hacer, estamos viendo la manera de crecer y creo que todos los fast food eso es lo que expresan Chilli's, Friday's, Kentucky, McDonald's con sus grandes restaurantes expresan la comodidad y ambientación, que uno se sienta cómodo comiendo, es más los colores influyen mucho en un fast food, mucho, hay momentos en el que uno no mira los errores porque lo colores te tienen hipnotizado. 
Moderadora: ¿Cuál es el plato de comida que suelen pedir con más frecuencia en un fast food? $y_{\text {¿Por qué? }}$

Experto: Hamburguesa, fast food es hamburguesa y pollo frito, fue creado en América y creo que así salió al mundo y la gente aún cree en eso, de que la hamburguesa es fast food, si es fast food, es un producto rápido para comer pero también puedes disfrutar de una muy buena hamburguesa. No una hamburguesa de 20 gramos de 50 gramos, sino una hamburguesa de 200 gramos de 250 gramos de bife molido con los mejores ingredientes y disfrutarlo a un precio asequible como lo que brindamos nosotros.

Moderadora: ¿Qué tipo de bebida alcohólica considera que es el mejor acompañamiento después del consumo de fast food? $\boldsymbol{Y}_{\boldsymbol{G}}$ Por qué?

Experto: Para mí personalmente sería una bebida fuerte, un vaso de whisky, pero con lo que funciona es con la cerveza; cerveza y Coca Cola, es el tema de fast food y si tu poner una hamburguesa acompañada de chicha morada, el $80 \%$ te va a decir que no, mejor sólo la hamburguesa, si tú les ofreces una hamburguesa y una Coca Cola más del 50\% te va a llevar esa promoción, es más que fijo. Coca Cola y Pepsi ahí compiten y la cerveza creo para nuestro mundo fast food que es la barbecue, una barwash con una cerveza o una hamburguesa pegan perfecto, es perfecto, es un maridaje perfecto, una alita búfalo y una cerveza de verdad te va dar ganas de ir a bailar.

Moderadora: ¿Qué insumos son los que se compran en cantidad y se usan más en los distintos platos de fast food? $\boldsymbol{y}_{\boldsymbol{i} \text { Por qué? }}$

Experto: Lechuga y tomate es lo que se utiliza, acompaña casi todo, las papas fritas, no hay fast food que no tenga papas fritas, luego ya la carne, el pollo, la lechuga y el tomate para los sanguches, los twister que saca Kentucky, la ensaladita que tienen alguno fast food, el tomate 
que se utiliza mucho para el tema de las pizzas, son insumos que sí o sí tienes que negociar cuando vas a abrir, las papas y las verduras, porque las avícolas si o si te surten pero para encontrar un producto fresco en verduras es lo que muchas veces diferencia un fast food, comer una papita andina recién frita o una papita recién cortada a una papa que después de un minuto va parecer un chicle, diferencia un fast food de otro, lo diferencia bastante.

Moderadora: ¿Qué días existe mayor afluencia de consumidores? ¿ ¿Por qué?

Experto: Por lo general son los fines de semana, jueves, viernes, sábado y domingo, lunes tiene su gran caída los fast food en más o menos un $20 \%$ que podemos decir de caída pero los miércoles en los fast food, es el peor día de venta, lunes mucha gente no lleva lonchera cuando salen a trabajar, la flojera del domingo, sales y te compras un fast food, una hamburguesita, una alita y eso almuerzan después del trabajo o de los estudios, tienes una caída en la noche, la gente no sale en la noche pero te recuperas en la hora del lunch, en la hora del almuerzo, los miércoles, la gente no sale por nada, ni a almorzar ni a cenar, es un día bastante bajo, el motivo no lo he investigado pero sí lo he vivido en 20 años de experiencia, lo he vivido, para mí, los miércoles es mídete tu mercadería, sí mide la mercadería, ahora hay un tema sorprendente aquí en Cusco para nosotros los sábados es el día más bajo en todos los Rupha’s porque como somos una ciudad pequeña, para mi análisis y lo que he visto es que la gente, el fin de semana en nuestra hora de venta de $6 \mathrm{pm}$ a $10 \mathrm{pm}$ u $11 \mathrm{pm}$ están o en el mal o en la plaza de armas o han salido a caminar con la familia, vemos las calles llenas pero en la zonas más comerciales y como nosotros hemos entrado a unas zonas que no son comerciales como Tullumayu que no es una zona altamente comercial, sí es de alto tránsito pero no es altamente comercial, los vemos por la plaza, los vemos por el Coricancha, dando vueltas a la gente pero no vienen, es más para el centro, es decir, el éxito es para ellos. 
Moderadora: Bien entonces pasamos a la última pregunta ¿En qué horarios existe mayor afluencia de consumidores? $\boldsymbol{y}$ ¿Por qué?

Experto: A partir de las 7 de la noche, 7, 8 de la noche los restaurantes revientan hasta las 9 de la noche están full venta, a partir de las 9pm ya empieza la caída hasta las 10:30pm que entran una o dos personas.

Moderadora: Martín hemos terminado, muchas gracias por la información brindada, es muy valiosa, hay cosas muy interesantes y bueno agradecerle nuevamente por tu tiempo. 


\section{Anexo 9.Transcripción Entrevista Gerente de Turno McDonald's}

ENTREVISTA A EXPERTO

GERENTE DE TURNO McDONALD'S

SRTA: MERCEDES BERNARDO HUAMBO

MODERADOR: Buenas noches mi nombre es Rick Puente López soy estudiante de la Maestría en Ciencias Empresariales de la Universidad San Ignacio de Loyola, y en esta ocasión nos encontramos realizando una investigación de mercado sobre los fast food y/o comida rápida en la ciudad de Cusco"

Bueno, la información que nos facilite en esta entrevista será tratada para fines exclusivamente de la investigación, no pudiendo ser utilizada de forma nominal ni facilitada a terceros.

Ahora por favor le invito a presentarse.

EXPERTO: Buenas noches Rick, mi nombre es Mercedes Bernardo Huambo, soy Administradora de Profesión, tengo 29 años y me encuentro laborando aproximadamente 5 años y medio en McDonald's, empecé a trabajar part time en atención al cliente e hice línea de carrera y hoy en día soy Gerente de turno de McDonald's en la ciudad de Cusco el cual se encuentra ubicado en el Portal de carnes de la plaza de armas.

MODERADOR: Bien, Gracias. Ahora procederemos a realizarle unas cuantas preguntas ¿Por qué nuestra gastronomía en general tiene buena percepción?

EXPERTO: Considero que nuestra gastronomía es una de las más variadas y ricas del mundo, así como también se caracteriza por su sabor y combinación nuestros productos típicos de cada región.

MODERADOR: 
¿Por qué la imagen de los fast food en Cusco esta desarrollada?

EXPERTO: Claro que sí, porque la publicidad que se utiliza hoy en día hace que llegue de alguna u otra forma a todas partes del mundo.

\section{MODERADOR:}

¿Por qué cree que en Cusco los fast food no han seguido la dinámica y tasa de crecimiento similar a los de Lima?

EXPERTO: Bueno yo creo que porque en Lima existe mayor afluencia de turistas nacionales y extranjeros, a parte Lima posee una gran cantidad de centros comerciales en donde existen los fast food. Cusco se encuentra en una etapa de crecimiento de centros comerciales todavía, y yo creo que ira aumentando aún más la preferencia por estos fast food.

\section{MODERADOR:}

¿Qué perspectiva prevé para los fast food en Cusco que no son parte de cadenas de fast food internacionales?

EXPERTO: Bueno los fast food cusqueños aunque no lo creas son los que tienen mayor afluencia por su misma gente, la cultura cusqueña y hasta podría decir que la peruana busca las 3 "b" bueno, bonito y barato se podría decir y que los fast food cusqueños no necesitan de publicidad ya que ellos le dan casi siempre un valor agregado ya sea con un plato más contundente o una bebida de cortesía, lo cual hace que de esta manera logre fidelizar a su cliente.

\section{MODERADOR:}

¿Por qué realizan solo algunos tipos de promociones y cuáles son?

EXPERTO: Con respecto a las promociones en McDonald's, la lanzamos exclusivamente para la gente de la zona, en este caso para los cusqueños solamente presentando su DNI en físico se les hace el $20 \%$ de descuento en cualquiera de nuestros productos. Y bueno hay infinidades de 
promociones que se realizan entre ellas las más conocidas como es el 2x1, bebidas de acompañamiento, combos familiares, etc. etc.

MODERADOR:

¿Por qué medios publicitarios se llega más al público objetivo?

EXPERTO: Bueno considero que las redes sociales y la publicidad televisiva son las más efectivas hoy en día.

\section{MODERADOR:}

¿Cuáles son los principales fast food en el Cusco? ¿Porque?

EXPERTO: Bueno entre los principales tendríamos empezando por nosotros que somos McDonald's, de ahí le seguiría KFC, BEMBOS, BURGER KING Y POPEYES, esas serían las principales, las que más resaltan en el Cusco se podría decir, y bueno como líder no tengo información de estadísticas a la mano pero considero que por poseer más tiendas seria KFC.

\section{MODERADOR:}

¿Cuál es el perfil del consumidor de este producto? (rango de edad)

EXPERTO: La mayoría de personas están en un rango de edad de 15 a 40 años es bastante combinado en realidad, vemos desde jóvenes hasta adultos consumiendo este tipo producto ya que es muy llamativo y por su rapidez de atención es bastante consumido.

\section{MODERADOR:}

¿Por qué el consumidor consume alimentos bajo este formato en Cusco?

EXPERTO: Creo que por el producto y la rapidez de atención no? Como su nombre mismo lo dice fast food o comida rápida. Hay gente que necesita ganar espacios de tiempo y hace que consuma este tipo de producto que es agradable en sí, y por otro lado también tenemos los costos no? Son precios accesibles. 


\section{MODERADOR:}

¿Por qué cree que los Fast Food en Cusco pueden mejorar su posicionamiento?

EXPERTO: Las posibilidades son bastante optimas ya que Cusco está creciendo bastante en cuanto a la instalación de nuevos centros comerciales grandes los cuales hacen que haya una mayor oportunidad para posicionarse tanto adentro como a los alrededores de los centros comerciales.

\section{MODERADOR:}

¿Considera que existe nichos de mercado para los fast food que falta explotar en la ciudad del Cusco?, ¿Por qué?

EXPERTO: $\mathrm{Si}$, creo q falta explotar bastantes segmentos en la ciudad de Cusco, ya que esta ciudad se caracteriza por poseer variedad y cantidad de productos andinos, los cuales deberían ser aprovechados para este tipo de negocio también

\section{MODERADOR:}

¿Por qué los empresarios del rubro del servicio en especial de fast food tienen que adoptar diferentes papeles en el mercado?

EXPERTO: Como bien sabemos el negocio de comida rápida es muy riesgoso y es conocido que muchos nuevos emprendimientos fallan. De hecho, algunos negocios de comida rápida cierran dentro de un periodo de corto plazo. Por ende un empresario debe contar con cierta cantidad de colaboradores y cada uno de ellos cumplir con el rol que se les encargo, deben comunicarse entre ellos de manera eficiente, también deben conocer todos los puestos en caso de que alguno tenga que encargarse de un puesto diferente al suyo. Otro papel que debe adopta el empresario en de capacitarlos constantemente para que proporcione un buen servicio al cliente pero también deben tener modales y conocer las técnicas de servicio al cliente para causar una 
buena impresión. Otro punto seria que es muy importante que el empleador valore las contribuciones de estos empleados y las utilice para mejorar el negocio continuamente. Otra forma seria un programa de incentivos o beneficios para los empleados. El empresario debe proporcionarles a los colaboradores lo necesario para que se sientan motivados y optimistas durante el trabajo. Cuando un centro de trabajo tiene empleados felices, satisfechos y motivados, suele reflejarse en el ambiente del establecimiento.

\section{MODERADOR:}

¿Considera que existen profesionales calificados en Cusco para trabajar en el servicio de fast food? ¿Por qué?

EXPERTO: Claro que sí, los cusqueños somos personas trabajadoras y emprendedoras a su vez, por lo que nos desempeñamos muy bien en el rol que nos encomiendan previa capacitación y también por los años de experiencia que tenemos en este rubro.

\section{MODERADOR:}

¿Cuáles son los factores más importantes que considera un consumidor al momento de elegir el fast food al cual asistirá y por qué?

EXPERTO: Como ya lo mencione anteriormente, el cliente nacional busca satisfacer sus expectativas en un solo producto, en este caso busca un producto que tenga las 3 "b" ósea bueno, bonito y barato. Por otro lado el cliente busca un lugar acogedor y placentero con una atención amable, cordial y sobre todo rápida.

\section{MODERADOR:}

¿Por qué el ambiente donde se brinda el servicio de fast food es una parte fundamental para llamar la atención del cliente? 
EXPERTO: Por su puesto, el ambiente es un factor muy importante ya todo entra por los ojos por así decirlo no, mucho influye el uso de colores y la combinación de estos para la ambientación del local, también tenemos que ver que nuestros clientes se sientan bastante cómodos durante su permanencia en el establecimiento por ende se debe contar con muebles ergonómicos que permitan una visita placentera.

\section{MODERADOR:}

¿Cuál es el plato de comida que suelen pedir con más frecuencia en un fast food? y ¿Por qué?

EXPERTO: Bueno mayormente en McDonald's las hamburguesas son las más pedida por nuestro público acompañadas de papas y gaseosas, seguidamente están las cajitas felices que son las más pedidas por los niños.

\section{MODERADOR:}

¿Qué tipo de bebida alcohólica considera que es el mejor acompañamiento después del consumo de fast food? $y_{\text {¿Por qué? }}$

EXPERTO: Yo considero que mejor sería al inicio, como una cortesía o un aperitivo como el pisco sour, ya que si implementaríamos la venta de bebidas alcohólicas perdería el toque de fast food, pienso que un fast food se caracteriza únicamente por expender alimentos y no bebidas alcohólicas porque tenemos que tener muy en cuenta que a estos establecimientos también concurren bastantes niños o menores de edad.

\section{MODERADOR:}

¿Qué insumos son los que se compran en cantidad y se usan más en los distintos platos de fast food? $y_{\text {¿Por qué? }}$

EXPERTO: En nuestros requerimientos lo que más solicitamos son las papas pre cocidas, el pan, las hamburguesas de pollo y carne, el queso, los vegetales entre otros 


\section{MODERADOR:}

¿Qué días existe mayor afluencia de consumidores? ¿ ¿Por qué?

EXPERTO: los fines de semana de viernes a domingo y feriados, donde los viernes y sábados hay mayor afluencia de consumidores jóvenes y turistas, los domingos y feriados son más familiares.

\section{MODERADOR:}

¿En qué horarios existe mayor afluencia de consumidores? ¿ ¿Por qué?

EXPERTO: A la hora de almuerzo y en las noches a partir de las 6 ya que muchas personas suelen venir a visitarnos después de sus jornadas laborales y en el caso de domingos y feriados generalmente se llena a partir de las 11:00 de la mañana en adelante.

MODERADOR: Eso sería todo Mercedes muchas gracias por su colaboración, sé que nos va servir bastante para nuestro trabajo de investigación muchas gracias. 


\section{Anexo 10.Transcripción Entrevista Gerente de Native Restaurants}

\section{FICHA TÉCNICA ENTREVISTA A PROFUNDIDAD: EXPERTOS DEL SECTOR}

Buenos días/tardes.

Soy estudiante de la Maestría en Ciencias Empresariales de la Universidad San Ignacio de

Loyola, y en esta ocasión nos encontramos realizando una investigación de mercado sobre los

fast food en la ciudad del Cusco"

Permiso para grabar.

La información que nos facilite en esta entrevista será tratada para fines exclusivamente de la investigación, no pudiendo ser utilizada de forma nominal ni facilitada a terceros.

\section{OBJETIVO DE LA INVESTIGACIÓN}

El objetivo de llevar a cabo la entrevista a expertos, es conocer la opinión sobre la dinámica y crecimiento en el sector de fast food en estos últimos tiempos, y como se vería este sector de acá a tres años en la ciudad del Cusco.

\section{OBJETIVOS ESPECÍFICOS}

Conocer en líneas generales la percepción del experto sobre la presente investigación.

Conocer la percepción real del servicio de los fast food en la ciudad de Cusco.

Conocer las tendencias tanto de la oferta y demanda del servicio de fast food.

Conocer a las competencias y/o propuestas similares.

\section{PERFIL DEL ENTREVISTADO}

Persona emprendedora con más de tres años de experiencia en el rubro de fast food, actualmente con negocio propio Native Restaurante y Fast Food.

Moderadora: Buenas tardes mi nombre es Lizbeth Huaman Arce soy estudiante de la maestría de ciencias empresariales de la Universidad San Ignacio de Loyola 
En esta oportunidad nos encontramos realizando una investigación de mercado de los fast food en la ciudad de Cusco.

La información que usted brindara en la siguiente entrevista será fara fines exclusivamente académicas y de investigación, la misma que será publicada.

Para empezar deseo que usted se presente y nos cuente a cerca su formación académica, puesto de trabajo y experiencia laboral.

Experto: Mi nombre es Edson Multhuafp mi anterior trabajo fue hacia aproximadamente tres a cuatro años en un fast food que en ese tiempo era el Bross y está situado en San Andrés , trabajamos ahí unos seis meses más o menos y bueno después decidimos armar nuestra propia empresa a la cual la nombramos como Native restaurante fast food.

Moderadora: ¿Hace cuánto ya está abierta la empresa?

Experto: Ya está formada hace tres años.

Moderadora: ¿Por qué nuestra gastronomía en general tiene buena percepción?

Experto: En Cusco sobre todo tenemos bastante que explotar, la gastronomía es bien diversa y hay nichos de especialización también.

Moderadora: ¿Por qué la imagen de los fast food en Cusco esta desarrollada?

Experto: Con la introducción de los mall por ejemplo tenemos el KFC, Bembos Popeyes, es una alternativa más pero aun creo yo que tenemos para explotar muchas otras cosas.

Moderadora: ¿Por qué cree que en Cusco los fast food no han seguido la dinámica y tasa de crecimiento similar a los de Lima? 
Experto: Debido a las costumbres también de la población, siempre en Cusco se ha encontrado es que la población requiere de un almuerzo bueno, pero eso también tiene sus etapas y las edades de cada individuo no es lo mismo hablar de un universitario a un profesional.

Moderadora: ¿Qué perspectiva prevé para los fast food en Cusco que no son parte de cadenas de fast food internacionales?

Experto: Si es que se especializa en algo creo que la expectativa es de un crecimiento rápido y se quedan estables en el mercado pienso yo

Moderadora: ¿Por qué realizan solo algunos tipos de promociones y cuáles son?

Experto: En general lo que tratamos de hacer son ofertas mandar a hacer panfletos trípticos o propagandas en la radio también, nuestro fast food está reconocido y por ende tratamos de hacer las publicidades por Facebook para que tengamos seguidores también.

Moderadora: ¿Cuáles son los principales fast food en el Cusco? ¿Porque?

Experto: Yo pienso que el más grande está en la plaza, Bembos y KFC

Moderadora: ¿Cuál cree usted que es el líder?

Experto: Bembos

Moderadora: ¿Cuál es el perfil del consumidor de este producto? (rango de edad)

Experto: El perfil es joven universitario generalmente quiere algo rápido va con amigos.

Moderadora: ¿Cuál es rango de edad?

Experto: De 18 a 25 años

Moderadora: ¿Por qué el consumidor consume alimentos bajo este formato en Cusco?

Experto: Tendría que hacerse una comida rápida de paso algo que no demore mucho, y que algunas veces sea para llevar.

Moderadora: ¿Por qué cree que los Fast Food en Cusco pueden mejorar su posicionamiento? 
Experto: Como le digo si los fast food se siguen especializando en alguna determinada rama van a estar estables y el posicionamiento que van a tener va ser muy bueno a corto y largo plazo Moderadora: ¿Considera que existe nichos de mercado para los fast food que falta explotar en la ciudad del Cusco?, ¿Por qué?

Experto: Si, si hay nichos aun por explotar

Moderadora: Cuáles cree usted

Experto: Por ejemplo en comidas naturales alternativas vegetarianas sobre todo las cuales no tenemos en Cusco.

Moderadora: ¿Por ejemplo un fas food vegetariano?

Experto: No conozco aquí en Cusco o ensaladas por ejemplo no hay en Cusco.

Moderadora: ¿Considera que existen profesionales calificados en Cusco para trabajar en el servicio de fast food? ¿Por qué?

Experto: Si hay, tenemos bastantes institutos que están sacando bastante personal para este tipo.

Moderadora: ¿Cuáles son los factores más importantes que considera un consumidor al momento de elegir el fast food al cual asistirá y por qué?

Experto: Sobretodo la limpieza es un factor determinante, porque la calidad en si uno lo ve o lo puede tomar en cuenta cuando lo ve o cuando consume el producto pero antes no considero que una buena limpieza va llamar más la atención.

Moderadora: ¿Y la ambientación?

Experto: La ambientación también, diferentes tipos de ambientación para diferentes tipos de consumidor 
Moderadora: ¿Por qué el ambiente donde se brinda el servicio de fast food es una parte fundamental para llamar la atención del cliente?

Experto: De hecho que sí, si tenemos una ambientación por ejemplo de los años 80 ochenteros con música rock y todo eso, va tener más afluencia de ese tipo de género, la gente que le gusta el rock primero va ir por la música después va seguir con las comidas.

Moderadora: ¿Cuál es el plato de comida que suelen pedir con más frecuencia en un fast food? y ¿Por qué?

Experto: Generalmente son los pollos, pollos broaster, alitas picantes, Nuggets.

Moderadora: ¿considera conveniente la venta de bebida alcohólicas en fast food? y ¿Por qué?

B: En los fast food no se da mucho, en nuestro medio debido a que es una comida rápida y por ende generalmente dura máximo de 20 a 30 minutos.

Moderadora: ¿Qué días existe mayor afluencia de consumidores a los fast food? y ¿Por qué? Experto: Los jueves viernes y sábado, vienes al menos fin de semana es bien concurrido

Moderadora: ¿En qué horarios existe mayor afluencia de consumidores a los fast food? $\boldsymbol{y}_{\boldsymbol{C}}$ Por qué?

Experto: La mayor afluencia es en la tarde empezando a las cuatro, cinco de la tarde hasta las siete, ocho de la noche.

Moderadora: ¿Cuáles son los medios publicitarios por el cual se llega más al público objetivo? y ¿̈Pr qué?

Experto: Estamos llegando más por el Facebook, por el internet también, lanzamos propagandas por radio y algún medio local televisivo. 
Moderadora: Bueno eso sería todas muchas gracias por su participación la información brindada en muy valiosa. 


\section{Anexo 11. Ficha Técnica de Investigación Cuantitativa}

\section{FICHA TECNICA INVESTIGACION CUANTITATIVA}

Encuesta de aceptación de una nueva empresa comida rápida - fast food en el mercado cusqueño que incorpore insumos regionales.

\section{A. OBJETIVO DE LA INVESTIGACIÓN}

Evaluar el grado de aceptación en el mercado de una nueva empresa de fast food en la ciudad de Cusco, a partir de la indagación sobre el consumo de productos y/o servicios de comida rápida, sus preferencias, gustos y condicionantes, y la posibilidad de lanzar productos nuevos y/o diferenciados.

\section{B. MARCO CONCEPTUAL}

\section{B.1. Definición de Fast Food o Comida Rápida}

Existen diversas definiciones de fast food. La EAE Business School la define como la comida que se sirve en restaurantes de servicio rápido (en los que no se atiende en la mesa), locales de comprar y llevar, puntos de venta en la calle (stands, furgonetas, etc.) y locales de ocio como teatros, cines, salas de juego o encuentros deportivos.

Sonia Allison la define como...comida preparada que se puede llevar caliente de los establecimientos y restaurantes y comida inmediatamente o platos precocinados que se venden en supermercados o tiendas de alimentación y que solamente hay que recalentar antes de servirlos (Allison, 1990). 
Estas definiciones no difieren mucho de los modelos de negocios de fast food instalados en el medio local, con las grandes franquicias internacionales (como KFC, McDonald's, Burger King, Pizza Hut, etc.) y las empresas nacionales e incluso locales (como Bembos, Rupha's, etc.) y este concepto se introduce cada día más en la vida de las personas a medida que la sociedad experimenta una mayor prisa por motivos de trabajo, estudio y hasta de ocio, es decir compatibiliza con los nuevos estilos de vida, y la gente quiere sacarle tiempo al tiempo y muchas veces este ahorro se busca en la comida.

\section{B.2. Productos}

Los productos de fast food se pueden clasificar en dos tipos: los de influencia y características anglosajonas, como hamburguesas, salchichas y papas fritas, acompañadas de salsas diversas; y los de procedencia mediterránea, como pizzas, bocadillos y kebabs, los cuales son bastante más saludables. Se debe mencionar que una parte de la fast food posee una elevada densidad energética con altos contenidos en grasas e hidratos de carbono, como hamburguesas, croquetas, salchichas, papas fritas e, incluso, el típico pastel de manzana. (Arbaiza, Cánepa, Cortez, \& Lévano, 2014)

Este anterior análisis de carácter nacional, no difiere mucho al de nuestro medio local, destacando además el importante consumo del pollo en sus diferentes presentaciones (piernitas, alitas, trozos variados, etc.), y las de bebidas como gaseosas y refrescos.

Cabe señalar además la oferta en gran parte de estos establecimientos de servicios complementarios que forman parte de la propuesta de valor de estos negocios como la 
decoración y ambientación moderna y con temáticas, música, wi fi gratuito, pago con tarjeta, juegos para niños, etc.

\section{B.3. Idea del negocio y propuesta de diferenciación}

La idea del negocio que se propone de manera preliminar, se basa en un local de comida rápida - fast food, ubicado en una zona céntrica de alto movimiento como es la Av. La Cultura, entre la Universidad San Antonio Abad de Cusco y El Hospital Regional de Cusco; que ofrece los productos considerados de mayor demanda en el medio, como son fritura de trozos de pollo, piernitas, alitas, papas fritas, sándwiches de pollo, de hamburguesas y todas sus presentaciones, butifarras, salchipapas, jugos, gaseosas y refrescos. Además contara con una ambientación y decoración agradable juvenil y a la vez ejecutiva, con wifi gratuito, etc.

Cabe destacar que la propuesta de diferenciación está referida al uso de insumos de la zona andina y de nuestro medio en particular, como es la carne de chancho y cuy, el uso de harinas de quinua y kiwicha, la muña, huacatay y rocoto para los aderezos y cremas; bebidas de frutas de la zona como naranja, piña, maíz morado, etc., que proporcionaran particulares sabores diferentes pero comunes al disfrute del paladar cusqueño.

\section{B.4. Perfil del Cliente}

Para el presente proyecto se determinó al segmento que está representado por la población urbana de los distritos céntricos y aledaños a la Av. La Cultura en la provincia de Cusco de los niveles socioeconómicos A, B y C entre las edades de 18 a 45 años de edad, quienes son estudiantes y trabajadores. 


\section{B.5. Cálculo de tamaño de muestra}

Para realizar el cálculo de la muestra, primero se determina el objetivo de la investigación el cual es:

Estimar la proporción de la población urbana de residentes y flotantes en los distritos donde se ubica la Av. La Cultura en la Provincia de Cusco, entre 18 y 45 años de edad de los niveles socioeconómicos A,B y C que consumirían sus alimentos en un establecimiento de comida Fast Food de cocina americana con insumos Novoandinos

Se calculará la muestra que representa a la población de estudio haciendo uso del muestreo probabilístico Sistemático, debido a que se espera obtener información de la población residente y flotante. El muestreo sistemático conlleva la selección de un individuo de la población aleatoriamente, luego de ello se realiza el muestreo en base a un intervalo constante abarcando el volumen total de encuestas a aplicar. (Gestión.pe, 2015)

Se utilizará una formula estadística para el cálculo de la muestra en base a una población infinita, es decir poblaciones mayores a 100,000 habitantes, se aplica esta fórmula debido a que la cantidad de elementos que conforman la población es tan grande y variado que puede presumirse infinita, la fórmula se muestra a continuación:

$$
n=\frac{Z^{2} p q}{e^{2}}
$$


Dónde:

$\mathrm{Z}=1.96$ que corresponde a un nivel de confianza de $95 \%$

$\mathrm{E}=3.5 \%$ (nivel de significancia)

$\mathrm{P}=50 \%$ (probabilidad de éxito)

$\mathrm{Q}=50 \%$ (probabilidad de fracaso)

El nivel de confianza de $95 \%$ se estableció puesto que se espera que por lo menos el $95 \%$ de los casos se encuentre dentro de la proporción de personas que serían potenciales clientes para el proyecto. Al ser un proyecto nuevo con un concepto que aún no se aplica en el mercado, se estima una probabilidad de éxito o fracaso de 50\%, además al ser un proyecto que mide el nivel de consumo de la población y cuya ejecución de la muestra es bajo el muestreo probabilístico sistemático, se estima un nivel de significancia o error de $3.5 \%$ es decir que la proporción resultante del muestro sea como máximo +/-3.5\% de la proporción real de la población de estudio.

De acuerdo a ello el cálculo de la muestra (n) es el siguiente:

La muestra (n) es:

$\mathrm{N}=784$

Para el desarrollo del muestreo sistemático se procede a determinar el intervalo constante para la aplicación de las encuestas, el factor " $K$ " de acuerdo a la fórmula que se muestra a continuación.

- Donde:

$$
k=\left[\frac{N}{n}\right]
$$

$\mathrm{K}=$ Muestreo sistemático

$\mathrm{N}=$ Número de elementos de la población

$\mathrm{n}=$ Tamaño de la muestra. 
Para determinar el intervalo, este se estimó utilizando como referencia la proporción de población de cada distrito la cual se dividió sobre el número total de encuestas, el resultado se dividió a su vez a la mitad para tener un intervalo más real en referencia al volumen de tránsito de personas en las zonas de estudio conforme Tabla 1a.

Tabla 1.a

Determinación del factor K/2, según población por distrito

\begin{tabular}{lccc}
\hline \multicolumn{1}{c}{ Población 2017} & \% Sobre pob. Total & $\mathrm{K}$ & $\mathrm{K} / 2$ \\
& & & \\
\hline 119580 & $25.9 \%$ & 153 & 76 \\
54072 & $11.7 \%$ & 69 & 34 \\
133927 & $29.0 \%$ & 171 & 85 \\
90702 & $19.6 \%$ & 116 & 58 \\
64230 & $13.9 \%$ & 82 & 41 \\
\hline 462511 & $100 \%$ & & \\
\hline
\end{tabular}

Nota. Fuente: Elaboración propia.

\section{B.5.1. Definición de distribución de muestra.}

A continuación se presenta la información estadística en base a la segmentación geográfica y psicográfica en estudio. En primer lugar se realizó la proyección de la población al 2017 conforme Tabla 1.b 
Tabla 1.b

Segmentación Geográfica: Población urbana proyectada al 2017

\begin{tabular}{|c|c|c|c|c|c|c|}
\hline & & & & & \multicolumn{2}{|c|}{ Proyección } \\
\hline & 2013 & 2014 & 2015 & 2016 & 2017 & Proporción \\
\hline Cusco & 118231 & 118322 & 118316 & 119005 & 119580 & $25.9 \%$ \\
\hline San Jerónimo & 43406 & 45236 & 47101 & 47374 & 54072 & $11.7 \%$ \\
\hline San Sebastián & 105388 & 110298 & 115305 & 115974 & 133927 & $29.0 \%$ \\
\hline Santiago & 90319 & 90274 & 90154 & 90677 & 90702 & $19.6 \%$ \\
\hline \multirow[t]{2}{*}{ Wanchaq } & 63858 & 63844 & 63778 & 64148 & 64230 & $13.9 \%$ \\
\hline & & & & TOTAL & 462511 & $100 \%$ \\
\hline
\end{tabular}

Nota. Diresa Cusco. Adaptado de Estadísticas de población. Recuperado de http://www.diresacusco.gob.pe/estaditica/modulo7.htm

Para desarrollar el esquema de aplicación de encuestas, se comenzó con el intervalo más bajo comenzando desde el día Lunes como mecanismo de medición y se distribuyó en orden ascendente de Lunes a Domingo en relación al k/2, obtenido. Se determinó aleatoriamente el punto de inicio en el individuo número siete para cada día.

Se consideraron cuatro zonas diferentes de alto tránsito de la Av. La Cultura como puntos de aplicación de encuestas, así mismo se asignó subjetivamente porcentajes de afluencia de personas estimados por día de semana que se aplicaron al número total de encuestas para obtener la distribución de encuestas por día de la semana, conforme Tabla 1.c. 
Tabla 1.c

Esquema de aplicación de encuestas bajo el sistema de muestreo sistemático

\begin{tabular}{lccccccc}
\hline & Lunes & Martes & Miércoles & Jueves & Viernes & Sábado & Domingo \\
\hline Afluencia de personas & $7 \%$ & $8 \%$ & $11 \%$ & $11 \%$ & $13 \%$ & $25 \%$ & $25 \%$ \\
$100 \%$ & & & & & & & \\
Total de Encuestas & 55 & 63 & 86 & 86 & 102 & 196 & 196 \\
784 & & & & & & & 85 \\
Intervalo Constante & 34 & 41 & 58 & 76 & 85 & & \\
K/2 & & & & & & & \\
\hline
\end{tabular}

Horario de aplicación de encuestas

Lunes a domingo De 12:00pm a 10:00pm

Nota. Fuente: Elaboración propia.

Con el fin de establecer la distribución de la muestra por día según nivel socioeconómico y edad, en primer lugar se realizó la segmentación por NSE según Figura A, para posteriormente definir la distribución proporcional a la muestra conforme Tabla 1.d.

Distribución de la población urbana por NSE, según departamento, 2015 (participación porcentual en cada departamento)

\begin{tabular}{|l|c|c|c|c|}
\hline & AB & C & D & E \\
\hline Apurímac & $9.7 \%$ & $17.8 \%$ & $26.4 \%$ & $46.1 \%$ \\
\hline Arequipa & $20.9 \%$ & $35.3 \%$ & $32.6 \%$ & $11.1 \%$ \\
\hline Cusco & $17.1 \%$ & $18.9 \%$ & $32.5 \%$ & $31.6 \%$ \\
\hline
\end{tabular}

Figura A. Segmentación demográfica - población urbana por NSE de la ciudad de Cusco. Recuperado de http://mercadosyregiones.com/niveles-socioeconomicos-y-voto-de-izquierda-enel-sur-peruano/ 
Considerando la distribución por nivel socioeconómico se tiene la siguiente distribución de la muestra por NSE.

Tabla 1.d

Porcentaje del Nivel socioeconómico proporcional a la muestra

\begin{tabular}{|c|c|c|}
\hline NSE & $\%$ NSE Población & $\begin{array}{c}\text { \%NSE Proporcional a la } \\
\text { muestra }\end{array}$ \\
\hline $\mathrm{AB}$ & $17.10 \%$ & $47.50 \%$ \\
\hline \multirow[t]{2}{*}{$\mathrm{C}$} & $18.90 \%$ & $52.50 \%$ \\
\hline & $36.00 \%$ & $100 \%$ \\
\hline
\end{tabular}

Nota. Fuente: Elaboración propia.

Posteriormente se realizó la segmentación por grupo etario, para ello se determinó la estación porcentual de edades según Tabla 1.e, para luego elaborar la estimación de la proporción de grupos etarios en relación a la muestra conforme Tabla 1.f.

Tabla 1.e

Segmentación demográfica: Estimación porcentual de edades por grupo etario

\begin{tabular}{lcc}
\hline & Grupo de edades & Población \\
\hline $18-24$ & 156450 & $11.75 \%$ \\
$25-34$ & 226123 & $16.98 \%$ \\
$35-45$ & 191001 & $14.34 \%$ \\
\hline Población total departamento de Cusco & 1331758 & $100 \%$ \\
\hline
\end{tabular}

Nota. Perú: Estimaciones y proyecciones de población departamental, por año calendario y edades simples 1995 2025. INEI, 2010. Recuperado de http://proyectos.inei.gob.pe/web/biblioineipub/bancopub/Est/Lib1039/libro.pdf 
Tabla 1.f

Porcentaje de rango de edades proporcional a la muestra

\begin{tabular}{lcc}
\hline \multicolumn{1}{c}{ Grupo de edades } & \% Edad Población & \%Edad Proporcional a la muestra \\
\hline $18-24$ & $11.75 \%$ & $27.28 \%$ \\
$25-34$ & $16.98 \%$ & $39.42 \%$ \\
$35-45$ & $14.34 \%$ & $33.30 \%$ \\
\hline & $43.07 \%$ & $100 \%$
\end{tabular}

Nota. Fuente: Elaboración propia.

En base a lo anterior según Tabla 1.g, se desarrolló la distribución de la muestra por día según rango de edad y Nivel socioeconómico. 
Tabla 1.g

Distribución de la Muestra por día según Rango de edad, Nivel socioeconómico

\begin{tabular}{|c|c|c|c|c|c|c|}
\hline \multicolumn{7}{|c|}{ Lunes } \\
\hline NSE & \multicolumn{2}{|c|}{$a b$} & $47.50 \%$ & \multicolumn{2}{|c|}{$\mathrm{c}$} & $52.50 \%$ \\
\hline \multirow{2}{*}{ Rango de Edad } & $18-24$ & $25-34$ & $35-45$ & $18-24$ & $25-34$ & $35-45$ \\
\hline & $27.28 \%$ & $39.42 \%$ & $33.30 \%$ & $27.28 \%$ & $39.42 \%$ & $33.30 \%$ \\
\hline $\mathrm{N}^{\circ}$ Encuestas & 7 & 10 & 9 & 8 & 11 & 10 \\
\hline \multicolumn{7}{|c|}{ Martes } \\
\hline NSE & \multicolumn{2}{|c|}{$a b$} & $47.50 \%$ & \multicolumn{2}{|c|}{$\mathrm{c}$} & $52.50 \%$ \\
\hline \multirow{2}{*}{ Rango de Edad } & $18-24$ & $25-34$ & $35-45$ & $18-24$ & $25-34$ & $35-45$ \\
\hline & $27.28 \%$ & $39.42 \%$ & $33.30 \%$ & $27.28 \%$ & $39.42 \%$ & $33.30 \%$ \\
\hline $\mathrm{N}^{\circ}$ Encuestas & 8 & 12 & 10 & 9 & 13 & 11 \\
\hline \multicolumn{7}{|c|}{ Miércoles } \\
\hline NSE & \multicolumn{2}{|c|}{$a b$} & $47.50 \%$ & \multicolumn{2}{|c|}{$\mathrm{c}$} & $52.50 \%$ \\
\hline \multirow{2}{*}{ Rango de Edad } & $18-24$ & $25-34$ & $35-45$ & $18-24$ & $25-34$ & $35-45$ \\
\hline & $27.28 \%$ & $39.42 \%$ & $33.30 \%$ & $27.28 \%$ & $39.42 \%$ & $33.30 \%$ \\
\hline $\mathrm{N}^{\circ}$ Encuestas & 11 & 16 & 14 & 12 & 18 & 15 \\
\hline \multicolumn{7}{|c|}{ Jueves } \\
\hline NSE & \multicolumn{2}{|c|}{$a b$} & $47.50 \%$ & \multicolumn{2}{|c|}{$\mathrm{c}$} & $52.50 \%$ \\
\hline \multirow{2}{*}{ Rango de Edad } & $18-24$ & $25-34$ & $35-45$ & $18-24$ & $25-34$ & $35-45$ \\
\hline & $27.28 \%$ & $39.42 \%$ & $33.30 \%$ & $27.28 \%$ & $39.42 \%$ & $33.30 \%$ \\
\hline $\mathrm{N}^{\circ}$ Encuestas & 11 & 16 & 14 & 12 & 18 & 15 \\
\hline \multicolumn{7}{|c|}{ Viernes } \\
\hline NSE & \multicolumn{2}{|c|}{$a b$} & $47.50 \%$ & \multicolumn{2}{|c|}{$\mathrm{c}$} & $52.50 \%$ \\
\hline \multirow{2}{*}{ Rango de Edad } & $18-24$ & $25-34$ & $35-45$ & $18-24$ & $25-34$ & $35-45$ \\
\hline & $27.28 \%$ & $39.42 \%$ & $33.30 \%$ & $27.28 \%$ & $39.42 \%$ & $33.30 \%$ \\
\hline $\mathrm{N}^{\circ}$ Encuestas & 13 & 19 & 16 & 15 & 21 & 18 \\
\hline \multicolumn{7}{|c|}{ Sábado } \\
\hline NSE & \multicolumn{2}{|c|}{$\mathrm{ab}$} & $47.50 \%$ & \multicolumn{2}{|c|}{$\mathrm{c}$} & $52.50 \%$ \\
\hline \multirow{2}{*}{ Rango de Edad } & $18-24$ & $25-34$ & $35-45$ & $18-24$ & $25-34$ & $35-45$ \\
\hline & $27.28 \%$ & $39.42 \%$ & $33.30 \%$ & $27.28 \%$ & $39.42 \%$ & $33.30 \%$ \\
\hline $\mathrm{N}^{\circ}$ Encuestas & 25 & 37 & 31 & 28 & 41 & 34 \\
\hline \multicolumn{7}{|c|}{ Domingo } \\
\hline NSE & \multicolumn{2}{|c|}{$a b$} & $47.50 \%$ & \multicolumn{2}{|c|}{$\mathrm{c}$} & $52.50 \%$ \\
\hline \multirow{2}{*}{ Rango de Edad } & $18-24$ & $25-34$ & $35-45$ & $18-24$ & $25-34$ & $35-45$ \\
\hline & $27.28 \%$ & $39.42 \%$ & $33.30 \%$ & $27.28 \%$ & $39.42 \%$ & $33.30 \%$ \\
\hline $\mathrm{N}^{\circ}$ Encuestas & 25 & 37 & 31 & 28 & 41 & 34 \\
\hline
\end{tabular}

Nota. Fuente: Elaboración propia. 


\section{B.6. Diseño de trabajo de campo}

Se tomó en cuenta para el diseño de la encuesta los objetivos de ventas, promoción, distribución, entre otros. Esta encuesta permitió conocer el nivel de aceptación del proyecto y la demanda potencial del mismo. El instrumento que se utilizo fue el cuestionario.

\section{B.6.1. Diseño de trabajo de campo.}

- Organización

El trabajo de campo se organiza en función de la cantidad de encuestas a aplicar a la población de estudio. Para ello se planifica el trabajo de la siguiente manera:

$\checkmark$ Numero de encuestas: 784

$\checkmark$ Zonas a encuestar: 04 puntos de alto tránsito en el Av. La Cultura

$\checkmark$ Tiempo: 07 días

$\checkmark$ Cantidad de encuestadores: 04 (un encuestador por zona)

$\checkmark$ Numero de encuestas por día: Según Tabla 36

$\checkmark$ Tiempo estimado de la aplicación de la encuesta: 10 a 15 min

Para las acciones de coordinación y control del trabajo de campo se contará con la participación de 01 Coordinador general, 01 Supervisor de campo.

Se realizaran de 6 a 8 encuestas piloto para medir si la encuesta satisface los objetivos del proyecto y si es de fácil aplicación y tabulación.

- Requerimientos

$\checkmark$ Personal

$\checkmark$ Coordinador general $(01)$

$\checkmark$ Supervisor de campo (01)

$\checkmark$ Encuestadores (04) 
- Materiales

$\checkmark$ Tablero (08)

$\checkmark$ Lápiz (08)

$\checkmark$ Papel bond x 80 gr (1/2 millar para los cuestionarios e informes)

$\checkmark$ Servicios de terceros

$\checkmark$ Impresiones

$\checkmark$ Movilidad

$\checkmark$ Presupuesto

Tabla 1.h

Presupuesto de Personal para aplicación de encuestas

\begin{tabular}{lccccc}
\hline Ítem & Descripción & Unidad de medida & Cantidad & Costo Unitario & Costo \\
& & & & & Parcial \\
\hline 1 & Coordinador general (01) & Día & 2 & 150.00 & 300.00 \\
2 & Supervisor de campo (01) & Día & 2 & 100.00 & 200.00 \\
3 & Encuestadores (04) & encuesta & 784 & 0.73 & 576.00 \\
\hline & TOTAL & & & & $1,076.00$
\end{tabular}

Nota. Fuente: Elaboración propia. 
Tabla 1.i

Presupuesto de Materiales para aplicación de encuestas

\begin{tabular}{lccccc}
\hline \multirow{2}{*}{ Ítem } & Descripción & Unidad de medida & Cantidad & Costo & Costo Parcial \\
& & & & Unitario & \\
\hline 1 & Tablero & Und & 8 & 11.4 & 90.00 \\
2 & Lápiz & Und & 8 & 0.75 & 6.00 \\
3 & Papel bond x 80 gr & Millar & 0.5 & 40.00 & 20.00 \\
\hline
\end{tabular}

Nota. Fuente: Elaboración propia.

Tabla 1.j

Presupuesto servicios de terceros para aplicación de encuestas

\begin{tabular}{lccccc}
\hline Ítem & Descripción & Unidad de & Costo & Costo Parcial \\
& & medida & & Unitario & \\
\hline 1 & Impresiones & Glb & 1 & 100.00 & 100.00 \\
2 & Movilidad & Glb & 1 & 50.00 & 50.00 \\
\hline & TOTAL & & & & 150.00 \\
\hline
\end{tabular}

Nota. Fuente: Elaboración propia.

Lo que suma un total presupuestado de 1, 342.00 soles. 


\section{Anexo 12.Encuesta acerca de un fast food en la ciudad del Cusco}

Buenos días/tardes, estamos realizando un estudio de mercado para determinar el nivel de aceptación de un nuevo fast food en la ciudad de Cusco. Le agradeceremos brindarnos su tiempo y responder las siguientes preguntas.

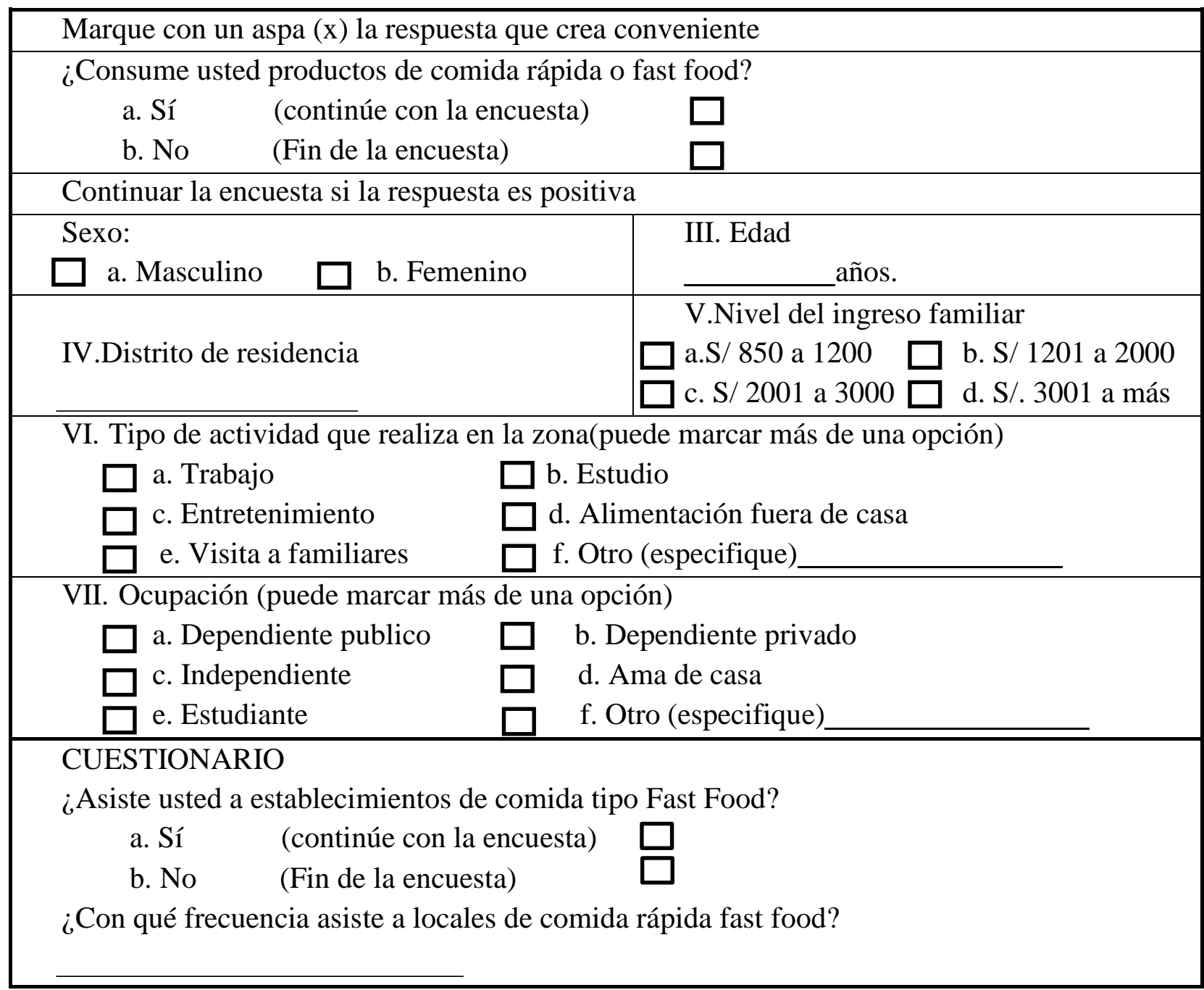


¿En qué horario suele frecuentar locales de comida rápida -fast food? Marque de una a más opciones

\begin{tabular}{|c|c|c|c|c|c|}
\hline \multirow{2}{*}{ Días } & \multicolumn{5}{|l|}{ Horas } \\
\hline & $9-12 a m$ & $12-3 p m$ & $3-6 p m$ & $6-9 \mathrm{pm}$ & 9- $12 \mathrm{pm}$ \\
\hline \multicolumn{6}{|l|}{ Lunes } \\
\hline \multicolumn{6}{|l|}{ Martes } \\
\hline \multicolumn{6}{|l|}{ Miércoles } \\
\hline \multicolumn{6}{|l|}{ Jueves } \\
\hline \multicolumn{6}{|l|}{ Viernes } \\
\hline \multicolumn{6}{|l|}{ Sábado } \\
\hline Domingo & & & & & \\
\hline
\end{tabular}

Cuando asiste a un fast food, indique cuánto tiempo en promedio permanece en este tipo de establecimientos.
a. De 5 a 15 minutos
c. De 31 a 60 minutos
b. De 16 a 30 minutos
d. Más de 1 hora

¿Con quiénes suele visitar los locales de comida rápida-fast food? Marque una sola respuesta
$\square$ a. Sólo
$\square$ d. Amigos
$\square$ b. Familiares
$\square$ e. Otros:
$\square$ c. Pareja

¿Qué tan importante considera usted que son los siguientes factores para un fast food? Enumere del 1 al 10 , donde 1 es menos importante y 10 muy importante

\begin{tabular}{|l|l|}
\hline Precio & \\
\hline Ubicación & \\
\hline Calidad de producto & \\
\hline Calidad de la atención & \\
\hline Variedad de productos & \\
\hline Sabor & \\
\hline Tamaño de porción & \\
\hline Horario de Atención & \\
\hline Ambiente & \\
\hline Infraestructura & \\
\hline
\end{tabular}
Indique cuáles son los productos de su preferencia en un Fast food. Puede marcar más de una opción

\begin{tabular}{|l|l|}
\hline Hamburguesa & \\
\hline Empanada & \\
\hline Pollo frito & \\
\hline Pollo broaster & \\
\hline Pizza & \\
\hline Otros (especifique) & \\
\hline
\end{tabular}


¿Cuáles son las bebidas que usted suele adquirir en un fast food? Puede marcar más de una opción

\begin{tabular}{|l|l|}
\hline Gaseosa & \\
\hline Jugos & \\
\hline Café & \\
\hline Infusiones & \\
\hline Cerveza & \\
\hline Otros (especifique) & \\
\hline
\end{tabular}

Indique su ranking de asistencia a los establecimientos de fast food que suele visitar cuando sale a comer fuera. Enumere desde el primer lugar (1) a más de acuerdo a su asistencia.

\begin{tabular}{|l|l|}
\hline Burguer King & \\
\hline Kentucky Fried Chicken (KFC) & \\
\hline Bembos & \\
\hline Popeyes & \\
\hline Rupha's & \\
\hline Otros (especifique) & \\
\hline
\end{tabular}

¿Qué tan importante considera usted que son los siguientes factores para la elección de su fast food preferido? Enumere del 1 al 10, donde 1 es menos importante y 10 más importante.

\begin{tabular}{|l|l|l|l|}
\hline a. Rapidez del servicio & & b. Precio & \\
\hline c. Tipo de producto & & d. Promociones y descuentos & \\
\hline e. Sabor & & f. Ubicación & \\
\hline g. Tamaño de la porción & & h. Infraestructura & \\
\hline i. Ambiente & & j. Variedad de productos & \\
\hline
\end{tabular}

Si se abriera un nuevo local de comida rápida - fast food donde se preparen hamburguesas y pollos tipo broasters, donde se incorpore además ingredientes andinos o de la región, tanto en la preparación de los productos principales como en las bebidas y postres, indique usted:

¿Qué insumos andinos le gustaría fuesen utilizados en la preparación de las hamburguesas y pollos broaster? Puede marcar más de una opción

$\square$ Carne de chancho

Harina de kiwicha

Harina de quinua

Harina de Maíz

Aderezo de Lechón

Aderezo de huacatay

Otros (especificar):
¿Qué tipo de complementos o adicionales andinos le gustaría encontrar en el local? Puede marcar más de una opción

$\square$ Aji Uchucuta

$\square$ Torreja de Maíz

$\square$ Papa helada con Queso

$\square$ Moroya con Queso

$\square$ Papas nativas en diferentes

presentaciones

$\square$ Choclo con Queso

$\square$ Otros (especificar): 
¿Qué tipo de bebidas andinas le gustaría encontrar en local? Puede marcar más de una opción

$\square$ a. Emoliente
$\square$ b. Chicha de Quinua
$\square$ c. Chicha de kiwicha
$\square$ d. Otros (especificar):

¿Cuánto está dispuesto a pagar en promedio por un combo personal (pollo o hamburguesa más complemento y bebida) en este tipo de local?

$\square \quad$ a.S/ 10.00 soles a S/ 15.00 soles $\square$ b. S/ 16.00 soles a S/ 25.00 soles

$\square$ c. S/ 26.00 soles a S/ 35.00 soles $\square$ d. de S/ 36.00 soles a más

¿Cuánto está dispuesto a pagar por en promedio por un adicional (complemento o bebida) en este tipo de local?
$\square \quad$ a.S/ 5.00 soles a S/ 7.00 soles
$\square$ b. S/ 8.00 soles a S/ 10.00 soles
c. S/ 11.00 soles a S/ 12.00 soles
$\square$ d. de S/ 13.00 soles a más

¿Qué tipo de postres andinos le gustaría encontrar en esta propuesta de fast food? Puede marcar más de una opción
$\square$
$\square$
a. Pastel de Choclo
b. Dulce de Sacha tómate
c. Budín de Quinua
$\square$
d. Gelatina de Pata de vaca
e. Dulce de Melocotón
Otros especificar):

¿Cuánto está dispuesto a pagar por en promedio por un postre andino en este tipo de local?
$\square$
a .S/ 5.00 soles a $\mathrm{S} / 7.00$ soles
b. S/ 8.00 soles a S/ 10.00 soles
c. S/ 11.00 soles a más

Considera que de aperturarse este tipo de establecimiento de fast food, usted:

Definitivamente asistiría

Probablemente asistiría

Indiferente

Probablemente no asistiría

Definitivamente no asistiría

(Fin de la Encuesta)

¿Cuánto tiempo está dispuesto a esperar por su pedido en este tipo de fast food?

$\square \quad$ De 10 min. - 15 min.

$\square$ De 16 min. - 20 min.

$\square$ De 21 min. - 25 min.

$\square$ De 26 min a más

Indique cuánto tiempo permanecería en este tipo de local
$\square$ a. De 10 a 15 minutos
c. De 21 a 30 minutos
b. De 16 a 20 minutos
d. Más de 31 minutos 
¿En qué horario estaría dispuesto a frecuentar este nuevo local de comida rápida? Marque de una a más opciones

\begin{tabular}{|c|c|c|c|c|c|}
\hline \multirow{2}{*}{ Días } & \multicolumn{5}{|l|}{ Horas } \\
\hline & $9-12 a m$ & $12-3$ pm & $3-6 \mathrm{pm}$ & $6-9 \mathrm{pm}$ & 9- $12 \mathrm{pm}$ \\
\hline \multicolumn{6}{|l|}{ Lunes } \\
\hline \multicolumn{6}{|l|}{ Martes } \\
\hline \multicolumn{6}{|l|}{ Miércoles } \\
\hline \multicolumn{6}{|l|}{ Jueves } \\
\hline \multicolumn{6}{|l|}{ Viernes } \\
\hline \multicolumn{6}{|l|}{ Sábado } \\
\hline Domingo & & & & & \\
\hline
\end{tabular}

Ranking de medios de comunicación por el cual considera se debería realizar la promoción del nuevo local. Donde 1 es menos importante y 5 más importante

\begin{tabular}{|l|l|}
\hline Televisión & \\
\hline Radio & \\
\hline Periódico & \\
\hline Afiche & \\
\hline Redes Sociales & \\
\hline
\end{tabular}

Indique en que zona de la Av. La Cultura le gustaría encontrar el nuevo local de comida rápida.

\begin{tabular}{|l|l|l|}
\hline & $\begin{array}{c}\text { Distr } \\
\text { ito de } \\
\text { Cusco }\end{array}$ & $\begin{array}{c}\text { Distrit } \\
\text { o de } \\
\text { Wanchaq }\end{array}$ \\
\hline Cerca del Colegio Inca Garcilaso de la Vega & & \\
\hline $\begin{array}{c}\text { Cerca de la Universidad San Antonio Abad del } \\
\text { Cusco }\end{array}$ & & \\
\hline Cerca del Centro Comercial Real Plaza & & \\
\hline Cerca del Supermercado Orión & & \\
\hline
\end{tabular}




\begin{tabular}{|c|c|c|c|c|c|c|c|c|c|c|c|c|}
\hline \multirow{2}{*}{$\begin{array}{l}\text { Marque con un a } \\
\text { siguientes servicios } \\
\text { Música moderna }\end{array}$} & $\begin{array}{l}\text { spa }(\mathrm{x}) \text { el niv } \\
\text { o característ }\end{array}$ & & & onal & & & & & & & $\begin{array}{l}\text { ació } \\
\text { foo }\end{array}$ & de los \\
\hline & $\begin{array}{l}\text { Nada } \\
\text { importante }\end{array}$ & 1 & 2 & 3 & 4 & 5 & 6 & 7 & 8 & 9 & 10 & $\begin{array}{l}\text { Muy } \\
\text { importante }\end{array}$ \\
\hline Wifi & $\begin{array}{l}\text { Nada } \\
\text { importante }\end{array}$ & 1 & 2 & 3 & 4 & 5 & 6 & 7 & 8 & 9 & 10 & $\begin{array}{l}\text { Muy } \\
\text { importante }\end{array}$ \\
\hline Delivery & $\begin{array}{l}\text { Nada } \\
\text { importante }\end{array}$ & 1 & 2 & 3 & 4 & 5 & 6 & 7 & 8 & 9 & 10 & $\begin{array}{l}\text { Muy } \\
\text { importante }\end{array}$ \\
\hline Cajita Feliz & $\begin{array}{l}\text { Nada } \\
\text { importante }\end{array}$ & 1 & 2 & 3 & 4 & 5 & 6 & 7 & 8 & 9 & 10 & $\begin{array}{l}\text { Muy } \\
\text { importante }\end{array}$ \\
\hline $\begin{array}{l}\text { Combos } \\
\text { familiares }\end{array}$ & $\begin{array}{l}\text { Nada } \\
\text { importante }\end{array}$ & 1 & 2 & 3 & 4 & 5 & 6 & 7 & 8 & 9 & 10 & $\begin{array}{l}\text { Muy } \\
\text { importante }\end{array}$ \\
\hline $\begin{array}{l}\text { Zona de juego } \\
\text { para niños }\end{array}$ & $\begin{array}{l}\text { Nada } \\
\text { importante }\end{array}$ & 1 & 2 & 3 & 4 & 5 & 6 & 7 & 8 & 9 & 10 & $\begin{array}{l}\text { Muy } \\
\text { importante }\end{array}$ \\
\hline $\begin{array}{l}\text { Entrega de } \\
\text { pedido en mesa. }\end{array}$ & $\begin{array}{l}\text { Nada } \\
\text { importante }\end{array}$ & 1 & 2 & 3 & 4 & 5 & 6 & 7 & 8 & 9 & 10 & $\begin{array}{l}\text { Muy } \\
\text { importante }\end{array}$ \\
\hline $\begin{array}{l}\text { Decoración } \\
\text { acorde a la } \\
\text { temática andina. }\end{array}$ & $\begin{array}{l}\text { Nada } \\
\text { importante }\end{array}$ & 1 & 2 & 3 & 4 & 5 & 6 & 7 & 8 & 9 & 10 & $\begin{array}{l}\text { Muy } \\
\text { importante }\end{array}$ \\
\hline
\end{tabular}

Nota. Fuente: Elaboración propia. 


\section{Anexo 13. Regresión lineal de población}

\begin{tabular}{|c|c|c|c|c|c|c|c|c|c|c|c|c|}
\hline \multirow[b]{2}{*}{ Años } & \multirow[b]{2}{*}{$\mathbf{X}$} & \multirow[b]{2}{*}{$\mathrm{X}^{2}$} & \multicolumn{2}{|c|}{ CUSCO } & \multicolumn{2}{|c|}{ SAN JERONIMO } & \multicolumn{2}{|c|}{ SAN SEBASTIAN } & \multicolumn{2}{|c|}{ SANTIAGO } & \multicolumn{2}{|c|}{ WANCHAQ } \\
\hline & & & $\mathbf{Y}$ & $\mathrm{YX}$ & $\mathbf{Y}$ & $\mathrm{YX}$ & \begin{tabular}{l|l}
$\mathbf{Y}$ \\
\end{tabular} & $\mathrm{YX}$ & \begin{tabular}{l|l}
$\mathbf{Y}$ \\
\end{tabular} & $Y X$ & \begin{tabular}{l|l}
$\mathbf{Y}$ \\
\end{tabular} & $\mathrm{YX}$ \\
\hline 2012 & -2.0 & 4.00 & 118052 & -236104 & 41617 & -83234 & 100585 & -201170 & 90296 & -180592 & 63825 & -127650 \\
\hline 2013 & -1.0 & 1.00 & 118231 & -118231 & 43406 & -43406 & 105388 & -105388 & 90319 & -90319 & 63858 & -63858 \\
\hline 2014 & 0.0 & - & 118322 & 0 & 45236 & 0 & 110298 & 0 & 90274 & 0 & 63844 & 0 \\
\hline 2015 & 1.0 & 1.00 & 118316 & 118316 & 47101 & 47101 & 115305 & 115305 & 90154 & 90154 & 63778 & 63778 \\
\hline 2016 & 2.0 & 4.00 & 119005 & 238010 & 47374 & 94748 & 115974 & 231948 & 90677 & 181354 & 64148 & 128296 \\
\hline \multirow[t]{3}{*}{ SUMA } & 0 & 10.00 & 591,926 & 1,991 & 224,734 & 15,209 & 547,550 & 40,695 & 451,720 & 597 & 319,453 & 566 \\
\hline & & & $\mathrm{a}$ & $118,385.20$ & $\mathrm{a}$ & $44,946.80$ & $\mathrm{a}$ & $109,510.00$ & $\mathrm{a}$ & $90,344.00$ & $\mathrm{a}$ & $63,890.60$ \\
\hline & & & $b$ & 199.10 & $\mathrm{~b}$ & $1,520.90$ & $b$ & $4,069.50$ & $\mathrm{~b}$ & 59.70 & $\mathrm{~b}$ & 56.60 \\
\hline Años & & 2017 & 2018 & 2019 & 2020 & 2021 & 2022 & 2023 & & & & \\
\hline $\mathrm{X}$ & & 6 & 7 & 8 & 9 & 10 & 11 & 12 & & & & \\
\hline \multirow{5}{*}{$\begin{array}{c}\text { Población } \\
\text { (miles) }\end{array}$} & CUSCO & 119,580 & 119,779 & 119,978 & 120,177 & 120,376 & 120,575 & 120,774 & & & & \\
\hline & SAN JERONIMO & 54,072 & 55,593 & 57,114 & 58,635 & 60,156 & 61,677 & 63,198 & & & & \\
\hline & SAN SEBASTIAN & 133,927 & 137,997 & 142,066 & 146,136 & 150,205 & 154,275 & 158,344 & & & & \\
\hline & SANTIAGO & 90,702 & 90,762 & 90,822 & 90,881 & 90,941 & 91,001 & 91,060 & & & & \\
\hline & WANCHAQ & 64,230 & 64,287 & 64,343 & 64,400 & 64,457 & 64,513 & 64,570 & & & & \\
\hline
\end{tabular}




\section{Anexo 14. Cotizaciones}

$\checkmark$ Afiches $50 \times 70$ full color (medio millar): S/490.00

$\checkmark$ Afiches $1 / 2$ pliego full color (medio millar): S/600.00

$\checkmark$ Volantes 1/4 A4 full color (un millar): S/95.00

$\checkmark$

$\checkmark$ Volantes 1/4 A4 full color (un millar): S/170.00

$\checkmark$ Llaveros destapadores (medio millar): S/450.00

$\checkmark$ Llaveros destapadores (medio millar): S/400.00

$\checkmark$ Lapiceros estampados (un millar): S/950.00

$\checkmark$ Lapiceros estampados metalizados (un millar): S/800.00

$\checkmark$ Lapiceros estampados en cuerpo blanco (un millar): S/650.00

$\checkmark$ Aviso radial en Rueda de Negocios: S/50.00

$\checkmark$ Aviso en radio Salkantay: S/150.00 por dos días

$\checkmark$

$\checkmark$ Web master: $\$ 300.00$ dólares mensuales por los siguientes servicios

$\checkmark$ Alexa

$\checkmark$ Trafico mensual (visitas de 200 a 300 visitas web al día de USA y UKA

$\checkmark$ Términos claves de búsqueda: 8-10

$\checkmark$ Soporte para actualizaciones web

$\checkmark$ Redes sociales (Fanpage Fans, Twitter seguidores, YouTube Channel videos)

$\checkmark$ Reviews: Trip Advisor reviews, Google plus reviews, fanpage reviews.

$\checkmark$ Apoyo para contacto con Social deals que venden sus tours por comisión

\begin{tabular}{lccc}
\hline & \multicolumn{2}{c}{ BOTIQUIN (costeo anual ) } & \\
\hline PRODUCTO & ESPECIFICACIÓN & PRESENTACIÓN & PPS \\
ALCOHOL & Alcohol Puro de $96^{\circ}$ & Fco. X 1000 ml & S/. 22.49 \\
ALGODÓN & Algodón Hidrófilo & Rollo x 1000g & S/. 95.69 \\
ESPARADRAPO & Venditas Adhesivas & Esp. Cure Band 1 x 1 x 12u. & S/. 87.62 \\
GASAS & Gasa Fraccionada & Env. X 20m. x 0.20m. & S/. 17.96 \\
GUANTES & Guantes & Caja x 100 u. Talla 7-8-9 & S/. 52.06 \\
SUERO & Suero Fisiológico & Fco. X 1000 ml & S/. 23.25 \\
TERMÓMETRO & Termómetro Digital & Classic x 1 u. & S/. 100.33 \\
VENDAS & Vendas de Gasa & Rollo x 1 10cm. X 5 m. & S/. 8.07 \\
VENDITAS & Venditas Cure Band & Caja x 100 u. & S/. 18.47 \\
\hline TOTAL & & & S/. 425.93 \\
\hline
\end{tabular}

Nota. Fuente: Elaboración propia. Datos obtenidos de consulta en Incafarma - Cusco, Av- La Cultura. 


\begin{tabular}{|c|c|c|c|r|r|}
\hline COSTO DE UNIFORME: & & Personal operativo & SIN IGV & Personal administrativo SIN IGV \\
\hline Gorro & $\mathrm{S} / .5 .00$ & 6 & $\mathrm{~S} / .25 .42$ & 10 & $\mathrm{~S} / .42 .37$ \\
\hline Polo Camisero & $\mathrm{S} / .10 .00$ & 6 & $\mathrm{~S} / .50 .85$ & 10 & $\mathrm{~S} / .84 .75$ \\
\hline Mandil & $\mathrm{S} / .8 .00$ & 6 & $\mathrm{~S} / .40 .68$ & 10 & $\mathrm{~S} / .211 .86$ \\
\hline Pantalón & $\mathrm{S} / .25 .00$ & 6 & $\mathrm{~S} / .127 .12$ & 10 & $\mathrm{~S} / .423 .73$ \\
\hline Zapatillas Negras & $\mathrm{S} / .50 .00$ & 6 & $\mathrm{~S} / .254 .24$ & $\mathrm{~S} / .762 .71$ \\
\hline
\end{tabular}

Nota. Fuente: Elaboración propia. Datos obtenidos de consulta en sastrería, Av.Pera - Cusco

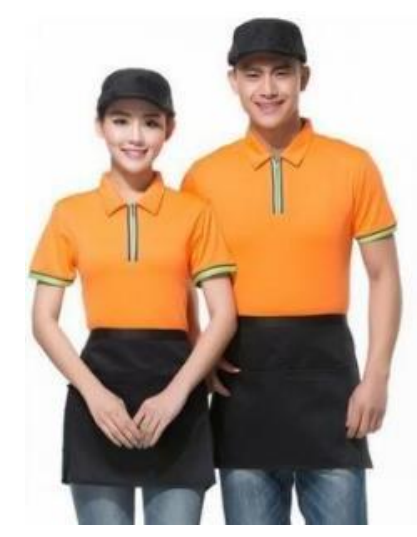

\begin{tabular}{|c|c|c|c|c|c|c|c|}
\hline \multicolumn{4}{|c|}{ PROFORMA " PLASTICOS 2000" } & \multicolumn{2}{|c|}{ Area de produccion } & \multicolumn{2}{|c|}{ area de administración } \\
\hline CANT. & ARTICULOS DE LIMPIEZA & PRECIO UNIT. & $\begin{array}{l}\text { PREC.XPAQUETE } \\
\text { (100und) }\end{array}$ & $\begin{array}{l}\text { CANTIDAD } \\
\text { REQUERIDA }\end{array}$ & Costo Anual SIN IGV & $\begin{array}{r}\text { CANTIDAD } \\
\text { REQUERIDA }\end{array}$ & osto Anual SIN IG \\
\hline 1 & GUANTES & $\mathrm{S} / .6 .90$ & & 24.00 & S/. 140.34 & & \\
\hline 1 & Guante quirurgicos & & S/. 16.00 & 92.16 & $S / .1,249.63$ & & \\
\hline & MALLAS DE CABEZA & S/. 2.00 & & 2304.00 & S/. 3,905.08 & & \\
\hline 1 & BOLSAS GRANDES & & S/. 18.00 & 10.00 & S/. 152.54 & 2 & S/. 30.51 \\
\hline 1 & BOLSAS MEDIANAS & & $S / .15 .00$ & 10.00 & S/. 127.12 & 2 & S/. 25.42 \\
\hline 1 & BOLSAS PEQUEÑAS & & S/. 10.00 & 10.00 & S/. 84.75 & 2 & S/. 16.95 \\
\hline 1 & BANDEJAS PLASTICAS & S/. 13.00 & & 100.00 & $S / .1,101.69$ & & \\
\hline & ESCOBA & S/. 10.00 & & 3.00 & S/. 25.42 & 2 & S/. 16.95 \\
\hline & RECOGEDOR & $\mathrm{S} / .8 .00$ & & 3.00 & S/. 20.34 & 2 & S/. 13.56 \\
\hline & DESINFECTANTE DE INODORO (GALON) & $S / .15 .02$ & & 7.00 & S/. 89.10 & 3 & S/. 38.19 \\
\hline & JABON LIQUIDO (GALON) & S/.23.12 & & 4.00 & S/. 78.37 & 6 & S/. 117.56 \\
\hline & ROLLO DE PAPEL HIGIENICO GRANDE & $S / .15 .00$ & & 160.00 & $S / .2,033.90$ & 32 & S/. 406.78 \\
\hline & TRAPEADOR & S/. 25.62 & & 1.00 & S/. 21.71 & 2 & $S / .43 .42$ \\
\hline & VALDE & $\mathrm{S} / .12 .00$ & & 2.00 & S/. 20.34 & 2 & S/. 20.34 \\
\hline & DETERGENTE LIQUIDO (GALON) & S/. 18.88 & & 10.00 & S/. 160.00 & & \\
\hline & LIMPIA VIDRIOS (GALON) & $\mathrm{S} / .6 .34$ & & 0.00 & S/. 0.00 & 5 & S/. 26.86 \\
\hline & AMBIENTADOR (GALON) & $S / .10 .60$ & & 4.00 & S/. 35.93 & 6 & $S / .53 .90$ \\
\hline & ISOPO PARA INODORO & $\mathrm{S} / .7 .43$ & & 2.00 & S/. 12.59 & 3 & S/. 18.89 \\
\hline 1 & DESATORADOR & $\mathrm{S} / .2 .30$ & & 2.00 & S/. 3.90 & 3 & S/. 5.85 \\
\hline & & & & Total años sig & $S / .9,262.76$ & & S/. 835.18 \\
\hline & & & & Totalaño1pl & $S / .8,056.76$ & & \\
\hline
\end{tabular}

Nota. Fuente: Elaboración propia. Datos obtenidos de consulta Plastiqueria, Plásticos 2000 - Cusco 


\begin{tabular}{|c|c|c|c|c|}
\hline UTILES OFICINA & CARACTERISTICAS & \begin{tabular}{|c|} 
COSTO POR \\
UNIDAD
\end{tabular} & CANT. REQUERIDA & $\begin{array}{c}\text { COSTO TOTAL SIN } \\
\text { IGV }\end{array}$ \\
\hline Software & office 2007ultimate & $\mathrm{S} / .1,160.00$ & 1 & S/. 974.79 \\
\hline Papel fotocopia A4 - Copimax & millar & \begin{tabular}{|l|l}
$\mathrm{S} / .44 .32$ \\
\end{tabular} & 4 & S/. 37.24 \\
\hline Cuaderno 100 hojas & unidad & $\mathrm{S} / .6 .93$ & 5 & S/. 5.82 \\
\hline Bolígrafo Faber Castell color negro & caja $\times 50$ & S/. 11.05 & 4 & S/. 9.29 \\
\hline Bolígrafo Faber Castell color rojo & caja $\times 50$ & S/. 11.05 & 4 & S/. 9.29 \\
\hline Borrador Faber Castell & caja $\times 40$ & S/. 10.14 & 1 & $\mathrm{~S} / .8 .52$ \\
\hline Calculadora Cientifica & Casio & S/. 98.00 & 2 & S/. 82.35 \\
\hline Calculadora & casio & S/. 20.00 & 4 & S/. 16.81 \\
\hline Lapiz Mongol & caja $\times 12$ & S/. 14.40 & 5 & S/. 12.10 \\
\hline Regla de $30 \mathrm{~cm}$ Artesco & caja $\times 12$ & S/. 10.96 & 2 & S/. 9.21 \\
\hline Resaltador Stabilo color amarillo & unidad & S/. 30.00 & 20 & S/. 25.21 \\
\hline Tajador de metal doble - Artesco & unidad & $\mathrm{S} / .1 .83$ & 5 & S/. 1.54 \\
\hline Bandeja de 2 pisos & unidad & $\mathrm{S} / .37 .17$ & 5 & S/. 31.24 \\
\hline Chinches Artesco & caja $\times 100$ & $\mathrm{~S} / .1 .62$ & 4 & $\mathrm{~S} / .1 .36$ \\
\hline Clips Artesco & caja $\times 100$ & $\mathrm{~S} / .3 .42$ & 5 & $\mathrm{~S} / .2 .87$ \\
\hline Cortador (cuchilla) & unidad & S/. 4.16 & 2 & $S / .3 .50$ \\
\hline Engrapador & unidad & S/. 35.20 & 4 & S/. 29.58 \\
\hline Grapas & caja $\times 5000$ & $\mathrm{~S} / .32 .50$ & 10 & S/. 27.31 \\
\hline Perforador & unidad & S/. 29.20 & 4 & S/. 24.54 \\
\hline Portaclips Artesco & unidad & $\mathrm{S} / .2 .39$ & 4 & S/. 2.01 \\
\hline Post it & paquete & S/. 10.15 & 4 & $\mathrm{~S} / .8 .53$ \\
\hline Sello fechador & unidad & $\mathrm{S} / .30 .00$ & 5 & $S / .25 .21$ \\
\hline Tampón Artesco & unidad & S/. 13.00 & 5 & S/. 10.92 \\
\hline Tijera & unidad & $\mathrm{S} / .12 .53$ & 5 & S/. 10.53 \\
\hline Sobre manila & 50 sobres & S/. 7.02 & 3 & $\mathrm{~S} / .5 .90$ \\
\hline Memoria USB de 8GB Kingston & unidad & S/. 447.00 & 3 & S/. 375.63 \\
\hline Libro contable (50 hojas) & unidad & $\mathrm{S} / .7 .33$ & 2 & $\mathrm{~S} / .6 .16$ \\
\hline Cinta adhesiva Pegafan & unidad & S/. 10.75 & 3 & $S / .9 .03$ \\
\hline Dispensador de cinta adhesiva & unidad & S/. 16.32 & 3 & S/. 13.71 \\
\hline Goma David & frasco & S/. 5.75 & 5 & $S / .4 .83$ \\
\hline \multirow[t]{2}{*}{ Tintas para impresora } & color y negro & $\mathrm{S} / .2,136.00$ & 12 & S/. 1,794.96 \\
\hline & & \multicolumn{2}{|c|}{\begin{tabular}{|l|l} 
TOTAL \\
\end{tabular}} & S/. 3,579.99 \\
\hline
\end{tabular}

Nota. Fuente: Elaboración propia. Datos obtenidos de consulta Tay Long - Centro de Lima. 


\begin{tabular}{|c|c|c|c|c|}
\hline UTENSILIOS DE COCINA & CARACTERISTICAS & $\begin{array}{c}\text { COSTO POR } \\
\text { UNIDAD } \\
\end{array}$ & CANT. REQUERIDA & $\begin{array}{c}\text { COSTO TOTAL SIN } \\
\text { IGV } \\
\end{array}$ \\
\hline EXPRIMIDOR LIMON & & S/. 10.50 & 2 & $\mathrm{~S} / .21 .00$ \\
\hline AFILADOR DE CUCHILLOS & & $\mathrm{S} / .7 .98$ & 2 & $\mathrm{~S} / .15 .96$ \\
\hline BALANZA DIGITAL & $1.5 \mathrm{~kg}$. & $\mathrm{S} / .38 .66$ & 3 & S/. 115.98 \\
\hline RALLADOR & & $\mathrm{S} / .3 .68$ & 2 & $\mathrm{~S} / .7 .36$ \\
\hline BATIDOR GLOBO & $30 \mathrm{~cm}$. & $\mathrm{S} / .10 .08$ & 3 & $\mathrm{~S} / .30 .24$ \\
\hline BATIDORA & ommercial 5 Serie & S/. $1,450.00$ & 1 & $S / .1,450.00$ \\
\hline RAMIKINES & & $S / .4 .20$ & 24 & S/. 100.80 \\
\hline RODILLO & & $\mathrm{S} / .13 .45$ & 3 & S/. 40.35 \\
\hline COLADOR CHINO & $9^{*}$ & $\mathrm{~S} / .71 .43$ & 2 & S/. 142.86 \\
\hline COLADORES & $\# 15$ & $\mathrm{~S} / .23 .19$ & 3 & $\mathrm{~S} / .69 .57$ \\
\hline CUCHARA DE MADERA & MEDIANO & $\mathrm{S} / .5 .46$ & 6 & $\mathrm{~S} / .32 .76$ \\
\hline ESPUMADERAS MEDIANA & & S/. 10.92 & 3 & S/. 32.76 \\
\hline GUANTES PARA HORNOS & & $\mathrm{S} / .33 .45$ & 2 & $\mathrm{~S} / .66 .90$ \\
\hline CUCHILLO COCINA TRAMONTINA & $12^{\prime \prime}$ & $\mathrm{S} / .33 .19$ & 6 & $\mathrm{~S} / .199 .14$ \\
\hline OLLA DE ACERO INOXIDABLE C/TA & \#36 & S/. 334.45 & 2 & $\mathrm{~S} / .668 .90$ \\
\hline ESPATULAS P/ PLANCHA & & $\mathrm{S} / .10 .50$ & 3 & $\mathrm{~S} / .31 .50$ \\
\hline CUCHILLO DESHUESADOR & 6" & $\mathrm{S} / .14 .71$ & 2 & $\mathrm{~S} / .29 .42$ \\
\hline EMBUDOS & & $\mathrm{S} / .1 .51$ & 3 & S/. 4.53 \\
\hline ESPATULA DE SILICONA & & S/. 7.56 & 3 & S/. 22.68 \\
\hline CUCHARAS MEDIDORAS & & S/. 4.62 & 2 & S/. 9.24 \\
\hline ESPOLVOREADOR & & S/. 7.85 & 1 & $\mathrm{~S} / .7 .85$ \\
\hline ESPONJA DE ALUMINIO & & $\mathrm{S} / .2 .58$ & 12 & $\mathrm{~S} / .30 .96$ \\
\hline ABRELATAS & & S/. 1.22 & 1 & $\mathrm{~S} / .1 .22$ \\
\hline CUCHARON DE ACERO INOXIDABL & GRANDE & $\mathrm{S} / .13 .87$ & 6 & $\mathrm{~S} / .83 .22$ \\
\hline BANDEJA DE ALUMINIO & $50 \times 35 \mathrm{~cm}$. & $\mathrm{S} / .47 .06$ & 6 & S/. 282.36 \\
\hline CUCHILLO CARNICERO TRAMONTI & $10^{*}$ & $\mathrm{~S} / .29 .41$ & 2 & $\mathrm{~S} / .58 .82$ \\
\hline \begin{tabular}{|l|l} 
MANGAS PASTELERAS \\
\end{tabular} & $\# 21$ & $\mathrm{~S} / .26 .47$ & 3 & S/. 79.41 \\
\hline OLLA DE ACERO INOXIDABLE C/TA & $\# 20$ & S/. 68.07 & 2 & S/. 136.14 \\
\hline OLLA DE ACERO INOXIDABLE C/TA & \#26 & S/. 110.92 & 2 & $\mathrm{~S} / .221 .84$ \\
\hline \begin{tabular}{|l|l|} 
JARRAS MEDIDORAS & \\
\end{tabular} & 1LT & $\mathrm{S} / .2 .69$ & 3 & $\mathrm{~S} / .8 .07$ \\
\hline PELADORES & & $\mathrm{S} / .1 .15$ & 3 & $\mathrm{~S} / .3 .45$ \\
\hline PINZAS & & $\mathrm{S} / .7 .14$ & 3 & $\mathrm{~S} / .21 .42$ \\
\hline SARTEN DE ACERO INOXIDABLE & $14 "$ & $\mathrm{~S} / .94 .12$ & 5 & $\mathrm{~S} / .470 .60$ \\
\hline SARTEN DE TEFLON & $\# 30$ & $\mathrm{~S} / .49 .06$ & 3 & S/. 147.18 \\
\hline CUCHARON DE ACERO INOXIDABL & MEDIANO & $\mathrm{S} / .10 .08$ & 6 & $\mathrm{~S} / .60 .48$ \\
\hline SACACORCHOS & 2 tiempos & $\mathrm{S} / .13 .45$ & 10 & $\mathrm{~S} / .134 .45$ \\
\hline SARTEN DE ACERO INOXIDABLE & $10 "$ & $\mathrm{~S} / .60 .50$ & 5 & S/. 302.50 \\
\hline BOWL DE ACERO INOXIDABLE & $2 \mathrm{LT}$. & $\mathrm{S} / .7 .98$ & 12 & $\mathrm{~S} / .95 .76$ \\
\hline BOWL DE ACERO INOXIDABLE & $5 \mathrm{LT}$. & $\mathrm{S} / .36 .13$ & 4 & S/. 144.52 \\
\hline SET DE BOQUILLAS & & $\mathrm{S} / .18 .07$ & 2 & $\mathrm{~S} / .36 .14$ \\
\hline TABLA PARA PICAR BLANCA & & $\mathrm{S} / .37 .82$ & 8 & $\mathrm{~S} / .302 .56$ \\
\hline TERMOMETRO DE BOLSILLO & & S/. 16.39 & 2 & $\mathrm{~S} / .32 .78$ \\
\hline \begin{tabular}{|l|l|} 
BANDEJAS ANTIDESLIZANTES \\
\end{tabular} & \begin{tabular}{|c|}
$16 "$ \\
\end{tabular} & $\mathrm{~S} / .0 .00$ & 10 & $\mathrm{~S} / .0 .00$ \\
\hline \multicolumn{4}{|c|}{$\begin{array}{l}\text { TOTAL UTENSILIOS DE COCINA } \\
\end{array}$} & $\mathrm{S} / .5,753.68$ \\
\hline
\end{tabular}

Nota. Fuente: Elaboración propia. Datos obtenidos de consulta en Mercado Central - Lima, tiendas varias. 

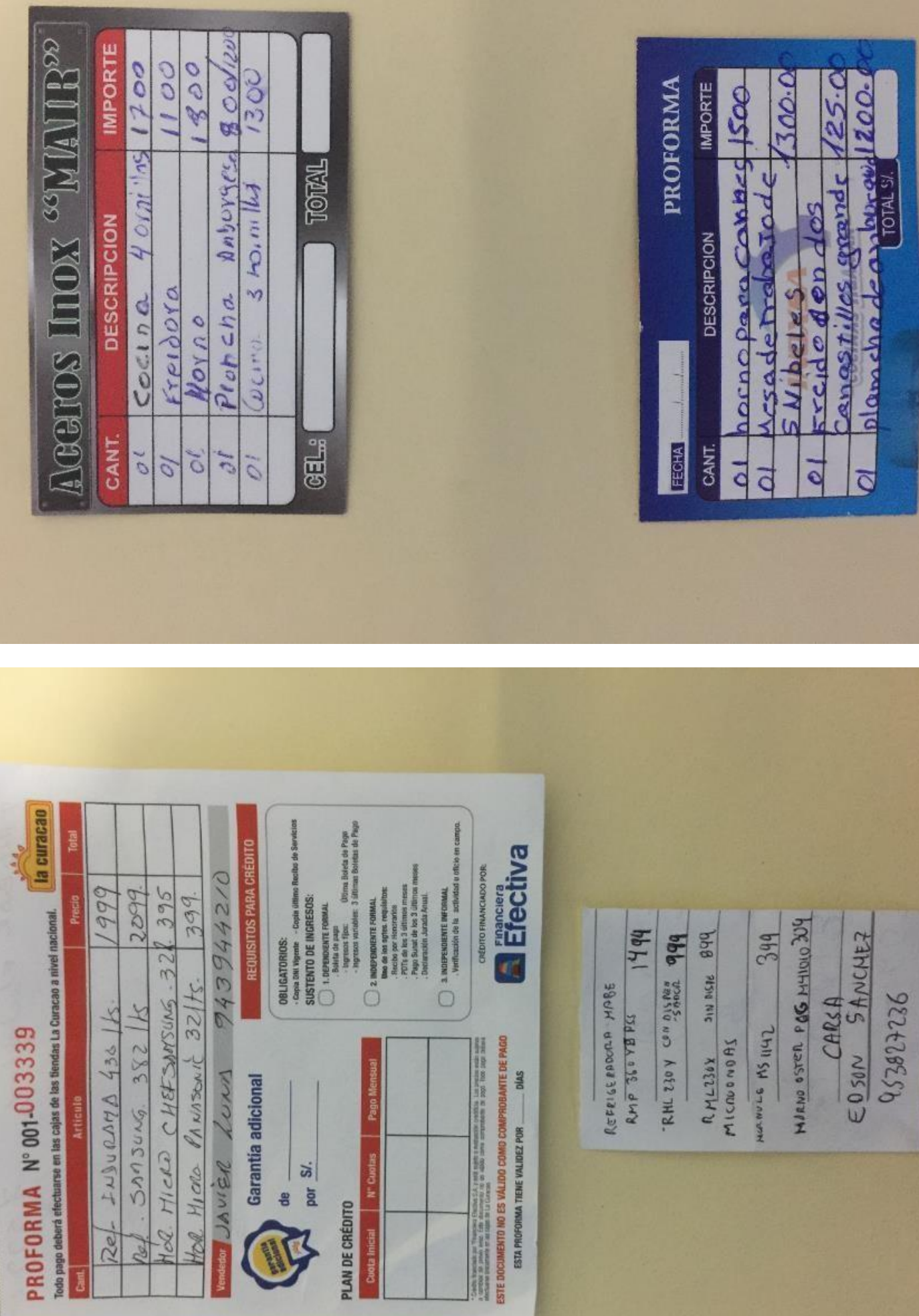

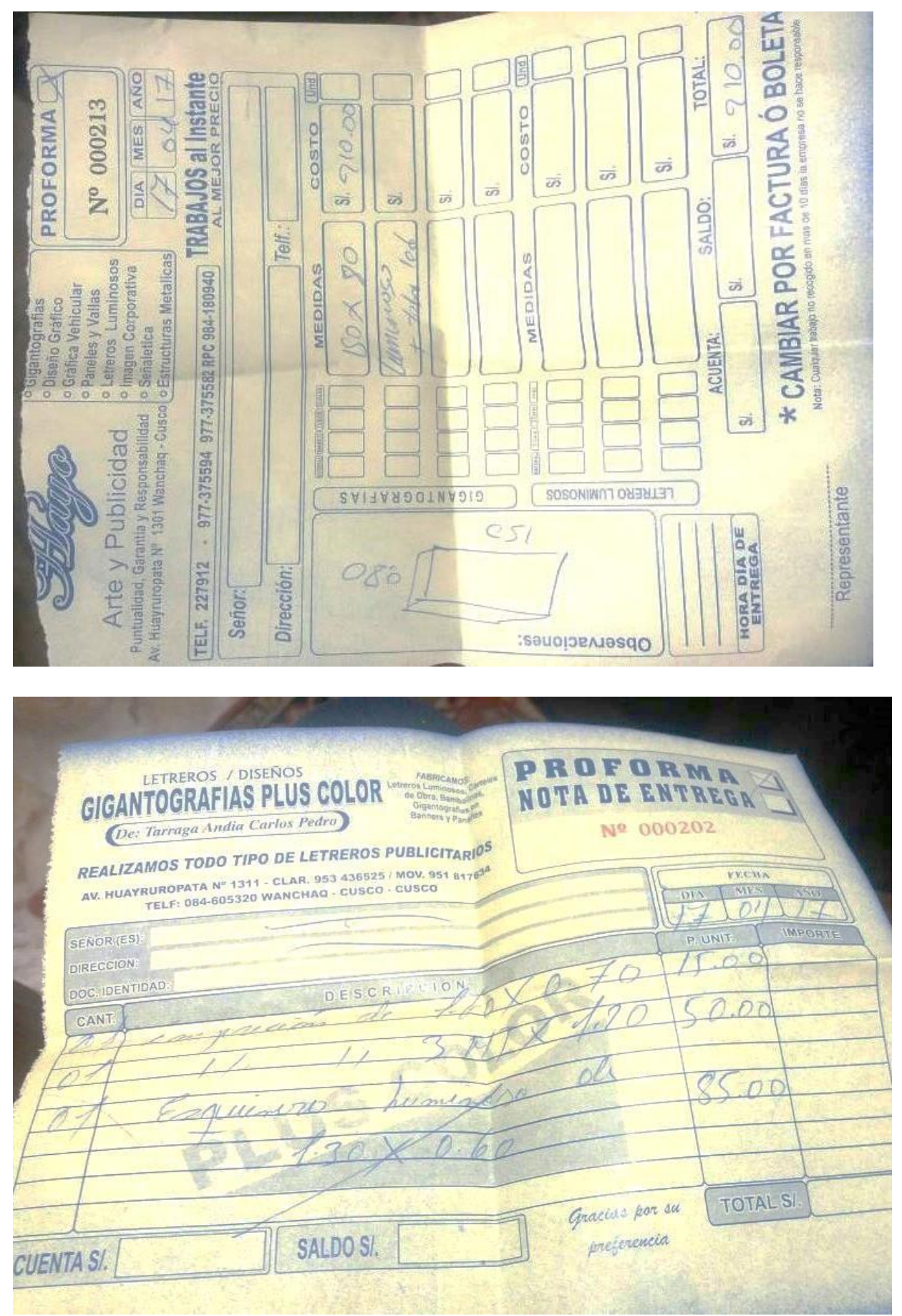


\section{Anexo 15. Trámites, Licencias, remodelación de local y Tasa de Inversión Financiera}

\section{$\underline{\text { Trámites }}$}

- SUNARP:

$\checkmark$ Reserva + búsqueda de nombre con vigencia de duración 30 días S/24.00

$\checkmark$ Inscripción a Registros Públicos S/344.00

$\checkmark$ Pago por nombramiento de cada gerente S/25.00

- NOTARIA - ABOGADOS:

$\checkmark$ Elaboración de Minuta S/350.00

$\checkmark$ Elaboración de Escritura Pública S/250.00

- LICENCIA DE FUNCIONAMIENTO MUNICIPALIDAD:

$\checkmark$ Licencia con anuncio luminoso para locales entre $100 \mathrm{mt} 2$ y $500 \mathrm{mt} 2$, presentando formulario, diseño del anuncio con dimensiones y tamaños, fotografías del entorno urbano y edificación, Declaración Jurada de diseño e instalación S/645.00

- LIBROS CONTABLES - LEGALIZACIÓN:

$\checkmark$ Registro de compras S/25.00

$\checkmark$ Registro de ventas S/25.00

- INSCRIPCIÓN DE TRABAJADORES A ESSALUD

$\checkmark$ Presentar a SUNAT formulario PDT ESSALUD.

$\checkmark$ Aportación mensual: 9\% de sueldo mensual. 


\section{COTIZACIÓN REMODELACIÓN DEL LOCAL}

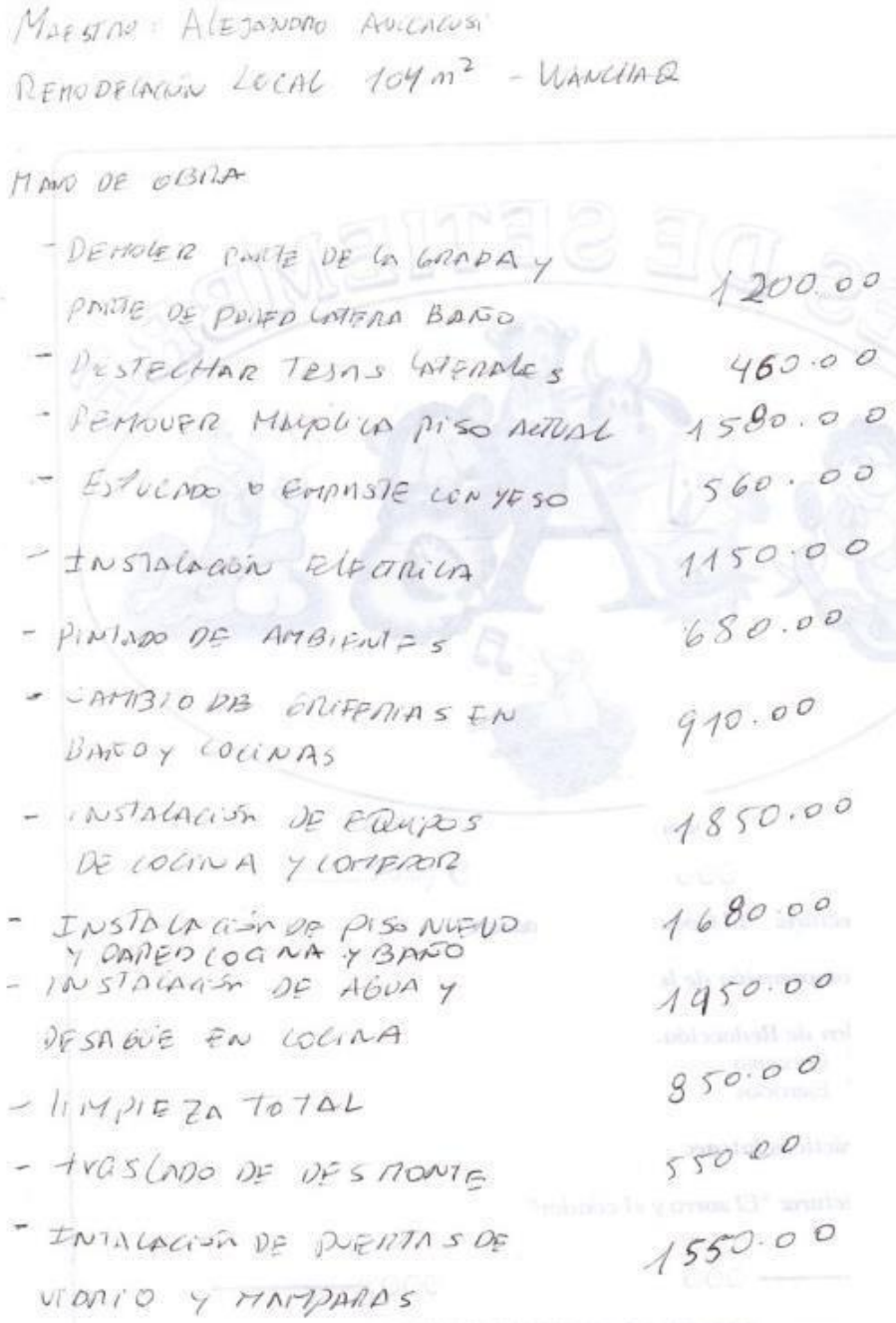

\section{MATENIALS}

- 60 Belsns do yéso

480.00

- 30 Bolsns DE CEMPNTO $\quad 180.00$

- Y undOS DE AGMFGADO 260.00

- 4 varillas de 3/0 60.00

- 4kilos de clarode 21/2 90.00

- 3 HElOS DE HCMHBRE WEGRO N\% 85.00

- 200 Bloquer dF $12 \times 20 \times 30 \quad 400.00$

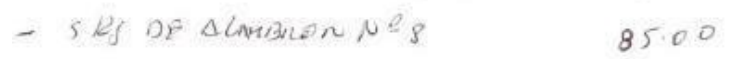

- jnstiremia 450.00

- O2 ubos DE AnENA 280.00

- puentas de udino Compdions $2.90 \times 3.00 \quad 4650.00$ $1.50 \times 070$

- mayolicas colina 1000.00 y pisos Total hatenales 8620.00 


\title{
TASA DE INVERSIÓN FINANCIERA
}

\author{
Santo Domingo de Guzmón
}

\section{IASAS ACTIVAS VIGENTES}

CREDITOS MICRO EMPRESAS - PEQUENA EMPRESA - MEDIANA EMPRESA - GRANDE EMPRESA CORPORATIVOS

\section{CREDITOS MYPES}

Moneda Nacional

Vigente a partir del 08/10/2016

Remplaza tarifario vigente del $03 / 12 / 2014$

\begin{tabular}{|c|c|c|c|c|c|}
\hline TEA MAXIMA & TEA MINIMA & COMISIONES & GASTOS & TRIBUTOS & $\begin{array}{c}\text { OPORTUNIDAD } \\
\text { DE COBRO }\end{array}$ \\
\hline $28.32 \%$ & $11.22 \%$ & $\begin{array}{c}\text { Tarifario de } \\
\text { comisiones } \\
\text { vinculado a } \\
\text { operaciones } \\
\text { activas } \\
\text { vigentes }\end{array}$ & $\begin{array}{c}\text { Seguro de } \\
\text { desgravamen }\end{array}$ & No aplica & $\begin{array}{c}\text { Al momento } \\
\text { que se solicite }\end{array}$ \\
\hline \multicolumn{6}{|c|}{ TEA DE INTERES MORATORIA A NIVEL NACIONAL 146.28\% } \\
\hline
\end{tabular}

* La tasa de interés apicable al clente, se fiaró al momento de ia evaluación credilicia, conforme a su perfl de riesgo, siendo informoda y aceptodo previo al desembolso, conforme a la solicilud de crédito, Contrato y hoja resumen.

Créditos destinados a financiar actividades de producción, comercialización o prestación de servicios. otorgados a personas naturales o jurídicas. cuyo endeudamiento total en el sistema financiero es superior a S/ 20,000 pero no mayor a S/ 300.000 en los últimos sels (6) meses (sin incluir los créditos hipotecarios para vivienda)

\section{REQUISITOS}

- Fotocopia de DNI de los representantes legales.

- Copia del Testimonio de Constitución de la Empresa.

- Copia Literal de la Vigencia de Poderes de los representantes legales.

- Fotocopia de RUC y Licencia de Funcionamiento. y/u otros que prueben la actividad económica no menor a seis meses

- Documentos de domicilio o local comercial (título de propledad /autoavalúo certificado de posesión, copia literal de dominio o su equivalente).

- Tres últimas declaraciones mensuales a la SUNAT.

- Recibo cancelado de agua o luz de domicilio y negocio.

- Dos últimas declaraciones anuales a la SUNAT (de ser necesario).

- Del inmueble otorgado en garantio

- Certificado de Registro Inmobiliario CRI o libre de gravamen.

- Titulo de propiedad.

- Auto avalúo y pago del año.

- Tasación (Profesional autorizado por la SBS).

- Certificado de numeración municipal (de ser necesario),

(*) La información es propocionoda de contomidad a la Ley Compiementaria a la Ley de Protección at Consumidor en materia de servicios financlaros fley $\mathrm{N}^{n}$ 29587), el Reglamento de Transparencia de información y Disposiciones qplicabiles a la contratación con usucrios del Sistemo financiero (Resol. SBS 8181-2012) y el Código de Protecclón y Defenso del Consumidor (Ley N29571).

(") TREA: Tasa de rendimiento efectivo anud. Determinodo score la bose de 360 dics, es igual a la Tasa Electiva Anual TEA. Pitasas de interés de los productos pasivas vigentes a partir del 08 de octubre del 2016 en moneda nocional. 
Anexo 16. Calculo del Cok real de Estados Unidos

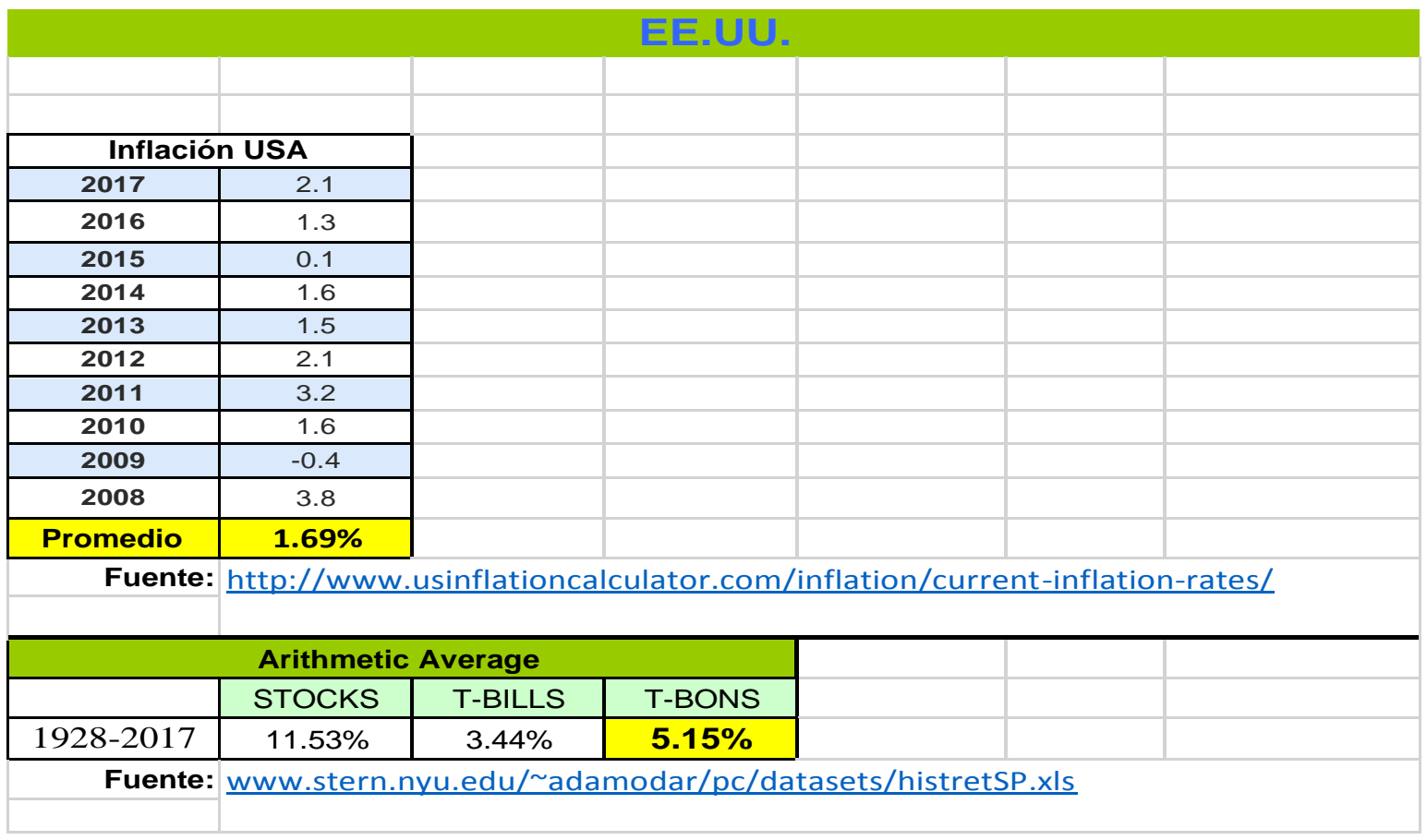

\begin{tabular}{|c|c|}
\hline \multicolumn{2}{|c|}{ PERU } \\
\hline Año & Riesgo País \\
\hline 2008 & 150 \\
\hline 2009 & 278 \\
\hline 2010 & 208 \\
\hline 2011 & 181 \\
\hline 2012 & 208 \\
\hline 2013 & 162 \\
\hline 2014 & 162 \\
\hline 2015 & 201 \\
\hline 2016 & 200 \\
\hline 2017 & 112 \\
\hline & \\
\hline & \\
\hline & Tasa \\
\hline Año & Inflación \\
\hline 2008 & $5.80 \%$ \\
\hline 2009 & $2.90 \%$ \\
\hline 2010 & $1.50 \%$ \\
\hline 2011 & $3.40 \%$ \\
\hline 2012 & $3.70 \%$ \\
\hline 2013 & $2.81 \%$ \\
\hline 2014 & $3.25 \%$ \\
\hline 2015 & $4.40 \%$ \\
\hline 2016 & $3.20 \%$ \\
\hline 2017 & $1.36 \%$ \\
\hline & \\
\hline
\end{tabular}

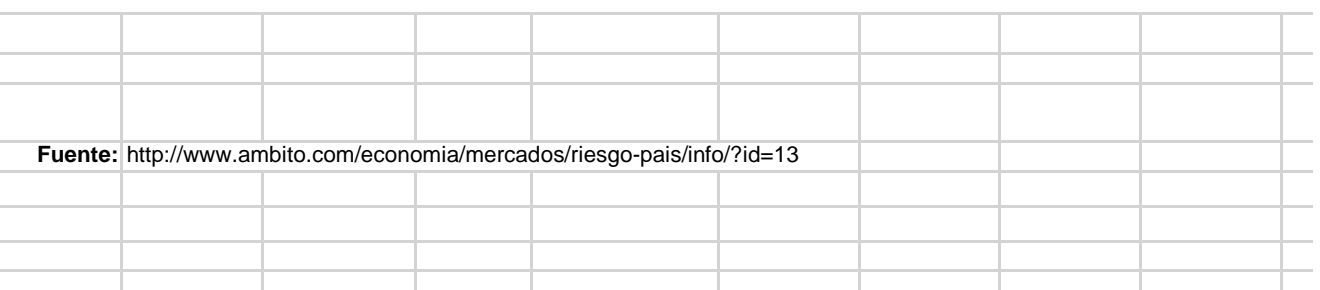

Fuente: http://larepublica.pe/31-12-2010/riesgo-pais-de-peru-bajo-tres-puntos-basicos-154-puntos-porcentuales-en-la-vispera Fuente: http://www.bvl.com.pe/eeff/OE3056/20130326164602/MEOE30562012AIA01.PDF

Fuente: www.bcrp.gob.pe/docs/.../Nota.../resumen-informativo-01-2012.pdf

Fuente: http://www.bcrp.gob.pe/estadisticas/cuadros-anuales-historicos.html INDICADORES DE RIESGO PARA PAÍSES EMERGENTES: Índice de Bonos de Mercados Emergentes (EMBIG) Fuente: http://www.bcrp.gob.pe/docs/Estadisticas/Cuadros-Estadisticos/NC_037.xls https://gestion.pe/economia/mercados/riesgo-pais-peru-punto-basico-1-12-puntos-porcentuales-222617

Fuente: http://www.bcrp.gob.pe/estadisticas/cuadros-anuales-historicos.html http://www.bcrp.gob.pe/docs/Publicaciones/Reporte-Inflacion/2017/marzo/reporte-de-inflacion-marzo-2017-sintesis.pdf http://rpp.pe/economia/economia/inflacion-de-peru-subio-136-en-2017-la-mas-baja-desde-2009-noticia-1097371 
RIESGO PAÍS PERU Spread - EMBI + Perú (puntos básicos)

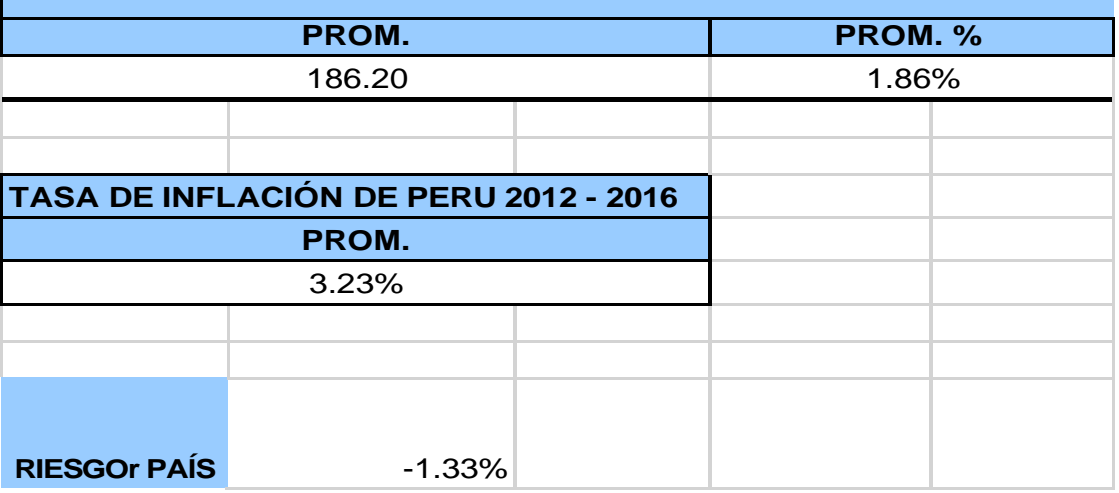

\section{COK $(\mathrm{Ke})$}

\begin{tabular}{|c|c|c|c|c|}
\hline \multicolumn{2}{|c|}{ COK NOMINAL USA } & & & \\
\hline \multicolumn{5}{|c|}{ COKn USA = Rf + Bwl(Rm-Rf) } \\
\hline$(\mathrm{Rm}-\mathrm{Rf})$ & $6.38 \%$ & \multicolumn{3}{|c|}{ Equity Risk premium: http://pages.stern.nyu.edu/ adamodar/New_Home_Page/datafile/ctryprem.html } \\
\hline Rf & $5.15 \%$ & \multicolumn{3}{|c|}{10 years t.bond: http://pages.stern.nyu.edu/ adamodar/New_Home_Page/datafile/histretSP.html } \\
\hline Bwl & 0.85 & \multicolumn{3}{|c|}{ Bwl (apalancado de la Industria de restaurantes a ENE 2018): } \\
\hline COKn USA & $10.58 \%$ & \multicolumn{3}{|c|}{ http://pages.stern.nyu.edu/ adamodar/New_Home_Page/datafile/Betas.html } \\
\hline \multicolumn{5}{|c|}{ COK REAL USA } \\
\hline \multicolumn{5}{|c|}{ COKr USA = (COKn USA - INFLAC. USA)/(1+INFLAC.) } \\
\hline \multicolumn{2}{|c|}{ COKn USA } & \multicolumn{2}{|c|}{$10.58 \%$} & \\
\hline \multicolumn{2}{|l|}{ INFLAC. USA } & \multicolumn{2}{|c|}{$1.69 \%$} & \\
\hline \multicolumn{2}{|l|}{ COKr USA } & \multicolumn{2}{|c|}{$8.74 \%$} & \\
\hline \multicolumn{5}{|c|}{ COK REAL PERÚ } \\
\hline \multirow{2}{*}{\multicolumn{4}{|c|}{$\begin{array}{c}\text { COKr PERÚ = COKr USA + RIESGO PAÍS + } \\
\text { RIESGO NEGOCIO }\end{array}$}} & \\
\hline & & & & \\
\hline \multicolumn{2}{|c|}{ COKr USA } & \multicolumn{2}{|c|}{$8.74 \%$} & \\
\hline \multicolumn{2}{|c|}{ RIESGOr PAÍS } & \multicolumn{2}{|c|}{$1.86 \%$} & \\
\hline \multicolumn{2}{|c|}{ RIESGOr NEGOCIO } & \multicolumn{2}{|c|}{$15.53 \%$} & \\
\hline \multicolumn{2}{|c|}{ COKr PERÚ } & & $26.13 \%$ & \\
\hline Inflación & & $3.23 \%$ & & \\
\hline \multicolumn{2}{|c|}{ COKn Peru(ke) } & $30.21 \%$ & & \\
\hline
\end{tabular}


Anexo 17. Costo unitario de producción, ingresos por ventas

\begin{tabular}{|c|c|c|c|c|c|c|c|c|c|c|c|}
\hline & \multicolumn{5}{|c|}{ cantidad de producción } & \multirow[b]{2}{*}{ COSTO PROD.UNIT } & \multicolumn{5}{|c|}{ Costo de ventas } \\
\hline ALITAS/POLLO FRTIO & 2019 & 2020 & 2021 & 2022 & 2023 & & 2019 & 2020 & 2021 & 2022 & 2023 \\
\hline ALITASENSALSA DEMARACUYA & 1389 & 1851 & 2320 & 2797 & 3280 & S/. 3.18 & $S / .4,412.93$ & $S / .5,882.73$ & S/. 7,374.75 & $S / .8,888.95$ & $S / .10,425.38$ \\
\hline ALITASENSALSA DESAUCO & 1389 & 1851 & 2320 & 2797 & 3280 & S/. 3.06 & $S / .4,242.30$ & $S / .5,655.28$ & $S / .7,089.61$ & S/. $8,545.26$ & $S / .10,022.29$ \\
\hline ALITASENSALSA DEBBQ & 1389 & 1851 & 2320 & 2797 & 3280 & S/. 2.89 & $S / .4,012.84$ & S/. 5,349.39 & S/. 6,706.14 & $S / .8,083.06$ & $S / .9,480.19$ \\
\hline 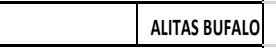 & 1389 & 1851 & 2320 & 2797 & 3280 & S/. 2.99 & $S / .4,150.92$ & $S / .5,533.46$ & S/. 6,936.90 & S/. 8,361.19 & $S / .9,806.40$ \\
\hline ALITAS EMPANIZADAS & 1389 & 1851 & 2320 & 2797 & 3280 & S/. 2.76 & $S / .3,831.08$ & S/. 5,107.09 & S/. 6,402.38 & $S / .7,716.93$ & $S / .9,050.78$ \\
\hline ALITASCONSALSADETAMARINDO & 1389 & 1851 & 2320 & 2797 & 3280 & S/. 3.06 & $S / .4,249.88$ & S/. 5,665.38 & $S / .7,102.27$ & $S / .8,560.52$ & S/. $10,040.19$ \\
\hline \begin{tabular}{|l|l|} 
& ALITAS DULCES \\
\cline { 2 - 2 }
\end{tabular} & 1389 & 1851 & 2320 & 2797 & 3280 & $S / .3 .00$ & $S / .4,159.64$ & $S / .5,545.08$ & S/. $6,951.46$ & S/. $8,378.75$ & $S / .9,827.00$ \\
\hline \multicolumn{12}{|l|}{ HAMBURGUESAS } \\
\hline HAMBURGUESA CLASICA & 2587 & 3449 & 4323 & 5211 & 6112 & S/. 3.72 & $S / .9,623.83$ & S/. $12,829.22$ & S/. $16,083.05$ & S/. 19,385.26 & S/. 22,735.95 \\
\hline HAMBURGUESA DE CERDO & 2587 & 3449 & 4323 & 5211 & 6112 & S/. 4.91 & S/. $12,710.78$ & S/. $16,944.33$ & S/. 21,241.87 & S/.25,603.29 & S/. 30,028.75 \\
\hline HAMBURGUESA DE POLLO & 2587 & 3449 & 4323 & 5211 & 6112 & $S / .4 .09$ & S/. $10,580.62$ & S/. $14,104.68$ & $S / .17,682.01$ & $S / .21,312.51$ & S/. 24,996.32 \\
\hline HAMBURGUESA DE QUINUA & 2587 & 3449 & 4323 & 5211 & 6112 & S/. 2.07 & $S / .5,355.23$ & $S / .7,138.88$ & $S / .8,949.49$ & $S / .10,787.02$ & $S / .12,651.52$ \\
\hline HAMBURGUESA PAYPI FAST & 2587 & 3449 & 4323 & 5211 & 6112 & $S / .5 .38$ & $S / .13,918.15$ & S/. $18,553.84$ & $S / .23,259.59$ & $S / .28,035.29$ & S/. 32,881.12 \\
\hline HAMBURGUESA VEGETARIANA & 2587 & 3449 & 4323 & 5211 & 6112 & $S / .3 .83$ & $S / .9,915.89$ & $S / .13,218.56$ & $S / .16,571.14$ & S/. 19,973.56 & S/. $23,425.93$ \\
\hline \begin{tabular}{|l|l|} 
& BROASTER \\
\end{tabular} & 16483 & 21973 & 27546 & 33201 & 38940 & $S / .2 .24$ & S/. 36,945.90 & S/. 49,251.39 & $S / .61,742.86$ & $S / .74,420.02$ & $S / .87,283.33$ \\
\hline EMOLIENTE & 15994 & 21322 & 26729 & 32218 & 37786 & $S / .0 .84$ & S/. 13,419.09 & S/. $17,888.55$ & S/. 22,425.57 & $S / .27,030.03$ & $S / .31,702.10$ \\
\hline CHICHA DE QUINUA & 15763 & 21013 & 26342 & 31751 & 37239 & $S / .0 .51$ & $S / .7,992.65$ & S/. $10,654.74$ & S/. $13,357.07$ & S/. 16,099.57 & S/. $18,882.34$ \\
\hline CHICHADEKIWICHA & 9272 & 12360 & 15495 & 18677 & 21905 & $S / .0 .51$ & $S / .4,701.56$ & $S / .6,267.50$ & $S / .7,857.10$ & $S / .9,470.34$ & $S / .11,107.26$ \\
\hline CHICHA MORADA & 657 & 876 & 1098 & 1323 & 1552 & $S / .0 .48$ & S/. 317.28 & S/. 422.95 & $S / .530 .22$ & S/. 639.09 & S/. 749.56 \\
\hline \multicolumn{12}{|l|}{ LIMONADA } \\
\hline LIMONADA FROZZEN & 13 & 17 & 22 & 26 & 30 & $S / .0 .84$ & S/. 10.80 & S/. 14.40 & S/. 18.06 & S/. 21.76 & S/. 25.53 \\
\hline LIMONADA CON HIERBABUENA & 13 & 17 & 22 & 26 & 30 & $S / .0 .19$ & S/. 2.47 & S/. 3.29 & S/. 4.12 & S/. 4.97 & $S / .5 .83$ \\
\hline LIMONADA CON MUÑA & 13 & 17 & 22 & 26 & 30 & $S / .0 .18$ & $S / .2 .32$ & $S / .3 .09$ & $S / .3 .87$ & $S / .4 .67$ & $S / .5 .47$ \\
\hline \begin{tabular}{l|l|} 
& PAPAS NATIVAS \\
\end{tabular} & 18201 & 24263 & 30416 & 36661 & 42998 & $S / .1 .21$ & S/. $22,038.77$ & S/.29,379.17 & S/. $36,830.52$ & $S / .44,392.63$ & $S / .52,065.78$ \\
\hline CHOCLO CON QUESO & 11921 & 15892 & 19923 & 24013 & 28164 & S/. 3.73 & S/. $44,505.72$ & $S / .59,329.14$ & S/. $74,376.61$ & S/. 89,647.75 & S/. $105,143.13$ \\
\hline PAPA HELADA CON QUESO & 11603 & 15467 & 19390 & 23372 & 27411 & $S / .4 .32$ & $S / .50,155.84$ & $S / .66,861.13$ & $S / .83,818.91$ & S/. $101,028.76$ & S/. $118,491.33$ \\
\hline \multicolumn{12}{|c|}{\begin{tabular}{l|l} 
& Programa de producción POSTRES \\
\end{tabular}} \\
\hline PASTEL DE CHOCLO & 6182 & 8241 & 10331 & 12452 & 14605 & S/. 2.36 & S/. $14,566.72$ & S/. $19,418.43$ & S/. 24,343.47 & S/. 29,341.71 & S/. 34,413.35 \\
\hline \multirow[t]{2}{*}{ BUDIN DE QUINUA } & 6164 & 8217 & 10302 & 12417 & 14563 & $S / .0 .82$ & $S / .5,065.30$ & $S / .6,752.39$ & $S / .8,464.97$ & S/. $10,203.02$ & S/. $11,966.58$ \\
\hline & & & & & & Total & $S / .290,888.52$ & $S / .387,774.10$ & $S / .486,124.01$ & $S / .585,935.89$ & $S / .687,213.41$ \\
\hline
\end{tabular}




\begin{tabular}{|c|c|c|c|c|c|c|c|}
\hline & FM & O DE VENTA SI & 2019 & 2020 & 2021 & 2022 & 2023 \\
\hline ALITAS/POLLO FRITO & & & \multicolumn{5}{|c|}{ INGRESOS POR VENTAS } \\
\hline ALITAS EN SALSA DE MARACUYA & 2.50 & 7.95 & 11032.32 & 14706.83 & 18436.88 & 22222.38 & 26063.46 \\
\hline ALITAS EN SALSA DE SAUCO & 2.50 & 7.64 & 10605.76 & 14138.20 & 17724.02 & 21363.15 & 25055.72 \\
\hline ALITAS EN SALSA DE BBQ & 2.50 & 7.22 & 10032.11 & 13373.48 & 16765.35 & 20207.64 & 23700.48 \\
\hline ALITAS BUFALO & 2.50 & 7.47 & 10377.31 & 13833.66 & 17342.24 & 20902.98 & 24516.01 \\
\hline ALITAS EMPANIZADAS & 2.50 & 6.90 & 9577.70 & 12767.72 & 16005.96 & 19292.33 & 22626.96 \\
\hline ALITAS CON SALSA DE TAMARINDO & 2.50 & 7.65 & 10624.70 & 14163.45 & 17755.68 & 21401.31 & 25100.47 \\
\hline $\begin{array}{l}\text { ALITAS DULCES } \\
\end{array}$ & 2.50 & 7.49 & 10399.10 & 13862.70 & 17378.66 & 20946.88 & 24567.49 \\
\hline \multicolumn{8}{|l|}{ HAMBURGUESAS } \\
\hline HAMBURGUESA CLASICA & 2.50 & 9.30 & 24059.58 & 32073.05 & 40207.64 & 48463.14 & 56839.87 \\
\hline HAMBURGUESA DE CERDO & 2.50 & 12.28 & 31776.95 & 42360.83 & 53104.67 & 64008.22 & 75071.88 \\
\hline HAMBURGUESA DE POLLO & 2.50 & 10.22 & 26451.55 & 35261.70 & 44205.02 & 53281.27 & 62490.80 \\
\hline HAMBURGUESA DE QUINUA & 2.50 & 5.18 & 13388.07 & 17847.20 & 22373.73 & 26967.54 & 31628.81 \\
\hline HAMBURGUESA PAYPI FAST & 2.50 & 13.45 & 34795.37 & 46384.59 & 58148.96 & 70088.22 & 82202.79 \\
\hline HAMBURGUESA VEGETARIANA & 2.50 & 9.58 & 24789.74 & 33046.40 & 41427.85 & 49933.89 & 58564.84 \\
\hline BROASTER & 2.50 & 5.60 & 92364.75 & 123128.47 & 154357.15 & 186050.05 & 218208.33 \\
\hline EMOLIENTE & 2.50 & 2.10 & 33547.72 & 44721.38 & 56063.92 & 67575.07 & 79255.25 \\
\hline CHICHA DE QUINUA & 2.50 & 1.27 & 19981.62 & 26636.86 & 33392.68 & 40248.93 & 47205.85 \\
\hline CHICHA DE KIWICHA & 2.50 & 1.27 & 11753.90 & 15668.74 & 19642.75 & 23675.84 & 27768.15 \\
\hline CHICHA MORADA & 2.50 & 1.21 & 793.19 & 1057.38 & 1325.56 & 1597.73 & 1873.89 \\
\hline \multicolumn{8}{|l|}{ LIMONADA } \\
\hline LIMONADA FROZZEN & 2.50 & 2.10 & 27.01 & 36.01 & 45.14 & 54.41 & 63.81 \\
\hline LIMONADA CON HIERBABUENA & 2.50 & 0.48 & 6.17 & 8.22 & 10.31 & 12.43 & 14.57 \\
\hline LIMONADA CON MUÑA & 2.50 & 0.45 & 5.79 & 7.72 & 9.68 & 11.66 & 13.68 \\
\hline PAPAS NATIVAS & 2.50 & 3.03 & 55096.92 & 73447.92 & 92076.29 & 110981.56 & 130164.44 \\
\hline CHOCLO CON QUESO & 2.50 & 9.33 & 111264.31 & 148322.86 & 185941.52 & 224119.37 & 262857.84 \\
\hline \multirow[t]{2}{*}{ PAPA HELADA CON QUESO } & 2.50 & 10.81 & 125389.60 & 167152.83 & 209547.27 & 252571.90 & 296228.31 \\
\hline & & VTAS COMBOS & 678141.24 & 904008.20 & 1133288.92 & 1365977.91 & 1602083.70 \\
\hline \multicolumn{8}{|l|}{ Programa de producción POSTRES } \\
\hline PASTEL DE CHOCLO & 2.86 & 6.73 & 41619.21 & 55481.23 & 69552.76 & 83833.46 & 98323.86 \\
\hline \multirow[t]{3}{*}{ BUDIN DE QUINUA } & 6.67 & 5.48 & 33768.66 & 45015.91 & 56433.16 & 68020.12 & 79777.22 \\
\hline & & VTAS POSTRES & 75387.88 & 100497.15 & 125985.92 & 151853.58 & 178101.08 \\
\hline & & $\begin{array}{l}\text { INGRESOS } \\
\text { TOTAL }\end{array}$ & 753529.11 & 1004505.34 & 1259274.84 & 1517831.49 & 1780184.78 \\
\hline
\end{tabular}


Anexo 18. Costeo de receta estándar

\section{VARIDEDADES DE ALITAS/POLLO FRITO}

\begin{tabular}{|c|c|c|c|c|c|c|c|c|c|c|c|c|}
\hline & & & & & & & QX RECETA & 1389 & 1851 & 2320 & 2797 & 3280 \\
\hline ALITAS EN SALSA DE MARACUYA & & & & & & & & COMPRAS & & & & \\
\hline $\begin{array}{l}\text { INGREDIENTES } \\
\end{array}$ & CANTIDAD & UND MEDIDA & KG BRUTO & MERMA & KG NETO & COSTO POR KILO & COSTO TOTAL & 2019 KG & $2020 \mathrm{KG}$ & 2021 KG & 2022 KG & $2023 \mathrm{KG}$ \\
\hline ALITAS & 200 & GRAMOS & 0.2 & $12.33 \%$ & 0.228 & 6.78 & 1.547 & 316.75 & 422.25 & 529.34 & 638.02 & 748.30 \\
\hline SAL & 30 & GRAMOS & 0.03 & $0.00 \%$ & 0.030 & 0.85 & 0.025 & 41.66 & 55.53 & 69.61 & 83.91 & 98.41 \\
\hline AJO MOLIDO & 10 & GRAMOS & 0.01 & $43.76 \%$ & 0.018 & 10.17 & 0.181 & 24.69 & 32.91 & 41.26 & 49.73 & 58.33 \\
\hline PIMIENTA & 5 & GRAMOS & 0.005 & $0.00 \%$ & 0.005 & 8.47 & 0.042 & 6.94 & 9.26 & 11.60 & 13.98 & 16.40 \\
\hline COMINO & 5 & GRAMOS & 0.005 & $0.00 \%$ & 0.005 & 10.17 & 0.051 & 6.94 & 9.26 & 11.60 & 13.98 & 16.40 \\
\hline MERMELADA DE MARACUYA & 80 & GRAMOS & 0.08 & $0.00 \%$ & 0.080 & 10.17 & 0.814 & 111.08 & 148.08 & 185.64 & 223.75 & 262.43 \\
\hline HARINA DE CHUÑO & 50 & GRAMOS & 0.05 & $0.00 \%$ & 0.050 & 4.24 & 0.212 & 69.43 & 92.55 & 116.02 & 139.85 & 164.02 \\
\hline CEBOLLA PICADA & 15 & GRAMOS & 0.015 & $13.91 \%$ & 0.017 & 2.12 & 0.037 & 24.19 & 32.25 & 40.43 & 48.73 & 57.16 \\
\hline AZÚCAR BLANCA & 20 & GRAMOS & 0.02 & $0.00 \%$ & 0.020 & 2.54 & 0.051 & 27.77 & 37.02 & 46.41 & 55.94 & 65.61 \\
\hline ACEITE & 30 & MILILITROS & 0.03 & $0.00 \%$ & 0.030 & 5.08 & 0.153 & 41.66 & 55.53 & 69.61 & 83.91 & 98.41 \\
\hline APIO & 20 & GRAMOS & 0.02 & $36.15 \%$ & 0.031 & 2.12 & 0.066 & 43.50 & 57.98 & 72.69 & 87.61 & 102.76 \\
\hline TOTAL & & & & & & & 3.178 & & & & & \\
\hline ALITAS EN SALSA DE SAUCO & & & & & & & & COMPRAS & & & & \\
\hline $\begin{array}{ll}\text { INGREDIENTES } \\
\end{array}$ & CANTIDAD & UND MEDIDA & KG BRUTO & MERMA & KG NETO & COSTO POR KILO & COSTO TOTAL & 2019 KG & $2020 \mathrm{KG}$ & $2021 \mathrm{KG}$ & 2022 KG & $2023 \mathrm{KG}$ \\
\hline ALITAS & 200 & GRAMOS & 0.2 & $12.33 \%$ & 0.228 & 6.78 & 1.547 & 316.75 & 422.25 & 529.34 & 638.02 & 748.30 \\
\hline SAL & 20 & GRAMOS & 0.02 & $0.00 \%$ & 0.020 & 0.85 & 0.017 & 27.77 & 37.02 & 46.41 & 55.94 & 65.61 \\
\hline AJO MOLIDO & 10 & GRAMOS & 0.01 & $43.76 \%$ & 0.018 & 10.17 & 0.181 & 24.69 & 32.91 & 41.26 & 49.73 & 58.33 \\
\hline PIMIENTA & 5 & GRAMOS & 0.005 & $0.00 \%$ & 0.005 & 8.47 & 0.042 & 6.94 & 9.26 & 11.60 & 13.98 & 16.40 \\
\hline COMINO & 5 & GRAMOS & 0.005 & $0.00 \%$ & 0.005 & 10.17 & 0.051 & 6.94 & 9.26 & 11.60 & 13.98 & 16.40 \\
\hline MERMELADA DE SAUCO & 50 & GRAMOS & 0.05 & $0.00 \%$ & 0.050 & 12.71 & 0.636 & 69.43 & 92.55 & 116.02 & 139.85 & 164.02 \\
\hline HARINA DE CHUÑO & 50 & GRAMOS & 0.05 & $0.00 \%$ & 0.050 & 4.24 & 0.212 & 69.43 & 92.55 & 116.02 & 139.85 & 164.02 \\
\hline CEBOLLA PICADA & 15 & GRAMOS & 0.015 & $13.91 \%$ & 0.017 & 2.12 & 0.037 & 24.19 & 32.25 & 40.43 & 48.73 & 57.16 \\
\hline AZÚCAR BLANCA & 5 & GRAMOS & 0.005 & $0.00 \%$ & 0.005 & 2.54 & 0.013 & 6.94 & 9.26 & 11.60 & 13.98 & 16.40 \\
\hline OREGANO & 10 & GRAMOS & 0.01 & $0.00 \%$ & 0.010 & 10.17 & 0.102 & 13.89 & 18.51 & 23.20 & 27.97 & 32.80 \\
\hline ACEITE & 30 & MILILITROS & 0.03 & $0.00 \%$ & 0.030 & 5.08 & 0.153 & 41.66 & 55.53 & 69.61 & 83.91 & 98.41 \\
\hline APIO & 20 & GRAMOS & 0.02 & $36.15 \%$ & 0.031 & 2.12 & 0.066 & 43.50 & 57.98 & 72.69 & 87.61 & 102.76 \\
\hline TOTAL & & & & & & & 3.055 & & & & & \\
\hline ALITAS EN SALSA BBQ & & & & & & & & COMPRAS & & & & \\
\hline \begin{tabular}{|l|} 
INGREDIENTES \\
\end{tabular} & CANTIDAD & UND MEDIDA & KG BRUTO & MERMA & KG NETO & COSTO POR KILO & COSTO TOTAL & 2019 KG & $2020 \mathrm{KG}$ & 2021 KG & 2022 KG & $2023 \mathrm{KG}$ \\
\hline ALITAS & 200 & GRAMOS & 0.2 & $12.33 \%$ & 0.228 & 6.78 & 1.547 & 316.75 & 422.25 & 529.34 & 638.02 & 748.30 \\
\hline KETCHUP & 50 & MILILITROS & 0.05 & $0.00 \%$ & 0.050 & 5.93 & 0.297 & 69.43 & 92.55 & 116.02 & 139.85 & 164.02 \\
\hline MOSTAZA & 5 & GRAMOS & 0.005 & $0.00 \%$ & 0.005 & 6.78 & 0.034 & 6.94 & 9.26 & 11.60 & 13.98 & 16.40 \\
\hline AZÚCAR RUBIA & 20 & GRAMOS & 0.02 & $0.00 \%$ & 0.020 & 2.54 & 0.051 & 27.77 & 37.02 & 46.41 & 55.94 & 65.61 \\
\hline AJO MOLIDO & 10 & GRAMOS & 0.01 & $43.76 \%$ & 0.018 & 10.17 & 0.181 & 24.69 & 32.91 & 41.26 & 49.73 & 58.33 \\
\hline CEBOLLA PICADA & 15 & GRAMOS & 0.015 & $13.91 \%$ & 0.017 & 2.12 & 0.037 & 24.19 & 32.25 & 40.43 & 48.73 & 57.16 \\
\hline PIMIENTA & 5 & GRAMOS & 0.005 & $0.00 \%$ & 0.005 & 8.47 & 0.042 & 6.94 & 9.26 & 11.60 & 13.98 & 16.40 \\
\hline MANTEQUILLA & 10 & GRAMOS & 0.01 & $0.00 \%$ & 0.010 & 5.93 & 0.059 & 13.89 & 18.51 & 23.20 & 27.97 & 32.80 \\
\hline ZUMO DE LIMÓN & 50 & MILILITROS & 0.05 & $42.86 \%$ & 0.088 & 3.39 & 0.297 & 121.50 & 161.96 & 203.04 & 244.73 & 287.03 \\
\hline SAL & 30 & GRAMOS & 0.03 & $0.00 \%$ & 0.030 & 0.85 & 0.025 & 41.66 & 55.53 & 69.61 & 83.91 & 98.41 \\
\hline OREGANO & 10 & GRAMOS & 0.01 & $0.00 \%$ & 0.010 & 10.17 & 0.102 & 13.89 & 18.51 & 23.20 & 27.97 & 32.80 \\
\hline \begin{tabular}{|l} 
ACEITE \\
\end{tabular} & 30 & MILILITROS & 0.03 & $0.00 \%$ & 0.030 & 5.08 & 0.153 & 41.66 & 55.53 & 69.61 & 83.91 & 98.41 \\
\hline APIO & 20 & GRAMOS & 0.02 & $36.15 \%$ & 0.031 & 2.12 & 0.066 & 43.50 & 57.98 & 72.69 & 87.61 & 102.76 \\
\hline TOTAL & & & & & & & 2.890 & & & & & \\
\hline
\end{tabular}




\begin{tabular}{|c|c|c|c|c|c|c|c|c|c|c|c|c|}
\hline \begin{tabular}{|l|} 
ALITAS BUFALO \\
\end{tabular} & & & & & & & & COMPRAS & & & & \\
\hline $\begin{array}{ll}\text { INGREDIENTES } \\
\end{array}$ & CANTIDAD & UND MEDIDA & KG BRUTO & MERMA & KG NETO & COSTO POR KILO & COSTO TOTAL & $2019 \mathrm{KG}$ & $2020 \mathrm{KG}$ & $2021 \mathrm{KG}$ & $2022 \mathrm{KG}$ & $2023 \mathrm{KG}$ \\
\hline ALITAS & 200 & GRAMOS & 0.2 & $12.33 \%$ & 0.228 & 6.78 & 1.547 & 316.75 & 422.25 & 529.34 & 638.02 & 748.30 \\
\hline KETCHUP & 50 & MILILITROS & 0.05 & $0.00 \%$ & 0.050 & 5.93 & 0.297 & 69.43 & 92.55 & 116.02 & 139.85 & 164.02 \\
\hline \begin{tabular}{|l|} 
MOSTAZA \\
\end{tabular} & 5 & GRAMOS & 0.005 & $0.00 \%$ & 0.005 & 6.78 & 0.034 & 6.94 & 9.26 & 11.60 & 13.98 & 16.40 \\
\hline AZÚCAR RUBIA & 20 & GRAMOS & 0.02 & $0.00 \%$ & 0.020 & 2.54 & 0.051 & 27.77 & 37.02 & 46.41 & 55.94 & 65.61 \\
\hline AJO MOLIDO & 10 & GRAMOS & 0.01 & $43.76 \%$ & 0.018 & 10.17 & 0.181 & 24.69 & 32.91 & 41.26 & 49.73 & 58.33 \\
\hline \begin{tabular}{|l} 
CEBOLLA PICADA \\
\end{tabular} & 15 & GRAMOS & 0.015 & $13.91 \%$ & 0.017 & 2.12 & 0.037 & 24.19 & 32.25 & 40.43 & 48.73 & 57.16 \\
\hline \begin{tabular}{|l|} 
PIMIENTA \\
\end{tabular} & 5 & GRAMOS & 0.005 & $0.00 \%$ & 0.005 & 8.47 & 0.042 & 6.94 & 9.26 & 11.60 & 13.98 & 16.40 \\
\hline MANTEQUILLA & 10 & GRAMOS & 0.01 & $0.00 \%$ & 0.010 & 5.93 & 0.059 & 13.89 & 18.51 & 23.20 & 27.97 & 32.80 \\
\hline ZUMO DE LIMÓN & 50 & MILILITROS & 0.05 & $42.86 \%$ & 0.088 & 3.39 & 0.297 & 121.50 & 161.96 & 203.04 & 244.73 & 287.03 \\
\hline AJI LIMO & 10 & GRAMOS & 0.01 & $14.78 \%$ & 0.012 & 8.47 & 0.099 & 16.29 & 21.72 & 27.23 & 32.82 & 38.49 \\
\hline SAL & 30 & GRAMOS & 0.03 & $0.00 \%$ & 0.030 & 0.85 & 0.025 & 41.66 & 55.53 & 69.61 & 83.91 & 98.41 \\
\hline OREGANO & 10 & GRAMOS & 0.01 & $0.00 \%$ & 0.010 & 10.17 & 0.102 & 13.89 & 18.51 & 23.20 & 27.97 & 32.80 \\
\hline \begin{tabular}{|l|} 
APIO \\
\end{tabular} & 20 & GRAMOS & 0.02 & $36.15 \%$ & 0.031 & 2.12 & 0.066 & 43.50 & 57.98 & 72.69 & 87.61 & 102.76 \\
\hline ACEITE & 30 & MILILITROS & 0.03 & $0.00 \%$ & 0.030 & 5.08 & 0.153 & 41.66 & 55.53 & 69.61 & 83.91 & 98.41 \\
\hline TOTAL & & & & & & & 2.989 & & & & & \\
\hline ALITAS EMPANIZADAS & & & & & & & & COMPRAS & & & & \\
\hline \begin{tabular}{|l|} 
INGREDIENTES \\
\end{tabular} & CANTIDAD & UND MEDIDA & KG BRUTO & MERMA & KG NETO & COSTO POR KILO & COSTO TOTAL & $2019 \mathrm{KG}$ & $2020 \mathrm{KG}$ & $2021 \mathrm{KG}$ & 2022 KG & $2023 \mathrm{KG}$ \\
\hline ALITAS & 200 & GRAMOS & 0.2 & $12.33 \%$ & 0.228 & 6.78 & 1.547 & 316.75 & 422.25 & 529.34 & 638.02 & 748.30 \\
\hline ACEITE & 50 & MILILITROS & 0.05 & $0.00 \%$ & 0.050 & 5.08 & 0.254 & 69.43 & 92.55 & 116.02 & 139.85 & 164.02 \\
\hline SAL & 5 & GRAMOS & 0.005 & $0.00 \%$ & 0.005 & 0.85 & 0.004 & 6.94 & 9.26 & 11.60 & 13.98 & 16.40 \\
\hline \begin{tabular}{|l|} 
PIMIENTA \\
\end{tabular} & 20 & GRAMOS & 0.02 & $0.00 \%$ & 0.020 & 8.47 & 0.169 & 27.77 & 37.02 & 46.41 & 55.94 & 65.61 \\
\hline HUEVO & 10 & GRAMOS & 0.01 & $0.00 \%$ & 0.010 & 5.08 & 0.051 & 13.89 & 18.51 & 23.20 & 27.97 & 32.80 \\
\hline HARINA DE KIWICHA & 50 & GRAMOS & 0.05 & $0.00 \%$ & 0.050 & 5.93 & 0.297 & 69.43 & 92.55 & 116.02 & 139.85 & 164.02 \\
\hline KIWICHA POP & 10 & GRAMOS & 0.01 & $0.00 \%$ & 0.010 & 16.95 & 0.169 & 13.89 & 18.51 & 23.20 & 27.97 & 32.80 \\
\hline APIO & 50 & GRAMOS & 0.05 & $36.15 \%$ & 0.078 & 2.12 & 0.166 & 108.74 & 144.96 & 181.72 & 219.04 & 256.90 \\
\hline OREGANO & 10 & GRAMOS & 0.01 & $0.00 \%$ & 0.010 & 10.17 & 0.102 & 13.89 & 18.51 & 23.20 & 27.97 & 32.80 \\
\hline TOTAL & & & & & & & 2.759 & & & & & \\
\hline \multicolumn{2}{|c|}{ ALITAS CON SALSA DE TAMARINDO } & & & & & & & COMPRAS & & & & \\
\hline INGREDIENTES & CANTIDAD & UND MEDIDA & KG BRUTO & MERMA & KG NETO & COSTO POR KILO & COSTO TOTAL & $2019 \mathrm{KG}$ & $2020 \mathrm{KG}$ & 2021 KG & 2022 KG & $2023 \mathrm{KG}$ \\
\hline ALITAS & 200 & GRAMOS & 0.2 & $12.33 \%$ & 0.228 & 6.78 & 1.547 & 316.75 & 422.25 & 529.34 & 638.02 & 748.30 \\
\hline \begin{tabular}{|l|} 
ACEITE \\
\end{tabular} & 30 & GRAMOS & 0.03 & $0.00 \%$ & 0.030 & 5.08 & 0.153 & 41.66 & 55.53 & 69.61 & 83.91 & 98.41 \\
\hline SALSA DE TAMARINDO & 60 & GRAMOS & 0.06 & $0.00 \%$ & 0.060 & 4.66 & 0.280 & 83.31 & 111.06 & 139.23 & 167.82 & 196.82 \\
\hline GENGIBRE EN POLVO & 5 & GRAMOS & 0.005 & $0.00 \%$ & 0.005 & 33.90 & 0.169 & 6.94 & 9.26 & 11.60 & 13.98 & 16.40 \\
\hline SAL & 30 & GRAMOS & 0.03 & $0.00 \%$ & 0.030 & 0.85 & 0.025 & 41.66 & 55.53 & 69.61 & 83.91 & 98.41 \\
\hline AJO MOLIDO & 10 & GRAMOS & 0.01 & $43.76 \%$ & 0.018 & 10.17 & 0.181 & 24.69 & 32.91 & 41.26 & 49.73 & 58.33 \\
\hline ZUMO DE LIMÓN & 100 & GRAMOS & 0.1 & $42.86 \%$ & 0.175 & 3.39 & 0.593 & 242.99 & 323.93 & 406.08 & 489.46 & 574.06 \\
\hline \begin{tabular}{|l|} 
AZÚCAR RUBIA \\
\end{tabular} & 15 & GRAMOS & 0.015 & $0.00 \%$ & 0.015 & 2.54 & 0.038 & 20.83 & 27.77 & 34.81 & 41.95 & 49.21 \\
\hline \begin{tabular}{|l|l|} 
APIO \\
\end{tabular} & 20 & GRAMOS & 0.02 & $36.15 \%$ & 0.031 & 2.12 & 0.066 & 43.50 & 57.98 & 72.69 & 87.61 & 102.76 \\
\hline KIWICHA POP & 0.5 & GRAMOS & 0.0005 & $0.00 \%$ & 0.001 & 16.95 & 0.008 & 0.69 & 0.93 & 1.16 & 1.40 & 1.64 \\
\hline \begin{tabular}{|l|l} 
TOTAL \\
\end{tabular} & & & & & & & 3.061 & & & & & \\
\hline ALITAS DULCES & & & & & & & & COMPRAS & & & & \\
\hline \begin{tabular}{|l|} 
INGREDIENTES \\
\end{tabular} & CANTIDAD & UND MEDIDA & KG BRUTO & MERMA & KG NETO & COSTO POR KILO & COSTO TOTAL & $2019 \mathrm{KG}$ & $2020 \mathrm{KG}$ & $2021 \mathrm{KG}$ & 2022 KG & $2023 \mathrm{KG}$ \\
\hline ALITAS & 200 & GRAMOS & 0.2 & $12.33 \%$ & 0.228 & 6.78 & 1.547 & 316.75 & 422.25 & 529.34 & 638.02 & 748.30 \\
\hline ACEITE & 30 & GRAMOS & 0.03 & $0.00 \%$ & 0.030 & 5.08 & 0.153 & 41.66 & 55.53 & 69.61 & 83.91 & 98.41 \\
\hline MIEL & 60 & GRAMOS & 0.06 & $0.00 \%$ & 0.060 & 8.47 & 0.508 & 83.31 & 111.06 & 139.23 & 167.82 & 196.82 \\
\hline GENGIBRE EN POLVO & 5 & GRAMOS & 0.005 & $0.00 \%$ & 0.005 & 33.90 & 0.169 & 6.94 & 9.26 & 11.60 & 13.98 & 16.40 \\
\hline SAL & 30 & GRAMOS & 0.03 & $0.00 \%$ & 0.030 & 0.85 & 0.025 & 41.66 & 55.53 & 69.61 & 83.91 & 98.41 \\
\hline ZUMO DE LIMÓN & 100 & GRAMOS & 0.1 & $42.86 \%$ & 0.175 & 3.39 & 0.593 & 242.99 & 323.93 & 406.08 & 489.46 & 574.06 \\
\hline TOTAL & & & & & & & 2.996 & & & & & \\
\hline
\end{tabular}


HAMBURGUESA CLASICA

\begin{tabular}{|c|c|}
\hline COSTO TOTAL \\
\hline 2.542 \\
\hline 0.025 \\
\hline 0.007 \\
\hline 0.042 \\
\hline 0.197 \\
\hline 0.063 \\
\hline 0.254 \\
\hline 0.063 \\
\hline 0.044 \\
\hline 0.102 \\
\hline 0.381 \\
\hline 3.720
\end{tabular}

COMPRAS

\begin{tabular}{|c|c|c|c|c|c|c|}
\hline INGREDIENTES & CANTIDAD & UND MEDIDA & KG BRUTO & MERMA & KG NETO & COSTO POR KILO \\
\hline CARNE DE RES MOLIDA & 200 & GRAMOS & 0.2 & $0.00 \%$ & 0.200 & 12.71 \\
\hline PAN MOLIDO & 10 & GRAMOS & 0.01 & $0.00 \%$ & 0.010 & 2.54 \\
\hline SAL & 8 & GRAMOS & 0.008 & $0.00 \%$ & 0.008 & 0.85 \\
\hline PIMIENTA & 5 & GRAMOS & 0.005 & $0.00 \%$ & 0.005 & 8.47 \\
\hline CEBOLLA PICADA & 80 & GRAMOS & 0.08 & $13.91 \%$ & 0.093 & 2.12 \\
\hline PIMENTON & 30 & GRAMOS & 0.03 & $19.05 \%$ & 0.037 & 1.69 \\
\hline HUEVO & 50 & GRAMOS & 0.05 & $0.00 \%$ & 0.050 & 5.08 \\
\hline TOMATE & 20 & GRAMOS & 0.02 & $32.26 \%$ & 0.030 & 2.12 \\
\hline LECHUGA & 20 & GRAMOS & 0.02 & $22.22 \%$ & 0.026 & 1.69 \\
\hline OREGANO & 10 & GRAMOS & 0.01 & $0.00 \%$ & 0.010 & 10.17 \\
\hline BOLLO DE PAN & 100 & GRAMOS & 0.1 & $0.00 \%$ & 0.100 & 3.81 \\
\hline
\end{tabular}

\begin{tabular}{|c|}
\hline 2019 KG \\
\hline 517.401 \\
\hline 25.870 \\
\hline 20.696 \\
\hline 12.935 \\
\hline 240.409 \\
\hline 95.871 \\
\hline 129.350 \\
\hline 76.378 \\
\hline 66.523 \\
\hline 25.870 \\
\hline 258.701 \\
\hline
\end{tabular}

\begin{tabular}{|c|c|c|c|}
\hline 2020 KG & 2021 KG & 2022 KG & 2023 KG \\
\hline 689.731 & 864.665 & 1042.199 & 1222.341 \\
\hline 34.487 & 43.233 & 52.110 & 61.117 \\
\hline 27.589 & 34.587 & 41.688 & 48.894 \\
\hline 17.243 & 21.617 & 26.055 & 30.559 \\
\hline 320.481 & 401.763 & 484.254 & 567.956 \\
\hline 127.803 & 160.217 & 193.113 & 226.493 \\
\hline 172.433 & 216.166 & 260.550 & 305.585 \\
\hline 101.817 & 127.641 & 153.848 & 180.441 \\
\hline 88.680 & 111.171 & 133.997 & 157.158 \\
\hline 34.487 & 43.233 & 52.110 & 61.117 \\
\hline 344.865 & 432.332 & 521.100 & 611.170 \\
\hline
\end{tabular}

TOTAL

HAMBURGUESA DE CERDO INGREDIENTES
CARNE DE CERDO PICADA PAN MOLIDO SAL \begin{tabular}{l} 
SAL \\
\hline PIMIENTA \\
\hline CEBOLLA PICAD
\end{tabular}

CEBOLLA PICADA HUEVO

AJO MOLIDO

PEREJIL FRESCO TOMATE

LECHUGA BOLOO DE PAN

OREGANO

TOTAL

HAMBURGUESA DE POLLO INGREDIENTES

\begin{tabular}{|c|c|c|c|}
\hline CANTIDAD & UND MEDIDA & KG BRUTO & MERMA \\
\hline 200 & GRAMOS & 0.2 & $17.14 \%$ \\
\hline 10 & GRAMOS & 0.01 & $0.00 \%$ \\
\hline 5 & GRAMOS & 0.005 & $0.00 \%$ \\
\hline 5 & GRAMOS & 0.005 & $0.00 \%$ \\
\hline 80 & GRAMOS & 0.08 & $13.91 \%$ \\
\hline 50 & GRAMOS & 0.05 & $0.00 \%$ \\
\hline 5 & GRAMOS & 0.005 & $43.76 \%$ \\
\hline 3 & GRAMOS & 0.003 & $73.24 \%$ \\
\hline 20 & GRAMOS & 0.02 & $32.26 \%$ \\
\hline 20 & GRAMOS & 0.02 & $22.22 \%$ \\
\hline 100 & GRAMOS & 0.1 & $0.00 \%$ \\
\hline 10 & GRAMOS & 0.01 & $0.00 \%$ \\
\hline
\end{tabular}

\begin{tabular}{|l|l} 
& \\
\hline
\end{tabular}

\begin{tabular}{|c|c|c|c|c|c|c|c|}
\hline & \multirow{2}{*}{\multicolumn{2}{|c|}{$0.17<0$}} & \multirow{2}{*}{ COMPRAS } & & & & \\
\hline & & & & & & & \\
\hline KG NETO & COSTO POR KILO & COSTO TOTAL & 2019 KG & $2020 \mathrm{KG}$ & $2021 K G$ & 2022 KG & 2023 KG \\
\hline 0.241 & 15.25 & 3.682 & 624.451 & 832.435 & 1043.563 & 1257.829 & 1475.242 \\
\hline 0.010 & 2.54 & 0.025 & 25.870 & 34.487 & 43.233 & 52.110 & 61.117 \\
\hline 0.005 & 0.85 & 0.004 & 12.935 & 17.243 & 21.617 & 26.055 & 30.559 \\
\hline 0.005 & 8.47 & 0.042 & 12.935 & 17.243 & 21.617 & 26.055 & 30.559 \\
\hline 0.093 & 2.12 & 0.197 & 240.409 & 320.481 & 401.763 & 484.254 & 567.956 \\
\hline 0.050 & 5.08 & 0.254 & 129.350 & 172.433 & 216.166 & 260.550 & 305.585 \\
\hline 0.009 & 10.17 & 0.090 & 23.000 & 30.661 & 38.437 & 46.329 & 54.337 \\
\hline 0.011 & 2.54 & 0.029 & 29.002 & 38.662 & 48.468 & 58.419 & 68.517 \\
\hline 0.030 & 2.12 & 0.063 & 76.378 & 101.817 & 127.641 & 153.848 & 180.441 \\
\hline 0.026 & 1.69 & 0.044 & 66.523 & 88.680 & 111.171 & 133.997 & 157.158 \\
\hline 0.100 & 3.81 & 0.381 & 258.701 & 344.865 & 432.332 & 521.100 & 611.170 \\
\hline 0.010 & 10.17 & 0.102 & 25.870 & 34.487 & 43.233 & 52.110 & 61.117 \\
\hline
\end{tabular}

\section{COMPRAS}

PECHUGA DE POLLO

PAN MOLIDO

SAL

\begin{tabular}{|l}
\hline PIMIENTA \\
\hline CEBOLLA PICADA \\
\hline
\end{tabular}

HUEVO

\begin{tabular}{l} 
PEREJIL FRESCO \\
\hline A
\end{tabular}

AJO MOLIDO

TOMATE

LECHUGA

BOLLO DE PAN

OREGANO

TOTAL

\begin{tabular}{|c|c|}
\hline CANTIDAD & \\
\hline 200 & \\
10 & \\
\hline 8 & \\
5 & \\
80 & \\
\hline 50 & \\
\hline 3 & \\
\hline 5 & \\
\hline 20 & \\
\hline 20 & \\
100 & \\
\hline 10 & \\
\hline
\end{tabular}

\begin{tabular}{|c|c|c|c|c|}
\hline UND MEDIDA & KG BRUTO & MERMA & KG NETO & COSTO POR KILO \\
\hline
\end{tabular}

\begin{tabular}{|c|c|}
\hline COSTO TOTAL \\
\hline 2.856 \\
\hline 0.025 \\
\hline 0.007 \\
\hline 0.042 \\
\hline 0.197 \\
\hline \\
0.254 \\
\hline 0.029 \\
\hline 0.090 \\
\hline 0.063 \\
\hline 0.044 \\
\hline 0.381 \\
\hline 0.102 \\
\hline .090
\end{tabular}

2019 KG

COMPRAS

\begin{tabular}{|l|l|l|l|l|}
\hline 2019 KG & 2020 KG & 2021 KG & 2022 KG & 2023 KG \\
\hline
\end{tabular}

\begin{tabular}{|c|c|c|c|c|}
\hline & & & & \\
\hline GRAMOS & 0.01 & $0.00 \%$ & 0.010 & 2.54 \\
\hline GRAMOS & 0.008 & $0.00 \%$ & 0.008 & 0.85 \\
\hline GRAMOS & 0.005 & $0.00 \%$ & 0.005 & 8.47 \\
\hline GRAMOS & 0.08 & $13.91 \%$ & 0.093 & 2.12 \\
\hline GRAMOS & 0.05 & $0.00 \%$ & 0.050 & 5.08 \\
\hline GRAMOS & 0.003 & $73.24 \%$ & 0.011 & 2.54 \\
\hline GRAMOS & 0.005 & $43.76 \%$ & 0.009 & 10.17 \\
\hline GRAMOS & 0.02 & $32.26 \%$ & 0.030 & 2.12 \\
\hline GRAMOS & 0.02 & $22.22 \%$ & 0.026 & 1.69 \\
\hline GRAMOS & 0.1 & $0.00 \%$ & 0.100 & 3.81 \\
\hline GRAMOS & 0.01 & $0.00 \%$ & 0.010 & 10.17 \\
\hline
\end{tabular}

4.090

\begin{tabular}{|c|c|c|c|c|}
\hline 2019 KG & 2020 KG & 2021 KG & 2022 KG & 2023 KG \\
\hline 726.563 & 968.558 & 1214.210 & 1463.514 & 1716.479 \\
\hline 25.870 & 34.487 & 43.233 & 52.110 & 61.117 \\
\hline 20.696 & 27.589 & 34.587 & 41.688 & 48.894 \\
\hline 12.935 & 17.243 & 21.617 & 26.055 & 30.559 \\
\hline 240.409 & 320.481 & 401.763 & 484.254 & 567.956 \\
\hline & & & & \\
129.350 & 172.433 & 216.166 & 260.550 & 305.585 \\
\hline 29.002 & 38.662 & 48.468 & 58.419 & 68.517 \\
\hline 23.000 & 30.661 & 38.437 & 46.329 & 54.337 \\
\hline 76.378 & 101.817 & 127.641 & 153.848 & 180.441 \\
\hline 66.523 & 88.680 & 111.171 & 133.997 & 157.158 \\
\hline 258.701 & 344.865 & 432.332 & 521.100 & 611.170 \\
\hline 25.870 & 34.487 & 43.233 & 52.110 & 61.117 \\
\hline & & & & \\
\hline
\end{tabular}




\begin{tabular}{|c|c|c|c|c|c|c|c|c|c|c|c|c|}
\hline HAMBURGUESA DE QUINUA & & & & & & & & COMPRAS & & & & \\
\hline \begin{tabular}{|c|} 
INGREDIENTES \\
\end{tabular} & CANTIDAD & UND MEDIDA & KG BRUTO & MERMA & KG NETO & COSTO POR KILO & COSTO TOTAL & 2019 KG & 2020 KG & $2021 \mathrm{KG}$ & 2022 KG & $2023 \mathrm{KG}$ \\
\hline QUINUA PERLADA & 200 & GRAMOS & 0.2 & $0.00 \%$ & 0.200 & 5.08 & 1.017 & 517.401 & 689.731 & 864.665 & 1042.199 & 1222.341 \\
\hline PEREJIL FRESCO & 3 & GRAMOS & 0.003 & $73.24 \%$ & 0.011 & 2.54 & 0.029 & 29.002 & 38.662 & 48.468 & 58.419 & 68.517 \\
\hline CEBOLLA PICADA & 8 & GRAMOS & 0.008 & $13.91 \%$ & 0.009 & 2.12 & 0.020 & 24.041 & 32.048 & 40.176 & 48.425 & 56.796 \\
\hline AJO MOLIDO & 3 & GRAMOS & 0.003 & $43.76 \%$ & 0.005 & 10.17 & 0.054 & 13.800 & 18.396 & 23.062 & 27.797 & 32.602 \\
\hline HUEVO & 50 & GRAMOS & 0.05 & $0.00 \%$ & 0.050 & 5.08 & 0.254 & 129.350 & 172.433 & 216.166 & 260.550 & 305.585 \\
\hline PAN MOLIDO & 10 & GRAMOS & 0.01 & $0.00 \%$ & 0.010 & 2.54 & 0.025 & 25.870 & 34.487 & 43.233 & 52.110 & 61.117 \\
\hline SAL & 8 & GRAMOS & 0.008 & $0.00 \%$ & 0.008 & 0.85 & 0.007 & 20.696 & 27.589 & 34.587 & 41.688 & 48.894 \\
\hline PIMIENTA & 5 & GRAMOS & 0.005 & $0.00 \%$ & 0.005 & 8.47 & 0.042 & 12.935 & 17.243 & 21.617 & 26.055 & 30.559 \\
\hline KION RALLADO & 3 & GRAMOS & 0.003 & $22.16 \%$ & 0.004 & 8.47 & 0.033 & 9.971 & 13.292 & 16.663 & 20.084 & 23.556 \\
\hline TOMATE & 20 & GRAMOS & 0.02 & $32.26 \%$ & 0.030 & 2.12 & 0.063 & 76.378 & 101.817 & 127.641 & 153.848 & 180.441 \\
\hline LECHUGA & 20 & GRAMOS & 0.02 & $22.22 \%$ & 0.026 & 1.69 & 0.044 & 66.523 & 88.680 & 111.171 & 133.997 & 157.158 \\
\hline BOLLO DE PAN & 100 & GRAMOS & 0.1 & $0.00 \%$ & 0.100 & 3.81 & 0.381 & 258.701 & 344.865 & 432.332 & 521.100 & 611.170 \\
\hline OREGANO & 10 & GRAMOS & 0.01 & $0.00 \%$ & 0.010 & 10.17 & 0.102 & 25.870 & 34.487 & 43.233 & 52.110 & 61.117 \\
\hline TOTAL & & & & & & & 2.070 & & & & & \\
\hline HAMBURGUESA PAYPI FAST & & & & & & & & COMPRAS & & & & \\
\hline $\begin{array}{l}\text { INGREDIENTES } \\
\end{array}$ & CANTIDAD & UND MEDIDA & KG BRUTO & MERMA & KG NETO & COSTO POR KILO & COSTO TOTAL & 2019 KG & 2020 KG & $2021 \mathrm{KG}$ & 2022 KG & 2023 KG \\
\hline CARNE DE RES PICADA & 250 & GRAMOS & 0.25 & $21.70 \%$ & 0.319 & 12.71 & 4.059 & 825.970 & 1101.074 & 1380.336 & 1663.750 & 1951.324 \\
\hline QUESO & 15 & GRAMOS & 0.015 & $0.00 \%$ & 0.015 & 11.86 & 0.178 & 38.805 & 51.730 & 64.850 & 78.165 & 91.676 \\
\hline CEBOLLA PICADA & 10 & GRAMOS & 0.01 & $13.91 \%$ & 0.012 & 2.12 & 0.025 & 30.051 & 40.060 & 50.220 & 60.532 & 70.995 \\
\hline MOSTAZA & 10 & GRAMOS & 0.01 & $0.00 \%$ & 0.010 & 6.78 & 0.068 & 25.870 & 34.487 & 43.233 & 52.110 & 61.117 \\
\hline KETCHUP & 5 & GRAMOS & 0.005 & $0.00 \%$ & 0.005 & 5.93 & 0.030 & 12.935 & 17.243 & 21.617 & 26.055 & 30.559 \\
\hline HUEVO & 60 & GRAMOS & 0.06 & $0.00 \%$ & 0.060 & 5.08 & 0.305 & 155.220 & 206.919 & 259.399 & 312.660 & 366.702 \\
\hline PAN MOLIDO & 10 & GRAMOS & 0.01 & $0.00 \%$ & 0.010 & 2.54 & 0.025 & 25.870 & 34.487 & 43.233 & 52.110 & 61.117 \\
\hline SAL & 20 & GRAMOS & 0.02 & $0.00 \%$ & 0.020 & 0.85 & 0.017 & 51.740 & 68.973 & 86.466 & 104.220 & 122.234 \\
\hline TOMATE & 20 & GRAMOS & 0.02 & $32.26 \%$ & 0.030 & 2.12 & 0.063 & 76.378 & 101.817 & 127.641 & 153.848 & 180.441 \\
\hline LECHUGA & 20 & GRAMOS & 0.02 & $22.22 \%$ & 0.026 & 1.69 & 0.044 & 66.523 & 88.680 & 111.171 & 133.997 & 157.158 \\
\hline KIWICHA POP & 5 & GRAMOS & 0.005 & $0.00 \%$ & 0.005 & 16.95 & 0.085 & 12.935 & 17.243 & 21.617 & 26.055 & 30.559 \\
\hline BOLLO DE PAN & 100 & GRAMOS & 0.1 & $0.00 \%$ & 0.100 & 3.81 & 0.381 & 258.701 & 344.865 & 432.332 & 521.100 & 611.170 \\
\hline OREGANO & 10 & GRAMOS & 0.01 & $0.00 \%$ & 0.010 & 10.17 & 0.102 & 25.870 & 34.487 & 43.233 & 52.110 & 61.117 \\
\hline TOTAL & & & & & & & 5.380 & & & & & \\
\hline HAMBURGUESA VEGETARIANA & & & & & & & & COMPRAS & & & & \\
\hline $\begin{array}{c}\text { INGREDIENTES } \\
\end{array}$ & CANTIDAD & UND MEDIDA & KG BRUTO & MERMA & KG NETO & COSTO POR KILO & COSTO TOTAL & 2019 KG & $2020 \mathrm{KG}$ & $2021 \mathrm{KG}$ & 2022 KG & 2023 KG \\
\hline CEBOLLA PICADA & 15 & GRAMOS & 0.015 & $13.91 \%$ & 0.017 & 2.12 & 0.037 & 45.077 & 60.090 & 75.331 & 90.798 & 106.492 \\
\hline PIMENTON & 10 & GRAMOS & 0.01 & $19.05 \%$ & 0.012 & 1.69 & 0.021 & 31.957 & 42.601 & 53.406 & 64.371 & 75.498 \\
\hline CEBOLLA CHINA & 10 & Cucharada & 0.01 & $24.30 \%$ & 0.013 & 0.85 & 0.011 & 34.174 & 45.557 & 57.111 & 68.837 & 80.736 \\
\hline AJI VERDE & 5 & GRAMOS & 0.005 & $16.00 \%$ & 0.006 & 5.08 & 0.030 & 15.399 & 20.528 & 25.734 & 31.018 & 36.379 \\
\hline PORO & 60 & GRAMOS & 0.06 & $57.61 \%$ & 0.142 & 2.54 & 0.360 & 366.181 & 488.144 & 611.950 & 737.597 & 865.088 \\
\hline DIENTES DE AJO & 10 & GRAMOS & 0.01 & $34.90 \%$ & 0.015 & 3.81 & 0.059 & 39.739 & 52.975 & 66.411 & 80.046 & 93.882 \\
\hline CULANTRO & 20 & GRAMOS & 0.02 & $72.73 \%$ & 0.073 & 1.69 & 0.124 & 189.714 & 252.901 & 317.044 & 382.140 & 448.192 \\
\hline HARINA DE TRIGO INTEGRAL & 20 & GRAMOS & 0.02 & $0.00 \%$ & 0.020 & 5.93 & 0.119 & 51.740 & 68.973 & 86.466 & 104.220 & 122.234 \\
\hline AJONJOLI TOSTADO & 200 & GRAMOS & 0.2 & $0.00 \%$ & 0.200 & 12.71 & 2.542 & 517.401 & 689.731 & 864.665 & 1042.199 & 1222.341 \\
\hline SAL & 10 & GRAMOS & 0.01 & $0.00 \%$ & 0.010 & 0.85 & 0.008 & 25.870 & 34.487 & 43.233 & 52.110 & 61.117 \\
\hline PIMIENTA & 5 & GRAMOS & 0.005 & $0.00 \%$ & 0.005 & 8.47 & 0.042 & 12.935 & 17.243 & 21.617 & 26.055 & 30.559 \\
\hline ACELGA & 5 & GRAMOS & 0.005 & $53.10 \%$ & 0.011 & 2.54 & 0.027 & 27.580 & 36.766 & 46.091 & 55.554 & 65.157 \\
\hline HUACATAY & 5 & GRAMOS & 0.005 & $69.99 \%$ & 0.017 & 4.24 & 0.071 & 43.096 & 57.450 & 72.020 & 86.808 & 101.812 \\
\hline BOLLO DE PAN & 100 & GRAMOS & 0.1 & $0.00 \%$ & 0.100 & 3.81 & 0.381 & 258.701 & 344.865 & 432.332 & 521.100 & 611.170 \\
\hline TOTAL & & & & & & & 3.833 & & & & & \\
\hline
\end{tabular}




\begin{tabular}{|c|c|c|c|c|c|c|c|c|c|c|c|c|}
\hline POLLO BROASTER ANDINO & & & & & & & & COMPRAS & & & & \\
\hline $\begin{array}{ll}\text { INGREDIENTES } \\
\end{array}$ & CANTIDAD & UND MEDIDA & KG BRUTO & MERMA & KG NETO & COSTO POR KILO & COSTO TOTAL & 2019 KG & $2020 \mathrm{KG}$ & $2021 \mathrm{KG}$ & $2022 \mathrm{KG}$ & 2023 KG \\
\hline ALITAS & 200 & GRAMOS & 0.2 & $12.33 \%$ & 0.228 & 6.78 & 1.547 & 3760.021 & 5012.363 & 6283.633 & 7573.800 & 8882.912 \\
\hline SAL & 30 & GRAMOS & 0.03 & $0.00 \%$ & 0.030 & 0.85 & 0.025 & 494.488 & 659.185 & 826.372 & 996.045 & 1168.209 \\
\hline HARINA DE CHUÑO & 20 & GRAMOS & 0.02 & $0.00 \%$ & 0.020 & 4.24 & 0.085 & 329.658 & 439.457 & 550.915 & 664.030 & 778.806 \\
\hline PIMIENTA & 5 & GRAMOS & 0.005 & $0.00 \%$ & 0.005 & 8.47 & 0.042 & 82.415 & 109.864 & 137.729 & 166.007 & 194.701 \\
\hline HUEVO & 20 & GRAMOS & 0.02 & $0.00 \%$ & 0.020 & 5.08 & 0.102 & 329.658 & 439.457 & 550.915 & 664.030 & 778.806 \\
\hline MOSTAZA & 5 & GRAMOS & 0.005 & $0.00 \%$ & 0.005 & 6.78 & 0.034 & 82.415 & 109.864 & 137.729 & 166.007 & 194.701 \\
\hline ACEITE & 80 & MILILITROS & 0.08 & $0.00 \%$ & 0.080 & 5.08 & 0.407 & 1318.633 & 1757.828 & 2203.660 & 2656.120 & 3115.223 \\
\hline TOTAL & & & & & & & 2.241 & & & & & \\
\hline
\end{tabular}

BEBIDAS

\begin{tabular}{|c|c|c|c|c|c|c|c|c|c|c|c|c|}
\hline & & & & & & & QX RECETA & 15994 & 21322 & 26729 & 32218 & 37786 \\
\hline ICE BARLEY/EMOLIENTE & & & & & & & & COMPRAS & & & & \\
\hline INGREDIENTES & CANTIDAD & UND MEDIDA & KG BRUTO & MERMA & KG NETO & COSTO POR KILO & COSTO TOTAL & 2019 KG & $2020 \mathrm{KG}$ & $2021 \mathrm{KG}$ & $2022 \mathrm{KG}$ & 2023 KG \\
\hline CEBADA & 50 & GRAMOS & 0.05 & $0.00 \%$ & 0.050 & 8.47 & 0.424 & 799.723 & 1066.085 & 1336.473 & 1610.880 & 1889.317 \\
\hline ZUMO DE LIMÓN & 30 & GRAMOS & 0.03 & $42.86 \%$ & 0.053 & 3.39 & 0.178 & 839.710 & 1119.390 & 1403.297 & 1691.424 & 1983.783 \\
\hline \begin{tabular}{|l|} 
LINAZA \\
\end{tabular} & 20 & GRAMOS & 0.02 & $0.00 \%$ & 0.020 & 5.08 & 0.102 & 319.889 & 426.434 & 534.589 & 644.352 & 755.727 \\
\hline COLA DE CABALLO & 20 & GRAMOS & 0.02 & $0.00 \%$ & 0.020 & 4.24 & 0.085 & 319.889 & 426.434 & 534.589 & 644.352 & 755.727 \\
\hline AZÚCAR BLANCA & 20 & GRAMOS & 0.02 & $0.00 \%$ & 0.020 & 2.54 & 0.051 & 319.889 & 426.434 & 534.589 & 644.352 & 755.727 \\
\hline \multirow[t]{3}{*}{\begin{tabular}{|l|} 
TOTAL \\
\end{tabular}} & & & & & & & 0.839 & & & & & \\
\hline & & & & & & & & & & & & \\
\hline & & & & & & & QX RECETA & 13 & 17 & 22 & 26 & 30 \\
\hline LIMONADA FROZZEN & & & & & & & & COMPRAS & & & & \\
\hline $\begin{array}{l}\text { INGREDIENTES } \\
\end{array}$ & CANTIDAD & UND MEDIDA & KG BRUTO & MERMA & KG NETO & COSTO POR KILO & COSTO TOTAL & 2019 KG & $2020 \mathrm{KG}$ & $2021 \mathrm{KG}$ & 2022 KG & 2023 KG \\
\hline ZUMO DE LIMÓN & 10 & GRAMOS & 0.01 & $42.86 \%$ & 0.018 & 3.39 & 0.059 & 0.225 & 0.300 & 0.377 & 0.454 & 0.532 \\
\hline \begin{tabular}{|l|} 
HIELO \\
\end{tabular} & 200 & GRAMOS & 0.2 & $0.00 \%$ & 0.200 & 3.39 & 0.678 & 2.576 & 3.433 & 4.304 & 5.188 & 6.085 \\
\hline AZÚCAR BLANCA & 20 & GRAMOS & 0.02 & $0.00 \%$ & 0.020 & 2.54 & 0.051 & 0.258 & 0.343 & 0.430 & 0.519 & 0.608 \\
\hline HUEVO & 10 & GRAMOS & 0.01 & $0.00 \%$ & 0.010 & 5.08 & 0.051 & 0.129 & 0.172 & 0.215 & 0.259 & 0.304 \\
\hline TOTAL & & & & & & & 0.839 & & & & & \\
\hline LIMONADA CON HIERBABUENA & & & & & & & & COMPRAS & & & & \\
\hline INGREDIENTES & CANTIDAD & UND MEDIDA & KG BRUTO & MERMA & KG NETO & COSTO POR KILO & COSTO TOTAL & $2019 \mathrm{KG}$ & $2020 \mathrm{KG}$ & $2021 \mathrm{KG}$ & $2022 \mathrm{KG}$ & $2023 \mathrm{KG}$ \\
\hline ZUMO DE LIMÓN & 10 & GRAMOS & 0.01 & $42.86 \%$ & 0.018 & 3.39 & 0.059 & 0.225 & 0.300 & 0.377 & 0.454 & 0.532 \\
\hline AZÚCAR BLANCA & 20 & GRAMOS & 0.02 & $0.00 \%$ & 0.020 & 2.54 & 0.051 & 0.258 & 0.343 & 0.430 & 0.519 & 0.608 \\
\hline HUEVO & 10 & GRAMOS & 0.01 & $0.00 \%$ & 0.010 & 5.08 & 0.051 & 0.129 & 0.172 & 0.215 & 0.259 & 0.304 \\
\hline HIERBA BUENA & 2 & GRAMOS & 0.002 & $66.77 \%$ & 0.006 & 5.08 & 0.031 & 0.078 & 0.103 & 0.130 & 0.156 & 0.183 \\
\hline TOTAL & & & & & & & 0.192 & & & & & \\
\hline
\end{tabular}




\begin{tabular}{|c|c|c|c|c|c|c|c|c|c|c|c|c|}
\hline LIMONADA CON MUÑA & & & & & & & & COMPRAS & & & & \\
\hline INGREDIENTES & CANTIDAD & UND MEDIDA & KG BRUTO & MERMA & KG NETO & COSTO POR KILO & COSTO TOTAL & 2019 KG & $2020 \mathrm{KG}$ & $2021 \mathrm{KG}$ & 2022 KG & 2023 KG \\
\hline ZUMO DE LIMÓN & 10 & GRAMOS & 0.01 & $42.86 \%$ & 0.018 & 3.39 & 0.059 & 0.225 & 0.300 & 0.377 & 0.454 & 0.532 \\
\hline AZÚCAR BLANCA & 20 & GRAMOS & 0.02 & $0.00 \%$ & 0.020 & 2.54 & 0.051 & 0.258 & 0.343 & 0.430 & 0.519 & 0.608 \\
\hline HUEVO & 10 & GRAMOS & 0.01 & $0.00 \%$ & 0.010 & 5.08 & 0.051 & 0.129 & 0.172 & 0.215 & 0.259 & 0.304 \\
\hline MUÑA & 2 & GRAMOS & 0.002 & $64.00 \%$ & 0.006 & 3.39 & 0.019 & 0.072 & 0.095 & 0.120 & 0.144 & 0.169 \\
\hline \multirow[t]{3}{*}{ TOTAL } & & & & & & & 0.180 & & & & & \\
\hline & & & & & & & & & & & & \\
\hline & & & & & & & QX RECETA & 657 & 876 & 1098 & 1323 & 1552 \\
\hline CHICHA MORADA & & & & & & & & COMPRAS & & & & \\
\hline INGREDIENTES & CANTIDAD & UND MEDIDA & KG BRUTO & MERMA & KG NETO & COSTO POR KILO & COSTO TOTAL & 2019 KG & $2020 \mathrm{KG}$ & 2021 KG & 2022 KG & 2023 KG \\
\hline MAíZ MORADO & 250 & GRAMOS & 0.042 & $0.00 \%$ & 0.042 & 2.12 & 0.088 & 27.366 & 36.480 & 45.733 & 55.123 & 64.651 \\
\hline PIÑA & 250 & GRAMOS & 0.042 & $34.70 \%$ & 0.064 & 2.54 & 0.162 & 41.908 & 55.866 & 70.035 & 84.415 & 99.005 \\
\hline ZUMO DE LIMÓN & 75 & MILILITROS & 0.013 & $42.86 \%$ & 0.022 & 3.39 & 0.074 & 14.367 & 19.152 & 24.010 & 28.939 & 33.942 \\
\hline AZÚCAR BLANCA & 80 & GRAMOS & 0.013 & $0.00 \%$ & 0.013 & 2.54 & 0.034 & 8.757 & 11.674 & 14.634 & 17.639 & 20.688 \\
\hline MANZANA DE AGUA & 100 & GRAMOS & 0.017 & $27.86 \%$ & 0.023 & 5.08 & 0.117 & 15.173 & 20.226 & 25.356 & 30.563 & 35.845 \\
\hline CANELA EN POLVO & 5 & GRAMOS & 0.001 & $0.00 \%$ & 0.001 & 8.47 & 0.007 & 0.547 & 0.730 & 0.915 & 1.102 & 1.293 \\
\hline AGUA & 2000 & MILILITROS & 0.333 & - & 0.000 & 0.00 & 0.000 & 0.000 & 0.000 & 0.000 & 0.000 & 0.000 \\
\hline \multirow[t]{3}{*}{ TOTAL } & & & & & & & 0.483 & & & & & \\
\hline & & & & & & & & & & & & \\
\hline & & & & & & & QX RECETA & 15763 & 21013 & 26342 & 31751 & 37239 \\
\hline CHICHA DE QUINUA & & & & & & & & COMPRAS & & & & \\
\hline INGREDIENTES & CANTIDAD & UND MEDIDA & KG BRUTO & MERMA & KG NETO & COSTO POR KILO & COSTO TOTAL & 2019 KG & $2020 \mathrm{KG}$ & $2021 \mathrm{KG}$ & 2022 KG & 2023 KG \\
\hline HARINA DE QUINUA & 200 & GRAMOS & 0.033 & $0.00 \%$ & 0.033 & 5.93 & 0.198 & 525.422 & 700.423 & 878.069 & 1058.356 & 1241.290 \\
\hline HARINA DE ARROZ & 100 & GRAMOS & 0.017 & $0.00 \%$ & 0.017 & 11.86 & 0.198 & 262.711 & 350.212 & 439.035 & 529.178 & 620.645 \\
\hline AZÚCAR BLANCA & 80 & GRAMOS & 0.013 & $0.00 \%$ & 0.013 & 2.54 & 0.034 & 210.169 & 280.169 & 351.228 & 423.342 & 496.516 \\
\hline CANELA EN POLVO & 5 & GRAMOS & 0.001 & $0.00 \%$ & 0.001 & 8.47 & 0.007 & 13.136 & 17.511 & 21.952 & 26.459 & 31.032 \\
\hline CHICHA DE JORA & 250 & MILILITROS & 0.042 & $0.00 \%$ & 0.042 & 1.69 & 0.071 & 656.778 & 875.529 & 1097.587 & 1322.945 & 1551.613 \\
\hline AGUA & 2000 & MILILITROS & 0.333 & & 0.000 & & & 0.000 & 0.000 & 0.000 & 0.000 & 0.000 \\
\hline \multirow[t]{3}{*}{ TOTAL } & & & & & & & 0.507 & & & & & \\
\hline & & & & & & & & & & & & \\
\hline & & & & & & & QX RECETA & 9272 & 12360 & 15495 & 18677 & 21905 \\
\hline CHICHA DE KIWICHA & & & & & & & & COMPRAS & & & & \\
\hline INGREDIENTES & CANTIDAD & UND MEDIDA & KG BRUTO & MERMA & KG NETO & COSTO POR KILO & COSTO TOTAL & 2019 KG & $2020 \mathrm{KG}$ & $2021 \mathrm{KG}$ & 2022 KG & 2023 KG \\
\hline HARINA DE KIWICHA & 200 & GRAMOS & 0.033 & $0.00 \%$ & 0.033 & 5.93 & 0.198 & 309.072 & 412.014 & 516.511 & 622.562 & 730.171 \\
\hline HARINA DE ARROZ & 100 & GRAMOS & 0.017 & $0.00 \%$ & 0.017 & 11.86 & 0.198 & 154.536 & 206.007 & 258.256 & 311.281 & 365.085 \\
\hline AZÚCAR BLANCA & 80 & GRAMOS & 0.013 & $0.00 \%$ & 0.013 & 2.54 & 0.034 & 123.629 & 164.805 & 206.605 & 249.025 & 292.068 \\
\hline CANELA EN POLVO & 5 & GRAMOS & 0.001 & $0.00 \%$ & 0.001 & 8.47 & 0.007 & 7.727 & 10.300 & 12.913 & 15.564 & 18.254 \\
\hline CHICHA DE JORA & 250 & MILILITROS & 0.042 & $0.00 \%$ & 0.042 & 1.69 & 0.071 & 386.340 & 515.017 & 645.639 & 778.203 & 912.714 \\
\hline AGUA & 2000 & MILILITROS & 0.333 & & 0.000 & 0.00 & 0.000 & 0.000 & 0.000 & 0.000 & 0.000 & 0.000 \\
\hline TOTAL & & & & & & & 0.507 & & & & & \\
\hline
\end{tabular}




\begin{tabular}{|c|c|c|c|c|c|c|c|c|c|c|c|c|}
\hline \multicolumn{13}{|l|}{ POSTRES } \\
\hline \multirow[b]{2}{*}{ PASTEL DE CHOCLO } & & & & & & & QX RECETA & 6182 & 8241 & 10331 & 12452 & 14605 \\
\hline & & & & & & & & COMPRAS & & & & \\
\hline $\begin{array}{l}\text { INGREDIENTES } \\
\end{array}$ & CANTIDAD & UND MEDIDA & KG BRUTO & MERMA & KG NETO & COSTO POR KILO & COSTO TOTAL & 2019 KG & 2020 KG & 2021 KG & 2022 KG & 2023 KG \\
\hline CHOCLO DESGRANADO PELADO & 150 & GRAMOS & 0.15 & $62.23 \%$ & 0.397 & 4.24 & 1.683 & 2454.809 & 3272.427 & 4102.402 & 4944.715 & 5799.396 \\
\hline AZÚCAR BLANCA & 50 & GRAMOS & 0.05 & $0.00 \%$ & 0.050 & 2.54 & 0.127 & 309.100 & 412.051 & 516.559 & 622.619 & 730.237 \\
\hline HARINA DE TRIGO & 20 & GRAMOS & 0.02 & $0.00 \%$ & 0.020 & 4.24 & 0.085 & 123.640 & 164.821 & 206.623 & 249.048 & 292.095 \\
\hline SAL & 5 & GRAMOS & 0.005 & $0.00 \%$ & 0.005 & 0.85 & 0.004 & 30.910 & 41.205 & 51.656 & 62.262 & 73.024 \\
\hline POLVO DE HORNEAR & 5 & GRAMOS & 0.005 & $0.00 \%$ & 0.005 & 8.47 & 0.042 & 30.910 & 41.205 & 51.656 & 62.262 & 73.024 \\
\hline LECHE & 20 & MILILITROS & 0.02 & $0.00 \%$ & 0.020 & 3.81 & 0.076 & 123.640 & 164.821 & 206.623 & 249.048 & 292.095 \\
\hline MANTEQUILLA & 20 & GRAMOS & 0.02 & $0.00 \%$ & 0.020 & 5.93 & 0.119 & 123.640 & 164.821 & 206.623 & 249.048 & 292.095 \\
\hline ANIS & 5 & GRAMOS & 0.005 & $0.00 \%$ & 0.005 & 8.47 & 0.042 & 30.910 & 41.205 & 51.656 & 62.262 & 73.024 \\
\hline HUEVO & 10 & GRAMOS & 0.01 & $0.00 \%$ & 0.010 & 5.08 & 0.051 & 61.820 & 82.410 & 103.312 & 124.524 & 146.047 \\
\hline PASAS & 10 & GRAMOS & 0.01 & $0.00 \%$ & 0.010 & 12.71 & 0.127 & 61.820 & 82.410 & 103.312 & 124.524 & 146.047 \\
\hline TOTAL & & & & & & & 2.356 & & & & & \\
\hline & & & & & & & & & & & & \\
\hline & & & & & & & QXRECETA & 6164 & $|8217|$ & \begin{tabular}{|c|}
10302 \\
\end{tabular} & \begin{tabular}{|c|c|}
12417 \\
\end{tabular} & 14563 \\
\hline BUDIN DE QUINUA & & & & & & & & COMPRAS & & & & \\
\hline INGREDIENTES & CANTIDAD & UND MEDIDA & KG BRUTO & MERMA & KG NETO & COSTO POR KILO & COSTO TOTAL & 2019 KG & 2020 KG & 2021 KG & 2022 KG & 2023 KG \\
\hline QUINUA PERLADA & 50 & GRAMOS & 0.05 & $0.00 \%$ & 0.050 & 5.08 & 0.254 & 308.217 & 410.874 & 515.083 & 620.840 & 728.151 \\
\hline AZÚCAR BLANCA & 20 & GRAMOS & 0.02 & $0.00 \%$ & 0.020 & 2.54 & 0.051 & 123.287 & 164.350 & 206.033 & 248.336 & 291.260 \\
\hline AGUA & 15 & GRAMOS & 0.015 & $0.00 \%$ & 0.015 & 0.00 & 0.000 & 92.465 & 123.262 & 154.525 & 186.252 & 218.445 \\
\hline CANELA EN POLVO & 5 & GRAMOS & 0.005 & $0.00 \%$ & 0.005 & 8.47 & 0.042 & 30.822 & 41.087 & 51.508 & 62.084 & 72.815 \\
\hline LECHE & 25 & MILILITROS & 0.025 & $0.00 \%$ & 0.025 & 3.81 & 0.095 & 154.108 & 205.437 & 257.541 & 310.420 & 364.076 \\
\hline HUEVO & 20 & GRAMOS & 0.02 & $0.00 \%$ & 0.020 & 5.08 & 0.102 & 123.287 & 164.350 & 206.033 & 248.336 & 291.260 \\
\hline ZUMO DE NARANJA & 15 & GRAMOS & 0.015 & $47.23 \%$ & 0.028 & 4.24 & 0.120 & 175.213 & 233.571 & 292.810 & 352.931 & 413.934 \\
\hline MANTEQUILLA & 5 & GRAMOS & 0.005 & $0.00 \%$ & 0.005 & 5.93 & 0.030 & 30.822 & 41.087 & 51.508 & 62.084 & 72.815 \\
\hline PASAS & 10 & GRAMOS & 0.01 & $0.00 \%$ & 0.010 & 12.71 & 0.127 & 61.643 & 82.175 & 103.017 & 124.168 & 145.630 \\
\hline TOTAL & & & & & & & 0.822 & & & & & \\
\hline COMPLEMENTOS & & & & & & & & & & & & \\
\hline & & & & & & & QX RECETA & 18201 & 24263 & 30416 & 36661 & 42998 \\
\hline COMPLEMENTO PAPA NATIVA FR & ITAS & & & & & & & COMPRAS & & & & \\
\hline \begin{tabular}{c|} 
INGREDIENTES \\
\end{tabular} & CANTIDAD & UND MEDIDA & KG BRUTO & MERMA & KG NETO & COSTO POR KILO & COSTO TOTAL & 2019 KG & 2020 KG & $2021 \mathrm{KG}$ & 2022 KG & 2023 KG \\
\hline PAPAS NATIVAS & 300 & GRAMOS & 0.3 & $10.34 \%$ & 0.335 & 2.54 & 0.851 & 6090.175 & 8118.615 & 10177.714 & 12267.421 & 14387.813 \\
\hline ACEITE & 60 & MILILITROS & 0.06 & $0.00 \%$ & 0.060 & 5.08 & 0.305 & 1092.031 & 1455.752 & 1824.969 & 2199.675 & 2579.884 \\
\hline SAL & 5 & GRAMOS & 0.005 & $0.00 \%$ & 0.005 & 0.85 & 0.004 & 91.003 & 121.313 & 152.081 & 183.306 & 214.990 \\
\hline OREGANO & 5 & GRAMOS & 0.005 & $0.00 \%$ & 0.005 & 10.17 & 0.051 & 91.003 & 121.313 & 152.081 & 183.306 & 214.990 \\
\hline TOTAL & & & & & & & 1.211 & & & & & \\
\hline & & & & & & & & & & & & \\
\hline & & & & & & & QXRECETA & 11921 & \begin{tabular}{|c|}
15892 \\
\end{tabular} & 19923 & 24013 & 28164 \\
\hline COMPLEMENTO CHOCLO CON Q & JESO & & & & & & & \begin{tabular}{l|l} 
COMPRAS \\
\end{tabular} & & & & \\
\hline \begin{tabular}{c|} 
INGREDIENTES \\
\end{tabular} & CANTIDAD & UND MEDIDA & KG BRUTO & MERMA & KG NETO & COSTO POR KILO & COSTO TOTAL & 2019 KG & 2020 KG & 2021 KG & 2022 KG & $2023 \mathrm{KG}$ \\
\hline CHOCLO DESGRANADO & 350 & GRAMOS & 0.35 & $52.77 \%$ & 0.741 & 4.24 & 3.140 & 8834.363 & 11776.804 & 14763.718 & 17795.032 & 20870.857 \\
\hline QUESO & 50 & GRAMOS & 0.05 & $0.00 \%$ & 0.050 & 11.86 & 0.593 & 596.067 & 794.598 & 996.129 & 1200.656 & 1408.187 \\
\hline TOTAL & & & & & & & 3.733 & & & & & \\
\hline & & & & & & & & & & & & \\
\hline & & & & & & & QX RECETA & 11603 & $\mid 15467$ & \begin{tabular}{|c|c|}
19390 \\
\end{tabular} & 23372 & 27411 \\
\hline COMPLEMENTO PAPA HELADA C & JN QUESO & & & & & & & COMPRAS & & & & \\
\hline \begin{tabular}{l|} 
INGREDIENTES \\
\end{tabular} & CANTIDAD & UND MEDIDA & KG BRUTO & MERMA & KG NETO & COSTO POR KILO & COSTO TOTAL & 2019 KG & $2020 \mathrm{KG}$ & 2021 KG & 2022 KG & 2023 KG \\
\hline PAPA HELADA (VARIEDAD DE PAP & 300 & GRAMOS & 0.3 & $29.51 \%$ & 0.426 & 8.47 & 3.607 & 4937.950 & 6582.621 & 8252.151 & 9946.498 & 11665.724 \\
\hline QUESO & 60 & GRAMOS & 0.06 & $0.00 \%$ & 0.060 & 11.86 & 0.712 & 696.170 & 928.042 & 1163.418 & 1402.293 & 1644.676 \\
\hline SAL & 5 & GRAMOS & 0.005 & $0.00 \%$ & 0.005 & 0.85 & 0.004 & 58.014 & 77.337 & 96.951 & 116.858 & 137.056 \\
\hline TOTAL & & & & & & & 4.323 & & & & & \\
\hline
\end{tabular}




\section{Anexo 19. Estimaciones de servicios}

Fuente: http://www.movistar.com.pe/negocio/internet-seguridad/internet-tradicional

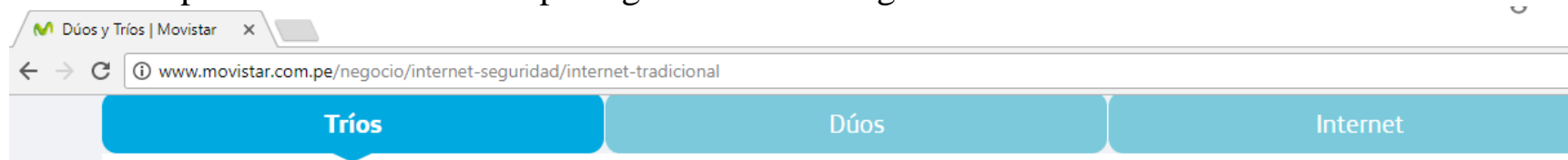

\section{Tríos: Internet + Telefonía fija +TV}

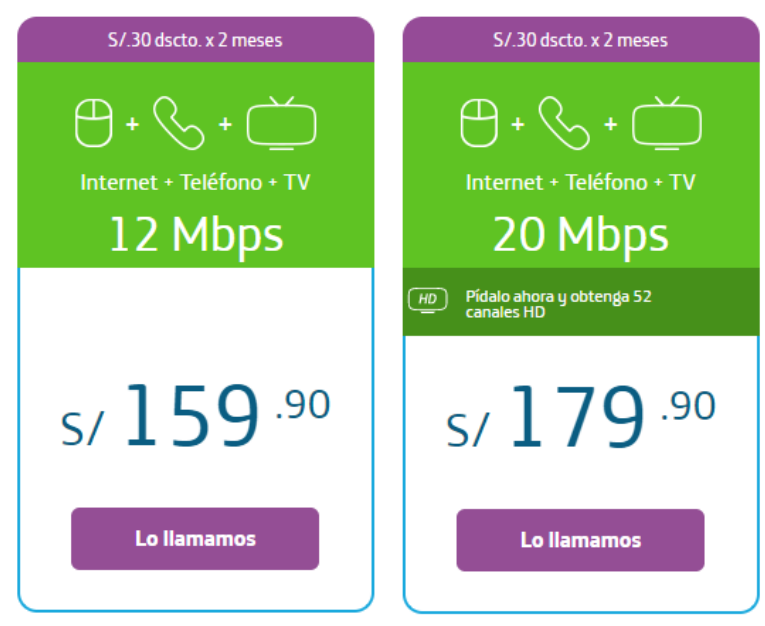

* Exclusivo para clientes con Ruc 20 y Ruc 10 con Negocios
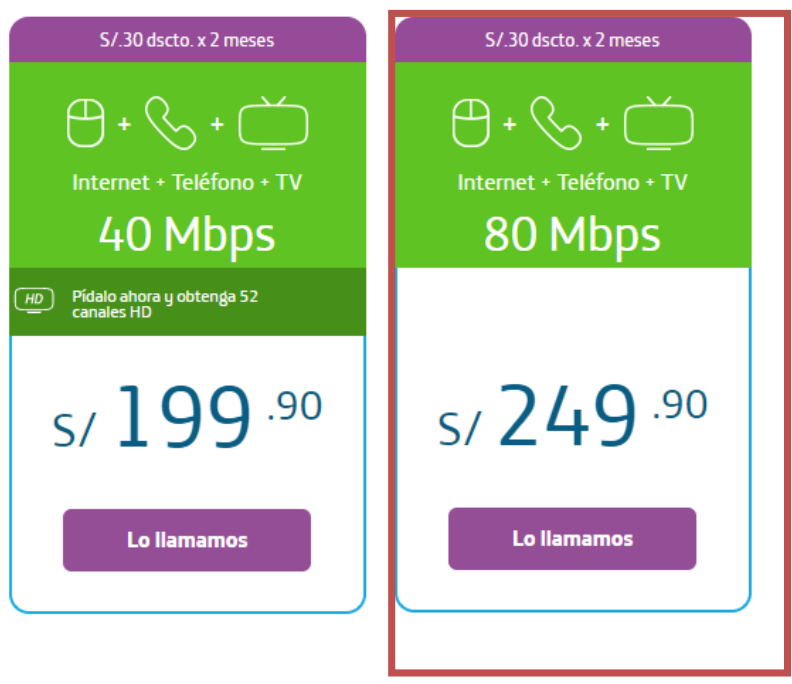

Fuente: http://www.sedacusco.com/estructura-tarifaria-de-los-servicios/

\begin{tabular}{|c|c|c|}
\hline AGUA & & \\
\hline Consumo m3 (doble de 93.28 m3 x consumo de cocina) & 208.62 & \\
\hline Precio $\times \mathrm{m} 3$ & 3.89 & \\
\hline Cargo fijo & 4.12 & \\
\hline Total Mensual & $\mathrm{S} / .815 .67$ & \\
\hline año & $\mathrm{S} / .9,787.98$ & \\
\hline 0.03 & 1251.74 & m3 al año \\
\hline m3 x usuario al día & 104.31 & m3 al mes \\
\hline http://ecodes.org/docs/Guias_bolsillo/Bar.pdf & & \\
\hline
\end{tabular}


Fuente: http://www.else.com.pe/else/servicios/OpcionesTarifarias.aspx

\begin{tabular}{|c|c|c|c|c|}
\hline \multicolumn{2}{|c|}{ LUZ+alumbrado publico } & \multicolumn{3}{|c|}{$81 \mathrm{kw} \cdot \mathrm{h} \times 30$ dias } \\
\hline costo $\times$ kw.h & 0.5873 & kw.h consumid & 2430 & 1427.139 \\
\hline alumbrado & 10.67 & & & 10.67 \\
\hline Cargo fijo $\mathrm{m}$ & 3.11 & & & 3.11 \\
\hline \multirow[t]{2}{*}{ Total mensual } & & & & S/. 1,440.92 \\
\hline & & & año & $\mathrm{S} / .17,291.03$ \\
\hline \multicolumn{5}{|c|}{$\begin{array}{l}\text { https://www.mge.com/Images/PDF/Brochures/Spanish/ManagingE } \\
\text { nergyCostsInRestaurants_Spanish.pdf }\end{array}$} \\
\hline \multicolumn{3}{|c|}{ consumo energia restaurantes $x$ dia } & & \\
\hline 81 kw.h & & & & \\
\hline
\end{tabular}

Fuente: https://drive.google.com/file/d/0B7bUa-Niigv-cG9iVXdsRGtfQzQ/view

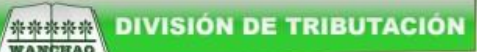
WAWERAO

\section{TASA DE IMPUESTO PREDIAL}

$1 \mathrm{UIT}=\mathrm{S} / .4050$

$0.4 \%$ UIT $=16.20$

\begin{tabular}{|c|c|c|}
\hline $\begin{array}{c}\text { BASE } \\
\text { IMPONIBLE }\end{array}$ & CONCEPTO & $\begin{array}{c}\text { MONTO A } \\
\text { PAGAR }\end{array}$ \\
\hline \multirow[t]{5}{*}{$198,391.98$} & IMPUESTO PREDIAL $20171^{\circ}$ Trimestre & $S / .236 .80$ \\
\hline & IMPUESTO PREDIAL $20172^{\circ}$ Trimestre & S/.236.80 \\
\hline & IMPUESTO PREDIAL $20173^{\circ}$ Trimestre & $S / .236 .80$ \\
\hline & IMPUESTO PREDIAL $20174^{\circ}$ Trimestre & $\mathrm{S} / .236 .80$ \\
\hline & D. Leg. $7760.4 \%$ UIT 2017 ARBITRIOS & $S / .12 .00$ \\
\hline
\end{tabular}




\section{Bibliografía}

5fuerzasdeporter.com. (n.d). Modelo de las cinco fuerzas competitivas de Porter. Obtenido de http://www.5fuerzasdeporter.com/

Acurio, G. (2015). Gastón Acurio: Los cinco ingredientes [Versión Electrónica]. Perú21. Recuperado el 2017, de http://peru21.pe/opinion/gaston-acurio-cinco-ingredientes2222615

Ahoracusco.com. (2008). Decreto supremo No. 025-2004-MINCETUR y la Resolución Ministerial No. 081-94-ITINCI. Obtenido de http://www.ahoracusco.com/normas.html

Alegria, L. (15 de Marzo de 2018). PBI de cuatro regiones del país cayeron en el 2017 [Versión Electrónica]. El Comercio. Recuperado el 2018, de https://elcomercio.pe/economia/pbicuatro-regiones-pais-cayeron-2017-noticia-504585

Ancona, D., Canul, C., Martinez, S., \& Nah, Y. (2012). Portafolio de productos. Obtenido de http://es.slideshare.net/claudia_canul47/02-portafolio-de-productos-14492266

Andina de Noticias. (2011). KFC abrirá diez nuevos restaurantes y cuatro estarán en Cusco, Huancayo, Cajamarca y Chimbote. Recuperado el 2017, de http://www.andina.com.pe/agencia/noticia-kfc-abrira-diez-nuevos-restaurantes-y-cuatroestaran-cusco-huancayo-cajamarca-y-chimbote-360131.aspx

Andina de Noticias. (2017). 15 regiones impulsaron el crecimiento del PBI. Recuperado el 2017, de http://andina.pe/agencia/noticia-peru-15-regiones-impulsaron-crecimiento-del-pbi-itrimestre-2017-674027.aspx 
Andina de Noticias. (2017). Cusco tendrá desarrollo económico sin precedentes con aeropuerto de chincheros. Recuperado el 2017, de http://www.andina.com.pe/agencia/noticia-cuscotendra-desarrollo-economico-sin-precedentes-aeropuerto-chinchero-652359.aspx

Arbaiza, L., Cánepa, M., Cortez, Ó., \& Lévano, G. (Octubre de 2014). Publicaciones Análisis prospectivo del sector de comida rápida en Lima:2014 2030. Lima: Esan ediciones. Recuperado el 31 de Octubre de 2016, de Esan Business : http://www.esan.edu.pe/publicaciones/2014/11/06/Comida\%20rapida\%20para\%20web.p df

Balandra, J. (28 de 04 de 2016). Estudio de Mercado. Recuperado el 2017, de juniorbalandra.wordpress.com: https://juniorbalandra.wordpress.com/

Banco Central de Reserva del Perú. (25 de Mayo de 2018). Cusco: Síntesis de Actividad Económica - Febrero 2018 [Versión Electrónica]. Recuperado el 2018, de http://www.bcrp.gob.pe/docs/Sucursales/Cusco/2018/presentacion-cusco-02-2018.pdf

Banco Central de Reserva del Perú. (Julio de 2018). Síntesis de Actividad Económica de CuscoJulio 2018 [Versión Electrónica]. Recuperado el 2018, de http://www.bcrp.gob.pe/docs/Sucursales/Cusco/2018/sintesis-cusco-07-2018.pdf Barakat Chávez, P. (5 de mayo de 2014). Cusco tuvo crecimiento más alto del mundo en los últimos 5 años [Versión Electrónica]. El Comercio. Recuperado el 2017 de enero de 02, de El comercio: http://elcomercio.pe/sociedad/cusco/cusco-tuvo-crecimiento-mas-altomundo-ultimos-5-anos-noticia-1727172

Barki, J. (2010). Las cadenas de fast food más grandes de mundo. Recuperado el 31 de 10 de 2016, de planeta joy: http://www.planetajoy.com/?page=ampliada\&id=1699 
Bembos. (2016). En la Actualidad . Recuperado el 2017, de Bembos Página Web: http://www.bembos.com.pe/en-la-actualidad/

Bembos.com. (n.d). Locales. Recuperado el 2017, de Bembos Página Web: http://www.bembos.com.pe/locales?Utm_source=search\&utm_medium=cpc\&utm_camp aign=bembosbranding16\&utm_content=Bembos\&utm_term=sitelinklocales\&gclid=cpa7 xsqgrnmcfuddhgode $6 \mathrm{cmia}$

Benner, J. (2017). Principales beneficios para las MYPES. Recuperado el 2017 de febrero de 2017, de Prom perú: http://www.prompex.gob.pe/Miercoles/Portal/MME/descargar.aspx ?archivo=C1DED215 -5C9C-44B1-9CE0-10484048C5F1.PDF

Bermúdez Talavera, P. (01 de 04 de 2013). Presupuesto de ventas. Obtenido de Slideshare: http://es.slideshare.net/pbermudez10/presupuesto-de-ventas-18001479

Bligoo. (2008). Cadena de hamburguesas Mc Donald abre primer local en Cusco. Recuperado el 2017, de http://ebiz.bligoo.com/cadena-de-hamburguesas-mcdonald-s-abre-primerlocal-en-el-cusco\#.WPUJY_k1_IU

Buenaventura Vera, G. (Marzo de 2002). El estudio de apalancamientos como metodología de análisis de la gestión en la empresa. 18. Cali, Colombia. Recuperado el 2018, de http://www.scielo.org.co/scielo.php?script=sci_arttext\&pid=S0123-59232002000100004

Buenosnegocios. (2014). El poder de negociación de los proveedores. Recuperado el 2017, de http://www.buenosnegocios.com/notas/683-el-poder-negociacion-los-proveedores

Buss Thofehrn, M., López Montesinos, M. J., Rutz Porto, A., Coelho Amestoy, S., Oliveira Arrieira, I. C., \& Mikla, M. (Junio de 2013). Grupo focal: Una técnica de recogida de 
datos en investigaciones cualitativas. 22(1-2). Granada, España. doi:10.4321/S113212962013000100016

Carreto, J. (2015). Segmentación de mercados industriales.(p.5). Recuperado el 2017, de https://www.slideshare.net/jcarreto/segmentacin-de-mercados-industriales52625829?ref=

Carro Paz, R., \& Gonzales Gomez, D. (n.d.). Diseño de procesos. Recuperado el 17 de 02 de 2017, de http://nulan.mdp.edu.ar/1613/1/08_diseno_procesos.pdf

Castillo Gamarra, A. (n.d.). Blog de Agustina Castillo Gamarra. Recuperado el 2017 de febrero de 12, de http://blog.pucp.edu.pe/blog/agustinacastillo/

Castro, J. C. (2016). Sector hoteles y restaurantes crecio $2.2 \%$ en abril y transporte aéreo decreció 3.1\%. Recuperado el 2017, de Portaldelturismo.pe: http://www.portaldeturismo.pe/index.php/otras-secciones/estadisticas/item/3198-sectorhoteles-y-restaurantes-crecio-2-2-en-abril-y-transporte-aereo-decrecio-3-1

CENEPRED. (n.d). Calculo Aforo. Obtenido de http://www.caplima.pe/PortalCAP/Data/Anexo_06_Calculo_de_Aforo.pdf

Chiarella, R. (2016). Bembos: la fast food peruana es cada vez menos rentable. Recuperado el 2017, de http://semanaeconomica.com/article/sectores-y-empresas/comercio/183636bembos-la-fast-food-peruana-es-cada-vez-menos-rentable/

Cifuentes, M. (Abril de 2010). Segmentación de Mercados. Recuperado el 2017, de http://segmentaciiondemerkdos.blogspot.com/p/la-segmentacion-del-mercado-de.html

Ciribeli , J., \& Miquelito, S. (28 de Febrero de 2014). La segmentación del mercado por el criterio psicográfico: un ensayo teórico sobre los principales enfoques psicográficos y su 
relación con los criterios de comportamiento. Brasil. Recuperado el 2018, de http://www.scielo.org.ar/scielo.php?script=sci_arttext\&pid=S1668-87082015000100002

Cocinasindustriales. (n.d). Como calcular el aforo y flujo de clientela. Recuperado el 2017, de http://www.cocinasindustriales.com/como-calcular-el-aforo-y-flujo-de-clientela

Código. (2017). Fast food en el Perú: con rentabilidad del $20 \%$ y con ventas de US\$700 millones este año. Recuperado el 2017, de http://www.codigo.pe/marketing/fast-foodperu-rentabilidad-del-20-ventas-us700-millones-este-ano/

collectiveloudperu. (2015). 6 aplicaciones para pedir delivery en Perú. Recuperado el 2017, de http://blog.collectivecloudperu.com/6-aplicaciones-para-pedir-delivery-en-peru/

Condori, Z. (2014). Según PerúCamaras la economia del sur crecio 4\% [ Versión Electrónica]. La República. Recuperado el 2017, de http://larepublica.pe/25-12-2014/segunperucamaras-la-economia-del-sur-crecio-4

Contreras, C. (2016). Picanteros del Cusco, guardianes de una cocina ancestral. Recuperado el 2017, de http://elcomercio.pe/gastronomia/noticias/picanteros-cusco-guardianes-cocinaancestral-noticia-1949876

Cordero Quinzacara, E. (2009). Los principios y reglas que estructuran el ordenamiento jurídico chileno. 15 (2):11-49. Chile. doi:10.4067/S0718-00122009000200002

Cusco Noticias. (2014). Real plaza Cusco de fiesta por su inaguración oficial. Recuperado el 2017, de http://cusconoticias.pe/07-06-2014/real-plaza-cusco-fiesta-por-su-inauguracionoficial

David, F. R. (2013). Administración Estratégica. México: Pearson Educación.

Daza, R. (2016). Niveles de producto del proyecto. Recuperado el 2017, de http://www.slideshare.net/RominaDazaRamos/tema-1-estrategia-de-productos. 
definicion.de. (n.d). Definición de ordenamiento jurídico. Obtenido de http://definicion.de/ordenamiento-juridico/

Definicionabc. (n.d). Definición de Financiamiento. Recuperado el 2018, de http://www.definicionabc.com/economia/financiamiento.php

Definicionabc. (n.d). Definición de Focus group. Obtenido de http://www.definicionabc.com/comunicacion/focus-group.php

Departamento de Desarrollo Económico y Competitividad. (16 de noviembre de 2016). Anexo I:Ficha técnica de entrevistas. Recuperado el 2018, de http://www.industria.ejgv.euskadi.eus/r44tu0014/es/contenidos/informacion/8013/es_2598/adjuntos/tb4_12.pdf

DePeru. (n.d.). Fast Food comida rápida. Recuperado el 31 de enero de 2017, de http://www.deperu.com/abc/restaurantes/477/fast-food-comida-rapida

Destino Negocios. (2015). Conoce a los Millennials y sus preferencias de compra. Recuperado el 2017, de http://destinonegocio.com/pe/negocio-por-internet-pe-pe/conoce-a-losmillennials-y-sus-preferencias-de-compra/

Diario Gestión. (2014). Peruanos realizan fuera del hogar 33.2\% sus gastos de alimentos [Versión Electrónica]. Diario Gestión. Recuperado el 2017, de http://gestion.pe/tendencias/peruanos-realizan-fuera-hogar-332-sus-gastos-alimentos2139149

Diario Gestión. (2014). Ropa, calzado y tecnología son lo que más compran los millenials en redes [Versión Electrónica]. Diario Gestión. Recuperado el 2017, de http://gestion.pe/tendencias/ropa-calzado-y-tecnologia-son-lo-que-mas-compranmillennials-redes-2102042 
Diario Gestión. (2014). Tres impuestos para regular el comportamiento del consumidor [Versión Electrónica]. Diario Gestión. Recuperado el 2017, de http://gestion.pe/economia/jurgenschuldt-tres-impuestos-regular-comportamiento-consumidor-2085695

Diario Gestión. (2015). Cadenas de Fast Food con más Fans en el Perú [Versión Electrónica]. Diario Gestión. Recuperado el 2017, de http://gestion.pe/tendencias/facebook-estas-soncadenas-fast-food-mas-fans-peru-2137470

Diario Gestión. (2015). Cuestión estrategica delosi saca ventaja a intercorp fast food [Versión Electrónica]. Diario Gestión. Recuperado el 2017, de http://gestion.pe/empresas/cuestion-estrategia-delosi-saca-ventaja-intercorp-fast-food2145853

Diario Gestión. (2015). Del granel a lo envasado: la ruta de transformación de la industria de alimentos [Versión Electrónica]. Diario Gestión. Recuperado el 2017, de http://gestion.pe/economia/granel-lo-envasado-ruta-transformacion-industria-alimentos2133718

Diario Gestión. (2015). Ley contra comida chatarra: Cambio de empaquetado podría tardar hasta un año [Versión Electrónica]. Diario Gestión. Recuperado el 2017, de Diario Gestión: http://gestion.pe/economia/ley-contra-comida-chatarra-cambio-empaquetado-podriatardar-hasta-ano-2131521

Diario Gestión. (2016). Buenísimo: KFC y su estrategia de sabor para el consumidor [Versión Electrónica]. Diario Gestión. Recuperado el 2017, de http://gestion.pe/empresas/buenisimo-kfc-y-su-estrategia-sabor-consumidor-2167972

Diario Gestión. (2016). Cadenas de comida rápida cortejan a fans de alimentación sana [Versión Electrónica]. Diario Gestión. Recuperado el 2017, de 
http://gestion.pe/tendencias/cadenas-comida-rapida-cortejan-fans-alimentacion-sana2174525

Diario Gestión. (2016). McDonald’s: La tendencia en Perú es el consumo de nuevos conceptos de hamburguesa [Versión Electrónica]. Diario Gestión. Recuperado el 2017, de Diario Gestión [Versión Electrónica]: http://gestion.pe/empresas/mcdonalds-tendencia-peruapertura-nuevos-conceptos-hamburguesa-2174191

Diario Gestión. (2016). Perú espera llegar a los siete millones de turistas el 2021 [Versión Electrónica]. Diario Gestión. Recuperado el 2017, de Diario Gestión: http://gestion.pe/tendencias/mincetur-peru-espera-llegar-siete-millones-turistas-20212173992

Diario Gestión. (2017). ¿Cuánto está dispuesto a pagar por un plato de comida saludable? [Versión Electrónica]. Diario Gestión. Recuperado el 2017, de http://gestion.pe/tendencias/cuanto-esta-dispuesto-pagar-plato-comida-saludable2179739

Diario Uno. (2016). KFC se renueva. Recuperado el 2017, de http://diariouno.pe/2016/07/17/kfc-se-renueva/

Diario Uno. (2016). Locales KFC en Cusco. Recuperado el 2017, de http://diariouno.pe/2016/07/17/kfc-se-renueva/

Digesa. (n.d). Manual Técnico de residuos. Recuperado el 2017, de http://www.digesa.minsa.gob.pe/publicaciones/descargas/MANUAL\%20TECNICO\%20 RESIDUOS.pdf

Diresa Cusco. (2016). Información estadistica de población. Recuperado el 2017, de http://www.diresacusco.gob.pe/estaditica/modulo7.htm 
Donawa Torres, Z. A., \& Morales Martínez, E. C. (2018). Fuerzas competitivas que moldean la estrategia en la gerencia del sector mipyme del distrito de Santa Marta. (84). Santa Marta, Magdalena, Colombia: Revista EAN. doi:10.21158/01208160.n84.2018.1919

EC, R. (7 de Julio de 2014). Burguer King abrio nuevo local en real plaza Salaverry [Versión Electrónica]. El Comercio. Recuperado el 2017, de http://elcomercio.pe/economia/negocios/burger-king-abrio-nuevo-local-real-plazasalaverry-noticia-1741248

EC, R. (14 de Julio de 2014). KFC abre su local número 100 [Versión Electrónica]. El Comercio. Recuperado el 2017, de http://elcomercio.pe/economia/negocios/kfc-abre-su-localnumero-100-peru-noticia-1742994

Efe Emprende. (2017). Delectatech aplica el big data a la gestión en restauración. Recuperado el 2017, de http://www.efeemprende.com/noticia/delectatech-aplica-big-data-la-gestionrestauracion/

El Comercio. (17 de Abril de 2013). Perú ya alberga más de 550 locales de comida rápida. El Comercio. Recuperado el 2017 de 01 de 31, de Diario el comercio: http://elcomercio.pe/economia/negocios/peru-ya-alberga-mas-550-locales-comida-rapidanoticia-1565099

El Comercio. (17 de 07 de 2016). ¿Cuantos pollos a la brasa consumen al año los Limeños? [Versión Electrónica]. El Comercio. Recuperado el 2017, de El Comercio: http://elcomercio.pe/sociedad/lima/cuantos-pollos-brasa-consumen-al-ano-hogareslimenos-noticia-1917491

El Comercio. (18 de Enero de 2017). Más de 20000 empresas migrarían a nuevo Régimen Mype [Versión Electrónica] . El Comercio. Recuperado el 2018, de 
http://elcomercio.pe/economia/peru/mas-20000-empresas-migrarian-nuevo-regimenmype-tributario-noticia-1961669

El Peruano. (2013). Ley de promoción de la alimentación saludable para niños, niñas y adolescentes - Ley 30021 [Versión Electrónica]. El Peruano. Recuperado el 2017, de http://busquedas.elperuano.com.pe/normaslegales/ley-de-promocion-de-la-alimentacionsaludable-para-ninos-ni-ley-n-30021-938532-1/

El Peruano. (2014). Modifican el artículo 24 de la Norma sanitaria para el funcionamiento de Restaurantes y servicios Afines [Versión Electrónica]. El Peruano. Recuperado el 2017, de http://busquedas.elperuano.com.pe/normaslegales/modifican-el-articulo-24-de-lanorma-sanitaria-para-el-func-rm-n-965-2014minsa-1176853-2/

El Plural. (2017). ¿Son las franquicias una buena idea para iniciar un negocio? Recuperado el 2017, de http://elplural.com/economia/2017/03/07/son-las-franquicias-una-buena-ideapara-iniciar-un-negocio

Enciclopediade. (2016). Definición de Lay out. Recuperado el 17 de 02 de 2017, de http://www.tiposde.org/empresas-y-negocios/1019-definicion-de-layout/

Escobar, J., Bonilla , F., \& Jimenez. (n.d de n.d de n.d). Universidad el bosque. Recuperado el 28 de Enero de 2017, de http://www.uelbosque.edu.co/sites/default/files/publicaciones/revistas/cuadernos_hispano americanos_psicologia/volumen9_numero1/articulo_5.pdf

Espinoza, R. (2012). Cómo definir misión, visión y valores en la empresa. Recuperado el 2017, de http://robertoespinosa.es/2012/10/14/como-definir-mision-vision-y-valores-en-laempresa 
Fattorini, V. O. (01 de Abril de 2015). Más de 70\% de limeños acude cada quince dias a Fast Foods [Versión Electrónica]. Recuperado el 2017, de Diario Gestión: http://gestion.pe/mercados/mas-70-limenos-acude-cada-quince-dias-fast-food-2127840

Finanzasdigital. (2017). Inflación de Perú en Febrero de 2017 fue 0.34\%. Recuperado el 2017, de http://www.finanzasdigital.com/2017/03/inflacion-peru-febrero-2017-fue-034/

Fred R., D. (2013). Administración Estratégica (Decimocuarta ed.). (V. Alba, \& E. Hernán, Trads.) México: Pearson Educación.

García, I. (06 de 12 de 2016). Como hacer el plan comercial de ventas. Recuperado el 2017, de http://www.emprendedores.es/gestion/como-hacer-plan-comercial-de-ventas

Gary, D. (2015). Administración de recursos humanos (Onceava ed.). México: Pearson Educacion.

Geominsa. (2016). Mapa de la Ciudad del Cusco. Recuperado el 2017, de http://www.geominsa.minsa.gob.pe/geominsa/

Gestiopolis. (n.d). Que es el costo de oportunidad. Recuperado el 2017, de http://www.gestiopolis.com/que-es-el-costo-de-oportunidad/

GFK Perú. (2014). Índice de Confianza del consumidor proyectado al 2015. Recuperado el 2017, de http://es.slideshare.net/GfKPeru/gfk-per-icc-marzo-2014

Gonzales Luca de Tena, C. (24 de Setiembre de 2015). El análisis estratégico de la empresa. Recuperado el 2017, de Likedin: https://www.linkedin.com/pulse/el-an\%C3\%A1lisisestrat\%C3\%A9gico-en-la-empresa-carlos-gonz\%C3\%A1lez-luca-de-tena

Google Documents. (n.d.). Localización, tamaño e ingenieria del proyecto. Recuperado el 17 de 02 de 2017, de https://docs.google.com/document/d/14K5oex-IuCYj7VSSkCNWICOS22bDR55ZJRmoFAVGe4/edit 
Grant, R. M. (2014). Dirección estrategica (Quinta ed.). Londres: Civitas Ediciones, S.L.

Guerras, M., \& López, N. (2007). Dirección Estratégica de la Empresa (Cuarta ed.). España: Thomson Reuters-Civitas.

Headways. (2016). Participación de Mercado. Recuperado el 2017, de https://www.headways.com.mx/glosario-mercadotecnia/palabra/participacion-demercado/

Hernández, F. (2017). Factores críticos de éxito (Primera ed.). Tudela: Sinergium.

Herrera, C. (2013). Presupuestos de gastos financieros. Recuperado el 2017, de https://prezi.com/feniic261gpo/presupuesto-de-gastos-financieros

Humpire, N. (Noviembre de 2013). Análisis y procesamiento de datos. Obtenido de Slideshare: https://es.slideshare.net/NikoHumpire/analisis-y-procesamiento-de-datos

Iborra, M., Dasí, Á., Dolz, C., \& Ferrer, C. (2014). Fundamentos de direccion de empresas (Segunda ed.). España: Paraninfo.

Impulso Regio. (15 de 06 de 2015). Pymes aprovechan TPP. Recuperado el 2017, de impulsoregio.wordpress.com: https://impulsoregio.wordpress.com

Indeci. (2009). Manual para la ejecución de inspecciones técnicas de seguridad, Resolución Jefatural No 251-2008-INDECI. Recuperado el 2017, de https://www.indeci.gob.pe/educ_cap/pdfs/man_itsdc.pdf

Indeci. (2018). Preguntas frecuentes, solicitud de certificado. Recuperado el 2017, de https://www.indeci.gob.pe/faqs.php

Indecopi. (2017). Registro de marcas y otros. Recuperado el 2017, de https://www.indecopi.gob.pe/web/signos-distintivos/registro-de-marca-y-otros-signos 
Infomarketing. (2016). KFC es la marca con mayor recordación por los consumidores peruanos. Recuperado el 2017, de http://www.infomarketing.pe/marketing/noticias/kfc-es-la-marcacon-mayor-recordacion-por-los-consumidores-peruanos/

Instituto Latino. (2016). ¿Qué es la cocina novoandina? Recuperado el 2017, de http://www.latino.edu.pe/wp/2016/07/19/que-es-la-cocina-novoandina/

Instituto Le cordon blue. (n.d). Gastronomía de la Ciudad de Cusco. Recuperado el 2018, de http://www.ilcb.edu.pe/index.php/es/component/k2/item/104-la-gastronom\%C3\%ADade-la-ciudad-del-cusco.htm

Instituto Nacional de Estadística e Informática. (2010). Estimaciones y proyecciones de población departamental 1995-2025. Recuperado el 2017, de http://proyectos.inei.gob.pe/web/biblioineipub/bancopub/Est/Lib1039/libro.pdf

Instituto Nacional de Estadística e Informática. (2016). Tasa de ocupación por departamento 2016. Recuperado el 2017, de http://www.inei.gob.pe/media/MenuRecursivo/publicaciones_digitales/Est/Lib1391/libro. pdf

Instituto Peruano de Economia. (Enero de 2018). Perspectivas de la economía y la competitividad del Perú y Cusco. Recuperado el 2018, de http://www.ipe.org.pe/portal/perspectivas-de-la-economia-y-la-competitividad-de-peru-ycusco/

Izaguirre, M. (16 de Mayo de 2017). Ley contra la comida chatarra cumple 4 años sin reglamento [Versión Electrónica]. El Comercio. Recuperado el 2017, de https://elcomercio.pe/economia/ley-comida-chatarra-cumple-4-anos-reglamento-422280 
Jaco, M. (2012). Tamaño y localización del proyecto. Recuperado el 2017, de http://es.slideshare.net/Manuel_jaco/tamao-y-localizacin-de-proyecto

Jornada Online. (2015). La cocina peruano conquista el mundo. Recuperado el 2018, de http://jornadaonline.com/Placeres/139736-La-cocina-peruana-conquista-el-mundo

Joseph, H. (2009). Investigación de mercados (Cuarta ed.). México: Mc Graw Hill.

Kotler, P. (n.d). Dirección de Mercado. Recuperado el 2018, de http://cvonline.uaeh.edu.mx/Cursos/Lic_virt/Mercadotecnia/DMKT012/UNIDAD\%20II/ 22_lec_direccion_mercadotecnia.pdf

Kotler, P., \& Armstrong, G. (2012). Marketing (Catorceava ed.). Mexico: Pearson Educacion. La Industria. (2017). Implemetan nuevo sistema de seguridad para turistas. Recuperado el 2017, de http://www.laindustria.pe/detallenoticias.php?Codarticulo=5821

La República. (2015). Estos son las 10 cadenas de comida rápida más valiosas en el mundo [Versión Electrónica]. La República. Recuperado el 2017, de http://larepublica.pe/marketing/705742-estos-son-las-10-cadenas-de-comida-rapida-masvaliosas-en-el-mundo

La República. (2016). Peruanos cambian sus hábitos alimenticios y apuestan por productos gourmet [Versión Electrónica]. La República. Recuperado el 2017, de http://larepublica.pe/turismo/rumbos-al-dia/787055-peruanos-cambian-sus-habitosalimenticios-y-apuestan-por-productos-gourmet

La República. (2016). Sueldo promedio en Cusco asciende a S/.1081 y es insuficiente [Versión Electrónica]. La República. Recuperado el 2017, de La República: http://larepublica.pe/impresa/sociedad/764154-sueldo-promedio-en-cusco-asciende-s1081-y-es-insuficiente 
La República. (2017). Perú contará este año con 1.2 millones de mujeres emprendedoras [Versión Electrónica]. La República. Recuperado el 2017, de http://larepublica.pe/economia/854623-peru-contara-este-ano-con-12-millones-demujeres-emprendedoras

La República. (2017). Ventas de Fast food en el Perú incrementan con $\$ 700$ millones este año [Versión Electrónica]. La República. Recuperado el 2018, de La República: http://larepublica.pe/marketing/852786-ventas-de-los-fast-food-en-el-peru-incrementancon-700-millones-este-ano

La Vanguardia. (2015). El rankind de paises con más restaurantes McDonald's. Recuperado el 2017, de http://www.lavanguardia.com/vangdata/20150820/54434771508/el-ranking-depaises-con-mas-restaurantes-mcdonald-s.html

Lawrence J., G., \& Chad J., Z. (2012). Administración Financiera (Decimosegunda ed.). (A. Brito, Trad.) Mexico: Pearson Educación.

Libélula. (2014). ¿Como el cambio climatico esta afectando ya al Perú? Recuperado el 2017, de http://libelula.com.pe/noticia/como-el-cambio-climatico-esta-ya-afectando-al-peru/ Llallarco, C. (2017). Pa' comer o pa' llevar: el negocio de la comida al paso. Recuperado el 2017, de http://reporteobligado.com/cusco-pa-comer-o-pa-llevar-el-negocio-de-lacomida-al-paso--1

Matarranz, A. (28 de 09 de 2012). Diseño de producto el puente entre la definición y la implementación. Recuperado el 2017, de https://conversisconsulting.com/2012/09/29/diseno-de-producto-el-puente-entre-ladefinicion-y-la-implementacion-del-producto-1/ 
Mercados y Regiones. (2016). Indicador compuesto de la actividad económica IT 2015-1T 2016. Recuperado el 2017, de http://mercadosyregiones.com/el-sur-del-peru-crecio-masdel-doble-que-el-pais-en-el-primer-trimestre/

Mercadosyregiones.com. (2016). ICAE: crecimiento regional según zonas IT 2015-1T 2016. Obtenido de http://mercadosyregiones.com/el-sur-del-peru-crecio-mas-del-doble-que-elpais-en-el-primer-trimestre/

Metrolibre.com. (2016). Índice de confianza del consumidor latinoamericano. Obtenido de http://metrolibre.com/economia/page-10

MINCETUR. (Copyright 2015). Prestadores de Servicios Túristicos. Recuperado el 2017, de https://www.mincetur.gob.pe/turismo/normas-legales/prestadores-de-servicios-turisticos/

Ministerio de economía y finanzas. (2017). Cambio en el crecimiento del PBI 2017-2018. Recuperado el 2017, de https://www.mef.gob.pe/contenidos/pol_econ/marco_macro/MMM_2018_2021.pdf

Mintzberg, H. (n.d). Diseño de organizaciones eficientes. Recuperado el 12 de febrero de 2017, de https://tecnoadministracionpub.files.wordpress.com/2016/08/u2-mintzberg-e28093disec3b1o-de-organizaciones-eficientes.pdf

Moncada, A. (2015). Índice de confianza para invertir. Recuperado el 2017, de http://semanaeconomica.com/article/management/164906-conflictos-sociales-corrupcioninseguridad-elecciones-2016/

Morales Castro, A., \& Morales Castro, J. (2014). Planeación Financiera (Primera ed.). Mexico: Grupo Editorial Patria.

Municipalidad del Cusco. (2018). Licencia de funcionamiento. Recuperado el 2018, de http://www.cusco.gob.pe/tramites/licencia-de-funcionamiento/ 
Nassir, S. (2014). Preparación y evaluación de proyectos (Cuarta ed.). Mexico: McGraw-Hill Interamericana.

Neyra, M. (7 de Julio de 2016). Basural en Machu Picchu Pueblo por mal manejo de residuos[Versión Electrónica]. El Comercio. Recuperado el 2017, de El Comercio: http://elcomercio.pe/sociedad/cusco/basural-machu-picchu-pueblo-mal-manejo-residuosnoticia-1914986

Nielsen. (18 de Mayo de 2018). La Confianza de los Latinoamericanos sigue en ritmo de crecimiento con 88 puntos. Recuperado el 2018, de https://www.nielsen.com/pe/es/insights/news/2018/La-confianza-de-loslatinoamericanos-sigue-en-ritmo-de-crecimiento-con-88-puntos.html

O’higgins, M. (2013). Diversificación del producto. Recuperado el 2017, de http://es.slideshare.net/palitocote/diversificacin-de-producto

Observatorio Turístico del Perú. (n.d). observatorioturisticodelperu. Recuperado el 2017, de http://www.observatorioturisticodelperu.com/mapas/restaurantes.pdf

Palitocote. (2013). Diversificación del producto. Recuperado el 2017, de http://es.slideshare.net/palitocote/diversificacin-de-producto

Parada, P. (2013). Análisis PESTEL. Recuperado el 2017, de http://www.pascualparada.com/analisis-pestel-una-herramienta-de-estudio-del-entorno/

Parada, P. (2013). La aceleradora Hub Emprende abre su segunda convocatoria para la selección de emprendedores. Recuperado el 2017, de http://www.pascualparada.com/tag/startups/page/6/ 
Pelaez, J. (20 de 03 de 2009). Mercado potencias vs Mercado objetico. Recuperado el 17 de 02 de 2017, de markegruop.blogspot.pe: http://markegruop.blogspot.pe/2009/03/mercadopotencial-vs-mercado-objetivo.html

Perú. (2016). Esto es lo que comen dos turistas en Cusco con menos de 1 dólar. Recuperado el 2017, de http://peru.com/actualidad/otras-noticias/youtube-esto-comen-dos-turistascanadienses-cusco-menos-1-dolar-noticia-469694

Perú21. (2014). Seis regiones en Perú crecieron más de 10\% [Versión Electrónica]. Perú21. Recuperado el 2017, de http://peru21.pe/opinion/seis-regiones-peru-crecieron-mas-102191305

Perú21. (26 de Octubre de 2018). ¿A cuánto asciende el sueldo mínimo en Perú este $2018 ?$ Perú21. Recuperado el 2018, de https://peru21.pe/economia/sueldo-minimo-peru-2018asciende-rmv-ano-402319

Peruempresa. (2007). Bembos abrirá cinco locales en Lima y Trujillo este año. Recuperado el 2017, de http://peruempresa.blogspot.pe/2007/06/bembos-abrir-cinco-locales-en-limay.html

Popeyes.com.pe. (n.d). Locales popeyes. Recuperado el 2017, de http://www.popeyes.com.pe/locales

Portal del Turismo. (2017). Inca rail lanza nuevo menú con productos nativos de Cusco en su servicio First Class. Recuperado el 2018, de http://portaldeturismo.pe/index.php/empresa/item/6970-inca-rail-lanza-nuevo-menu-conproductos-nativos-de-cusco-en-su-servicio-first-class 
Portal del Turismo. (2017). Sabores peruanos se lucieron en XV edición de Madrid Fusión.

Recuperado el 2018, de http://www.portaldeturismo.pe/index.php/local/item/6250sabores-peruanos-se-lucieron-en-xv-edicion-de-madrid-fusion

PQS. (2017). Sociedad anónima cerrada: Características y beneficios. Recuperado el 2017, de http://www.pqs.pe/emprendimiento/sociedad-anonima-cerrada-caracteristicas-ybeneficios

PQS. (2017). Sunarp: Pasos para inscribir a tu empresa. Recuperado el 2017, de http://www.pqs.pe/emprendimiento/sunarp-pasos-para-inscribir-tu-empresa

Proyectos Ingenotas. (25 de 02 de 2009). Ingenieria del proyecto. Recuperado el 17 de 02 de 2017, de http://proyectos.ingenotas.com/2009/02/ingenieria-del-proyecto-distribucionde.html

Revista Gana Más. (2015). Cadenas de Fast food incrementan importación de papas precocidas. Recuperado el 2017, de http://revistaganamas.com.pe/cadenas-de-fast-food-incrementanimportacion-de-papas-precocidas/

Rivadeneyra Unda, M. (n.d). La elaboración de presupuestos en empresas manufactureras. Recuperado el 2017, de http://www.eumed.net/libros-gratis/2014/1376/

Robles, C. (2007). La investigación cuantitativa. Recuperado el 2017, de http://es.slideshare.net/robles585/la-investigacin-cuantitativa

Rodriguez, A. (2014). Gestión de la fuerza de ventas y equipos comerciales. Obtenido de https://books.google.com.pe/books?id=GbpWDwAAQBAJ

Rosaline, B. (2013). Los grupos de discusión en Investigación Cualitativa (Primera ed.). Madrid: Morata. 
RPP noticias. (2016). ¿Cuál es el sueldo mínimo en Perú y en el resto de Sudamérica?

Recuperado el 2017, de http://rpp.pe/peru/actualidad/cual-es-el-sueldo-minimo-en-peruy-en-el-resto-de-sudamerica-noticia-985877

Ruphas Diner. (2018). Facebook Ruphas Diner - Red Social. Recuperado el 2018, de Facebook: https://es-la.facebook.com/ruphasdiner/

Safi. (22 de 10 de 2014). Política de servicio al cliente. Recuperado el 2017, de Slideshare.com: http://es.slideshare.net/S4F1/politica-de-servicio-al-cliente

Saldaña, P. (5 de Febrero de 2018). Mercados \& Regiones. Recuperado el 2018, de http://mercadosyregiones.com/2018/02/puno-con-inflacion-por-encima-del-promedioprecios-se-estancan-en-moquegua/

Sánchez, L. (n.d). Gestión de los costos del proyecto. Recuperado el 2017, de https://capitulo7pmbok.wordpress.com/gestion-de-los-costos-del-proyecto/

Sapag Chain, N. (2011). Proyectos de Inversión Formulación y Evaluación (Segunda ed.). Chile: Pearson Educación.

Sapag Chain, N. (2014). Preparacion y evaluación de proyectos (Quinta ed.). Chile: Pearson Educación.

Schmal, R. F., \& Olave, T. Y. (10 de Abril de 2014). Optimización del Proceso de Atención al Cliente en un Restaurante durante Períodos de Alta Demanda. 25. Chile. doi:10.4067/S0718-07642014000400005

Scribd. (2017). Selección de Maquinaria y Equipos. Recuperado el 17 de 02 de 2017, de https://es.scribd.com/doc/95169487/Seleccion-De-Maquinaria-Y-Equipo

Serperuano. (17 de abril de 2013). Existen 482 locales de las principales cadenas de fast food en el país. Recuperado el 01 de febrero de 2017, de 
http://www.serperuano.com/2013/04/existen-482-locales-de-las-principales-cadenas-defast-food-en-el-pais/

Shuttleworth, M. (Febrero de 2017). Diseño de la investigacion cualitativa. Recuperado el 2017, de https://explorable.com/es/diseno-de-la-investigacion-cualitativa: https://explorable.com/es/diseno-de-la-investigacion-cualitativa

Silva, M. (2016). Mincetur: Los millennials son el sector generacional de mayor crecimiento en el sector turismo. Recuperado el 2017, de http://larepublica.pe/turismo/rumbos-aldia/759944-mincetur-los-millennials-son-el-sector-generacional-de-mayor-crecimientoen-el-sector-turismo

Solo Contabilidad. (2012). Factores que afectan la proyección. Recuperado el 17 de 02 de 2017, de http://www.solocontabilidad.com/2012/10/factores-que-afectan-la-proyeccion-de.html

SUNARP. (2016). En 24 horas se puede inscribir una empresa. Recuperado el 2017, de https://www.sunarp.gob.pe/PRENSA/inicio/post/2016/10/31/en-24-horas-se-puedeinscribir-una-empresa-en-la-sunarp

SUNAT. (2017). Iniciando mi negocio. Recuperado el 2017, de http://emprender.sunat.gob.pe/como-me-inscribo-en-el-ruc

Terra. (2017). Internet: Más del 80\% de peruanos compra con tarjeta de crédito. Recuperado el 2017, de https://www.terra.com.pe/vidayestilo/internet-mas-del-80-de-peruanos-compracon-tarjeta-de-credito,8a9c3d4d2ff7a11db0aa5fc4bd58b651s2izo3ob.html

Torres Fernández, A., Almazán del Olmo, O., \& Hernández, B. (2015). Estudio de factibilidad económica de un proyecto de generación eléctrica, a partir de la gasificación de bagazo en un central azucarero cubano. Centro Azúcar, 42(1), 1-8. La Habana, Cuba. 
Recuperado el 2018, de http://scielo.sld.cu/scielo.php?script=sci_arttext\&pid=S2223$48612015000100001 \& \operatorname{lng}=$ es\&tlng=es.

Tripadvisor Perú. (n.d). Información Rhupas Diner. Recuperado el 2017, de https://www.tripadvisor.com.pe/showuserreviews-g294314-d8548073-r404589795Rupha_s_Diner-Cusco_Cusco_Region.html

Tuespuntoes. (16 de 05 de 2012). Análisis de Escenarios. Recuperado el 2017, de https://tuespuntoes.wordpress.com/2012/05/16/analisis-de-escenarios/

Ulrich, K., \& Eppinger, S. (2014). Diseño y desarrollo de productos (Quinta ed.). Mexico: Mc Graw Hill Education.

Universidad de Alicante. (n.d). La entrevista a profundidad. Recuperado el 2017, de https://personal.ua.es/es/franciscofrances/materiales/tema4/la_entrevista_en_profundidad.html

Universidad Privada de la Selva Peruana. (n.d.). Capitulo III: Estudio Técnico. Recuperado el 17 de 02 de 2017, de http://dspace.ups.edu.ec/bitstream/123456789/1461/4/CAPITULO\%203.pdf

Universidad Santo Tomas. (n.d). Descripción del producto o servicio. Recuperado el 2017, de Ustadistancia:

http://soda.ustadistancia.edu.co/enlinea/proyectodegradofase1_orlandofernandez/descripc in_del_producto_yo_servicio.html

Valarezo, K. (4 de Mayo de 2016). Universidad Técnica de Ambato (p.4). Recuperado el 2017, de Slideshare: https://www.slideshare.net/kiravalarezo1/tipos-de-empresa-61651586

Villalobos, M. (05 de Marzo de 2016). La hamburguesa deja el Fast Food para ser un negocio Gourmet [Versión Electrónica]. El Comercio. Recuperado el 2017, de El Comercio: 
http://elcomercio.pe/economia/peru/hamburguesa-deja-fast-food-negocio-gourmetnoticia- 1884090

Villalobos, M. (11 de Marzo de 2017). Gobierno busca crear 150 mil empleos con nuevo impulso fiscal. El Comercio. Recuperado el 2017, de http://elcomercio.pe/economia/peru/gobierno-creara-150-mil-empleos-nuevo-impulsofiscal-noticia-1974722

Wheelen, T. L., Wheelen , K. E., \& Hunger, J. D. (2013). Administracion estratégica y política de negocios (Treceava ed.). Colombia: Pearson.

Zúñiga, O. (n.d). Las diferencias entre las funciones del controller y el auditor interno. Recuperado el 2017, de http://www.pymerang.com/administracion-de-empresas/852-lasdiferencias-entre-las-funciones-del-controller-y-el-auditor-interno 